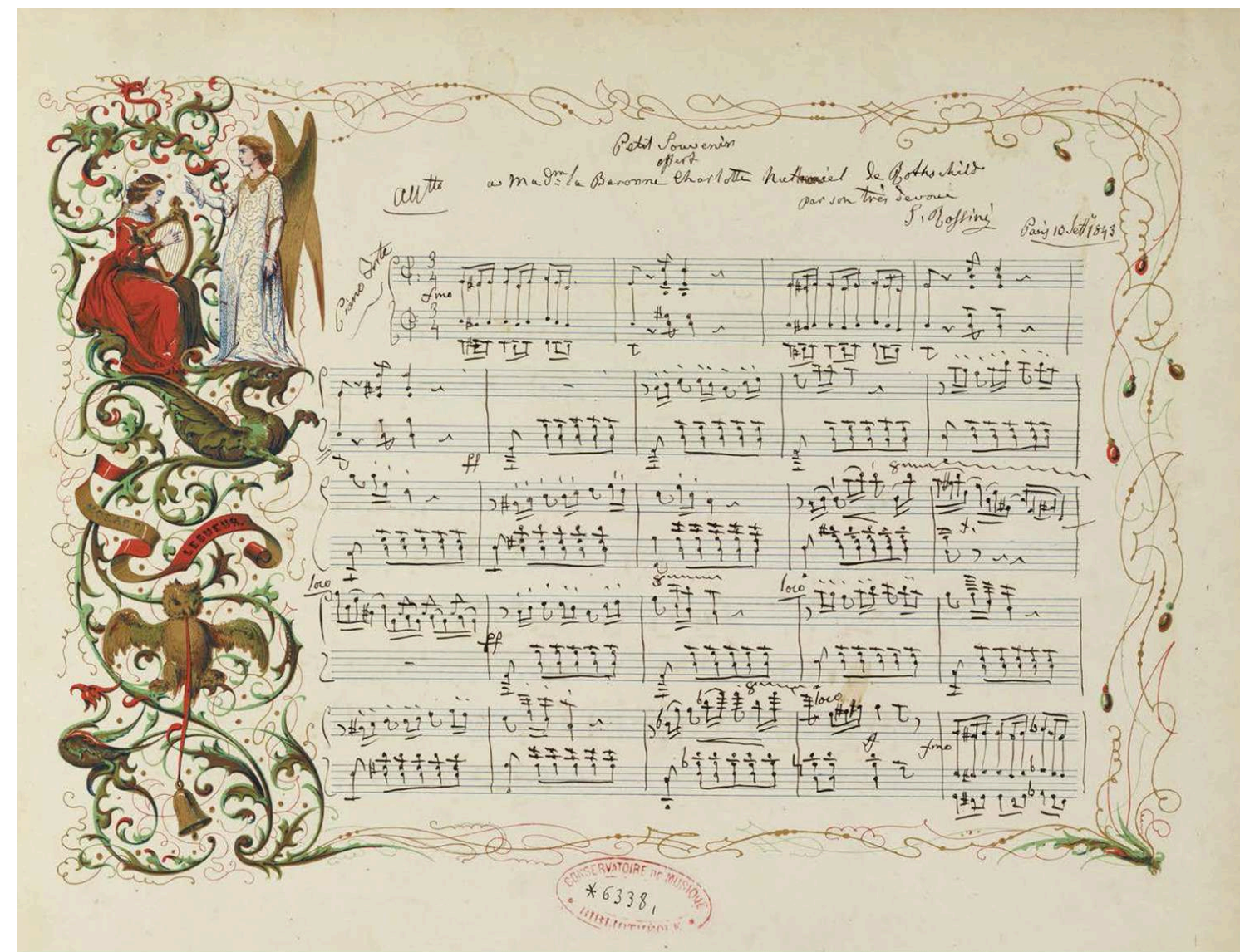

\title{
DE LA SPHÈRE PRIVÉE À LA SPHÈRE PUBLIQUE
}

Les collections Rothschild dans les institutions publiques françaises

Pauline Prevost-Marcilhacy, Laura de Fuccia et Juliette Trey

Gioacchino Rossini, Petit souvenir offert à $M^{\text {me }}$ la baronne Charlotte Nathaniel de Rothscbild, le 10 septembre 1843, Paris, Bibliothèque nationale de France, département de la Musique, INV. ms.-1338 () Bibliothèque nationale de France.

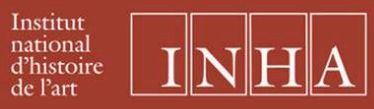




\section{De la sphère privée à la sphère publique}

Les collections Rothschild dans les institutions publiques françaises

Pauline Prevost-Marcilhacy, Laura de Fuccia et Juliette Trey (dir.)

DOI : 10.4000/books.inha.10632

Éditeur : Publications de l'Institut national d'histoire de l'art

Lieu d'édition : Paris

Année d'édition : 2019

Date de mise en ligne : 4 décembre 2019

Collection : Actes de colloques

EAN électronique : 9782917902875

\section{QboOoks}

http://books.openedition.org

\section{Référence électronique}

PREVOST-MARCILHACY, Pauline (dir.) ; DE FUCCIA, Laura (dir.) ; et TREY, Juliette (dir.). De la sphère privée à la sphère publique : Les collections Rothschild dans les institutions publiques françaises. Nouvelle édition [en ligne]. Paris : Publications de l'Institut national d'histoire de l'art, 2019 (généré le 21 septembre 2021). Disponible sur Internet : <http://books.openedition.org/inha/10632>. ISBN : 9782917902875. DOI : https://doi.org/10.4000/books.inha.10632.

Ce document a été généré automatiquement le 21 septembre 2021.

(c) Publications de l'Institut national d'histoire de l'art, 2019

Conditions d'utilisation:

http://www.openedition.org/6540 
Dans la suite de l'ouvrage somme de Pauline Prevost-Marcilhacy, Les Rothschild. Une dynastie de mécènes en France (Louvre/BNF/Somogy, 2016) et dans le cadre du développement du programme Les collections Rothschild dans les institutions publiques françaises à l'INHA, les actes du colloque « De la sphère privée à la sphère publique », qui s'est tenu les 4, 5 et 6 décembre 2018, se proposent de dresser un panorama des dons aux institutions publiques venus des différents membres de la famille Rothschild, en s'intéressant plus particulièrement aux ensembles moins étudiés jusqu'à aujourd'hui. Ce sont des antiquités, des partitions musicales, des écailles piquées, des pipes, des manuscrits, des porcelaines chinoises, des curiosités, autant d'objets qui furent donnés aux musées et aux institutions publiques à partir de 1863, au moment où l'espace public s'institue aussi comme lieu de partage et d'exposition de la culture. 
Les collections Rothschild dans les institutions publiques françaises : perspectives de recherche

Pauline Prevost-Marcilhacy

\section{Le goût de l'Antique}

Un chapiteau du temple oraculaire d'Apollon à Didymes

Une redécouverte dans le jardin de l'hôtel Marigny, ancienne propriété de la famille Rothschild

Pierre Bonnaure et Ludovic Laugier

Les antiquités d'Asie Mineure entrées au musée du Louvre au XIX ${ }^{e}$ siècle

Le chapiteau du Didyméion à l'hôtel Marigny

Le trésor de Boscoreale au musée du Louvre : un mécénat exceptionnel d'Edmond de Rothschild pour les collections nationales

Cécile Giroire

Le contexte archéologique

La dispersion du mobilier

Et le trésor?

Boscoreale à Paris

Edmond de Rothschild (1845-1934)

La restauration du trésor

Boscoreale au Louvre

\section{Dessins et estampes}

Ce qu'Edmond ne donna pas : réflexions sur la collection personnelle d'arts graphiques du baron Edmond de Rothschild

Séverine Lepape

Les dessins français du XVIII ${ }^{\mathrm{e}}$ siècle

La collection d'estampes et de dessins du XIX ${ }^{\mathrm{e}}$ siècle

L'importance de l'eau-forte

Des lithographes romantiques en petit nombre

Les caricatures

Des graveurs de reproduction

Conclusion

"Un ensemble harmonieux et instructif » : la collection de livres imprimés et de recueils d'estampes du baron Edmond de Rothschild Victoria Fernandez

État des lieux suite à l'informatisation

Les grandes catégories de la collection de livres et de recueils du baron

La gravure d'histoire au temps des premiers Bourbons: une catégorie méconnue de la collection d'estampes d'Edmond de Rothschild

Estelle Leutrat 


\section{Manuscrits, livres et imprimés}

\section{Doucet chez Rothschild}

La Bibliothèque d'art et d'archéologie de 1923 à 1935

Jérôme Delatour

Donation de Doucet et genèse de l'Institut d'art et d'archéologie (1912-1922)

De la mort de la baronne de Rothschild à l'inauguration de la bibliothèque (1922-1924)

1924-1929 : l'hôtel Salomon de Rothschild institut d'art ?

Locaux et organisation de la bibliothèque

Traitement des collections

Épilogue

La collection Rothschild et l'édition italienne de la Renaissance

Carlo Alberto Girotto

Reliures, provenances illustres et réseau de bibliophiles

Exemplaires uniques et éditions populaires

James Édouard de Rothschild à Venise : un jeune bibliophile face à la dispersion des collections de la famille Mocenigo

Laura de Fuccia

Les archives Mocenigo à la bibliothèque de la Sorbonne

Le corpus

L'histoire de la République de Venise, de ses institutions et de son gouvernement

Histoire(s) familiale(s)

Une provenance prestigieuse : les Mocenigo de la Casa Vecchia

Sur le don d'un millier de pièces à la Biblioteca Marciana

\section{Les Rothschild et la musique}

Le salon musical de la famille Rothschild : autour du legs de Charlotte de Rothschild à la bibliothèque du Conservatoire

Rosalba Agresta

La musique chez les Rothschild

Le legs de Charlotte de Rothschild au Conservatoire

\section{Objets d'art et Beaux-Arts et curiosités}

Les vitraux suisses de l'hôtel Salomon de Rothschild dans le contexte du patrimoine verrier de l'ancienne Confédération helvétique

Uta Bergmann

La coutume d'offrir des vitraux

Les vitraux suisses de l'hôtel Salomon de Rothschild

L'atelier et l'évolution des techniques du vitrail

Conclusion 
Les cuirs dorés des collections Rothschild dans les institutions publiques françaises Jean-Pierre Fournet

La tenture murale de l'hôtel Salomon de Rothschild

La tenture murale de l'hôtel Marigny

Le panneau de la Villa Ephrussi de Rothschild

Le bouclier d'apparat vénitien

La collection de porcelaines chinoises de l'hôtel Salomon de Rothschild

Pauline d'Abrigeon

Retracer l'histoire de la collection

Un ensemble insolite de plats à décors de la famille rose

Conclusion

Remerciements

\section{Perspectives nationales}

Béatrice Ephrussi de Rothschild et l'Italie. Architecture et mobilier Louis Mézin

Les loggias aux sculptures à l'antique du château de Ferrières

Philippe Sénéchal

Alphonse de Rothschild, acteur de la " médaillomanie » fin XIX - début XXe siècle Katia Schaal

Un mécénat privilégiant une douzaine de médailleurs

La multiplication des voies et du réseau d'approvisionnement

Le dispositif original du " cadre de médailles »

Les dons Rothschild et l'histoire de l'art de la médaille 1900

Les écailles piquées napolitaines : une " passion Rothschild " Alexis Kugel

L'art du piqué

La collection d'écailles piquées de Mayer Carl von Rothschild

La collection de pipes d'Alice de Rothschild à Grasse

André Leclaire

Une âme de collectionneuse

La porcelaine

Les bois

Des matières fort diverses

Les boîtes d'allumettes

\section{Perspectives internationales}

L'exception anglaise? Constance Battersea et la philanthropie artistique des Rothschild d'outre-manche

Thomas Stammers

Alice de Rothschild's collection of arms and armour at Waddesdon Manor Pippa Shirley 


\title{
Les collections Rothschild dans les institutions publiques françaises : perspectives de recherche
}

\author{
Pauline Prevost-Marcilhacy
}

1 Je tiens tout d'abord à remercier vivement Éric de Chassey, directeur général de l'Institut national d'histoire de l'art; France Nerlich, directrice du département des Études et de la Recherche, et Juliette Trey, directrice adjointe du département des Études et de la Recherche, de nous avoir accueillis à l'INHA pour ce colloque prévu à l'initiative d'Ariane James-Sarrazin, aujourd'hui directrice adjointe du musée de l'Armée. Tous mes remerciements vont également à Laura de Fuccia, chef du programme de recherche « Les Rothschild dans les institutions publiques françaises » à l'INHA, dont j'assure la direction scientifique.

2 C'est en 2007 qu'a débuté le vaste chantier d'étude sur l'action de la dynastie Rothschild auprès de deux cents institutions françaises. Ce travail hors norme a permis, neuf ans plus tard, en 2016, la publication des trois volumes sous ma direction, Les Rothschild. Une dynastie de mécènes en France, aux éditions du Louvre, de la Bibliothèque nationale de France et Somogy, grâce à une recherche collective rassemblant une équipe pluridisciplinaire internationale de cinquante-trois conservateurs et universitaires qui, chacun dans leur domaine de spécialité, ont contribué à faire de cet ouvrage une référence.

3 Cette publication marque une étape importante dans la reconnaissance du mécénat exceptionnel exercé par la famille Rothschild en France, sujet essentiel, à la croisée de plusieurs domaines de recherche - l'histoire de l'art, l'histoire matérielle, l'histoire visuelle -, car leur goût a servi de référence pour le collectionnisme et le marché de l'art. Il est en très grande partie inédit car, si le nombre d'études consacrées aux collectionneurs s'est multiplié depuis trente ans, l'histoire du mécénat n'a pas bénéficié de la même attention. L'utilisation des humanités numériques s'imposait pour compléter et valoriser cette importante publication scientifique, mais surtout pour proposer une base documentaire indispensable à la recherche. Ces inventaires sont 
désormais accessibles sur le portail Rothschild de l'INHA ${ }^{1}$ qui recense l'ensemble des dons identifiés à ce jour et les institutions qui les détiennent.

4 Comme nous l'avons souligné, la singularité du mécénat Rothschild est à la fois quantitative et institutionnelle, ce travail de fond ayant en effet permis de montrer de manière inédite et globale à la fois l'ampleur des dons, illustrant toutes les facettes prises en compte de l'antiquité à nos jours, mais aussi toutes les techniques de la connaissance artistique, et la diversité géographique. C'est en outre un sujet pluridisciplinaire, car la variété des objets est aussi à l'origine de ce colloque, étant donné qu'ils appartiennent aussi bien à l'archéologie qu'à l'histoire de l'art ou à l'ethnologie. L'originalité est également géographique, comme nous l'avons montré : la famille Rothschild, à la différence d'autres donateurs, a enrichi plus de deux cents musées et institutions françaises.

5 En rédigeant des textes de synthèse et en identifiant ces milliers d'œuvres disséminées sur tout le territoire, nous avons constaté qu'elles étaient souvent inconnues du public et même des spécialistes. Nous avons jeté ensemble les premiers jalons de la mise en œuvre du portail Rothschild et surtout impulsé à plus d'un titre une véritable réflexion sur l'histoire du mécénat artistique en France. Travailler sur la famille Rothschild a présenté l'avantage d'étudier, à partir d'un observatoire prestigieux, des phénomènes à la croisée de plusieurs domaines : le collectionnisme, le marché de l'art ou encore les liens avec les musées. Leur mécénat met aussi l'accent sur la place de la communauté juive au sein de la République, les tensions entre la sphère privée et la sphère publique, le rôle des agents et des experts qui permettront le passage entre les deux, l'émulation au sein de la famille Rothschild et le rôle majeur de la branche française incarnant ce modèle européen ou encore la place des femmes dans un mécénat souvent conjugué au masculin.

$6 \quad$ La mise au jour de ces cent trente mille œuvres d'art appelait une valorisation de plus grande ampleur. En effet, si de nombreuses institutions comme le département des Arts graphiques au Louvre par le biais d'expositions régulières et la numérisation de ses collections depuis 2004 avaient mis en valeur les pièces majeures, des milliers d'œuvres modestes, insolites voire insignes avaient été parfois oubliées ou restaient méconnues. Grâce à l'engagement de la famille Rothschild, qui reçoit ici toute ma reconnaissance, celui de l'INHA et de ses partenaires, le musée du Louvre, la BnF, le service des musées de France, la Villa Ephrussi de Rothschild et la FNAGP (aujourd'hui « Fondation des artistes »), une seconde étape essentielle a été franchie avec la mise en ligne, depuis 2016, des inventaires rédigés par les conservateurs et complétés par les équipes de l'INHA, sous la direction attentive de Laura de Fuccia. Sorties de l'ombre grâce à notre publication et au portail, ces œuvres, ces curiosités appartiennent autant au champ de l'histoire de l'art qu'à celui de l'histoire matérielle.

7 Il semble évident que la publication de la trilogie Les Rothschild. Une dynastie de mécènes en France et le portail Rothschild devaient susciter de nouveaux accrochages et une mise en valeur de ces collections. L'organisation des trois journées d'études à l'INHA et, aujourd'hui, la publication de leurs actes en apporte la preuve. Elles ont permis une fructueuse collaboration internationale entre conservateurs, universitaires et chercheurs indépendants autour des collections Rothschild et ont été l'occasion de présenter un certain nombre de découvertes. À l'image du caractère encyclopédique et éclectique de ces dons, les communications ont privilégié des études de cas concernant des corpus souvent inédits et se sont organisées autour de six thématiques : «Le goût 
de l'Antique " (Ludovic Laugier, Pierre Bonnaure, Cécile Giroire, Philippe Sénéchal), «Les dessins et estampes » (Séverine Lepape, Victoria Fernandez, Estelle Leutrat), «Les livres et imprimés » (Jérôme Delatour, Carlo Alberto Girotto, Régis Stauder), «les Rothschild et la musique» (Rosalba Agresta, Marie-Pauline Martin et Thierry Maniguet), «Les objets d'art et curiosités» (Uta Bergmann, Jean-Pierre Fournet, Pauline d'Abrigeon, Louis Mézin, André Leclaire, Katia Schaal, Célia Fleury et Alexis Kugel) enfin « Les perspectives internationales » (Pippa Shirley et Tom Stammers) ${ }^{2}$.

D'autres exemples de l'intérêt suscité par la publication et le portail Rothschild pourraient être évoqués. Je mentionnerai également la réouverture, après de nombreuses années, du cabinet de curiosités de l'hôtel Salomon de Rothschild, grâce à la ténacité de sa directrice Laurence Maynier. Le travail de recherche sur les différents inventaires et la reconstitution en deux dimensions, à partir des photographies du XIX ${ }^{e}$ siècle, menés sous la direction de Laura de Fuccia à l'INHA, ont permis d'identifier près de cinq cents œuvres d'art, qui en faisaient partie initialement, et de reconstituer virtuellement ce qui demeure le dernier témoignage parisien du goût Rothschild. La restauration et l'ouverture, prévue en 2022, de la rotonde Balzac compléteront ce quadruple mémorial dédié à Mayer Carl, Salomon et Adèle de Rothschild et Honoré de Balzac. Les trois communications présentées ici dans ce colloque (Uta Bergmann, JeanPierre Fournet, Pauline d'Abrigeon) témoignent du travail accompli en partie d'après cet inventaire.

9 Le partenariat entre l'INHA et l'Académie des beaux-arts a permis, grâce à Louis Mézin, directeur de la Villa Ephrussi de Rothschild à Saint-Jean-Cap-Ferrat, de mettre en ligne la majorité des dons de la baronne Ephrussi de Rothschild (environ trois mille objets), à partir des inventaires effectués par Philippe Malgouyres, Esther Moench, Ulrich Leben, Guillaume Seret, dans le cadre de nos trois volumes.

10 Mais bien d'autres exemples seraient à citer comme celui récent du musée Petiet à Limoux qui, en 2018, a sorti de ces réserves des médailles de Chaplain envoyées par Alphonse de Rothschild ou celui, plus spectaculaire, organisé à la fondation Bemberg à Toulouse en 2018, qui présentait la collection de tête de morts léguée en 1926 par la baronne Henri de Rothschild au musée des Arts décoratifs, jusqu'ici en réserve. Le projet d'exposition sur les collections de pipes et de boîtes d'allumettes léguées à la bibliothèque de Grasse (ici étudiées par André Leclair) et celles conservées au manoir de Waddesdon (Pippa Shirley) est un autre exemple de ce mécénat européen et montre bien l'intérêt d'une étude placée dans une perspective internationale.

11 Nous sommes aujourd'hui à un tournant: la numérisation des inventaires sera quasiment achevée fin 2019, mais l'inventaire déjà numérisé des collections Rothschild a aussi fait émerger de nouvelles possibilités de valorisation. D'autres projets pourraient être pris en compte: par exemple, la présentation au public, en réalité augmentée, du cabinet de curiosités et de ses collections, celles actuellement présentées ou celles déposées dans des institutions françaises provenant de l'ancien hôtel Salomon de Rothschild, aujourd'hui ouvert au public. Cela permettrait de mieux faire connaître ces œuvres, également par le biais d'une exposition virtuelle, et de proposer de nouveaux modes d'exploitation des objets du patrimoine.

Un autre projet pourrait être celui de reconstituer l'éphémère "musée Rothschild " créé par le baron Alphonse au musée de Cannes en 1898: ce sont, en effet, plus d'une centaine d'œuvres (peintures, objets d'art et d'art graphique, sculptures, photographies); elles témoignent de l'originalité de cette politique culturelle 
décentralisatrice dont Alphonse de Rothschild est à l'origine, en marge du rôle de l'administration des Beaux-Arts, et qui fut poursuivie par son frère Edmond et sa sœur Charlotte. Enfin les collections scientifiques léguées par la famille Rothschild, qui n'avaient pas été prises en compte dans le cadre de la publication de 2016, représentent aussi un immense champ d'étude ${ }^{3}$. Là encore, la mise en perspective avec les collections scientifiques anglaises, notamment celle de Walter de Rothschild à Tring en Angleterre, s'impose.

13 L'approfondissement des recherches a montré la nécessité de ne pas réduire l'étude de ce mécénat à la France, mais d'étudier les échanges avec les institutions de manière plus large dans le contexte de l'internationalisation de la collection et du mécénat. Il s'agit de considérer ce phénomène sous un double aspect: d'une part, à travers l'examen des dons effectués par plusieurs membres de la branche française, qui ont doté des institutions muséales étrangères. J'en veux pour exemple James Édouard de Rothschild, dont les legs se partagent entre la bibliothèque Marciana à Venise et la bibliothèque de la Sorbonne, comme le démontre ici Laura de Fuccia, mais aussi la baronne Salomon de Rothschild qui à la fois enrichit le musée de Francfort et lègue son hôtel rue Berryer et ses collections parisiennes à la France pour en faire une maison d'art.

14 Le cas le plus spectaculaire reste cependant la collection d'art graphique d'Edmond de Rothschild. En effet, la plupart des gravures et livres illustrés sont allés au musée du Louvre, mais un exceptionnel ensemble de dessins d'ornement et d'architecture des $\mathrm{XVIII}^{\mathrm{e}}$ et XIX ${ }^{\mathrm{e}}$ siècles a rejoint les collections du Waddesdon Manor, grâce à son fils James, comme le montre ici Séverine Lepape. Dans un autre domaine, la très importante collection d'objets ethnographiques d'Alix de Rothschild est partagée aujourd'hui entre le musée du quai Branly (autrefois au musée de l'Homme) et le musée d'Israël à Jérusalem.

15 Cette pratique exemplaire de mécénat doit s'inscrire dans une démarche comparative à la fois diachronique et géographique. Les Rothschild étaient des Européens avant l'heure dans leurs affaires et par leurs liens familiaux très étroits, qui sont une des composantes de leur identité, il serait donc tentant d'inclure dans le portail les donations d'autres branches de la famille, que ce soit à Francfort, celles d'Anselm Salomon ou d'Hannah Louise de Rothschild, ou encore à Genève, celles d'Edmond de Rothschild.

16 Les relations entre les branches françaises et anglaises nous semblent à ce titre particulièrement dignes d'intérêt. Il est utile de rappeler à cette occasion l'importance des collections de Ferdinand de Rothschild léguées en 1898 au British Museum et remarquablement étudiées en 2015 par Dora Thronton; celles du Waddesdon Manor données au National Trust en 1957, mises en valeur par les très nombreux volumes publiés à l'initiative de Dorothy de Rothschild, ou encore celles d'Antony de Rothschild, à Ascott, données en 1950 au National Trust et dont nous parle ici Tom Stammers.

17 Les transferts culturels et les circulations internationales constituent un domaine d'investigation qui concerne de nombreuses disciplines. Le portail Rothschild, qui a permis de présenter les outils rassemblant des données éparses, pourrait jouer un rôle majeur dans ces nouvelles approches liées à l'internationalisation des collections, en s'appuyant sur l'expertise technique des nombreux universitaires et conservateurs ayant déjà pris part à ce projet, et sur le centre des Archives Rothschild à Londres qui développe de longue date de nombreuses passerelles avec les chercheurs. 
Enfin, tous mes remerciements vont bien sûr aux intervenants qui, par la qualité de leurs recherches et leurs communications, ont permis la réussite de ce colloque ainsi qu'aux membres du Comité scientifique (Cécile Colonna, Laura de Fuccia, Isabelle Le Masne de Chermont, Séverine Lepape et Juliette Trey) qui ont assuré la difficile tâche de relecture des actes, et enfin au service des éditions de l'INHA aidé par Maryse Bideault (Cloé Brosseau, Marianne Dautrey, Étienne Diemert, Anne-Cécile Schreiner et Quentin Viricel) qui a permis de réaliser cette publication.

\section{NOTES}

1. Depuis 2016, ce portail est accessible à l'adresse suivante : collections.rothschild.inha.fr.

2. Le colloque a été ponctué par plusieurs évènements, un concert organisé avec Mathias Auclair, directeur du département de la Musique de la Bibliothèque nationale de France, et Marie-Pauline Martin, directrice du musée de la Musique, conservateur à la Cité de la musique/Philharmonie de Paris, ainsi qu'une visite du cabinet de curiosités de la Fondation des artistes. Voir la mise en ligne du colloque : youtube.com/playlist?list=PLsl8NWzVv6T2FmSTnUzGgmGRoVqC66Ffa.

3. Je prépare une communication sur ce sujet dans le cadre du colloque international organisé par la chancellerie des universités de Paris et la Bibliothèque interuniversitaire de la Sorbonne (2019), sur « Patrimoine, philanthropie et mécénat. $\mathrm{XX}^{\mathrm{e}}-\mathrm{XXI}^{\mathrm{e}}$ siècles ». Certains naturalia sont déjà mis en ligne sur le portail : les objets donnés au musée du Mans et ceux donnés au Musée africain, à la Fondation Gourgaud, à l'île d'Aix voir: collections.rothschild.inha.fr/frinstiutions/ cartographie-des-etablissements/musees-de-france/lemans-museum-d'histoire-naturelle-dumans. 
Le goût de l'Antique 


\section{Un chapiteau du temple oraculaire d'Apollon à Didymes}

Une redécouverte dans le jardin de l'hôtel Marigny, ancienne propriété

de la famille Rothschild

Pierre Bonnaure et Ludovic Laugier

1 En 2018, de fructueux échanges entre le département Jardins des résidences présidentielles et le département des Antiquités grecques, étrusques et romaines du musée du Louvre ont conduit à l'identification d'un chapiteau colossal du temple d'Apollon à Didymes : celui-ci avait été rapporté en France en 1873 par Olivier Rayet, à la suite de la grande fouille menée dans la région de Milet, en Asie Mineure, grâce au généreux mécénat d'Edmond et de Gustave de Rothschild. La mémoire de ce bloc s'était quelque peu perdue: le voici redécouvert et affecté au Louvre, où il rejoindra prochainement, dans la cour du Sphinx, l'ensemble des décors du temple d'Apollon Didyméen, offerts par les frères Rothschild en 1873.

2 Le mécénat des barons Edmond et Gustave de Rothschild en faveur des collections nationales a déjà été soigneusement étudié ces dernières années, notamment par Pauline Prevost-Marcilhacy et, pour ce qui touche aux antiquités classiques en particulier, par Alain Pasquier et François Baratte ${ }^{1}$. Pour mettre en contexte l'intérêt du chapiteau du temple d'Apollon de Didymes, récemment repéré dans le jardin de l'hôtel Marigny, rappelons toutefois les circonstances de l'entreprise que les deux frères décident de soutenir financièrement en 1872-1873: une ambitieuse mission archéologique en Asie Mineure, dans la région de Milet et son arrière-pays, alors partie intégrante de l'Empire ottoman, sous la conduite du jeune archéologue Olivier Rayet.

\section{Les antiquités d'Asie Mineure entrées au musée du Louvre au XIX siècle}

Dans les années 1870, les antiquités classiques d'Asie Mineure ne sont pourtant pas absentes à Paris, quand les frères Rothschild envisagent de soutenir cette mission scientifique dans la région de Milet. Elles font en effet leur entrée au musée du Louvre 
tout au long du XIXe siècle. Parmi les acquisitions les plus anciennes figurent notamment les marbres du comte de Choiseul-Gouffier, achetés à la vente après le décès de leur célèbre propriétaire, en 1818. Il s'agit de sculptures provenant de Grèce ou d'Asie Mineure, notamment des stèles funéraires et des reliefs votifs de Cyzique ${ }^{2}$, en Mysie, ou encore d'Alexandrie de Troade ${ }^{3}$ et d'Héraclée du Pont ${ }^{4}$. Sous le règne de Louis-Philippe, il faut noter plusieurs cadeaux diplomatiques du sultan Mahmoud II, à replacer dans le contexte des relations diplomatiques franco-ottomanes. C'est ainsi qu'en 1838 arrivent à Paris le grand vase de Pergame ${ }^{5}$, mais aussi une part significative du décor du temple d'Athéna à Assos, en Troade ${ }^{6}$. La mission que Charles Texier mène en Ionie en 1842 , grâce à l'autorisation de la Sublime Porte et à la bienveillance du même sultan Mahmoud II, permet de faire entrer au Louvre 43 blocs de la frise ionique du temple colossal d'Artémis Leucophryène à Magnésie du Méandre, soit plus du tiers de l'ensemble de cette Amazonomachie, aujourd'hui répartie entre Istanbul, Berlin et Paris ${ }^{7}$. S'y ajoutent quelques fragments de chapiteaux ioniques et cinq blocs de chéneau à gargouille léonine ainsi que des éléments épars de l'entablement du temple. À la fin du Second Empire, quand Edmond et Gustave de Rothschild commencent à développer leur goût pour l'antique et leurs premiers projets de mécénat, les deux frères pourraient a priori considérer que le Louvre compte parmi les grands musées européens abritant un ensemble significatif de sculptures architecturales provenant de sites prestigieux d'Asie Mineure. Toutefois, la collection parisienne paraît relativement modeste en nombre d'œuvres. Surtout, les antiques arrivés à Paris sont d'un intérêt relatif, comparés à ceux qui sont alors présentés à Londres, au British Museum. Le vase en marbre de Pergame, probablement un marqueur de tombe, se distingue certes par son échelle monumentale, mais beaucoup moins par la qualité de sa frise de cavaliers en bas-relief ${ }^{8}$. De même, le décor du temple d'Assos est sculpté dans une roche volcanique, l'andésite, qui paraît bien ingrate à l'œil de l'antiquaire du XIX siècle. En outre, frises et métopes datent de l'époque archaïque, vers 530 av. J.-C. : si, aujourd'hui, la fraîcheur des productions artistiques de cette période enchante le regard, il est loin d'en être de même dans les années 1840-1880. Quant à la frise du temple d'Artémis Leucophryène, à son arrivée à Paris, son décor en haut relief déçoit beaucoup les antiquisants: le style de l'Amazonomachie, mettant inlassablement en scène des combats répétitifs, pratiquement à la manière d'une frise de rinceaux, paraît médiocre à la majorité de ses commentateurs. Parmi beaucoup d'autres savants, le comte de Clarac, conservateur des Antiques au musée du Louvre, émet sur leur compte un jugement des plus sévères ${ }^{9}$. La frise, d'abord destinée à l'École des beaux-arts, est remisée dans la colonnade, puis dans les réserves du Louvre durant de longues années ${ }^{10}$. En comparaison, le musée britannique parait bien mieux doté, puisque, sans évoquer les marbres Elgin acquis dès 1816 et en provenance d'Asie Mineure, Londres reçoit, en 1842-1843, les marbres de l'acropole de Xanthos découverts par Sir Charles Fellows, puis ceux du fameux mausolée d'Halicarnasse grâce aux entreprises de Lord Stratford de Redcliffe et de Sir Charles Thomas Newton au fort Saint-Pierre de Bodrum. Du côté de l'Allemagne, unifiée aux dépens de la France, si les missions archéologiques d'Olympie et de Pergame ne sont pas encore lancées dans les années qui nous occupent, celle d'Heinrich Schliemann à Troie fait grand bruit dès le début des années 1870.

4 L'initiative d'Edmond et de Gustave de Rothschild, tous deux hellénistes et férus d'histoire de l'art, consistant à financer une mission archéologique française de grande envergure, répond donc de fait à un réel besoin de compléter les collections nationales dans le domaine de la sculpture architecturale grecque, en se tournant vers l'Asie 
Mineure, dont les sites sont encore, pour beaucoup, à étudier et dont les sculptures monumentales peuvent être importées (moyennant, il est vrai, de longues négociations avec la Sublime Porte). S'y mêle une forme de sincère patriotisme : Gustave et Edmond de Rothschild ont été frappés par la débâcle de la France à Sedan, en 1870. La rivalité avec l'Empire allemand se joue dorénavant à couteaux tirés, non seulement sur les plans militaires, économiques, diplomatiques, mais aussi dans les domaines des sciences et des beaux-arts. Il paraît urgent aux deux mécènes de soutenir la science archéologique française face à celle de l'école allemande et d'aider la France à concurrencer les musées de Berlin ou de Munich. C'est dans cet état d'esprit qu'ils se tournent vers Olivier Rayet, jeune archéologue qui leur est présenté par l'une de leurs nombreuses connaissances, Ernest Desjardins, historien et géographe du monde antique. Ce dernier fut le professeur de Rayet, d'abord au lycée Bonaparte (actuel lycée Condorcet), puis à l'École normale supérieure, rue d'Ulm. Devenu membre de l'École française d'Athènes à la suite de son succès à l'agrégation d'histoire, Olivier Rayet se montre, en Grèce, un archéologue très actif, voire intrépide. Très vite, en 1870, il décide d'explorer les régions orientales du monde grec, sillonne le Dodécanèse, mais aussi, assez brièvement, l'Asie Mineure, notamment la vallée du Méandre et le site de Milet. Quand il s'agit de répondre à la proposition de Gustave et d'Edmond de Rothschild de financer ses propres projets de mission archéologique, en un temps où les hellénistes ne peuvent guère compter sur les maigres crédits alloués par l'École française d'Athènes, Milet et sa région font tout naturellement partie des choix envisagés, avec Samos, Pergame ou encore Cnide. Olivier Rayet, en bon topographe, comprend bien tout l'intérêt de la patrie de Thalès et de son sanctuaire oraculaire de Didymes. Les lieux sont d'ailleurs déjà connus des Français: en effet, Jean-Nicolas Huyot, pensionnaire de l'Académie de France à Rome, a dessiné le site de Didymes en 1820, et Charles Texier l'explore en 1835 , lors de sa première mission dans la vallée du Méandre. L'affaire est donc entendue : ce seront Milet et les sites du golfe Latmique pour étudier les vestiges antiques qui s'y trouvent, faire progresser la science archéologique française et rapporter en France de précieux témoignages de la civilisation hellénique. Encore faut-il qu'Olivier Rayet obtienne, avec l'appui de la diplomatie française, les précieux firmans que délivrent les autorités ottomanes pour quiconque souhaite entreprendre la moindre campagne de fouilles. Ensuite, il faut aussi convaincre les paysans qui ont établi leurs maisons, leurs potagers ou leurs champs à Hiéronda, l'antique Didymes: tout cela nécessite des moyens financiers considérables, qu'apportent les frères Rothschild. Des fonds, il en faut encore pour rémunérer la maind'œuvre locale et se fournir de matériel lourd, nécessaire pour soulever les blocs effondrés des édifices antiques, avant de pouvoir entreprendre toute étude précise. Enfin, il en faut pour déposer blocs d'architecture et statues à rapporter en France. Ainsi, les deux campagnes successives au temple d'Apollon Didyméen, en 1872 et en 1873, furent des entreprises titanesques, hélas inachevées, puisque, Olivier Rayet le reconnaît lui-même, il aurait fallu encore plus de moyens et plusieurs saisons de fouilles pour dégager entièrement le théâtre de Milet et le temple de Didymes, notamment abattre le moulin à vent logé au cœur du temple.

5 Fort heureusement, Olivier Rayet peut compter sur l'aide d'un jeune architecte talentueux, Albert-Félix-Théophile Thomas (1847-1907), pour exécuter les prises de mesures, les relevés et les restitutions graphiques de l'état antique du temple d'Apollon Didyméen (fig. 1). Ce patient travail, parfois périlleux quand l'architecte travaille au sommet des colonnes depuis une plate-forme en bois qui tangue au gré du vent, permet 
notamment de faire mieux connaître l'architecture d'ordre ionique, originaire de Grèce de l'Est, dont les développements en Asie Mineure sont particulièrement significatifs durant les époques hellénistiques et impériales. De ce point de vue, les publications des fouilles de Rayet et de Thomas remplissent parfaitement les objectifs qu'eux-mêmes et leurs mécènes se sont fixés ${ }^{11}$.

1. Albert-Félix-Théophile Thomas, Vue panoramique du temple d'Apollon à Milet, 1875, aquarelle et mine de plomb sur papier entoilé, 70 × $191 \mathrm{~cm}$, Paris, École nationale supérieure des beaux-arts.

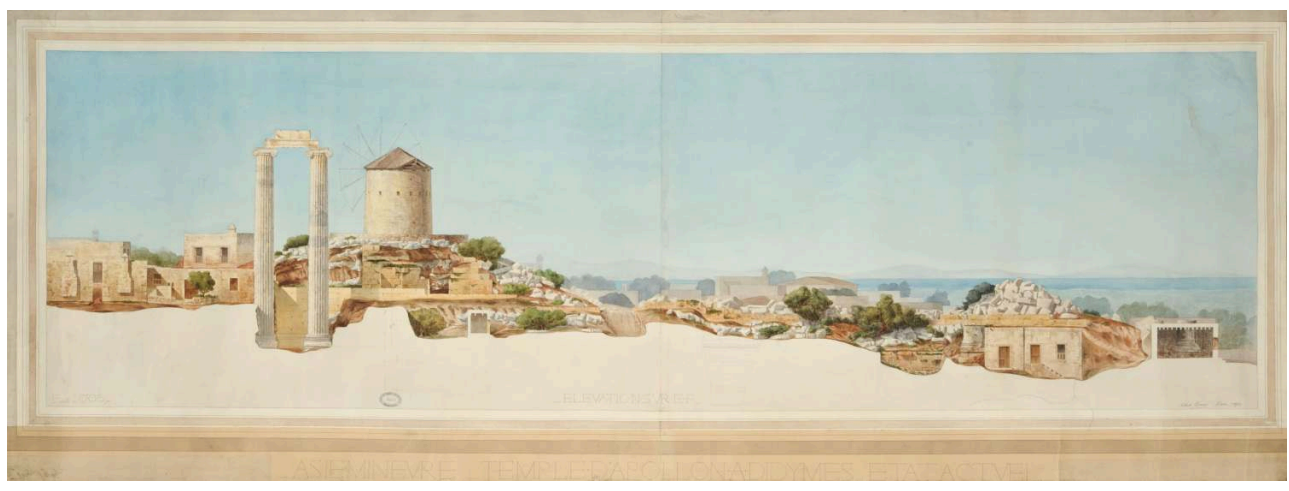

(c) École nationale supérieure des beaux-arts (Ensba)/RMN

Olivier Rayet comme les frères Rothschild ont eu d'emblée le souhait d'enrichir les collections nationales à l'occasion de la mission archéologique de Milet et du golfe Latmique. De Palatia, autrement dit de la cité de Milet, Olivier Rayet prélève trois des cariatides archaïsantes qui décoraient le mur de scène ${ }^{12}$, datées de l'époque julioclaudienne, découvertes dans les éboulements de l'orchestra du théâtre, tout comme une grande femme drapée d'époque hellénistique ${ }^{13}$, un torse qui deviendra célèbre sous le titre usuel de Torse de Milet ${ }^{14}$, une figure masculine de la période du style sévère remployée dans le décor du théâtre, enfin un second torse masculin vêtu d'une chlamyde, d'époque impériale et de moindre intérêt ${ }^{15}$. Dans la plaine de Palatia, dans les broussailles, Olivier Rayet a aussi découvert un lion archaïque colossal et trois femmes assises, typiques des productions de Grèce de l'Est. Longtemps liés à une possible nécropole, ces marbres sont en fait à mettre en rapport avec le sanctuaire d'Artémis Chithoné, situé sur la pente orientale de Kalabak Tepe ${ }^{16}$.

Pendant que l'archéologue et l'architecte attendent leurs autorisations pour fouiller à Hiéronda, ils explorent, durant six semaines, Tralles, Priène et Héraclée du Latmos (Kapi-Kéré). Dans cette dernière cité, Olivier Rayet choisit de collecter surtout des inscriptions ou encore un double cadran solaire dédié à Ptolémée II, signé par un astronome d'Alexandrie ${ }^{17}$. Pour le site qui nous occupe, Didymes, l'entreprise d'expédier vers la France une partie du décor architectural du temple relève d'une véritable gageure. Il faut d'abord retirer les éléments du décor architectural du temple de leur emplacement ou, le plus souvent, du lieu où ils se sont effondrés. Pour être transportables, les blocs les plus importants doivent ensuite être amincis ou évidés afin qu'ils pèsent moins lourd. Il faut encore construire une route de cinq kilomètres ainsi qu'un quai pour le brick venu de l'île de Chios, à bord duquel sont chargés les marbres, dans des conditions souvent très périlleuses. Certains blocs du temple pèsent en effet plus de trois tonnes, même amincis, et le matériel à la disposition de l'équipe française et des ouvriers de fouille turcs paraît fort rudimentaire, à lire le rapport de Rayet ${ }^{18}$. Au prix de tant d'efforts, ce sont deux bases de colonne colossale, une série des chapiteaux 
de pilastres et des blocs de frise (ou épicranitis) de la cour à ciel ouvert du temple, l'adyton, où se tenait l'oracle, qui gagnent bientôt Paris.

8 Cette moisson de sculptures grecques d'Asie Mineure, de Milet, d'Héraclée du Latmos et de Didymes, les frères Gustave et Edmond de Rothschild l'offrent donc au musée parisien : Félix Ravaisson-Mollien, conservateur des Antiques au Louvre, reçoit de leur part une lettre, datée du 24 novembre 1873, qui exprime tout le sens de leur démarche :

Monsieur le Conservateur,

Dans l'intention de rechercher des objets dignes de nos galeries du Louvre, nous avons fait exécuter sous la direction de $\mathrm{Mr} \mathrm{O}$. Rayet, membre de l'École française d'Athènes, des fouilles en Asie Mineure, dans la ville antique de Milet. Les antiquités trouvées dans ces fouilles et que nous avons fait venir en France ont été déposées, d'après l'autorisation que vous avez eu l'obligeance de nous accorder, dans une salle dépendant du département des Antiques où elles ont été soumises à votre appréciation. Nous sommes charmés de les offrir à notre musée du Louvre, très heureux s'il a pu nous être permis d'enrichir nos collections nationales et de concourir aux progrès de la science archéologique.

Agréez, Monsieur le Conservateur, l'assurance de ma haute considération.

Gustave de Rothschild

Edmond de Rothschild

Cette donation remarquable concerne 14 éléments de sculpture architecturale du Didyméion, datant de l'époque hellénistique à l'époque impériale romaine, qui sont le fruit des fouilles de la mission Rayet, à l'exception d'un seul chapiteau colossal, dont les frères Rothschild se réservent l'agrément, celui qui nous occupe précisément. Cette exception parait bien modeste au vu de l'importance du don consenti, tant et si bien que ce chapiteau finit par tomber dans l'oubli au musée du Louvre, comme le montre la suite des événements.

Tableau récapitulatif des marbres du Didyméion offerts par Gustave et Edmond de Rothschild

\begin{tabular}{|l|l|l|l|}
\hline Description & Datation & Hauteur & Numéro d'inventaire \\
\hline $\begin{array}{l}\text { Chapiteau d'angle du mur extérieur de } \\
\text { l'adyton }\end{array}$ & $\begin{array}{l}\text { Deuxième quart du } \\
\text { II } \text { siècle av. J.-C. }\end{array}$ & $118 \mathrm{~cm}$ & Ma 2779. MNB 671 \\
\hline $\begin{array}{l}\text { Chapiteau de pilastre de la partie sud du } \\
\text { mur est, dans l'adyton }\end{array}$ & $\begin{array}{l}\text { Seconde moitié du } \\
\text { III' siècle av. J.-C. }\end{array}$ & $90 \mathrm{~cm}$ & Ma 2766. MNB 669 \\
\hline $\begin{array}{l}\text { Chapiteau de pilastre de la partie nord du } \\
\text { mur est, dans l'adyton }\end{array}$ & $\begin{array}{l}\text { Seconde moitié du } \\
\text { III' siècle av. J.-C. }\end{array}$ & $90 \mathrm{~cm}$ & Ma 2768. MNB 670 \\
\hline $\begin{array}{l}\text { Demi-chapiteau d'un pilastre d'angle, } \\
\text { premier pilastre du mur ouest, dans } \\
\text { l'adyton }\end{array}$ & II siècle av. J.-C. & $90 \mathrm{~cm}$ & Ma 2771. MNB 674 \\
\hline $\begin{array}{l}\text { Demi-chapiteau d'un pilastre d'angle, } \\
\text { onzième pilastre du mur sud, dans l'adyton }\end{array}$ & II siècle av. J.-C. & $90 \mathrm{~cm}$ & Ma 2769. MNB 672 \\
\hline
\end{tabular}




\begin{tabular}{|c|c|c|c|}
\hline $\begin{array}{l}\text { Demi-chapiteau d'un pilastre d'angle, } \\
\text { cinquième pilastre du mur ouest, dans } \\
\text { l'adyton }\end{array}$ & II ${ }^{\mathrm{e}}$ siècle av. J.-C. & $90 \mathrm{~cm}$ & Ma 2770. MNB 673 \\
\hline $\begin{array}{l}\text { Deux blocs de frise superposés, dans } \\
\text { l'adyton, entre les pilastres }\end{array}$ & II ${ }^{\mathrm{e}}$ siècle av. J.-C. & $105 \mathrm{~cm}$ & $\begin{array}{l}\text { Ma 2776-2777. MNB } \\
679 \text { et MNB } 675\end{array}$ \\
\hline Bloc de frise (bloc de l'assise supérieure) & II ${ }^{\mathrm{e}}$ siècle av. J.-C. & $61 \mathrm{~cm}$ & Ma 2772. MNB 680 \\
\hline Bloc de frise (bloc de l'assise supérieure) & II ${ }^{\mathrm{e}}$ siècle av. J.-C. & $59 \mathrm{~cm}$ & Ma 2774. MNB 677 \\
\hline Bloc de frise (bloc de l'assise supérieure) & II siècle av. J.-C. & $60 \mathrm{~cm}$ & Ma 2775. MNB 678 \\
\hline $\begin{array}{l}\text { Fragment de bloc de frise (bloc de l'assise } \\
\text { inférieure) }\end{array}$ & II ${ }^{\mathrm{e}}$ siècle av. J.-C. & $60 \mathrm{~cm}$ & Ma 2773. MNB 676 \\
\hline $\begin{array}{l}\text { Fragment d'un bloc d'architrave, dans } \\
\text { l'adyton }\end{array}$ & II ${ }^{\mathrm{e}}$ siècle av. J.-C. & $40 \mathrm{~cm}$ & Ma 2778. MNB 681 \\
\hline $\begin{array}{l}\text { Base de colonne ionique, troisième colonne } \\
\text { de la façade du temple }\end{array}$ & $\begin{array}{l}\text { Premier quart du } \\
\text { II }^{\mathrm{e}} \text { siècle apr. J.-C. }\end{array}$ & $106 \mathrm{~cm}$ & Ma 2764. MNB 667 \\
\hline $\begin{array}{l}\text { Base de colonne ionique, quatrième } \\
\text { colonne de la façade du temple }\end{array}$ & $\begin{array}{l}\text { Premier quart du } \\
\mathrm{II}^{\mathrm{e}} \text { siècle apr. J.-C. }\end{array}$ & $92 \mathrm{~cm}$ & Ma 2765. MNB 666 \\
\hline $\begin{array}{l}\text { Fragment d'un bloc d'architrave, au-dessus } \\
\text { des colonnes, dans l'adyton }\end{array}$ & II ${ }^{\mathrm{e}}$ siècle av. J.-C. & $40 \mathrm{~cm}$ & Ma 2778. MNB 681 \\
\hline
\end{tabular}

10 Le don Rothschild inclut en outre 47 éléments de scellement de blocs de marbre du temple de Didymes, en bronze, en fer, en plomb ou en bois : tenons, crapaudines, agrafes, beaucoup moins connus et en cours d'étude pour mieux comprendre les techniques de construction du bâtiment (MNC 716-MNC 750)

11 À cette liste d'œuvres entrées au Louvre en 1873, il faut ajouter deux fragments offerts ultérieurement par Albert Thomas, en 1896.

\begin{tabular}{|l|l|l|l|}
\hline Fragment de moulure lesbique & II $^{\mathrm{e}}$ siècle av. J.-C. & $31 \mathrm{~cm}$ & Ma 2780. MNC 899 \\
\hline Fragment de moulure ionique & II $^{\mathrm{e}}$ siècle av. J.-C. & $22,5 \mathrm{~cm}$ & Ma 2782. MNC 901 \\
\hline
\end{tabular}

12 L'afflux de ces œuvres produit bientôt un effet décisif quant à la présentation des collections de sculpture architecturale dans les salles du département des Antiquités grecques et romaines. En 1877, dans l'aile nord de la cour Carrée, assez loin du reste du parcours des antiquités classiques, c'est notamment en raison de la récente arrivée à Paris des marbres de la mission Rayet que sont créées deux salles entièrement consacrées à l'Asie Mineure : la salle de Milet et la salle de Magnésie du Méandre ${ }^{19}$. Dans un accrochage très dense, propre aux usages muséographiques du XIX ${ }^{e}$ siècle, on décide donc de privilégier une sélection géographique des œuvres, en réunissant les marbres de Grèce de l'Est entrés au Louvre depuis longtemps: les frises du temple d'Athéna 
archaïque d'Assos, le vase de Pergame, le décor ionique du temple d'Artémis à Magnésie du Méandre, mais aussi l'Apollon Lycien de Smyrne, acquis pour Louis XIV en 1680, saisi à Versailles à la Révolution, en $1798^{20}$. Dans la salle de Milet, le produit des fouilles permises par le généreux mécénat des Rothschild constitue alors la fine fleur de cette présentation : le Torse de Milet trône au centre de l'espace, flanqué par les deux bases de colonne du temple de Didymes. Au mur, les chapiteaux de pilastre du Didyméion alternent avec des éléments du décor du temple d'Assos, dans une mise en scène où les effets de symétrie l'emportent sur tout classement topographique précis et, plus encore, sur toute forme d'ordre chronologique (fig. 2).

2. Vue de la salle de Milet à la fin du xix ${ }^{e}$ siècle, Paris, musée du Louvre, documentation du département des Antiquités grecques, étrusques et romaines.

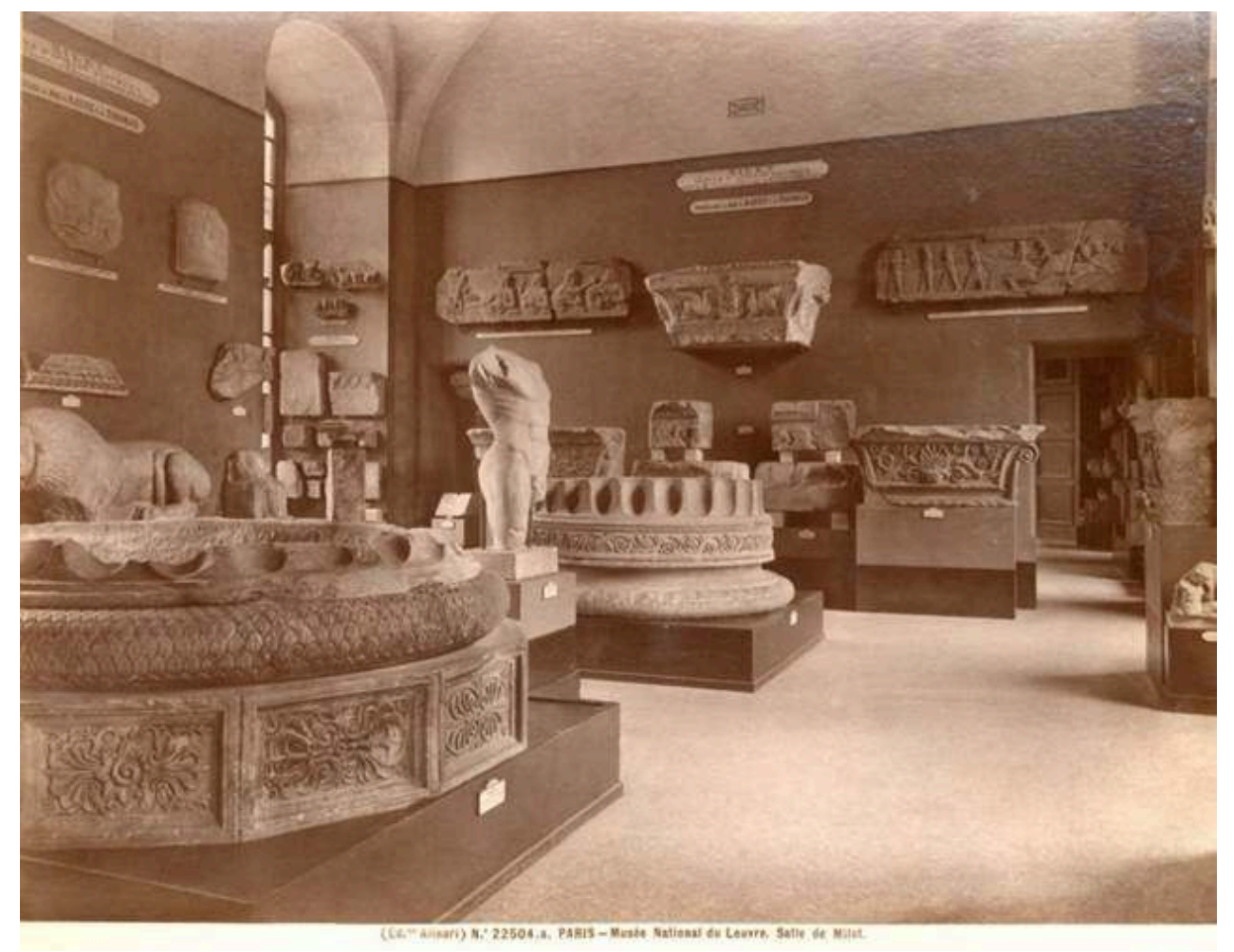

(C) Musée du Louvre

13 Au début des années 1930, dans le cadre du plan d'Henri Verne, directeur du Louvre, le département des Antiquités grecques et romaines obtient le couvrement de la cour du Sphinx afin d'y offrir plus d'espace à la présentation de la sculpture architecturale. L'espace est doté d'une verrière dès 1934 ; et en 1936 y sont déployés les marbres de Magnésie du Méandre, de Milet et de Didymes, principalement sur les côtés sud et ouest de la salle nouvellement créée. Côté ouest, sur une longue banquette, les chapiteaux et les blocs de frise du Didyméion alternent avec les cariatides du théâtre de Milet, sous l'alignement en quatre registres des blocs de la frise du temple d'Artémis à Magnésie du Méandre (fig. 3). Dans ce secteur, la cour du Sphinx reste pratiquement en l'état jusqu'à aujourd'hui, sauf certains marbres retirés pour rejoindre d'autres espaces, comme le vase de Pergame qui gagne la salle d'Asie Mineure, créée en 2010, au sein de la nouvelle galerie consacrée à l'époque hellénistique ${ }^{21}$. Mais, dans la cour du Sphinx, rien n'a 
jamais rappelé l'existence du chapiteau de Didymes conservé par la famille Rothschild, et la mémoire de ce dernier s'estompe peu à peu au Louvre ${ }^{22}$.

3. Vue de la cour de Sphinx, état durant la fin des années 1930, Paris, musée du Louvre, documentation du département des Antiquités grecques, étrusques et romaines.

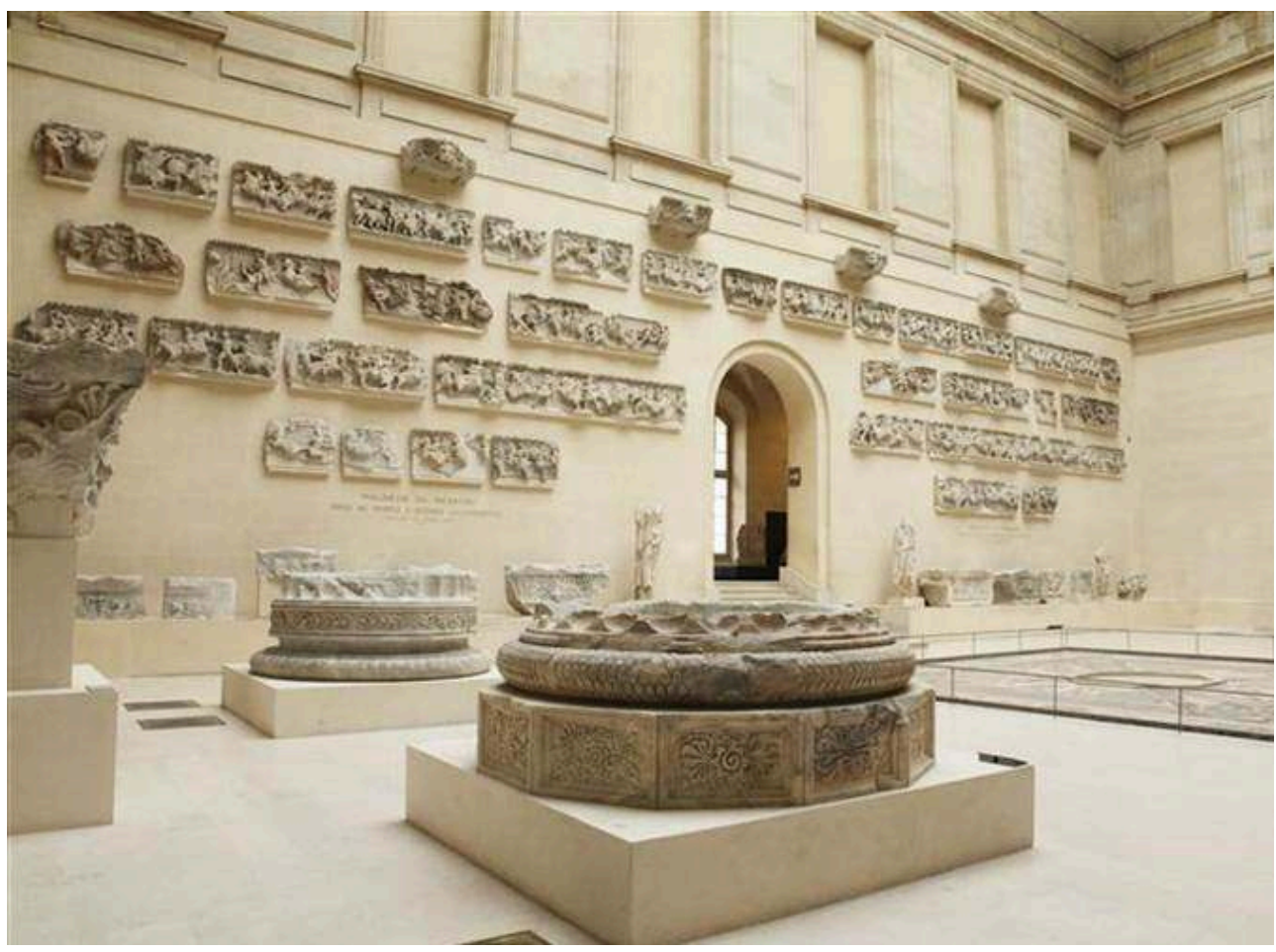

(c) Musée du Louvre

En 2016, le département des Antiquités grecques, étrusques et romaines prépare une exposition dédiée à Milet et à son vaste réseau de colonies en mer Noire, à l'initiative de Françoise Gaultier, directrice du département. En faisant le recensement de toutes les œuvres du musée provenant du territoire de Milet, notre attention s'arrête alors sur une vue de la salle de Milet ouverte en 1877 (fig. 2), datée de la fin du XIXe siècle : y figure, accroché au mur, un chapiteau en sofa du type de ceux de l'adyton du Didyméion, mais dont le décor, deux griffons mâle et femelle, affrontés de part et d'autre d'un bouquet de rinceaux d'acanthe, n'est pas comparable à celui des chapiteaux de la cour du Sphinx, simplement ornés de rinceaux d'acanthe. Dans la collection du Louvre, seuls les demi-chapiteaux d'angle de l'adyton du temple sont décorés d'un griffon. En agrandissant cette photographie, on s'avise que cet exemplaire est un moulage, dont on trouve d'ailleurs bientôt une vue séparée (fig. 4). Le cartel placé sous le plâtre dissipe tout malentendu: "Milet. Moulage d'un chapiteau de pilastre décoré de deux griffons affrontés de part et d'autre d'une palmette. Original chez le baron Gustave de Rothschild.» Le moulage (qui correspond au numéro MNB $668 \mathrm{du}$ livre d'entrées du département des Antiquités grecques et romaines du musée du Louvre et au numéro Ma 2767 du catalogue des marbres antiques de 189623) est alors recherché dans la collection de la gypsothèque, abritée dans la petite écurie du château de Versailles, qui dépend du département des Antiquités grecques, étrusques et romaines du musée du Louvre, mais il n'en existe aucune trace. Tout laisse alors à penser que, hélas!, le moulage en question a été détruit quand la salle de Milet fut 
démontée à la fin des années 1920. Le projet d'exposition consacrée à Milet n'étant pas retenu en définitive au Louvre, les recherches concernant ce chapiteau, situé « chez le baron Gustave de Rothschild », s'arrêtent là, temporairement.

4. Moulage du chapiteau en sofa à griffons affrontés, offert par Gustave de Rothschild, présenté dans la salle de Milet.

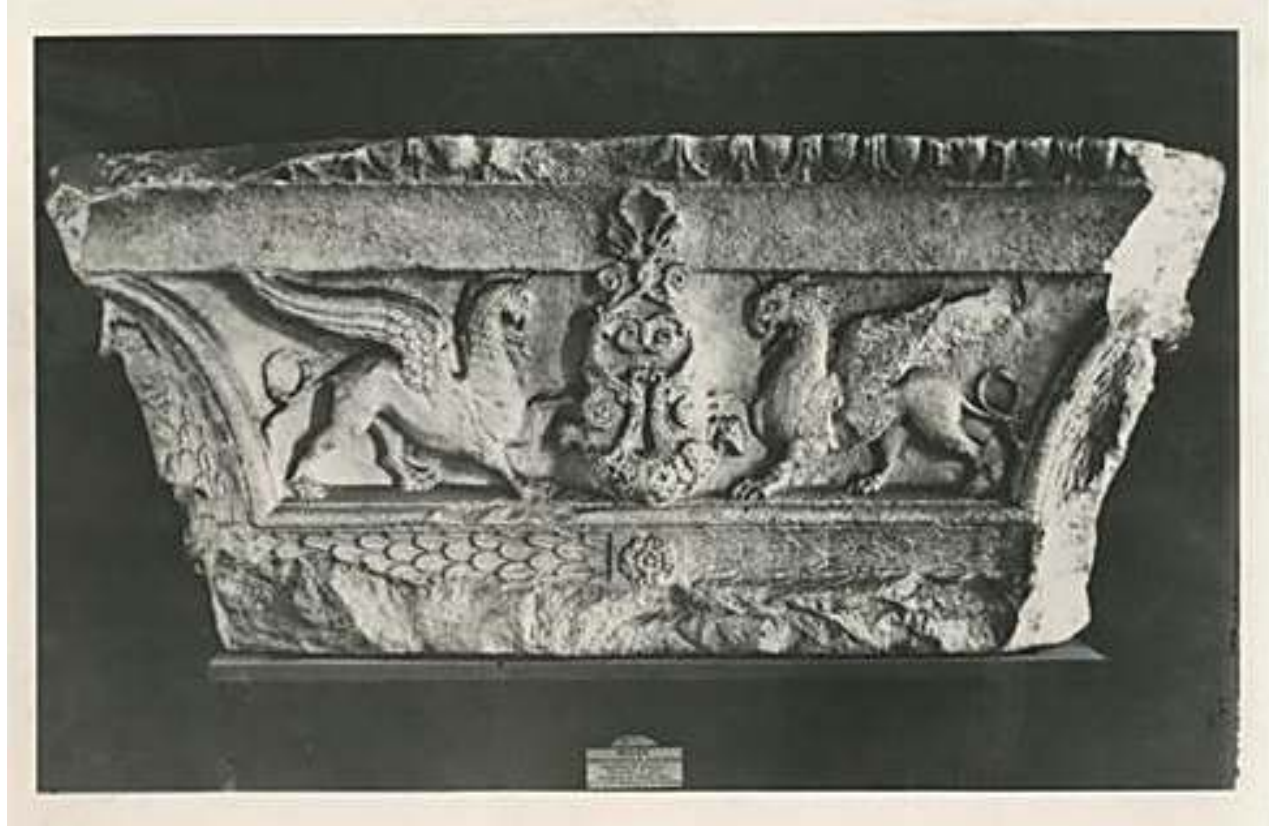

(c) Musée du Louvre

15 Mais bientôt, cette fois dans les jardins de l'hôtel Marigny, l'intérêt se porte sur un chapiteau colossal se trouvant au fond du jardin. Cet antique est bientôt identifié par rapprochement avec deux demi-chapiteaux du même type, conservés au musée du Louvre $^{24}$. Analogie confortée à la lecture de la monographie consacrée au mécénat de la famille Rothschild en France ${ }^{25}$, qui permet d'émettre l'hypothèse d'une provenance commune pour ce chapiteau et ceux du Louvre : la mission archéologique Rayet en Asie Mineure de 1872-1873. L'examen de son revers confirme aussi cet historique : on l'a retaillé grossièrement pour l'alléger et faciliter son enlèvement, son transport jusqu'à la mer, puis son chargement sur un navire. Cette taille est caractéristique de tous les gros blocs rapportés par Rayet en 1873.

16 En 2018, il suffit de quelques échanges avec le Louvre, à l'initiative de l'Élysée, pour que les questions des uns et les trouvailles des autres permettent de confirmer une découverte toute simple: Gustave de Rothschild, qui s'était réservé la propriété du chapiteau à deux griffons de Didymes, l'avait installé dans le jardin de l'hôtel Marigny, tout juste achevé.

\section{Le chapiteau du Didyméion à l'hôtel Marigny}

17 Le baron Gustave de Rothschild fait bâtir son hôtel particulier au 23, avenue de Marigny, en $1873^{26}$, l'année même où il finance, avec son frère Edmond, la mission archéologique Rayet en Asie Mineure. 
18 En 1971, sous la présidence de Georges Pompidou, l'État fait l'acquisition de l'hôtel Rothschild de l'avenue de Marigny ${ }^{27}$, pour y recevoir les hôtes de la France ${ }^{28}$. Il abrite aujourd'hui le Centre national de contre-terrorisme (CNCT) ainsi que des salons, bureaux et locaux techniques de la présidence de la République.

19 À l'extrémité sud de son jardin se trouvait un bas-relief en marbre $(\text { fig. } 5 \text { et } 6)^{29}$. Ni inventorié ni répertorié, il passait jusqu'à présent pour un chapiteau du palais des Tuileries $^{30}$. À tort : la rapide vérification que nous venons d'exposer a permis d'écarter cette origine et de retrouver son véritable pedigree.

5. Le chapiteau au fond du jardin de l'hôtel Marigny, état en 2017.

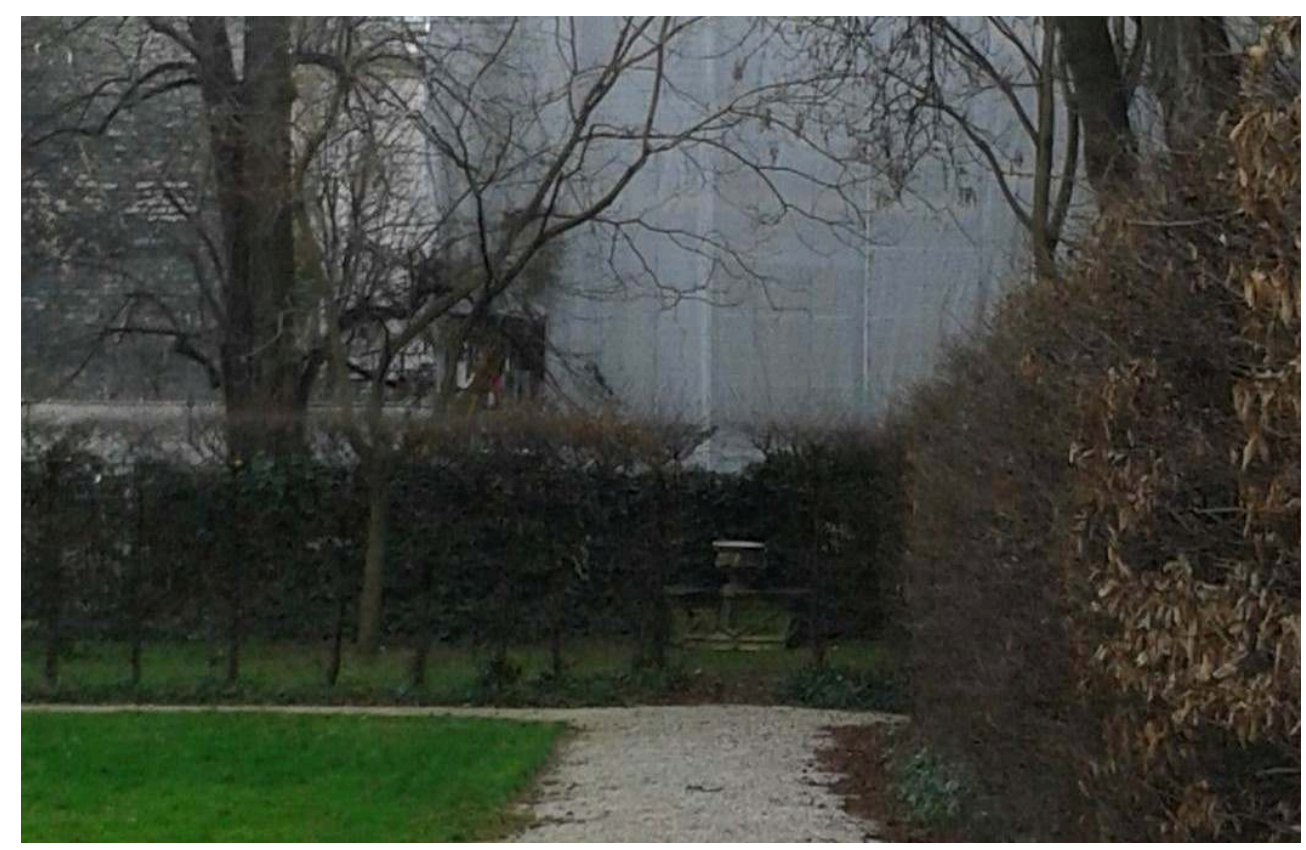

(c) Présidence de la République/Pierre Bonnaure 
6. Chapiteau de pilastre de l'adyton du temple d'Apollon à Didymes, Paris, présidence de la République, hôtel Marigny, marbre, début du ॥e siècle av. J.-C., état en 2017.

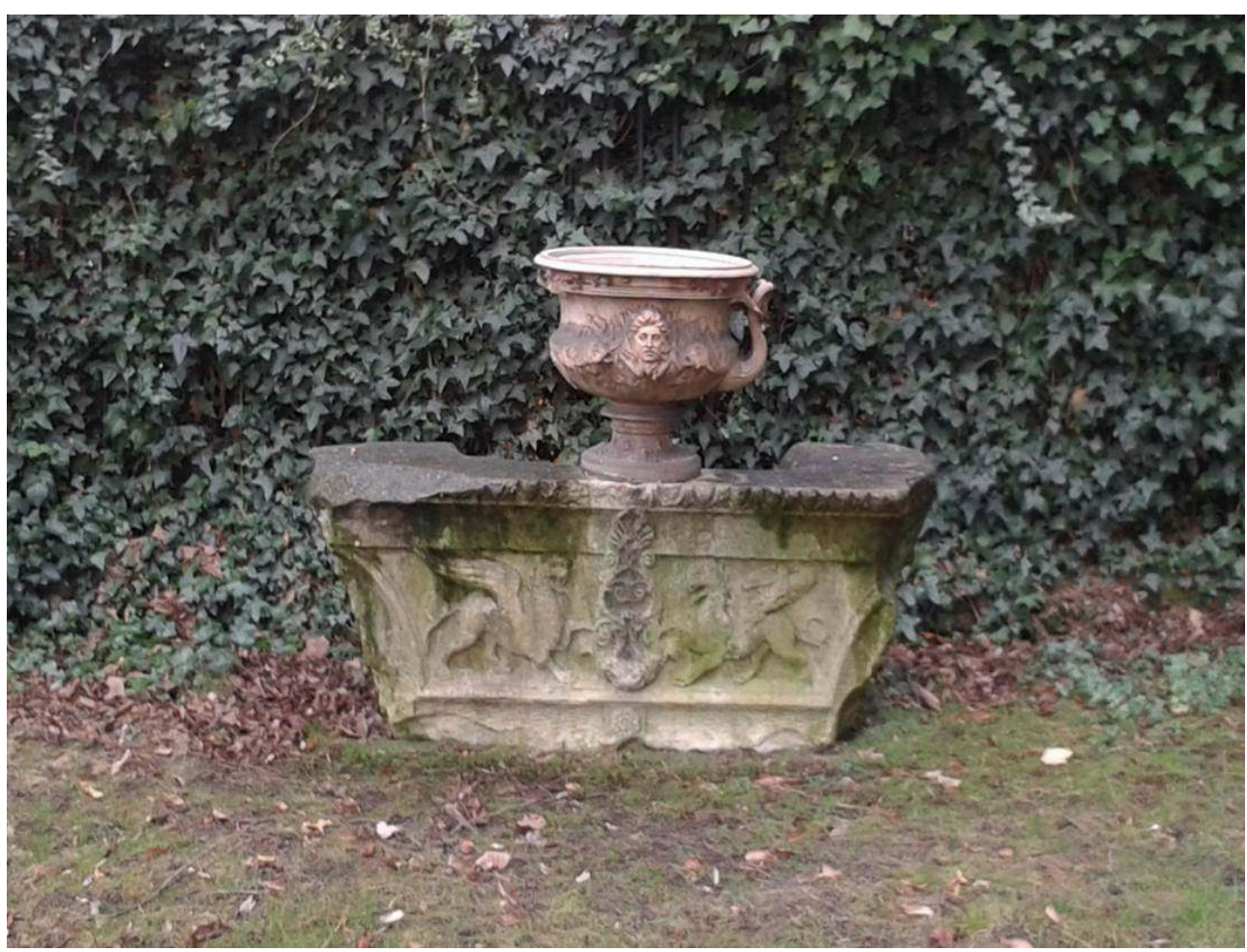

(c) Présidence de la République/Pierre Bonnaure

Le jardin de l'hôtel Marigny, agrandi dès 1879, a été remanié à plusieurs reprises et notamment en 1928, pour Robert de Rothschild ${ }^{31}$. Peu après son acquisition par l'État, le jardin est réaménagé en 1974 par les architectes Joseph Belmont et Guy Nicot ${ }^{32}$. Il est profondément restructuré par Gabor Mester de Parajd en 1997, à l'issue des travaux d'aménagement d'un garage en sous-sol. Il est enfin remis en état en 2014, suite à diverses occupations ${ }^{33}$.

21 C'est peu dire que le chapiteau en marbre de Didymes n'a pas beaucoup retenu l'attention jusqu'à nos jours. Nous en voulons pour preuve que le chapiteau est totalement absent des relevés et projets de Moreux, Belmont, Nicot et Mester de Parajd ${ }^{34}$. Il n'apparaît pas non plus sur la Vue de la façade sur jardin de l'hôtel Gustave de Rothschild d'Alexandre Serebriakoff, en $1975^{35}$. Il n'est situé pour la première fois qu'en 1993, sur un plan qui l'identifie comme une "stèle ${ }^{36}$ ". Il servait alors de jardinière (fig. 7). Il échappe complètement au diagnostic archéologique de 1994³7. En 1996, pour permettre le creusement du garage souterrain, il est déplacé et relégué, avec l'ensemble du décor sculpté du jardin, tout au bout de la parcelle ${ }^{38}$ (fig. 5 et 8 ). Il faillit alors partir pour un dépôt lapidaire ${ }^{39}$. À la fin du réaménagement du jardin qui s'ensuivit, Mester de Parajd se penche enfin sur le sort de cette " pierre [sic] sculptée entreposée au fond du jardin » : elle « devra être déplacée et posée sur un socle derrière la haie ${ }^{40}$ ». 
7. Vue du jardin de l'hôtel Marigny, état avant les travaux de 1996. Le chapiteau était utilisé comme jardinière et se trouvait alors plus proche de l'hôtel, la face tournée à l'est, vers l'avenue de Marigny.

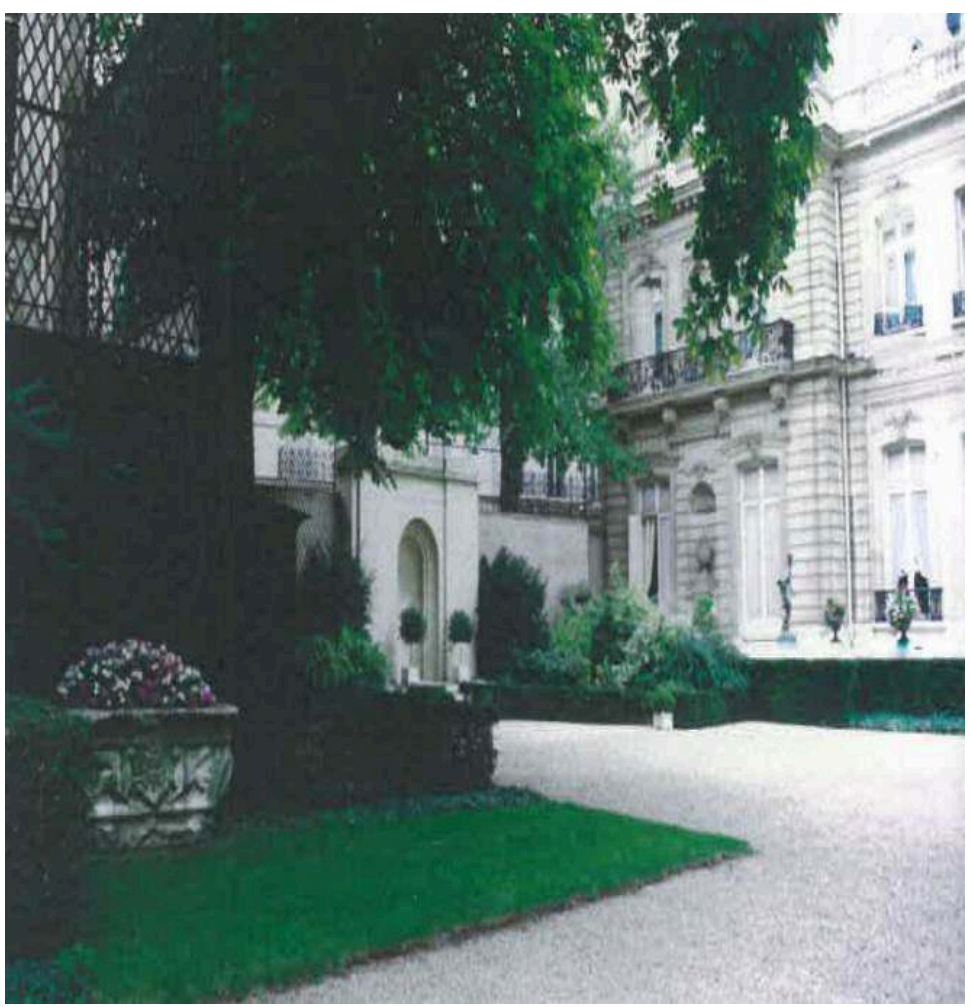

(c) Présidence de la République/Pierre Bonnaure

8. Plan de la partie sud du jardin de l'hôtel Marigny, état 2014-2019. L'emplacement du chapiteau, de 1997 à 2019, est indiqué par le rectangle bleu, en haut à gauche.

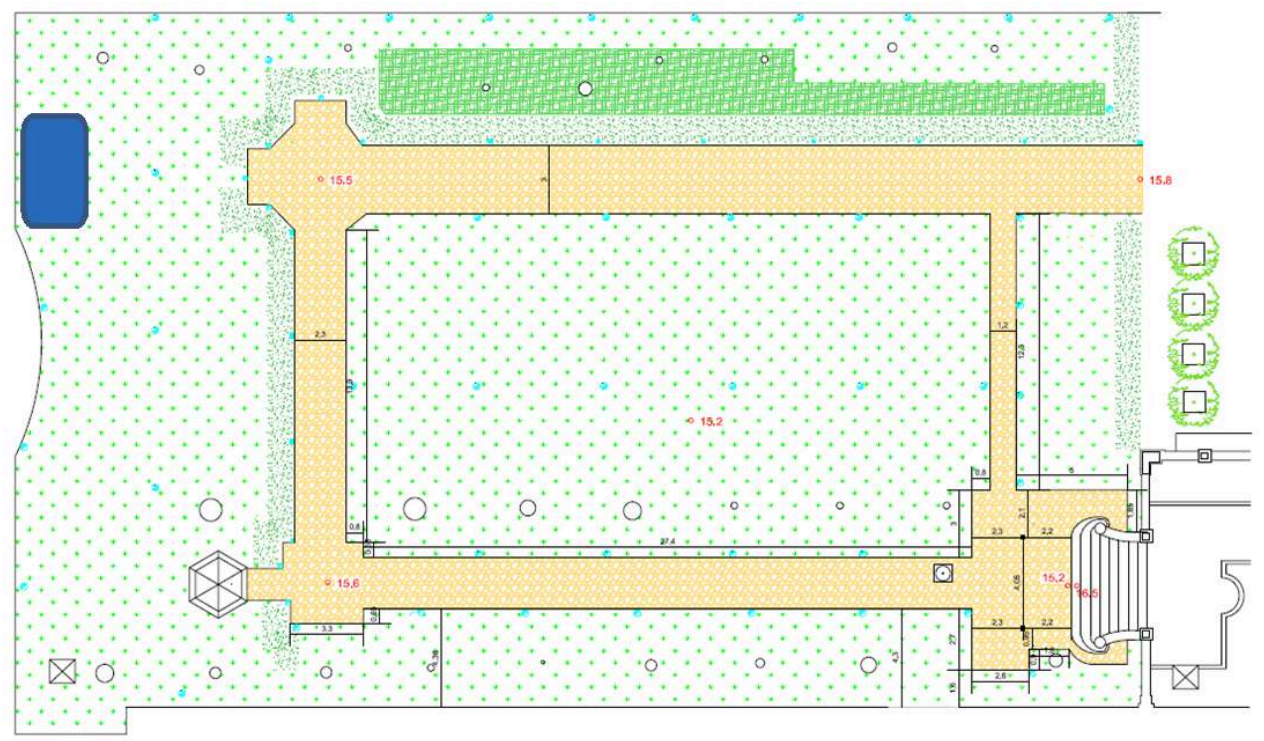

(c) D.R.

Lors de son identification en 2017, le chapiteau était surmonté d'un vase fragmentaire en grosse porcelaine de Sèvres (fig. 6) ${ }^{41}$. Gagné par le lierre, ce triste décor lapidaire servait alors à dissimuler des accessoires d'arrosage sous une tôle ondulée. 
Exposé au nord, en pleine ombre, sous un très vieux tilleul menaçant ${ }^{42}$, son état devenait préoccupant : son épiderme, saccharoïde par endroits, était largement tapissé de lichens, de mousses et d'algues, masquant de possibles microfissures. Ces conditions de conservation inquiétaient et ne pouvaient plus être prolongées indéfiniment. Rejeté tout au fond du jardin, à moitié caché par une charmille, ce chapiteau ne contribuait plus que fort modestement et discrètement au décor de l'hôtel particulier, devenu résidence présidentielle. Il était, par ailleurs, totalement invisible du public. Comme cet antique constituait le plus ancien ornement des résidences présidentielles, sa valeur patrimoniale et sa fragilité imposaient de l'abriter. Nous avons suggéré qu'il puisse être confié au musée du Louvre, plus à même d'en assurer la restauration, la conservation, l'étude et surtout l'exposition. C'est chose faite depuis le 18 mars 2019, date de son enlèvement de l'avenue de Marigny ${ }^{43}$. Transféré le jour même dans la cour du Sphinx et placé à l'abri derrière une palissade, il est aussitôt restauré par Anna Martinotta. Au Louvre, le chapiteau de l'hôtel Marigny revêtira un intérêt particulier : c'est le seul exemplaire de ce type précis conservé au musée, comparable à trois chapiteaux identiques provenant du mur sud de l'adyton, demeurés à Didymes et déposés à proximité du temple par les archéologues de la mission allemande de Milet-Didymes au début $d u x^{e}$ siècle. Il sera visible au début de l'année 2020, dès qu'une restauration de grande ampleur sera achevée, celle de la mosaïque des Saisons de Daphné, faubourg d'Antioche sur l'Oronte, et que la cour du Sphinx sera de nouveau entièrement ouverte au public (fig. 9).

9. Victoria Gertenbach, Esquisse pour l'implantation du chapiteau de Didymes provenant de l'hôtel Marigny, 2018, direction de la Médiation et de la production culturelle, Paris, musée du Louvre.

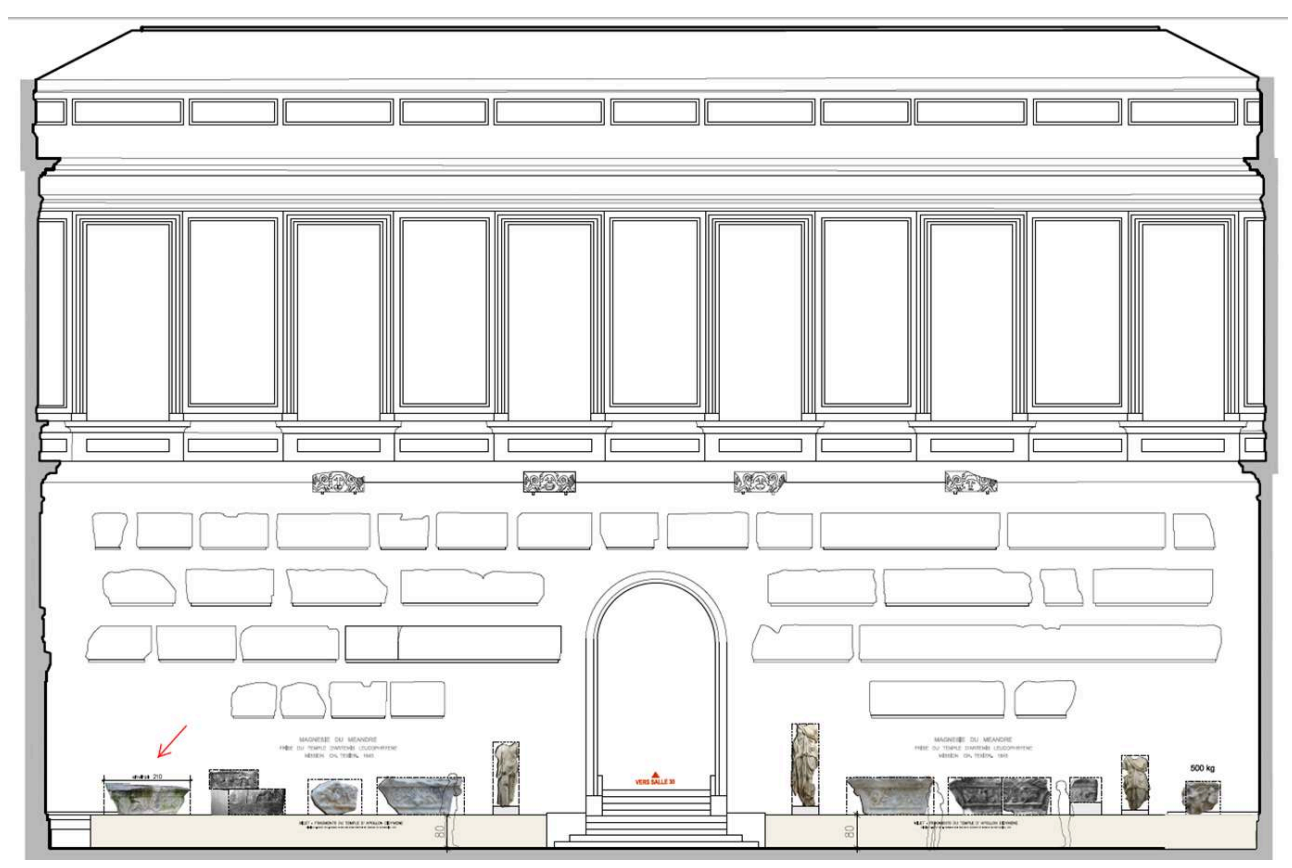

(c) Musée du Louvre 


\section{NOTES}

1. Pauline Prevost-Marcilhacy (dir.), Les Rothschild. Une dynastie de mécènes en France, 3 vol., Paris, Louvre/BnF/Somogy, 2016; Alain Pasquier, «Edmond et Gustave de Rothschild, mécènes de l'archéologue Olivier Rayet et donateurs au musée du Louvre, 1873 ", ibid., vol. I, p. 60-69 ; François Baratte, «Le trésor de Boscoreale au musée du Louvre, 1895 », ibid., vol. I, p. 70-81.

2. Musée du Louvre, département des Antiquités grecques, étrusques et romaines, Ma 197, Ma 129, Ma 165, Ma 210, Ma 164, Ma 2857, Ma 2867 Ma 2921 ; Ludovic Laugier, Catalogue raisonné des sculptures des provinces hellénophones de l'Empire romain, à paraître en 2020.

3. Musée du Louvre, département des Antiquités grecques, étrusques et romaines, Ma 2867, Ma 2871 ; Ludovic Laugier, Catalogue raisonné des sculptures des provinces hellénophones de l'Empire romain, op. cit.

4. Musée du Louvre, département des Antiquités grecques, étrusques et romaines, Ma 2860 ; Ludovic Laugier, Catalogue raisonné des sculptures des provinces hellénophones de l'Empire romain, op. cit.

5. Musée du Louvre, département des Antiquités grecques, étrusques et romaines, Ma 2825Ma 2837 ; Marianne Hamiaux, Les Sculptures grecques. II, La période hellénistique, Paris, RMN, 1998, $\mathrm{n}^{\circ} 215$, p. 196-197.

6. Musée du Louvre, département des Antiquités grecques, étrusques et romaines, Ma 2825-Ma 2837 ; Marianne Hamiaux, Les Sculptures grecques. I, Des origines à la fin du IVe siècle avant J.-C., Paris, RMN, 2001, LP 2585, nº 58-70, p. 67-75.

7. Musée du Louvre, département des Antiquités grecques, étrusques et romaines; Marianne Hamiaux, Les Sculptures grecques, op. cit., t. I, nº 336-396, p. 276-308.

8. Le vase de Pergame revêt toutefois une forme d'intérêt indirect, dans la mesure où les deux urnes découvertes avec lui ont été placées au cœur de Sainte-Sophie de Constantinople sur les ordres du sultan.

9. Frédéric de Clarac, Musée de sculpture antique et moderne, 13 vol., Paris, 1847, t. II, p. 1225 : «Après ce qui vient d'être exposé sur Magnésie et sur son temple, nous espérions ne plus avoir à en occuper le lecteur, qui trouve peut-être que nous ne l'y avons arrêté que trop longtemps et que pour ne lui offrir que peu de chose. "

10. Alain Davesne, La Frise du temple d'Artémis à Magnésie du Méandre. Catalogue des fragments du Musée du Louvre, Paris, Éditions Recherche sur les civilisations, 1982, p. 20.

11. Olivier Rayet, "Fouilles faites en Asie Mineure aux frais de MM. les barons G. et E. de Rothschild », Revue archéologique, 1874, t. I, p. 9-21 ; Olivier Rayet, « Inscriptions inédites trouvées à Milet, Didymes et Héraclée du Latmos, aujourd'hui conservées au Louvre », Revue archéologique, 1874, t. II, p. 103-114 ; Olivier Rayet et Albert Thomas, Milet et le golfe Latmique : Tralles, Magnésie du Méandre, Priène, Milet, Didymes, Héraclée du Latmos. Fouilles et explorations archéologiques, faites aux frais de MM. les barons $G$. et T. de Rothschild et publiées sous les auspices du ministère de l'Instruction publique et des Beaux-Arts, 2 vol., 1 vol. de planches, Paris, J. Baudry, 1877-1880.

12. Musée du Louvre, département des Antiquités grecques, étrusques et romaines, Ma 2793-2795 ; Ludovic Laugier, Catalogue raisonné des sculptures des provinces hellénophones de l'Empire romain, op. cit.

13. Musée du Louvre, département des Antiquités grecques, étrusques et romaines, Ma 2796 ; Marianne Hamiaux, Les Sculptures grecques, op. cit., t. II, p. 26-27, $\mathrm{n}^{\circ} 1$.

14. Musée du Louvre, département des Antiquités grecques, étrusques et romaines, Ma 2792 ; Marianne Hamiaux, Les Sculptures grecques, op. cit., t. I, p. 100-101, nº 90. 
15. Musée du Louvre, département des Antiquités grecques, étrusques et romaines, Ma 2791 ; Ludovic Laugier, Catalogue raisonné des sculptures des provinces hellénophones de l'Empire romain, op. cit.

16. Alain Duplouy, Le Prestige des élites. Recherches sur les modes de reconnaissance sociale en Grèce entre les $X^{e}$ et $V^{e}$ siècles avant J.-C., Paris, Les Belles Lettres, 2006, p. 222-224. Ma 2790, Ma 2787-2789 ; Marianne Hamiaux, Les Sculptures grecques, op. cit., t. I, p. 53-55, nº 45-47, p. 58, $\mathrm{n}^{\circ} 50$.

17. Musée du Louvre, département des Antiquités grecques, étrusques et romaines, Ma 2820 ; Marianne Hamiaux, Les Sculptures grecques, op. cit., t. II, p. 202, $\mathrm{n}^{\circ} 218$.

18. Olivier Rayet et Albert Thomas, Milet et le golfe Latmique, op. cit., t. I, p. 18.

19. Antoine Héron de Villefosse, Catalogue sommaire des marbres antiques, Paris, Musées nationaux, 1896, p. 160-174, salle XXXVI et salle XXXVII.

20. Musée du Louvre, département des Antiquités grecques, étrusques et romaines, Ma 928 ; Ludovic Laugier, Catalogue raisonné des sculptures des provinces hellénophones de l'Empire romain, op. cit.

21. Les marbres d'Assos quittent la cour du Sphinx dès le début des années 1980, pour rejoindre la nouvelle salle consacrée à l'époque archaïque dans l'espace situé sous l'escalier Daru ; puis ils sont installés, en 1997, dans la nouvelle galerie préclassique conçue par Sophie Decamps dans le cadre de la seconde phase du projet « Grand Louvre ».

22. Alain Pasquier évoque brièvement ce chapiteau dans son article sur le mécénat des fouilles de Milet et de Didymes par les frères Rothschild: «Edmond et Gustave de Rothschild, mécènes de l'archéologue Olivier Rayet et donateurs au musée du Louvre, 1873 », art. cit., p. 68. Voir aussi Olivier Rayet et Albert Thomas, Milet et le golfe Latmique, op. cit., t. II, p. 16.

23. Voir Héron de Villefosse, Catalogue sommaire des marbres antiques, op. cit., p. 161.

24. Exposés dans la cour du Sphinx, Ma 2769 et Ma 2771.

25. Pauline Prevost-Marcilhacy (dir.), Les Rothschild. Une dynastie de mécènes en France, op. cit., vol. I.

26. Paris, VIII ${ }^{\mathrm{e}}$ arr. Architecte : Alfred-Philibert Aldrophe. Classé «monument historique " par arrêté du 20 août 1992. Il est appelé hôtel Marigny depuis son acquisition par l'État (nota : « hôtel de Marigny" semble abusif). Cf. fiche $\mathrm{n}^{\circ}$ PA00088896 de la base Mérimée du ministère de la Culture. Sur l'histoire de cet hôtel, voir Jean Coural et Jeanine Warnod, « L'Hôtel Marigny. Quand une propriété privée devient résidence officielle », Plaisir de France, $41^{\mathrm{e}}$ année, $\mathrm{n}^{\circ} 429$, mai 1975, p. 36 et p. 74 ; et Pauline Prevost-Marcilhacy, Les Rothschild, bâtisseurs et mécènes, Paris, Flammarion, 1995.

27. Acte passé le 8 décembre 1971, par-devant $\mathrm{M}^{\mathrm{e}}$ Durant des Aulnois, notaire à Paris, entre M. le baron Alain de Rothschild et ses enfants, Béatrice, Éric et Robert, d'une part, et l'État français représenté par M. Marcel Lambinon, d'autre part, pour 20000000 francs, hors frais et droits. Nous remercions Évelyne Van den Neste et ses collègues de la cellule Archives et mémoire de la présidence de la République, pour avoir retrouvé cet acte ainsi que le protocole d'accord en date du 25 octobre 1971, une " Note sur les servitudes à prévoir dans le contrat de vente ", sans date, et le projet de contrat de vente, et Astrid Malmezat pour nous les avoir communiqués.

28. Sous la III et la IV ${ }^{\mathrm{e}}$ République, les chefs d'État étrangers étaient reçus et logés au palais de l'Élysée ou à l'hôtel du ministre des Affaires étrangères, sis quai d'Orsay. Aux débuts de la $V^{e}$ République, le général de Gaulle fit aménager le Grand Trianon et le château de Champs-surMarne pour ce faire, mais leur relatif éloignement de la capitale s'avéra peu commode. Le dernier à avoir été accueilli en visite d'État à l'hôtel Marigny fut Mouammar Kadhafi, en décembre 2007.

29. Dimensions à vue (la base était enterrée) : environ $80 \times 100 \times 200 \mathrm{~cm}$; poids estimé entre 2,5 et $3 \mathrm{t}$ par Michel Goutal, que nous remercions.

30. Communication orale de Yannick Cadet, jardinier des résidences présidentielles. Mais le chapiteau ne correspond, bien sûr, à aucun décor du palais des Tuileries, bâti pour l'essentiel en pierre calcaire. 
31. Jean-Charles Moreux édifie alors, le long de la rue du Cirque, une piscine couverte, complétée d'une salle de gymnastique et d'un garde-meuble, dont la façade sur jardin, tapissée de miroirs, était ornée en son centre d'une niche peinte à fresque par Giorgio de Chirico et flanquée de colonnes jumelées. Rien ne subsiste de ce décor. Ce bâtiment a été presque entièrement reconstruit pour abriter une salle de presse, puis des réserves et maintenant un local technique.

32. Projet daté du 7 mars 1973, copie consultée à Charenton-le-Pont, Médiathèque de l'architecture et du patrimoine, 2015/020/44 doc. 96.

33. Voir ci-dessus note 4.

34. Voir Pauline Prevost-Marcilhacy, Les Rothschild, bâtisseurs et mécènes, op. cit., et Charenton-lePont, Médiathèque de l'architecture et du patrimoine, 2001/021/0005 et 2015/020/44 doc. 96.

35. Aquarelle sur papier, France, coll. part., dimensions inconnues, reproduite dans Pauline Prevost-Marcilhacy, Les Rothschild, bâtisseurs et mécènes, op. cit.

36. Plan topographique partiel (planche 1), dressé par Daniel Legrand, géomètre-expert, daté du 4 novembre 1993, Charenton-le-Pont, Médiathèque de l'architecture et du patrimoine, 2015/020/44 doc. 96.

37. Diagnostic qui se limita, il est vrai, à un sondage en tranchée à l'emplacement du futur garage souterrain. Voir Jean-Claude Durand, Parc de la résidence Marigny; Paris $8^{e}$ Avenue de Marigny; Document final de synthèse de diagnostic, mené du 28 novembre au 28 décembre 1994, Saint-Denis, Service régional de l'archéologie d'Île-de-France, déc. 1994, Charenton-le-Pont, Médiathèque de l'architecture et du patrimoine, 0080/0068/0477-A75/0000/84.

38. Gabor Mester de Parajd (dir.), « Rapport d'état des lieux, visite du 2 décembre 1996, dossier photographique », Réaménagement des jardins, 1996-1997, Charenton-le-Pont, Médiathèque de l'architecture et du patrimoine, 2015/020/44 doc. 96.

39. Il fut sauvé in extremis sur l'insistance de Yannick Cadet, jardinier des résidences présidentielles.

40. Charenton-le-Pont, Médiathèque de l'architecture et du patrimoine, 2015/020/44 doc. 96, G. Mester de Parajd, «Compte rendu de réunion de chantier nº 18 du 24 mars 1997 », p. 3, point $n^{\circ} 9$. 41. Vase d'un ensemble de deux, en forme de cratère assez trapu et ramassé, d'inspiration néobaroque, celui sur notre chapiteau à deux têtes masculines (l'une glabre, l'autre barbue), emblèmes et décor aquatiques (tridents, dauphins et roseaux), l'autre à six mascarons féminins, signés et datés «J. Devicq 1919 - Sèvres ", pour Jules Devicq (1867-1930), sculpteur et modeleur actif à Sèvres de 1881 à 1928, marqués au tampon "Man[ufactu] ${ }^{\text {re }}$ de l'État, Sèvres, 1920, G » et numérotés respectivement $\mathrm{A}$ et $\mathrm{B}$. Déposés à cette date dans le fond du parc du palais de l'Élysée, sur une balustrade (disparue), réformés (à une date inconnue), puis placés dans le jardin de l'hôtel Marigny (historique établi avec l'aide de Yannick Cadet, que nous remercions). Récolés et retournés à Sèvres, Cité de la céramique, en 2018.

42. Probablement contemporain de la construction de l'hôtel et rare témoin du tout premier aménagement du jardin.

43. Suite à son affectation, commission des prêts et dépôts du service des Musées de France, arrêté du 25 avril 2019. Enlèvement et transport effectués par la société Bovis. La dépose aura nécessité au préalable l'intervention du restaurateur, Daniel Ibled, le chapiteau étant scellé au mortier de ciment sur une semelle de béton. Opération rendue possible et facilitée par Jean Salomon, directeur des ressources et de la modernisation, Astrid Malmezat, chargée de mission « récolement et dépôts d'œuvres dans les résidences présidentielles», et Jean-Luc Martinez, président-directeur du Louvre, que nous remercions. 
INDEX

Index chronologique : Antiquité, XIXe siècle

Thèmes : Architecture, archéologie, collections, mécénat, Louvre, Rothschild

Index géographique : Asie Mineure, Didymes, Milet 


\title{
Le trésor de Boscoreale au musée du Louvre : un mécénat exceptionnel d'Edmond de Rothschild pour les collections nationales
}

\author{
Cécile Giroire
}

1 La tenue de ce colloque a été l'occasion de revenir sur un mécénat exceptionnel effectué par le baron Edmond de Rothschild en 1895, au profit des collections du musée du Louvre. Par ce geste insigne, Edmond de Rothschild, esprit cultivé et éclairé s'il en est, philanthrope et grand collectionneur, devient le premier mécène de la famille presque quarante ans avant le legs, à sa mort, de sa collection d'arts graphiques ${ }^{1}$. Des publications et des pièces d'archives permettent de retracer le destin singulier de l'inestimable trésor d'argenterie romaine caché au fond d'une des citernes d'une villa agricole enfouie sous les cendres du Vésuve ${ }^{2}$ et de comprendre le contexte qui porta Edmond de Rothschild à ce geste si généreux à l'égard de la collectivité.

\section{Le contexte archéologique}

Boscoreale est aujourd'hui une petite ville située au sud-est du Vésuve, à quelques kilomètres au nord de Pompéi. Dans l'Antiquité, elle faisait partie du Pagus Augustus Felix Suburbanus, à savoir la banlieue de Pompéi, au cœur de la riche région de Campanie. Les fouilles de la villa Pisanella, d'où provient le trésor de Boscoreale, sont connues, entre autre, grâce à la publication fondamentale d'Antoine Héron de Villefosse (1845-1919), qui propose une synthèse des faits ${ }^{3}$. En 1876, un propriétaire du pays, Luigi Modestino Pulzella, entreprend des travaux pour clore son terrain au niveau du chemin public Settetermini alla Pisanella : il repère des constructions antiques avec quantité de jarres et d'amphores. Giuseppe Fiorelli (1823-1896), qui dirige alors les fouilles de Pompéi et d'Herculanum, est informé de ces découvertes et pense que le terrain doit recouvrir une villa rustica (propriété agricole) qui produisait du vin. Il dépêche une équipe d'ouvriers pour y ouvrir un chantier. Il convient de rappeler que 
Fiorelli est une figure majeure de l'archéologie italienne, puisqu'il a œuvré à en faire une discipline scientifique : il met fin à la véritable chasse aux trésors qui avait cours jusque-là et réorganise les fouilles de Pompéi avec de nouvelles méthodes, plus rigoureuses. Avant lui, les maisons étaient déblayées, les fresques et les objets retirés et envoyés au musée de Naples, lorsqu'ils n'étaient pas détournés, et ensuite le tout était remblayé. Fiorelli applique une méthodologie nouvelle avec notamment la tenue d'un journal de fouilles plus détaillé que celui de ses prédécesseurs et qui répertorie chaque trouvaille, les déblais placés plus loin, la protection des édifices mis au jour et le dégagement de secteurs qui mettent en relation les édifices entre eux. Ainsi parvient-il au déblaiement systématique de la partie ouest de la ville, maison par maison, rue par rue, ce qui lui permet d'établir un plan général de Pompéi ; la cité antique est divisée en îlots, et un numéro d'identification est attribué à chaque maison. Fiorelli décide par ailleurs de ne plus détacher systématiquement les fresques des murs, mais de les protéger in situ. C'est également à lui que l'on doit les moulages en plâtre des victimes de Pompéi. Avec le temps, les cendres durcirent, et les corps recouverts par celles-ci disparurent en poussière, laissant des cavités. Fiorelli a l'idée de couler du plâtre liquide dans les cavités afin de restituer l'attitude des victimes saisies dans les derniers instants de leur vie. La technique révèle en détail les traits des visages, les plis des vêtements et même les coiffures. La mise au jour de la villa Pisanella s'inscrit donc dans un contexte où l'archéologie campanienne connaît de profondes mutations.

3 C'est le successeur de Fiorelli à partir de 1875, l'architecte Michele Ruggiero (1811-1900), qui dirige les fouilles de Boscoreale. Il met au jour une pièce pavée en mosaïque, une cuisine et une écurie dans les limites du terrain de Pulzella. La villa dégagée empiète sur le terrain d'un voisin, le chanoine Angelo Andrea De Prisco (? 1894), qui s'oppose à la destruction de son domaine et à la poursuite des fouilles sur son terrain : les fouilles sont arrêtées le 31 décembre 1876 et citées dans la publication qui fait autorité dans le domaine de l'archéologie italienne: les Notizie degli scavi di antichità. Atti della Reale Accademia dei Lincei ${ }^{4}$.

4 Après la mort d'Angelo Andrea De Prisco en 1894, son descendant, Vincenzo De Prisco (1855-1921), fonctionnaire au ministère des Finances, futur député au Parlement italien et archéologue amateur, prend l'initiative du déblaiement de son domaine et commence des fouilles le 10 septembre 1894, qui seront menées jusqu'en juin 1895, puis reprises le 4 mai 1896 jusqu'en 1899, sous le contrôle de l'Ufficio degli Scavi di Pompei et des inspecteurs Antonio Sogliano (1854-1942) et Angelo Pasqui (? - ?). Ces travaux sont régulièrement portés à la connaissance de la communauté scientifique dans diverses publications ${ }^{5}$.

5 L'hypothèse d'une villa rustica (propriété agricole), formulée par Fiorelli, se confirme lors du dégagement complet de la villa et de ses abords. Le domaine couvre une superficie de $1000 \mathrm{~m}^{2}$ environ, selon un plan quadrangulaire de $40 \mathrm{~m}$ sur $25 \mathrm{~m}$ (fig. 1). On distingue le secteur destiné à l'habitation (pars urbana), au nord-ouest, et les bâtiments liés à l'exploitation (pars rustica), bien plus étendus, au sud-est. L'entrée donne sur une cour bordée par des portiques qui ouvre sur un lieu d'habitation assez modeste et désordonné, sans plan logique, mais doté d'un petit complexe thermal équipé d'un système de chauffage particulièrement bien conservé. Quelques enduits peints sont mis au jour dans des pièces où l'on a identifié un triclinium (salle à manger) et des cubicula (chambres), ainsi que dans les thermes, qui présentent également les vestiges d'un pavement de mosaïque bicolore représentant un dauphin. Au sud de cette 
pars urbana s'étend la pars rustica, qui comprend un double pressoir à vin, un pressoir à huile, quelques chambres de service et un grand cellier à ciel ouvert, où s'alignaient quatre-vingt-quatre grandes jarres en terre cuite destinées à conserver le vin, les dolia.

1. Plan de la villa d'après Antoine Héron de Villefosse, dans «Le Trésor de Boscoreale ", Monuments et mémoires de la Fondation Eugène Piot, 1899, vol. V, fig. 1, p. 13.

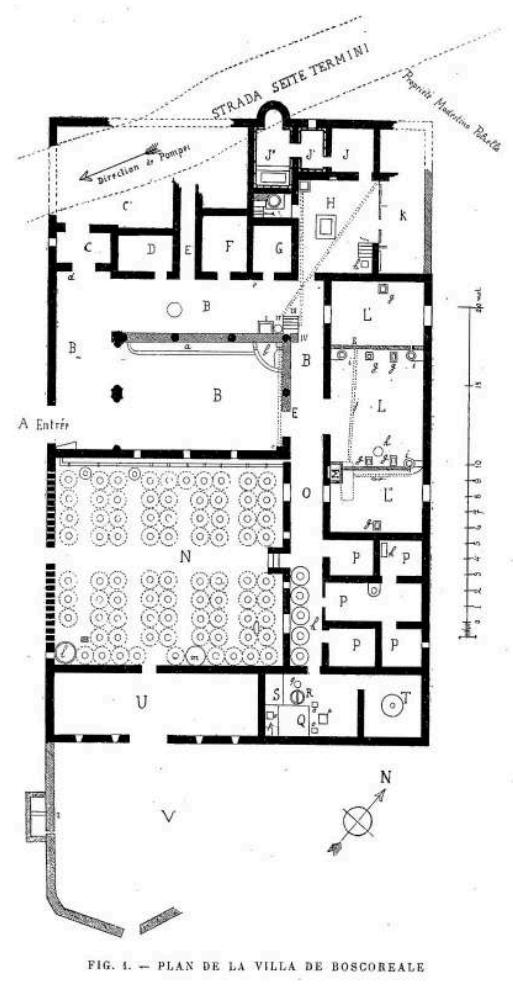

\section{La dispersion du mobilier}

De nombreux objets (près de quatre cents) sont découverts dans toutes les pièces, sans forcément de rapport avec la fonction de ces dernières. Considérés comme le bien propre de Vincenzo De Prisco, parfaitement conscient de la valeur matérielle de ces objets sortis des fouilles, ils sont dispersés. Les frères Canessa, célèbres antiquaires napolitains ${ }^{6}$, se chargent de la vente du matériel, en essayant d'en tirer le maximum de profit. En dépit de la législation italienne, qui prévoit une demande d'exportation en bonne et due forme adressée au gouvernement pour la sortie du territoire des antiquités, le Field Museum de Chicago ${ }^{7}$, le British Museum de Londres ${ }^{8}$, les Staatliche Museen de Berlin', auxquels s'ajoutent des collectionneurs privés plus difficiles à repérer, acquièrent ainsi des objets provenant de la villa Pisanella, mais aussi d'autres villae rusticae de Boscoreale dégagées dans ces mêmes années. Par ailleurs, tout n'est pas vendu: une part importante du matériel de la villa Pisanella est donnée par De Prisco aux Scavi di Pompei, l'ancêtre de l'actuelle surintendance de Pompéi, et exposée, dans un premier temps, dans un petit musée aménagé sur le site même des fouilles. Ces objets sont ensuite transférés à Pompéi, où ils sont partagés entre l'Antiquarium et une réserve connue sous le nom de Granai del foro (greniers du forum). Malheureusement, l'essentiel disparaîtra lors du bombardement de Pompéi durant la Seconde Guerre mondiale. 


\section{Et le trésor?}

7 En dépit des publications et des documents d'archives, une certaine part d'ombre entoure la découverte du trésor dans des circonstances qui n'ont pas été rigoureusement documentées, et l'on comprend pourquoi. Dans la publication fondamentale de $1899^{10}$, la synthèse des faits proposée par Héron de Villefosse repose sur des témoignages oraux, recueillis auprès de De Prisco lui-même et d'un des ouvriers qui lui était proche, un certain Michele Finelli. On y apprend que la découverte a été faite la veille de Pâques, le samedi 13 avril 1895, au fond de la citerne d'un des pressoirs. Le dénommé Michele descend dans cette citerne, découvre des pièces d'argenterie, remonte et ne révèle ce qu'il a vu qu'à De Prisco. Tous deux y retournent à la nuit tombée, en dehors de tout contrôle, pour exhumer toutes les pièces et les mettre en «lieu sûr ", à la galerie Canessa de Naples. Sur ces témoignages oraux se greffent d'autres sources, venues notamment des archives administratives ${ }^{11}$. Un télégramme adressé par Giulio De Petra (1841-1925), directeur des musées de Naples, à l'attention du ministre de l'Instruction publique, à la date du 9 avril $1895^{12}$, précise que la découverte est antérieure de quelques jours à ce qu'indique Héron de Villefosse et il pointe d'emblée la question des fonds nécessaires à l'acquisition de cet ensemble. La réponse est apportée dans une lettre datée du 13 avril, qui précise qu'aucun fonds spécial n'est disponible pour l'acquisition de ce qui est qualifié de "trésor ${ }^{13}$ ». La découverte - dont la date exacte reste inconnue - est donc portée rapidement à la connaissance des autorités qui ne disposent pas des moyens nécessaires pour se porter acquéreur. C'est dans ce contexte que la sortie d'Italie du trésor est arrangée par les frères Canessa, mais demeure encore mal connue et le demeurera sans doute toujours, puisqu'elle s'est faite sans autorisation. D'après Francesco Canessa, l'un des descendants des antiquaires, qui relaie un témoignage oral transmis au sein de la famille ${ }^{14}$, elle serait liée à l'organisation d'une course de vélo entre San Remo et Nice, durant laquelle les coureurs portaient, dans leurs sacs et dans leurs gourdes, les pièces du trésor...

\section{Boscoreale à Paris}

Quel qu'en soit le mode de sortie du territoire italien, quarante et une pièces du trésor se trouvent à Paris à la mi-mai ${ }^{15}$. Ernest Babelon (1854-1924), conservateur du Cabinet des Médailles de la Bibliothèque nationale, en est informé et en fait part à son collègue et ami, Antoine Héron de Villefosse, conservateur du département des Antiques du musée du Louvre et membre de l'Institut. Le 23 mai, Vincenzo De Prisco et Ercole Canessa entament une démarche officielle auprès du directeur des musées nationaux, Albert Kaempfen (1826-1907), dans l'intention de vendre ce premier ensemble. Cette proposition d'acquisition est présentée devant le comité consultatif des Musées nationaux le 30 mai, comme en témoigne le procès-verbal ${ }^{16}$ qui souligne le caractère exceptionnel de cet ensemble constitué des pièces majeures du trésor : les deux coupes à $e m b l e m a^{17}$; la paire de skyphoi ${ }^{18}$ au décor historié ${ }^{19}$ (fig. 2) ; la paire de gobelets aux squelettes $^{20}$; la paire d'œnochoés ${ }^{21}$ aux victoires sacrifiant ${ }^{22}$; la paire de skyphoï aux xenia ${ }^{23}$; la paire de canthares ${ }^{24}$ aux rinceaux habités ${ }^{25}$ et deux des trois miroirs du trésor ${ }^{26}$. La somme demandée est considérable (500 000 francs), bien au-delà de 
l'estimation faite par le conservateur (165000 francs). Même en cas de conciliation, le comité ne dispose pas des moyens suffisants pour financer cette acquisition qui ne pourrait être envisagée qu'à la condition d'une subvention exceptionnelle accordée par le ministre et votée par le Parlement. Des discussions sont entamées au sein du ministère pour négocier cette acquisition au prix de 227000 francs, avec un paiement sur quatre annuités ${ }^{27}$. Dans une note manuscrite datée du 17 juin et adressée à Albert Kaempfen, Antoine Héron de Villefosse précise les motivations qui le conduisent à proposer l'acquisition de cet ensemble : l'importance de la découverte, la qualité de l'exécution et du style, l'intérêt de l'iconographie, motivations auxquelles il ajoute des arguments fondés sur des questions de prestige et d'émulation entre les grands musées européens : «La Bibliothèque nationale possède le célèbre trésor d'argenterie trouvé près de Bernay. Le musée de Berlin expose avec orgueil le trésor d'argenterie d'Hildesheim. Le musée britannique a pu acquérir deux trésors d'argenterie trouvés en France, celui de Caubiac près de Toulouse et celui de Montcornet près de Chaourse (Aisne). Seul le musée du Louvre ne peut rien montrer de semblable à ses nombreux visiteurs. " Pourtant, au terme de trois semaines de négociations, les marchands refusent les " offres de l'administration ${ }^{28}$ » et souhaitent conclure l'affaire rapidement, avant qu'elle ne soit rendue publique. La rumeur se répand parmi les collectionneurs. Des offres sont faites à Ercole Canessa par des collectionneurs français aussi bien qu'étrangers, comme le craint Héron de Villefosse : « Un amateur délicat, poussé par un noble sentiment de patriotisme, a voulu conserver à la France ce précieux ensemble, au moment où l'on pouvait redouter sa dispersion prochaine ou son acquisition par quelque musée étranger ${ }^{29}$.»

2. Coupe d'Auguste d'après Antoine Héron de Villefosse, dans "Le Trésor de Boscoreale ", Monuments et mémoires de la Fondation Eugène Piot, 1899, vol. V, 1899, pl. XXXI.

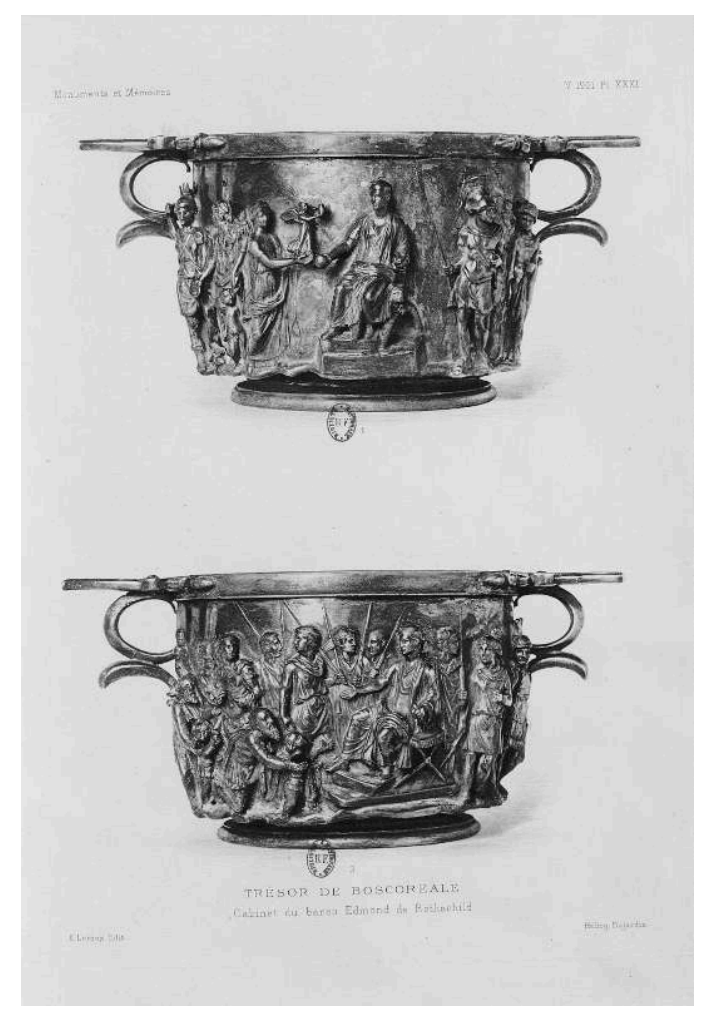




\section{Edmond de Rothschild (1845-1934)}

9 Comme le souligne Pauline Prevost-Marcilhacy ${ }^{30}$, Edmond de Rothschild, le plus jeune fils de Jacob James (1792-1868), se distingue par son envergure intellectuelle, mêlant à la fois ouverture d'esprit, érudition et philanthropie. Grand collectionneur - sa collection compte aussi quelques pièces antiques -, il est le premier mécène de la famille auprès des musées français, d'abord dans le domaine de l'archéologie ${ }^{31}$ puis dans celui de la gravure. C'est par une lettre du 24 juin 1895 qu'il informe le directeur des Musées nationaux de son intention ${ }^{32}$ (fig. 3):

\section{Lettre du baron de Rothschild à Albert Kaempfen du 24 juin 1895, Pierrefitte-sur-Seine, Archives} nationales, Archives des musées nationaux.

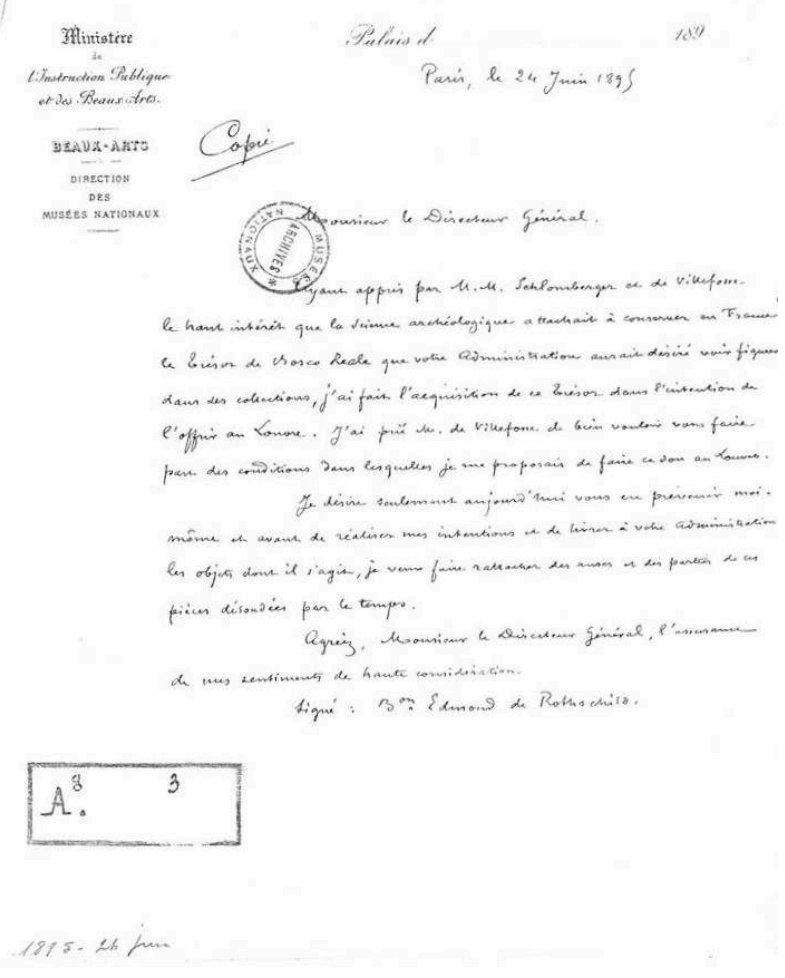

Par cette acquisition faite en vue d'un don, Edmond de Rothschild se substitue donc à l'État et lui apporte son soutien, sans contrepartie et pour l'intérêt général, trois notions inhérentes à l'acte de mécénat. La presse se fait immédiatement l'écho de cette acquisition prestigieuse dans ce contexte de concurrence entre les musées occidentau ${ }^{33}$. Ce don de quarante et une des quelque cent pièces que compte le trésor est formalisé lors de la séance du comité consultatif des Musées nationaux, trois jours plus tard, et est accepté à l'unanimité. cinquante-cinq autres pièces d'argenterie, qualifiées d'« ustensiles variés [...] formant un lot, moins important que le premier, mais offrant néanmoins un très grand intérêt ", sont acquises durant l'été par Edmond de Rothschild, qui en fait don à l'État ${ }^{34}$. Un acte notarié en date du 23 octobre 1895 recense quatre-vingt-quinze pièces d'argenterie achetées pour la somme totale de 370000 francs. Donation est faite à l'État français pour le musée du Louvre à Paris, à la condition que tous les objets légués soient exposés dans une des salles du musée. Elle est acceptée par le ministère de l'Instruction publique et des Beaux-Arts par décret signé le 26 janvier 1896, indiquant que les conditions de la donation seront respectées. 
Parallèlement au service d'argenterie, les marchands proposent une série de bijoux ${ }^{35} \mathrm{de}$ même provenance, trouvés près d'un squelette, à côté de la cachette où était placé le trésor d'argenterie, ils sont proposés au Louvre pour 20000 francs. Quelques pièces demeurent au sein de la famille ${ }^{36}$, parmi lesquelles les skyphoï historiés qui figurent dans la publication magistrale d'Antoine Héron de Villefosse ${ }^{37}$ et rejoignent les collections nationales en 1990, lors de la dation Rothschild ${ }^{38}$.

11 Mais certaines pièces avaient été soustraites du trésor avant même son acquisition par Edmond de Rothschild et étaient passées en d'autres mains privées. L'émulation générée par le don d'Edmond de Rothschild se joint à la nécessité de rassembler le trésor. Le 31 octobre 1895, le comité consultatif des Musées nationaux accepte le don d'une petite œnochoé et d'une petite coupe à deux anses ${ }^{39}$, consenti par Edward Perry Warren (1860-1928), citoyen américain, membre des trustees du musée de Boston ${ }^{40}$. En 1897, le comte Michel Tyszkiewicz (1828-1897), archéologue et grand collectionneur polonais ${ }^{41}$, offre le miroir à manche en massue d'Hercule ${ }^{42}$. L'année suivante, Ercole Canessa, l'intermédiaire de De Prisco dans la vente du trésor, qui a gardé quatre pièces $^{43}$, tente de les vendre au Louvre pour la somme de 2000 francs, avant de se résoudre à les donner, grâce à la persuasion de Héron de Villefosse ${ }^{44}$.

\section{La restauration du trésor}

Dans la monographie consacrée au trésor, quelques lignes donnent des indications sur l'état de conservation des pièces :

L'or n'avait subi aucune altération. L'argent avait souffert de certains contacts; il était noirci et plusieurs pièces étaient couvertes de dépôts sulfureux. Les anses et les pieds des vases étaient dessoudés; mais à part ce détail, la plupart des pièces d'argenterie se trouvaient encore dans un état de conservation étonnant. La voûte solide du réservoir à vin les avait protégées; les cendres, en pénétrant par l'ouverture du puits, s'étaient entassées en colonne et solidifiées sans envahir complètement le fond de la citerne ${ }^{45}$.

Comme il l'indique dans la lettre qu'il adresse au directeur des musées nationaux (fig. 3), Edmond de Rothschild souhaite restaurer les pièces du trésor avant de les donner au musée du Louvre. Cette campagne de restauration est confiée à «M. Alfred André, qui s'en acquitta avec son habileté ordinaire et en y apportant la plus juste mesure. Il se borna à consolider les parties malades, à enlever, quand cela était possible et sans danger pour la pièce, les matières étrangères agglomérées sur le métal, à rattacher les anses et les pieds ${ }^{46}$.» Fait rare pour l'époque, certaines pièces sont photographiées avant de subir une intervention de restauration. Les photographies sont consignées dans un recueil ${ }^{47}(\mathrm{fig} .4)$ qui est donné à la Bibliothèque des musées nationaux par arrêté du 5 mai 1897. 
4. Gobelets aux squelettes, dans Trésor de Boscoreale, 1895, pl. VI, Bibliothèque de l'INHA, fonds BCMN, inv. : RES Gr.fol.BA 0178.

14 Une seconde campagne photographique est organisée après la restauration et consignée dans un autre recueil ${ }^{48}$ (fig.5). À l'issue du transfert du fonds de la Bibliothèque centrale des musées nationaux, les deux recueils ont pu être repérés ${ }^{49}$ et se trouvent aujourd'hui au sein du fonds de la bibliothèque de l'Institut national d'histoire de l'art (INHA). 
5. Enochoé aux victoires sacrifiant, dans Trésor de Boscoreale, 1895, pl. XXVII, Bibliothèque de I'INHA, fonds BCMN, inv. : RES Gr.fol.BA 0177.

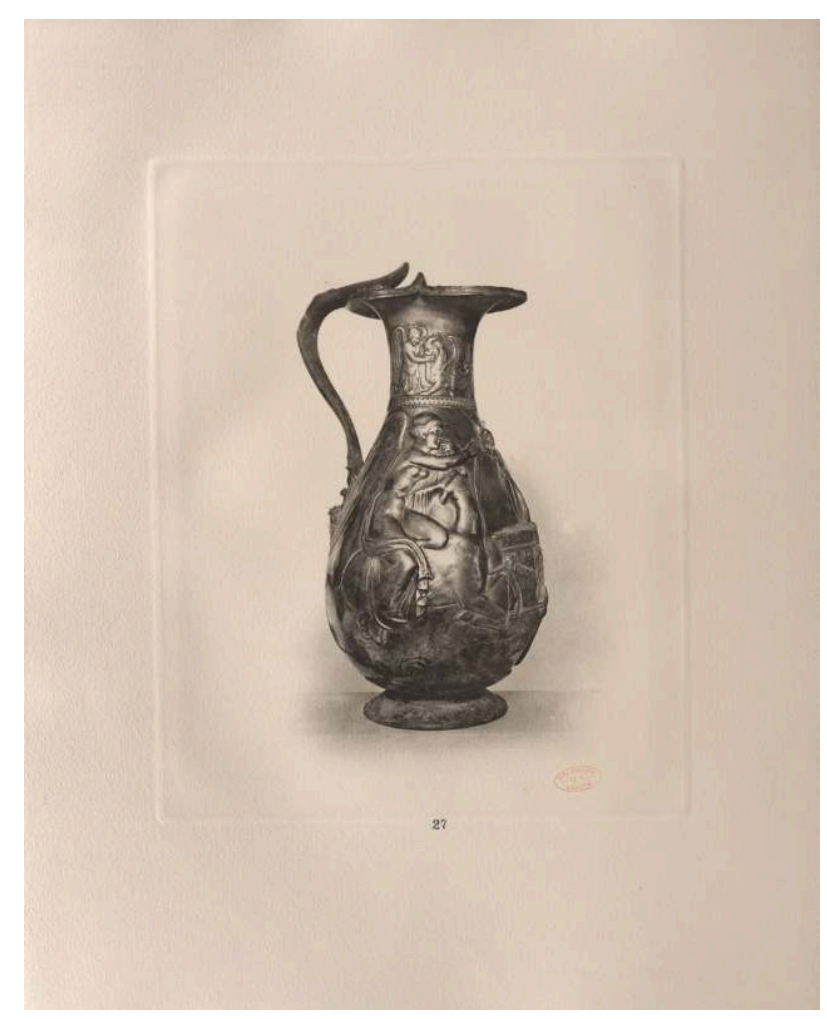

\section{Boscoreale au Louvre}

Dans le palais parisien, le trésor est exposé, dès octobre 1895, au sein des appartements du Roi, dans l'ancien cabinet de Louis XIV édifié par Louis Le Vau de 1655 à 1658, appelé alors la "salle des bijoux ». Il y demeurera pendant près d'un siècle (fig. 6), avant d'être transféré dans l'antichambre, une salle voisine, communément nommée "salle Henri II ${ }^{50} »$.

Grâce à la générosité et à la magnanimité d'Edmond de Rothschild, le musée du Louvre peut s'enorgueillir de conserver l'un des plus fastueux et complets trésors d'argenterie romaine, le premier exhumé des pentes du Vésuve ${ }^{51}$, dont l'éruption de l'an 79 figea une page d'histoire. 
6. Le trésor de Boscoreale dans la salle des bijoux en 1957, dans Christiane Aulanier, Histoire du palais et du musée du Louvre, vol. VII : Le Pavillon du Roi. Les appartements de la Reine, Paris, Les Musées nationaux, 1958, pl. 66.

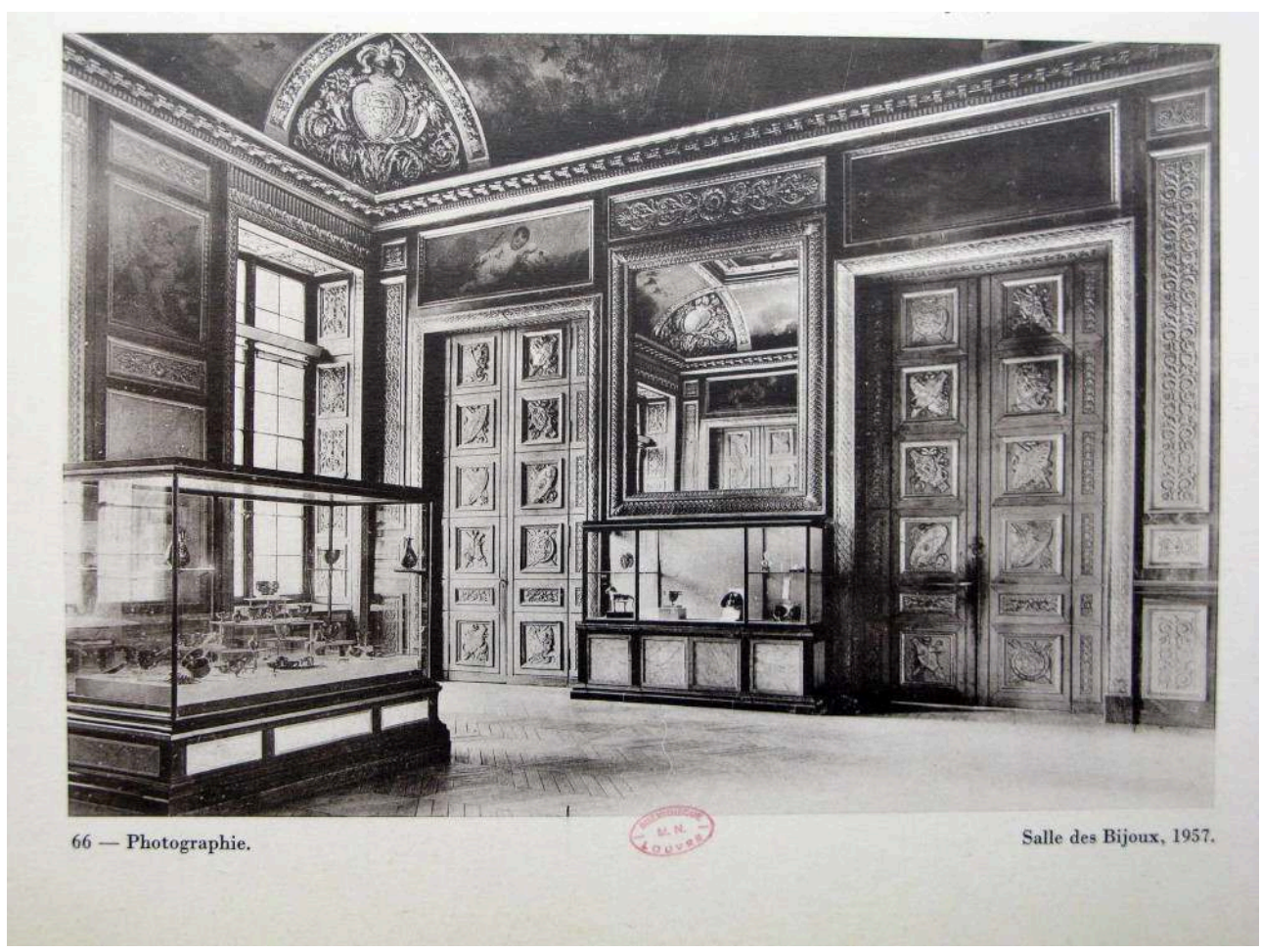

\section{NOTES}

1. Pour le mécénat d'Edmond de Rothschild, voir la section dirigée par Pauline PrevostMarcilhacy, « Edmond James de Rothschild, 1845-1934 », dans Pauline Prevost-Marcilhacy (dir.), Les Rothschild. Une dynastie de mécènes en France, Paris, Louvre/BnF/Somogy, 2016, vol. I, p. 42-116. 2. Voir également à ce sujet, François Baratte, «Le trésor de Boscoreale: un ensemble exceptionnel de vaisselle d'argent romaine", dans Pauline Prevost-Marcilhacy (dir.), Les Rothschild. Une dynastie de mécènes en France, op. cit., vol. I, p. 70-81.

3. Antoine Héron de Villefosse, «Le Trésor de Boscoreale », Monuments et mémoires de la Fondation Eugène Piot, 1899, vol. V, p. 7-132.

4. Giuseppe Fiorelli, « Notizie degli scavi di antichità », Atti della Reale Accademia dei Lincei. 1876, Rome, Tipografia della R. Accademia dei Lincei, 1876, p. 196 ; Giuseppe Fiorelli, « Notizie degli scavi di antichità ». Atti della Reale Accademia dei Lincei. 1877, Rome, Tipografia della R. Accademia dei Lincei.1877, op. cit., p. 17.

5. Par ordre chronologique: August Mau, "Scavi di Boscoreale », Mitteilungen des Kaiserlich deutschen archaeologischen Instituts, Roemische Abteilung, IX, 1894, p. 349-358; Notizie degli scavi di antichità. Atti della Reale Accademia dei Lincei. 1895, p. 207 ; Antonio Sogliano, «IX. Boscoreale. Scoperta di una villa rustica", Notizie degli scavi di antichità. Atti della Reale Accademia dei Lincei. 1896, op. cit., p. 207-214 ; August Mau, « Ausgrabungen von Boscoreale », Mitteilungen des Kaiserlich deutschen archaeologischen Instituts. Roemische Abteilung, XI, Rome, W. Regenberg, 1896, p. 131-140, 
pl. III ; Angelo Pasqui, «XXI. Boscoreale. Nuove ricerche nell'area della villa rustica in contrada Pisanella. Giornale redatto dalle Guardie degli scavi », dans Notizie degli scavi di antichità. Atti della Reale Accademia dei Lincei. 1897, op. cit., p. 230-236; Angelo Pasqui, «X. Boscoreale. Nuove esplorazioni nella villa rustica in contrada Pisanella. Giornale redatto dalle Guardie degli scavi », Notizie degli scavi di antichità. Atti della Reale Accademia dei Lincei. 1897, op. cit., p. 204-206; Angelo Pasqui, «La villa Pompeiana della Pisanella presso Boscoreale », Monumenti antichi pubblicati per cura della reale Accademia dei Lincei. 1897, vol. VII, col. 398 à 554, avec une pl. (Tav. XIV) et 76 fig. ; Antonio Sogliano, «VIII. Boscoreale. Nuove esplorazioni nella villa romana della Pisanella», Notizie degli scavi di antichità. Atti della Reale Accademia dei Lincei. 1899, op. cit., p. 14.

6. Cesare Canessa (? - 1922), responsable de la galerie de Naples, de renommée internationale, installée dans le Palazzo Nunziante, avec une salle des ventes attenante; Ercole Canessa (1868-1929), en charge de la galerie de la place Vendôme à Paris ; et Amedeo Canessa (? - ?) de celle de New York sur la Cinquième Avenue.

7. Herbert F. De Cou, Antiquities from Boscoreale in Field Museum of Natural History, Chicago, Field Museum of Natural History, 1912.

8. Henry Beauchamp Walters, Catalogue of the Bronzes in the British Museum. Greek, Roman \& Etruscan, 2 vol., Londres, British Museum Press, 1899 ; Henry Beauchamp Walters, Catalogue of the Silver Plate (Greek, Etruscan and Roman) in the British Museum, Londres, British Museum Press, 1921 ; Roger Packman Hinks, Catalogue of the Greek, Etruscan \& Roman Paintings \& Mosaics in the British Museum, Londres, British Museum Press, 1933 ; Donald Michael Bailey, Catalogue of the Lamps in the British Museum, 4 vol., Londres, British Museum Press, 1975; Cesare Canessa, «Le trésor monétaire de Boscoreale ", Le Musée, vol. VI, 1909, p. 259-265. Harold Mattingly, Coins of the Roman Empire in the British Museum. II, Vespasian to Domitian, Londres, British Museum Press, 1976.

9. Andreas Oettel, Bronzen aus Boscoreale in Berlin, Berlin, Antikenmuseum, Staatliche Museen zu Berlin, Preussischer Kulturbesitz, 1991.

10. Antoine Héron de Villefosse, Le Trésor de Boscoreale, op. cit.

11. Deux publications récentes et complémentaires font le point sur la découverte de ce trésor et sur sa sortie illégale d'Italie : Paola Poli Capri (dir.), Pompei : i tesori di Boscoreale, lettere e documenti, 5 vol., Rome, Halsted B. Van der Poel, 2001 ; et Angelandrea Casale et Antonio Cirillo, Il Tesoro di Boscoreale e il suoscopritore, Pompei, 2004, qui cherchèrent plus tard à comprendre les circonstances exactes de ce qui est décrit comme "il trafugamento", la «soustraction frauduleuse ». La seconde en constitue la synthèse, en apportant des précisions.

12. Angelandrea Casale et Antonio Cirillo, Il Tesoro di Boscoreale e il suoscopritore, op. cit., p. 55-56.

13. Ibid.

14. Dans un article publié dans Il Mattino de Naples le 10 juillet 1988, à l'occasion de l'exposition d'une partie du trésor à Pompéi.

15. Antoine Héron de Villefosse, Le Trésor de Boscoreale, op. cit., p. 32-33.

16. Pierrefitte-sur-Seine, Archives nationales, Archives des musées nationaux, Registres des procès-verbaux $d u$ conservatoire du musée du Louvre, des musées impériaux et nationaux, du comité consultatif des Musées nationaux, du conseil artistique de la RMN et des commissions révolutionnaires, $1 \mathrm{BB} 31$.

17. Paris, musée du Louvre, département des Antiquités grecques, étrusques et romaines, Bj 1969 et Bj 1970. L'emblema est le médaillon central placé au centre de la coupe.

18. Le skyphos (skyphoï au pluriel) est un vase à boire, de forme ouverte et basse, à vasque large et profonde, munie de deux anses latérales horizontales peu développées, parfois soutenues par des anses verticales pour y passer le pouce.

19. Bj 2366 et Bj 2367.

20. Bj 1923 et Bj 1924.

21. L'œnochoé est un vase à panse arrondie, pourvu d'une seule anse, utilisé pour puiser le vin dans le cratère où il a été mélangé à de l'eau, le contenir puis le verser. 
22. Bj 1898 et $\mathrm{Bj} 1899$.

23. Bj 1913 et Bj 1914. Une xenia est constituée des mets offerts aux hôtes.

24. Le canthare est une coupe à pied dont la panse est ovoïde ou hémisphérique, flanquée de deux anses verticales, parfois hautes.

25. Bj 1907 et $\mathrm{Bj} 1908$.

26. Bj 2158, Bj 2159 et $\mathrm{Bj} 2160$.

27. Pierrefitte-sur-Seine, Archives nationales, Archives des musées nationaux Registres des procès-verbaux du conservatoire du musée du Louvre, des musées impériaux et nationaux, du comité consultatif des Musées nationaux, du conseil artistique de la RMN et des commissions révolutionnaires, 1 BB 31, procès-verbal de la séance du 13 juin 1895.

28. Antoine Héron de Villefosse, «Le trésor d'argenterie de Boscoreale ", Gazette des Beaux-Arts, 1895, t. 2, p. 90 .

29. Antoine Héron de Villefosse, «Le trésor d'argenterie de Boscoreale », Comptes rendus des séances de l'Académie des Inscriptions et Belles-Lettres, 1895, 39-6, p. 587.

30. Pauline Prevost-Marcilhacy, Les Rothschild. Une dynastie de mécènes en France, op. cit., vol. I, p. 42-59.

31. Voir la communication de Pierre Bonnaure et Ludovic Laugier, « Un chapiteau du temple oraculaire d'Apollon à Didymes, redécouvert dans le jardin de l'hôtel Marigny, ancienne propriété de la famille Rothschild », dans Pauline Prevost-Marcilhacy, Laura de Fuccia, Juliette Trey (dir.), De la sphère privée à la sphère publique, actes de colloque (Paris, 2018), Paris, INHA, 2019, disponible ici : https://books.openedition.org/inha/11221.

32. Cette lettre est publiée dans Antoine Héron de Villefosse, Le Trésor de Boscoreale, op. cit., p. 33-34.

33. «Déçus dans leur espoir, les marchands allaient partir avec leur trésor pour les États-Unis, où le musée de Boston leur faisait des propositions d'achat, quand M. Edmond de Rothschild, poussé par un sentiment de patriotisme, s'est rendu acquéreur de cette précieuse trouvaille pour l'offrir au musée du Louvre », Le Temps, 26 juin 1895.

34. Pierrefitte-sur-Seine, Archives nationales, Archives des musées nationaux, Registres des procès-verbaux du conservatoire du musée du Louvre, des musées impériaux et nationaux, du comité consultatif des Musées nationaux, du conseil artistique de la RMN et des commissions révolutionnaires, 1 BB 31, procès-verbal de la séance du 17 octobre 1895.

35. Une double chaîne avec des rouelles Bj 495, une paire de bracelets serpentiformes Bj 976 et Bj 977, une paire de bracelets ouverts composés de demi-sphères Bj 990 et Bj 991 , une paire de boucles d'oreilles à cabochons Bj 408 et Bj 409 et une bague ornée d'une ancre gravée Bj 1095 .

36. À la mort d'Edmond de Rothschild, une liste conservée dans les archives de Waddesdon Manor fait état de 6 pièces de Boscoreale dans sa collection: les deux skyphoï historiés (aujourd'hui conservés au Louvre, Bj 2366 et Bj 2367), un « support coquetier » (sans doute du même type que ceux du Louvre Bj 2011 et $\mathrm{Bj}$ 2012), une « petite coupe à deux anses montée sur un pied tourné » et «deux plateaux ronds ornementés montés sur trois pieds ». Je remercie vivement ma collègue Séverine Lepape, conservateur en chef du patrimoine, en charge de la collection Edmond de Rothschild au département des Arts graphiques du musée du Louvre, d'avoir porté à ma connaissance ce document d'archives.

37. Antoine Héron de Villefosse, Le Trésor de Boscoreale, op. cit., p. 133-168 et pl. XXXI-XXXVI.

38. Ayant eu lieu le 27 septembre 1990.

39. Bj 1902 et $\mathrm{Bj} 1919$.

40. Edward Perry Warren fut sans doute à l'origine de la proposition d'achat par le musée de Boston, mentionnée dans Le Temps du 26 juin 1895.

41. Donateur au Louvre, en 1862, d'une collection de près de 200 objets, en majorité des statuettes de divinités en bronze de la Basse Époque, constituée lors d'un voyage en Égypte en 1860. Établi à Rome, il rassemble d'importants ensembles de monnaies et de médailles romaines, 
des camées, des pierres gravées, des pièces d'orfèvrerie grecques. Sa collection est dispersée entre Londres, Paris, Berlin et Copenhague.

42. Bj 2160 ; don Tyszkiewicz présenté à la séance du comité le 7 janvier 1897, accepté par l'arrêté du 13 février 1897.

43. Une coupe à anses et à pied bas $B \mathrm{j} 1921$, une coupelle $\mathrm{Bj} 2030$, des fragments de feuille d'argent $B j 14$ et une coupe très fragmentaire $B j 1972$.

44. Don de Cesare et Ercole Canessa, présenté au comité consultatif des musées nationaux le 21 avril 1898.

45. Antoine Héron de Villefosse, Le Trésor de Boscoreale, op. cit., p. 30-31.

46. Ibid., note 1 , p. 34 .

47. Bibliothèque de l'INHA, fonds BCMN, RES Gr.fol. BA 0178.

48. Bibliothèque de l'INHA, fonds BCMN, RES Gr.fol. BA 0177.

49. Je remercie chaleureusement ma collègue Cécile Colonna, conservateur du patrimoine, conseillère scientifique à l'INHA, pour le domaine de recherche Histoire de l'art antique et de l'archéologie, de m'avoir mise sur la piste de ces deux recueils qui demeuraient introuvables - car non cotés - dans le fonds de la Bibliothèque centrale des musées nationaux.

50. Le redéploiement des collections étrusques et italiques dans les appartements du Roi, au premier étage, a conduit au déplacement du trésor de Boscoreale, qui doit rejoindre les salles dédiées au secteur romain, installées dans les appartements d'été de la reine Anne d'Autriche, au rez-de-chaussée.

51. Pour les découvertes ultérieures, voir Pietro Giovanni Guzzo (dir.), Argenti a Pompei, cat. exp., (Naples, musée national d'Archéologie, 2006), Milan, Electa, 2006.

\section{INDEX}

Thèmes : Archéologie, collections, mécénat, Rothschild, Louvre

Index chronologique : Antiquité, XIXe siècle

Index géographique : Boscoreale, Pompéi, Italie 
Dessins et estampes 


\title{
Ce qu'Edmond ne donna pas : réflexions sur la collection personnelle d'arts graphiques du baron Edmond de Rothschild
}

\author{
Séverine Lepape
}

1 La collection d'estampes et de dessins d'Edmond de Rothschild léguée au musée du Louvre par ses trois enfants, le 28 décembre 1935, a fait l'objet de nombreuses expositions et publications depuis son entrée dans ce prestigieux établissement ${ }^{1}$. En 2016, l'ouvrage Les Rothschild. Une dynastie de mécènes en France, sous la direction de Pauline Prevost-Marcilhacy, avec ses quinze chapitres consacrés à la description de la collection ${ }^{2}$, a permis une véritable remise en contexte du goût d'Edmond, de sa sphère familiale, de son réseau, de ses conservateurs. Ce n'était que justice, tant ce legs à une institution publique reste à ce jour d'une ampleur, d'une générosité et d'une originalité inégalées. L'ouvrage fait date à l'évidence pour l'histoire des Rothschild et, plus largement, pour celle du goût et des collections en France. Mais il a eu aussi une autre grande vertu : celle de mettre en évidence, pour ne pas dire en compétition, l'activité de collectionneur chez les différents membres de cette foisonnante dynastie et notamment des contemporains d'Edmond. Il a également montré que, si Edmond s'était passionnément intéressé à l'art de l'estampe, au point d'y consacrer une part significative de sa fortune et de constituer un musée de la gravure, son champ d'action était beaucoup plus large : don de monnaies et de médailles à la Bibliothèque nationale, mécénat de fouilles archéologiques et achat pour les musées de prestigieux objets mis au jour, intérêt partagé avec son épouse Adelheid pour les costumes de théâtre, collection d'art islamique, tous ces éclairages bienvenus dans l'ouvrage de la très vaste curiosité si propre à ce mécène, célèbre pour sa passion de l'art du $\mathrm{XVIII}^{\mathrm{e}}$ siècle (peintures, sculptures, grands décors, mobiliers), des livres et manuscrits mais peutêtre moins, par exemple, pour la paléontologie ${ }^{3}$ ! 
conservatrice tout juste nommée à la tête d'une si formidable collection peut émettre : est-ce que la collection d'arts graphiques léguée par le baron au musée du Louvre constituait l'essentiel de ce qu'il avait réuni de son vivant? L'absence, au sein de sa donation au Louvre, d'œuvres de deux graveurs majeurs, Francisco de Goya et Giovanni Battista Piranèse, ne manquait pas de nous étonner. Nous savions qu'Edmond avait procédé à des choix comme tout collectionneur, mais plus encore dans son cas, car il ne pouvait ignorer que, par l'ampleur de ses acquisitions et de ses dons, il écrivait des pages significatives de l'histoire de l'art et des collections pendant le Second Empire et la Troisième République. Sa collection de dessins français du xvIII ${ }^{e}$ siècle, non donnée au Louvre, est renommée et nombre d'éminents spécialistes dans ce domaine y font souvent référence ${ }^{4}$. Enfin, la part échue à son fils aîné, James Armand, est maintenant bien connue car elle a été léguée par ce dernier et son épouse au Waddesdon Manor ${ }^{5}$. Néanmoins, il ne s'agit que du tiers d'un ensemble qui reste encore bien mystérieux, à la mesure de la discrétion dont font preuve aujourd'hui encore les descendants du baron. Les différentes investigations menées dans les archives du Waddesdon Manor, dont les inventaires destinés à établir le partage entre les trois enfants à sa mort, nous ont permis d'en mieux connaître l'ampleur et surtout de découvrir la collection de dessins et d'estampes du XIX ${ }^{e}$ siècle qu'Edmond avait réunie. Il s'agit là de documents précieux, donnant un instantané de la collection avant sa spoliation par les Nazis et la longue et pénible aventure que constitua la récupération des biens par les descendants d'Edmond après la guerre.

3 Les sources du présent article sont donc un premier inventaire pour les dessins du $\mathrm{xVIII}^{\mathrm{e}}$ siècle réunis en portefeuilles, un deuxième pour les dessins $\mathrm{du}$ XVIII ${ }^{\mathrm{e}}$ siècle encadrés, un troisième pour les dessins du XIX ${ }^{\mathrm{e}}$ rassemblés en portefeuilles, un autre pour les dessins du XIX ${ }^{e}$ siècle encadrés ${ }^{6}$, un inventaire pour les gravures modernes $d u$ $\mathrm{XIX}^{\mathrm{e}}$ siècle en portefeuille ${ }^{7}$, enfin, un dernier pour des recueils gravés ${ }^{8}$ (gravures et illustrations). Tous sont conservés aux archives du Waddesdon Manor. Il s'agit de documents de travail, dactylographiés sur papier ordinaire ou pelure, souvent annotés, parfois biffés. Ils peuvent bien sûr être lacunaires, de sorte que les conclusions que nous tirerons de leur exploitation resteront prudentes et modestes. Ces sources ne nous offrent sans doute pas un aperçu complet de la collection graphique personnelle du baron : elles ne nous renseignent pas, par exemple, sur les cessions que le baron a pu faire de son vivant. Néanmoins, en les croisant avec les registres d'entrées des dessins et des estampes du baron, également conservés au Waddesdon Manor, elles nous ont semblé de nature à pouvoir nous fournir de précieux renseignements sur le goût, les intérêts et la conception que le baron Edmond de Rothschild pouvait avoir d'une collection. Elles nous fournissent, en creux, à la manière d'une matrice gravée sur cuivre, des informations pour comprendre ce qu'un mécène et amateur d'art aussi important qu'Edmond décida de conserver et de transmettre au sein de la sphère familiale.

\section{Les dessins français du XVIII ${ }^{\mathrm{e}}$ siècle}

4 Les dessins réunis en portefeuilles décrits dans l'inventaire sont classés selon un système bien connu des amateurs et que l'on trouve à l'œuvre également dans la collection donnée par le baron au musée du Louvre, reposant sur une distinction entre première et seconde garniture. Ainsi, les dessins de premier choix étaient rangés dans 
dix portefeuilles, dans la $6^{\mathrm{e}}$ vitrine de la travée XI de la bibliothèque, et comprenaient peu d'éléments. Plus fournie, la deuxième catégorie (quatorze portefeuilles), était répartie en trois armoires du cabinet des estampes. On y trouve tous les grands artistes qui ont assuré le renom du dessin français, classés sans ordre apparent a priori, certaines feuilles attribuées à un même artiste pouvant être réparties dans des portefeuilles différents, et sans logique d'entrée dans la collection, le numéro d'inscription précédant systématiquement chaque description, au demeurant succincte puisque limitée au nom de l'artiste et au titre de l'œuvre. Nous nous arrêterons sur quelques artistes emblématiques de l'âge d'or du XVIII siècle français et représentatifs de ce goût galant qu'affectionnait particulièrement Edmond de Rothschild.

1. Liste du portefeuille huit des dessins du XVIII siècle : Boucher et autres. Waddesdon Manor Archives.

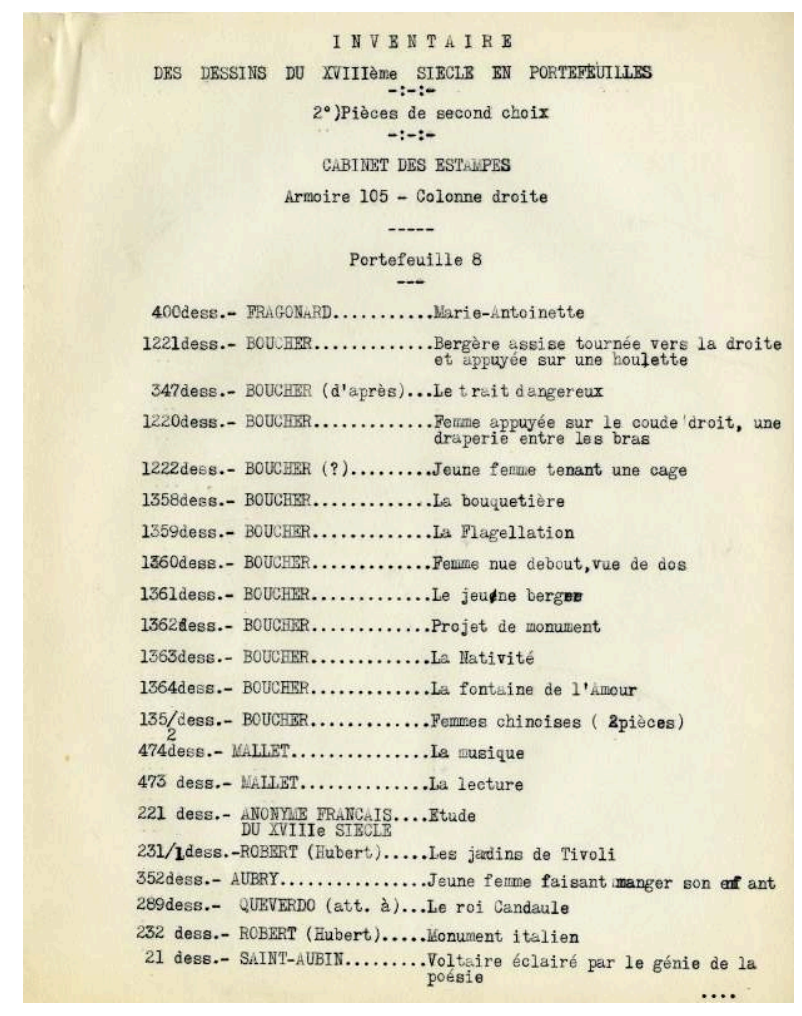

(c) Waddesdon Manor

5 François Boucher y occupe une place importante, onze dessins lui sont attribués dans le portefeuille 8 (fig. 1), dont La Flagellation aujourd'hui conservée au Waddesdon Manor et daté de $1735-1740^{9}$, ou Les Femmes chinoises, deux feuilles où l'on peut reconnaître l'une d'entre elles récemment passée entre les mains de Didier Aaron en 2018 (fig. 2) ${ }^{10}$. Mais les dessins les plus importants sont rangés ailleurs, car ils font partie de la catégorie des dessins encadrés, sur laquelle nous reviendrons. C'est notamment le cas de La Courtisane amoureuse de $1736^{11}$ accroché dans la chambre du baron. 


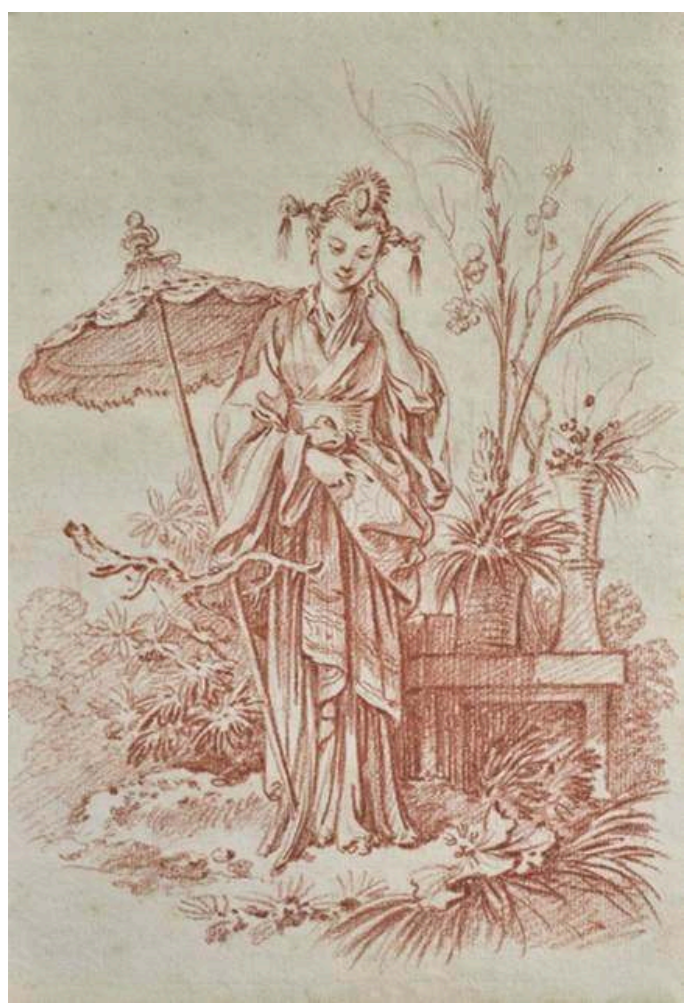

(C) Galerie Didier Aaron, 2018

Les belles feuilles de Jean-Honoré Fragonard ayant appartenu au baron sont bien connues, mais on se permettra de donner quelques précisions sur leur entrée dans la collection. Ainsi, Le Verrou, plume et lavis de bistre à la prestigieuse provenance de Varanchan de Saint-Géniès, Mercier et Fiquet, était signalé par Alexandre Ananoff ${ }^{12}$ comme entré vers 1889 dans les collections du baron, avec son pendant, L'Armoire ${ }^{13}$, de même provenance. Le registre d'entrées nous donne cependant une date plus ancienne, mai 1878, et indique une acquisition faite auprès de M. Lemarié ou Lemarcé, peut-être un marchand agissant pour Rothschild ${ }^{14}$. Ces deux dessins sont décrits dans la liste des pièces de choix encadrées, sans oublier l'attestation manuscrite de Fragonard qui les accompagne. Leur localisation est aujourd'hui inconnue ${ }^{15}$. En revanche, L'Amour et Psyché, figurant sur la même liste que les précédents, a été acquis en 1990 par le Louvre en paiement de droits de succession d'Edmond, fils de Maurice et petit-fils d'Edmond ${ }^{16}$. Dans le registre des entrées, il est mentionné comme acheté auprès de M. Pradeau en mai 1878 pour $1200 \mathrm{frs}^{17}$. Il faut sans doute voir, derrière ce Pradeau, l'homme dont la collection de dessins anciens fut vendue les 23 et 24 janvier 1882 à Paris ${ }^{18}$ et auprès de qui Edmond acheta, en même temps que la feuille de Fragonard, quinze autres dessins français $d u \mathrm{XVIII}^{\mathrm{e}}$ siècle, et des dessins flamands des $\mathrm{XVI}^{\mathrm{e}}$ et $\mathrm{XVII}{ }^{\mathrm{e}}$ siècles. L'Éducation fait tout est aujourd'hui au Waddesdon Manor ${ }^{19}$. Il fut acheté à la vente de François Hippolyte Walferdin (1795-1880), avec trois autres Fragonard (La Croisée ${ }^{20}$; Le Chat emmaillotée ${ }^{21}$ et La Première Leçon d'équitation ${ }^{22}$ ). Quant au S'il m'était aussi fidèle! du Getty Museum, il figurait au registre d'entrées, biffé d'une annotation expliquant qu'il avait été donné à $\mathrm{M}^{\mathrm{me}} \mathrm{de}$ Goldschmidt, c'est-à-dire à Miriam Alexandrine, fille d'Edmond, sans doute du vivant du baron ${ }^{23}$. 
7 Autre figure incontournable de la collection d'Edmond, Antoine Watteau. De nombreux dessins figurant dans les inventaires de la collection ne lui sont aujourd'hui plus attribués, c'est le cas de L'Arabesque avec au centre un couple assis, décrit comme un dessin d'ornement dans le portefeuille 13, aujourd'hui rejeté du corpus de Watteau par Louis-Antoine Prat et Pierre Rosenberg ${ }^{24}$ ou la Femme tenant un loup ${ }^{25}$, sans doute une copie de la gravure réalisée à partir du tableau de Saint-Pétersbourg, Coquettes qui pour voir galans...

8 Deux études d'enfants coiffés de bonnets, vus à mi-corps, daté de 1715-1716, est entré au musée du Louvre en 1990 en même temps que L'Amour et Psyché et Le Chat emmailloté de Fragonard. Le dessin a une prestigieuse provenance : Horace His de La Salle, $\mathrm{M}^{\mathrm{me}}$ White, Jacques Doucet, puis Edmond de Rothschild ${ }^{26}$. Toutefois, à la différence des deux autres cédés en 1990, nous ne sommes pas certaine qu'il ait réellement fait partie de la collection d'Edmond: il n'apparaît, en effet, ni dans le registre d'entrée à la date de $1912^{27}$, ce qui pourrait être un oubli, ni dans les inventaires que nous avons étudiés (dessins en portefeuilles ou dessins encadrés) et, fait encore plus surprenant, il ne porte pas au verso le numéro d'entrée dans la collection suivi de « Dess », présent sur toutes les feuilles ayant appartenu à Edmond. Trois éléments qui pourraient plaider pour une autre voie de transmission à Maurice, fils d'Edmond.

9 Signalons, sans nous y attarder davantage, les nombreux dessins de la famille des SaintAubin, de Gabriel, Germain et Augustin. On retiendra Le Catalogue du duc d'Aumont de 1782, illustré de cent cinq dessins de Germain ${ }^{28}$ ou de Gabriel de Saint-Aubin, L'Allégorie sur l'érection de la statue de Louis XV de 1765, de provenance Doucet, acheté par Auguste Danlos en mai $1919^{29}$. Les Watteau de Lille sont nombreux dans les portefeuilles du baron. Ils ont été pour la plupart achetés en lot auprès de Lacroix, en mai $1890^{30}$, et certaines feuilles sont identifiables : la Femme marchant vers la gauche, s'appuyant sur une canne qui correspond sans doute à la Jeune Élégante coiffée, aujourd'hui conservée au Waddesdon Manor $^{31}$. On notera également la présence de plusieurs dessins de Nicolas Lancret, décrits succinctement dans huit portefeuilles de premier choix, au sein d'un lot de cent treize études pour tableaux et gravures attribués à ce dernier, à Watteau et à Pater $^{32}$ et, dans un genre tout autre, soixante vues de ports et des marines de Nicolas Ozanne $^{33}$.

10 Les dessins du $\mathrm{xVIII}^{\mathrm{e}}$ siècle étaient des intimes du baron et de sa famille : près d'une centaine d'entre eux était encadrée et accrochée au mur des différentes pièces des trois demeures d'Edmond, comme nous le révèlent l'inventaire de cette catégorie de dessins et une petite liste ${ }^{34}$ décrivant, pour l'hôtel rue du Faubourg-Saint-Honoré, la répartition des dessins dans le salon rouge (uniquement des dessins anciens donnés au Louvre), le salon de nuit, le salon de famille, la chambre et le cabinet de toilette de la baronne et la chambre et l'antichambre du baron. Là encore, nous ne ferons pas une description exhaustive, mais nous attarderons sur la chambre et l'antichambre d'Edmond. La Courtisane amoureuse de Boucher, déjà mentionnée, ainsi que trois dessins des SaintAubin : Portrait de jeune femme $e^{35}$ de Gabriel, deux autres sur le même sujet d'Augustin ${ }^{36}$, ainsi que La Navigation, et La Poésie de Pierre-Paul Prud'hon, sans doute un héritage familial ${ }^{37}$, se trouvent dans la première pièce, confirmant que cet artiste était, aux yeux de James et d'Edmond, l'héritier de ce goût de l'art français du xvIII siècle, puisqu'Edmond continua d'acheter ses dessins tout au long de sa vie et forma un œuvre gravé très complet, donné au musée du Louvre ${ }^{38}$. 
11 Dans l'antichambre du baron, on trouvait, outre le seul dessin de Greuze présent dans les inventaires, Le Bénédicité ${ }^{39}$, des dessins de Jean-Démosthène Dugourc et de Nicolas Lavreince, et surtout, un ensemble très important de Jean-Michel Moreau dit « Moreau le Jeune » préparatoire à la célèbre Suite d'estampes pour servir à l'histoire des mœurs et du costume des Français dans le dix-huitième siècle, aussi appelé Monument du costume physique et moral (fig. 3).

3. Liste des dessins encadrés, accrochés dans l'antichambre du baron Edmond de Rothschild, hôtel du Faubourg Saint-Honoré, à Paris, Waddesdon, Waddesdon Manor Archives.

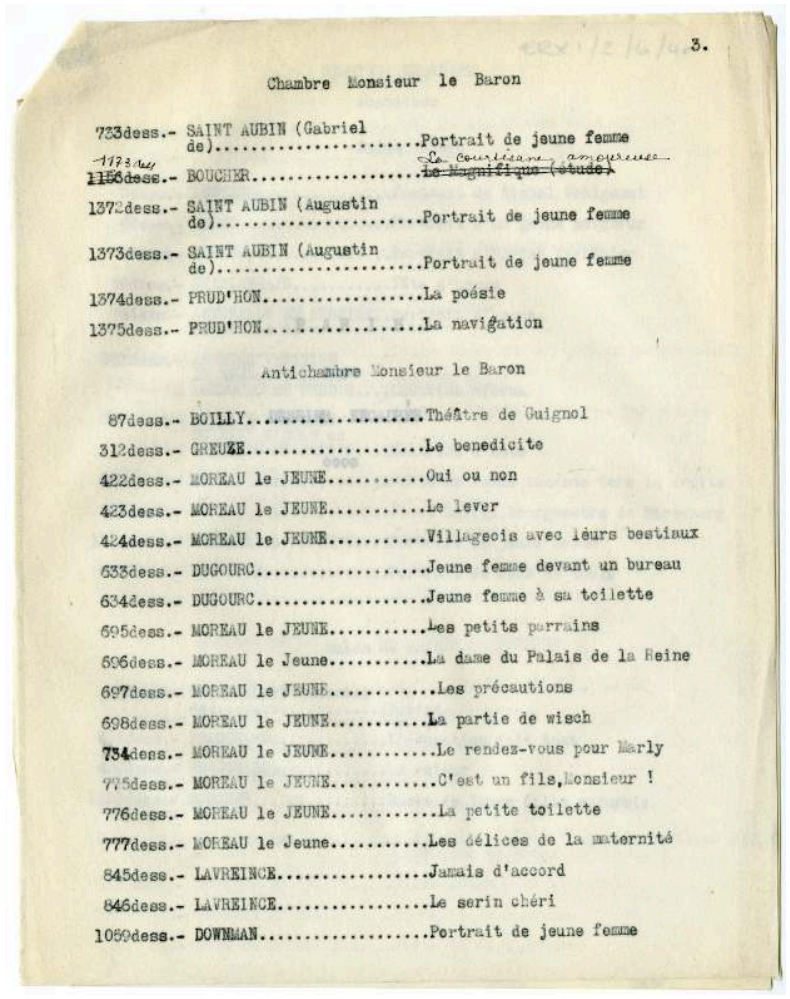

\section{(c) Waddesdon Manor}

12 L'intérêt d'Edmond pour ce que les Goncourt qualifièrent de "moment suprême du goût galant» est connu ${ }^{40}$, ainsi que celui que d'autres membres de la famille y portaient, comme l'a montré Juliet Carey à propos des dessins du Waddesdon Manor relatifs à cette Suite provenant d'Alice de Rothschild ${ }^{41}$, mais l'ampleur de sa collection n'avait jusque-là jamais été mise en évidence. Edmond possédait onze feuilles de Moreau, complétées par quatre autres de Freudenberger, appelé Freudeberg en France, accrochées dans la chambre (Le Lever, Le Coucher) et dans le cabinet de toilette de la baronne ( $L a$ Toilette et Le Bain). En pistant ces dessins dans le registre d'entrées, on mesure l'opiniâtreté avec laquelle Edmond les rechercha, car ils sont issus de différentes ventes s'étalant sur une période de dix-neuf ans. Les premiers de Moreau, Oui ou non et Le Lever ${ }^{42}$, furent achetés en mai 1880 auprès de Danlos, pour la coquette somme de 13200 frs chacun. Onze ans plus tard, en mai 1891, le baron put acheter par l'intermédiaire de Damascène Morgand, Le Lever et La Toilette de Freudeberg, (5 000 frs chaque), Les Petits Parrains, La Dame du palais de la reine, Les Précautions, La Partie de whist et Le Vrai Bonheur ${ }^{43}$ de Moreau, pour 14586 frs, chacun des quatre premiers et 5000 le dernier. En juin 1896, Rendez-vous pour Marly fut acquis par le truchement de Danlos à 
$13500 \mathrm{frs}^{44}$ et, en avril 1899, C'est un fils, Monsieur! et La Petite Toilette de Moreau le Jeune, à la vente organisée à Paris, le 22 avril 1899 par Chevalier et Féral pour ces deux seuls dessins ${ }^{45}$, achetés 23875 frs et 24400 frs $^{46}$. Enfin, en mai de la même année, à la vente Mühlbacher, Les Délices de la maternité du même fut acquis à 34050 frs et Le Coucher de Freudeberg, à $9010 \mathrm{frs}^{47}$. Ces sommes disent combien ces feuilles étaient recherchées sur le marché de l'art : présenté à la même vente Mühlbacher, le Portrait de Hans Pfaffrot von Dantzig par Albrecht Dürer était vendu par Danlos au baron 10009 frs.

Nous ne nous attarderons pas sur la collection de dessins d'ornement, très importante, car elle a déjà fait l'objet d'une bonne étude par Alastair Laing ${ }^{48}$. Notons seulement que l'inventaire comprend vingt-cinq portefeuilles, et que cet ensemble forme bien une section à part dans la collection de dessins du baron, localisée dans l'armoire $11 \mathrm{du}$ cabinet des estampes (fig. 4).

4. Première page de la liste des dessins d'ornements du XVIII e siècle, Waddesdon, Waddesdon Manor Archives.

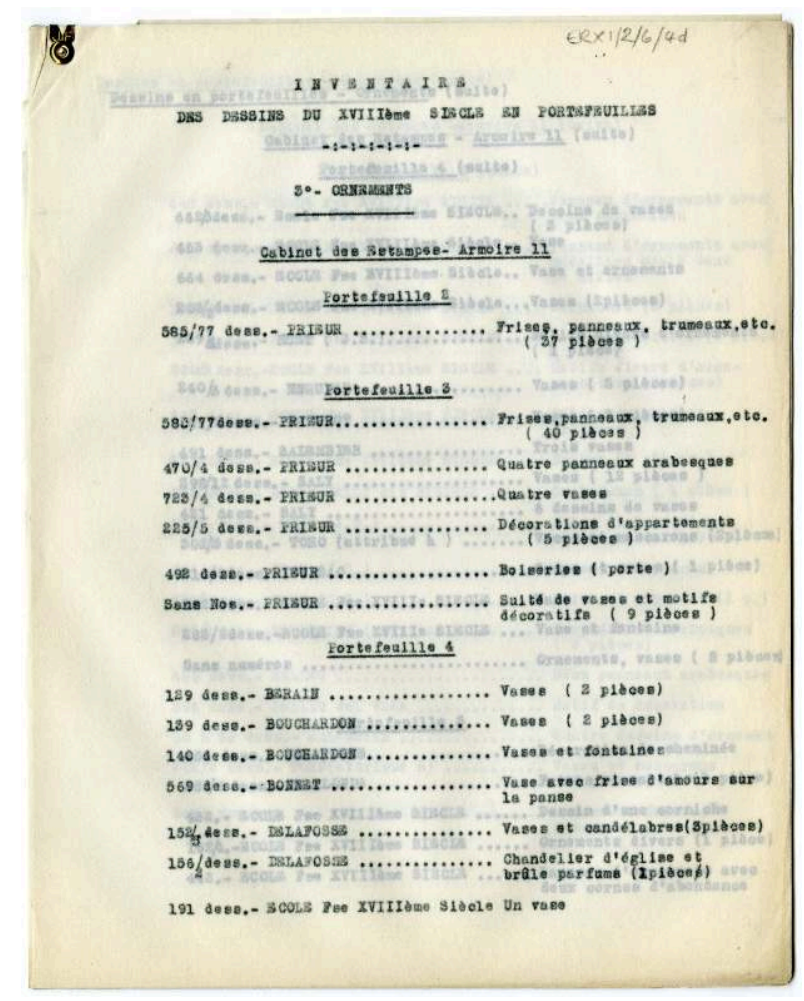

(c) Waddesdon Manor

14 On retrouve les mêmes noms d'ornemanistes que dans la collection d'estampes cédée par le baron au musée du Louvre ${ }^{49}$ : Prieur, Bouchardon, Berain, Delafosse, Oppenordt, Pillement, Cauvet, Toro. Le classement reste cependant assez approximatif: des ensembles cohérents par artiste se distinguent (pf. 13 entièrement dédié à Pillement, pf. 19 à Cauvet), mais d'autres ont été constitués selon une logique assez nébuleuse, parfois thématique (pf. 18 réunit des dessins d'ornement pour des tombeaux ou des objets à destination religieuse), parfois non, et les ensembles conséquents d'un même artiste achetés en un même lot, comme par exemple les dessins de Delafosse à la vente Carré, ont été répartis dans différents portefeuilles. Mais force est de constater une 
forme de continuité dans le goût que le baron nourrissait pour ce genre si particulier de l'ornement, qu'il soit dessiné ou gravé.

Cette remarque peut être généralisée à l'ensemble des dessins, tels qu'ils apparaissent dans les inventaires et le journal des entrées : ils sont parfaitement complémentaires des estampes et des recueils collectionnés par Edmond de Rothschild et légués au musée du Louvre. Que l'on songe à l'ensemble d'estampes d'après Boucher (1750 feuilles), au Recueil Jullienne de Watteau, à celui de Charles Nicolas Cochin, aux nombreuses estampes des Saint-Aubin, à l'intégralité du Monument du costume de Freudeberg et Moreau conservé sous divers états, planches et recueils. Par conséquent, le choix de scinder ces deux ensembles peut paraître étrange: il ne relève pas seulement d'un choix rationnel ou scientifique, mais peut-être aussi affectif ou pécuniaire (nous avons vu que le prix des dessins $d u$ xvIII siècle était souvent très élevé), voire décoratif: certes le don au Louvre des dessins français du XvIII ${ }^{\mathrm{e}}$ siècle aurait peut-être rendu moins lisible la volonté du baron de doter le Louvre d'un musée de la gravure ; cependant, leur présence sur les murs de l'hôtel rue du Faubourg-SaintHonoré, qualifié par André Blum de vitrine de l'art français du XVIII siècle, avec les merveilleuses reconstitutions d'intérieurs Louis XV et Louis XVI et, dans les deux autres demeures d'Edmond, rendait peut-être leur cession plus difficile, car ils étaient devenus des objets familiers d'Edmond et de sa famille.

\section{La collection d'estampes et de dessins du XIX ${ }^{\mathrm{e}}$ siècle}

Trois autres inventaires révèlent qu'Edmond était en possession d'estampes et de dessins des $\mathrm{XIX}^{\mathrm{e}} \mathrm{et} \mathrm{XX}^{\mathrm{e}}$ siècles. Ici, une autre logique sera à l'œuvre : dans la mesure où le fonds du Louvre est très pauvre en œuvres $d u$ XIX (hormis les estampes d'après Prud'hon), l'examen de ces œuvres graphiques ne se fera pas à l'aune de ce que le baron a cédé au musée du Louvre, mais sera replacé dans le contexte général artistique de l'époque, afin de mieux analyser le goût d'Edmond pour les artistes ayant travaillé dans la première moitié du XIX ${ }^{e}$ siècle ou produisant encore de son vivant.

Les gravures du $\mathrm{XIX}^{\mathrm{e}}$ et celles modernes étaient conservées en quarante et un portefeuilles, constitués d'ensembles relativement cohérents, souvent rassemblés par technique. La collection laisse, comme pour les dessins, l'impression d'un classement flottant. Comme pour l'ensemble donné au Louvre, Edmond de Rothschild conservait également des estampes du xix siècle sous forme de livres ou de recueils, nous les avons également pris en compte pour cette analyse. Enfin, un inventaire succinct des dessins et aquarelles encadrés du XIX ${ }^{e}$ siècle complète cette vue d'ensemble.

\section{L'importance de l'eau-forte}

Plusieurs portefeuilles permettent d'entrevoir l'importance de la technique de l'eauforte, notamment des planches publiées par l'intermédiaire de la Société des amis de l'eau-forte, dont les tirages des années 1897, 1905, 1913-1914 constituent parfois des portefeuilles entiers. Il n'est donc pas étonnant de retrouver, dans ces ensembles, les Eaux-fortes sur Paris de Charles Meryon (1821-1868), publiées en suites de 1852 à 1854 et les Vues de Paris d'Adolphe Martial Potémont (1827-1883), sans doute issues de sa série L'Ancien Paris publiée en 1864. Tous les deux, membres de la Société des aquafortistes, 
représentent une référence pour l'eau-forte de la première moitié du XIX siècle. Félix Braquemond, (trente-sept œuvres) et Francis Seymour Haden, (vingt-cinq aux-fortes modernes avec textes et paysages), y tiennent également une bonne place. Pour ce dernier, la liste renvoie à un numéro du registre d'entrées - 1866 - malheureusement inexploitable car, sur les trois volumes du registre des entrées des estampes du baron, seuls les deuxième et troisième ont été conservés à partir du numéro 9978 et de l'année 1874. Tout au plus pouvons-nous dire qu'Edmond a fait cette acquisition bien avant cette date. On remarque ici le choix d'artistes à la technique experte, qui, notamment pour Francis Seymour Haden, faisaient référence aux grands maîtres du passé, tels Rembrandt. Mais il est difficile de voir dans ces portefeuilles relativement hétéroclites une cohérence ferme et solide: on ne trouve pas, par exemple, les fameux albums d'eaux-fortes de la Société des aquafortistes fondée par Alfred Cadart, ni les œuvres des artistes qui participèrent à cette aventure (François Flameng, Édouard Manet, CharlesFrançois Daubigny, Johan Barthold Jongkind). Néanmoins, ce goût pour l'eau-forte est assez caractéristique de l'époque d'Edmond et rejoint celui d'amateurs éclairés ; il n'est finalement pas étonnant qu'un portefeuille complet ait été consacré à un artiste aujourd'hui quasiment tombé dans l'oubli, Auguste Brouet (1872-1941), lui aussi virtuose de l'eau-forte et formé par Eugène Delâtre : Edmond était en possession d'une trentaine de ses œuvres, assez représentatives des thèmes de prédilection de l'artiste:la guerre de 1914-1918, mais aussi le petit peuple parisien et les prostituées ${ }^{50}(f i g .5)$.

5. Liste décrivant le début du portefeuille contenant les estampes d'Auguste Brouet, Waddesdon, Waddesdon Manor Archives.

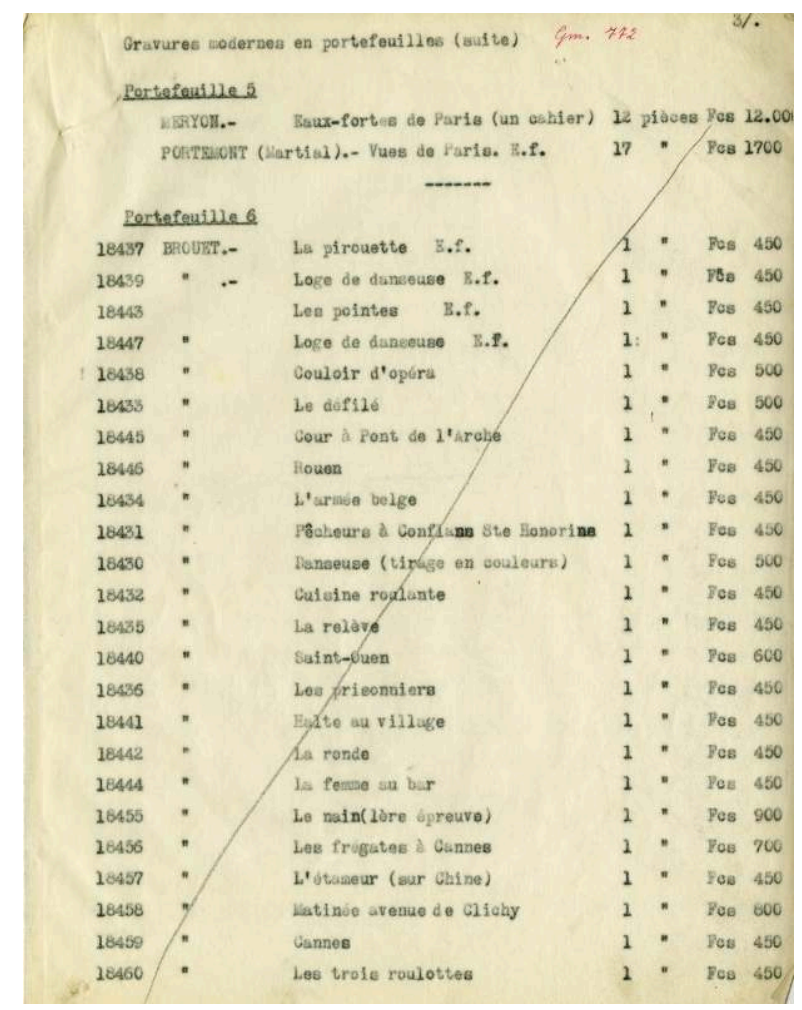

(c) Waddesdon Manor 
On y trouve quelques pépites, comme Le Nain, une pointe-sèche, première épreuve, acquise au prix élevé de 800 frs, une rareté si l'on en croit le catalogue en ligne qui indique qu'elle n'a été tirée qu'à un seul exemplaire. Dans les années 1920, cet artiste connut un succès fulgurant, comme le rapportent Loÿs Delteil ou Jean Alexis ${ }^{51}$. Or cet ensemble est entré dans les collections du baron entre avril 1922 et janvier $1923^{52}$, par le biais de $\mathrm{M}^{\mathrm{me}}$ de Goldschmidt, qui en fit don à son frère Grégoire, ce dernier vendant l'ensemble à Edmond à des prix relativement élevés, oscillant en moyenne entre 300 et 700 francs.

\section{Des lithographes romantiques en petit nombre}

Estampes et dessins des grands artistes romantiques sont certes présents, mais de manière très discrète. De Géricault, on trouve mention de deux lithographies, dont $L e$ Porte-étendard ${ }^{53}$, exécutée en 1817 mais tirée seulement après la mort de l'auteur et dont on n'a imprimé que peu d'épreuves. Edmond possédait quelques dessins de cette génération et les avait encadrés, ainsi des Guerriers orientaux d'Eugène Delacroix, d'une feuille de Paul Delaroche, L'Archevêque prisonnier bénissant Lord Strafford, sans doute en relation avec le célèbre tableau de 1836 représentant Strafford mené à l'échafaud, d'un Théodore Rousseau, $L a$ Forêt ${ }^{54}$, d'une feuille d'Ary Scheffer et de deux dessins de Nicolas Toussaint Charlet, Le Concert rustique et Le Cabaret. Ce dernier est davantage présent dans la collection par ses estampes, avec cinq albums de lithographies de sujets militaires, datés de 1823-1831, aux côtés d'autres suites sur le même thème réalisées par Hippolyte Bellangé (1800-1866) ou par Horace Vernet (1789-1863). Sont-ce des artistes du goût d'Edmond ou des héritages de son père ? Ces dessins et ces estampes sont pour la plupart malheureusement sans indication de provenance.

\section{Les caricatures}

Un artiste semble avoir particulièrement passionné Edmond : Paul Gavarni (1804-1866), dont les très nombreuses suites sont conservées dans trois portefeuilles $(9,10$ et 11) (fig.6) et dont les séries publiées en recueils constituent vingt-neuf volumes dans la collection d'albums modernes d'Edmond. 
6. Portefeuille neuf et dix de la collection d'estampes du baron, contenant les suites de lithographies de caricatures de Gavarni, Waddesdon, Waddesdon Manor Archives.

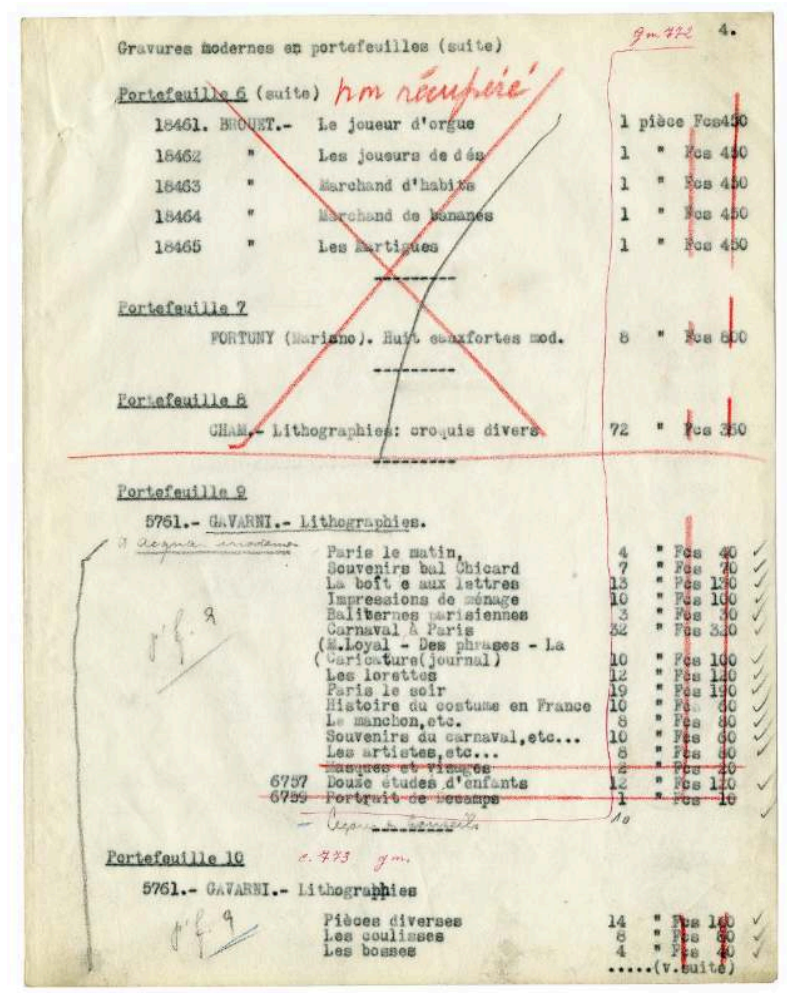

(c) Waddesdon Manor

S'y trouve la quasi-totalité de ce que Gavarni a pu dessiner pour la lithographie: Balivernes parisiennes, Carnaval à Paris, Les Lorettes, Paris le soir, Les Bohèmes, Les maris me feront toujours rire. À l'évidence, la finesse avec laquelle l'artiste sut croquer les mœurs du Second Empire, et notamment celles des bourgeois, devait plaire à Edmond. La plupart des suites comporte un même numéro d'entrée, antérieur à 1874 , ce qui ne nous permet pas de savoir comment elles ont été acquises. Une chose est néanmoins certaine : quand le baron constitue sa collection, Gavarni est l'objet d'un véritable engouement, avec la parution de l'ouvrage des Goncourt ${ }^{55}$ et le catalogue de son œuvre d'estampes par Marie-Joseph-François Mahérault, dit Armelhault et Bocher ${ }^{56}$. Edmond se passionnait également pour les aquarelles du même Gavarni, dont il possédait un ensemble conséquent (fig. 7) : vingt-cinq dessins, pour lesquels les numéros dans le registre d'acquisition ${ }^{57}$ nous indiquent une entrée en 1875 , selon une liste ajoutée à la fin, sans prix ni provenance exacte. S'agirait-il d'aquarelles déjà présentes dans les collections de James, père d'Edmond ? En tous les cas, elles étaient bien connues, car elles se trouvent décrites dans l'ouvrage sur Gavarni de Paul-André Lemoisne ${ }^{58}$ comme bien localisées dans la collection d'Edmond de Rothschild, dont le nom figure au milieu d'autres illustres collectionneurs de Gavarni, tels Édouard Rahir, Georges Wildenstein, Maurice Fenaille ou Henri Béraldi. L'attrait que Gavarni exerçait sur Edmond rejoint le goût plus général du baron pour la caricature, que l'on retrouve dans la collection donnée au Louvre et dans les albums d'estampes du XIX siècle relevant de ce genre qu'il avait conservés, qu'il s'agisse de caricatures anglaises (George Cruikshank, Caricatures, 1832-1836 ; H. B., Political Sketches, 1829-1851, Londres, 197 planches et du même Caricatures anglaises 1830-1831, paru à Londres en 1832, 2 vols, 197 planches) ou de 
caricatures françaises (Album comique d'Amédée de Noé, dit Cham, et La Crinolonomanie, suite de quarante-cinq lithographies de Charles Vernier, Paris, Destouches, série d'abord publiée dans le Charivari). Edmond collectionnait également l'incontournable Daumier, dont il conservait plusieurs suites en albums, Les Cent et un Robert Macaire, cent lithographies en couleurs publiées au bureau du Journal pour rire en 1839 ou un ensemble de lithographies en deux volumes parues dans Le Charivari. Il possédait en outre une autre suite très célèbre, Les Métamorphoses du jour en couleurs, de Grandville. D'autres artistes aux styles plus divers sont particulièrement bien représentés dans l'inventaire des gravures, des dessins et albums du XIx siècle. Alexandre-Gabriel Decamps (1803-1860) est l'un d'entre eux. On trouve un important ensemble de dessins et de gravures d'après lui, dont des sujets à la veine orientaliste, comme la série Village de Turquie (deux tirages des Ânes sous le toit) et une École en Turquie ${ }^{59}$, lithographiée par Dupont. D'autres estampes relèvent de sujets de genre, ainsi Le Gardien de porcs, ou La Vieille Mendiante $e^{60}$. L'artiste semble avoir passionné Edmond toute sa vie, puisque ce dernier acheta assez tardivement, en 1920, deux dessins de Decamps, Maison arabe à Constantine et Le Singe dessinateur ${ }^{61}$, ce dernier étant représentatif des dessins de singeries dont Edmond possédait deux autres sur ce même thème (Singe Musicien et Singe Peintre) héritier de Téniers et d'un certain XVIII siècle. Ce sont les seuls dont la provenance soit correctement décrite dans le registre d'entrées, alors même qu'Edmond conservait, en outre, dix autres dessins encadrés de l'artiste.

Edmond de Rothschild avait en sa possession plusieurs gravures d'illustrations d'après Jean-Louis Ernest Meissonier (1815-1891), encensé par le critique Henri Béraldi, qui proclamait que l'artiste "laisserait pour son art de l'illustration un nom glorieux, ineffaçable » : onze vignettes pour La Chaumière indienne de Bernardin de Saint-Pierre et dix estampes pour le Lazarillo de Tormes dans la traduction de Louis Viardot, publié en $1846^{62}$. On trouve également quelques eaux-fortes de l'artiste, comme Le Petit Fumeur et Le Sergent rapporteur, achetés en février $1884^{63}$. Edmond avait également un dessin de l'artiste, Homme assis sur un banc et lisant, acheté auprès du marchand Gandouin en septembre $1890^{64}$. La présence de Meissonier dans les portefeuilles d'estampes et de dessins ne doit pas nous étonner : Edmond appréciait particulièrement l'artiste, dont il avait acquis deux tableaux, rares parmi les toiles du XIX siècle de sa collection, Un Incroyable et Une lecture chez Diderot ${ }^{65}$.

Terminons par un artiste incontournable pour un Rothschild, Eugène Lami. Ce dernier avait su s'attirer la confiance et l'admiration du père d'Edmond, James, qui l'avait chargé de la décoration du château de Ferrières, achevé en 1859 et du château de Boulogne-Billancourt, en $1861^{66}$. Un ensemble important d'aquarelles de sa main se trouvait donc encore en possession d'Edmond, soit en feuilles (neuf dans le portefeuille 3 des dessins $\mathrm{du}$ xix ${ }^{\mathrm{e}}$ siècle), soit encadrés (quatorze dénombrés dans la liste). Les dessins rassemblés en portefeuilles (aucune provenance n'est précisée pour les dessins encadrés) sont en partie décrits dans le registre d'entrées qui fait état, en 1875, d'un important ensemble de dessins de Lami ${ }^{67}$, sans que la provenance ne soit précisée ni le prix mentionné, ce qui laisserait penser que, tout comme les aquarelles de Gavarni, cet ensemble pourrait provenir de la collection du père d'Edmond. La correspondance entre les sujets décrits dans le registre d'entrées et les œuvres listées dans l'inventaire n'étant que partielle, il faut en réalité comprendre qu'il ne se limitait pas aux vingtcinq consignés dans les inventaires et que le baron devait posséder au moins une trentaine de dessins de Lami. Pour ceux décrits dans le registre d'entrées, les numéros 
de la publication de Paul-André Lemoisne de $1914^{68}$ ont été ajoutés. Deux autres sont étrangers à cette provenance et démontrent que le baron continuait d'enrichir sa collection : La Vue du château de Boulogne, $\mathrm{n}^{\circ} 1170,450$ francs, aquarelle, acquise auprès de S. Mayer en mai 1913 ou Le Jardin français à Boulogne, $\mathrm{n}^{\circ} 1353$ du registre d'entrée, provenant du baron Robert de Rothschild, sans date.

\section{Des graveurs de reproduction}

Une grande partie des estampes conservées dans les portefeuilles est en réalité constituée des gravures réalisées par des artistes contemporains d'Edmond, qui le sollicitaient pour un achat et des recommandations. Edmond de Rothschild était en effet connu pour soutenir des artistes, et notamment des graveurs, action qui va à l'évidence de pair avec sa politique de dons de tableaux et de sculptures d'artistes contemporains aux musées parisiens et provinciaux avant la Première Guerre mondiale ${ }^{69}$.

Ces graveurs qu'Edmond achète sont pour la plupart de bons praticiens, érudits, au métier sûr, mais ils ne se distinguent pas vraiment par leur audace artistique. C'est ainsi que de nombreuses gravures d'Alphonse Lamotte (1844-1914) ponctuent différents portefeuilles de la collection du baron ${ }^{70}$. Élève d'Henriquel-Dupont, graveur de reproduction, professeur à l'École des beaux-arts duHavre, il était en outre conservateur du musée de cette ville ${ }^{71}$. Edmond lui achète par exemple, en juillet 1896, trois épreuves de La Vérité (premier, deuxième et état final) d'après Jules Lefebvre, gravées pour la Société des graveurs au burin ${ }^{72}$. Il acquiert également à la même date une estampe représentant un Buste de jeune fille d'après Fragonard ou La Famille de Largillière d'après Nicolas de Largillière ${ }^{73}$ (fig. 8 ) et, en mai 1905, toujours d'après Fragonard, La Fuite à dessein ${ }^{74}$. 
8. Alphonse Lamotte, La Famille de Largillière d'après Largillière, gravure au burin, Paris, Bibliothèque nationale de France, département des Estampes, AA-3 (Lamotte Alphonse).

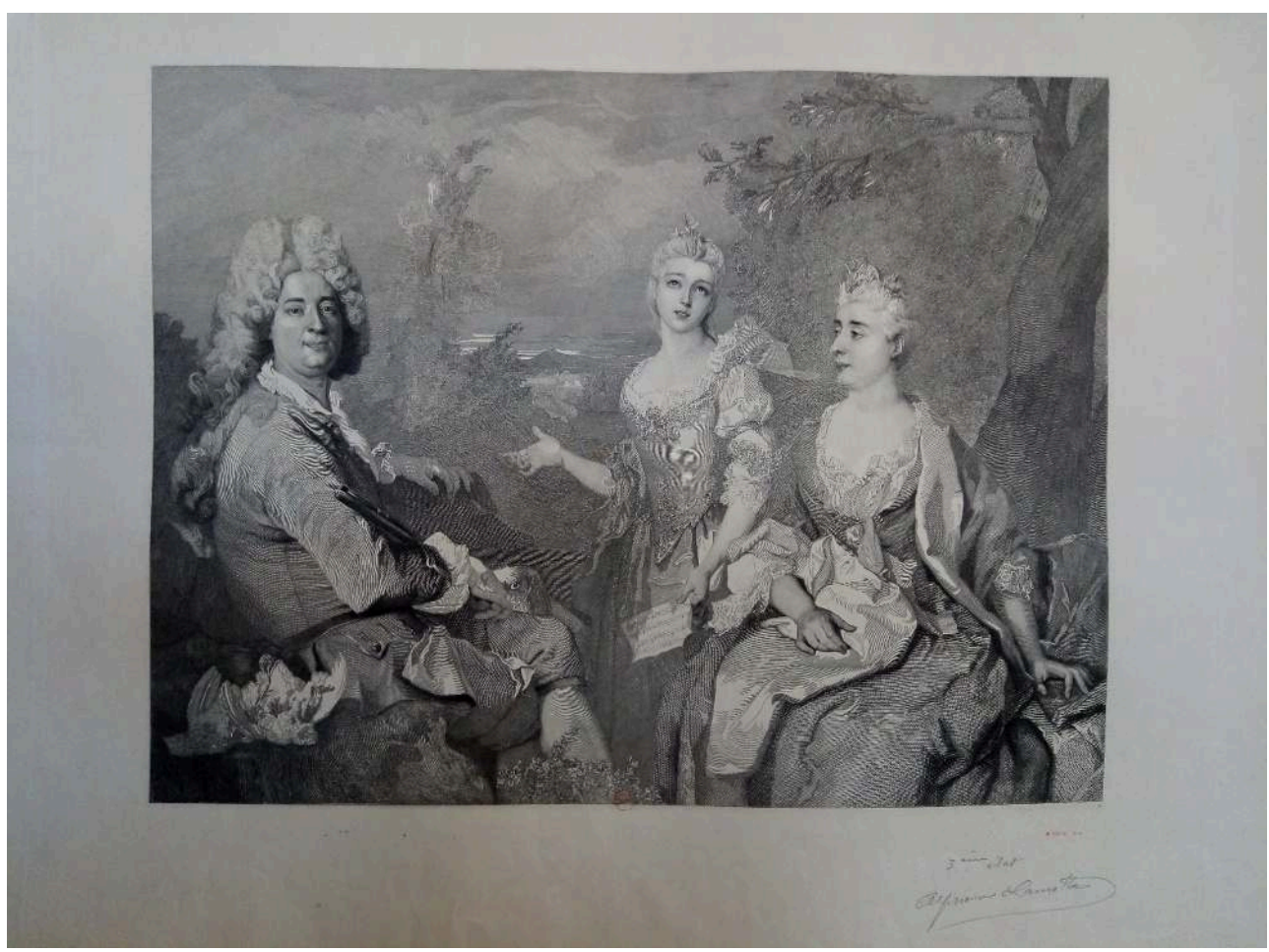

Photographie : Séverine Lepape

Louis Isidore Journot est un artiste à qui Edmond acheta régulièrement plusieurs feuilles. Graveur de reproduction né en $1867^{75}$, il a été l'élève d'Alphonse Lamotte et est l'un de ceux qui militèrent pour qu'une galerie d'estampes soit installée au musée du Louvre $^{76}$. Edmond semble l'avoir également aidé financièrement dans des moments difficiles ${ }^{77}$. On notera, par exemple, en juin $1905^{78}$, l'acquisition auprès de l'artiste de deux épreuves avant la lettre, l'une sur japon, l'autre sur chine de La Madone du Magnificat de Botticelli, que l'on trouve décrites dans le portefeuille 19 et, en novembre 1908, plusieurs estampes d'après Le Brun, Teniers, Largillière ${ }^{79}$.

Citons également André Charles Coppier (?-1948) peintre-graveur, qui fit œuvre d'historien de l'estampe en écrivant sur Rembrandt ou sur les maîtres $\mathrm{du} \mathrm{Xv}^{\mathrm{e}}$ siècle $^{80}$, il vendit à Edmond la gravure représentant La Joconde en novembre 1808 pour 500 francs $^{81}$. Quant à Jean Corabœuf $(1870-1947)^{82}$, il est très représenté dans la collection personnelle du baron. Né en 1870, il obtint le grand prix de Rome en 1898 et devint le spécialiste du portrait mondain et des estampes de reproduction. C'est à ce titre qu'Edmond lui confia l'exécution de son portrait au crayon en $1912^{83}$ et lui acheta de nombreuses estampes d'après des artistes de la Renaissance italienne, comme Le Portrait de Lucrezia Panciatichi d'après Bronzino ${ }^{84}$, La Vierge à la chaise d'après Raphaë ${ }^{85}$ et des estampes d'après les tableaux d'Ingres, pour lesquelles il était particulièrement reconnu ${ }^{86}$. Par ailleurs, Jean Corabœuf fut le lauréat du prix biennal pour son tableau L'Odalisque en 1909; destiné à encourager les travaux d'un artiste de mérite, ce prix avait été créé par Edmond en 1908, . L'œuvre fut donnée au musée d'Angers, conformément à l'esprit de ce prix dont la finalité était, au-delà du mécénat en faveur de jeunes artistes, d'enrichir les collections des musées régionaux ${ }^{87}$. 
Le métier académique de taille-doucier d'Achille Jacquet (1846-1908) convainquit à l'évidence le baron, qui acheta pour 6000 francs vingt-six estampes d'après divers maitres $^{88}$ (Joshua Reynolds, Alexandre Cabanel, Ernest Meissonier). Les gravures d'après Mantegna de ce grand prix de Rome de 1870 étaient, selon les rédacteurs de l'Inventaire $d u$ fonds français, « le Clou de la Chalcographie nationale ${ }^{89}$ ", mais pouvaient par ailleurs être moins appréciées quand l'artiste partait de sa propre invention : en témoigne l'anecdote selon laquelle le président Félix Faure aurait été assez mécontent du portrait officiel gravé par Jacquet en 1895 ; il aurait déclaré : « Les graveurs savent très bien graver d'après les peintres, mais ils ne savent pas graver d'après nature ${ }^{90}$. »

La collection des estampes du baron compte un ensemble documentaire sur la guerre de 1870 et sur la Commune qui se distingue quelque peu du reste de la collection. Dans le portefeuille 27 , se trouvaient conservées des listes de prisonniers, de bâtiments incendiés ou détruits, des affiches, des tracts et des photographies, ainsi que des exemplaires de la revue Le Grelot, journal politique républicain et anti-communard, publiant des textes satyriques et des caricatures (fig. 9).

9. Liste du portefeuille 27 contenant des documents relatifs à la Commune (photographies, affiches, tracts, numéros de la revue Le Grelot), Waddesdon, Waddesdon Manor Archives.

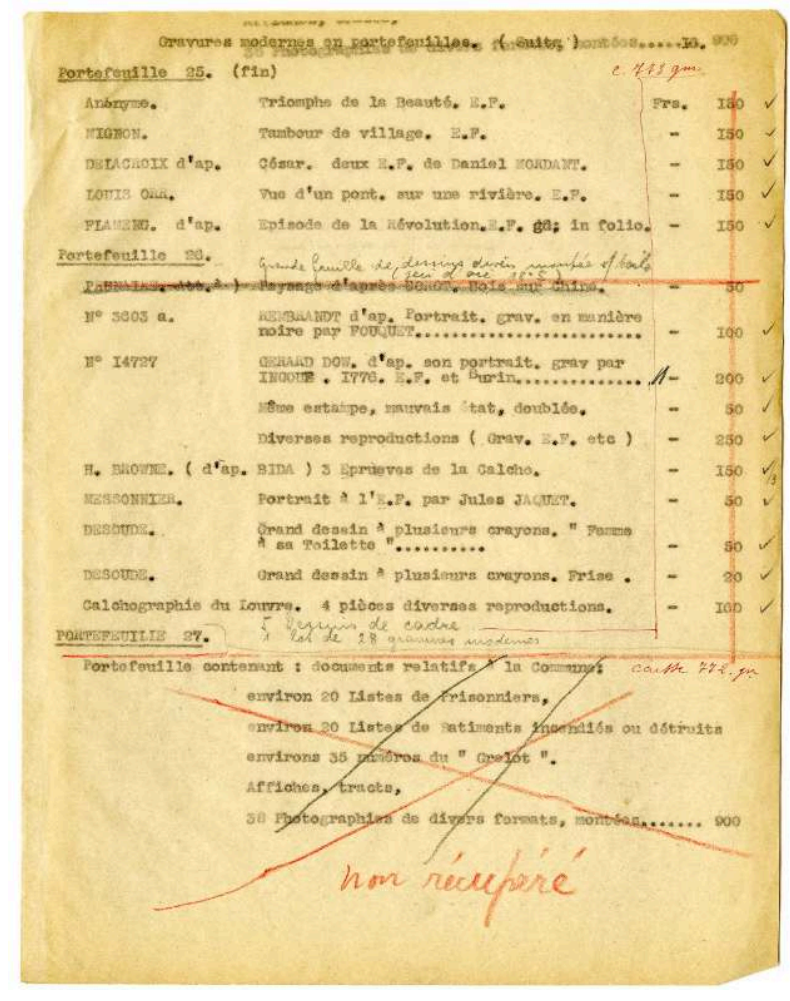

(c) Waddesdon Manor

Le portefeuille 40 est constitué de suites de caricatures sur la guerre de 1870 et le premier portefeuille de la collection contient la suite gravée L'Incendie de Saint-Cloud brûlé par François Pierdon, publiée en 1871. Cet intérêt rejoint ce que nous savons de l'attitude d'Edmond lors de la défaite française. Fervent patriote et ayant servi dans la garde nationale pendant la guerre, ce dernier considérait qu'il devait contribuer au paiement de la dette et fit plusieurs voyages en ce sens pour convaincre ses cousins anglais d'aider à la reconstruction financière de la France ${ }^{91}$. 
Enfin, quelques estampes laissent entrevoir le soutien d'Edmond pour des artistes juifs promouvant des sujets sur le judaïsme. Le recueil intitulé Types de Juifs, douze eauxfortes de René Wiener (1855-1939) en est un exemple. Cet artiste lorrain, relieur, bibliophile et éditeur, collectionnait les judaïca qu'il légua en grande partie au musée lorrain de Nancy ${ }^{92}$. Edmond acquit par ailleurs plusieurs œuvres d'Alphonse Lévy, à qui l'on doit de nombreuses scènes sur la vie juive, notamment en Alsace. Deux dessins de l'artiste, Homme priant le jour de Kippour et Rabbin lisant sont documentés dans le journal des entrées, sans provenance ni prix ${ }^{93}$, et des estampes du même, Le Scribe et La Lecture de la loi entrèrent dans la collection du baron en mai 1913, par achat direct auprès de l'artiste ${ }^{94}$. L'importance de l'affaire Dreyfus dans la société de l'époque et dans la vie d'Edmond s'entrevoit également dans sa collection, puisque ce dernier possédait des caricatures antisémites et antidreyfusardes parues dans les numéros du Journal Psst...! en 1899, publié par Caran d'Ache et Forain, côtoyant, dans le même portefeuille, celles du Sifflet, journal conçu comme la réplique à Psst... ! par Ibels, ami de Zola (fig. 10). Ces gravures d'artistes juifs sur la vie juive et ces journaux témoignant du séisme provoqué par l'affaire Dreyfus renvoient au positionnement identitaire d'Edmond dans une société comptant de virulents antisémites. Sans être pratiquant, ni sioniste, Edmond consacra une partie de son action charitable à l'installation d'immigrés Juifs en Palestine, avec l'idée que la création d'une patrie servirait de refuge aux hommes et femmes juifs persécutés en Europe centrale et en Russie ${ }^{95}$.

10. Liste du portefeuille 29 contenant des numéros des revues Psst et Le Sifflet et une caricature de Caran d'Ache sur l'affaire Dreyfus, Waddesdon, Waddesdon Manor Archives.

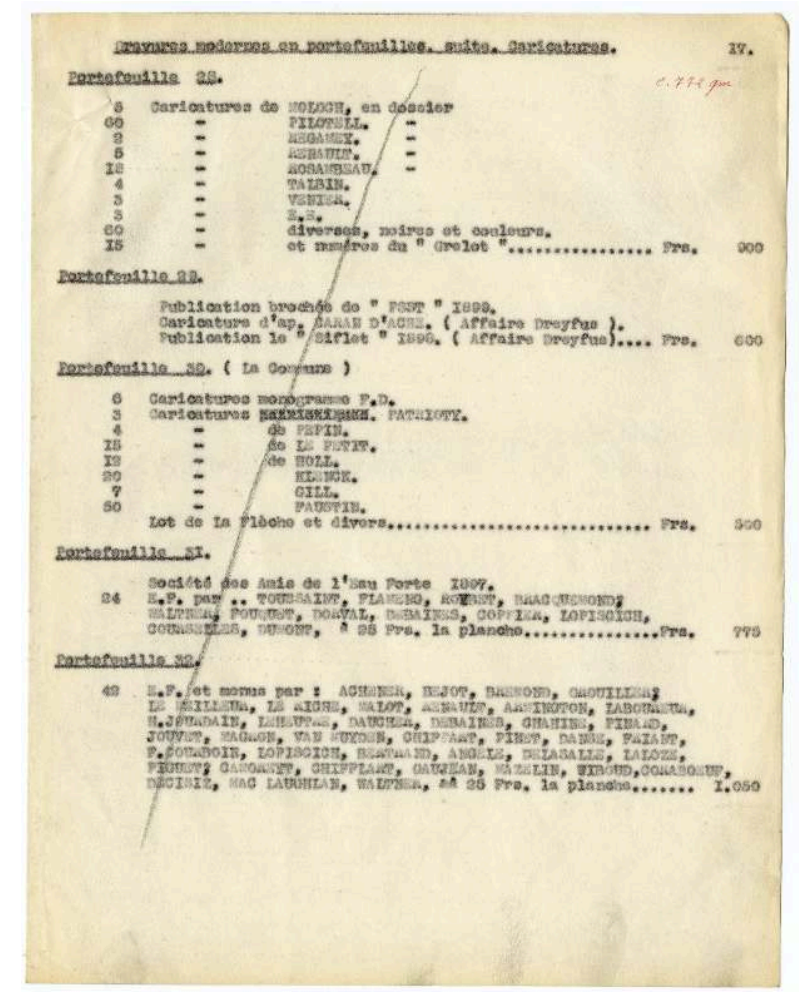

(C) Waddesdon Manor 


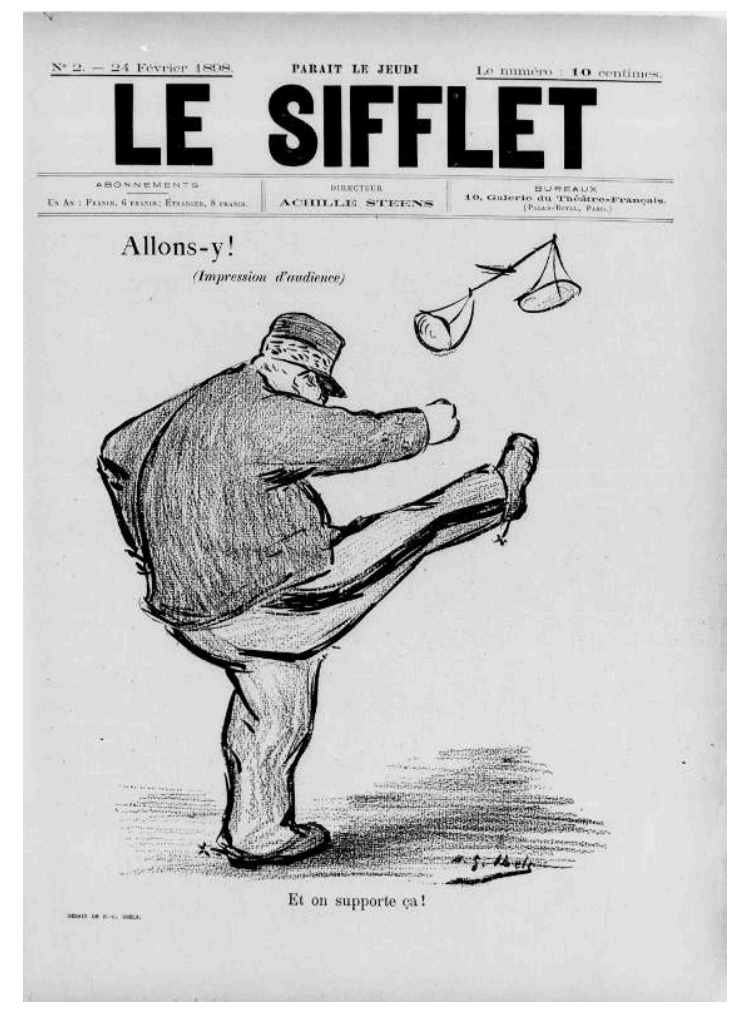

Photographie : Séverine Lepape

\section{Conclusion}

$\mathrm{Au}$ terme de ce voyage dans les inventaires de la collection graphique personnelle d'Edmond, nous n'avons pas trouvé de suites de Piranèse, ni de Goya, chose surprenante puisqu'Edmond avait accroché dans son cabinet d'estampes de l'hôtel du Faubourg-Saint-Honoré Les Majas au balcon ${ }^{96}$, et que Loÿs Delteil avait écrit au baron pour savoir s'il possédait des Goya susceptibles d'être signalés dans son catalogue raisonnép7. Il est fort possible qu'Edmond en ait acquis et que les inventaires lacunaires nous donnent une image quelque peu partielle de sa collection. Néanmoins, ils en indiquent les grandes tendances, confirmées par ce que l'on connaît effectivement de ses collections de peintures ou de sculptures.

On ne peut que souligner l'écart entre le goût de ce grand collectionneur et ce qu'un amateur d'aujourd'hui retient des artistes majeurs du xIX $x^{e}$ siècle ou du premier quart du $\mathrm{Xx}^{\mathrm{e}}$ siècle. Point d'impressionnistes ${ }^{98}$, aucune estampe de Manet par exemple, nulle lithographie de Toulouse-Lautrec ou des nabis, chez notre collectionneur. Des artistes symbolistes, Edmond ne semble avoir apprécié que Gustave Moreau, dont il conservait plusieurs dessins ${ }^{99}$, et à qui il commanda également des peintures ${ }^{100}$. Les belles lithographies d'Odilon Redon auraient pu logiquement trouver leur place dans les portefeuilles du baron, mais nous n'en avons trouvé aucune. Edmond semble être quelque peu resté à l'écart du phénomène japoniste, car seules deux gravures japonaises et la suite de dix eaux-fortes intitulée Japonisme, par Félix Buhot et Henri Guérard d'après les objets de la collection de Philippe Burty sont recensées. Dans ce contexte, on comprend d'autant mieux qu'on ne trouve aucune estampe d'artistes 
cubistes, fauves ou même, plus généralement, d'œuvres de Pablo Picasso ou d'Henri Matisse. Edmond était un collectionneur hermétique à l'avant-garde, il aimait les dessins de Rosa Bonheur ou de l'illustratrice pour enfants Kate Greenaway ${ }^{101}$. Peut-être aurait-il pu faire siennes les réserves qu'André Blum, son conseiller et secrétaire, plus tard premier conservateur de la collection Edmond de Rothschild au Louvre, publia en 1925 dans son Histoire générale de l'art : "Les Maîtres d'aujourd'hui mériteraient aussi, comme ceux d'autrefois, une place dans l'histoire de l'art. Mais il faut laisser s'écouler du temps. [...] Quelles que soient les opinions sur leurs talents, les exigences de l'histoire nous interdisent d'étudier l'histoire des artistes vivants, encore trop voisins de nous ${ }^{102}$.» En cela, la collection personnelle contemporaine d'Edmond n'anticipe guère ce que la postérité portera aux nues, contrairement à sa collection de dessins du $\mathrm{XVIII}^{\mathrm{e}}$ siècle et la collection d'estampes anciennes qu'il donna au musée du Louvre.

\section{NOTES}

1. Citons entre autres, André Blum, Chefs-d'ouvre de la collection Edmond de Rothschild du Musée du Louvre. Dessins et gravures, cat. exp. (Paris, musée de l'Orangerie, mai-juin 1954), Paris, 1954 ; Pascal Torres (dir.), Maestros de la invención. De la colección E. de Rothschild del Museo del Louvre, cat. exp. (Madrid, Fundación Juan March, 2004), Madrid, Fundación Juan March, 2004.

2. Pauline Prevost-Marcilhacy, Les Rothschild. Une dynastie de mécènes en France, Paris, Louvre/BnF/ Somogy, 3 vol., 2016 ; pour la collection Edmond de Rothschild, voir vol. III, p. 10-207.

3. Edmond aida à l'acquisition des squelettes de trois ours, de trois lions, d'une hyène et d'un loup de l'époque du quaternaire, provenant de la caverne de l'Herm (Ariège), et ayant appartenu à Henri Filhol, pour le Muséum d'histoire naturelle. Une vitrine au sein de la galerie de Paléontologie réunissant ces ossements lui est encore aujourd'hui consacrée. MNHN F. 1903-20.

4. Louis-Antoine Prat, Le Dessin français au XVIII'siècle, Paris, Somogy/Louvre, 2017.

5. Sur les ornements, voir Alistair Laing, Drawings for Architecture, Design and Ornament, 2 vol., Aylesbury, The Alice Trust, 2006 ; Juliet Carey, Theatres of Life: Drawings from the Rothschild Collection at Waddesdon Manor, cat. exp. (Londres, Wallace collection, 2008, Nottingham, Djanogly museum and art gallery, 2007-2008, Waddesdon, Waddesdon Manor, 2009), Waddesdon, The Alice Trust/Waddesdon Manor/The National Trust, 2007.

6. Tous conservés sous la même cote : Waddesdon Manor Archives, ERX1/2/6/4.

7. Waddesdon Manor Archives, ERX2/2/42/1.

8. Waddesdon Manor Archives, ERX1/2/6/1.

9. Waddesdon Manor, registre des entrées $n^{\circ} 1359$ [abrégé par la suite en reg. entr.], noté comme provenant $\mathrm{du} \mathrm{D}^{\mathrm{r}}$ Didier-Roth, sans date. Non décrit dans Alexandre Ananoff, L'Euvre dessiné de François Boucher (1703-1770). Catalogue raisonné, Paris, F. de Nobele, 1966 ; Juliet Carey, Theatres of Life: Drawings from the Rothschild Collection at Waddesdon Manor, op. cit., $\mathrm{n}^{\circ} 66, \mathrm{p} .170-171$ (repr.).

10. Reg. entr. $\mathrm{N}^{\circ} 135 / 2$, sanguine, mai 1878 , collection Carré $n^{\circ} 18$, sans prix.

11. Waddesdon Manor, inv. 2622 ; Prat 2017, p. 176. Non décrit dans Alexandre Ananoff, L'Euvre dessiné de François Boucher (1703-1770). Catalogue raisonné, op. cit. Reg. entr. n¹173, décrit comme une " grisaille ", provenance Heseltine, achat auprès de Guiraud, mai 1913.

12. Alexandre Ananoff, L'EEuvre dessiné de Jean-Honoré Fragonard, Paris, F. de Nobele, 1961-1971 $\mathrm{n}^{\circ} 2002$; Pierre Rosenberg (dir), Fragonard, cat. exp. (Paris, Galeries nationales du Grand Palais 
1987- 1988), Paris, Réunion des musées nationaux, 1987, n²36, dessin en rapport, fig. 1 (dessin) et 2 (ceurtificat).

13. Alexandre Ananoff, L'Euvre dessiné de Jean-Honoré Fragonard, op. cit., n¹987, fig. 542 ; Pierre Rosenberg (dir.), Fragonard, op. cit.,, n²38, dessin en rapport, fig. 1.

14. Reg. entr. $n^{\circ} 98,99$ et 99 bis pour 4000 frs.

15. Ils ont sans doute échu à Maurice de Rothschild car ils font partie d'une liste dactylographiée de 17 dessins remis le 26 décembre 1935 à M. Vaudaux pour ce dernier. Waddesdon Manor Archives, ERX1/2/6/4.

16. Louvre, DAG, RF 4266. Alexandre Ananoff, L'CEuvre dessiné de Jean-Honoré Fragonard, op. cit., n405; Guillaume Faroult (dir), Fragonard amoureux, cat. exp. (Paris, Musée du Luxembourg, 2015-2016), Paris, Gallimard/RMN-Grand Palais, 2015, cat. 94. Sur la dation de 1990, voir Alain Pasquier et Marc Bascou, «Objets antiques, peintures, dessins et objets d'arts du XvIII ${ }^{\mathrm{e}}$ siècle. Dation de 1990 », dans Pauline Prevost-Marcilhacy, Les Rothschild. Une dynastie de mécènes en France, op. cit., vol. III, p. 364-379, et sur ce dessin en particulier, p.370. Jean-François Méjanès, «Trois dessins par Watteau et Fragonard », Revue du Louvre, 1991, p. 52.

17. Reg. entr. $n^{\circ} 85$.

18. Lugt, 41573.

19. Reg. entr. $\mathrm{N}^{\circ} 415$, bistre. Vente François Walferdin (12-16 avril 1880, $\left.\mathrm{n}^{\circ} 216\right)$, achat par l'intermédiaire de Lacroix, pour 3300 frs ; Alexandre Ananoff, L'Euvre dessiné de Jean-Honoré Fragonard, op. cit., $\mathrm{n}^{\circ} 11$, fig. 6 ; Pierre Rosenberg (dir), Fragonard, op. cit., $\mathrm{n}^{\circ} 226$, dessin en rapport.

20. Reg. entr. $\mathrm{N}^{\circ} 413$ pour 638 frs. VenteWalferdin, $\mathrm{n}^{\circ} 186$. Aujourd'hui à Waddesdon Manor, 395.1995 ; Juliet Carey, Theatres of Life: Drawings from the Rothschild Collection at Waddesdon Manor, op. cit, , $\mathrm{n}^{\circ} 68$, p. $174-175$.

21. Reg. entr. $\mathrm{N}^{\circ} 414,990$ fr. Vente Walferdin $n^{\circ} 197$. Donné du vivant d'Edmond à Mme Goldschmidt le 20 décembre 1912 selon une annotation sur le registre d'entrée puis entré en dation au Louvre comme le dessin d'Amour et Psyché, aujourd'hui, DAG RF 42670. Pasquier et Bascou, dans Pauline Prevost-Marcilhacy, Les Rothschild. Une dynastie de mécènes en France, op. cit., vol. III, p. 368. Jean-François Méjanès, "Trois dessins par Watteau et Fragonard ", art. cit., p. 50-51 (qui a identifié une appartenance antérieure à Saint-Morys).

22. Reg. entr. $\mathrm{N}^{\circ} 416,1045$ frs. Vente Walferdin $n^{\circ} 224$.

23. Reg. entr. $\mathrm{N}^{\circ} 1117$, achat en mai 1911 à la vente Pierre Decourcelle par Danlos, pour 27600 frs (!). Pierre Rosenberg (dir), Fragonard, op. cit, ${ }^{\circ} 119$ (repr.)

24. Pierre Rosenberg et Louis-Antoine Prat, Antoine Watteau, 1684-1721 : catalogue raisonné des dessins, Paris, Gallimard/Electa, 1996, nR34. Aujourd'hui conservé au Waddesdon Manor, inv. $\mathrm{n}^{\circ}$ 586. Attribué à Jean-Baptiste Pater ou à Gabriel Huquier père par Alastair Laing, Drawings for Architecture, Design and Ornament, op. cit., t. I, n²71. Reg. entr. $n^{\circ} 586$, achat auprès d'Alphonse Wyatt Thibaudeau, 2500 frs, décembre 1888.

25. Pierre Rosenberg et Louis-Antoine Prat, Antoine Watteau, 1684-1721, op. cit., n591. Reg. entr. $\mathrm{n}^{\circ} 1174$, sanguine et pierre noire, sans prix, mai 1913, vente John Postle Heseltine, par l'intermédiaire de Guiraud.

26. Louvre, DAG, RF 42668. Pierre Rosenberg et Louis-Antoine Prat, Antoine Watteau, 1684-1721, op. cit., $\mathrm{n}^{\circ}$ 409. Pasquier et Bascou, dans Pauline Prevost-Marcilhacy, Les Rothschild. Une dynastie de mécènes en France, op.cit., vol. III, p. 368. Jean-François Méjanès, «Trois dessins par Watteau et Fragonard ", art. cit., p. 49-50. Vente Jacques Doucet, Dessins et pastels du XVIII ${ }^{\mathrm{e}}$ siècle, 5 juin 1912, experts Émile Dacier et Marcel Nicolle, Paris, Georges Petit, n 58, p. 62.

27. Elément déjà remarqué par Pasquier et Bascou dans Pauline Prevost-Marcilhacy, Les Rothschild. Une dynastie de mécènes en France, op. cit, vol. IIII, note 12, sans explications.

28. Reg. entr. $n^{\circ} 1118$, mai 1911, vente Montgermont, achat par Danlos, 17365 frs.

29. Reg. entr. $\mathrm{N}^{\circ} 1190,14030$ frs.

30. Reg. entr. $\mathrm{N}^{\circ} 616-626$, tous encadrés, pour $1500 \mathrm{frs}$. 
31. Inv. 6243470TG. Gaëtane Maes, Les Watteau de Lille : Louis Watteau, 1731-1798 ; François Watteau, 1758-1823, Paris, Arthena, 1998, FD 98, p. 430.

32. Reg. entr. $\mathrm{N}^{\circ} 1145 / 113$, acquis par l'intermédiaire de Lacroix à la vente Fourquevaux, 18-20 avril 1876 ; Lugt $\mathrm{n}^{\circ} 36423 .$, lot 549.

33. Reg. entr. $n^{\circ} 739$ à 751 et Reg. entr. $1144 / 37$ pour 1800 frs

34. ERX1.2.6.4

35. Reg. entr. 733, crayons de couleurs sur vélin, coll. Jean Gigoux, achat à la vente Destailleur par Danlos, en mai 1896 pour 3300 frs.

36. Reg. entr. $\mathrm{N}^{\circ} 1372$ et 1373 , aux trois crayons, sans date ni provenance.

37. La Poésie : reg. entr. $\mathrm{N}^{\circ} 1374$, pierre noire, prov. De Boisfrémont [Charles Boulanger], sans prix, 1870 ; La Navigation : Reg. entr. $\mathrm{N}^{\circ} 1375$, même provenance, date de 1876. Alastair Laing, Drawings for Architecture, Design and Ornament, op. cit., t. I, note 3 p. 9, précise que les dessins furent vendus à la vente de la fille du peintre, Madame Power, en 1864. Nous pensons, au vu de la date de cette vente (Edmond aurait eu alors 19 ans) et du fait que cette mention arrive en fin du registre d'entrées, comme s'il s'agissait d'une régularisation, qu'il s'agit en plutôt d'un achat de James, père d'Edmond, donné en deux temps à son fils.

38. Pierre Wachenheim et Jean-Gérald Castex, «Les estampes du XVIII ${ }^{\mathrm{e}}$ siècle » dans Pauline Prevost-Marcilhacy, Les Rothschild. Une dynastie de mécènes en France, op. cit., vol. III, p. 141. Pour d'autres dessins de Prud'hon dans la collection d'Edmond, voir Alastair Laing, Drawings for Architecture, Design and Ornament, op. cit.,t. I, p. 9.

39. Reg. entr. $\mathrm{N}^{\circ} 312$, encre de chine, de Clément pour 500 frs, juillet 1878.

40. Prat 2017, p. 454-457.

41. Juliet Carey, Theatres of Life: Drawings from the Rothschild Collection at Waddesdon Manor, op. cit, n43-45, p. 117-125 :Les Adieux, La Petite Loge, Le Souper fin. Alice de Rothschild les avait achetés à la vente de Jean Gigoux.

42. Reg. entr. ${ }^{\circ} 422$ et 423.

43. Reg. entr. $n^{\circ} 695-699$.

44. Reg. entr. $n^{\circ} 734$.

45. Lugt 57132.

46. Reg. entr. $n^{\circ} 775$ et 776.

47. Reg. entr. $n^{\circ} 777$ et 778.

48. Alastair Laing, Drawings for Architecture, Design and Ornament, op. cit.,, t. I, p. 9-18.

49. Frédéric Dassas, «Les gravures d'architecture, d'ornements et d'arts décoratifs » dans Pauline Prevost-Marcilhacy, Les Rothschild. Une dynastie de mécènes en France, op. cit., vol. III, p. 144-153.

50. On consultera avec profit le catalogue en ligne de ses eaux-fortes : auguste-brouet.org/

51. auguste-brouet.org/Biographie/Biographie_1.htm

52. Reg entr. n¹8430 à 18447 et 18455 à 18465 . Dans ce lot se trouve également Cain et Abel d'Odilon Redon.

53. Reg entr. $n^{\circ} 15299$, vente Maherault, par l'intermédiaire de Lacroix, mai 1880.

54. Reg. entr. $n^{\circ} 1038$, juin 1907 , vente Sedelmeyer pour 98,40 francs.

55. Edmond et Jules de Goncourt, Gavarni. L'homme et l'œuvre, Paris, Charpentier, 1879.

56. Marie-Joseph-François Armelhault et Emmanuel Bocher, L'Euvre de Gavarni.Lithographies originales et essais d'eau-forte et de procédés nouveaux. Ccatalogue raisonné, Paris, Librairie des bibliophiles, 1873 .

57. Reg. entr. n¹298 à 1322 .

58. Paul-André Lemoisne, Gavarni. Peintre et lithographe, Paris, H. Floury, 1924-1928.

59. Reg. entr. $n^{\circ} 5741$ et $3618 \mathrm{a}$, numéros figurant dans le premier registre ayant disparu, antérieurs donc à 1874 .

60. Reg. entr. n¹5272-15274, vente Maherault par l'intermédiaire de Lacroix, mai 1880. 
61. Reg. entr. $\mathrm{n}^{\circ} 1204$ et 1205, vente Beurdeley, 517 frs et 5290 frs, tous deux encadrés, 2 juin 1920.

62. Il s'agit d'un ensemble entré au même moment car les numéros se suivent (5617 à 32) mais sont hélas antérieurs à ceux du deuxième registre.

63. Reg. entr. $n^{\circ} 16640$ et 16641 .

64. Reg. entr. $n^{\circ} 631$.

65. Pauline Prevost-Marcilhacy, «Edmond James de Rothschild», dans id., Les Rothschild. Une dynastie de mécènes en France, op. cit, vol. I, p. 49.

66. Voir sur les relations entre James et Lami, Pauline Prevost-Marcilhacy, Les Rothschild, bâtisseurs et mécènes, Paris, Flammarion, 1995.

67. Reg. entr. $\mathrm{n}^{\circ} 1323$ à 1342.

68. Paul-André Lemoisne, L'OEuvre d'Eugène Lami, 1800-1890 : lithographies, dessins, aquarelles, peintures. Essai d'un catalogue raisonné, Paris, H. Champion, 1914. Ce dernier a pu consulter à de nombreuses reprises la collection du baron Edmond et s'est entretenu par correspondance avec André Blum en 1910 et 1911 dans ce but: Londres, Archives Rothschild, Moscow Paper, 58-1-817, fol. 36, 37, 39, 44, 45, 47.

69. Pauline Prevost-Marcilhacy (dir.), Les Rothschild. Une dynastie de mécènes en France, op. cit., vol. I, p. 92-111.

70. Ces acquisitions sont confirmées, outre par leur présence dans l'inventaire et dans le registre d'entrées, par la correspondance de Lamotte à Silvy dans les Archives Rothschild de Londres, comme par exemple en 1891, où il est question de propositions par Lamotte de vente de ses œuvres au baron : Moscow Papers, 58-1-817.

71. Jean Adhémar, Françoise Gardey, Jacques Lethève, Inventaire du fonds français après 1800 , Paris, Bibliothèque nationale, 1963, t. 12, p. 360-364.

72. Reg. entr. $\mathrm{N}^{\circ} 17953$ à 17955.

73. Reg. entr. $\mathrm{N}^{\circ} 17956$ à 17958 . Une épreuve du troisième état de la Famille de Largillière est conservée à la Bibliothèque nationale de France, Estampes et photographie, AA-3 Lamotte. Adhémar et al. $1963, n^{\circ} 30$, p. 362.

74. Reg. entr. $\mathrm{N}^{\circ} 18206,100$ frs.

75. Jean Adhémar, Françoise Gardey, Jacques Lethève, Inventaire du fonds français après 1800, Paris, Bibliothèque nationale, 1960, t. 11, p. 514, qui ne donnent pas sa date de mort.

76. Ibid. et Marianne Grivel, « Histoire de la constitution d'un Musée de la gravure » dans Pauline Prevost-Marcilhacy, Les Rothschild. Une dynastie de mécènes en France, op. cit, vol. III, p. 41.

77. Londres, Rothschild Archives, Moscow Papers 58-1-817, fol. 78 : le 5 octobre 1911, lettre où Journot demande une aide financière au baron car son fils est malade. Il fait état des bonnes relations avec la famille d'Edmond car par le passé, il s'adressait au baron Alphonse [Mayer Alphonse, frère d'Edmond] dont on lui avait demandé le portrait à l'aquarelle en 1892, lorsqu'il avait des besoins urgents d'argent.

78. Reg. entr. ${ }^{\circ} 18207$ et 18208,150 frs chaque.

79. Reg. entr. $n^{\circ} 18329$ à 18333.

80. Jean Adhémar, Inventaire du fonds français après 1800, Paris, Bibliothèque nationale, 1949, t. 5, p. 156.

81. Reg. entr. ${ }^{\circ} 18336$

82. Jean Adhémar, Inventaire du fonds français après 1800, op. cit., p. 165.

83. Reg. entr. $n^{\circ} 1147,500$ frs.

84. Reg. entr. $n^{\circ} 18196$, novembre 1904.

85. Reg. entr. $n^{\circ} 18197$, même date.

86. Reg. entr. $\mathrm{n}^{\circ} 18198-201$, Mme Destouches d'après Ingres (trois gravures, des états différents jusqu'à l'épreuve finale), même date et Reg. entr. $N^{\circ} 18228$ à 232 , diverses estampes d'après Ingres en juin 1906. 
87. Pauline Prevost-Marcilhacy, Les Rothschild. Une dynastie de mécènes en France, op. cit., , vol. I, p. 95-96.

88. Reg. entr. $n^{\circ} 18240$ à 18266 , mai 1907.

89. Estampes d'après la prédelle du retable de San Zeno, dont les plaques sont conservées en effet à la Chalcographie du Louvre.

90. Jean Adhémar, Françoise Gardey, Jacques Lethève, Inventaire du fonds français après 1800, op. cit., t. 11, p. 204-205.

91. Prevost-Marcilhacy, « Edmond James de Rothschild», art. cit., vol. I, p. 44.

92. René Wiener, relieur et animateur de la vie artistique au temps de l'École de Nancy, cat. exp. (Nancy, Musée historique lorrain, 1999), Nancy, 1999.

93. Reg. entr. n 1175 et 1176 , en mai 1913.

94. Reg. entr. $n^{\circ} 18387-18388$.

95. Pauline Prevost-Marcilhacy, « Edmond James de Rothschild», art. cit., p. 44.

96. Acheté en 1911 auprès de Durand-Ruel. Ibid., p. 55-56.

97. Marianne Grivel, «Histoire de la constitution d'un "Musée de la gravure" ", art. cit., p. 13. Londres, Archives Rothschild, Moscow papers, 58-1-824, fol. 114, novembre 1921.

98. On note néanmoins la présence d'un dessin de Pissarro, Route à la sortie d'un village, Reg. Entr. $\mathrm{N}^{\circ} 1152$, provenance veuve Rouart, achat auprès de Durand-Ruel, sans prix, décembre 1912, aquarelle gouachée, encadré.

99. David dansant devant l'arche et Apollon et Marsyas, listés dans l'inventaire des dessins du XIX siècle encadrés.

100. Pauline Prevost-Marcilhacy, «Edmond James de Rothschild », art. cit, , p. 51-52.

101. Quatre dessins de Rosa Bonheur et six de Kate Greenaway sont listés dans l'inventaire des dessins du XIXe siècle encadrés.

102. Pauline Prevost-Marcilhacy, «Le mécénat envers les artistes vivants, 1906-1920 », art. cit., p. 96.

\section{INDEX}

Index géographique : France

Thèmes : Estampes, collections, Rothschild

Index chronologique : xviiie siècle, xixe siècle, xxe siècle

\section{AUTEUR}

\section{SÉVERINE LEPAPE}

Sévérine Lepape est conservatrice, en charge de la collection Edmond de Rothschild, au département des Arts Graphiques, musée du Louvre. 


\title{
«Un ensemble harmonieux et
} instructif $»$ : la collection de livres imprimés et de recueils d'estampes du baron Edmond de Rothschild

\author{
Victoria Fernandez
}

1 La collection de livres imprimés et de recueils de gravures d'Edmond de Rothschild est peut-être la partie la moins bien connue de l'ensemble généreusement donné en 1935 au musée du Louvre. Les premières expositions, dans les années suivant la donation, ont servi à présenter les livres les plus précieux, qui ont fait l'objet de notices succinctes. Il faut attendre 1974 pour que paraisse la première étude poussée sur les incunables xylographiques et typographiques ${ }^{1}$, faite par Pierrette Jean-Richard, puis complétée par l'analyse codicologique de Dominique Coq quarante-deux ans plus $\operatorname{tard}^{2}$. Enfin, l'article d'Isabelle de Conihout ${ }^{3}$ est revenu sur l'intérêt bibliophilique des Rothschild avant Edmond et il a notamment fait le point sur les ouvrages dont ce dernier a hérité de son père, James.

Grâce à la description de la fameuse vente de la collection de Félix Solar de 1860, détaillée dans le Bulletin du bibliophile ${ }^{4}$, nous savons qu'Edmond s'imprégna de l'amour des livres en fréquentant les salles de ventes avec son père, l'ambiance décrite étant sans doute la plus propice à l'échange des savoirs et à la formation à la bibliophilie d'un jeune homme de 15 ans. Conseillé par des conservateurs et des experts marchands, il étoffa progressivement sa bibliothèque, qui s'enrichit d'au moins 130 volumes à la mort de son père, survenue en $1868^{5}$. Il poursuivit ses achats, toujours en parfaite correspondance avec sa riche collection d'estampes, jusqu'en $1914^{6}$, environ.

\section{État des lieux suite à l'informatisation}

Comme l'a signalé Marianne Grivel', les sources qui nous permettent aujourd'hui de comprendre la formation de la collection du baron ne sont pas nombreuses, et cela vaut 
d'autant plus pour sa sélection d'ouvrages imprimés. Un fichier manuscrit établi par les anciens collaborateurs du baron et conservé au sein de la collection fournit des informations d'une précision inégale sur le contenu des livres et, parfois, sur l'ancien possesseur, la date et le lieu d'acquisition. Mais aucun registre d'entrées ou d'acquisitions spécifiquement dédié aux ouvrages imprimés n'a été retrouvé pour l'instant, et nous n'avons pas la certitude que le baron en ait fait tenir un par ses différents collaborateurs. Les seules preuves d'achat permettant de retracer les acquisitions faites d'août 1874 à 1914 figurent dans le deuxième et le troisième registre d'entrées des estampes. Le premier, où étaient inscrits les achats à partir d'environ 1860 , est aujourd'hui introuvable ${ }^{8}$. À la lecture des autres registres, nous identifions l'immatriculation de seulement 29 livres et recueils 9 parmi les 539 conservés au Louvre $^{10}$. Enfin, six recueils d'estampes d'ornement figurent dans un registre supplémentaire dédié à ce genre, tenu de février 1877 à mai $1888^{11}$. Cet écart entre le nombre de volumes inscrits et ceux actuellement conservés au musée nous conduit à formuler plusieurs hypothèses : le père d'Edmond lui donna les livres ne figurant pas dans les registres, c'est-à-dire la plupart de la donation faite au musée du Louvre. Les volumes qui ne sont pas inscrits dans les registres conservés à Waddesdon pourraient avoir été achetés avant 1874, date à laquelle commence le deuxième registre, ou bien le baron tenait un cahier pour les achats de livres et de recueils qui nous reste aujourd'hui inconnu. Mais pourquoi, dans ce cas, inscrire certaines acquisitions à la suite des estampes? La seule certitude est qu'il est difficile de dresser une liste précise d'ouvrages effectivement acquis par le baron du fait du manque d'un ou de plusieurs cahiers d'entrées.

4 Durant la dernière décennie (de 2008 à 2017), le département des Arts graphiques du musée du Louvre a mené une ambitieuse campagne d'informatisation, visant à une meilleure connaissance et à une plus large diffusion du fonds confié par le baron. Ce travail s'est conclu par la mise en ligne, sur l'inventaire informatisé et illustré du département, des 539 volumes qui forment la donation ${ }^{12}$.

5 La méthodologie appliquée a consisté, dans un premier temps, à examiner chaque volume afin de récolter les informations relatives à l'exemplaire (éditeur, date et lieu d'édition, imprimeur, etc.) et, dans un second temps, à analyser les illustrations contenues, puisque chacune d'elles a fait l'objet d'une fiche d'inventaire rattachée au volume. L'actualisation des informations se poursuit avec l'analyse plus fine de chaque ouvrage afin d'identifier les graveurs et d'étudier les illustrations.

6 L'informatisation des livres de la collection Rothschild n'a pas été sans écueil, car nous avons rencontré les difficultés liées à la singularité du don d'un ensemble de livres imprimés à un musée et, donc, celles liées à la saisie des informations des volumes reliés dans une base de données initialement conçue pour héberger des œuvres en feuilles ou en carnet d'artiste.

7 La donation d'une collection de livres à un musée est un choix rare, dans la mesure où ces ensembles sont accordés en règle générale aux institutions qui conservent les mêmes items, c'est-à-dire les bibliothèques. Le musée du Petit Palais partage cette particularité avec le Louvre, puisqu'en 1902 le grand collectionneur et mécène Auguste Dutuit (1812-1902) a donné à la Ville de Paris un ensemble de 20000 œuvres, noyau fondateur de l'actuel musée. Cet important lot était riche de 12000 estampes $^{13}$ et de 789 livres imprimés et recueils de gravures, passionnément réunis par son frère, Eugène (1807-1886), savant amateur d'estampes. Au-delà de la quantité presque 
similaire d'exemplaires réunis par Eugène Dutuit et par le baron Edmond, il nous a semblé intéressant de comparer les collections de ces grands connaisseurs, qui partageaient un rare intérêt pour les nielles du Quattrocento, un même attrait bien connu pour l'estampe hollandaise $\mathrm{du} \mathrm{XVII}^{\mathrm{e}}$ siècle et, en particulier, pour Rembrandt ainsi que, comme nous allons le démontrer, une même volonté de réunir des livres imprimés et des recueils en plus de leur extraordinaire collection d'estampes en feuilles.

Eugène Dutuit rappelle, dans la préface de son ouvrage de référence, le Manuel de l'amateur d'estampes, ce que doit contenir une collection d'estampes :

«Dans l'histoire de la gravure, on ne saurait séparer les estampes isolées ou les recueils d'images des livres à gravures, où le texte joue un rôle égal ou prépondérant. Certaines manifestations de cet art ne se trouvent d'ailleurs que là, comme, par exemple, l'imagerie religieuse des livres d'heures. Une collection d'estampes sérieuse doit donc obligatoirement comprendre des livres illustrés typiques en tout genre, de manière à présenter un ensemble harmonieux et instructif ${ }^{14}$.»

Cette introduction pourrait laisser entendre qu'Eugène Dutuit s'inspira de l'ensemble réuni par le baron pour décrire la collection exemplaire d'un passionné d'estampes, mais ce serait oublier que les deux amateurs fréquentaient les mêmes salles des ventes durant une trentaine d'années et que, donc, la constitution de leur ensemble d'œuvres est quasi contemporaine.

\section{Les grandes catégories de la collection de livres et de recueils du baron}

10 Le catalogue de la collection des livres du baron étant encore à rédiger, nous présentons ici un aperçu des exemplaires les plus remarquables de l'« ensemble des livres typiques en tout genre ", suivant les cinq catégories et sections que le libraire parisien Édouard Rahir (1862-1924) établit dans le catalogue de la collection des manuscrits et des livres des frères Auguste et Eugène Dutuit, à savoir "Théologie ", "Jurisprudence », "Sciences et arts », «Belles-Lettres » et " Histoire ». Ces divisions furent aussi utilisées par Émile Picot (1844-1918) pour la rédaction du catalogue de la bibliothèque de James Édouard de Rothschild ${ }^{15}$.

11 Un premier groupe de volumes précieux à thématique majoritairement religieuse est formé par les incunables xylographiques et typographiques ${ }^{16}$, qui suscitèrent à l'époque une vive attention parmi les bibliophiles qui suivaient attentivement les conseils du conservateur de la Bibliothèque nationale, Georges Duplessis ${ }^{17}$ (1834-1899). Au même titre que pour sa collection d'estampes, le critère de choix d'Edmond de Rothschild pour se constituer une collection d'incunables fut la rareté des exemplaires : preuves en sont les deux livrets xylographiques répertoriés aujourd'hui à moins d'une dizaine d'exemplaires ${ }^{18}$, qui reflètent sa connaissance fine des origines du livre imprimé. Alors qu'il avait pour habitude de donner des indications de prix d'achat à ne pas dépasser à ses collaborateurs, le baron fut prêt à débourser des sommes très conséquentes pour les obtenir. Tel fut le cas de l'un des fleurons de sa collection, l'Apocalypsis Johannis ${ }^{19}$ (fig. 1), livret xylographique colorié et imprimé aux Pays-Bas, entre 1466 et 1470, acquis auprès de l'éminence de la gravure sur bois, Wilhelm Ludwig Schreiber. 
1. Apocalypsis Johannis, entre 1466 et 1470 , Paris, musée du Louvre, département des Arts graphiques, collection Edmond de Rothschild.

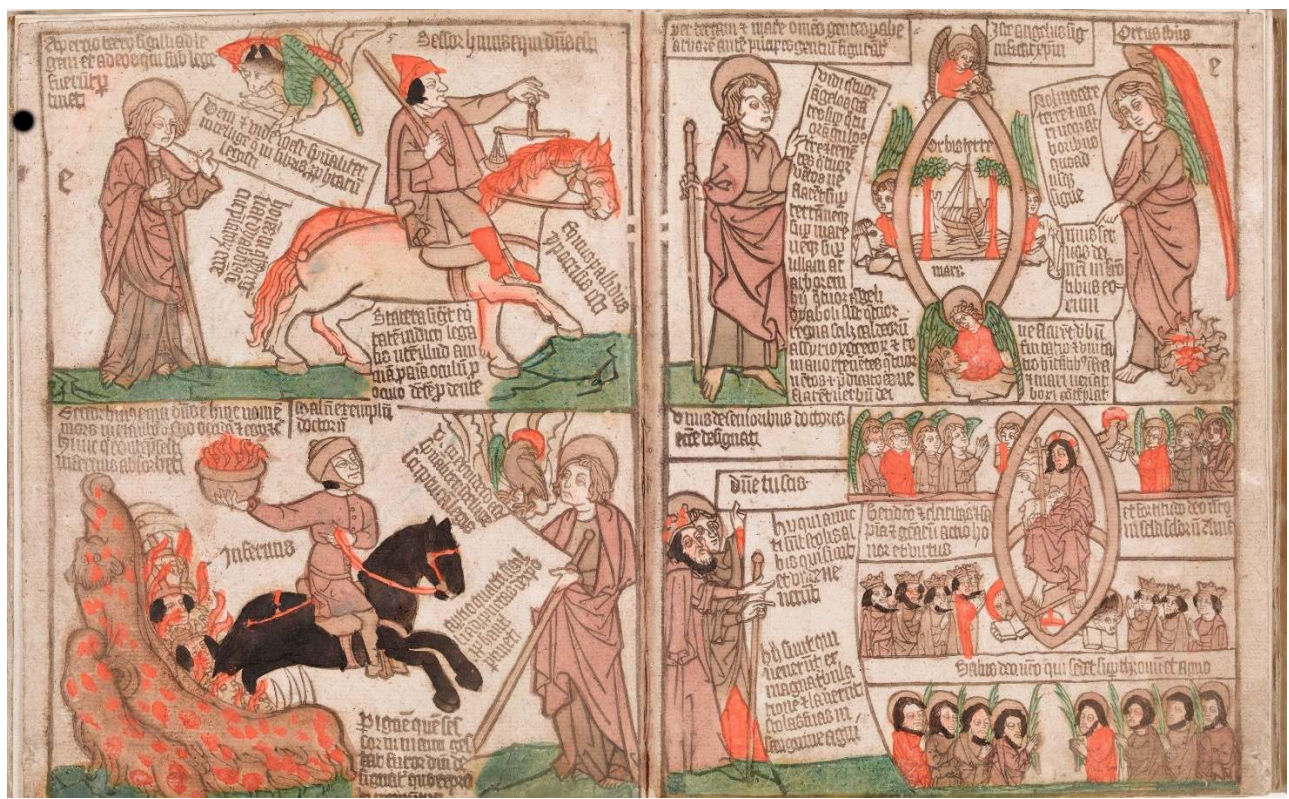

(c) Musée du Louvre

Pour mieux évaluer l'ampleur et l'importance de la collection de livres à sujet religieux du baron Edmond, il convient de signaler qu'au moins la moitié de sa collection de volumes manuscrits était composée de livres d'heures et de livres de prières chrétiens ${ }^{20}$. Certes, cet ensemble ne fut pas légué au musée du Louvre; seuls nous sont parvenus 13 livres d'heures à usage divers, publiés à Paris autour de 1490-1530 par les principaux libraires et imprimeurs de l'époque, tels que Philippe Pigouchet ou Germain Hardouyn. La redécouverte, à l'occasion de l'exposition des «Enluminures du Louvre $^{21}$ ", du précieux Livre d'heures à l'usage de Rouen ${ }^{22}$, incunable unicum imprimé à Paris par Jacques Le Forestier et orné de treize gravures sur bois peintes, rappelle la valeur inestimable de ces délicats ouvrages aux yeux du baron.

Lors de la vente précédemment mentionnée de la collection de Félix Solar ${ }^{23}$, James de Rothschild acquit un groupe de livres à thème religieux ${ }^{24}$, ensemble qu'Edmond acheta également, à deux titres près ${ }^{25}$. Ces acquisitions reflètent probablement une rivalité avec le père, mais elles révèlent surtout son goût pour la gravure sur bois exécutée à Lyon et à Francfort entre 1530 et 1560, illustrant plusieurs épisodes de l'Ancien et du Nouveau Testament, dont l'Apocalypse, sujet cher au baron. Les Quadrins historiques de la Bible ${ }^{26}$ (Lyon, 1533), contenant des gravures sur bois de Bernard Salomon, sont un exemple de petites bibles qui eurent un succès extraordinaire à l'époque, comme le démontrent les sept éditions publiées par Jean de Tournes en l'espace de six ans.

C'est dans la section intitulée "Sciences et $\operatorname{arts}^{27}$ » du catalogue de Rahir que la collection des frères Dutuit et celle du baron Edmond de Rothschild trouvent leurs plus grandes divergences, puisqu'y sont décrits une cinquantaine d'exemplaires consacrés à la philosophie, aux sciences naturelles, aux mathématiques ou à l'astrologie, qui intéressèrent les amateurs rouennais, alors que ces sujets sont absents de la collection du Louvre, probablement à cause des thématiques abordées, sans correspondance avec sa collection d'estampes en feuilles. Un seul livre imprimé fait exception à l'intérieur de 
cette section : le Fasciculus Medicinae ${ }^{28}$ (fig. 2) de Johannes de Khetam, qui intéressa sans doute le baron en tant que premier traité de médecine, orné de gravures sur bois.

2. Fasciculus Medicinae, 1495, Paris, musée du Louvre, département des Arts graphiques, collection Edmond de Rothschild.

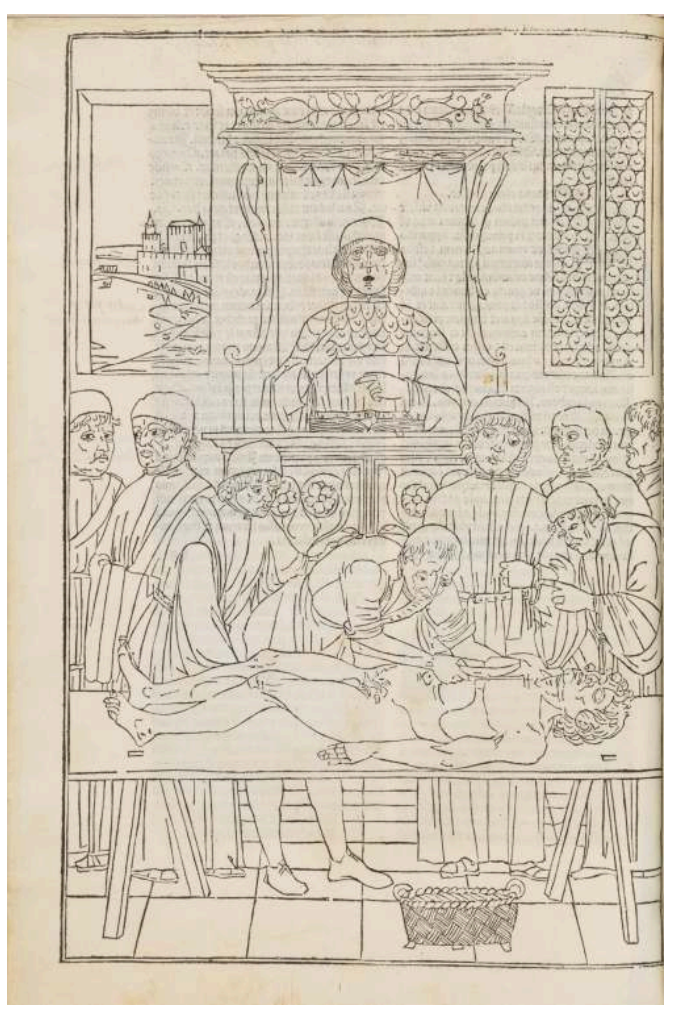

(C) Musée du Louvre

Les livres de beaux-arts constituent une sous-section à l'intérieur de la catégorie des "Sciences et arts", où Édouard Rahir décrit, au sein de la collection Dutuit, une quarantaine de titres aux sujets très différents (des recueils d'estampes de mode, des livres de fables, des imprimés allemands du XviII ${ }^{\mathrm{e}}$ siècle, l'Iconographie d'Antoine Van Dyck ou une série des Caprichos de Goya, pour ne citer que quelques exemples). Dans cette liste, figurent aussi deux publications qui apparaissent dans de nombreux catalogues de vente de l'époque et que le baron ne manqua pas d'acheter, bien que, vraisemblablement, il ne jugeât pas opportun de les inclure dans sa donation, comme on le voit quand on compare le registre des entrées de gravures et les volumes conservés au Louvre. Il s'agit du Recueil d'estampes gravées d'après les tableaux du cabinet de Monseigneur le Duc de Choiseul... et de la Collection de cent vingt estampes gravées d'après les Tableaux \& Dessins qui composoient le Cabinet de M. Poullain... ${ }^{29}$. Nous ignorons les raisons d'un tel choix, qui est loin d'être unique ${ }^{30}$, mais il est possible qu'il réservât ces volumes comme cadeaux ou legs à des membres de sa famille.

Les 82 volumes d'architecture et les 50 livres et recueils dédiés à l'ornement indiquent clairement la place privilégiée que le baron réserva à ces deux sujets, d'autant plus que le parallèle avec la collection Dutuit, conservée aujourd'hui au Petit Palais, met particulièrement en relief les différences de goût entre ces deux amateurs d'estampes ${ }^{31}$. La collection de livres d'architecture du $\mathrm{XVI}^{\mathrm{e}}$ siècle d'Edmond, composée d'une dizaine de titres, révèle la manière dont le baron se passionne pour un artiste et, au contraire, 
son indifférence, parfois surprenante, pour l'œuvre de certains graveurs majeurs. Nous notons ainsi l'absence du Premier Livre d'architecture et du Second Livre de perspective de Sebastiano Serlio ou de l'œuvre majeure d'Andrea Palladio, Les Quatre Livres de l'architecture. En revanche, les travaux réalisés par l'architecte, dessinateur et graveur Jacques I ${ }^{\text {er }}$ Androuet du Cerceau l'intéressèrent particulièrement, comme le prouvent les sept exemplaires légués au Louvre ${ }^{32}$, reflet probable de son penchant nationaliste, partagé d'ailleurs par Eugène Dutuit, car des quatre livres d'architecture conservés dans sa collection, trois sont du même architecte français. Parmi les volumes du baron, certains ont une provenance illustre, tel le De Architectura, ayant appartenu au notable bibliophile Jacques Auguste de Thou (1553-1617) ou la première édition des Plus Excellents Bastiments de France, en possession de $\mathrm{M}^{\mathrm{me}}$ de Pompadour et de George III d'Angleterre ${ }^{33}$.

Le groupe de livres d'architecture du XVIII ${ }^{e}$ siècle confirme une nouvelle fois le goût d'Edmond pour cette période, puisqu'on en compte 70 volumes, contre seulement sept pour le $\mathrm{XVII}^{\mathrm{e}}$ siècle. Les nombreux traités, livres et cours d'architecture révèlent un aspect de sa personnalité parfois oublié, celui d'un amoureux d'architecture et de jardins, qui fit construire, remodeler ou aménager de nombreux bâtiments suivant les créations des plus grands architectes. Ainsi, le musée du Louvre conserve plusieurs traités, dont ceux d'Augustin-Charles d'Aviler, de Germain Boffrand, de Charles-Étienne Briseux, de Jacques-François Blondel ou de Jean-François de Neufforge, mais aussi des recueils des œuvres d'architectes anglais, tels que William Chambers $^{34}$, ou bien de celles de l'Augsbourgeois Salomon Kleiner ${ }^{35}$.

L'ornement occupe un chapitre à part dans la collection du Louvre, tant le sujet attira l'attention d'Edmond comme de la plupart des collectionneurs de sa génération. La même proportion valant pour les ouvrages d'architecture peut être établie entre les livres d'ornements $d u x^{e}{ }^{e}$ siècle et ceux $d u$ xviII siècle, reflétant ainsi la forte augmentation des ouvrages produits à cette période. Ici, de nouveau, un artiste sculpteur et graveur se démarque des autres: il s'agit de Pierre II Woeiriot (vers 1532-1599), dont le burin maîtrisé et précis captiva le baron, au point qu'il acquit ses œuvres tout au long de sa vie de collectionneur ${ }^{36}$. Il ne se contenta pas d'épreuves sans marges représentant des motifs de gardes d'épées ${ }^{37}$; son œil expert et passionné chercha aussi de belles épreuves qu'il trouva à la vente Foulc de $1914^{38}$.

La cinquantaine de recueils d'ornements $\mathrm{du} \mathrm{xvIII}^{\mathrm{e}}$ siècle complète une collection d'estampes riche d'environ 3500 feuilles, prouvant l'exhaustivité recherchée par Edmond dans ce pan de sa collection et se démarquant aussi de la collection Dutuit, dans laquelle on ne trouve aucun titre concernant cette catégorie d'ouvrages. Les œuvres des plus grands ornemanistes du style Régence, comme Gilles Marie Oppenordt ou Juste Aurèle Meissonnier, gravées à l'eau-forte par Gabriel Huquier, figurent parmi celles que le baron eut le plus de plaisir à collectionner ${ }^{39}$.

Les romans, les livres de linguistique et de poésie qu'Édouard Rahir range dans la section dédiée aux «Belles-Lettres", constituent probablement le point fort de la collection Dutuit. Comparativement, ce type d'ouvrages ne trouve presque pas de représentation dans la collection Edmond de Rothschild du Louvre. Ce sont néanmoins des volumes qu'un homme érudit comme le baron dut acheter et qui furent certainement offerts à des membres de sa famille, à ses enfants et notamment à sa fille, Miriam Alexandrine, passionnée de littérature, comme nous le laisse supposer la longue liste de ses livres spoliés pendant la Seconde Guerre mondiale ${ }^{40}$. 
Le baron semble donc avoir fait un choix dans sa bibliothèque, en léguant au musée les exemplaires qui étaient en rapport évident avec son amour pour la gravure sur bois et les origines du livre imprimé ; ainsi, parmi les 18 volumes conservés, nous trouvons de précieux incunables, prolongation cohérente de sa collection d'estampes en feuilles. Une des pièces maîtresses est un précieux exemplaire de la huitième édition de $L a$ Divine Comédie de Dante ${ }^{41}$, commentée par Cristoforo Landino et ornée des 19 burins de Baccio Baldini, graveur et orfèvre dont Edmond réunit la presque totalité de l'œuvre.

L'édition aldine de l'Hypnerotomachia Poliphili ${ }^{42}$, l'adaptation traduite par Jacques Martin et éditée par Jacques Kerver du Songe de Poliphile ${ }^{43}$ et Les Tableaux des riches inventions de François Béroalde de Verville ${ }^{44}$ prouvent la fine connaissance bibliophilique du baron ainsi que sa volonté de léguer au musée du Louvre un ensemble cohérent illustré de gravures sur bois.

23 Les sujets historiques plurent particulièrement au baron, puisqu'on compte 85 volumes qui révèlent une nette préférence pour les imprimés illustrant la gloire de l'empereur Maximilien $\mathrm{I}^{\mathrm{er}}$ ainsi que la belliqueuse histoire de la France au XvI ${ }^{\mathrm{e}}$ siècle.

Les livres illustrés par des graveurs travaillant avec ou d'après Albrecht Dürer enrichissent et complètent l'ensemble d'estampes en feuilles de qualité exceptionnelle exécutées par des artistes de la Renaissance allemande, l'une des richesses de la collection. Edmond se laissa indéniablement guider par son goût, mais aussi par les préconisations de Georges Duplessis, qui, dans la première édition des Merveilles de la gravure $^{45}$, en 1869, décrit les quatre livres les plus importants de la gravure sur bois allemande $\mathrm{du} \mathrm{xvI}^{\mathrm{e}}$ siècle ${ }^{46}$. Parmi ceux-ci figure Der Theuerdannck (fig.3), poème chevaleresque imprimé à Nuremberg par Johann Schönsperger en 1517, où, à travers les 118 gravures sur bois réalisées pour la plupart par Hans Schäuffelein, nous suivons les aventures du chevalier Theuerdannck, alter ego de Maximilien I ${ }^{\text {er }}$, dans sa quête pour prétendre la main de Marie de Bourgogne. Au-delà des exceptionnelles gravures, le baron fut sans doute attiré par la singularité et l'importance historique des caractères typographiques qui décorent ce magnifique exemplaire sur vélin non enluminé, choix qui peut paraitre étrange de nos jours. Néanmoins, si l'on en croit Jacques-Charles Brunet, les volumes coloriés avaient "peu de prix aux yeux des amateurs ${ }^{47}$ ", contrairement aux impressions sur vélin, comme le démontre la forte somme que paya le baron en $1880^{48}$. 
3. Der Theuerdannck, 1517, Paris, musée du Louvre, département des Arts graphiques, collection Edmond de Rothschild.

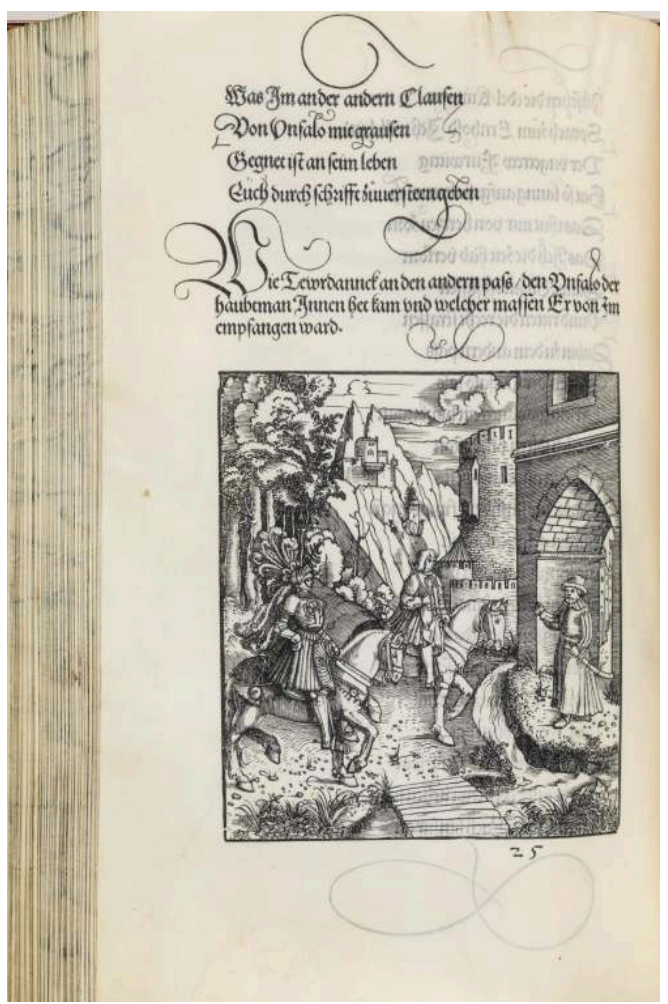

(c) Musée du Louvre

Edmond de Rothschild veilla à laisser au Louvre une collection riche en livres et en estampes, retraçant les événements et les figures marquantes $d u \mathrm{xvI}^{\mathrm{e}}$ siècle français. L'exemple le plus représentatif de son choix est formé par les Tableaux de l'Histoire de France $^{49}$ (fig. 4) de Jean Perrissin et Jacques Tortorel, recueil qui représente quarante scènes des guerres de Religion, de la fin du règne d'Henri II à celui de Charles IX, selon une propagande protestante. Conservés en deux exemplaires, l'un en allemand et l'autre en français, ces livres rendent compte de sa curiosité pour l'histoire de la gravure française dans la période de transition entre la pratique de la gravure sur bois et la gravure en taille-douce. Une des particularités des Tableaux est de contenir des estampes gravées selon différentes techniques, et la comparaison des deux volumes reliés met en relief cette richesse. En effet, l'analyse montre que trois scènes ${ }^{50}$ ne furent pas gravées avec la même technique, puisque, dans l'exemplaire en français, elles furent exécutées à l'eau-forte, tandis que, dans l'édition en allemand ${ }^{51}$, il s'agit de gravures sur bois. Les différentes éditions en diverses langues traduisent la volonté des éditeurs, probablement installés à Genève, de diffuser à travers l'Europe les horreurs de la guerre. 
4. La Représentation de la bataille de deux armées françaises sur le Rhône en 1570 dans Tableaux de l'Histoire de France, 1570, Paris, musée du Louvre., département des Arts graphiques, collection Edmond de Rothschild.

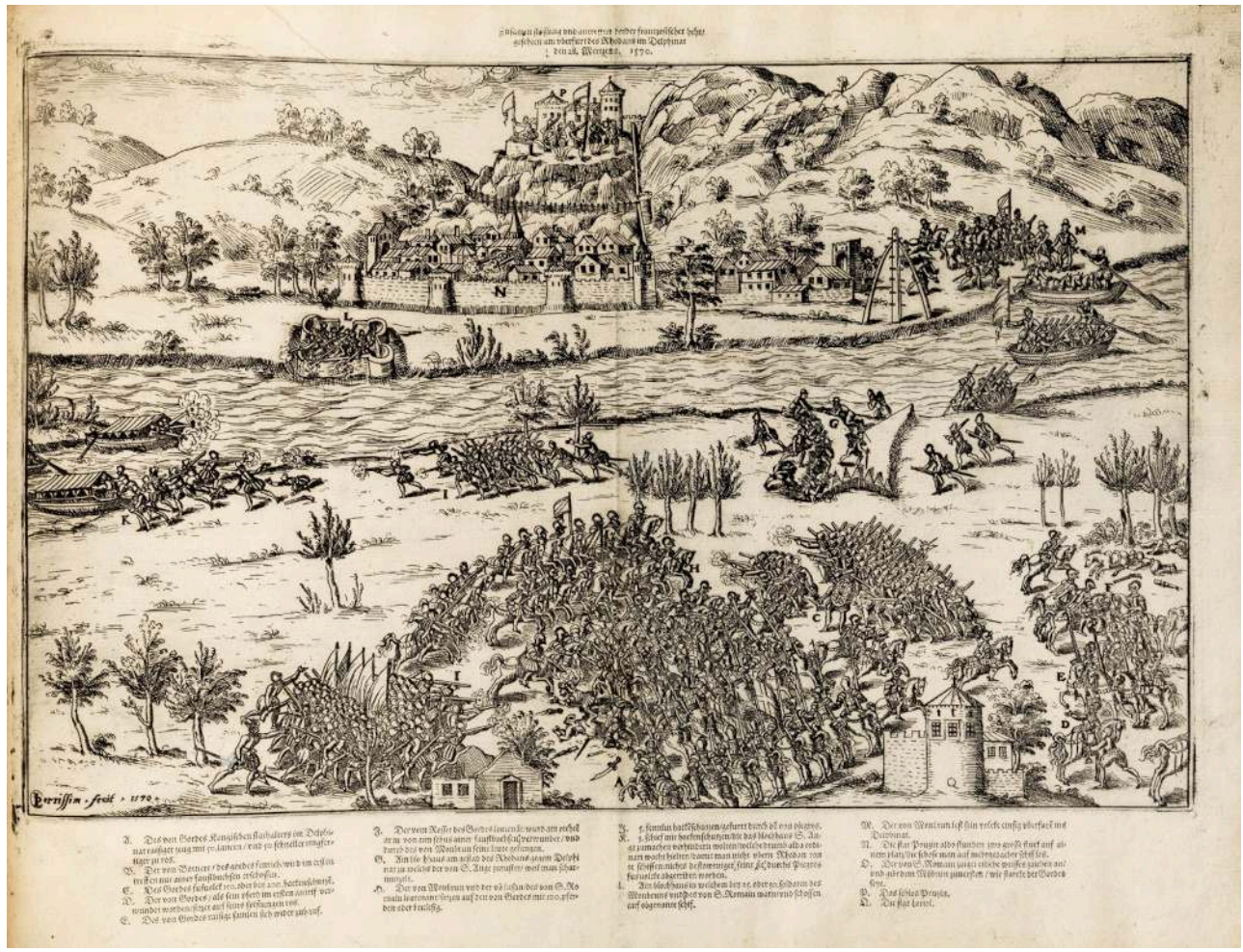

(C) Musée du Louvre

La discrétion dont fit preuve Edmond à l'égard des signes d'appartenance apposés sur ses livres est révélatrice de son respect envers les ouvrages et de sa volonté de s'effacer pour mettre en avant l'objet. Le Sacre et le couronnement de Louis XVI $I^{52}$ est le seul exemplaire de la collection qui porte un petit ex-libris collé sur le contreplat de devant (fig. 5), visiblement méconnu de Germaine Meyer-Noirel ${ }^{53}$. Le baron fit imprimer, en lettres dorées à chaud sur le cuir rouge, un double monogramme en recto et en miroir, aux caractères fortement inspirés de l'alphabet de Charles Mavelot ${ }^{54}$, surmonté d'une couronne de baronnie et entouré d'une ceinture fermée à la façon de celle qui orne le blason de l'ordre anglais de la Jarretière. L'étonnante appropriation de ce blason par Edmond - consistant à remplacer la devise Honni soit qui mal y pense!, sur le pourtour du ruban, par ses prénom et nom - n'est pas rare pour autant, car nous connaissons des exemples similaires adoptés par d'autres familles nobles de la deuxième moitié du XIX ${ }^{e}$ siècle ${ }^{55}$. 
5. Ex-libris du baron Edmond de Rothschild.

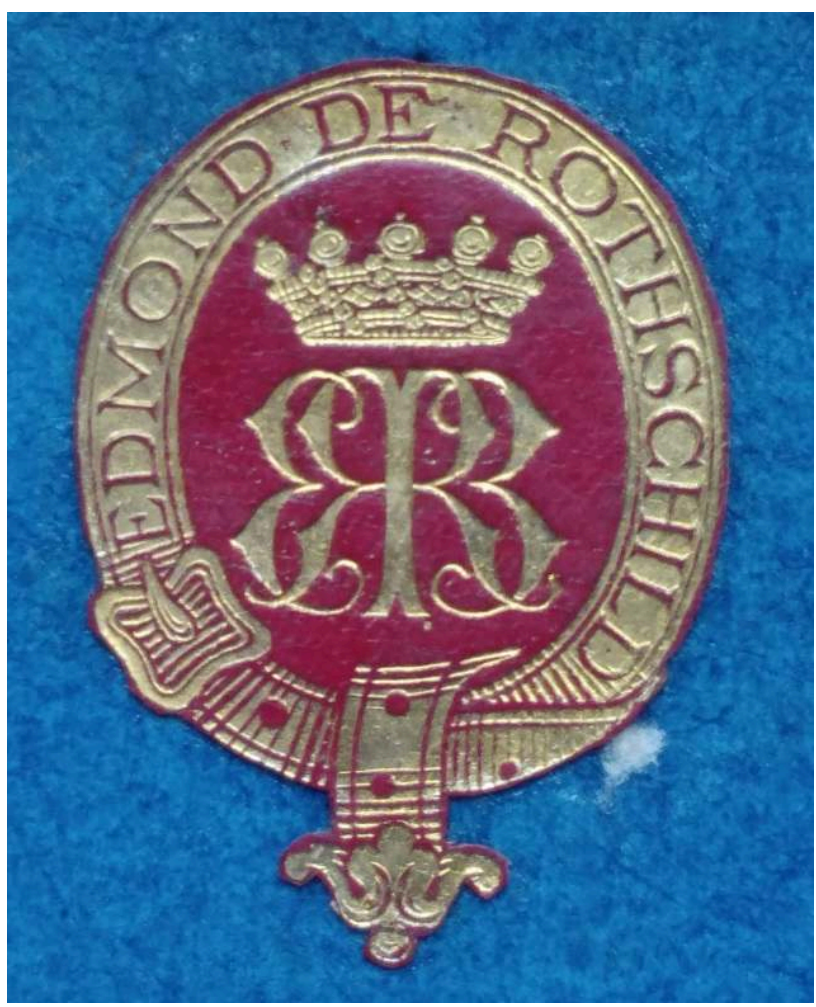

(c) D.R.

27 Tout comme d'autres notables collectionneurs de son époque, tels Jacques Doucet ou les frères Dutuit, Edmond était friand de livres illustrant les mœurs, les modes et les costumes de toutes époques. Le $\mathrm{XVI}^{\mathrm{e}}$ siècle est représenté surtout par les éditions allemandes ornées de gravures sur bois de Jost Amman (Habitus praecipuorum populorum... ${ }^{56}$, Nuremberg, 1577 ; Cleri totius Romanae Ecclesiae subjecti...57, Frankfurt, 1585). Pour le XVII ${ }^{\mathrm{e}}$ siècle, le baron continue avec cohérence sa collection d'estampes en feuilles d'Abraham Bosse sur les habits de la noblesse, en acquérant les gravures de mode éditées chez les Bonnart et gravées par Nicolas Arnoult, Jean Dieu de Saint-Jean, Antoine Trouvain et Jean Lepautre, pour ne citer que les plus renommés ${ }^{58}$.

Le Monument du costume (fig. 6), entreprise éditoriale due à Sigmund Freudenberg et à Jean-Michel Moreau le Jeune, publié en trois séries de douze estampes, résume à lui seul la passion du baron pour le costume et pour la scène de genre du XVIII ${ }^{\mathrm{e}}$ siècle, tant admirés par les collectionneurs de son époque. Il possédait cet ensemble en deux exemplaires : l'un avec les estampes des trois suites, augmenté d'un texte de NicolasEdme Restif de la Bretonne ${ }^{59}$, et l'autre contenant les estampes des deux dernières suites $^{60}$. De plus, il acquit, dans les mêmes années 1870 , de très belles épreuves, où l'on remarque, sinon une volonté d'exhaustivité, du moins un grand plaisir à réunir les divers états d'une estampe: avant la lettre, avant le titre et de nombreux états intermédiaires avant le dernier état. 
6. Le Coucher dans Suite d'estampes pour servir à l'histoire des mœurs et du costume des Français..., 1775, Paris, musée du Louvre, département des Arts graphiques, collection Edmond de Rothschild.

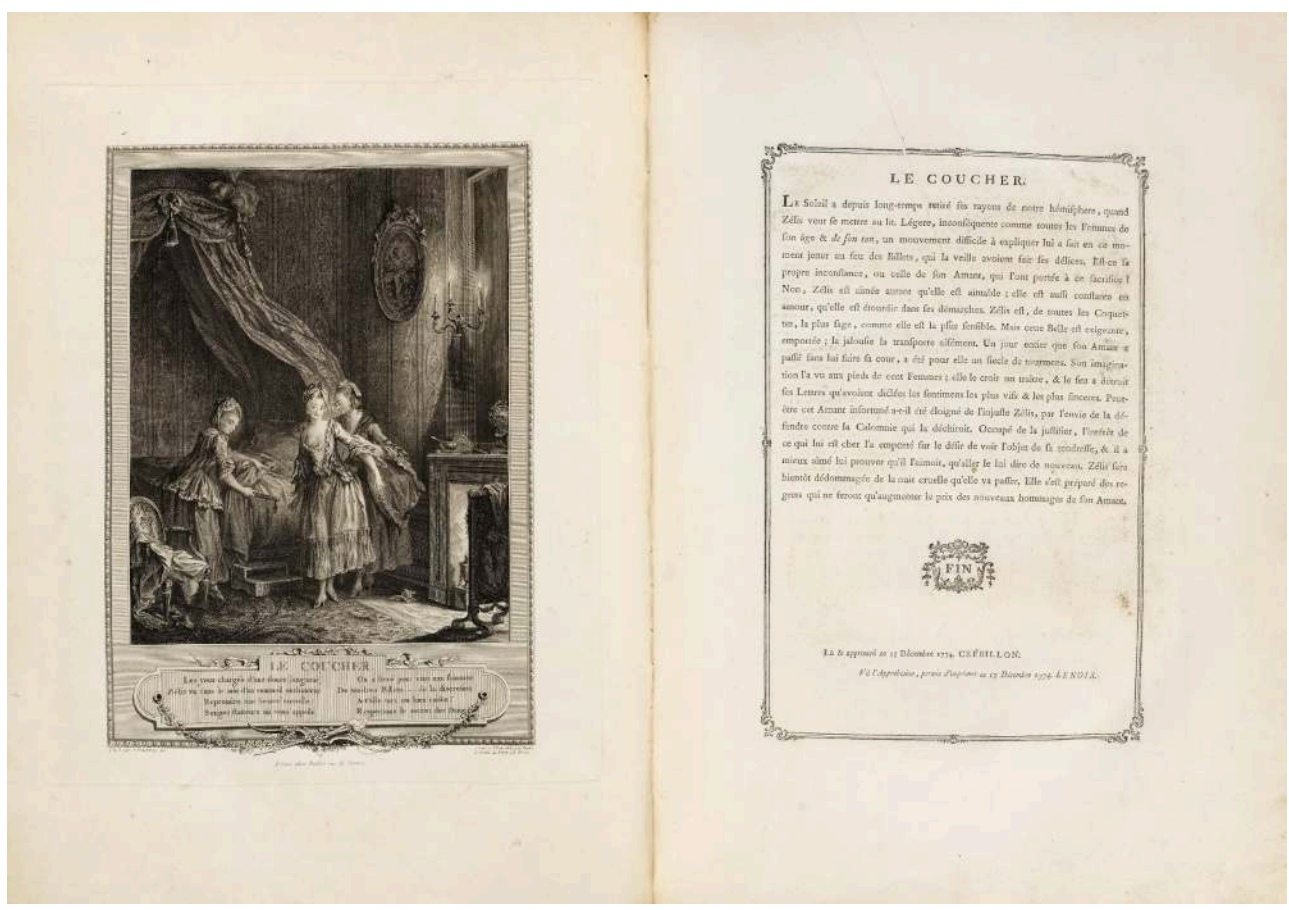

(c) Musée du Louvre

Ces catégories de classement, employées pour la collection Dutuit, se révèlent bien restrictives pour la collection du baron, tant la multiplicité de ses centres d'intérêt est grande et échappe à des sections trop strictement cloisonnées. Où classer, par exemple, la riche collection des recueils de caricatures politiques révolutionnaires, complémentaires de la vingtaine de recueils d'estampes historiques de la même période ? Ces témoignages historiques subjectifs et biaisés plurent particulièrement au baron et constituent une catégorie à part entière dans sa bibliothèque.

D'autres ouvrages, comme le livre de modèles pour broderies et dentelles intitulé Ricchezze delle bellissime et virtuosissime Donne ${ }^{61}$ (fig. 7), l'intéressèrent sans doute à plus d'un titre: les motifs décoratifs se révèlent de véritables ornements, sujet qui passionna le baron ; aussi, la technique - d'une grande complexité - de la gravure des grilles sur bois pour des modèles textiles éveilla forcément sa curiosité ; enfin, ce livre devait être indispensable dans la bibliothèque des Rothschild, car Adélaïde éprouvait une véritable admiration pour les dentelles ${ }^{62}$. 
7. Ricchezze delle bellisime et virtuosissime donne, 1557 et 1559, Paris, musée du Louvre, département des Arts graphiques, collection Edmond de Rothschild.

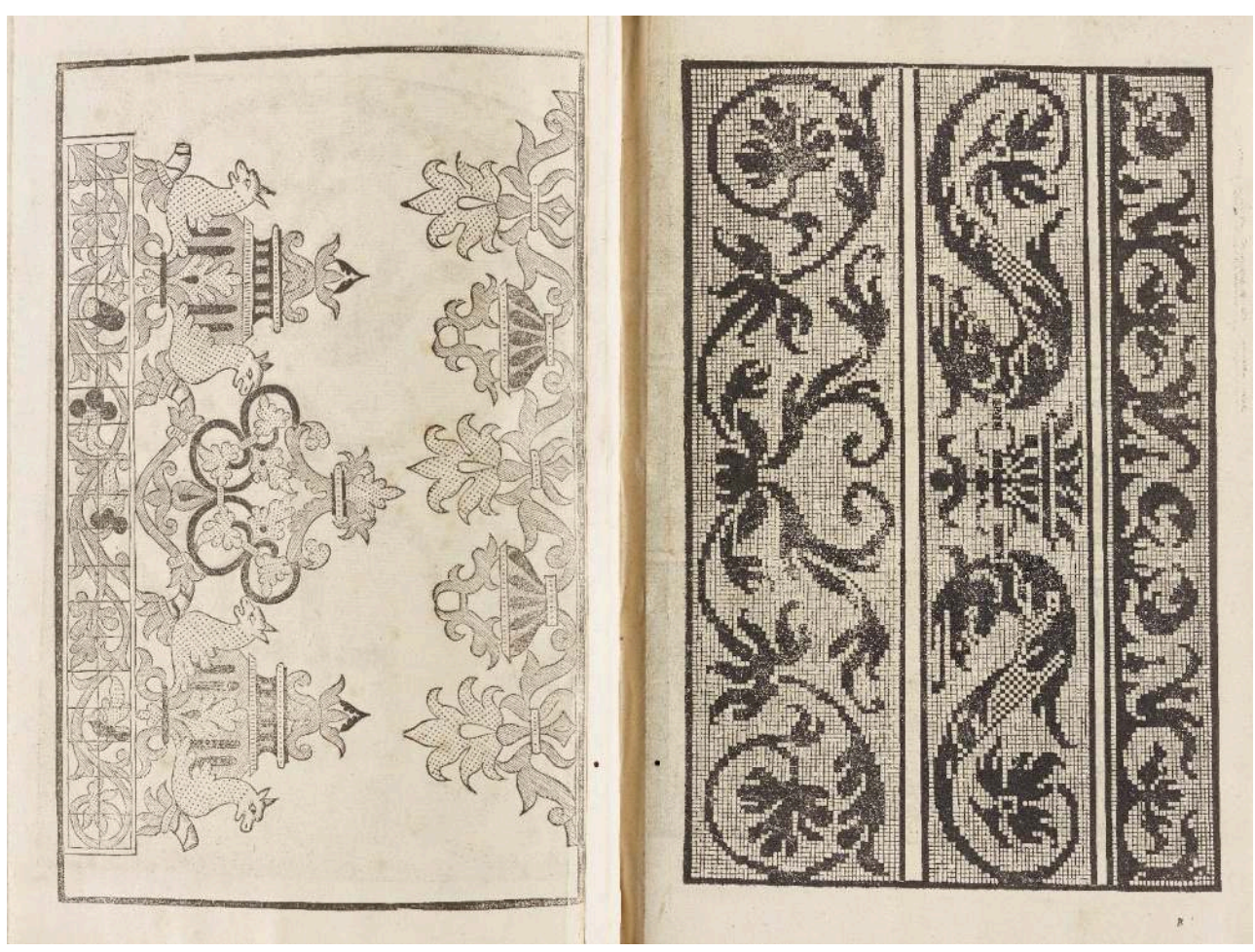

(c) Musée du Louvre

31 Ce rapide panorama des principales catégories de livres réunis par Edmond est loin d'être complet et ne souhaite que donner un premier aperçu de sa riche collection de livres imprimés.

Un premier constat, en guise de conclusion, concerne la quantité relativement peu importante de volumes donnés au musée du Louvre, si nous la comparons aux bibliothèques données à d'autres institutions publiques par d'illustres bibliophiles de la famille Rothschild, comme son neveu James Édouard ou son frère Salomon (au moins 2558 et 1700 volumes, respectivement). Ni l'étendue ni la typologie des livres réunis par Edmond ne semblent comparables à celles des différents membres de sa famille ; en revanche, sa collection présente davantage de similitudes de taille avec la celle des frères Dutuit, comme nous l'avons vu. Aussi, il nous semble légitime de nous interroger sur l'ampleur originelle de la bibliothèque du baron, car l'ensemble conservé aujourd'hui au Louvre semble correspondre à une sélection réfléchie et cohérente à l'intérieur d'une collection plus large.

33 Par ailleurs, il nous paraît important de signaler que la collection de livres imprimés et de recueils du baron ne vise pas l'exhaustivité, même en ce qui concerne les artistes qu'il admirait particulièrement, comme Abraham Bosse, dont il acquit de très belles et nombreuses estampes en feuilles, mais aucun des traités de perspective. De même, l'enthousiasme du baron pour l'œuvre de Rembrandt, partagé par les frères Dutuit, ne le poussa pas à posséder son seul livre illustré, La Piedra gloriosa ${ }^{63}$.

Les exemplaires de sa bibliothèque confirment les convergences entre sa collection de livres imprimés et celle d'estampes en feuilles. Ils démontrent une claire préférence pour les origines de l'estampe, le $\mathrm{XVI}^{\mathrm{e}}$ et le $\mathrm{xVIII}{ }^{\mathrm{e}}$ siècle et a contrario son goût moins 
prononcé pour le $\mathrm{XVII}^{\mathrm{e}}$ siècle, période pour laquelle il réunit à peine quatre-vingts ouvrages. Finalement, la priorité du baron n'aura pas été la recherche d'exemplaires précieux aux reliures soignées, puisque la grande majorité des volumes fut réassemblée à son goût par les relieurs attitrés de la famille, comme Hippolyte Duru, CharlesFrançois Capé ou bien A. Motte, qui ennoblissaient ainsi les ouvrages « harmonieux et instructifs ».

\section{NOTES}

1. Pierrette Jean-Richard (dir.), Les Incunables de la collection Edmond de Rothschild. La gravure en relief sur bois et sur métal, cat. exp., $\mathrm{X}^{\mathrm{e}}$ exposition de la collection Edmond de Rothschild (Paris, Musée du Louvre, 1974), Paris, Éditions des Musées nationaux, 1974, p. 32-44.

2. Dominique Frasson-Cochet (dir.), avec la collaboration de Pierre Aquilon, Catalogues régionaux des incunables des bibliothèques publiques de France, vol. XX, Genève, Droz, 2016.

3. Isabelle de Conihout, "Les livres illustrés», dans Pauline Prevost-Marcilhacy (dir.), Les Rothschild. Une dynastie de mécènes en France, 3 vol., Paris, Louvre/BnF/Somogy, 2016, vol. III, p. 172-191.

4. Joseph Techener, « Vente de la bibliothèque de M. Félix Solar », dans Bulletin du bibliophile et du bibliothécaire, Paris, Chez J. Techener, 1861, p. 145-158.

5. L'étude d'Isabelle de Conihout, réalisée à partir de l'analyse des reliures et des ex-libris, comptabilise un certain nombre d'ouvrages qui entrèrent en possession du baron seulement au décès de sa mère, Betty Salomon de Rothschild, en 1886. Les doubles conservés dans les collections du Louvre proviendraient ainsi de cette donation.

6. Ses dernières acquisitions de livres imprimés documentées datent de 1914, où il achète trois volumes de gravures d'ornement: Euvres d'orfevvrerie à l'usage des églises par J. F. Forty, 1780 (L $77 \mathrm{LR}$; Recueil d'estampes d'après les plus beaux Tableaux et d'après les plus beaux Dessins..., 1763 (L 236 LR) ; et un recueil de huit estampes d'ornement de Pierre II Woeiriot (L 159 LR).

7. Marianne Grivel, «Histoire de la constitution d'un "Musée de la gravure" ", dans Pauline Prevost-Marcilhacy (dir.), Les Rothschild. Une dynastie de mécènes en France, op. cit., vol. III, p. 10-45.

8. Je tiens à remercier chaleureusement Pippa Shirley, Juliet Carey et, particulièrement, Michael Shrive pour avoir rendu possible la consultation des registres conservés dans la bibliothèque du Waddesdon Manor.

9. L 18 LR, L 58 LR, L 61 LR, L 67 LR, L 68 LR, L 73 LR, L 74 LR, L75 LR, L 77 LR, L 82 LR, L 83 LR, L 84

LR, L 130 bis LR, L 146 LR, L 155 LR, L 157 LR, L 159 LR, L 87 LR, L 213 LR, L 232 LR, L 236 LR, L 268

LR, L 278 LR, L 280 LR, L 294 LR, L 437 LR, L 438 LR, L 439 LR, L 445 LR.

10. La collection compte 539 volumes reliés, dont 369 livres imprimés et 170 recueils d'estampes et volumes reliés consacrés à l'œuvre gravée d'un artiste. Parmi ces derniers, 40 exemplaires sont composés d'estampes de petit format, achetées séparément ou par lot. L'œuvre gravée en petit format d'artistes comme Hans Brosamer ou Franz Brun était destinée à " faire un volume », mais ce projet ne se concrétisa jamais.

11. L 340 LR, L 387 LR, L 406 LR, L 448 LR, L 449 LR, L 450 LR

12. Consultable sur le portail Internet du musée : arts-graphiques.louvre.fr/

13. Nous rappelons que la collection d'estampes en feuilles du Louvre compte environ 40000 items. 
14. Eugène Dutuit, Manuel de l'amateur d'estampes. I, Première partie, "Introduction générale ", Paris, A. Lévy, 1884, p. III.

15. [Émile Picot], Catalogue des livres composant la bibliothèque de feu M. le Baron James de Rothschild, 5 vol., Paris, D. Morgand libraire, 1884-1920.

16. La collection conserve quinze incunables, quatre incunables xylographiques : L 51 LR, L 52 LR, L 53 LR, L 54 LR et onze incunables typographiques : L 55 LR, L 56 LR, L 57LR, L 58 LR, L 59 LR, L 60 LR, L 62 LR, L 63 LR, L 220 LR, L 221 LR et L 228 LR.

17. Voir Georges Duplessis, «Essai sur la gravure dans les livres », dans Catalogue illustré des livres précieux, manuscrits et imprimés, faisant partie de la bibliothèque de M. Ambroise Firmin-Didot, Paris, Firmin-Didot et $C^{\text {ie }}, 1879$, p. X.

18. Biblia Pauperum (L 52 LR), Defensorium Mariae (L 54 LR).

19. Édition I/II, II état. Prix : 109288 francs. Numéro 18278 du registre d'entrées conservé au Waddesdon Manor (L 51 LR).

20. Christopher de Hamel, Les Rothschild collectionneurs de manuscrits, Paris, BnF Éditions, 2004.

21. François Avril, Nicole Reynaud et Dominique Cordellier (dir.), Les Enluminures du Louvre. Moyen Âge et Renaissance, cat. exp. (Paris, musée du Louvre, 2011), Paris, Louvre/Hazan, 2011, nº 120 , p. 226-227.

22. L 228 LR.

23. Voir note 4 .

24. Historiae Biblicae, avec des illustrations de Hans Sebald Beham ( $\mathrm{n}^{\circ} 40$ de la vente); Bible de Paradin ( $\left.\mathrm{n}^{\circ} 41\right)$; Quatrains de la Bible $\left(\mathrm{n}^{\circ} 42\right)$; Les Figures de la Bible, avec des illustrations de Virgil Solis ( $\left.n^{\circ} 43\right)$; Figures du Nouveau Testament de Jean de Tournes ( $\left.{ }^{\circ} 54\right)$; Figures de l'Apocalypse de Groulleau ( $\left.n^{\circ} 56\right)$; Icones Catechesos $\left(n^{\circ} 64\right) ;$ Meditationi della Passione $\left(n^{\circ} 65\right)$.

25. Joseph Techener, « Vente de la bibliothèque de M. Félix Solar », art. cit., $n^{\circ} 42$ et $n^{\circ} 65$.

26. L 140 LR.

27. Cette section contient les livres portant sur les sciences philosophiques (morale, politique, éducation des princes); les sciences naturelles (histoire naturelle; médecine); les sciences mathématiques (arithmétique, géométrie ; art militaire ; astrologie, sciences occultes) ; les beauxarts (peinture, généralités, galeries ; gravures, généralités, recueils d"estampes ; architecture ; catalogue de tableaux, de meubles et d'objets d'art ; biographies d'artistes) ; les arts mécaniques et métiers divers (céramique, orfèvrerie et bijouterie; travaux à l'aiguille ; art culinaire) ; les exercices gymnastiques (équitation, danse et chasse).

28. Édition des frères Giovanni et Gregorio De Gregori, Venise, 1495 (L 60 LR). Il en existe un second exemplaire édité en 1522 (L 61 LR).

29. Recueil d'estampes gravées d'après les tableaux du cabinet de Monseigneur le Duc de Choiseul, Paris, Basan, 1771 et Collection de cent-vingt estampes, gravées d'après les tableaux \& dessins qui composoient le cabinet de M. Poullain, Receveur Général des Domaines du Roi, décédé en 1780 ; Précédée d'un Abrégé historique de la Vie des Auteurs qui la composent; Dédiée a M. Le Comte d'Orsay, Paris, Basan et Poignant, 1781. No 16352 et no 16353 du registre III des entrées de gravures.

30. Les Sermons du pere Bourdalouë, Paris, Chez Rigaud, 1707 - l'une de ses premières acquisitions, faite à la vente Félix Solar de 1860 ( $\left.\mathrm{n}^{\circ} 197\right)$ - et les Vues remarquables des montagnes de la Suisse, gravées par Charles Melchior Descourtis ( $n^{\circ} 14719$ du registre II des entrées de gravures) sont également absents des rayons de la collection du Louvre.

31. Quatre livres d'architecture et deux livres d'ornements furent collectionnés par les frères Dutuit (numéros du catalogue d'Édouard Rahir : 185, 186, 187, 188, 200 et 201).

32. Jacques I $^{\text {er }}$ Androuet du Cerceau, De Architectura, Paris, Benoît Prévost, 1559 (L 64 LR) ; recueil de Meubles et entrelacs, vers 1565-1570 (L 65 LR); Fragmenta structurae veteris, Orléans, 1550 (L 66 LR) ; De Architectura, Paris, Benoît Prévost, 1559 (L 241 LR) ; recueil de Grotesques, vers 1550 (L 242 LR); Les Plus Excellents Bastiments de France, deux exemplaires, Paris, s.n., 1576-1579 (L 243 LR, L 244 LR). 
33. De Architectura et Fragmenta structurae veteris. Sur les historiques prestigieux, nous renvoyons à l'article d'Isabelle de Conihout, « Les livres illustrés », art. cit.

34. L 356 LR et L 357 LR.

35. L 388 LR, L 389 LR, L 390 LR.

36. Les numéros des acquisitions de certaines estampes datent des années 1860 .

37. 4857 LR à 4864 LR.

38. Recueil d'estampes L 159 LR, vente Edmond Foulc, Paris, Drouot, le 3 juin 1914, $\mathrm{n}^{\circ} 83$.

39. Gilles Marie Oppenordt, Livre de fragments d'architectures recueillis et dessinés à Rome d'après les plus beaux monuments, Paris, Huquier, 1745 (L 433 LR) ; recueil de l'œuvre de Gabriel Huquier, Livre d'orfèvrerie, s.d. (L 417 LR).

40. Bureau central des restitutions de la division Réparations. Restitution du groupe français du Conseil de contrôle, Répertoire des biens spoliés en France durant la guerre 1939-1945, t. VII, vol. 14, Archives, manuscrits et livres rares, 1948.

41. Dante, La Divine Comédie, Florence, Niccolo di Lorenzo della Magna, 1481 (L 58 LR).

42. Francesco Colonna, Hypnerotomachia Poliphili, Venise, Alde Manuce, 1499 (L 63 LR).

43. Francesco Colonna, Le Songe de Poliphile, Paris, Chez Jacques Kerver, 1546 (L 124 LR).

44. François Béroalde de Verville, Le Tableau des riches inventions, Paris, Chez Matthieu Guillemot, 1600 (L 164 LR).

45. Georges Duplessis, Les Merveilles de la gravure, Paris, Hachette et C ${ }^{\text {ie }}, 1869$, p. 173-175.

46. Der Theuerdannck, Nuremberg, Johann Schönsperger, 1517 (L 146 LR) ; Der Weisskunig, Vienne, 1775 (L 192 LR) ; l'exemplaire du Triomphe de Maximilien I $I^{e}$ est conservé en feuilles ; les Saints et saintes de la famille impériale, Vienne, 1799 (absent de la collection).

47. Jacques-Charles Brunet, Manuel du libraire et de l'amateur de livres, 6 vol. Paris, Firmin-Didot frères, 1860-1865, t. IV, p. 443-444.

48. Une note manuscrite en hongrois sur le verso de la page de garde mentionne l'ancien possesseur, collectionneur d'art et bibliophile hongrois Miklós Jankovic (1772-1846). Cet exemplaire (L 146 LR) fut vendu le 12 janvier 1852 pour 200 florins à un " acheteur étranger » (le comte de Sauvage ?), à qui le baron l'acheta en avril 1880, pour 14520 francs

49. Recueil des Tableaux de l'Histoire de France..., s.n., s.l., (L 138 LR et L 139 LR). Nous renvoyons pour ce sujet au livre de Philip Benedict, Graphic History: the Wars, Massacres and Troubles of Tortorel and Perrissin, Genève, Librairie Droz, 2007.

50. Jacques Tortorel, Le Massacre de Cahors en Quercy, le 19 novembre 1561 ; Le Massacre de Montbrison, dans le Forez, juillet 1562 et La Première Charge de la bataille de Dreux, où Monsieur le connétable fut pris le 19 décembre 1562. En tout, douze scènes furent gravées sur deux supports.

51. Enrichie d'une estampe supplémentaire: La Représentation de la bataille de deux armées françaises sur le Rhône en 1570.

52. Thomas Jean Pichon, Nicolas Gobet et Jean Baptiste Patas, Le Sacre et le couronnement de Louis XVI, Paris, chez Charles Emmanuel Patas et Emmanuel Vente, 1775 (L 464 LR).

53. Germaine Meyer-Noirel, Répertoire général des ex-libris français des origines à l'époque moderne (1496-1920), 20 vols. et 3 vols. de supplément, [Tomblaine], éd. Germaine Meyer-Noirel, 1983-2011.

54. Charles Mavelot, Nouveau Livre de chiffres qui contient en général tous les noms et surnoms entrelassez par alphabet, ouvrage utile et nécessaire aux peintres, sculpteurs, graveurs et autres..., Paris, Chez Mavelot, 1680 (L 181 LR).

55. Germaine Meyer-Noirel, L'Ex-Libris. Histoire, art, techniques, Paris, Picard, 1989, p. 185-190.

56. L 234 LR.

57. L 95 LR et L 95 LR bis.

58. Elles sont assemblées en quatre recueils : L 67 LR, L 68 LR, L 72 LR et L 88 LR.

59. Suite d'estampes pour servir à l'histoire des mœurs et du costume des Français dans le dix-huitième siècle, Chez Prault, Paris, 1775 ; Seconde suite d'estampes, pour servir à l'histoire des modes et du 
costume en France dans le dix-huitième siècle, Paris, Chez Prault, 1776 ; Troisième suite d'estampes..., Paris, Chez Prault, 1783 (L 87 LR).

60. Monument du costume physique et moral de la fin du dix-huitième siècle ou Tableaux de la vie, Neuwied-sur-le-Rhin, 1789, (L 86 LR)

61. Soncino, Giovanni Antonio Bindoni, 1557 et 1559 (L 144 LR).

62. Rachel Boak, « La collection de dentelles de la baronne Edmond James de Rothschild au musée des Arts décoratifs ", dans Pauline Prevost-Marcilhacy (dir.), Les Rothschild. Une dynastie de mécènes en France, op. cit., vol. III, p. 211-217.

63. La Piedra gloriosa o de la estatua de Nebuchadnesar, con muchas y diversas authoridades de la S. S. y antiguos sabios, Amsterdam, 1655. En revanche, nous comptons dans la collection une très rare épreuve des quatre estampes qui illustrent le livre, imprimées sur une seule feuille (2352 LR).

\section{INDEX}

Index géographique : France

Index chronologique : XIXe siècle, XXe siècle

Thèmes : Estampes, bibliophilie, collections, mécénat, Rothschild 


\title{
La gravure d'histoire au temps des premiers Bourbons : une catégorie méconnue de la collection d'estampes d'Edmond de Rothschild
}

\author{
Estelle Leutrat
}

Lorsqu'Edmond de Rothschild entreprend de constituer sa collection d'estampes à partir de 1860 environ, l'intérêt pour les pièces historiques est déjà fort ancien ${ }^{1}$. Que l'on songe à Bernard de Montfaucon qui, dans l'épître au lecteur du cinquième volume de ses Monumens de la monarchie françoise, justifie l'importance de ces œuvres :

La gravure devint encore plus commune sous Henri II et sous les Rois suivans ses trois fils, François II, Charles IX et Henri III. [...] Ces Regnes fournissent une quantité incroiable d'Estampes qui representent des batailles, des sieges et des prises de Villes, des massacres, des Conférences, des Assemblées, des Spectacles de toutes les manieres. [...] Le Lecteur remarquera que souvent ces Estampes nous apprennent bien des particularitez, que les Historiens ne disent pas $^{2}$.

Par ailleurs, dès la Régence, le contexte d'un regain de faveur pour Henri IV, si ce n'est même d'un culte henricien dont La Henriade de Voltaire est sans doute le marqueur le plus emblématique, éveille une appétence pour les estampes de ce temps. Il suffit de penser au recueil de gravures formé par Châtre de Cangé, proche de Philippe d'Orléans, dont un volume entier est consacré au règne d'Henri IV et réunit de nombreuses pièces historiques ${ }^{3}$. Toutefois, cet intérêt pour ces œuvres prend une tout autre ampleur au $\mathrm{XIX}^{\mathrm{e}}$ siècle, lorsque des historiens de l'estampe, tel Jules Renouvier, retracent leur histoire et leurs caractéristiques. Celui-ci explique, en 1856, dans son ouvrage Des types et des manières des maitres graveurs que les placards historiques « se multiplièrent tant à partir du règne d'Henri III que j'ai cru devoir en faire une classe séparée ${ }^{4}$ ». Parallèlement, les estampes commémorant les grands événements de l'histoire connaissent alors, et ce dès le début $\mathrm{du} \mathrm{XIX}^{\mathrm{e}}$ siècle, un engouement sans précédent auprès des collectionneurs, qui se traduit par une envolée des prix dans les ventes ${ }^{5}$. 
3 Cette passion pour les pièces historiques transparaît avec force dans l'introduction qu'Alfred Bonnardot compose pour la section « Dessins et estampes » du catalogue de la vente d'Antoine-Pierre-Marie Gilbert, savant antiquaire, spécialiste des monuments religieux en France, dont la collection a été dispersée après sa mort en 1858. L'auteur évoque tout d'abord les jeunes années du défunt, un temps béni pour les modestes collectionneurs, avant d'aborder des temps moins favorables, soumis aux mouvements déraisonnables du marché. Ainsi débute-t-il son propos par le doux souvenir de l'année 1806 :

C'était le bon temps pour les achats de vieille imagerie intéressante! [...] Alors pullulaient les pièces relatives à l'histoire et à la topographie de Paris; il se donnait des Israël Silvestre à 10 centimes ; les plus curieux sujets d'Abraham Bosse, Léonard Gaultier, Thomas de Leu, Séb. Le Clerc et autres graveurs, si prodigieusement relevés depuis dans l'estime publique, lui [Gilbert] coûtaient entre 25 et 75 centimes. En un mot, il payait par sous ce que trente ans plus tard j'ai payé par francs, et ce qu'on paie, à l'heure qu'il est, par napoléons. [...] il y eut [depuis la Restauration] un peu de hausse sur tout ce qui concerne les églises, les monastères, les portraits d'Henri IV, le héros bourbonien si largement fêté par ses petits-fils ramenés sur le trône. Néanmoins, les étalages et les boutiques étaient toujours bien fournis; n'enterrait-on pas chaque jour des vieillards qui avaient formé leurs bibliothèques sous Louis XV et l'avaient pu augmenter à bon marché après 1793 ? [...] Vint le Second Empire, ère formidable pour les anciens accapareurs d'estampes historiques; car des millionnaires, des ex-ministres, des princes, des têtes couronnées se sont mis sur les rangs, à tel point que le doyen et le mieux approvisionné des collectionneurs en ce genre, M. Hennin, s'est retiré dans sa tente, abandonnant la lutte ${ }^{6}$.

Cette hausse des prix n'en est alors qu'à ses débuts et, en 1877, Emmanuel Bocher, chargé de la célèbre vente Béhague, dont une large part concerne les estampes historiques - plusieurs belles pièces du fonds Rothschild en sont issues -, en vient à se demander: «Où l'on s'arrêtera dans les folies qu'on fait pour elles [... $]^{7}$ ?» La constitution de la collection d'Edmond de Rothschild s'inscrit donc dans ce contexte effervescent et il peut sembler intéressant de l'interroger sous cet angle bien précis, d'autant que le collectionneur lui-même, notamment par le biais de son abondant fonds d'almanachs du règne de Louis XIV, porte indéniablement son attention vers les représentations gravées de l'Histoire ${ }^{8}$.

5 Tout d'abord, à quoi s'apparentent ces pièces historiques? Une bonne part prend la forme de placards illustrés, c'est-à-dire de larges feuilles mesurant en moyenne $50 \times 40 \mathrm{~cm}$, mais pouvant parfois atteindre le double, alliant une image, le plus souvent une gravure sur cuivre, à un abondant texte typographié ? Jules Renouvier décrit le noyau dur qui s'en occupe : il évoque les éditeurs parisiens Jean Le Clerc, Nicolas et Michel de Mathonière, et les graveurs, parfois eux-mêmes éditeurs, Léonard Gaultier, Thomas de Leu, Pierre Firens, Isaac Briot ou encore Jan Ziarnko'. Tous ont gravé les grands moments du règne d'Henri IV et les premières années de celui de Louis XIII, moment charnière durant lequel se développent réellement en France les pièces historiques. L'entrée du roi à Paris en 1594, le baptême du Dauphin, l'effigie mortuaire d'Henri IV, le couronnement de Marie de Médicis, le sacre de Louis XIII, les mariages espagnols, la mort de Concino Concini, figurent parmi les représentations incontournables dont l'historien a dressé la liste et que chaque amateur essaie d'acquérir. Les grandes collections de pièces historiques - comme celles, dans les années 1850, d'Antoine-Pierre-Marie Gilbert, d'Armand Bertin, du baron d'Henneville, du $D^{r}$ Henry Wellesley, jusqu'à celles d'Adolphe Pécard en 1872, d'Octave de Béhague ou 
des frères Dutuit - s'articulent toutes autour de ce groupe d'œuvres que ces " estampophiles» tentent de compléter par d'autres pièces, plus ou moins rares. La collection d'Edmond de Rothschild suit la même logique, mais s'en distingue par l'abondance et, parfois, la rareté des œuvres réunies.

L'ensemble de ces collectionneurs s'appuie sur un modèle de collection qui va s'imposer durant plus d'un siècle: celle du parlementaire dijonnais Charles-Marie Fevret de Fontette, acquise par la Bibliothèque du roi en 1772 et décrite par le collectionneur à la fin du quatrième volume de la réédition de la Bibliothèque historique de l'abbé Lelong ${ }^{10}$. L'historien bibliophile rouennais Constant Leber évoque avec émotion cet achat dans ses jeunes années, l'ouvrage étant alors "d'une fraîcheur insultante ", tandis que, trente ans plus tard, il «n'est plus maintenant qu'un livre d'écolier, maculé, déformé, couvert d'écriture et de lambeaux ${ }^{11}$ ». Ce précieux inventaire demeure la référence principale jusqu'à la publication, en 1877, de celui de la collection de Michel Hennin, mort en 1863, par Georges Duplessis, dont on retrouve régulièrement la référence dans les inventaires manuscrits de la collection Rothschild dressés par André Blum, son conservateur jusqu'en $1957^{12}$. Par exemple, alors que le baron ne possède que le bandeau supérieur d'une estampe de Léonard Gaultier, originellement destinée à un almanach daté de 1611, il est fait un renvoi, sur la fiche manuscrite rédigée par Blum, à « Hennin 1640 », soit la pièce complète que le collectionneur et diplomate était parvenu à acquérir ${ }^{13}$. Fevret de Fontette et Hennin, par l'ampleur de leur fonds, constituent un point d'horizon et une référence pour toute collection d'estampes historiques.

7 Ces estampes ne sont pas réunies ensemble dans la collection Edmond de Rothschild, conservée au département des Arts graphiques du musée du Louvre. Elles se répartissent principalement entre deux portefeuilles spécifiquement dédiés aux pièces historiques: le premier rassemble les gravures portant sur la période comprise entre 1560 et 1610 ; le second, sur celle comprise entre 1610 et 1660 environ ${ }^{14}$. Lorsqu'un graveur fait l'objet d'une attention particulière et bénéficie d'un portefeuille spécifique, tel Léonard Gaultier, les estampes, pour l'essentiel, sont colligées dans ce portefeuille nominatif. Par exemple, Le Pourtraict du sacre et couronnement de Marie de Médicis, placard majeur édité par Jean Le Clerc en 1610, est classé parmi les œuvres de Gaultier et non parmi les pièces historiques ${ }^{15}$. Ajoutons à cela que certaines suites gravées, comme celle de Jean Perrissin et Jacques Tortorel sur les Guerres, massacres et troubles advenus en France durant les premières guerres de Religion, figurent à part dans des recueils reliés ${ }^{16}$. Enfin, les estampes en double ou jugées dans un état insatisfaisant sont réunies dans une autre catégorie de portefeuilles, plus modeste, celle du toutvenant ${ }^{17}$.

8 Très certainement, comme pour le reste de sa collection, Edmond de Rothschild a dû pouvoir adosser ses premières acquisitions au fonds réuni par son père, le baron James de Rothschild, qu'il est malheureusement actuellement encore difficile de cerner. Selon Marianne Grivel, lorsqu'un ancien numéro d'inventaire est accompagné de la lettre « a », celle-ci désigne l'ancienne collection, parmi laquelle figurent les pièces venant du baron James ${ }^{18}$ (mais pas seulement). Il serait alors plaisant de penser, mais l'hypothèse est fragile, qu'une planche isolée de la suite de l'Entrée d'Henri IV à Paris en 1594, qui en compte trois et qui appartient aujourd'hui au tout-venant, aurait été acquise par James de Rothschild ${ }^{19}$. Il s'agit en effet de l'une des pièces incontournables que se doit de posséder tout collectionneur d'estampes historiques de cette période. Jules Renouvier, en particulier, ne manque pas de louer ces planches et d'en rendre l'honneur à l'éditeur 
Jean Le Clerc : « Outre leur intérêt historique, elles ont le mérite de reproduire le dessin d'un peintre peu connu, Nicolas Bollery [...]. » Et Renouvier d'ajouter : «Je n'ose trop louer des compositions auxquelles manquent tant de qualités essentielles de l'art; cependant, les plus prévenus y trouveront ce qu'on chercherait en vain dans le savant tableau que fit sous la Restauration M. le baron Gérard, la vérité ; une bonhomie toute française y tient lieu d'expression et les costumes sont pris sur le fait ${ }^{20}$.» L'estampe, possiblement acquise par James de Rothschild, ne pouvait satisfaire son fils: isolée, sans les deux autres planches qui l'accompagnent, l'épreuve est par ailleurs rognée, dépourvue de l'encadrement typographié qui l'entoure et parsemée de taches brunes. C'est pourquoi elle n'a pas rejoint les plus beaux portefeuilles. Edmond de Rothschild s'est procuré par la suite les trois placards, certes dans une édition tardive due à la veuve de Jean Le Clerc, donc postérieure à 1621, mais dans un bon état de conservation, avec des marges ${ }^{21}$ (fig. 1). Ajoutons que le $\mathrm{D}^{\mathrm{r}}$ David-Didier Roth, proche, comme on le sait, d'Edmond de Rothschild, son «mentor» si l'on en croit les souvenirs de Frits Lugt $^{22}$, était un grand collectionneur d'estampes historiques, comme en témoigne notamment la vente d'une partie de sa collection en $1888^{23}$. Plusieurs pièces conservées au Louvre sont ainsi associées à son nom, comme les deux placards incomplets de l'Entrée de Louis XIII à Paris, l'un gravé en 1610 par Élie Dubois et l'autre en 1616 par Léonard Gaultier ${ }^{24}$.

1. Comment le roi vit sortir les troupes espagnoles, après 1621, Paris, Veuve Jean IV Le Clerc, Paris, musée du Louvre, département des Arts graphiques, collection Edmond de Rothschild, inv. $\mathbf{5 2 7 5}$ LR.

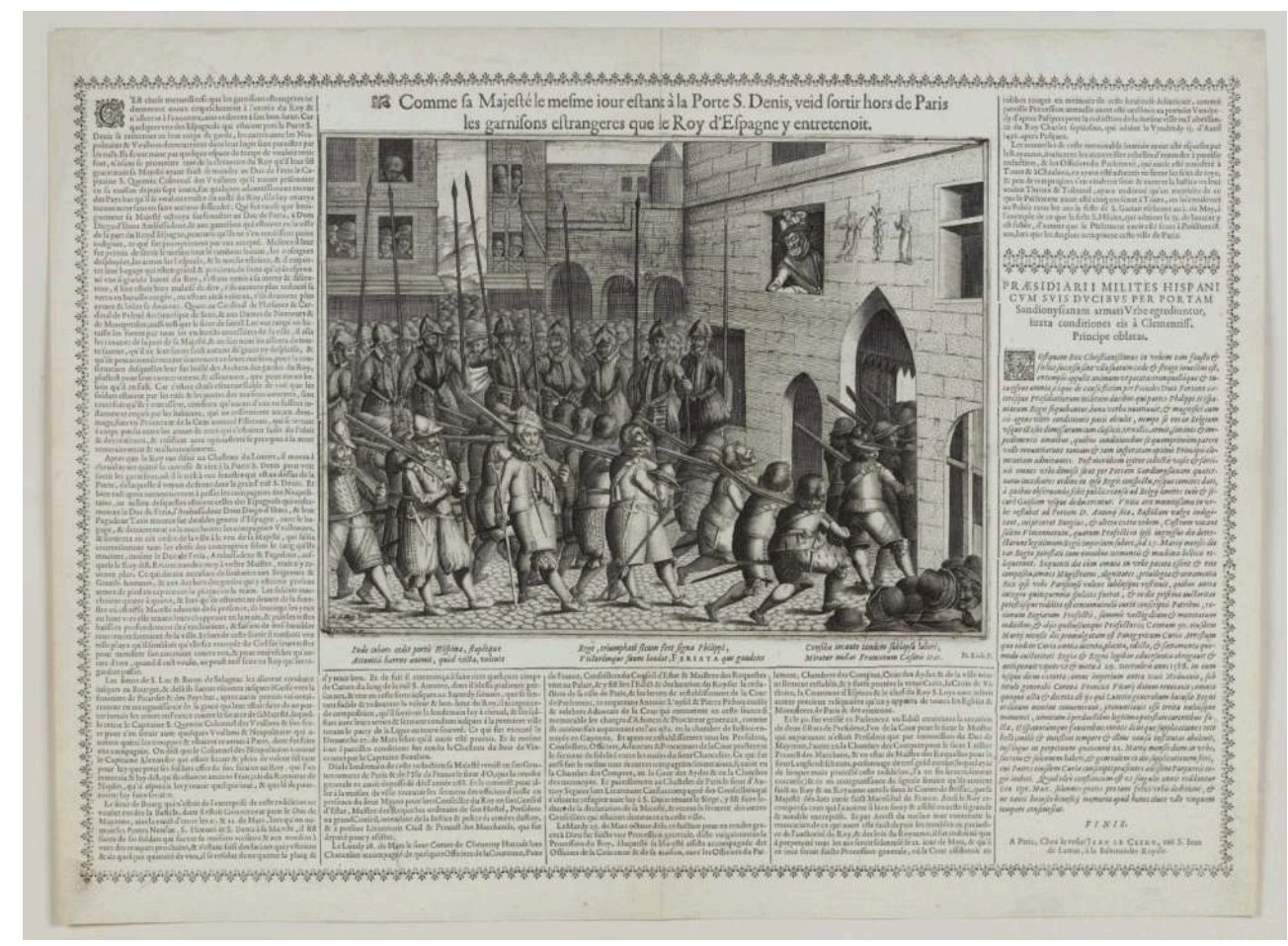

(c) Musée du Louvre

Comme l'a souligné Marianne Grivel, les années glorieuses de la collection Rothschild correspondent aux dix premières années d'acquisition, soit jusqu'en 1878 environ. Il en va ainsi des pièces historiques dont près de la moitié ont été acquises lors de trois ventes : celle de l'ancien directeur du musée archéologique de Tours, Adolphe Pécard, 
en 1872 ; celle d'Octave de Béhague, « en son genre la plus considérable qui ait jamais été faite ${ }^{25} »$; et, dans une moindre mesure, celle d'Ambroise Firmin-Didot, en 1877, par le biais de ses représentants Clément et Danlos ${ }^{26}$. Les différents Sacre de Louis XIII, toujours très recherchés, édités par Jean Le Clerc et Nicolas de Mathonière ${ }^{27}$ (fig. 2), ont été acquis lors de ces ventes, de même que la représentation du carrousel organisé sur la place Royale en 1612 par Jan Ziarnko, malheureusement sans le texte édité par Le Clerc qui, du reste, est rare, même si un exemplaire complet se trouve à la Bibliothèque nationale de $\mathrm{France}^{28}$. Michel Hennin ne le possédait pas non plus, et l'une des rares ventes où il semble apparaître entier est celle du $\mathrm{D}^{\mathrm{r}}$ Henry Wellesley en 1858 , l'œuvre ayant été vendue 220 francs $^{29}$. Des trois ventes précédemment citées proviennent aussi, notamment, Les Quatre Parties du monde de Pierre Firens ${ }^{30}$, sans le texte, L'Assemblée des notables à Rouen en 1617 du même Ziarnko, éditée par Le Clerc ${ }^{31}$, ou encore Louis XIII recevant la Justice et la Clémence devant le siège de La Rochelle, édité par Jean V Le Clerc, fils du précédent ${ }^{32}$ (fig. 3).

2. Sacre de Louis XIII, Paris, [Nicolas de Mathonière], 1610, Paris, musée du Louvre, département des Arts graphiques, collection Edmond de Rothschild, inv. 5295 LR.

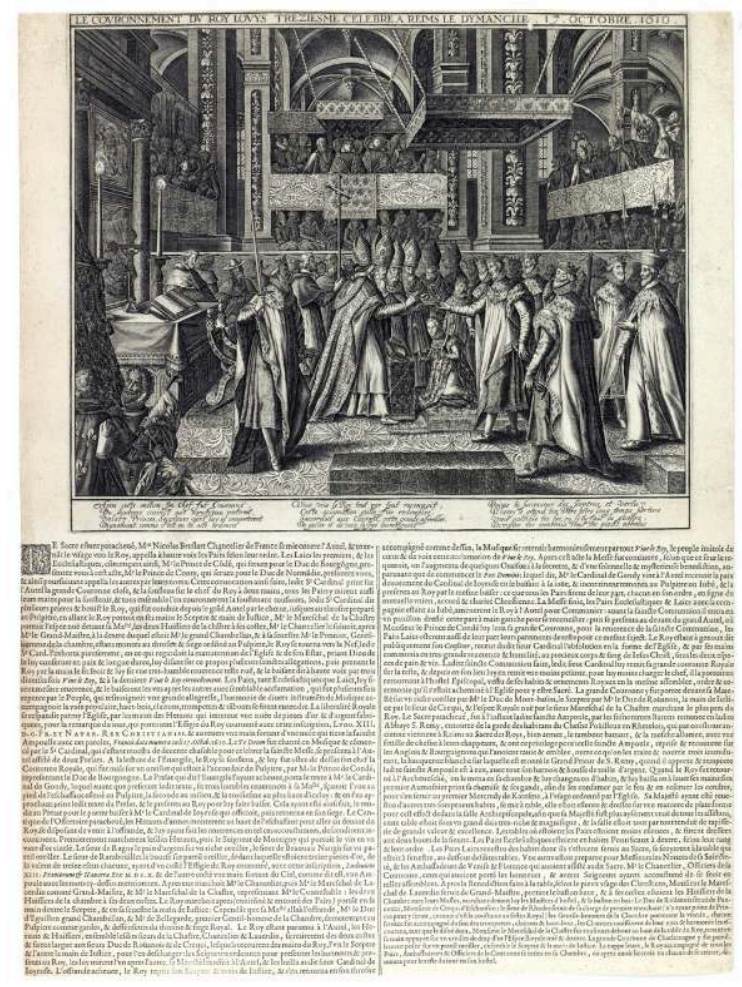


3. Justice et Clémence devant le siège de La Rochelle, Paris, Jean V Le Clerc, 1628, Paris, musée du Louvre, département des Arts graphiques, collection Edmond de Rothschild, inv. 5338 LR.

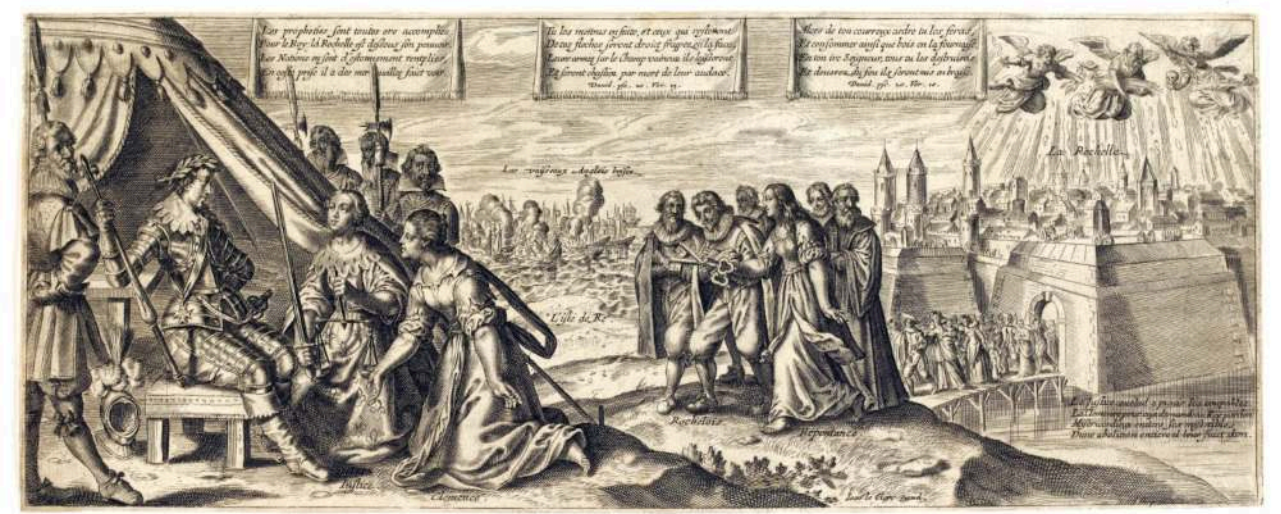

(C) Musée du Louvre

Empire et qui se prolongea sous la III ${ }^{e}$ République. Jusqu'à la fin des années 1850 , un placard illustré coûte entre 20 et 150 francs, la moyenne se situant autour de 80 ou 100 francs $^{33}$. La vente du carrousel de Jan Ziarnko à 220 francs était déjà tout à fait exceptionnelle pour ce type d'œuvres. Philippe Burty relate, dans la Gazette des beauxarts, en 1859, à propos de la vente Wellesley, une intéressante anecdote au sujet d'une estampe de Matthäus Merian, éditée par Nicolas de Mathonière en 1613 et figurant les feux d'artifice organisés au Louvre et aux Célestins en l'honneur de la fête de Saint Louis $^{34}$ : «L'événement de cette vente (nous allions dire la folie) a été le prix où l'on a vu s'élever la Représentation de deux artifices de feux et triomphes faicts à Paris, sur la rivière devant le Louvre, le dimanche $25^{e}$ et le jeudi $29^{e}$ jours d'Août 1613 [...]. Ces deux pièces, rares il est vrai, mais non point introuvables, avaient été mises sur table à 40 francs. Un amateur, M. Ruggieri, de la grande dynastie des Ruggieri, les désirait; la ville avait donné commission de les acheter à tout prix ; elles lui ont été adjugées pour 401 francs ! Les marchands, les amateurs, l'expert, M. Delbergue lui-même, n'y ont vu que du $\mathrm{feu}^{35}$ !» Cette somme, qui peut sembler exorbitante pour ce type d'œuvres, n'est pourtant rien en comparaison de ce qu'un Edmond de Rothschild, entre autres, déboursera quelques années plus tard. Ainsi, le baron acquiert-il, en 1875, pour 800 francs, la représentation des états généraux de 1614 par Jan Ziarnko, sur laquelle je reviendrai, vendue, quelques années plus tôt, à la vente Wellesley en 1858, 165 francs $^{36}$. En juillet 1882, Edmond de Rothschild obtient également le Baptême du Dauphin de Léonard Gaultier, avec le texte édité par Le Clerc en 1606, pour 1250 francs, alors qu'il était vendu 150 francs à la même vente Wellesley ${ }^{37}$.

11 Après les années les plus fastes, situées entre 1870 et 1878 , le baron de Rothschild ralentit, mais n'interrompt pas pour autant ses acquisitions et complète sa collection de pièces historiques avec les estampes considérées à l'époque comme indispensables, telles que l'Effigie d'Henri IV mort par Isaac Briot, éditée par Nicolas de Mathonière en $1610^{38}$, et, toujours de Jan Ziarnko, cet aquafortiste d'origine polonaise particulièrement prisé, le placard satirique sur la mort de Concino Concini en $1617^{39}$, toutes deux acquises par Danlos en mai 1912. Il enrichit aussi sa collection d'œuvres plus rares, souvent gravées sur bois, technique qui retient également l'intérêt des historiens de l'estampe, comme Jules Renouvier ou Georges Duplessis. En particulier, il achète, lors 
de la vente Pécard, la représentation du Siège de Saint-Jean-d'Angély en 1621, puis, surtout, lors de la vente Destailleur, le Sacre de Louis XIII (fig. 4), deux placards gravés sur bois et édités par Michel de Mathonière, bien moins fréquents que les versions gravées sur cuivre et éditées par le frère de l'éditeur, Nicolas de Mathonière ${ }^{40}$. Signalons encore l'épreuve rarissime, peut-être un unicum, désignée comme "très curieux placard mystique » dans le catalogue de la vente Destailleur, termes repris dans la fiche rédigée par André Blum, avec les portraits de Marguerite de Valois et de la famille royale, édité par Nicolas Barbotte ${ }^{41}$ (fig. 5). De la même vente provient aussi l'image de l'assassinat de Concini, le Tableau de la mort de Conchin, dont un exemplaire est conservé à la Bibliothèque nationale de France, mais qui demeure assez rare ${ }^{42}$. Il en va de même du placard ancien paru en 1570 chez le Lyonnais Benoît Rigaud, représentant l'exécution des comtes Egmont et Horne, acheté en 1894 à la vente Lignerolles, dont on trouve des exemplaires à la Bibliothèque nationale de France et au British Museum, et lui aussi rare dans les ventes ${ }^{43}$.

4. Ordre et cérémonie du sacre et couronnement du Tres-Chrestien Roy Louys Treziesme, Paris, Michel de Mathonière, 1610, Paris, musée du Louvre, département des Arts graphiques, collection Edmond de Rothschild, inv. 5296 LR.

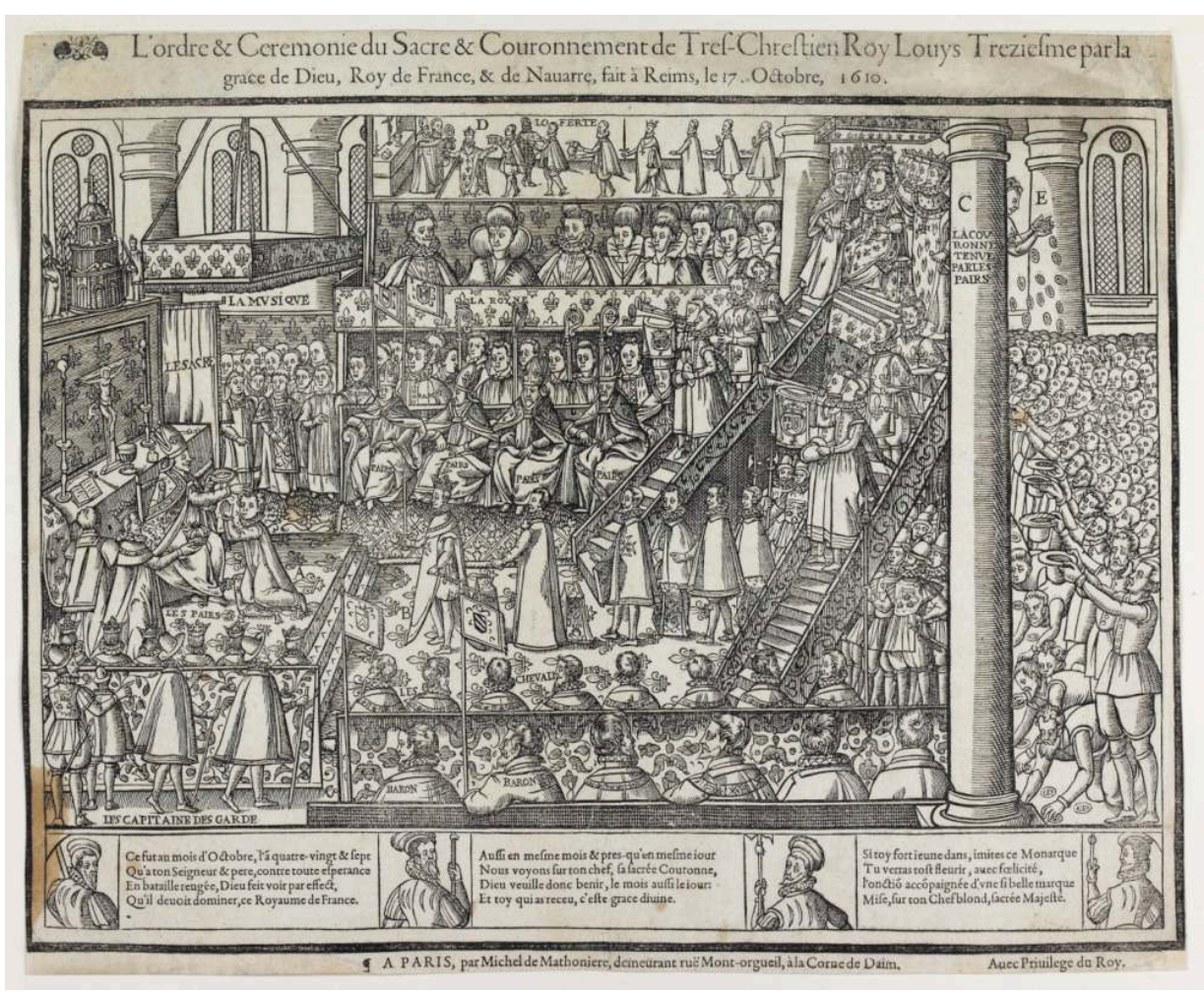

(C) Musée du Louvre 
5. Placard mystique avec le portrait de la famille royale, Paris, Nicolas Barbotte, Paris, musée du Louvre, département des Arts graphiques, collection Edmond de Rothschild, inv. 5298 LR.

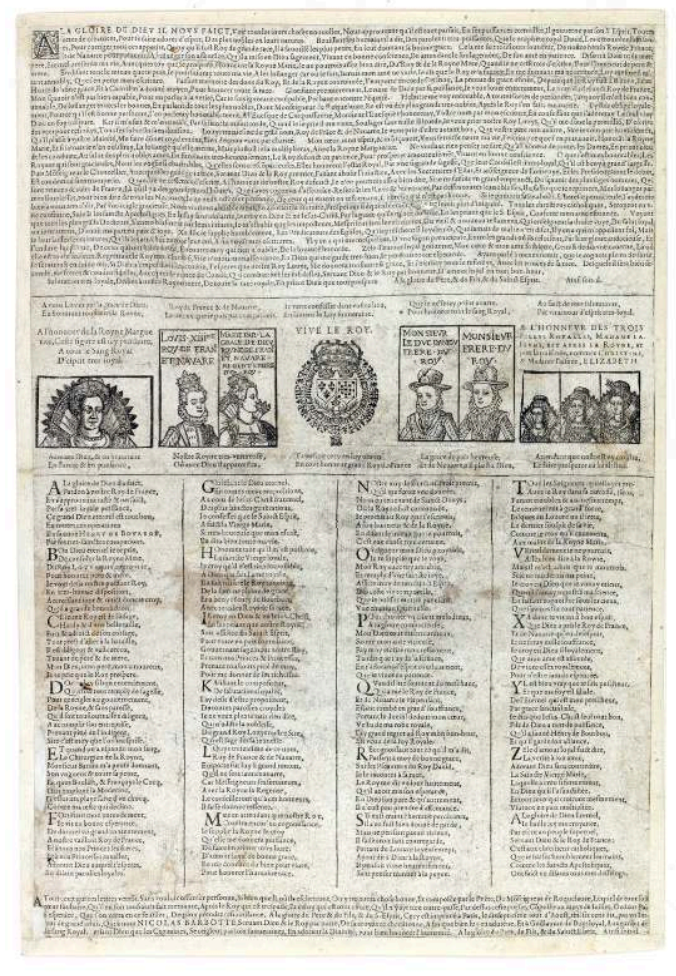

(c) Musée du Louvre

Il peut sembler étonnant ${ }^{44}$ que les placards $d u x v i^{e}$ siècle, du temps des guerres de Religion et surtout de la Ligue, soient peu représentés dans la collection Edmond de Rothschild. Bien sûr, la période n'est pas délaissée, et le collectionneur possède, on l'a vu, un très bel exemplaire de Perrissin et Tortorel, les suites gravées par Hogenberg, la procession de la Ligue et quelques portraits d'Henri III et de Jacques Clément. Mais, à titre de comparaison, sans même évoquer celle de Fevret de Fontette, la collection de Constant Leber conserve, par exemple, un exemplaire de la bataille de Dreux en 1562, ou encore Le Vray Pourtraict de l'assemblee des Estats tenuz en la ville de Blois en $1576^{45}$. Eugène Dutuit, pour sa part, a fait l'acquisition, lors de la vente Coste en 1854, de deux rares placards de la Ligue dirigés contre Henri III ${ }^{46}$. De tels placards ne semblent pas se rencontrer dans le fonds Rothschild, même si le baron possède un très rare exemplaire du Cakephachisme doctrinal et confession de foy ligueuse, pièce royaliste datée de 1594 environ, dirigée contre la Ligue et les jésuites ${ }^{47}$.

Enfin, comme ses contemporains et comme pour les autres pièces de sa collection, Edmond de Rothschild recherche les épreuves les plus belles, à toutes marges, ce qui est plutôt exceptionnel pour les placards du début du XVII ${ }^{e}$ siècle. Cette préoccupation se rencontre aussi dans les catalogues de vente de l'époque, comme celui de la vente Firmin-Didot, où figure la mention « très belle épreuve avec une petite marge " pour le Sacre de Louis XIII édité par Pierre Firens ou encore "grandes marges " pour les placards de l'Entrée d'Henri IV à Paris en $1594^{48}$. Les frères Dutuit eux-mêmes possédaient notamment un large portrait du défunt roi par le même Firens avec une belle marge ${ }^{49}$. On en trouve aussi bien sûr dans la collection Edmond de Rothschild. Ainsi semble-t-il préférer la monumentale composition des états généraux de 1614 de Jan Ziarnko avec 
les marges, mais sans le texte typographié de Jean-Baptiste du Val qui l'accompagne, plutôt que le placard complet ${ }^{50}$. Ici, le texte figure découpé et disposé à part dans le portefeuille, provenant d'un autre exemplaire ${ }^{51}$. Pourtant, dans la vente Destailleur, postérieure à l'acquisition de la planche de Jan Ziarnko, est mentionné le placard complet que le baron aurait pu se procurer. En revanche, contrairement aux pratiques dont il peut user pour d'autres pièces de sa collection, il ne recherche pas, ou peu, les différents états d'une planche, comme il en existe pourtant pour Le Couronnement de Marie de Médicis, avec ou sans le portrait d'Henri IV, ni les différentes éditions d'un placard. Par exemple, on relève dans la collection Dutuit deux éditions différentes de l'Effigie d'Henri IV mort par Isaac Briot, la première en 1610 et l'autre, beaucoup plus rare, datée de $1611^{52}$. Michel Hennin, quant à lui - mais sa collection est exceptionnelle -, traque les différents états et éditions, et réussit par exemple à réunir trois éditions différentes de l'Entrée d'Henri IV à Paris en 1594, publiée par Le Clerc.

En guise de conclusion toute provisoire, le baron Edmond de Rothschild, dont l'ambition, ou plutôt les visées n'étaient pas les mêmes que celles d'un Michel Hennin, s'est constitué un ensemble abondant et représentatif de pièces historiques du début du $\mathrm{xVII}^{\mathrm{e}}$ siècle, en particulier de placards illustrés, pour son projet de "musée de la gravure ", mais, on le sent bien, son intérêt le plus vif n'est pas là. Bien que ces placards, par leur format et la nouveauté de leurs sujets, constituent indéniablement les ancêtres des almanachs des décennies suivantes, le goût d'Edmond de Rothschild se tourne davantage vers ceux-ci et, comme l'écrit Emmanuel Bocher en introduction à la vente Béhague, qui réunit bon nombre de ces pièces qui finiront dans les portefeuilles du baron : "Nous arrivons maintenant à l'époque de Louis XIV, c'est-à-dire à la plus belle période de l'art de la gravure française [...] », même si l'auteur ajoute ensuite que le «joyau » de la collection est incontestablement formé des pièces en noir et en couleurs de l'école française du XviII ${ }^{e}$ siècle $^{53}$. Ajoutons aussi qu'en 1935, lors de la donation au musée du Louvre, l'engouement pour les pièces historiques des règnes d'Henri IV et de Louis XIII s'est estompé depuis longtemps et que les ventes ne font plus recette avec ce type d'estampes. Sur ce point précis, la collection Rothschild appartient pleinement à la période effervescente du dernier tiers du XIX ${ }^{e}$ siècle.

\section{NOTES}

1. Sur la collection d'estampes d'Edmond de Rothschild, voir André Blum, La Collection Edmond de Rothschild, Paris, Éditions des Musées nationaux, 1936; Suzanne Coblentz, «La collection d'estampes Edmond de Rothschild ", mémoire de recherche approfondie, Paris, École du Louvre, 1947 ; Pascal Torres, La Collection Edmond de Rothschild au musée du Louvre, Paris, Artulis, 2010 ; Pauline Prevost-Marcilhacy (dir.), Les Rothschild. Une dynastie de mécènes en France, 3 vol., Paris, Louvre/BnF /Somogy, 2016, vol. III, p. 10-153.

2. Bernard de Montfaucon, Les Monumens de la monarchie françoise qui comprennent l'histoire de France avec les figures de chaque regne que l'injure des tems a epargnées, Paris, Julien-Michel Gandouin/Pierre-François Giffart, 1733, t. V, « Au Lecteur ». 
3. Jean-Marc Chatelain, «Une collection pour mémoire: le cabinet des livres de châtre de Cangé ", dans La Bibliothèque de l'honnête homme. Livres, lecture et collections en France à l'âge classique, Paris, BnF Éditions, 2003, p. 161-197.

4. Jules Renouvier, Des types et des manières des maîtres graveurs pour servir à l'histoire de la gravure en Italie, en Allemagne, dans les Pays-Bas et en France, $2^{\mathrm{e}}$ partie, Montpellier, De Boehm, 1856, p. 62-63.

5. Il suffit pour s'en convaincre de consulter les catalogues de ventes annotés. Voir également ciaprès l'introduction d'Alfred Bonnardot au catalogue de la vente Gilbert en 1858 (note 6).

6. Alfred Bonnardot, "Quelques pages sur M. A.-P.-M. Gilbert et sur sa collection d'estampes", dans Catalogue des livres, dessins et estampes composant le cabinet de feu M. A.-P.-M. Gilbert, Paris, vente de décembre 1858, p. 99-115.

7. Emmanuel Bocher, "Notice", dans Catalogue des estampes françaises du XVIII siècle, pièces imprimées en noir et en couleur, almanachs, pièces historiques sur les mœurs et costumes, portraits composant la collection de M. Octave de Béhague, Paris, vente du 18 février - 3 mars 1877, p. VI.

8. Voir Véronique Meyer avec la collaboration de Marianne Grivel, «Les estampes du $\mathrm{XVII}^{\mathrm{e}}$ siècle ", dans Pauline Prevost-Marcilhacy (dir.), Les Rothschild. Une dynastie de mécènes en France, op. cit., vol. III, p. 106-125.

9. Jules Renouvier, Des types et des manières des maîtres graveurs, op. cit., p. 64-68.

10. Charles-Marie Fevret de Fontette, «Appendice de la Bibliothèque historique de la France; contenant diverses tables et listes de mémoires et d'estampes, qui ont rapport à l'histoire de ce royaume ", dans Bibliothèque historique de la France, contenant le catalogue des ouvrages imprimés et manuscrits qui traitent de l'histoire de ce royaume ou qui y ont rapport, Paris, 1775, t. IV. Voir Vanessa Selbach, «La collection d'estampes sur l'histoire de France du parlementaire bourguignon Charles-Marie Fevret de Fontette (1710-1772), conservée au département des Estampes et de la Photographie de la BnF", dans Marianne Grivel et al. (dir.), Curieux d'estampes. Collections et collectionneurs de gravures en Europe (1500-1815), actes de colloque (Paris, 2014), à paraître.

11. Constant Leber, Catalogue des livres imprimés, manuscrits, estampes, dessins et cartes à jouer composant la bibliothèque de M. C. Leber, Paris, Techener, 1839, t. III, $\mathrm{n}^{\circ} 6518$. Leber possède l'édition de 1768-1778 de la Bibliothèque historique de la France du père Lelong.

12. Georges Duplessis, Inventaire de la collection d'estampes relatives à l'histoire de France, léguée en 1863 à la Bibliothèque nationale par M. Michel Hennin, 5 vol., Paris, H. Menu, 1877-1884.

13. Paris, musée du Louvre, département des Arts graphiques, inv. $5310 \mathrm{LR}$, portefeuille 209 (ancien numéro d'inventaire 17253 mentionné sur la fiche d'André Blum). Sur l'estampe de Gaultier, voir Roger-Armand Weigert, Inventaire $d u$ fonds français. Graveurs du XVII ${ }^{e}$ siècle, Paris, Bibliothèque nationale de France, 1961, t. IV, nº 709, p. 548.

14. Il s'agit des portefeuilles 208 et 209.

15. Inv. $4679 \mathrm{LR}$, portefeuille $\mathrm{n}^{\circ}$ 194. Roger-Armand Weigert, Inventaire du fonds français. Graveurs du XVII siècle, op. cit., $\mathrm{n}^{\circ} 83$, p. 429.

16. Inv. L 138 LR. Volume avec ex-libris de James de Rothschild. Philip Benedict, Graphic History. The Wars, Massacres and Troubles of Tortorel and Perrissin, Genève, Droz, 2007.

17. Voir Marianne Grivel, avec la collaboration de Patrick Michel, «Histoire de la constitution d'un "Musée de la gravure" ", dans Pauline Prevost-Marcilhacy (dir.), Les Rothschild. Une dynastie de mécènes en France, op. cit., vol. III, p. 10-45.

18. Ibid. pour tout ce qui touche à la constitution du fonds et à son classement.

19. Inv. 23810 LR, portefeuille 527. Ancien numéro d'inventaire : $3551 \mathrm{a}$.

20. Jules Renouvier, Des types et des manières des maîtres graveurs, op. cit., p. 65. Le tableau du baron Gérard, peint en 1817, est aujourd'hui conservé au Musée national du château de Versailles.

21. Inv. 5274 LR, Inv. 5275 LR, Inv. 5276 LR, portefeuille 208.

22. Cité par Marianne Grivel, "Histoire de la constitution d'un "Musée de la gravure" ", art. cit., t. III, p. 16. Marianne Grivel ajoute que le $\mathrm{D}^{\mathrm{r}}$ Roth était déjà en contact avec James de Rothschild. 
23. Collection de feu M. le Docteur Roth. Estampes historiques et portraits relatifs à l'histoire de France. Vignettes du XVIII ${ }^{e}$ siècle. Livres, Paris, vente de juin 1888.

24. Inv. $4690 \mathrm{LR}$, portefeuille 194 et Inv. $5328 \mathrm{LR}$, portefeuille 209. Le placard gravé par Élie Dubois est édité par Nicolas de Mathonière. Voir Séverine Lepape, Gravures de la rue Montorgueil, Paris, BnF Éditions, 2015, n 442, p. 231. Celui gravé par Léonard Gaultier est édité par Jean Le Clerc. Voir Roger-Armand Weigert, Inventaire du fonds français. Graveurs du XVII ${ }^{e}$ siècle, op. cit., $\mathrm{n}^{\circ} 85$, p. 429. L'exemplaire conservé dans la collection Fevret de Fontette (Bibliothèque nationale de France, QB1 1615-1617) est incomplet, rogné dans la partie supérieure. En revanche, celui présent dans la collection Dutuit (Paris, Petit Palais, GDUT 10081) est entier.

25. Ainsi qualifiée dans les «ventes prochaines" de la Chronique des arts et de la curiosité, 17 février 1877, p. 63-64.

26. Sur les modes d'acquisition des estampes, voir Marianne Grivel, « Histoire de la constitution d'un "Musée de la gravure" ", art. cit.

27. Le placard du Sacre de Louis XIII édité par Nicolas de Mathonière, conservé au musée du Louvre (Inv. 5295 LR, portefeuille 208) et acquis lors la vente Béhague, est rogné dans la partie inférieure, et l'adresse de l'éditeur manque. Il en va de même de l'exemplaire conservé à la Bibliothèque nationale de France (QB1 1610-1611). En revanche, la librairie Chamonal a mis en vente, en 2017, le placard complet, daté de 1611. Sur le Sacre de Louis XIII, gravé par Jan Van Haelbeck et édité par Jean Le Clerc (Inv. 5302 LR, portefeuille 208), acquis lors de la vente Pécard, voir Charles Le Blanc, Manuel de l'amateur d'estampes, Paris, Jannet, 1856, t. II, nº 8, p. 336.

28. Inv. 5312 LR, portefeuille 209. Le placard complet est conservé à la Bibliothèque nationale de France (QB5). Sur Jan Ziarnko, voir Maria Stanislawa Sawicka, Jan Ziarnko, peintre-graveur polonais et son activité à Paris au premier quart du XVII siècle, Paris, Bibliothèque polonaise, 1938.

29. Paris, Bibliothèque nationale de France, Hennin, 1680. Catalogue d'une collection d'estampes historiques sur les règnes de Henri IV à Louis XVI [...] de M. le docteur $W^{* * *}$, Paris, vente du 18 décembre $1858, \mathrm{n}^{\circ} 175$.

30. Inv. $5322 \mathrm{LR}$, portefeuille 209. Acquis à la vente Firmin-Didot.

31. Inv. 5334 LR, portefeuille 209. Acquis à la vente Béhague.

32. Inv. 5338 LR, portefeuille 209. Acquis à la vente Pécard.

33. Nous nous appuyons sur les annotations manuscrites figurant dans les catalogues de vente.

34. Séverine Lepape, Gravures de la rue Montorgueil, op. cit., nº 494, p. 252.

35. Philippe Burty, "Ventes d'estampes et de dessins ", Gazette des beaux-arts, 1859, t. I, p. 123.

36. Sur les registres d'entrées des œuvres colligées par Edmond de Rothschild, voir Marianne Grivel, « Histoire de la constitution d'un "Musée de la gravure" ", art. cit., p. 10-13.

37. Inv. $5280 \mathrm{LR}$, portefeuille 208. Voir Roger-Armand Weigert, Inventaire du fonds français. Graveurs $d u$ XVII $^{e}$ siècle, op. cit., $\mathrm{n}^{\circ} 81$, p. 428. Précisons que ces sommes semblent dérisoires en comparaison de celles atteintes, par exemple, pour des estampes de Rembrandt.

38. Voir Séverine Lepape, Gravures de la rue Montorgueil, op. cit., $\mathrm{n}^{\circ}$ 388, p. 209-210.

39. Inv. 5353 LR, portefeuille 209.

40. Le Siège de Saint-Jean-d'Angély est conservé dans le portefeuille 527 (Inv. 23034 LR), le Sacre de Louis XIII dans le portefeuille 208 (Inv. 5296 LR). Voir Séverine Lepape, Gravures de la rue Montorgueil, op. cit., $\mathrm{n}^{\circ} 526$, p. 262 et $\mathrm{n}^{\circ} 520$, p. 258. Un exemplaire du Sacre de Louis XIII se trouve à la Bibliothèque nationale de France dans la collection Fevret de Fontette (QB-1 1610-1611), mais la partie inférieure est modifiée, en particulier la lettre est absente.

41. Inv. 5298 LR, portefeuille 208. Catalogue des estampes de l'école française du XVIII siècle imprimées en noir et en couleur. Pièces historiques et scènes de mours [...] composant la collection de M. H. D., Paris, vente du 14 au 23 avril 1890, nº 1424, p. 175.

42. Inv. 5335 LR, portefeuille 209.

43. Inv. 5260 LR, portefeuille 208.

44. Sans doute faudrait-il, pour s'en assurer, pousser les investigations plus avant. 
45. Constant Leber, Catalogue des livres imprimés, manuscrits, estampes, dessins et cartes à jouer composant la bibliothèque de M. C. Leber, op. cit., $\mathrm{n}^{\circ} 5948$ et $\mathrm{n}^{\circ} 5957$.

46. Paris, Petit Palais, LDUT 687 et LDUT 692.

47. L 85 LR / Bis 17 recto. Voir Alain Dufour, « Le catéchisme du docteur Pantalon et de Zani, son disciple (1594) », dans Aspects de la propagande religieuse, Genève, Droz, 1957. L'auteur ne semble pas connaître cet exemplaire.

48. Catalogue des dessins et estampes composant la collection de M. Ambroise Firmin-Didot, Paris, vente du 16 avril au 12 mai 1877.

49. Paris, Petit Palais, GDUT 4885.

50. Inv. 5333 LR, portefeuille 209.

51. Inv. 5331 et $5332 \mathrm{LR}$, portefeuille 209.

52. Paris, Petit Palais, GDUT 918 et 919.

53. Catalogue des estampes de l'école française du XVIII siècle. Pièces imprimées en noir et en couleur, almanachs, pièces historiques sur les mœurs et costumes, portraits, composant la collection de M. Octave de Béhague, Paris, vente du 19 février au 3 mars 1877, p. IX.

INDEX

Index géographique : France

Index chronologique : XVIIe siècle, XIXe siècle

Thèmes : Estampes, collections, mécénat, Rothschild, Louvre 
Manuscrits, livres et imprimés 


\section{Doucet chez Rothschild}

La Bibliothèque d'art et d'archéologie de 1923 à 1935

Jérôme Delatour

1 L'installation de la Bibliothèque d'art et d'archéologie à l'hôtel Salomon de Rothschild, 11, rue Berryer à Paris, inaugura la riche histoire de cet hôtel au service de l'art et des artistes. "De la sphère privée à la sphère publique », c'est aussi le chemin que cette bibliothèque dut emprunter à cette époque oubliée de son passé : faire le deuil de son fondateur, mettre en forme et accroître les collections magnifiques qu'il laissait, quitter la folle épopée de ses débuts pour se couler insensiblement dans les habits d'une bibliothèque universitaire ${ }^{1}$.

\section{Donation de Doucet et genèse de l'Institut d'art et d'archéologie (1912-1922)}

2 La Bibliothèque d'art et d'archéologie fut créée en 1906 par le couturier Jacques Doucet dans son logis du 19, rue Spontini à Paris, construit en 1904 dans le plus pur style Louis $\mathrm{XVI}^{2}$. Étendue peu à peu à une suite d'appartements loués dans la même rue, elle ouvrit au public en avril 1909, avec René-Jean (1879-1951) pour bibliothécaire.

3 Tenu jusqu'ici secret, l'accident qui la conduisit à déménager dans l'hôtel Salomon de Rothschild doit être conté. Depuis octobre 1908, Doucet vivait une idylle passionnée avec $\mathrm{M}^{\mathrm{me}} \mathrm{R}$. L'hôtel de la rue Spontini, garni de sa magnifique collection d'art du XVIII siècle, était l'écrin de leurs amours. En 1909, ils partaient en croisière sur le Nil. Mais le 28 février 1911, $\mathrm{M}^{\mathrm{me}} \mathrm{R}$. meurt brusquement, dans des circonstances sordides voire criminelles ${ }^{3}$. Les registres d'état civil de Paris conduisent à Jeanne Raimon, née Ruaud en 1867 d'un gantier et d'une modiste, rentière, décédée à son domicile $20^{\text {bis }}$ rue La Boétie ${ }^{4}$. La défunte était la sœur ainée de Paul Ruaud (1882-1960), architecte décorateur inconnu, à qui Doucet allait confier la réalisation de son fameux Studio de la rue SaintJames $^{5}$.

4 Passablement ébranlé, Doucet enchaîna bientôt les décisions radicales : vente de sa collection, abandon de la rue Spontini et de sa bibliothèque. Dès 1912, il s'accorde avec le vice-recteur de l'académie de Paris, Louis Liard, pour léguer sa bibliothèque à 
l'Université après sa mort ${ }^{6}$. René-Jean rend ce legs public en février 1914: «Pour seconder les efforts du vice-recteur de l'Université, désireux de fonder un Institut qui soit, pour l'histoire de l'art, ce que doit être pour l'océanographie l'œuvre du prince de Monaco, le fondateur de la bibliothèque d'art et d'archéologie entrait, l'an passé [sic], en relations avec $\mathrm{M}$. Liard et mettait à sa disposition la bibliothèque tout entière. C'est donc au quartier latin que, dans un avenir plus ou moins éloigné, la Bibliothèque d'art et d'archéologie viendra occuper des bâtiments élevés exprès pour elle ${ }^{7}$."

5 La guerre vient tout bouleverser. La maison de couture de Doucet tourne au ralenti, amorçant son déclin ${ }^{8}$. Faute de chauffage et de personnel (mobilisé), la bibliothèque ferme. On parle d'une dispersion de ses collections après la guerre; Doucet lui-même doit démentir'. En mars 1917, Paul Perdrizet lui suggère de la donner à Strasbourg une fois la ville rendue à la France ${ }^{10}$. Mais, victime de sa première crise cardiaque, pressé par des difficultés financières qui l'obligent à plusieurs ventes de dessins et de gravures ${ }^{11}$, Doucet ne peut plus attendre pour se décider. Il retire de sa bibliothèque quelques-uns de ses plus beaux livres illustrés contemporains pour alimenter la bibliothèque littéraire qu'il vient de créer $^{12}$. Après la mort du vice-recteur, le 21 septembre 1917, Doucet s'entend avec son successeur, Lucien Poincaré, et « sous la main encore plus rude de la nécessité ", transforme son legs post-mortem en donation de son vivant ${ }^{13}$. Le 15 décembre, il adresse une lettre de donation à l'université de Paris, avec date d'effet à compter du $1^{\mathrm{er}}$ janvier $1918^{14}$ - date choisie, selon Marie Dormoy, pour échapper à la loi sur la taxe de luxe (31 décembre 1917) devant entrer en vigueur $^{15}$.

6 Ne pouvant imposer comme directeur René-Jean, son bibliothécaire, car celui-ci n'est pas universitaire, Doucet désigne André Joubin pour lui succéder. Dandy, fin négociateur, cet ancien archéologue, normalien devenu directeur du musée Fabre de Montpellier, a su charmer le vieux couturier ${ }^{16}$. Jean Sineux, son ancien domestique, conserve son emploi de gardien et magasinier. La bibliothèque rouvre en 1918 avec ces deux personnes auxquelles s'adjoint, fin 1918, Clotilde Misme, recrutée comme secrétaire, mais remplissant bien vite, de fait, les fonctions d'une directrice adjointe, et véritable cheville ouvrière de la bibliothèque. Avec une nouvelle secrétaire, $\mathrm{M}^{\text {elle }}$ Courtois (1920), puis une bibliothécaire, Yvonne Chulliat (1924), ce trio constitua le seul personnel permanent de la bibliothèque à l'hôtel Salomon de Rothschild.

7 Doucet n'a pas abandonné sa bibliothèque, comme on le lui a parfois reproché. Il s'est effacé, s'abstenant d'assister aux réunions de la Société des amis de la Bibliothèque d'art et d'archéologie, constituée en 1925, mais continua de suivre de près la vie de sa créature. Quoique réfractaire aux mondanités officielles, Doucet participe aux visites qu'en font les présidents de la République les 4 mai 1921 et 5 novembre $1924^{17}$. Le 27 janvier 1923, il assiste à la réunion constitutive de l'éphémère commission administrative de la bibliothèque et y fut encore le 8 février suivant. " Il a considéré ", écrit Joubin, "comme un succès personnel et comme un hommage rendu à son initiative, le transfert en 1924 de la bibliothèque à la fondation Salomon de Rothschild ${ }^{18}$. » Plus encore, malgré sa promesse dans sa lettre de donation, de n'exercer « aucune ingérence » dans l'administration de la bibliothèque, il milite jusqu'à sa mort pour une installation définitive, puis pour la réunion de ses deux bibliothèques, dans l'hôtel Salomon de Rothschild. Il continue de donner des livres, participe aux frais du Répertoire d'art et d'archéologie ${ }^{19}$ et fait encore au moins un don magnifique, mais dans la plus grande discrétion : le Cahier pour Aline de Gauguin, en 1927. Et il la visite souvent : 
«Il suffit aussi, pour ceux qui ont connu Jacques Doucet, de se souvenir de l'heureux sourire qui éclairait son visage quand, visiteur discret, il parcourait les salles de l'hôtel Salomon de Rothschild, émerveillé presque de la réalisation de son rêve, murmurant à ceux qui l'accompagnaient: "C'est une ruche, une véritable ruche de travail"..$^{20}$ " «Il aimait y venir, en faire les honneurs, discrètement, à ses amis. Les jolies salles claires donnant sur les jardins, peuplées de lecteurs qui se servaient de ses livres, le remplissaient de joie ${ }^{21}$.»

\section{De la mort de la baronne de Rothschild à l'inauguration de la bibliothèque (1922-1924)}

\section{Rue Michelet ou rue Berryer : bataille universitaire, première manche} (1922)

8 Le 20 janvier 1920, la marquise Arconati Visconti a donné «deux millions » pour la construction d'un Institut d'histoire de l'art, qui s'élèvera rue Michelet ${ }^{22}$. Son architecte, Paul Bigot, place la bibliothèque en son centre ${ }^{23}$. Mais l'Université n'a pas d'argent pour la financer, ses loyers ont augmenté, et l'Institut n'est pas construit. L'exiguïté de la bibliothèque et sa «surveillance trop difficile " posent problème ${ }^{24}$. On envisage d'acheter l'hôtel Rodolphe Kann, 51, avenue d'Iéna ${ }^{25}$. Survient la mort de la baronne Adèle de Rothschild, le 10 mars 1922, qui lègue à l'État son hôtel et ses collections pour en faire "une maison d'art qui s'appellera "Fondation Salomon de Rothschild" $»^{26}$. Chargé de l'affaire, le ministère de l'Instruction publique informe le recteur de l'académie de Paris, le 27 mai, que la direction des Beaux-Arts offre d'héberger provisoirement la bibliothèque Doucet dans l'hôtel Salomon de Rothschild ${ }^{27}$.

Le conseil de l'Université, qui doit statuer sur cette offre, se tient le 19 juin 1922. Le doyen Ferdinand Brunot « déplore que le laboratoire de l'Institut d'histoire de l'art et d'archéologie qu'est la Bibliothèque d'art, soit séparé de l'Institut» et juge ce " cadeau... désastreux, encore une fois, pour l'Université ». Il veut au moins l'assurance "que certains enseignements pourront y être donnés; que la maison sera considérée comme un prolongement de l'Universitée ${ }^{8} »$. Le recteur expose les arguments que Joubin lui a préparés : « jusqu'ici », résume ce dernier, « les fonds nécessaires à la vie de la bibliothèque ont été exclusivement fournis par les particuliers et par l'État. L'Université n'a pas donné, depuis cinq ans, un centime ; sans doute parce qu'elle n'en a pas les moyens. Les particuliers ne donneront plus rien, et il est à craindre que, si l'Université refuse les offres de l'État, le Parlement, devant un pareil manque de bon sens, ne retire purement et simplement la subvention annuelle de $100000 \mathrm{fr}$ qu'il donne à la bibliothèque ${ }^{29}$. » Faute de solution alternative, la faculté cède, à condition que l'installation rue Berryer reste provisoire et qu'une commission administrative lui permette de contrôler la bibliothèque.

Se sentant à l'étroit dans l'hôtel de la cité Rougemont, la Société des gens de lettres rêvait de s'installer rue Berryer. Ignorant l'arbitrage qui venait d'être rendu, Maurice Barrès plaide sa cause dans une lettre ouverte au ministre de l'Instruction publique, parue dans l'Écho de Paris du 18 octobre 1922. Trop tard! 


\section{Travaux, transfert, inauguration (juin 1922-novembre 1924)}

11 L'hôtel Salomon de Rothschild avait été construit de 1874 à 1878. Émile Bois, architecte du gouvernement et de la Ville de Paris, en dresse des plans dès août $1922^{30}$. «On décida", résume Joubin, "de conserver les salons du rez-de-chaussée avec les collections qu'ils contiennent, pour y recevoir les artistes et les savants français et étrangers, et de mettre le premier étage et les combles à la disposition de l'université de Paris, pour y installer la Bibliothèque d'art et d'archéologie ${ }^{31}$. »

1. Émile Bois, plan du rez-de-chaussée de l'hôtel Salomon de Rothschild, 1922, Pierrefitte-surSeine, Archives nationales, AJ16 8406.

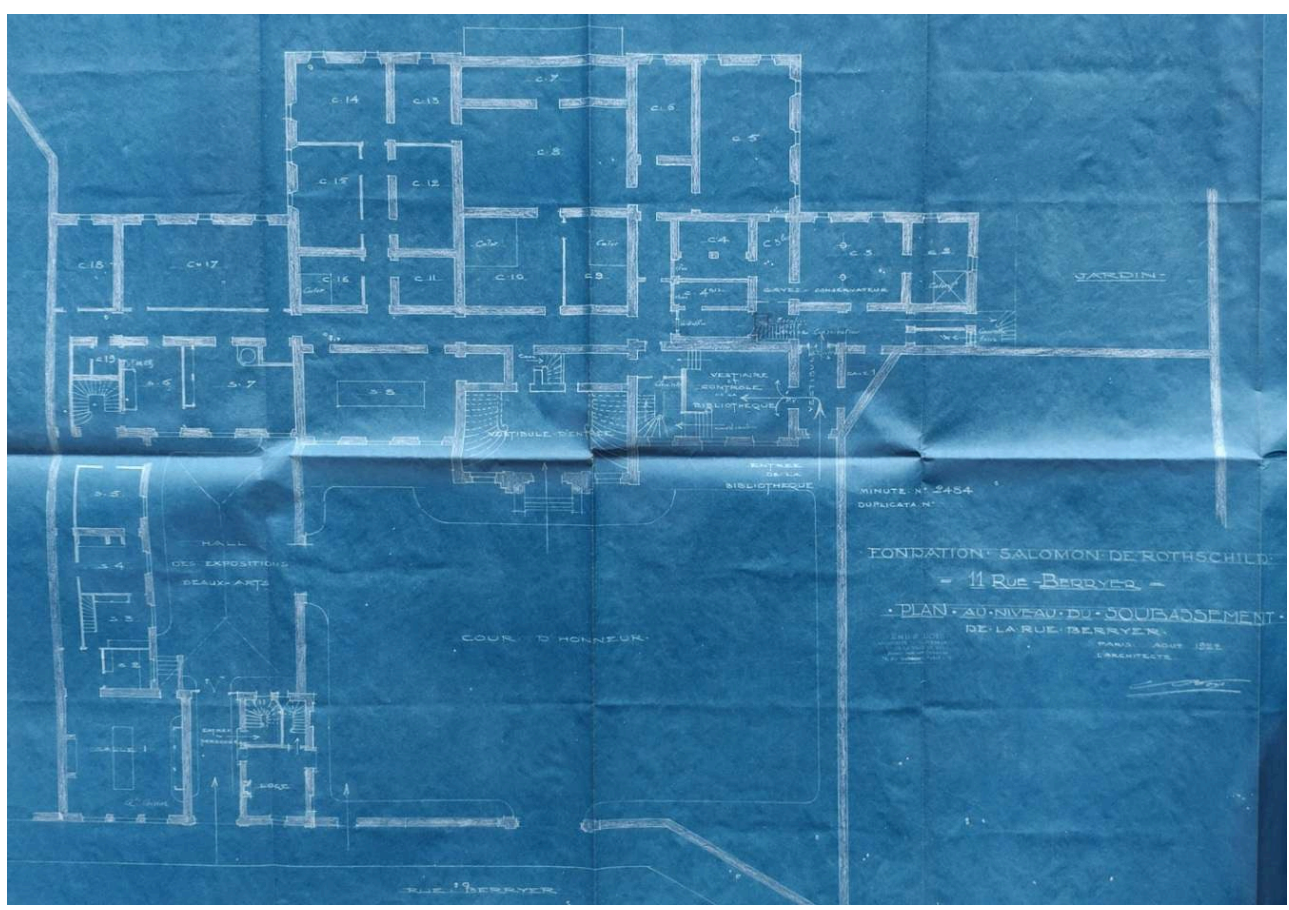

(C) Jérôme Delatour

Le 5 décembre, il détaille au président du conseil d'administration de la Fondation Rothschild les travaux à prévoir : «Les transformations à apporter se réduiront à de simples suppressions de cloisons, \& encore en très petit nombre. Les appartements une fois vidés des meubles \& objets qu'ils contiennent, le travail d'installation se réduira donc à la simple adaptation du matériel que nous possédons déjà. [...] L'établissement d'un monte-charge indispensable pour le service de la bibliothèque coûtera $10000 \mathrm{fr}$; le service téléphonique, 5000 ; le service d'incendie 30000 [...] En résumé, on peut admettre qu'avec une somme de $250000 \mathrm{fr}$ on installera complètement la bibliothèque \& on rendra l'hôtel utilisable pour les réceptions officielles. Plus tard, il sera possible d'envisager les travaux complémentaires, tels que par exemple l'organisation d'une ou de plusieurs salles d'exposition ${ }^{32}$.»

Sur les plans de l'architecte, Joubin a noté l'emplacement des principales collections de la bibliothèque et apporté des modifications. Le rez-de-chaussée (fig. 1) est finalement amputé d'une partie de ses pièces, dévolues à l'appartement de fonction du directeur de la bibliothèque. Pour le créer, Joubin fait détruire l'alcôve de la chambre de la baronne, y fait percer deux fenêtres supplémentaires, transforme la salle de bains en 
antichambre. Du premier étage, autrefois occupé par les appartements de la fille de la baronne, Joubin fait supprimer le seul élément de décor remarquable, «l'oratoire, de style arabe, conçu pour les cérémonies du culte juif ${ }^{33} »$. Il ôte quatre cheminées des $2^{e}$ et $3^{e}$ étages. Les plafonds sont renforcés pour soutenir le poids des magasins installés au $2^{\mathrm{e}}$, sous les combles. Les travaux durent jusqu'au début d'octobre 1923.

Le recteur autorise la bibliothèque à fermer à partir du 15 juin 1923 " pour permettre de procéder aux travaux préliminaires du déménagement ${ }^{34}$. La longueur de la fermeture et du transfert ( $u n a^{35}$ ) accentue les tensions avec l'Université et les musées. "Nous n'avons pas pu, en effet, empêcher le transfert de la bibliothèque », concédait le professeur Émile Mâle à Joubin, «mais nous espérons bien qu'elle ne restera pas trop longtemps dans ce quartier lointain - où elle ne rendra pas la centième partie des services qu'elle pourrait rendre - et qu'elle viendra bientôt prendre place dans notre institut d'art ${ }^{36}$."

Sommité du monde académique, Salomon Reinach s'improvise porte-parole des usagers. Devant ses critiques acerbes, Joubin doit souvent hausser le ton : «J'espère que vous ne voudrez pas compliquer notre tâche en joignant les potins du Louvre aux commérages de la Sorbonne. Il s'agit de sauver la bibliothèque \& de l'empêcher de périr. J'y ai, pour ma part, tout sacrifié, à commencer par mon travail scientifique. Ne mêlez pas à une si belle entreprise les racontars qui peuvent venir à vos oreilles. J'en ai déjà un dossier copieux, \& ceux que vous me communiquez ne sont sans doute pas les derniers.» Reinach l'oblige à se justifier sur son appartement de fonction: «Je n'ai point demandé à habiter l'hôtel S. de R. J'occupe rue Spontini un appartement des plus agréables que mes moyens me permettent de m'offrir, \& je le quitte à regret. Mais le ministre a jugé indispensable la présence du conservateur au milieu des collections dont il a la charge. Le $1^{\mathrm{er}} \&$ le $2^{\mathrm{e}}$ étages étant attribués intégralement à la bibliothèque, le rez-de-chaussée étant réservé pour les collections \& les réunions, on m'a laissé quatre pièces qui restaient à l'extrémité droite de l'hôtel, \& dont deux étaient en effet occupées par la testatrice ${ }^{37}$. » Mais un mois plus tard, Reinach écrit au recteur pour se faire « l'interprète des travailleurs déçus et bafoués. C'est le moment de l'année où les travailleurs sérieux et les provinciaux viennent à Paris, avec l'espoir de recueillir des informations dans les livres rares. L'an dernier, sous prétexte de vacances, la bibliothèque qui devait rester du moins accessible aux spécialistes, a été fermée rigoureusement pendant trois mois. Cette année, sous prétexte de déménagement, on la ferme complètement jusqu'en janvier 1924... Vu le classement des séries, qui est méthodique, le déménagement en bloc est une absurdité ; on crée à plaisir du désordre pour pouvoir fermer la porte à double tour. Permettez-moi d'exprimer l'opinion que tout ce qui concerne cette précieuse bibliothèque devrait être contrôlé par une petite commission de savants. Le règne du caprice et du bon plaisir y a plus qu'assez duré38 . "

En septembre 1923, les travaux sont en voie d'achèvement. "Je viens de passer 48 heures à Paris ", écrit Joubin au recteur. «J'ai voulu m'assurer par moi-même de la marche des travaux rue Berryer. Je suis heureux de vous envoyer les nouvelles les plus favorables. Tout sera prêt pour la fin du mois \& nous pourrons commencer à emménager le $1^{\text {er }}$ octobre. Un très grand effort a été fait \& je ne m'attendais pas à un pareil résultat. L'hôtel a été transformé, \& je crois que nous pourrons présenter une installation vraiment digne de l'université de Paris ${ }^{39}$. » Le transfert commence autour du 15 octobre. Le 19 février 1924, Pol Neveux, inspecteur général des bibliothèques, note que « le transfert des collections à l'hôtel Rothschild s'effectue dans les meilleures 
conditions et se termine peu à peu $»^{40}$. Le 19 mai, Reinach réclame la réouverture de la bibliothèque : «Les longs mois consacrés à un déménagement et à une installation que l'industrie privée eût accomplis en six semaines condamnent, une fois de plus, l'intervention et l'initiative de l'État ${ }^{41}$. » Le 10 juillet, le directeur des Beaux-Arts et le ministre de l'Instruction publique visitent les lieux ${ }^{42}$.

La bibliothèque reste à peu près fermée jusqu'à son inauguration par le président de la République, Gaston Doumergue, le 5 novembre 1924 à 11 heures. L'événement a été minutieusement préparé. Du côté de la bibliothèque, une cinquantaine de journaux, généralistes ou spécialisés, ont été invités, plus 17 " critiques indépendants ${ }^{43}$ »; Joubin a reçu ceux qui le souhaitaient le jour précédent. Du côté du rectorat, 55 invités - le conseil de l'Université, la commission de la bibliothèque et 27 autres personnalités professeurs, administrateurs, députés, journalistes, photographes ${ }^{44}$. L'inauguration, " réunion intime, point trop solennelle, tout à fait charmante ${ }^{45}$ ", est abondamment relayée par la presse.

\section{4-1929 : I'hôtel Salomon de Rothschild institut d'art?}

Deux jours avant l'inauguration, le doyen Brunot a écrit au président de la République pour réitérer les réserves du comité des professeurs d'histoire de l'art et le conseil de l'universitét6. Pierre Auscher, président de la section des Lettres de l'Association générale des étudiants de Paris, déplore peu après que les étudiants, «les premiers intéressés à cette question, ont vu se dérouler cette récente manifestation à laquelle ils n'ont pas été conviés ${ }^{47} »$.

19 La Faculté est en effet confrontée à un coup de force. D'accord avec le ministère, Doucet, Joubin et le rectorat intriguent pour maintenir durablement la bibliothèque rue Berryer. Dès le 23 décembre 1922, malgré des assurances de façade et en contradiction avec le conseil de l'Université, il a été demandé à l'architecte de l'Institut, Paul Bigot, de la supprimer de ses plans. La marquise Arconati Visconti elle-même voit cette idée d'un bon œil : «Ça économise deux étages dans mon institut de l'art" ${ }^{48}$. Le 29 juillet 1923, le doyen a refusé d'examiner ce projet, «la faculté n'admettant pas un institut d'art duquel serait exclu la bibliothèque Doucet $»^{49}$. Qu'à cela ne tienne : en février 1924, le recteur a demandé à l'architecte de suspendre ses études ; on envisage « la construction rue Berryer des locaux nécessaires pour l'Institut d'art ${ }^{50} »$ ! Bigot est désemparé : «Vous semblez vouloir », écrit-il au recteur, «d'un trait de plume, annuler l'œuvre à laquelle je travaille - vous savez avec quelle ferveur - depuis trois ans et demi. À cette œuvre j'ai tout sacrifié ${ }^{51}$.»

Finalement, la construction de l'Institut commence rue Michelet en mai $1924^{52}$. Joubin la critique vertement. "Si au lieu de faire des trous dans les catacombes de la rue Michelet \& de gaspiller son argent en moellons on pensait à la science, on aurait pu faire quelque chose d'utile. On se plaint de ne pas avoir d'argent pour acheter des bouquins, \& on fait de l'architecture de prix de Rome! Quelle folie, quelle stupidité ! Enfin, les professeurs auront un cabinet \& une clef à eux. Pour les bouquins, je crois que le Larousse suffira ${ }^{53}$. » Le 17 janvier 1925, Doucet prie Joubin de faire dire au ministre de l'Instruction publique qu'il est "formellement opposé » au transfert de sa bibliothèque rue Michelet; qu'il menace, s'il était effectué, de ne pas « compléter la donation qu'il a déjà faite par le legs de sa bibliothèque littéraire et de toute somme d'argent qui 
pourrait l'accompagner ${ }^{54}$ ». Le 22 janvier, le recteur fait dire à Joubin «qu'il est d'avis que la bibliothèque ne doit plus quitter la rue Berryer ${ }^{55}$ » et le 26 , le ministre assure " qu'il n'a jamais été question d'enlever cette collection de l'hôtel Rothschild pour la transférer dans un autre local. M. Doucet peut être certain que le désir exprimé par lui sera respectée ${ }^{56}$ ». Fort de ce soutien, le recteur répond aux critiques dans Le Figaro du 22 février 1925. Il prétend que la bibliothèque s'adresse surtout aux étudiants avancés, ce qui rend son éloignement moins problématique, et qu'une fois l'Institut d'art achevé, « je crois bien que le conseil [de l'Université] dira alors : "la bibliothèque est bien, très bien, rue Berryer. Pourquoi n'y resterait-elle pas ?"57 ».

21 La Faculté finit pourtant par l'emporter. Grâce à l'insistance d'Henri Focillon, professeur à la Sorbonne depuis 1924, malgré l'opposition persistante de Joubin et même la tiédeur de certains professeurs qui, finalement, jugeaient l'Institut trop petit pour l'accueillir, le décret de création de l'Institut, le 10 janvier 1928, incluait expressément la bibliothèque ${ }^{58}$. Par son testament du $1^{\mathrm{er}}$ juin 1929 , Doucet légua sa bibliothèque littéraire " pour qu'elle soit jointe à la Bibliothèque d'art et d'archéologie rue Berryer précédemment donnée par moi à l'Université ${ }^{59}$ ». Legs accepté par l'Université mais, l'hôtel Rothschild ne pouvant contenir les 20000 documents de la Littéraire, le recteur décida, au lendemain de la mort de Doucet (30 octobre 1929), de l'installer dans la réserve de la bibliothèque Sainte-Geneviève ${ }^{60}$. Quant à la bibliothèque cinématographique créée par Doucet en 1927, son testament omettait d'en parler, peutêtre parce qu'il la considérait comme une partie de sa bibliothèque littéraire. De ce fait, sa veuve ne voulut pas la céder à l'Université, qui n'insista pas pour la récupérer ${ }^{61}$. Ainsi, le rêve caressé par Doucet de faire de l'hôtel Rothschild l'écrin de ses trois bibliothèques réunies partit définitivement en fumée.

\section{Locaux et organisation de la bibliothèque}

Les étages de l'hôtel Salomon de Rothschild ont bien changé depuis les années 1920. L'implantation de la bibliothèque y demeure cependant bien visible, surtout au premier étage. Les anciennes salles des photographies, sur cour (fig. 4), ont conservé leurs portes d'origine ; les cellules de moine dévolues aux catalogues de ventes, à peine éclairées par un oculus, leur volume minuscule; côté jardin, les parquets gardent la trace des cloisons abattues des salles de lecture.

\section{Séparatisme et libre accès}

La bibliothèque était ouverte du lundi au samedi de 14 à 18 heures. Elle s'ouvrit peu à peu pendant les vacances universitaires d'août-septembre, grâce à un mécénat du collectionneur James Hyde ${ }^{62}$.

L'entrée se faisait par la porte de service droite de l'hôtel, qui donnait accès sur la gauche à une pièce servant de vestiaire et de contrôle (fig. 2). De là, un escalier garni des bustes d'artistes par Bourdelle, Rodin, Falguière, Dalou, etc. autrefois commandés par Doucet pour la bibliothèque, menait à l'étage ${ }^{63}$. 
2. Émile Bois, plan du rez-de-cour de l'hôtel Salomon de Rothschild, 1922, détail, Pierrefitte-surSeine, Archives nationales, AJ16 8406.

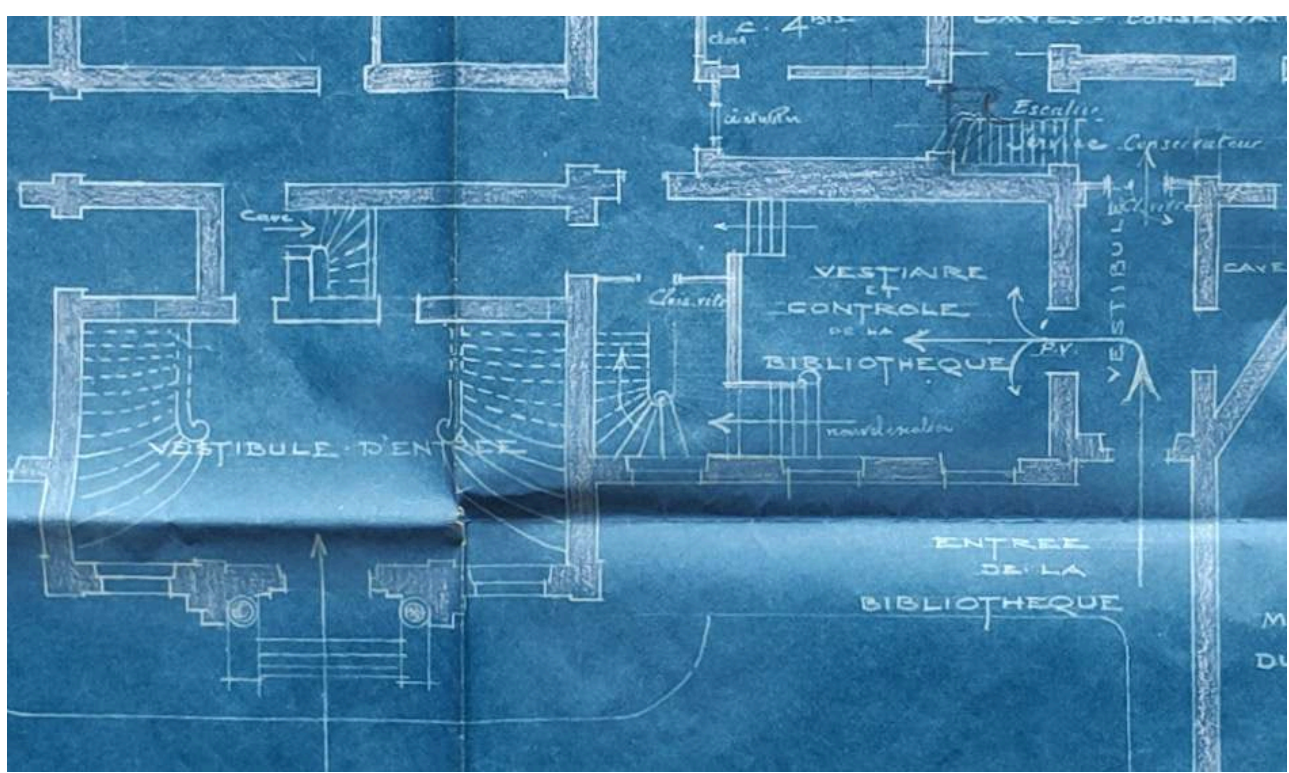

(C) Jérôme Delatour

Soucieux du confort des lecteurs, Joubin modifia les plans de l'architecte pour faire des trois grandes pièces sur jardin les principales salles de lecture. Parvenu au premier étage, le lecteur passait donc côté jardin et entrait par « une salle centrale, par laquelle on accède aux autres", "réservée aux catalogues, fichiers, répertoires, ouvrages de références ». Il trouvait là un "cadre luxueux, paisible, bien fait pour le travail et le recueillement». À "la douce impression du home» déjà présente rue Spontini, s'ajoutaient ici la lumière et la vue sur jardin : "Dans ce beau décor silencieux et clair de la rue Berryer, dans ces salles vastes et confortables où le développement des collections se trouve assuré pour longtemps, nos lecteurs ne regretteront certes pas les rez-de-chaussée étroits et tristes, bruyants et obscurs, de la rue Spontini ${ }^{64}$. »

Les rares photographies de la bibliothèque à cette époque montrent la grande salle de lecture dans l'ancien Salon de Mademoiselle ${ }^{65}$. L'une d'elles la présente garnie de lecteurs qui s'avèrent presque exclusivement des lectrices (fig. 3). 
3. "Une des salles de travail de la bibliothèque » (dans André Joubin, "La Bibliothèque d'art et d'archéologie de l'université de Paris », Sabaa, 1, 1929, p. 19)

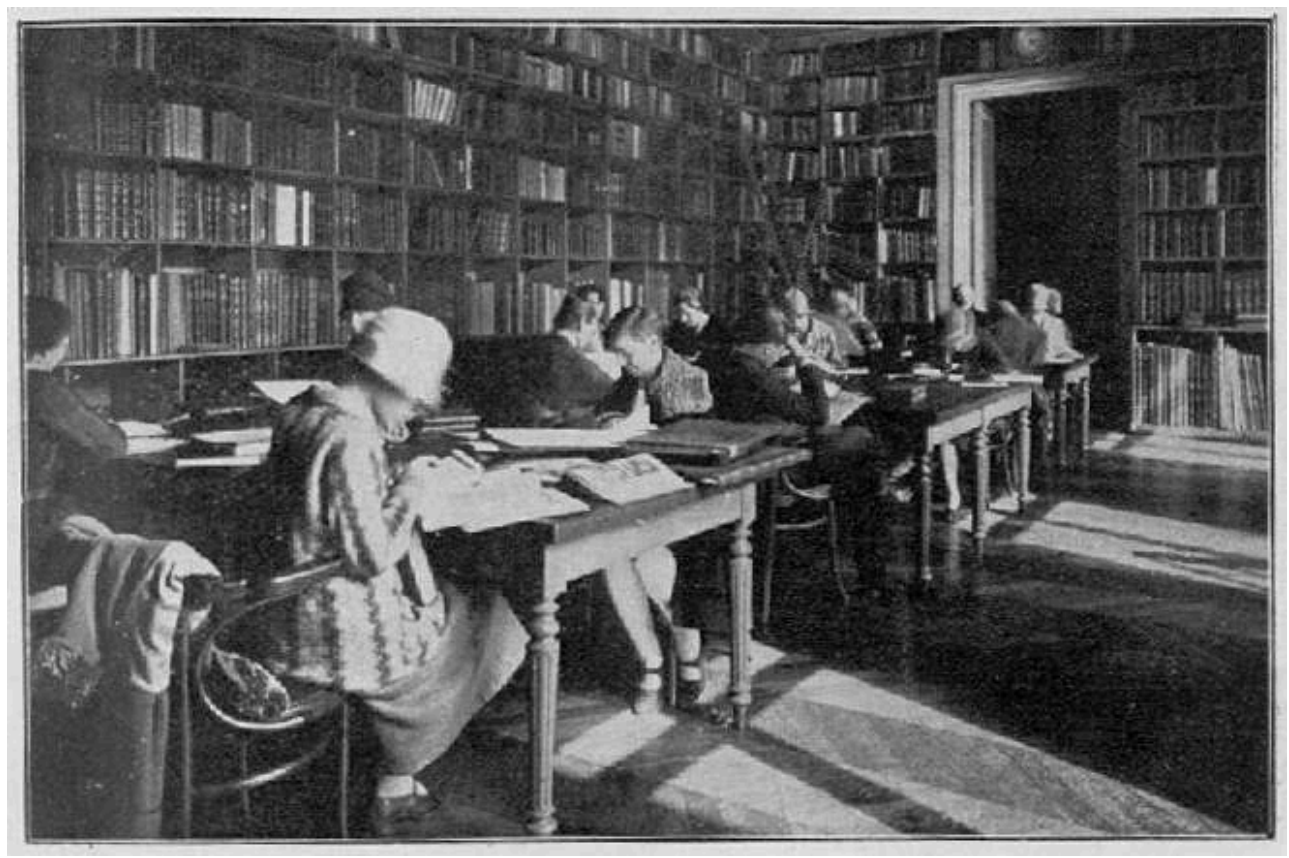

(c) D.R.

Joubin explique :

Il a fallu [...] démonter les boiseries de chaque pièce l'une après l'autre pour les remonter rue Berryer. Du reste nous avons voulu garder ici une des dispositions les plus appréciées rue Spontini, la division en cabinets séparés. Au lieu d'une salle unique avec des magasins inaccessibles au public, nous avons préféré transformer en salles de travail toutes les pièces donnant sur le jardin; ces pièces communiquent entre elles et chacune correspond, comme auparavant, à l'une des grandes divisions de l'histoire de l'art: antiquité, moyen âge, temps modernes, Extrême-Orient; une salle centrale groupe les catalogues, fichiers et ouvrages de références. Sur la façade principale, côté cour, on trouvera réunies les collections de photographies, les cabinets d'estampes et de manuscrits; dans les combles sont rassemblés les périodiques. Enfin, des cabinets spéciaux sont réservés à des séries importantes, par exemple les catalogues de vente (nous en possédons plus de 40000 ), les catalogues de musées et de collections privées, les catalogues d'expositions, etc., etc. Je n'ignore point que ce classement topographique ne paraît pas rigoureusement conforme aux règles les plus récentes de la bibliothéconomie, et les jeunes stagiaires de l'Université, qui m'ont aidé dans le travail de classement, ne me l'ont point caché66.

Émile Mâle lui-même avait insisté pour que ce classement fût maintenu, à cause de sa commodité ${ }^{67}$. «Je crois que les personnes qui viennent travailler chez nous apprécient l'organisation qui y a été adoptée ", notait Joubin en 1929. "J'ai reçu des éloges de beaucoup d'étrangers, même de ceux qui sont le plus portés à critiquer nos institutions scientifiques. Ils m'ont souvent dit qu'ils ne possédaient chez eux rien d'équivalent ${ }^{68}$. " "Considérée par les professionnels comme fantaisiste», confirme Dormoy, "cette disposition est grandement appréciée des travailleurs [...] - ils peuvent même explorer les rayons d'alentour, ce qui, bien souvent, leur cause le plaisir d'une découverte ${ }^{69}$. revendiquée par son directeur même, «de manière que l'égyptologue ne gêne pas le 
médiéviste, et que celui qui s'occupe de préhistoire soit séparé de celui qui étudie l'impressionnisme ${ }^{70}$ ». Cloisonnement social, également: les savants se plaçaient à proximité des collections qui leur convenaient le mieux, tandis que les étudiants étaient regroupés dans les grandes salles afin d'y être surveillés - c'est une féministe qui le remarque ${ }^{71}$. Professeurs et chercheurs ne manquaient d'ailleurs pas d'inviter les étudiants à aller travailler ailleurs, tel Reinach : « les neuf dixièmes des livres utiles de cette bibliothèque sont déjà à la Sorbonne et à l'École des beaux-arts ${ }^{72}$ ». L'idée d'utiliser «une salle de la bibliothèque, où les professeurs compétents pourraient conduire un petit groupe d'étudiants avancés pour examiner des photographies, des reproductions d'estampes, des livres rares etc. ${ }^{73}$ " semble avoir été rapidement abandonnée.

4. Émile Bois, plan du $1^{\text {er }}$ étage de l'hôtel Salomon de Rothschild, 1922, Pierrefitte-sur-Seine, Archives nationales, Archives nationales, AJ16 8406 (en rouge, emplacement des cotes des collections courantes).

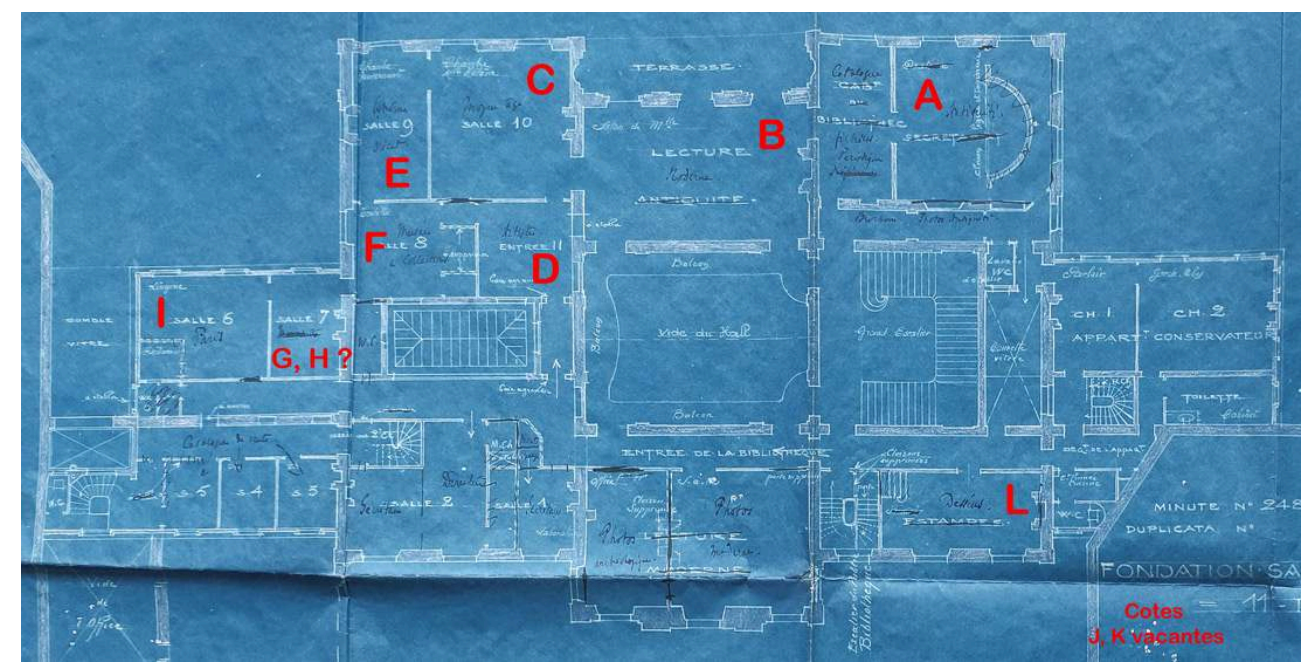

(C) Jérôme Delatour

Même séparatisme, d'ailleurs, entre la Fondation Rothschild au rez-de-chaussée et la bibliothèque aux étages. L'accès à la bibliothèque se faisait "par la petite porte », et non par la porte principale.

De son côté, Pol Neveux regrettait que la distribution de l'hôtel et la «médiocrité des crédits » eussent empêché d'aménager une bibliothèque moderne: il avait fallu renoncer aux rayonnages métalliques et à l'entresolage des étages existants. "Persistons à regretter l'usage compliqué des échelles ", ajoutait-il, "si fatal pour les livres, si dangereux pour le personnel - ainsi que l'accumulation de tant de matériaux combustibles dans des appartements déjà parquetés et ornés de boiseries ${ }^{74}$. "

Au premier étage (fig. 4) règne le libre accès - pas de places numérotées ni demande par bulletin $^{75}$. "Monsieur Jean [Sineux] will receive you, show you to a table and bring the books you wish. No red tape, such as there is at the Bibliothèque nationale, where to get you in you have to have a passport and to get out a visa. And at the Nationale there are other difficulties, for the catalogue is extremely trying to Americans ${ }^{76}$. » Les lecteurs autorisés peuvent se servir sur les rayonnages ${ }^{77}$. Le $2^{2}$ étage (fig. 5 ) est dédié à la fin des collections courantes et aux collections à communication différée - les périodiques, une partie des collections courantes organisées en magasins fermés; tout au fond de la bibliothèque, les 
documents précieux sont répartis en quatre pièces: manuscrits et autographes ${ }^{78}$, estampes anciennes et modernes ${ }^{79}$ et, enfin, rangés dans des vitrines ou des armoires grillagées et formant ce qu'on appelle déjà Réserve ${ }^{80}$, les livres d'architecture, de fêtes et d'ornements, et catalogues de ventes annotés ${ }^{81}$. En contradiction avec le plan de 1922, les livres sur le costume semblent avoir formé un cabinet à partprobablement la salle $n^{0} 3^{82}$. Marie Dormoy justifie l'éloignement des «pièces les plus rares, parce qu'elles ne sont communiquées qu'à un très petit nombre de lecteurs ${ }^{83}$ "; Pol Neveux souligne à l'inverse le danger d'un local "difficile à atteindre et à évacuer [...] en cas d'accident ${ }^{84}$.»

5. Émile Bois, plan du $2^{e}$ étage de l'hôtel Salomon de Rothschild, 1922, Pierrefitte-sur-Seine, Archives nationales, AJ16 8406 (en rouge, emplacement des cotes).

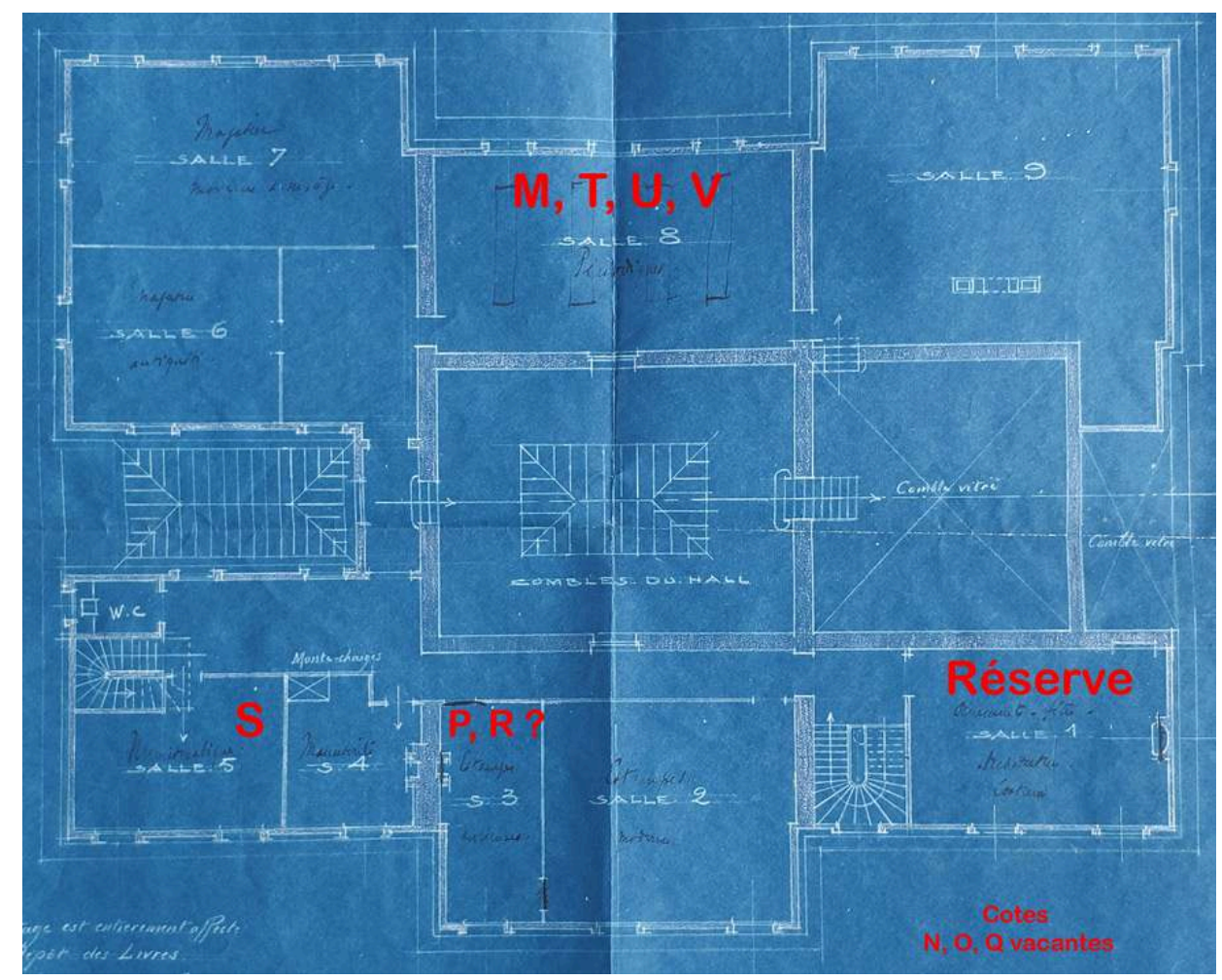

(C) Jérôme Delatour

\section{Traitement des collections}

Deux grands chantiers sont menés rue Berryer: le reclassement des livres et le traitement des photographies. Dans un contexte institutionnel et budgétaire difficile, Joubin n'hésite pourtant pas à faire recoter les 100000 imprimés de la bibliothèque ${ }^{85}$ selon un système entièrement nouveau ${ }^{86}$. Cette recotation s'accompagne d'une campagne d'estampillage et d'un "remaniement» des catalogues ${ }^{87}$. Ce "grand travail de reclassement de nos collections » ne fut achevé qu'en 1928. "Maintenant », écrivait Joubin en 1929, « on peut considérer la bibliothèque comme parfaitement en ordre et outillée pour le travail scientifique. Le seul grand classement qui resterait encore à faire, c'est celui de nos collections photographiques ${ }^{88}$ ". À cette époque, la bibliothèque ne dispose plus d'un atelier photographique. Les piles de photos à traiter s'entassent 
sur l'ancien billard de la baronne, reconverti en table ${ }^{89}$. Afin de faire revivre "ce département abandonné, pour lequel aucun crédit n'était prévu et qui était mort en $1928^{90}$ ", Clotilde Brière recrute sept jeunes femmes en 1931, la plupart à titre bénévole ${ }^{91}$. Elle relance les acquisitions, ouvre un registre d'inventaire, entreprend «un fichier définitif » des 200000 épreuves accumulées. Traitées en priorité car «les plus demandées par les lecteurs, les plus sujettes à s'accroître ", avant les photographies "de dessins et de sculptures ", 40000 photographies de peintures sont accessibles aux lecteurs en $1937^{92}$.

Sur d'autres fronts, la situation de la bibliothèque demeura précaire, faute de moyens. Presque interrompue pendant la guerre, l'acquisition de livres reprit sur un rythme quatre fois inférieur, et pour moitié grâce aux acquisitions gratuites - dons, dépôt légal, "réparations allemandes " $^{93}$. Il en va de même de la majorité des acquisitions spécialisées et patrimoniales - $92 \%$ des 19325 photographies acquises de mars 1930 à juillet 1935, par exemple, sont issues de dons. Le Répertoire d'art et d'archéologie, «qui est l'organe de la bibliothèque, périodique d'une importance scientifique considérable ${ }^{94}$ ", ne paraît que grâce à une multitude de collaborations extérieures bénévoles (bibliothécaires, conservateurs de musées, professeurs) et le concours financier de la Société des amis de la Bibliothèque. Quoique pressée de publier son catalogue ${ }^{95}$, la bibliothèque n'en trouva jamais les moyens, malgré l'engagement actif de l'un de ses principaux mécènes, Georges Wildenstein. De son ambitieux catalogue méthodique, envisagé comme une bibliographie "universelle des beaux-arts ${ }^{96}$ ", ne parut que le catalogue des périodiques, publié en $1937^{97}$.

\section{Épilogue}

Le 6 décembre 1933, le ministre de l'Éducation nationale ordonna le transfert de la bibliothèque dans l'Institut d'art enfin achevé. Le 13 janvier 1934, le recteur Charléty autorisa le lancement des travaux d'aménagement de la bibliothèque rue Michelet, qui durèrent jusqu'à l'été 1935. Le transfert s'effectua de septembre à octobre $1935^{98}$. Quant à l'hôtel Salomon de Rothschild, il n'en avait pas fini avec les bibliothèques : délocalisé pour travaux en 1937, le cabinet des Estampes de la Bibliothèque nationale occupa la place laissée par la Bibliothèque d'art et d'archéologie jusqu'en $1946^{99}$.

Ainsi se referma, pour la Bibliothèque d'art et d'archéologie, une heureuse parenthèse. Certes, le discret combat mené par Doucet pour faire de l'hôtel Rothschild l'écrin de ses trois bibliothèques, réunies en institut d'art, n'aboutit pas. Du moins les craintes émises par les universitaires, du fait de son éloignement du Quartier Latin, se révélèrent infondées. Le rapport d'André Joubin pour l'année universitaire 1930-1931 en témoigne : la fréquentation " a augmenté dans de telles proportions que j'ai dû prendre des mesures pour diminuer le nombre des lecteurs. Nous étions surtout envahis par de jeunes étudiants, ou étudiantes de l'École du Louvre, qui veulent préparer ici leurs examens et qui, certains jours, occupaient toutes les places disponibles ${ }^{100}$ ». À l'hôtel Salomon de Rothschild, la bibliothèque opéra sa mue universitaire, tout en conservant beaucoup de ses traits d'institution privée. La foule des collaborateurs-chercheurs de ses débuts, qui faisait d'elle un laboratoire, avait certes disparu; mais son magasinier était toujours l'ancien domestique de Doucet et son directeur comme sa bibliothécaire, toujours des historiens de l'art. De nouveau logée dans les enfilades de pièces d'une maison particulière, disposition contraire à une bibliothèque moderne, elle offrait une 
proximité avec les livres et un confort plébiscités par son public. Son activité demeurait essentiellement tributaire du mécénat et du bénévolat d'une petite communauté de passionnés.

\section{NOTES}

1. La présente étude complète la maîtrise de Marie-Édith de La Fournière, La Bibliothèque d'art et d'archéologie de l'université de Paris, université Paris 1 Panthéon-Sorbonne, 1995, p. 21-43 et passim. 2. Gérard Rousset-Charny, Les Palais parisiens de la Belle Époque, Paris, Action artistique de la Ville de Paris, 1990, p. 160-163.

3. Doucet éleva un cénotaphe en souvenir de cet amour tragique dans le parc de son pavillon de chasse de Nouan-le-Fuzelier, qui porte ces deux dates (Anne-Marie Peylhard, « De Jacques Doucet aux Angladon-Dubrujeaud, les origines d'un musée d'Avignon », dans Chantal Georgel (dir.), Jacques Doucet collectionneur et mécène, Paris, Les Arts décoratifs/Institut national d'histoire de l'art, 2016, p. 232). Officiellement victime d'un accident de chasse, $M^{\text {me }} \mathrm{R}$. aurait succombé, selon l'entourage de Doucet, sous les coups de son mari Jean-Marie-Albert Raimon (1862-après 1935), négociant en soieries. Celui-ci la trompait avec une vedette des cafés-concerts, Marie-Louise Fages, dite la "Jolie Fagette " (1879-après 1924), avec qui il se mit en ménage (Paul Léautaud, Journal littéraire, Paris, Mercure de France, 1986, t. 2, p. 420 ; Marie Dormoy, Souvenirs et portraits d'amis, Paris, Mercure de France, 1963, p. 194-196 ; François Chapon, C'était Jacques Doucet, Paris, Fayard, 2006, p. 116).

4. Archives de Paris, 8D 138, $n^{\circ} 542$. Le journal de René Gimpel révèle également son nom à la date du 16 février 1918 (Journal d'un collectionneur, Paris, Hermann, 2011, p. 15-16).

5. Marie-Laure Crosnier Leconte, Dictionnaire des élèves architectes de l'École des beaux-arts de Paris (1800-1968), INHA ( agorha.inha.fr/inhaprod/ark:/54721/00283152); François Chapon, C'était Jacques Doucet, op. cit., p. 510.

6. Sylvie Maignan, «Un critique d'art parisien, René-Jean, 1879-1951 », mémoire de recherche, Paris, École du Louvre, 1979, p. 115-116 ; François Chapon, C'était Jacques Doucet, op. cit., p. 234.

7. René-Jean, « La Bibliothèque d'art et d'archéologie ", Revue de synthèse historique, 28-1, février 1914, p. 168.

8. Marie Dormoy, Souvenirs et portraits d'amis, op. cit., p. 183.

9. Edmond Pottier à René-Jean, 20 janvier 1915 (INHA, Autographes 145, 1, 1061).

10. Paul Perdrizet à René-Jean, 20 et 26 mars 1917 (INHA, Autographes 144, 4, 912-913).

11. Suzanne Lemas, "Éléments pour une biographie de Jacques Doucet », dans Hommage à Jacques Doucet, Bulletin du bibliophile, 1 (1980), p. 16-17 ; France L'Heureux, «La Bibliothèque littéraire Jacques Doucet : lieu de mémoire du surréalisme?», mémoire de maîtrise, Montréal, Université du Québec, 2008, p. 48.

12. Un cas avéré est L'Après-midi d'un faune de Stéphane Mallarmé, illustré par Édouard Manet en 1876 (Bibliothèque littéraire, E IV 12) ; à l'entrée « Mallarmé » de l'ancien catalogue auteurs de la bibliothèque, la cote de ce livre est gommée et surchargée de la mention : « repris par M. Doucet en 1917 ».

13. Doucet à René-Jean, 29 décembre 1917 (Sylvie Maignan, « Un critique d'art parisien, RenéJean, 1879-1951 », op. cit., p. 116).

14. François Chapon, C'était Jacques Doucet, op. cit., p. 233-235. 
15. Marie Dormoy, « La Bibliothèque d'art et d'archéologie fondation Jacques Doucet », Bulletin du bibliophile, 1930, p. 131-132 ; Marie Dormoy, Souvenirs et portraits d'amis, op. cit., p. 199.

16. Clotilde Brière-Misme, Institut national d'histoire de l'art, ms. Bcmn 498 (9), t. 1, p. 83.

17. François Chapon, C'était Jacques Doucet, op. cit., p. 242.

18. André Joubin, « Jacques Doucet, 1843-1929 », Gazette des beaux-arts, février 1930, p. 80.

19. Réunions des 21 janvier 1924 et 9 janvier 1926 (Pierrefitte-sur-Seine, Archives nationales, AJ16 8387).

20. Marie Dormoy, «La Bibliothèque d'art et d'archéologie fondation Jacques Doucet ", art. cit., p. 229.

21. André Joubin, « Jacques Doucet, 1843-1929 », art. cit., p. 80.

22. Marie-Louise Arconati Visconti au recteur, 13 mai 1922 (AN 20010498/60); «La Donation Arconati Visconti », Le Bulletin de l'art ancien et moderne, 636, 10 février 1920, p. 17-18; Simon Texier, "L'Institut d'art et d'archéologie, antithèse d'une nouvelle modernité française », dans L'Institut d'art et d'archéologie. Paris 1932, Paris, Picard, 2005, p. 47.

23. Dominique Morelon, «La Bibliothèque Doucet, une installation difficile », dans L'Institut d'art et d'archéologie. Paris 1932, op. cit., p. 108.

24. Marie Dormoy, «La Bibliothèque d'art et d'archéologie fondation Jacques Doucet ", art. cit., p. 166.

25. Dominique Morelon, « La Bibliothèque Doucet, une installation difficile », art. cit., p. 108.

26. Paris, 13 mars 1907 (AN, 20010498/60).

27. Le recteur Paul Appell au ministre, $1^{\text {er }}$ juillet 1922 (AN, AJ16 8387).

28. Conseil de l'Université, 19 juin 1922, p. 16-17 (AN, 20010498/60).

29. André Joubin au recteur, 12 juin 1922 (AN, AJ16 8387).

30. AN, AJ16 8406.

31. André Joubin, «La Fondation Salomon de Rothschild: I, la Bibliothèque d'art et d'archéologie ", Gazette des beaux-arts, 10, décembre 1924, p. 318.

32. Pierrefitte-sur-Seine, Archives nationales, AJ16 8387.

33. Victor Champier, "Hôtel de Madame Salomon de Rothschild», Revue des arts décoratifs, 12, 1891-1892, p. 75.

34. Paul Appell à Salomon Reinach, 30 juin 1923 (Pierrefitte-sur-Seine, Archives nationales, AJ16 8387).

35. André Joubin, «La Fondation Salomon de Rothschild: I, la Bibliothèque d'art et d'archéologie ", art. cit., p. 322-323.

36. Émile Mâle à André Joubin, 26 novembre 1922 (Pierrefitte-sur-Seine, Archives nationales, AJ16 8387).

37. André Joubin à Salomon Reinach, 5 mai 1923 (Pierrefitte-sur-Seine, Archives nationales, AJ16 8387).

38. Salomon Reinach à Paul Appell, 29 juin 1923 (Pierrefitte-sur-Seine, Archives nationales, AJ16 8387).

39. André Joubin à Paul Appell, 5 septembre 1923 (Pierrefitte-sur-Seine, Archives nationales, 20010498/60).

40. AN, 20010498/60.

41. Salomon Reinach à Paul Appell, 19 mai 1924 (Pierrefitte-sur-Seine, Archives nationales, AJ16 8387).

42. Le recteur à Paul Léon, 10 juillet 1924, brouillon (Pierrefitte-sur-Seine, Archives nationales, 20010498/60).

43. AN, AJ16 8406.

44. AN, 20010498/60.

45. Le Bulletin de l'art ancien et moderne, 713, décembre 1924, col. 276A.

46. AN, 20010498/60. 
47. L'Université de Paris, décembre 1924, p. 8 (Pierrefitte-sur-Seine, Archives nationales, 20010498/60).

48. Lettre à Henri Focillon, 21 avril 1923, voir Dominique Morelon, « La Bibliothèque Doucet, une installation difficile ", art. cit., p. 109.

49. Simon Texier, "L'Institut d'art et d'archéologie, antithèse d'une nouvelle modernité française ", art. cit., p. 61.

50. Maurice Guyot, secrétaire général de l'Université, à André Joubin, 22 février 1924 (AN, AJ16 8387).

51. Simon Texier, "L'Institut d'art et d'archéologie, antithèse d'une nouvelle modernité française », art. cit., p. 63.

52. Ibid., p. 64.

53. André Joubin à Maurice Guyot, 12 janvier 1925 (Pierrefitte-sur-Seine, Archives nationales, AJ16 8387).

54. Israël au recteur, 19 janvier 1925 (Pierrefitte-sur-Seine, Archives nationales, AJ16 8387).

55. Maurice Guyot à André Joubin, 22 janvier 1925 (Pierrefitte-sur-Seine, Archives nationales, AJ16 8387).

56. Albert à Israël, secrétaire général de la présidence du Conseil, Paris, 26 janvier 1925 (Pierrefitte-sur-Seine, Archives nationales, AJ16 8387).

57. Jules Laurent, «La Bibliothèque d'art et d'archéologie : ce que dit M. Paul Appell », Le Figaro, 22 février 1925, col. 2 C.

58. Dominique Morelon, « La Bibliothèque Doucet, une installation difficile », art. cit., p. 109-111. 59. AN, F17/14666 (André Chastel, La création d'un Institut national d'histoire de l'art, 1984, p. 43).

60. Rose Adler, Journal, [Paris], Éditions des cendres, 2014, p. 6 ; Marie Dormoy, « La Bibliothèque littéraire Jacques Doucet ", dans Annales de l'université de Paris, 1, janvier-février 1938, p. 59 ; France L'Heureux, «La Bibliothèque littéraire Jacques Doucet: lieu de mémoire du surréalisme?», op. cit., p. 99. Son transfert eut lieu en 1932.

61. Anne-Élisabeth Buxtorf, "Jacques Doucet et le cinéma, une ultime bibliothèque ", dans Chantal Georgel (dir.), Jacques Doucet collectionneur et mécène, op. cit., 2016, p. 226-229.

62. Société des amis de la bibliothèque d'art et d'archéologie de l'université de Paris [ci-après : Sabaa], 2,1929, p. 27, 3,1930, p. 35 et 5,1931, p. 34.

63. Raymond Cogniat («M. Doumergue inaugure la fondation Salomon de Rothschild », Comoedia, 6 novembre 1924, col. 1D) omet de préciser s'il s'agit du petit escalier de service ou du grand escalier d'honneur.

64. Marie Dormoy, «La Bibliothèque d'art et d'archéologie fondation Jacques Doucet ", art. cit., p. 130, 134, 167 ; rapport de Pol Neveux, 19 février 1924, f. 6 (Pierrefitte-sur-Seine, Archives nationales, 20010498/60).

65. André Joubin, «La Fondation Salomon de Rothschild: I, la Bibliothèque d'art et d'archéologie », art. cit., p. 323 ; Excelsior, 6 novembre 1924, p. 6 ; fig. 3.

66. André Joubin, «La Fondation Salomon de Rothschild: I, la Bibliothèque d'art et d'archéologie », art. cit., p. 322-323.

67. 26 novembre 1922 (Pierrefitte-sur-Seine, Archives nationales, AJ16 8387).

68. André Joubin, « La Bibliothèque d'art et d'archéologie de l'université de Paris », Sabaa, 1, 1929, p. 20.

69. Marie Dormoy, «La Bibliothèque d'art et d'archéologie fondation Jacques Doucet », art. cit., p. 167.

70. André Joubin, « La Bibliothèque d'art et d'archéologie de l'université de Paris, art cit., p. 20.

71. Esther Welmoet Dyserinck, "Voor Vrouwen - Van 'n modekoning en "n werkende vrouw ", Groene Amsterdammer, 23 juillet 1927 (Pierrefitte-sur-Seine, Archives nationales, AJ16 8406).

72. Revue archéologique, 20, novembre-décembre 1924, p. 339. 
73. Commission administrative de la bibliothèque, 22 décembre 1923 (Pierrefitte-sur-Seine, Archives nationales, AJ16 8387).

74. Rapport d'inspection, 19 février 1924, f. 2-3 (Pierrefitte-sur-Seine, Archives nationales, 20010498/60).

75. Esther Welmoet Dyserinck, «Voor Vrouwen - Van 'n modekoning en 'n werkende vrouw », art. cit.

76. Dupont Wright, novembre 1925 (Pierrefitte-sur-Seine, Archives nationales, AJ16 8406) ; A. D., «Une visite à la bibliothèque d'art et d'archéologie de l'université de Paris ", dans L'Information universitaire, 146 (9 mai 1925), col. 1B.

77. André Joubin, « La bibliothèque d'art et d'archéologie de l'université de Paris, art. cit., p. 20.

78. Marie Dormoy, «La Bibliothèque d'art et d'archéologie fondation Jacques Doucet », art. cit., p. 228.

79. Raymond Cogniat, «M. Doumergue inaugure la fondation Salomon de Rothschild», art. cit., col. 1D.

80. A. D., "Une visite à la bibliothèque d'art et d'archéologie de l'université de Paris », art. cit., col. 1 C.

81. Raymond Cogniat, «M. Doumergue inaugure la fondation Salomon de Rothschild», art. cit., col. 1D; Esther Welmoet Dyserinck, «Voor Vrouwen - Van ' $n$ modekoning en ' $n$ werkende vrouw », art. cit.

82. Marie Dormoy, «La Bibliothèque d'art et d'archéologie fondation Jacques Doucet », art. cit., p. 227 ; Raymond Cogniat, «M. Doumergue inaugure la fondation Salomon de Rothschild», art. cit., col. 1D.

83. Marie Dormoy, «La Bibliothèque d'art et d'archéologie fondation Jacques Doucet », art. cit., p. 224.

84. Rapport, 19 février 1924, f. 5 (Pierrefitte-sur-Seine, Archives nationales, 20010498/60).

85. André Joubin, «La Fondation Salomon de Rothschild: I, la Bibliothèque d'art et d'archéologie ", art. cit., p. 322.

86. Les systèmes de cotation d'origine peuvent être reconstitués à partir du catalogue auteurs de la bibliothèque et des observations faites sur certains livres.

87. Rapport de Pol Neveux, 19 février 1924, f. 5-6 (Pierrefitte-sur-Seine, Archives nationales, 20010498/60).

88. Rapport de André Joubin, 19 juillet 1929, f. 4-5 (Pierrefitte-sur-Seine, Archives nationales, AJ16 8387).

89. Esther Welmoet Dyserinck, "Voor Vrouwen - Van 'n modekoning en 'n werkende vrouw ", art. cit.

90. Clotilde Brière-Misme, «Rapport sur le département des estampes et photographies d'octobre 1935 à octobre 1937 », [1937] (INHA, archives de la bibliothèque). Clotilde Brière a régulièrement rendu compte de l'activité du département dans le bulletin de la Sabaa (3 (1930), p. 3-11 ; 4 (1930), p. 11-14 ; 6 (1932), p. 15-18).

91. Rapports de André Joubin pour 1929-1930 (10 novembre 1930, f. 4), 1930-1931 (29 octobre 1931, f. 2) et 1931-1932 (15 octobre 1932, f. 4) (AN, AJ16 8387).

92. Clotilde Brière-Misme, « Rapport sur le département des estampes et photographies ", op. cit., f. II.

93. INHA, registres d'inventaire ; commission administrative de la BAA, 9 janvier 1926 (AN, AJ16 8387).

94. André Joubin à Louis Barthou, 5 décembre 1922 (Pierrefitte-sur-Seine, Archives nationales, AJ16 8387).

95. Requête du directeur de l'enseignement supérieur à Pol Neveux, 15 juillet 1930 (Pierrefittesur-Seine, Archives nationales, AJ16 8387). 
96. Assemblée générale de la Sabaa, 10 décembre 1927, p. 35 (INHA, archives de la bibliothèque) ; Georges Wildenstein, «Le Catalogue de la Bibliothèque d'art et d'archéologie de l'université de Paris ", dans Sabaa, 3, 1930, p. 18-20.

97. Bibliothèque d'art et d'archéologie, Catalogue général, XIV. Périodiques, [1937].

98. Suzanne Damiron, «La Bibliothèque d'art et d'archéologie (1934-1946) », Sabaa, 8, 1949, p. 3-4.

99. Roger-Armand Weigert, « Les Différents emplacements du Cabinet des Estampes, 1667-1954 », Bulletin d'informations de l'ABF 16, 1955, p. 217.

100. 29 octobre 1931 (Pierrefitte-sur-Seine, Archives nationales, AJ16 8387).

INDEX

Index géographique : France

Index chronologique : XXe siècle

Thèmes : Jacques Doucet, collections, Rothschild, Bibliothèque d'art et d'archéologie 


\title{
La collection Rothschild et l'édition italienne de la Renaissance
}

\author{
Carlo Alberto Girotto
}

1 Les collections de livres, d'estampes et de dessins de la famille Rothschild sont extrêmement variées, en fonction de l'intérêt que chaque membre de cette famille de mécènes a manifesté au cours des décennies. Comme plusieurs études ont pu le préciser, cet ensemble contient des manuscrits enluminés, des éditions anciennes et plus récentes, plusieurs placards, des recueils d'images et de dessins, des reliures, des exemplaires avec dédicace ou envoi d'auteur, etc. Dans tous les cas, la qualité exceptionnelle des volumes Rothschild, conservés aujourd'hui dans les collections publiques françaises, notamment à Paris, et dans les collections étrangères, est due à la recherche d'exemplaires de choix. Ceux-ci ont été sélectionnés en suivant de nombreux critères: la provenance, la qualité matérielle de l'objet, tout comme - pour les imprimés - la rareté de l'édition ou l'état de l'exemplaire, qu'il s'agisse d'objets liés au contexte culturel français, sûrement le plus représenté dans les collections Rothschild, ou venus d'autres milieux. Ces aspects ont été soulignés par les études de Christopher de Hamel et d'Harry W. Paul et, plus récemment, par les contributions de Geneviève Guilleminot-Chrétien, d'Isabelle de Conihout et de Catherine Faivre d'Arcier'1, qui ont étudié les collections de plusieurs membres de la famille Rothschild.

2 Même s'ils ne constituent pas le noyau le plus important, les volumes venant de la péninsule Italienne sont nombreux au sein des collections Rothschild, en raison d'une qualité et, parfois même, d'une primauté que les bibliophiles des $\mathrm{XIX}^{\mathrm{e}}$ et $\mathrm{du} \mathrm{Xx}^{\mathrm{e}}$ siècles ont souvent accordées aux manuscrits et aux éditions italiens. Nous souhaitons apporter quelques éléments à ce tableau en présentant les premiers résultats d'une recherche sur les éditions italiennes de la Renaissance conservées au sein de la collection Rothschild. Nous avons concentré notre attention sur les livres du baron James Édouard de Rothschild (1844-1881) et de son fils, Henri de Rothschild (1872-1947), collection que l'on peut consulter aujourd'hui au département des Manuscrits du site Richelieu de la Bibliothèque nationale de France. La section italienne de cet ensemble conserve seulement une part réduite du patrimoine littéraire italien : nous comptons peu d'éditions de classiques; il y a seulement quelques éditions d'Alde Manuce et 
plusieurs auteurs sont complètement absents. Cependant, l'importance de cette collection est indiscutable pour tout chercheur intéressé par la Renaissance italienne. Nous connaissons parfois l'histoire de ces objets, avant qu'ils n'arrivent au sein de la collection Rothschild: l'on doit par exemple à Henri de Rothschild l'achat de deux extraordinaires manuscrits venant des archives de la famille Trissino de Vicence (Paris, BnF, Manuscrits, Rothschild 3078/I-II). Plusieurs générations d'hommes et de femmes illustres de la première moitié du Cinquecento défilent sous les yeux des chercheurs qui feuillettent ces volumes - d'Andrea Alciato à Pietro Bembo, de Lucrèce Borgia au cardinal Bernardo Dovizi da Bibbiena -, sans comparaison avec ceux d'autres bibliothèques de recherche ${ }^{2}$. Il est aussi vrai que la qualité remarquable de ce recueil manuscrit et, plus généralement, d'autres documents similaires conservés au sein de la collection Rothschild peuvent reléguer dans l'ombre un riche patrimoine «mineur ", moins connu et pourtant notable par la rareté des objets et le caractère unique de chaque exemplaire.

\section{Reliures, provenances illustres et réseau de bibliophiles}

3 Parmi les nombreuses collections de livres réunies par les membres de la famille Rothschild, les volumes ayant appartenu à James Édouard et à son fils, Henri, bénéficient depuis longtemps d'un catalogue imprimé en cinq volumes, publié entre 1884 et 1920 et édité par Émile Picot $^{3}$. Cette publication a donné à l'ensemble une visibilité qui manque probablement aux autres « bibliothèques Rothschild» conservées dans les institutions publiques françaises ${ }^{4}$. Cependant, malgré la renommée de cette collection, souvent citée par les bibliographes en raison de la richesse de ses livres, elle est encore connue de manière incomplète par les chercheurs et plusieurs éléments restent à préciser. En effet, comme Christopher de Hamel l'avait déjà remarqué, le catalogue édité par Picot décrit plusieurs collections : celle de James Édouard, mort en 1881, mais aussi celle de son fils, Henri, qui hérita de son père cette passion bibliophilique, et au moins une partie des livres achetés par Laura-Thérèse, épouse de James Édouard et mère d'Henri, surtout intéressée par les manuscrits médiévaux. Après 1881, Laura-Thérèse et son fils purent élargir la collection construite par James Édouard en profitant, pour leurs achats, de l'avis d'experts de renom, tels que Seymour de Ricci et Émile Picot, que l'on chargea donc de rédiger le catalogue de la collection réunie par cette branche de la famille Rothschild 5 .

4 Il est pourtant difficile de préciser, pour chaque exemplaire, le moment et les circonstances de l'achat. Dans le catalogue Picot, l'ordre de présentation des ouvrages et les indications données sont parfois trompeurs, de telle sorte que, faute de documentation exhaustive, les exemplaires suscitent souvent nombre d'interrogations : qui a acheté tel livre ? À quelle occasion? Pour quelle raison et selon quels critères ? Si certaines de ces questions peuvent trouver réponse dans les documents d'archives, notamment ceux conservés à la Bibliothèque nationale de France, d'autres considérations s'imposent, dès que l'on souhaite préciser la valeur symbolique de ces volumes et les critères qui ont retenu l'attention des Rothschild.

5 Au premier regard, la collection italienne de James Édouard et de son fils, Henri, révèle un intérêt pour les reliures d'époque : un exemple éloquent vient d'un exemplaire de $L a$ vita di Consalvo Ferrando de l'évêque Paolo Giovio, publié en 1550 (Rothschild 2510)6. 
Particulièrement bien conservé, celui-ci montre une reliure française en maroquin brun, avec plusieurs compartiments de mosaïque et aux tranches ciselées (fig. 1). Sur les plats, il est possible de voir les armes de Paolo Giordano Orsini (1541-1585), personnage à la biographie romanesque, qui fut le mari d'Isabelle de Médicis (1542-1576) - et peutêtre le responsable de sa mort ${ }^{7}$. L'exemplaire appartient à une plus large collection, qui a été l'objet de plusieurs études. Selon une hypothèse présentée récemment, la reliure pourrait en être datée de 1558, année du mariage d'Orsini avec la jeune Médicis : il pourrait s'agir en effet, pour cet exemplaire comme pour d'autres de facture analogue, d'un cadeau de noces venant de Catherine de Médicis, arrière-grand-tante de l'épouse ${ }^{8}$. La présence de l'ex-libris d'Henri de Rothschild au plat supérieur (« EX-LIBRIS HENRI DE ROTHSCHILD ») nous permet de situer chronologiquement l'achat entre la fin du xix et le début du $\mathrm{Xx}^{\mathrm{e}}$ siècle. Mais de telles reliures anciennes avaient été recherchées aussi par James Édouard, qui avait acheté, à une époque qu'il est impossible de préciser, un exemplaire du traité De re militari d'Antonio Cornazzano, publié à Venise par Pietro Nicolini da Sabbio en 1536, qui avait fait partie, lui aussi, des livres de Giordano Orsini et qui avait été l'objet de la convoitise du bibliophile italien Guglielmo Libri'. La présence de ce diptyque de reliures anciennes souligne la continuité des intérêts bibliophiliques du père et du fils. Mais l'ancienneté des reliures semble avoir eu une importance moindre pour la sélection des volumes conservés dans les collections Rothschild ${ }^{10}$.

1. Paolo Giovio, La vita di Consalvo Ferrando di Cordova, detto il gran capitano [...] tradotta per M. Lodovico Domenichi, in Fiorenza, s.n., 1550, Paris, BnF, département des Manuscrits, Rothschild 2510. Plat inférieur de la reliure.

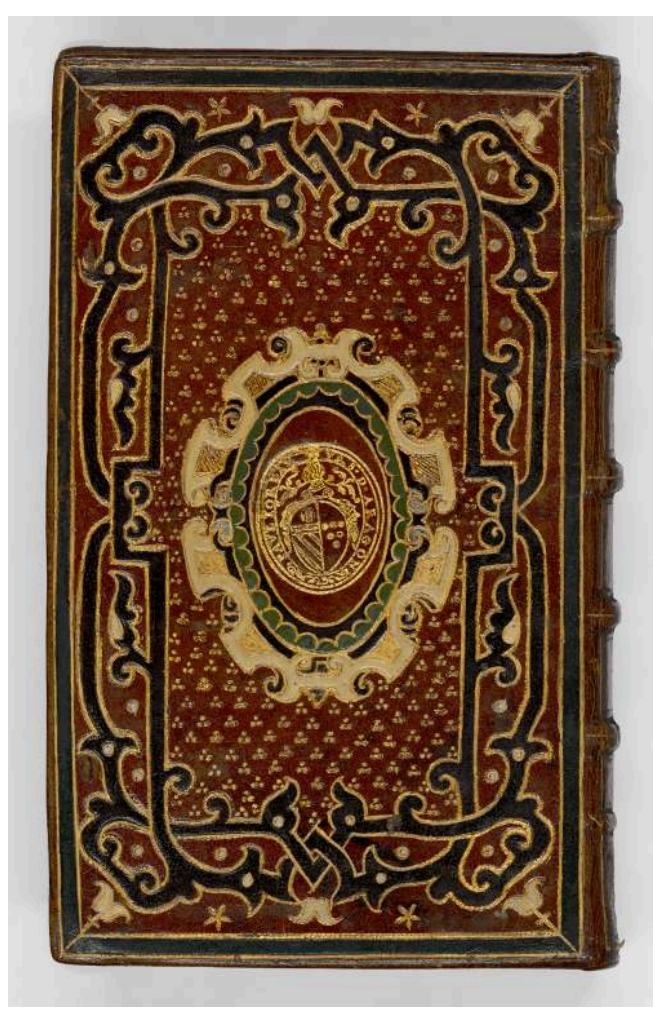

(c) Bibliothèque nationale de France

6 En effet, les exemplaires achetés par James Édouard exhibent souvent une reliure moderne, exécutée, dans la plupart des cas, par l'atelier de Georges Trautz, qui avait 
gardé le nom de l'entreprise qu'il avait fondée avec son beau-père, Antoine Bauzonnet. La prédilection pour les travaux issus de cet atelier était telle que, à la mort de Trautz en 1879, James Édouard en racheta tous les outils et les modèles pour les héberger dans sa résidence parisienne, sise avenue de Friedland ${ }^{11}$. Parmi les nombreux cas, nous pouvons citer l'exemplaire Rothschild de la première édition des Rime de Pietro Bembo, aux marges encore très larges ${ }^{12}$. Il présente une superbe reliure en maroquin cerise avec plusieurs encadrements aux plats, à sec ou en or, des petits fers dorés au dos et des gardes en papier marbré -, signée « Trautz-Bauzonnet » sur la marge inférieure du plat antérieur (fig. 2).

2. Pietro Bembo, Rime, s.n.t [Colophon : Venise, G.A. Sabbio, 1530], Paris, BnF, département des Manuscrits, Rothschild 1030. Plat supérieur de la reliure.

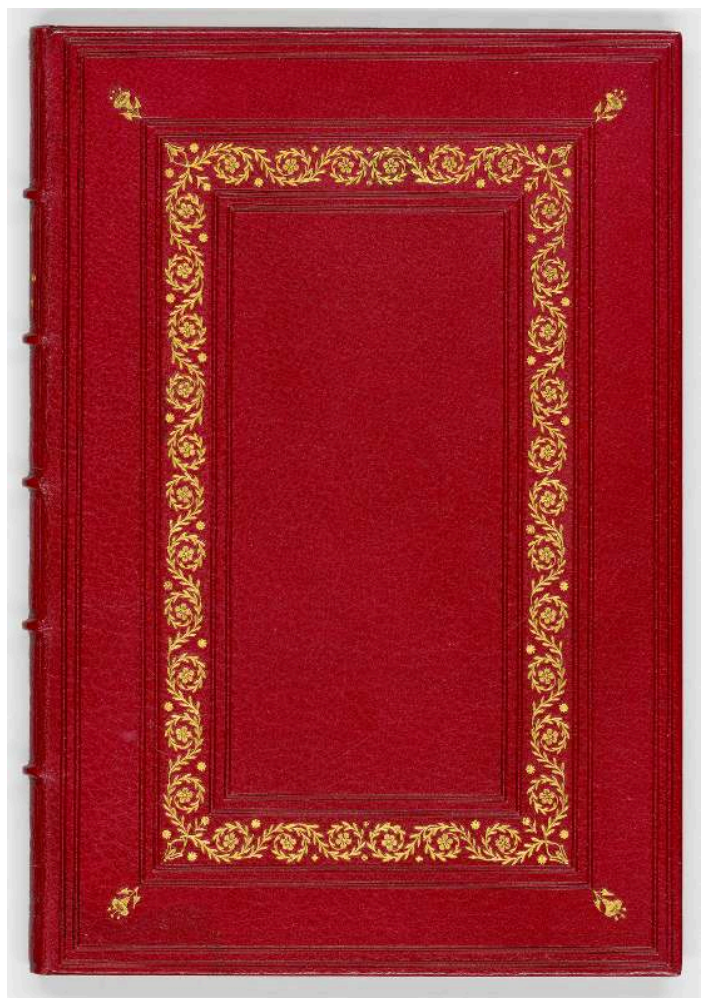

(c) Bibliothèque nationale de France

7 Le choix de décorer convenablement les exemplaires anciens ne concerne pas seulement les classiques de la littérature italienne, mais aussi des textes moins connus. Il convient d'évoquer l'exemplaire de l'édition milanaise de 1509 du recueil des Paesi novamente retrovati, texte relatant le voyage d'Amerigo Vespucci vers le continent américain, que l'on assigne, selon la tradition, à Fracanzio da Montalboddo (Rothschild 1950). La sobre reliure en maroquin rouge violet, elle aussi signée par les relieurs, ne présente aucun décor évident, tout en préservant, il faut le dire, une édition d'une certaine rareté, dont seulement quelques exemplaires sont aujourd'hui connus au monde ${ }^{13}$.

Plusieurs principes semblent donc s'associer au sein de l'ensemble des éditions italiennes, sans pour autant prédominer l'un sur l'autre : la qualité de la reliure; la provenance (ancienne ou moderne, par le biais de bibliophiles de renom); la rareté de l'édition. Ces critères étaient partagés avec les bibliophiles français de la même période, 
dont un grand nombre entretenait des relations régulières avec les Rothschild ${ }^{14}$. Plusieurs applications éloquentes de ces principes sont visibles au sein de la collection italienne : il suffira d'en rappeler une seule. À notre connaissance, le fonds Rothschild conserve le seul exemplaire connu au monde d'un recueil de textes poétiques intitulé Rufianela, non daté et pourtant - comme on le dira mieux par la suite - publié avant 1515 , avec une fausse attribution à Boccace ${ }^{15}$. Cette plaquette contient, entre autres, plusieurs compositions poétiques inconnues des études portant sur cette période de la poésie italienne. Ayant miraculeusement survécu aux dommages du temps, cette édition de seulement quatre feuillets montre tous les signes d'un " livre populaire » de la Renaissance italienne: format réduit, gravure de réemploi sur la page de titre, emploi de caractères gothiques pour le texte, recours à des genres poétiques destinés à un grand public (sonnet, barzelletta, capitolo, etc.). L'extrême rareté de l'édition s'allie à une provenance qui en augmente le caractère exceptionnel: comme la mention manuscrite à la fin du volume le confirme, il s'agit en effet d'un exemplaire provenant de la collection d'un illustre bibliophile, Fernando Colón (1488-1539), fils de Christophe Colomb. Selon une pratique courante, dont nous avons d'autres exemples parmi les volumes de sa bibliothèque, Colón a noté sur la marge inférieure du feuillet A4v le lieu et la date de l'achat (ce qui permet de préciser un terminus post quem pour l'édition), tout comme le prix de ce petit livre : «Este libro costò en Roma un quatrin por deziembre de 1515. Està registrado, $2320^{16} »$. L'exemplaire Rothschild fait partie d'un lot de volumes sortis de manière illégale de la Biblioteca Colombina de Séville (institution qui conserve l'important legs de Colón) autour de 1880, comme un chercheur de l'époque, Harry Harrisse, l'avait signalé1 ${ }^{17}$. Suite à cette dispersion, plusieurs exemplaires de Colón sont aujourd'hui conservés dans les fonds de nombreuses bibliothèques européennes : celui dont il est question, avant d'arriver entre les mains d'Henri de Rothschild, était passé par la collection du baron Jérôme Pichon (1812-1896), bibliophile de renom et président de la Société des bibliophiles français, qui fut aussi un intime de la famille Rothschild. Sans doute Pichon avait-il donné au volume la reliure que nous voyons encore aujourd'hui, exécutée vers la fin du XIX siècle par Léon Lemardeley. À l'occasion de la vente de la collection Pichon à Paris, en 1897, quelques mois après sa mort, Henri de Rothschild dut saisir la rareté de ce volume et l'acheta pour sa collection ${ }^{18}$, avec trois autres exemplaires provenant tous de l'ancienne collection de Colón ${ }^{19}$. L'intérêt pour les livres de ce dernier, souvent des éditions populaires devenues avec le temps d'une très grande rareté, continua par la suite: quelques années plus tard, au début des années 1900, il en acheta trois autres, dont un en langue italienne, lors de la vente aux enchères de la collection d'Eugène Paillet (1829-1901), ancien président de la Société des amis des livres et proche de James Édouard, et deux autres lors de celle d'Ernest Daguin (1817-1892), qui fut le fait de ses héritiers en $1905^{20}$. En suivant les traces d'un bibliophile de la Renaissance à travers la dispersion des collections des bibliophiles parisiens du XIX ${ }^{e}$ siècle, Henri de Rothschild façonna donc certains aspects de sa propre collection, en choisissant pour sa section italienne des objets au pedigree illustre.

\section{Exemplaires uniques et éditions populaires}

9 Ce cas n'est pas le seul à mettre à l'honneur la rareté, voire l'unicité, des ouvrages recherchés par les Rothschild dans le domaine italien. Ce critère de l'exemplaire unique, exceptionnel en raison de sa rareté, avait déjà été suivi par James Édouard de Rothschild, pour s'affiner, comme nous venons de le voir, avec les achats de son fils, 
Henri. Il semblerait même que cette attention aux unica se recentre autour de l'édition italienne de la Renaissance, puisque les deux collectionneurs montrent une prédilection très marquée pour les éditions populaires italiennes, destinées à une " consommation" vorace de la part de leurs lecteurs et donc à un taux de conservation extrêmement faible. À la différence de la plupart des bibliophiles de l'époque, qui formaient souvent des collections "belles-lettristes ", par exemple en réunissant toutes les éditions reconnues comme importantes d'une période donnée ou en créant un socle d'éditions de classiques, James Édouard et Henri de Rothschild s'intéressèrent aussi à des ouvrages à la nature bibliographique plus faible, souvent négligés par les collectionneurs et aujourd'hui presque introuvables dans les collections publiques internationales ${ }^{21}$.

Si l'on ajoute foi aux mots d'Émile Picot, la passion de James Édouard pour ces objets aurait commencé en Italie, pendant sa jeunesse, vers la moitié du XIX siècle, à l'occasion de ses vacances : à Venise, il aurait en effet « sauvé » plusieurs documents de ce genre, notamment «un millier de pièces, presque toutes italiennes, relatives à la bataille de Lépante ", allusion dans laquelle il est facile de reconnaître les nombreuses publications vénitiennes, presque toutes à caractère éphémère, qui relatent cet événement si marquant de la Renaissance italienne ${ }^{22}$. De nombreux éléments suggèrent que l'édition populaire italienne n'est pas un volet secondaire dans la formation de sa collection et de celle de ses héritiers. Au sein du catalogue Picot, un espace inhabituel est accordé à cette typologie éditoriale, avec une présence fort étonnante des sousgenres typiques de cette production: les recueils de textes poétiques destinés à une large diffusion, le récit d'événements extraordinaires, la chronique des faits concernant les guerres d'Italie, le lamento. Si l'on considère ce dernier sous-genre, nous remarquons que plusieurs items viennent de la collection de James Édouard, tel l'étonnant exemplaire de la Cosa nuova. El lamento universale di tutta Italia (Rothschild 1042, fig. 3). Ce faible lamento de 4 feuillets, imprimé en caractères gothiques, fut publié à Rome autour de 1520 , en reproduisant un texte déjà paru à plusieurs reprises au cours des années 1510 et relatant les événements historiques qui marquèrent la péninsule Italienne l'édition est cependant totalement inconnue des répertoires bibliographiques ${ }^{23}$. Accompagné par l'ex-libris de James Édouard ("Ex-Libris James de Rothschild»), l'exemplaire est fastueusement relié avec un maroquin bleu signé par Adolphe Cuzin, ce qui souligne la conscience qu'avait le collectionneur de la rareté de l'objet. En revanche, un exemplaire d'un autre lamento politique, imprimé quelques années plus tôt et que l'on attribue à Giovan Battista Dragoncino da Fano (Rothschild 1038, fig. 4), n'a pas été relié et il est conservé à présent dans une simple pochette en carton qui remonte au $\mathrm{XIX}^{\mathrm{e}}$ siècle $^{24}$. De façon similaire, l'exemplaire d'une édition non datée du Contrasto o vero battaglia de lo Carnovale et de la Quaresima (Rothschild 1027) est conservé dans un papier cartonné qui préserve des feuillets non reliés. Chose presque unique pour des exemplaires d'édition populaire du début du xvi siècle, ses marges n'ont pas été rognées, ce qui fait croire que l'exemplaire, acheté par James Édouard, apparaît aujourd'hui avec la physionomie qu'il possédait en sortant de l'imprimerie ${ }^{25}$. Malgré le traitement différent de la reliure, ces trois éditions partagent un caractère primordial : sauf erreur, il s'agit des seuls exemplaires connus au monde. Ces éditions doivent donc leur survivance bibliographique à l'intérêt de collectionneur de James Édouard Rothschild, qui a sauvé ces témoignages de l'oubli où plusieurs autres éditions similaires sont tombées, en les faisant parvenir jusqu'à nos jours. 
3. Cosa nova. El lamento de Italia universale, e come Italia se lamenta de la morte de li soi famosissimi figlioli romani [...], Rome, s.n., s.d. [1520?], Paris, BnF, département des Manuscrits, Rothschild 1042. Page de titre.

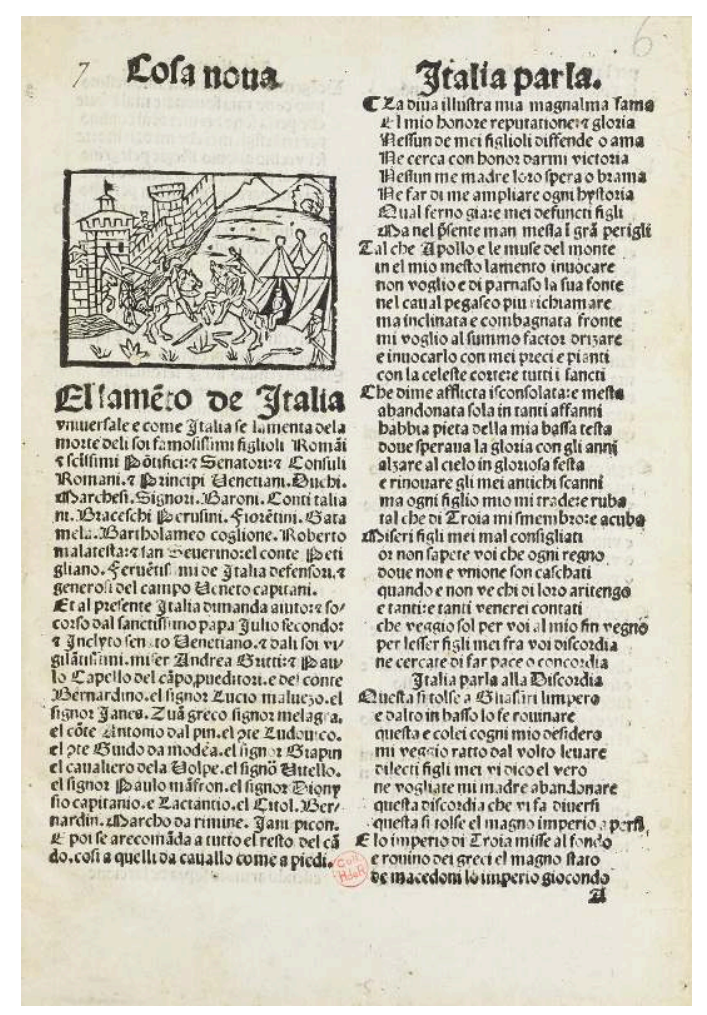

(c) Bibliothèque nationale de France 
4. Giovan Battista Dragoncino da Fano, Lamento de lo sfortunato reame de Neapoli, s.n.t. [Venise, 1504?], Paris, BnF, département des Manuscrits, Rothschild 1038. Page de titre.

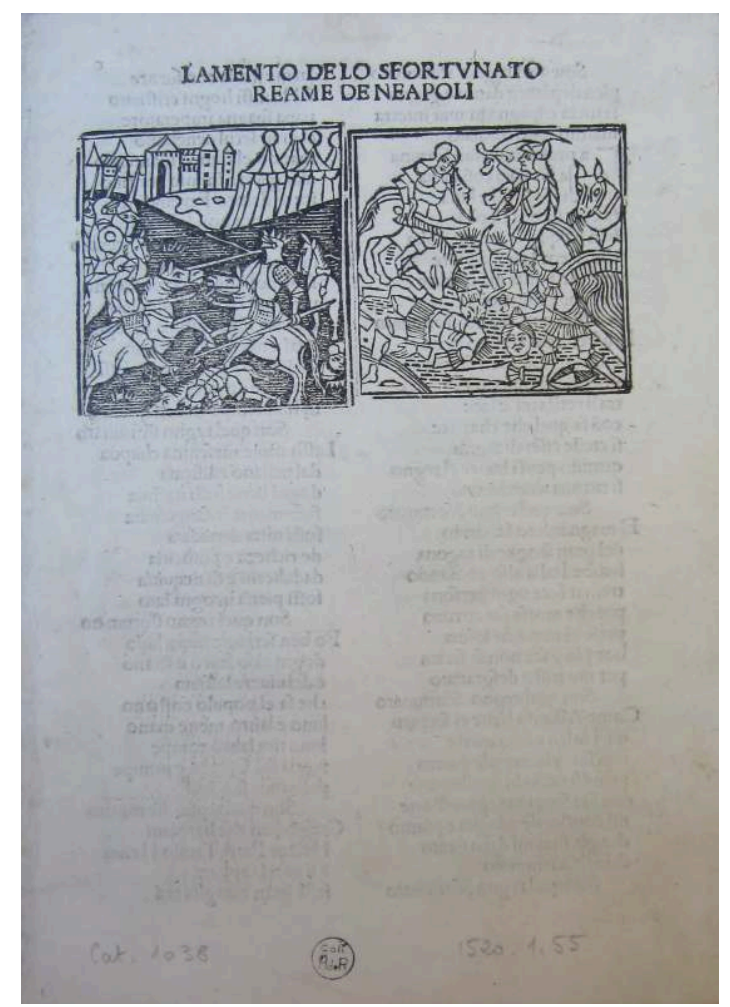

(c) Carlo Alberto Girotto

11 Ces détails concernant la conservation matérielle de ces opuscules de la collection Rothschild ne sont pas anecdotiques : au contraire, ils nous permettent de saisir la faible distance qui existe entre l'état d'origine de l'exemplaire et ses conditions actuelles, ce qui est un point qualifiant pour tout bibliophile. Tout en gardant un véritable intérêt pour ce même genre éditorial, Henri de Rothschild proposa des modalités de conservation plus conformes à la qualité, souvent modeste, de ces publications. L'exemplaire qu'il acheta du Gran lamento che fa Turchetto e Triultio (fig. 5), texte parodique composé à Rome vers la moitié du Cinquecento, est conservé aujourd'hui dans une pochette de papier plus épais, et les feuillets sont réunis par une ficelle assez grossière ${ }^{26}$, selon une pratique qui devait être d'origine et que l'on retrouve, entre autres, dans la plaquette Consiglio e deliberatione del Tevere con gli altri fiumi suoi vassalli d'innondar Roma, publiée à Rome après la violente crue du Tibre qui eut lieu en $1557^{27}$. Les exemplaires Rothschild sont les seuls connus aujourd'hui au monde : cela n'est pas sans conséquence, puisque cette constellation d'unica non seulement modifie nos connaissances sur certains ateliers d'éditeurs, mais nous invite également à considérer les plus larges implications que la bibliophilie des Rothschild a eues dans la conservation de la mémoire écrite de l'édition de la Renaissance italienne ${ }^{28}$. 
5. Il gran lamento che fa Turchetto e Triultio, hosti di Roma, perché $i$ maritati non possono andar più all'hostaria [...], s.n.t. [Rome, 1556?], Paris, BnF, département des Manuscrits, Rothschild 3303. Page de titre.

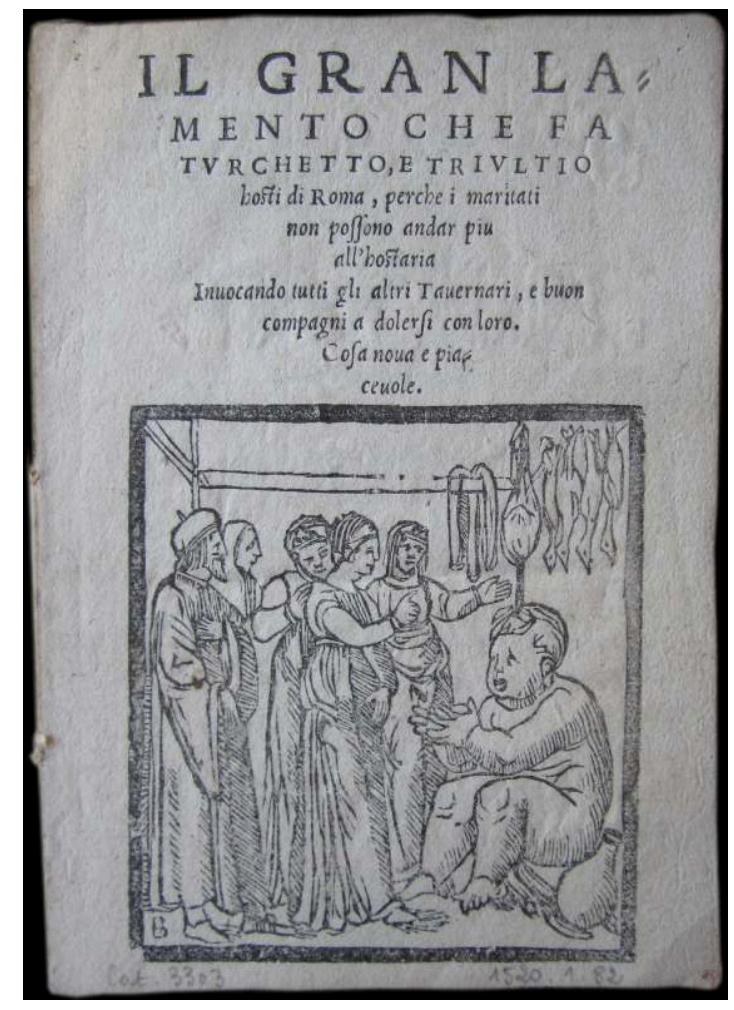

(c) Carlo Alberto Girotto

12 Le parcours que nous venons de proposer est partiel et incomplet. De nouvelles recherches seront nécessaires afin de préciser la chronologie, les moyens et les circonstances de ces acquisitions au sein de la bibliothèque créée par James Édouard Rothschild, sa femme, Laura-Thérèse, et leur fils, Henri, et afin de déterminer le rôle joué par chacune des personnes évoquées. Il est néanmoins possible de percevoir, même à partir des quelques documents ici présentés, le caractère unique de la section italienne de la collection Rothschild. La présence de ces objets nous oblige à nous demander si ces pratiques d'achat et de collectionnisme sont proches de celles d'autres collectionneurs de la même période (il suffit de penser aux collections réunies, lors de ce même tournant historique, par le duc d'Aumale ou par Victor Masséna, prince d'Essling). Il faudra aussi préciser quel est le rôle d'Émile Picot dans la construction de cette collection, au vu de son réseau assez étendu de connaissances parmi les chercheurs de l'époque, intéressés par ces mêmes sujets. À l'évidence, il y a ici la prise de conscience précoce de l'importance de ces témoignages parfois " périphériques » de l'édition italienne, y compris les éditions au caractère éphémère. En approfondissant les questions soulevées par cette piste de recherche, il sera possible de mieux comprendre le rôle primordial du collectionnisme des Rothschild dans la conservation de documents fondamentaux pour la mémoire culturelle de la Renaissance italienne. 


\section{NOTES}

1. Christopher de Hamel, Les Rothschild collectionneurs de manuscrits, Paris, BnF Éditions, 2004 ; Harry W. Paul, « La bibliothèque léguée par Henri de Rothschild, œuvre de plusieurs générations de bibliophiles ", dans Claude Collard et Mélanie Aspey (dir.), Les Rothschild en France au XIX ${ }^{e}$ siècle, cat. exp. (Paris, Bibliothèque nationale de France, 2012-2013), Paris, BnF, 2012, p. 163-177 ; Geneviève Guilleminot-Chrétien, «Livres et estampes, 1922 », dans Pauline Prevost-Marcilhacy (dir.), Les Rothschild. Une dynastie de mécènes en France, 3 vol., Paris, Louvre/BnF/Somogy, 2016, vol. II, p. 164-175 ; Isabelle de Conihout, « Les livres illustrés », ibid., vol. III, p. 172-191; Catherine Faivre d'Arcier, «La bibliothèque de James Édouard de Rothschild, 1844-1881 », ibid., vol. III, p. 228-263. Je renvoie aussi aux documents publiés sur la base de données «Les collections Rothschild dans les institutions publiques françaises" (consultable ici : collections.rothschild.inha.fr/fr/index.html), qui présentent des approfondissements très utiles sur plusieurs aspects ponctuels.

2. Sur ce manuscrit, dont les trois autres volumes sont conservés à la Bibliothèque ambrosienne de Milan, voir Franco Tomasi, «Giovan Giorgio Trissino", dans Autografi dei letterati italiani. Il Cinquecento, 2 vol., Roma, Salerno Editrice, 2013, t. II, p. 369-385 et spéc. p. 370.

3. [Émile Picot], Catalogue des livres composant la bibliothèque de feu M. le Baron James de Rothschild, 5 vol., Paris, D. Morgand libraire, 1884-1920.

4. Je fais allusion aux collections de Salomon et Edmond de Rothschild, qui ont été récemment étudiées : voir Geneviève Guilleminot-Chrétien, «Livres et estampes, 1922 », art. cit., et Isabelle de Conihout, «Les livres illustrés ", art. cit.

5. Sur ce point de l'histoire de la collection Rothschild et sur le rôle joué par Laura-Thérèse, voir Édouard Rahir, "La bibliothèque James de Rothschild et son catalogue », dans Revue des bibliothèques, $\mathrm{n}^{\text {os }}$ 30-31, 1921, p. 1-14 et spéc. p. 3 ; Christopher de Hamel, Les Rothschild collectionneurs de manuscrits, op. cit., p. 95-104 ; Catherine Faivre d'Arcier, «La bibliothèque de James Édouard de Rothschild, 1844-1881 ", art. cit., p. 228.

6. Paolo Giovio, La vita di Consalvo Ferrando di Cordova detto il gran capitano [...] tradotta per Lodovico Domenichi, in Fiorenza, [Lorenzo Torrentino], 1550 (Émile Picot, Catalogue des livres, op. cit., vol. III, $\mathrm{n}^{\circ} 2510$, p. 264). Cette édition correspond au code CNCE 21171, fourni par la base de données «Edit16. Censimento nazionale delle edizioni italiane del XVI secolo» (edit16.iccu.sbn.it, dorénavant notée Edit16), code numérique qui sera aussi indiqué pour les autres éditions dont nous parlerons par la suite.

7. Voir Barbara Furlotti, A Renaissance Baron and his Possessions. Paolo Giordano I Orsini, Duke of Bracciano (1541-1585), Turnhout, Brepols, 2013.

8. La provenance française des reliures des exemplaires Orsini a été suggérée par Federico et Livio Macchi, « Le legature francesi di Paolo Giordano Orsini d'Aragona (1537-1585) : storia di un personaggio e di una legatura ", dans L'Esopo, XXXIX, 2007, n 111-112, p. 41-56 et spéc. p. 53-54. Voir aussi Carlo Alberto Girotto, « Da tre biblioteche parigine per Lodovico Domenichi, autore ed editore ", dans Bollettino storico piacentino, CX, 2015, nº 1, p. 98-119 et spéc. p. 108-109.

9. Paris, BnF, département des Manuscrits, Rothschild 1031 (Émile Picot, Catalogue des livres composant la bibliothèque de feu M. le Baron James de Rothschild, op. cit., t. I, $\mathrm{n}^{\circ} 1031$, p. 656, avec reproduction de la reliure; Edit16, CNCE 13329). La provenance libre de cet exemplaire est assurée par le Catalogue de la bibliothèque de $M . L^{* * *}$, dont la vente se fera le 28 juin 1847 , et les vingtneuf jours suivants, Paris, L.C. Silvestre et P. Jannet, 1847, nº 1003, p. 153.

10. James Édouard se défaisait souvent des anciennes reliures, comme le déplorait Édouard Rahir dans «La bibliothèque James de Rothschild et son catalogue », art.cit., p. 11-12: "Il était également très difficile sur l'état extérieur des livres : il les voulait beaux et bien habillés [...]. 
Lorsque la reliure primitive n'était pas suffisante, il n'hésitait pas à faire relier le livre à nouveau. »

11. Voir Émile Picot, Catalogue des livres, op. cit., t. I, p. XVI ; Harry W. Paul, « La bibliothèque léguée par Henri de Rothschild, œuvre de plusieurs générations de bibliophiles », art. cit., p. 165-166 ; et Catherine Faivre d'Arcier, «La bibliothèque de James Édouard de Rothschild, 1844-1881 ", art. cit., p. 252.

12. Pietro Bembo, Rime, s.n.t. [Colophon : Venise, G.A. Sabbio, 1530], Paris, BnF, département des Manuscrits, Rothschild 1030 (Émile Picot, Catalogue des livres, op.cit., t. I, nº 1030 p. 656 ; Edit16, CNCE 5002). L'exemplaire ne porte pas d'ex-libris de James Édouard, mais, en raison de la mention des deux relieurs, il fut sûrement acheté avant 1879, date de la mort de Trautz.

13. Paris, BnF, département des Manuscrits, Rothschild 1950 (Émile Picot, Catalogue des livres, op. cit., t. II, no 1950 p. 426-428 ; Edit16, CNCE 54523). Voir aussi Luigi Balsamo, Giovann'Angelo Scinzenzeler tipografo in Milano, 1500-1526. Annali e bibliografia, Firenze, Sansoni Antiquariato, 1959, $\mathrm{n}^{\circ}$ 72, p. 102-103. Comme pour l'exemplaire précédent, faute d'ex-libris, l'achat de la part de James Édouard est certain grâce à la signature des relieurs.

14. Les trois critères que l'on vient de rappeler sont à la source, par exemple, des choix qui ont façonné la collection du baron Jérôme Pichon, dont nous parlerons par la suite : voir Catalogue des livres rares et précieux, manuscrits et imprimés, de la bibliothèque de M. le Baron J. ${ }^{* * * * *}$, Paris, L. Potier, 1869 , p. VII-IX.

15. Rufianela de miser Ioanne Bocazo, con una barzeletta e sonetti e cancione e capituli novamente azonti, s.n.t., Paris, BnF, département des Manuscrits, Rothschild 2998 (Émile Picot, Catalogue des livres, op. cit., t. IV, n² 2998, p. 354-355). L'édition, qui manque à la base de données Edit16, date sans doute des années 1510 et reproduit probablement une édition plus ancienne datant des années 1490 (ISTC ib00760500).

16. Le chiffre final renvoie à l'inventaire de la collection, rédigé par Colón lui-même, sous le titre de Registrum librorum don Ferdinandi Coloni et conservé à Séville, Biblioteca Colombina y Capitular, ms. 905, n' 2320, f. [48]v. De cet inventaire, nous disposons aussi d'un fac-similé : Archer Milton Huntington, Catalogue of the Library of Ferdinand Colombus. Reproduced in Facsimile from the Unique Manuscript in the Columbine Library of Seville, New York, s.n., 1905.

17. Voir Henry Harrisse, Excerpta Colombiniana. Bibliographie de quatre cents pièces gothiques françaises, italiennes et latines du commencement $d u \mathrm{XVI}^{e}$ siècle non décrites jusqu'ici, Paris, H. Welter, 1887, p. 44-53. Pour la dispersion des volumes de Colón, voir Edoardo Barbieri, «Tra gli stampati antichi della Trivulziana: noterelle a tre pezzi unici, a una miscellanea colombina e a una contraffazione cinquecentesca», dans Libri e Documenti, XVII, 1992, n 2, p. 66-74 et spéc. p. 70-72.

18. Voir Catalogue de la Bibliothèque de feu M. le Baron Jérôme Pichon, Président honoraire de la Société des Bibliophiles françois [sic]. Première partie. Livres rares et précieux, manuscrits et imprimés, Paris, Librairie Techener, 1897, n 924, p. 269.

19. Il s'agit des exemplaires Rothschild 2829 bis, 3011 et 3134 (Émile Picot, Catalogue des livres, op. cit., t. IV, $\mathrm{n}^{\circ} 2829$ bis, p. 162-163; t. IV, $\mathrm{n}^{\circ} 3011$, p. 378-380; t. IV, $\mathrm{n}^{\circ} 3134$, p. 514) de trois éditions lyonnaises que l'on peut dater autour de 1530 . Les trois volumes correspondent à ceux signalés dans le Catalogue Pichon, 1897, n 772, p. 222 ; n 939, p. 273 ; et $n^{\circ} 1416$, p. 405.

20. L'exemplaire Rothschild 2809, venant de la collection Pichon déjà citée (voir Catalogue Pichon, op. cit., $\mathrm{n}^{\circ} 758$, p. 218-219), fut acheté à l'occasion de la vente Paillet en 1902 : voir La Bibliothèque de feu M. Eugène Paillet. Première partie, Paris, Librairie E. Rahir, 1902, n 23, p. 14. Viennent de la collection Daguin les exemplaires Rothschild 3021 et 3058 (Émile Picot, Catalogue des livres, op. cit., t. IV, $\mathrm{n}^{\circ}$ 3021, p. 393-395; et $\mathrm{n}^{\circ} 3058$, p. 411-416) : voir Catalogue de beaux livres rares et précieux, anciens et modernes, ayant appartenu à $M^{r}$ E. Daguin, ancien président du tribunal de Commerce, officier de la Légion d'honneur, Paris, A. Durel, 1905, t. IV, nº 1243, p. 34, et nº 1238, p. 32-33.

21. Voir Catherine Faivre d'Arcier, «La bibliothèque de James Édouard de Rothschild, 1844-1881", art. cit., p. 252-253. Une inversion de la tendance commence, justement, à se 
manifester dans la seconde moitié du XIX ${ }^{\mathrm{e}}$ siècle, comme le montre la riche section dédiée à ces documents dans le Catalogue Libri, 1847, p. 224-233.

22. Émile Picot, Catalogue des livres, op. cit., t. I, p. III ; voir aussi Catherine Faivre d'Arcier, « La bibliothèque de James Édouard de Rothschild, 1844-1881», art. cit., p. 231. Pour les placards publiés au lendemain de la bataille de Lépante, voir Dennis E. Rhodes, «La battaglia di Lepanto e la stampa popolare a Venezia. Studio bibliografico ", Miscellanea Marciana, vol. X-XI, 1995-1996, p. 9-63, et Ugo Rozzo, «La battaglia di Lepanto nell'editoria dell'epoca e una miscellanea fontaniniana ", Rara volumina, vol. VII, 2000, p. 41-69. Voir aussi dans ce même volume, Laura de Fuccia « James Édouard de Rothschild à Venise... ».

23. Émile Picot, Catalogue des livres, op. cit., t. I, no 1042 p. 660-661. Sur ce genre voir l'importante recherche de Florence Alazard, Le Lamento dans l'Italie de la Renaissance. "Pleure, belle Italie, jardin du monde », Rennes, PUR, 2010.

24. Giovan Battista Dragoncino da Fano, Lamento de lo sfortunato reame de Neapoli, s.n.t. [Venise, 1504 ?], Paris, BnF, département des Manuscrits, Rothschild 1038 (Émile Picot, Catalogue des livres, op. cit., t. I, no 1038, p. 659). Une édition similaire, qui présente un texte plus long, est conservée à la Biblioteca nazionale Marciana de Venise : voir Bibliografia delle stampe popolari italiane della $R$. Biblioteca nazionale di S. Marco di Venezia, per cura di Arnaldo Segarizzi, Bergamo, Istituto italiano d'arti grafiche, 1913, $\mathrm{n}^{\circ}$ 152, p. 134 (Edit16, CNCE 50659).

25. Émile Picot, Catalogue des livres, op. cit., t. I, n 1027, p. 654 ; l'édition manque à Edit16. L'intérêt de James Édouard pour ce texte devait être assez vif, comme le montre son recensement des éditions italiennes du Contrasto publié dans Anatole de Montaiglon et James de Rothschild (dir.), Recueil de poésies françoises des $\mathrm{XV}^{e}$ et $\mathrm{XVI}^{e}$ siècles. Morales, facétieuses, historiques, 13 vol., Paris, Paul Daffis, 1875, t. X, p. 111-115. L'exemplaire contient aussi les épreuves de trois textes anciens en langue italienne, tirées d'une édition et corrigées par une main que je n'ai pas pu identifier.

26. Il gran lamento che fa Turchetto e Triultio, hosti di Roma, perché i maritati non possono andar più all'hostaria [...], s.n.t. [Rome, 1556 ?], Paris, BnF, département des Manuscrits, Rothschild 3303 (Émile Picot, Catalogue des livres, op. cit., t. V, n³ 3303, p. 87-88). L'édition manque à Edit16.

27. Consiglio e deliberatione del Tevere con gli altri fiumi suoi vassalli d'innondar Roma [...], s.n.t. [Rome, post 1557 ?], Paris, BnF, département des Manuscrits, Rothschild 3305 (Émile Picot, Catalogue des livres, op. cit., t. V, n 3305, p. 88-89). L'édition manque à Edit16.

28. Sur cette question, voir Neil Harris, "L' unicum in biblioteca: per un'analisi della sopravvivenza del libro antico ", dans Neil Harris (dir.), Gli incunaboli e le cinquecentine della Biblioteca Comunale di San Gimignano, 2 vol., San Gimignano, Città di San Gimignano, 2007, t. II, p. 51-64; id., «La sopravvivenza del libro, ossia appunti per una lista della lavandaia », dans Ecdotica, IV, 2007, p. 24-65 ; Andrew Pettegree, «The Legion of the Lost. Recovering the Lost Books of Early Modern Europe", dans Flavia Bruni et Andrew Pettegree (dir.), Lost Books. Reconstructing the Print World of Pre-Industrial Europe, Leiden, Brill, 2016, p. 1-27.

\section{INDEX}

Index géographique : France, Italie

Index chronologique : Renaissance, XIXe siècle

Thèmes : Bibliophilie, collections, Rothschild 


\title{
James Édouard de Rothschild à Venise : un jeune bibliophile face à la dispersion des collections de la famille Mocenigo
}

\author{
Laura de Fuccia
}

\begin{abstract}
Dans sa biographie de James Édouard de Rothschild (1844-1881) (fig. 1)1, Émile Picot nous renseigne sur des séjours vénitiens prolongés du jeune baron, pendant ses vacances d'été, à l'époque où il était étudiant à la faculté de droit de Paris : «Après avoir passé dix mois de l'année dans un labeur assidu, il prenait généralement ses vacances en Italie, de préférence à Venise. "Ces souvenirs datent des années 1862-1865 ; James Édouard aurait alors profité de ces vacances vénitiennes pour visiter les «musées » et explorer les «boutiques des libraires ». Ce n'est que par cette même source que nous apprenons qu'il aurait acquis à cette époque les archives de la famille Mocenigo pour les sauver de la dispersion, en en faisant don, vraisemblablement dès les années 1860, à la bibliothèque de la Sorbonne à Paris. Cette acquisition, présentée par Émile Picot comme un engagement précoce de James Édouard dans la sauvegarde d'ensembles et de collections notables ( «l lui arriva plusieurs fois de sauver de la dispersion des collections précieuses ${ }^{3} »$ ), livre un témoignage capital sur les intérêts du jeune James Édouard, nous renseignant par la même occasion sur la dispersion des archives d'une famille dont l'histoire est étroitement liée à celle de la Sérénissime. Les Mocenigo ont en effet occupé des charges de premier plan au sein des institutions de la République, sept des membres des diverses branches de la famille ayant même été élus doges au fil du temps, entre le $\mathrm{XV}^{\mathrm{e}}$ et le XvIII ${ }^{\mathrm{e}}$ siècle $^{4}$.
\end{abstract}


1. Pierre Petit, James Édouard de Rothschild, 1881, Paris, Bibliothèque nationale de France, département Société de géographie, SG PORTRAIT-344.

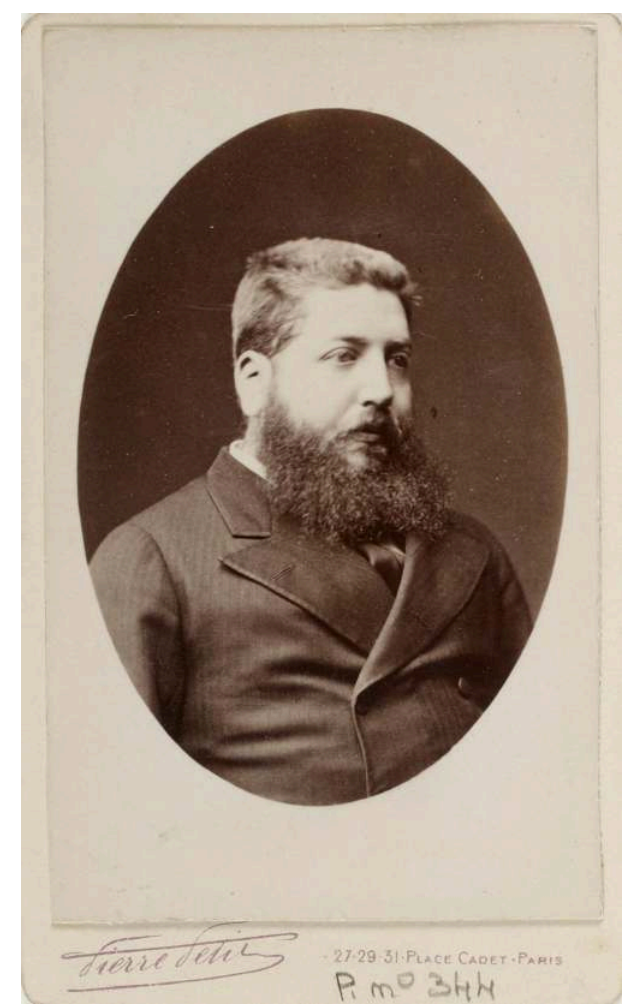

(c) Bibliothèque nationale de France

Les registres de la bibliothèque de la Sorbonne étant lacunaires pour les années 1860, ce don, pourtant prestigieux, n'est pas mentionné dans ses archives où l'on ne trouve par ailleurs qu'un seul manuscrit explicitement rattaché à la famille Mocenigo ${ }^{5}$. Le récit d'Émile Picot nous a néanmoins permis d'identifier ces documents avec un ensemble de manuscrits encore conservé dans la réserve de la bibliothèque et dont la provenance était jusqu'alors considérée comme inconnue. Il s'agit d'un corpus de 81 volumes - mss. 464-545 -, de contenu à première vue cohérent par sa thématique "vénitienne », mais paradoxalement hétérogène, dès que l'on examine l'ensemble de près, par la nature des documents.

Cet article se propose de fournir quelques pistes de réflexion et d'analyse de ce fonds, qui nous renseigne de manière inédite sur l'une des familles les plus en vue de l'histoire de la Sérénissime, mais aussi sur la sensibilité bibliophilique précoce développée par James Édouard et sur les liens que la famille Rothschild tisse avec le milieu culturel lagunaire dès la fin du XIX ${ }^{e}$ siècle.

Fils aîné de Nathaniel (1812-1870) et de Charlotte de Rothschild (1825-1899), artiste elle-même, collectionneuse et mécène, James Édouard est très tôt introduit par sa mère tant auprès d'artistes que de la plupart des grands bibliophiles de son époque ${ }^{6}$. C'est sans doute aussi Charlotte qui l'oriente vers Venise, devenue sujet de prédilection de ses propres aquarelles dans ces mêmes années 1860, comme en témoignent les Barques à l'angle d'un canal sur la lagune de Venise (fig. 2) ou la Vue de Venise, acquise par l'État et attribuée au musée du Luxembourg en $1886^{7}$. Érudit raffiné, auteur, mais aussi éditeur, James Édouard est à l'origine d'une très importante collection de livres anciens et de reliures, léguée à la Bibliothèque nationale de France par ses héritiers ${ }^{8}$. Le don à la 
bibliothèque de la Sorbonne, alors que le jeune juriste n'avait que $20 \mathrm{ans}^{9}$ et qu'il n'avait pas encore intégré la banque familiale aux côtés d'Alphonse, Gustave, Edmond et Arthur de Rothschild, constitue donc l'un des premiers témoignages du mécénat de James Édouard, qui disparut précocement à l'âge de 36 ans. Il nous offre par ailleurs des informations inédites sur l'enrichissement des collections de la bibliothèque de la Sorbonne à une époque sur laquelle nous manquons presque totalement d'informations ${ }^{10}$.

2. Charlotte de Rothschild, Barques à l'angle d'un canal sur la lagune de Venise, c. 1860, aquarelle sur papier, 54 x $78 \mathrm{~cm}$, La Tronche, musée Hébert, $\mathrm{n}^{\circ}$ inv. H.U.80/31.

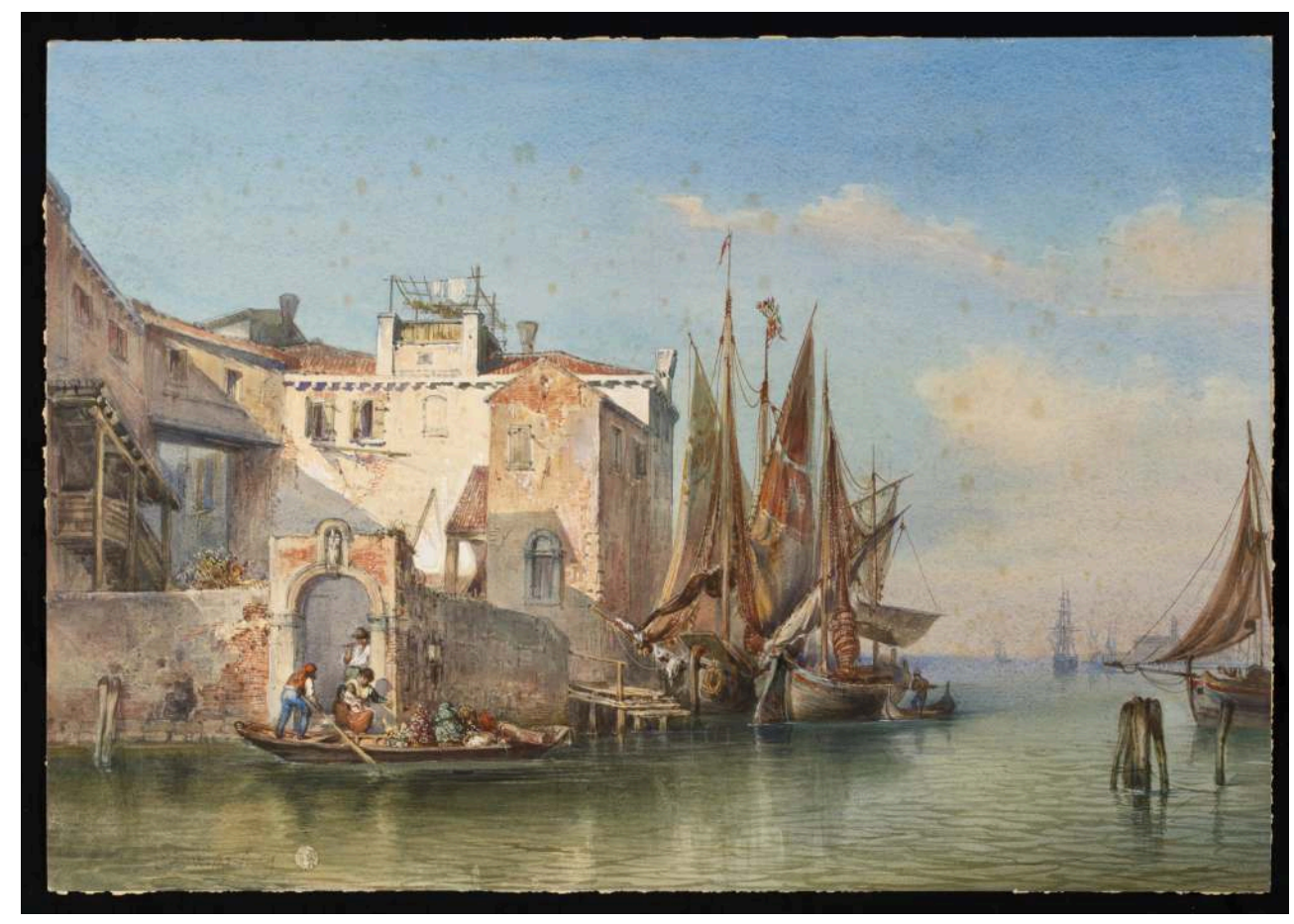

(c) Musée Hébert/Département de l'Isère

\section{Les archives Mocenigo à la bibliothèque de la Sorbonne}

Lorsqu'en 1918 ce corpus de 81 manuscrits est mentionné pour la première fois dans le catalogue général de la bibliothèque de l'Université de Paris ${ }^{11}$, il est répertorié sans distinction à la suite d'autres documents et couvre une partie non négligeable des collections alors conservées par cette institution. Celle-ci s'enrichit considérablement à partir du 1er février 1865, à la suite d'un arrêté du ministre de l'Instruction publique du 15 décembre 1864 qui lui destine une partie importante des archives de l'ancienne Université12 . Au moment de son don, James Édouard entend sans doute contribuer à cette phase du développement de la bibliothèque de la Sorbonne, qui sera réglementée par l'«Instruction générale relative au service des bibliothèques universitaires » du 4 mai 1878, destinée à valoriser les universités en tant que centres d'études et de recherche à part entière ${ }^{13}$. La démarche de James Édouard se situe, y compris symboliquement, dans une lignée prestigieuse, car son don de manuscrits suit le legs 
capital de livres imprimés, autographes et manuscrits fait par le célèbre philosophe et bibliophile Victor Cousin (1792-1867) à la bibliothèque de la Sorbonne, en $1863^{14}$.

\section{Le corpus}

6 Nous proposons de distinguer dans ce corpus de manuscrits donnés par James Édouard deux parties, faisant abstraction de l'actuel ordre de classement du fonds qui devrait dater du début du $\mathrm{Xx}^{\mathrm{e}}$ siècle $^{15}$. Un premier ensemble se distingue par son rattachement à la sphère publique, relatant notamment l'histoire de la République de Venise et de ses institutions; un second relève d'une dimension privée, liée à un certain nombre de familles de l'aristocratie vénitienne. Il n'est par ailleurs pas étonnant que ces deux aspects coexistent dans un fonds d'archives qui émanerait d'une prestigieuse famille dont l'histoire est inévitablement amenée à se confondre avec celle de la République. Dans cette perspective, nous pouvons évoquer le témoignage du noble vénitien Marco Foscarini (1696-1763), bibliothécaire de la Marciana et doge de la République entre 1762 et 1763. Dans son autobiographie, ce dernier défend la nécessité de se former à la sagesse civile et politique ${ }^{16}$ et souligne l'importance des études historiques pour les hommes voués à gérer la République, conseillant explicitement de constituer une collection d'ouvrages imprimés et de manuscrits qui puissent être utiles à ces fins. Ces archives Mocenigo pourraient donc s'apparenter à un fonds de références, de sources d'étude et de travail, ayant appartenu à une famille qui l'aurait aussi tout naturellement enrichi de documents plus strictement issus de l'histoire familiale.

\section{L'histoire de la République de Venise, de ses institutions et de son gouvernement}

7 Une partie de ces documents retracent plus particulièrement l'histoire de la ville depuis sa fondation (ms. 464); d'autres sont de nature militaire (xvIII ${ }^{\mathrm{e}}$-XIX ${ }^{\mathrm{e}}$ siècle, mss. 477-478, mss. 494-495, ms. 518) ${ }^{17}$, administrative ${ }^{18}$, diplomatique (ms. 531) ou juridique. Quelques-uns concernent spécifiquement le fonctionnement d'institutions de la République, telles que le Conseil des Dix ${ }^{19}$ - un comité exécutif et judiciaire créé dès 1310 - ou le Magistrat des eaux - institution créée en 1501 pour veiller à la gestion de la lagune ${ }^{20}$. D'autres, documents juridiques et correspondance administrative, concernent l'administration des villes des provinces de la Terre Ferme, appartenant alors à la République de Venise: Brescia ${ }^{21}$, Vérone ${ }^{22}$, Padoue, Bergame ${ }^{23}$, Trévise $^{24}$ ou Split ${ }^{25}$. Dans ce corpus, une place importante est tout particulièrement accordée à la législation fiscale de la Sérénissime.

8 Il est ainsi à signaler une histoire de la fiscalité écrite par le patricien Alessandro Priuli (1732-1807) intitulée Storia delle antiche gravezze, dadie, tanse di genti di arme, alloggi di cavalleria o sia ordine di banca, o sia foraggi per la milizia equestre, scritta dal N. U. e Alessandro Priuli, avvocato fiscale della serenissima Signoria (fig. 3). Ce titre porté sur le ms. 498 est significatif car cet ouvrage se révèle n'être qu'un fragment d'un recueil plus vaste, demeuré inédit, de lois fiscales couvrant une large période de l'histoire de la République, $d u \mathrm{XV}^{\mathrm{e}}$ au $\mathrm{XVIII}^{\mathrm{e}}$ siècle, et rédigé par Alessandro Priuli ${ }^{26}$, probablement à partir de l'année 1784, date à laquelle il devient avocat fiscaliste de la République de Venise, et ce jusqu'à sa mort en 1807. Il n'est donc pas absurde d'associer au ms. 498 
une suite d'autres pièces manuscrites et imprimées relatives aux "gravezze » [impôts] de Venise, notamment les mss. 499-508. Par leur manière de traiter le thème de la fiscalité et parce que classés à la suite des premiers, d'autres manuscrits pourraient en outre être rattachés au même ouvrage ${ }^{27}$ : il s'agit des mss. 509-516 - huit volumes consacrés à la fiscalité des couvents pour la période 1781-1784, dates qui correspondraient à la période d'activité de Priuli -, mais aussi, très probablement, des mss. 540-542. Ainsi, au total, au moins 19 des 81 manuscrits de la Sorbonne concernent spécifiquement la fiscalité et devraient renvoyer au recueil Priuli, désormais conservé dans un état fragmentaire.

3. Alessandro Priuli, « Storia delle antiche gravezze [...] », t. I, [Venise, après 1784], Paris, Bibliothèque de la Sorbonne, ms. 498.

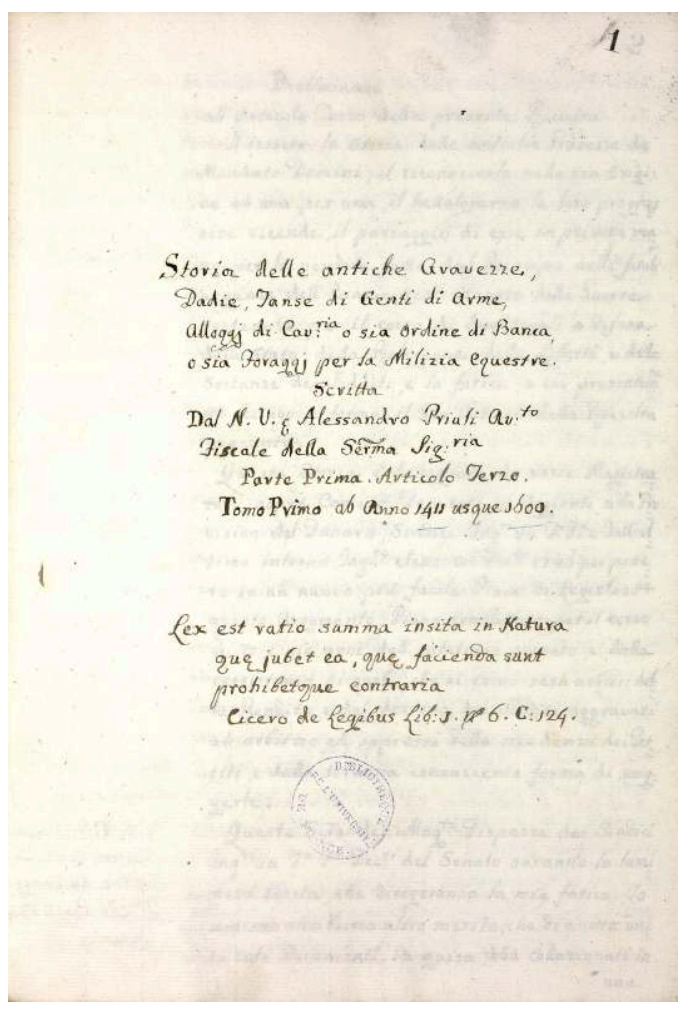

(C) Bibliothèque de la Sorbonne

Car de son caractère lacunaire témoignent quelques indices. Le ms. 498, divisé en plusieurs parties, n'est par exemple manifestement qu'un troisième « chapitre » d'une première partie (« Parte Prima. Articolo terzo. Tomo primo, ab anno 1411 usque 1600 », fol. 1), suivie par d'autres parties consacrées aux lois fiscales des provinces vénitiennes ${ }^{28}$. Il suggère donc l'existence d'au moins deux chapitres précédents (un «articolo primo » et un "articolo secondo » d'une première partie) dont il n'y a pas trace à la bibliothèque de la Sorbonne, mais qui renvoient à des manuscrits aujourd'hui conservés à la bibliothèque du musée Correr à Venise qui possède un deuxième ensemble significatif de ce même recueil Priuli (mss. Correr 564-684, fig. 4) ${ }^{29}$. À ces deux ensembles, nous pouvons également désormais rattacher un autre volume de ce même recueil tout récemment acheté, en 2019, par la faculté de droit de l'université de Californie, Berkeley School of Law (fig. 5) ${ }^{30}$. 
4. Alessandro Priuli, « Raccolta in proposito della pesca del pesce novello dall'anno 1314 sino all'anno 1699 » [Recueil sur la fiscalité concernant la pêche], vol. 4, t. I [Venise, après 1784], Venise, Bibliothèque Correr, ms. 564.

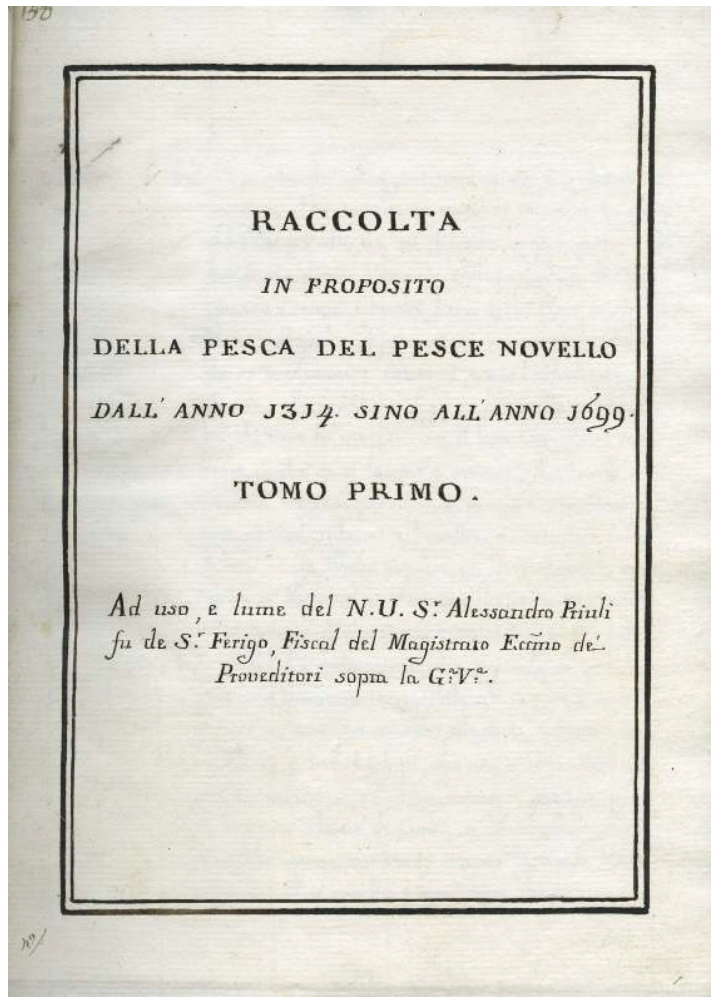

(c) Bibliothèque Correr 
5. Alessandro Priuli, « Raccolta di leggi del ser.mo Maggior Consiglio, ducali dell'ecc. Consiglio di Dieci [...] in proposito di gravezze de mandato dominii ", [Venise, après 1784], Berkeley, CA, The Robbins Collection in Civil and Religious Law, Université de la Californie, Berkeley Law.

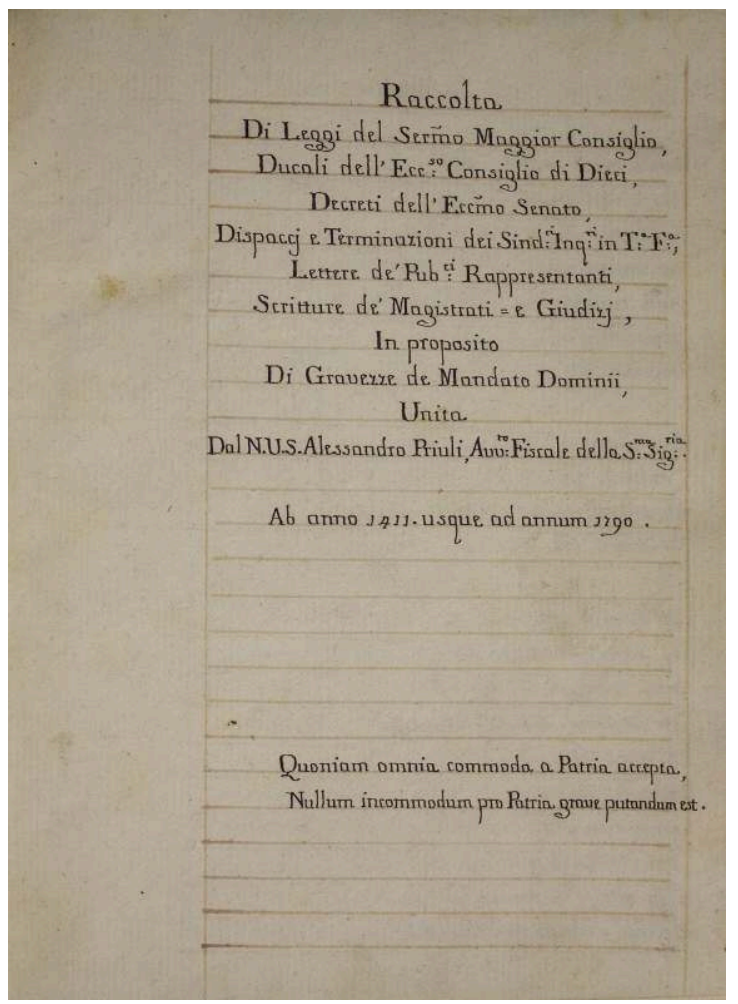

(c) Berkeley CA, Berkeley, School of Law, The Robbins Collection in Civil and Religious Law

10 Il n'est par ailleurs pas anodin que le baron James Édouard ait porté un intérêt à ce recueil, rédigé par un avocat - Alessandro Priuli -, alors qu'il était lui-même en train de se former aux études juridiques, avant d'obtenir son diplôme à Paris en 1865. Dans cette perspective, il est également à signaler la mention d'un étonnant « agenda d'un avocat italien", datant du XVII ${ }^{e}$ siècle $^{31}$, faisant partie du même fonds acquis à Venise par James Édouard.

\section{Histoire(s) familiale(s)}

11 Si certains manuscrits de ce fonds concernent l'histoire de la République, de ses institutions et de ses lois, d'autres sont clairement liés à la gouvernance de quelques familles aristocrates de la ville ${ }^{32}$, telles que les Sagredo ou les Contarini. Concernant ces manuscrits, aucun indice ne permet d'établir une provenance Mocenigo. Émile Picot reste donc la source essentielle pour en déterminer l'origine, le fonds lui-même ne possédant qu'un seul volume faisant mention explicite de cette famille ${ }^{33}$. Néanmoins, à la faveur d'une analyse plus approfondie, des liens avec la famille Mocenigo peuvent être décelés.

De nombreux documents concernent par exemple les familles Badoer, Morosini ${ }^{34}$ et Corner, et couvrent plusieurs siècles de leur histoire ( $\mathrm{XVI}^{\mathrm{e}}$-XVIII $\mathrm{e}^{\mathrm{e}}$ siècle). Il s'agit essentiellement de feuilles manuscrites reliées, mais parfois aussi de pages imprimées. Or ces familles ont des liens familiaux avec les Mocenigo. Les archives conservent par exemple la correspondance d'Andrea Corner, "provveditore general da mar », avec le 
doge ${ }^{35}$ durant la période 1721-1724. Elles remontent alors au dogat d'Alvise III Sebastiano Mocenigo (1662-1732), élu en 1722, il ne serait donc pas étonnant de les retrouver dans les archives de la famille Mocenigo.

Il convient de signaler également la présence d'un ensemble de documents concernant la ville de Brescia pour des périodes spécifiques, faisant référence à l'époque où elle était administrée par le podestà Nicolò Contarini (1773-1775). Ces feuilles concernent les années où l'un des plus turbulents membres de la famille Mocenigo, Alvise $\mathrm{V}$ Sebastiano, se trouvait emprisonné dans le château San Felice de Brescia pour conduite dissolue, après une carrière diplomatique prestigieuse - il fut, entre autres, ambassadeur en Espagne et en France ${ }^{36}$. Cette documentation, émanant du podestà de la ville, principale autorité politique et judiciaire locale, pourrait être liée aux problèmes judiciaires rencontrés par Alvise $\mathrm{V}$, emprisonné sept ans durant. Par ailleurs, ces manuscrits renvoient également aux années du dogat d'un autre membre de la famille, Alvise IV Giovanni Mocenigo (1701-1778), élu en $1763^{37}$. Il n'est donc pas déraisonnable de désigner ce fonds comme «fonds Mocenigo ».

Les liens spécifiques entre chacun des manuscrits semblent dès lors pouvoir être restitués, encore que de manière non systématique. Il est, par exemple, impossible pour l'instant de prouver la provenance Mocenigo du recueil de la fiscalité d'Alessandro Priuli, néanmoins la présence d'un tel recueil Priuli n'aurait rien d'étonnant dans la bibliothèque d'une famille aristocratique qui pouvait naturellement trouver intérêt à cette vaste synthèse sur la fiscalité vénitienne.

Sans le témoignage fondamental d'Émile Picot, il n'aurait été pas facile de déterminer l'origine exacte de l'ensemble de ce fonds vénitien ou les modalités de son acquisition, James Édouard n'étant pas mentionné dans les archives de la bibliothèque de la Sorbonne et la famille Mocenigo comptant par ailleurs plusieurs branches distinctes. Or pour mieux comprendre l'origine de ces fonds, il convient de retracer brièvement l'histoire de ces diverses branches.

\section{Une provenance prestigieuse : les Mocenigo de la Casa Vecchia}

À partir du XVII ${ }^{e}$ siècle, les Mocenigo se partagent en deux branches principales nommées selon la localisation de leur résidence principale : celle dite de la Casa Nuova ou des Mocenigo de San Stae, et celle dite de la Casa Vecchia ou des Mocenigo de San Samuele (la branche aînée), situées respectivement dans les paroisses de San Stae et de San Samuele. C'est notamment à la branche de la Casa Vecchia de San Samuele (fig. 6) que nous nous proposons de rattacher le fonds Mocenigo de la bibliothèque de la Sorbonne. 
6. Arbre généalogique de la Maison aînée des Mocenigo de San Samuele, Venise, Bibliothèque Correr, dans Marco Barbaro, « Discendenze patrizie veneziane», ms. Cicogna, 2502, fol. $119 \mathrm{v}$.

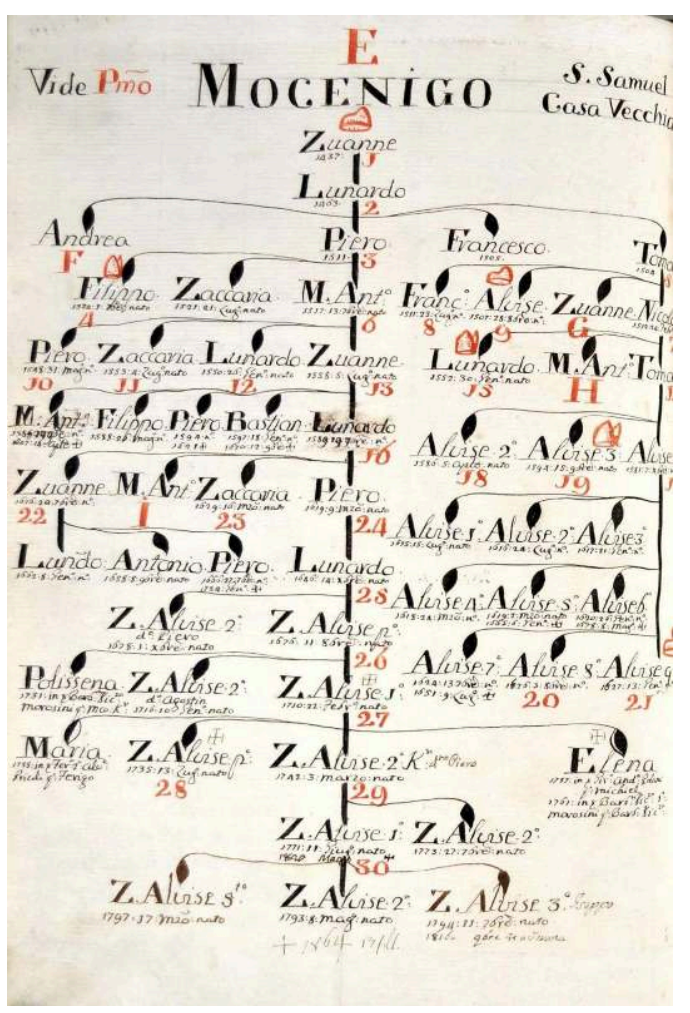

(c) Bibliothèque Correr

Cette famille de grands collectionneurs et mécènes possédait plusieurs propriétés sur le Grand Canal, décorées par les artistes les plus représentatifs de l'école vénitienne entre le $\mathrm{XV}^{\mathrm{e}}$ et le XVIII ${ }^{\mathrm{e}}$ siècle. Les Mocenigo de San Samuele avaient par exemple commandé à Jacopo Robusti dit le Tintoret La Vierge à l'Enfant avec le doge Alvise Mocenigo, la dogaresse Loredana Marcello et d'autres membres de la famille (fig. 7) et réuni les œuvres des maîtres les plus en vue de la lagune. Le Titien, Giorgione, Véronèse, les Bassans, Giovanni Bellini, Andrea Schiavone, Pietro Liberi, Sebastiano Ricci et Pietro Longhi étaient bien représentés dans ces prestigieuses collections auxquelles Stefania Mason a consacré une étude approfondie ${ }^{38}$. Leur palais était, entre autre, décoré d'une Aurore dispersant les nuages de Giambattista Tiepolo (Boston, Museum of Fine Arts, vers 1755-1760) et d'un cycle dédié au thème nuptial de Vénus au miroir avec des petits amours, peint par Gianantonio Guardi vers 1750-1760 et dont cinq toiles se trouvent aujourd'hui à l'ambassade d'Italie à Paris (fig. 8) ${ }^{39}$. Une aquarelle de William Henry Lake Price, datée du 4 septembre 1839 (fig. 9), nous livre un aperçu de la décoration d'une des pièces principales de ce palais vénitien, tel que James Édouard a dû la connaître quelques années plus tard. Ce palais avait, par le passé, accueilli et hébergé des personnalités illustres, telles que le philosophe Giordano Bruno, dès 1591-1592, puis la comtesse d'Arundel, Lady Mary Wortley Montagu, mais aussi Lord Byron, représenté dans l'aquarelle de Price, assis dans un salon décoré du Paradis de Domenico Tintoretto ${ }^{40}$. 
7. Jacopo Robusti dit le Tintoret, La Vierge à l'Enfant avec le doge Alvise Mocenigo, la dogaresse Loredana Marcello et d'autres membres de la famille, vers 1575, huile sur toile, $216 \times 416 \mathrm{~cm}$, Washington, National Gallery of Art (Samuel H. Kress Collection), nº inv. 1961.9.44.

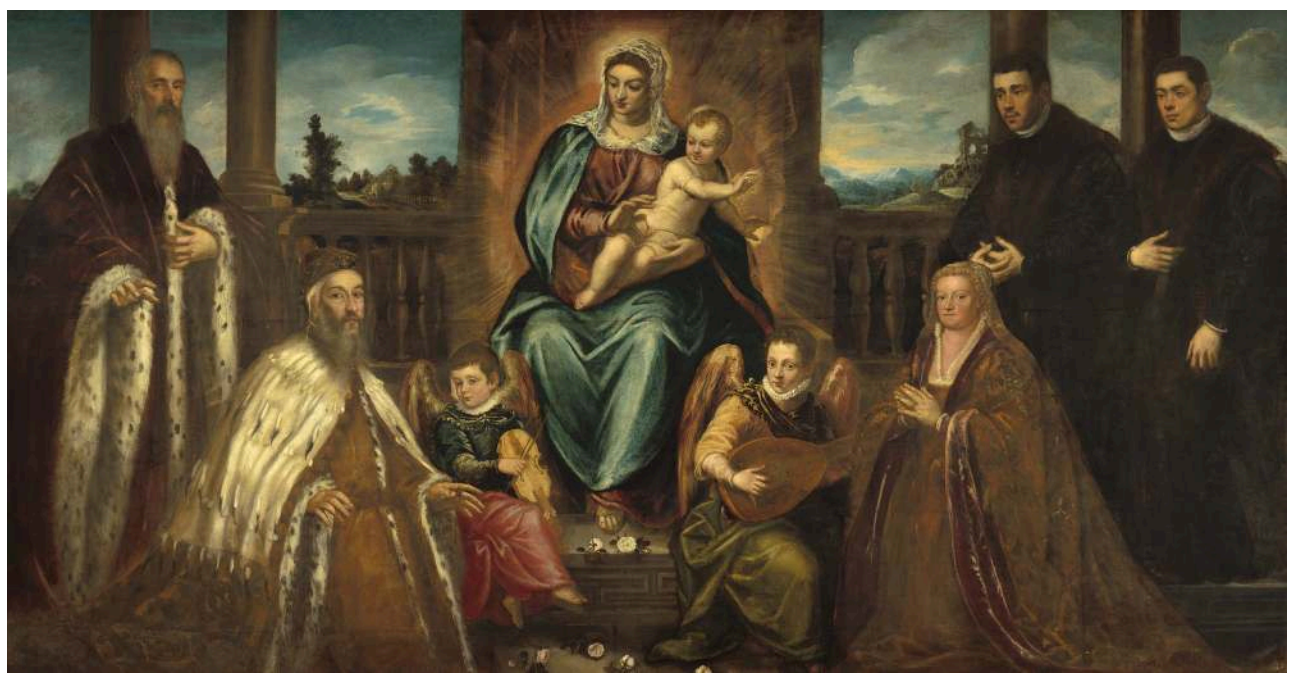

(c) National Gallery of Art

8. Gianantonio Guardi, Amours jouant avec un paon, vers 1750-1760, Paris, Ambassade d'Italie en France.

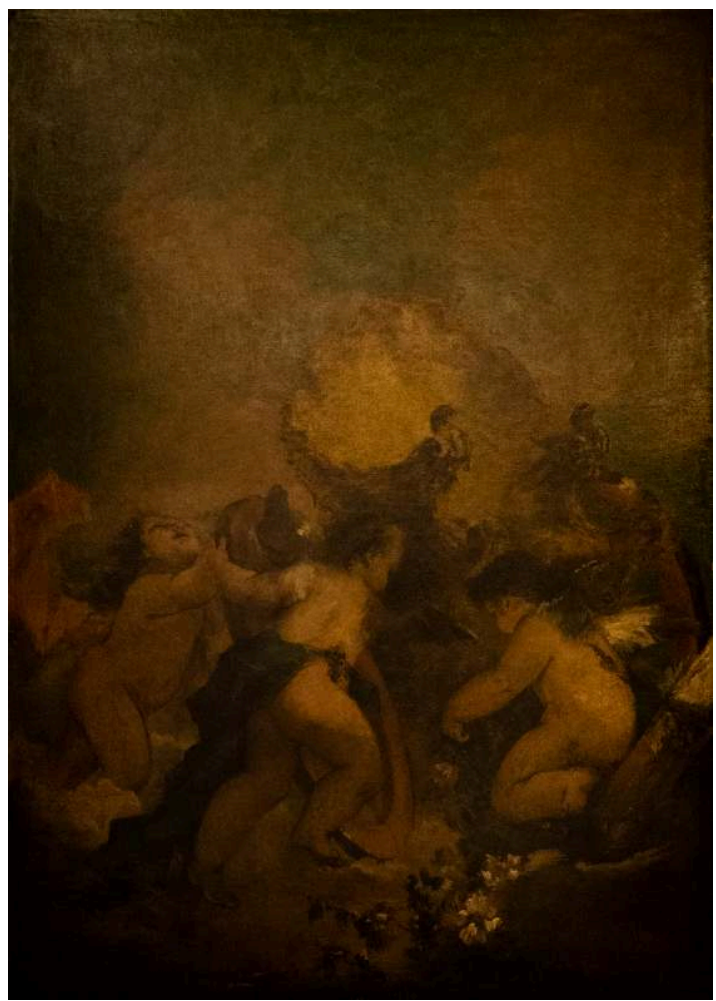


9. William Henry Lake Price, Lord Byron au Palais Mocenigo en 1839, San Marino, CA, The Huntington Library, Art Museum and Botanical Gardens, Gilbert Davis Collection, Inv. 59.55.410, consultable ici : emuseum.huntington.org/objects/1328/lord-byron-in-the-palazzo-mocenigo-venice? $c t x=45 b 22364-7 b 9 a-4672-8 d 3 b-0 c b a 75304366 \& i d x=0$

18 C'est dans ce même palais que le 27 février 1864 s'éteint Alvise II Mocenigo, « ultimo di casa vecchia Mocenigo ${ }^{41}$ » (dernier membre de la branche aînée des Mocenigo), le décès aboutissant à la dispersion du patrimoine familial. Nous savons que sa demeure devient par la suite la propriété du comte de Robilant ${ }^{42}$ et que ses collections d'œuvres d'art sont dispersées à la fin du XIX ${ }^{\mathrm{e}}$ siècle. Il est vraisemblable que c'est à cette date décisive que James Édouard s'est porté acquéreur d'une partie des archives familiales, date qui correspondrait par ailleurs aux séjours du jeune baron à Venise. Il est aussi probable que ce même événement ait fourni à James Édouard de Rothschild l'opportunité d'autres acquisitions.

\section{Sur le don d'un millier de pièces à la Biblioteca Marciana}

19 C'est le témoignage déjà cité d'Émile Picot qui, considéré dans son intégralité, nous livre quelques indices. De manière apparemment anodine, Émile Picot juxtapose la mention du don des archives de la famille Mocenigo à la bibliothèque de la Sorbonne et celle du don d'un ensemble d'un millier de pièces à la bibliothèque Marciana de Venise : «Il lui arriva plusieurs fois de sauver de la dispersion des collections précieuses. Ce fut ainsi qu'il conserva à l'Italie un millier de pièces, presque toutes italiennes, relatives à la bataille de Lépante. Cette réunion unique est aujourd'hui une des curiosités de la Bibliothèque marcienne. Une autre fois, il se rendit acquéreur des archives de la famille Mocenigo; il les offrit à la bibliothèque de la Sorbonne ${ }^{43}$. "

Les deux dons ne sont pas clairement liés dans le souvenir d'Émile Picot et, comme c'était déjà le cas pour les manuscrits, le don de ces pièces ne semble pas avoir laissé de trace dans les archives de la bibliothèque Marciana ${ }^{44}$. Bien que ces documents n'aient pas pu être identifiés dans les collections de cette bibliothèque et que le témoignage de Picot ne soit pas explicite sur leur provenance, il n'est pas impossible que le millier de documents acquis par James Édouard à Venise ne soit aussi lié à la famille Mocenigo.

Il se trouve en effet que la bataille de Lépante du 7 octobre 1571 date de l'époque du dogat d'un autre membre de la famille Mocenigo, Alvise I $^{\mathrm{er}}$ Mocenigo. Il s'agit d'une victoire historique pour les forces chrétiennes qui entendaient venir en aide à la République de Venise dans sa défense de l'île de Chypre, en se réunissant sous le nom de Sainte Ligue à l'initiative du pape Pie V. Cette ligue avait réussi à s'imposer sur la puissante marine ottomane, alors que l'Empire ottoman était en pleine expansion et que le contrôle de la Méditerranée était en jeu. Cette bataille navale - qui aura des échos dans l'Europe entière - est un événement marquant dans l'histoire de Venise et l'apogée du dogat d'Alvise I $^{\text {er }}$ Mocenigo ${ }^{45}$. Pour célébrer l'anniversaire de cette victoire, tombée le jour de la fête de sainte Justine, ce doge fera même battre une nouvelle monnaie d'argent, nommée précisément "Giustina ${ }^{46}$ ". Ce même thème est aussi à rattacher à la toile du Doge Alvise Mocenigo (1507-1577) présenté au Rédempteur réalisée par Tintoret (fig. 10), destinée au palais des Doges (Sala del Collegio), où la bataille de Lépante est évoquée par la présence de bateaux en arrière-plan. 
10. Jacopo Robusti dit le Tintoret, Le Doge Alvise Mocenigo (1507-1577) présenté au Rédempteur, vers 1577, huile sur toile, 97.2 x $198.1 \mathrm{~cm}$, New York, Metropolitan Museum of Art, $n^{\circ}$ inv. 10.206.

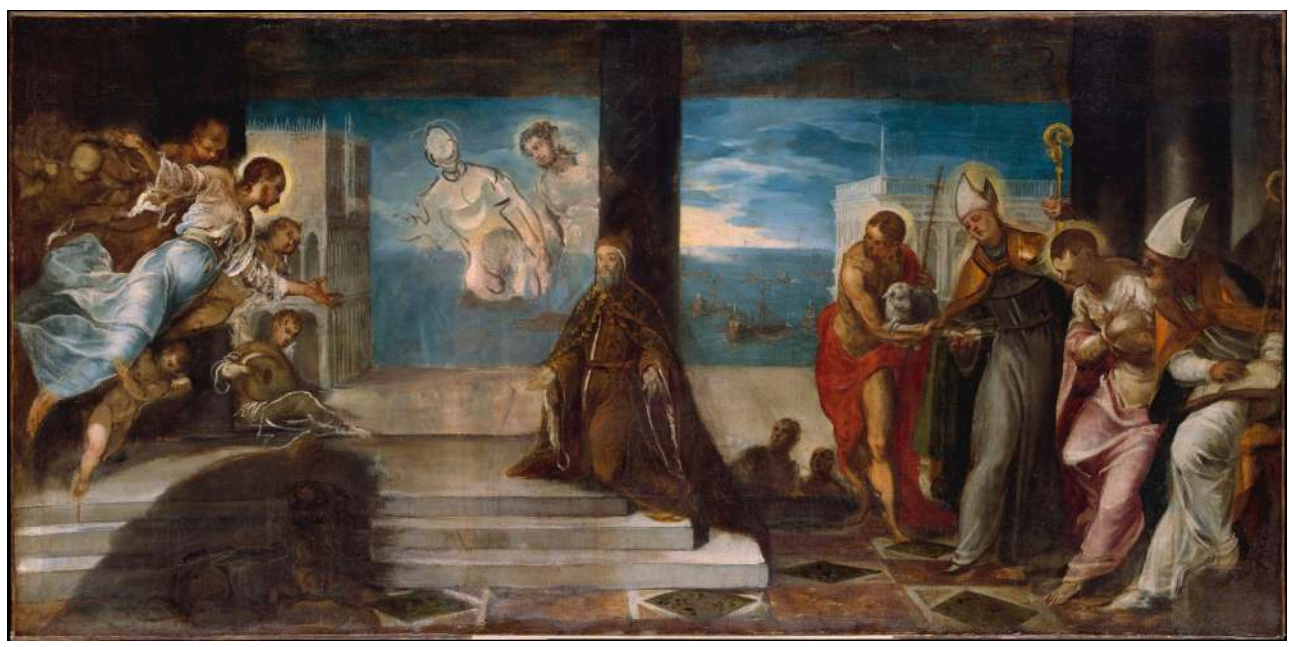

(c) Metropolitan Museum of Art, Fonds John Stewart Kennedy, 1910

De nombreux textes furent rédigés en l'honneur de cette victoire, dès 1571, et certains de leurs possesseurs ont réuni en recueils ces opuscules éphémères pour en assurer la pérennitée ${ }^{47}$. Il existe plusieurs exemples d'imprimés relatifs à cet événement notamment conservés à la Bibliothèque nationale de France, à la British Library, mais aussi à la bibliothèque Marciana.

Bien que ces dons n'aient pu encore être identifiés dans les collections de cette bibliothèque vénitienne - cet article ne présentant que les premiers résultats de notre recherche -, il est possible que l'ensemble d'un millier de pièces mentionné par Émile Picot et consacré à cet événement puisse être aussi mis en rapport avec une collection de documents sur ce thème conservée par les Mocenigo au xixe siècle, puis dispersée au moment de l'extinction du lignage en 1864, parallèlement à la dispersion des archives familiales.

S'il n'a pas encore été possible de confirmer cette hypothèse, il convient toutefois de souligner que la démarche de James Édouard Rothschild, avec ces deux dons d'archives et de recueils de publications "éphémères ", prélude à la contribution fondamentale que ses collections de livres et de manuscrits apporteront à la Bibliothèque nationale de France. Il s'agit également d'une manifestation précoce de son intérêt pour la sauvegarde du patrimoine à l'échelle internationale, qui anticipe d'autres épisodes significatifs de mécénat de la part de la famille Rothschild à Venise. À partir de 1878, Sara Louise de Rothschild (1834-1924), fille d'Anselm de la branche viennoise de la famille, et son époux Raimondo Franchetti s'installeront dans le palais CavalliFranchetti (l'actuel Istituto Veneto di Scienze, Lettere ed Arti). Leur fils, Giorgio Franchetti, sera à l'origine de la donation à l'État italien en 1916 du palais Ca' d'Oro et de sa destination muséale (aujourd'hui Galleria Giorgio Franchetti alla Ca' d'Oro). 


\section{NOTES}

1. * Nous remercions William Barcham, Stefania Mason et Pierre Rosenberg pour les informations qu'ils ont généreusement partagées avec nous dans le cadre de cette étude. Cette recherche a été réalisée dans le cadre du programme «Les collections Rothschild dans les institutions publiques françaises " promu par l'INHA à partir de 2015, en collaboration avec la Bibliothèque nationale de France, le musée du Louvre, le Service des musées de France, la Villa Ephrussi de Rothschild et la Fondation des artistes à Paris.

Émile Picot, «Le Baron James de Rothschild, 1844-1881 », Paris, 7 décembre 1884, dans [Émile Picot], Catalogue des livres composant la bibliothèque de feu M. le baron James de Rothschild, Paris, D. Morgand libraire, 5 vol., 1881-1920 ; consultable ici : archivesetmanuscrits.bnf.fr/ark:/12148/ cc4448f. Concernant le baron James Édouard et ses collections de manuscrits, voir aussi Henri de Rothschild, Un bibliophile d'autrefois. Le baron James Édouard de Rothschild (1844-1881), Genève, Droz, 1934 ; Christophe de Hamel, Les Rothschild collectionneurs de manuscrits, Paris, BnF, 2004, p. 92-99 ; Pauline Prevost-Marcilhacy, " James Édouard de Rothschild (1844-1881) et Thérèse de Rothschild (1847-1931) », dans Pauline Prevost-Marcilhacy (dir.), Les Rothschild. Une dynastie de mécènes en France, 3 vol., Paris, Louvre/BnF/Somogy, 2016, vol. I, p. 282-301. Les dons des collections de James Édouard de Rothschild à la Bibliothèque nationale de France sont consultables à partir du portail du programme «Les collections Rothschild dans les institutions publiques françaises » à l'adresse suivante: collections.rothschild.inha.fr/fr/institutions/cartographie-desetablissements/partenaires/paris-bibliotheque-nationale-de-france.html?search-

keywords=biblioth\%C3\%A8que+nationale. À ce propos, voir aussi Catherine Faivre d'Arcier, «La bibliothèque de James Édouard de Rothschild (1844-1881)", dans Pauline Prevost-Marcilhacy (dir.), Les Rothschild. Une dynastie de mécènes en France, op. cit., vol. III, p. 228-263.

2. «Après avoir passé dix mois de l'année dans un labeur assidu, il prenait généralement ses vacances en Italie, de préférence à Venise et, là, il visitait les musées et fouillait les boutiques des libraires. Il lui arriva plusieurs fois de sauver de la dispersion des collections précieuses. Ce fut ainsi qu'il conserva à l'Italie un millier de pièces, presque toutes italiennes, relatives à la bataille de Lépante. Cette réunion unique est aujourd'hui une des curiosités de la Bibliothèque marcienne. Une autre fois, il se rendit acquéreur des archives de la famille Mocenigo ; il les offrit à la bibliothèque de la Sorbonne. Quand venait la fin des vacances, James reprenait ses études au jour dit. », Émile Picot, « Le Baron James de Rothschild, 1844-1881 », art. cit.

3. Ibidem.

4. Il s'agit de Tommaso (1414-1423), Pietro (1474-1476), Giovanni (1478-1485), Alvise I er (1570-1577), Alvise II (1700-1709), Alvise III (1722-1732) Alvise IV (1763-1778). Sur cette famille et ses collections, voir notamment Stefania Mason, « Il caso Mocenigo di San Samuele », dans Linda Borean, Stefania Mason (dir.), Il collezionismo a Venezia nel Settecento, Venise, Marsilio, 2009, p. $172-191$.

5. Nous remercions très sincèrement Jacqueline Artier, conservateur au département des Manuscrits et Livres anciens de la bibliothèque interuniversitaire de la Sorbonne, qui nous a renseignée et aidée dans le cadre de cette recherche.

6. Voir Pauline Prevost-Marcilhacy, «Charlotte de Rothschild (1825-1899) et Nathaniel de Rothschild (1812-1870)», dans Pauline Prevost-Marcilhacy (dir.), Les Rothschild. Une dynastie de mécènes en France, op. cit., vol. I, p. 182-234.

7. La baronne avait orienté le goût de son fils vers la peinture de paysage grâce à son propre maître Hercule Trachel (1820-1872), en séjournant au moins cinq fois dans la ville en sa compagnie. Voir ibid., vol. I, p. 184. 
8. Marie-Hélène Tesnière, «Les manuscrits de la première rédaction des œuvres de Brantôme à la Bibliothèque nationale, 1903 ", dans ibid., vol. I, p. 292-297; Mathilde Avisseau-Broustet, Dominique Hollard et Julien Olivier, « Monnaies et pierres gravées au cabinet des médailles de la Bibliothèque nationale, 1903-1904 ", dans ibid., vol. I, p. 298-299; voir infra, dans le présent volume, Carlo Alberto Girotto, « La collection Rothschild et l'édition italienne de la Renaissance ». 9. Il s'agirait d'un des premiers achats de James Édouard. Voir Catherine Faivre d'Arcier, «La bibliothèque de James Édouard de Rothschild (1844-1881)» dans Pauline Prevost-Marcilhacy (dir.), Les Rothschild. Une dynastie de mécènes en France, op. cit., vol. I, p. 283.

10. Au sujet des collections universitaires antérieurement à 1870, Alban Daumas écrit en 1973 : «L'histoire des bibliothèques françaises est peu connue, celle des bibliothèques universitaires l'est moins encore." Voir Alban Daumas, «Les bibliothèques universitaires ", Bulletin des bibliothèques de France (BBF), 1973, $\mathrm{n}^{\circ}$ 7, p. 316-327 : bbf.enssib.fr/consulter/bbf-1973-07-0316-003 (consulté en ligne en juillet 2019).

11. Voir Charles Beaulieux, Catalogue général des manuscrits des bibliothèques publiques de France: Université de Paris et universités des départements, Paris, Plon, 1918, p. 131-137. Ce catalogue est en grande partie repris dans l'inventaire actuellement en ligne dans la base Calames.

12. Ce décret est mentionné dans Charles Beaulieux, Catalogue général des manuscrits des bibliothèques publiques de France: Université de Paris et universités des départements, op. cit., p. IX-X ; voir « État des cartons et registres composant les archives de l'ancienne Université de Paris, retirés du Ministère de l'Instruction publique le 1er février 1865 et déposés le même jour à la bibliothèque de l'Université impériale de France, conformément à l'arrêté de M. le Ministre de l'Instruction publique en date du 15 décembre de l'année 1864 ", MSAU 106.

13. Alban Daumas, "Les bibliothèques universitaires ", art. cit. C'est à cette date que la bibliothèque de la Sorbonne devient officiellement bibliothèque universitaire.

14. Concernant ce legs, voir Paul Deschamp, « Manuscrits de Victor Cousin à la Sorbonne ", dans Charles Beaulieux, Catalogue général des manuscrits des bibliothèques publiques de France: Université de Paris et universités des départements, op. cit., p. 269.

15. Voir par exemple le ms. 498 qui porte la mention manuscrite «Volume de 111 feuillets, 23 Mai 1912 ».

16. Marco Foscarini, Storia arcana ed altri scritti inediti di Marco Foscarini, aggiuntovi un catalogo dei manoscritti storici della sua collezione, Florence, Gio Pietro Vieusseux, 1843, p. X-XI.

17. Paris, Bibliothèque de la Sorbonne, «Lettere a magistrati e reggimenti »,1725-1726, mss. 477-478; " Lettres écrites par la direction du génie, à Ferrare », " alla municipalita centrale del Basso Po », « al ministro [francese] della Guerra », etc., du « 17 piovoso » au « 21 fruttidoro, anno $9^{\circ}$ ", XIX siècle, mss. 494-495; "Piano istruttivo, generale ed analitico, dei prezzi d'ogni genere di fabbricazione per service ai lavori di casermaggio nella piazza di Ferrara. Parte prima. Ferrara, 1807 ", ms. 496; "Affari dei reggimenti" de Venise : correspondance et pièces administratives, manuscrites et imprimées, XVII ${ }^{\mathrm{e}}$-XVIII ${ }^{\mathrm{e}}$ siècle, mss. 519-520; [Rubbi] "Copia lettere » militaires de Venise, «Registri intrapresi nel 1802, assumendo il servizio il capitano Rubbi », 1802-1803, mss. 521-527 ; «Lettere di Contarini, capitano di Verona, da 3 marzo 1617 sino 26 febraio 1618 ", XVII ${ }^{\mathrm{e}}$ siècle, ms. 518 ; "Registro di lettere publiche del reggimento dell' ill $^{\mathrm{mo}}$ et ecc ${ }^{\mathrm{mo}}$ signor Nicolò Contarini, capitanio e V. podestà di Padova, negl' anni 1704, 1705, $1706 »$, ms. 470.

18. Paris, Bibliothèque de la Sorbonne, "Amministrazione publica. Corrieri ", XVII ${ }^{e}-\mathrm{XVIII}^{\mathrm{e}}$ siècle, ms. 517.

19. Paris, Bibliothèque de la Sorbonne, "Supplemento al codice dell'eccelso Consiglio di Dieci », XVIII ${ }^{\mathrm{e}}$ siècle, ms. 466.

20. Paris, Bibliothèque de la Sorbonne, «Pratica universale del magistrato eccellentissimo delle acque [in Venezia], divisa in tre libri ; nel primo si tratta della laguna e sue parti ; nel secondo de Lidi, et Fiumare, et nel terzo degl'ordini et regole principiando dall'erettione del magistrato. 
Fatica di d. Antonio Piscina » [1656], ms. 467. Un exemplaire de ce manuscrit était conservé dans la bibliothèque des Foscarini et se trouve actuellement à la bibliothèque Correr (Correr 554), voir Marco Foscarini, Storia arcana ed altri scritti inediti di Marco Foscarini, aggiuntovi un catalogo dei manoscritti storici della sua collezione, op. cit., p. 428, ms. $\mathrm{n}^{\circ} 6570$.

21. Paris, Bibliothèque de la Sorbonne, "Registro di lettere publiche, scritte nel reggimento dell'ecc $^{\text {mo }}$ signor Marino Tiepolo, capitanio di Bressa, principiato a $4 \mathrm{X}^{\text {bre }} 1650$ sino per tutto agosto 1652 », 1650-1652, ms. 474 ; "Lettere publiche da Brescia ", XVIIIe siècle, mss. 475-476; «Registro di lettere de rappresentanti et magistrati» de Brescia, 1733, XVIII siècle, ms. 479 ; «Cariche straordinarie. Lettres adressées au provéditeur général de Brescia, 1733-1734 ", XVIII ${ }^{\mathrm{e}}$ siècle, ms. 480; "Registro di lettere eccelentissimo Senato reggimento eccelentissimo Nicolò Contarini $3^{\circ}$ podestà » (Brescia, 1773-1775), XVIII ${ }^{\mathrm{e}}$ siècle, ms. 481.

22. Paris, Bibliothèque de la Sorbonne, «Lettere di Contarini, capitano di Verona, da 3 marzo 1617 sino 26 febraio $1618 », 1617-1618$, ms. 518.

23. Paris, Bibliothèque de la Sorbonne, «Registro di lettere a magistrati» de Bergame, 1716-1717, ms. 493.

24. Paris, Bibliothèque de la Sorbonne, "Registri lettere de magistrati sotto il reggimento di Giacomo Badoer, podestà e capitanio di Treviso ", XVIII siècle, mss. 482-492.

25. Paris, Bibliothèque de la Sorbonne, « Registro di lettere di Aloise Mocenigo del suo generalato di Dalmazia ", 1716-1718, ms. 472.

26. Concernant Alessandro Priuli, voir Marco Barbaro, Discendenze patrizie, Venise, Biblioteca del Museo Correr, ms. Cicogna 2503 fol. 156-157.

27. Paris, Bibliothèque de la Sorbonne, "Mensuali dei conventi soppressi d'Italia ", XVIII siècle, mss. 509-516.

28. Paris, Bibliothèque de la Sorbonne, "Raccolta di leggi e pubblici documenti [...]. Articolo Prima. Parte seconda, Tomo Primo, ab anno 1500 usque 1600 », « Articolo Primo. Parte Seconda. Tomo Secondo ab Anno 1600 usque 1700 ", " Articolo Prima. Parte seconda. Tomo Terzo, ab anno 17000 usque 1789 », ms. 498 , fol. $34,65,81$.

29. Je remercie Andrea Pavanello (Archivio della biblioteca del Museo Correr) pour les informations qu'il a mises à notre disposition au sujet du fonds Mocenigo du Museo Correr. La bibliothèque d'Alessandro Priuli a été partiellement achetée par Teodoro Correr (1750-1830).

30. Alessandro Priuli, Raccolta di leggi del ser.mio Maggior Consiglio, ducali dell'ecc.so Consiglio di Dieci [...] in proposito di gravezze de mandato domini, unita dal N. U. S. Alessandro Priuli, avv.to Fiscale della S.ma Sig.ria. Ab anno 1411 uque ad annum 1790, [Venise, vers 1790]. Je remercie Leo Cadogan (Leo Cadogan Rare Books de Londres) et Jennifer K. Nelson (The Robbins Collection in Civil and Religious Law, UC Berkeley School of Law) qui nous ont renseignée sur ce volume.

31. Paris, Bibliothèque de la Sorbonne, ms. 544, 1615.

32. Paris, Bibliothèque de la Sorbonne, «Criminale »: papiers relatifs à des affaires criminelles de Venise, recueillis par Badoer, 1509-1793, ms.528; 530-531; "Armamento di Pietro Badoer, capitanio delle galeazze ", 1690-1796, ms. 529 ; «Procès soutenus par la famille Badoer », 1797, ms. 530-533 ; «Papiers relatifs aux familles Morosini et Badoer », XVIII ${ }^{\mathrm{e}}$ siècle, mss. 534-539.

33. Paris, Bibliothèque de la Sorbonne, « Registro di lettere di Aloise Mocenigo del suo generalato di Dalmazia », 1716-1718, ms. 472.

34. Paris, Bibliothèque de la Sorbonne, «Criminale » : papiers relatifs à des affaires criminelles de Venise, recueillis par Badoer, 1509-1793, mss. 528 ; 530-531; «Armamento di Pietro Badoer, capitanio delle galeazze ", 1690-1796, ms. 529 ; «Procès soutenus par la famille Badoer », 1797, mss. 530-533 ; « Papiers relatifs aux familles Morosini et Badoer », XVIII ${ }^{\mathrm{e}}$ siècle, mss. 534-539.

35. Paris, Bibliothèque de la Sorbonne, «Lettere ducali del Senato al signor Andrea Corner, provveditore general da mar », 1721-1724, ms. 471. 
36. Voir Linda Borean, Stefania Mason (dir.), Il collezionismo a Venezia nel Settecento, op. cit., p. 183-184; Michela Martini, «Spigolature d'arte e di costume dall'archivio Mocenigo: Giandomenico Tiepolo testimone nel processo contro Alvise V Sebastiano », Arte in Friuli Arte a Trieste, 20, 2000, p. 97-102.

37. À la même époque remontent également les «Conti artefici per lavori publici da primo giugno 1771 a tutto maggio 1772 » («Comptes originaux, acquittés, des travaux faits au palais de l'ambassade de Venise à Rome »), 1771-1772, ms. 497.

38. Linda Borean, Stefania Mason (dir.), Il collezionismo a Venezia nel Settecento, op. cit.

39. Henry Lapauze, Un nouveau chapitre sur l'oeuvre de Francesco Guardi, Paris, La Renaissance de l'art français et des industries de luxe, 1922, p. 20-24; Maria Teresa Caracciolo, «La sala da pranzo del Guardi : cinque tele di Gian Antonio Guardi », dans E. Gentile Ortona, M. Caracciolo, M. Tavella (dir.), L'Ambasciata d'Italia a Parigi. Hôtel de la Rochefoucauld-Doudeauville, Milan, Skira, 2009, p. 157-163.

40. Linda Borean, Stefania Mason (dir.), Il collezionismo a Venezia nel Settecento, op. cit., p. 186.

41. Voir Marco Barbaro, Discendenze patrizie, Venise, Biblioteca del Museo Correr, ms. Cicogna 2502. Il s'agit d'un homonyme par rapport au doge Alvise II Mocenigo (1628-1709), élu en 1700. Le prénom Alvise est par ailleurs récurrent chez les Mocenigo, voir l'arbre généalogique de la branche de San Samuele, fig. 5.

42. Linda Borean, Stefania Mason (dir.), Il collezionismo a Venezia nel Settecento, op. cit.

43. Voir note 1.

44. Je remercie très sincèrement Carlo Campana et Enrico Noè pour l'aide apportée dans cette recherche (communication écrite, 2015).

45. Voir la notice "Alvise I Mocenigo", dans Enciclopedia Treccani; consultable ici : www.treccani.it/enciclopedia/alvise-i-mocenigo/.

46. Sur ces monnaies, sainte Justine figurait au revers, tenant la palme du martyre, alors qu'à l'avers, le doge était montré recevant un étendard de la main de saint Marc, le saint protecteur de la Sérénissime. Giuseppe Castellani, « Giustina », dans Enciclopedia italiana, 1933 : consultable ici : www.treccani.it/enciclopedia/giustina_res-e0e0724e-b6ac-11df-9cd8-d5ce3506d72e/. La «Giustina » sera battue en pièces de la valeur de 40, 80,124 et 160 sous.

47. Nous remercions Isabelle Le Masne de Chermont de nous avoir signalé cette pratique qui nous a permis de préciser le contenu de ce don. Voir aussi Sylvie Favalier, «Lépante : la fabrication d'une gloire vénitienne », dans Agnès Morini (éd.), L'histoire mise en œuvres. Fresques, collages, trompe-l'œil: des modalités de "fictionnalisation " de l'histoire dans les arts et la littérature italienne, actes du colloque (Saint-Étienne, 2 et 3 mai 2000), Saint-Étienne, Université de Saint-Étienne, 2001, p. 217-231 ; Simona Mammana, Lepanto. Rime per la Vittoria sul Turco, Regesto (1571-1573) e studio critico, Roma, Bulzoni, 2007 ; Cecilia Gibellini, L'immagine di Lepanto. La celebrazione della vittoria nella letteratura e nell'arte veneziana, Venise, Marsilio, 2008, p. 47-49, 193.

\section{INDEX}

Index géographique : France, Italie, Venise

Index chronologique : XVIIIe siècle, XIXe siècle

Thèmes : Bibliophilie, collections, Rothschild, Mocenigo 
Les Rothschild et la musique 


\title{
Le salon musical de la famille Rothschild : autour du legs de Charlotte de Rothschild à la bibliothèque du Conservatoire
}

\author{
Rosalba Agresta
}

\begin{abstract}
$\mathrm{Au}$ XIX $\mathrm{X}^{\mathrm{e}}$ siècle, la musique fait partie des arts que cultivent les gens de goût. Partageant un caractère à la fois artistique et mondain, elle est en effet, à cette époque, un critère de distinction et de culture. Si, dans plusieurs salons du beau monde, l'art musical n'est qu'un prétexte à la sociabilité et se réduit à un simple divertissement permettant aux chanteurs d'opéra et aux virtuoses de briller, de nombreux salons sont de véritables "institutions musicales", où l'on cultive et l'on apprécie cet art avec une ferveur presque religieuse. Très peu d'études ont été consacrées, à ce jour, au mécénat musical de la famille Rothschild dans le Paris du $\mathrm{xIX}^{\mathrm{e}}$ siècle $^{1}$. Il est néanmoins connu que celle-ci a soutenu de nombreux compositeurs, dont Chopin, Rossini et Meyerbeer. En effet, ces musiciens fréquentaient le salon de James et Betty de Rothschild (fig.1 et 2) et entretenaient des relations privilégiées avec leur famille, comme en témoignent les manuscrits légués à la bibliothèque du Conservatoire par Charlotte de Rothschild ${ }^{2}$, qui, tout en étant mécène comme ses parents, était également pianiste - elle a été l'élève de Frédéric Chopin - et compositrice. Cette étude se propose de présenter le mécénat musical des Rothschild ainsi que les différentes formes d'activités musicales qu'ils promurent.
\end{abstract}


1. Southworth \& Hawes, Baron James Rothschild, 1845-1861, daguerréotype, Boston, Museum of Fine Arts.

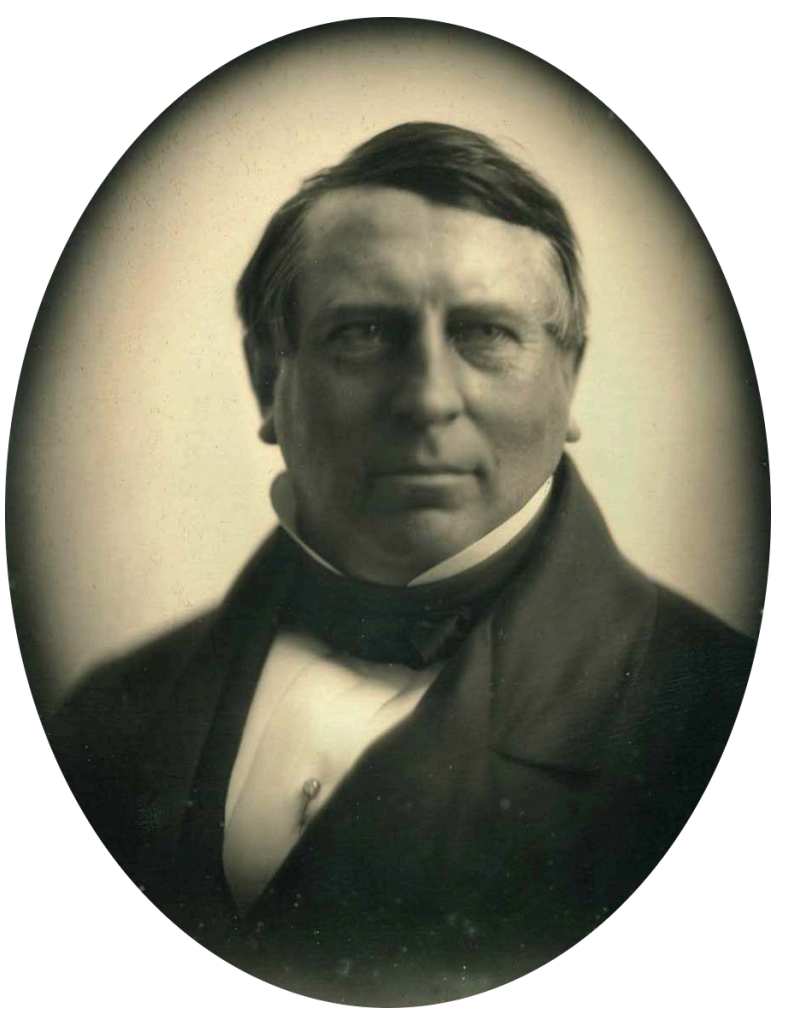

2. Jean-Léon Gérôme, Portrait de la baronne Nathaniel de Rothschild, née Charlotte de Rothschild (1825-1899), 1866, huile sur bois, 49,6 × 35,8 cm, Paris, musée d'Orsay.

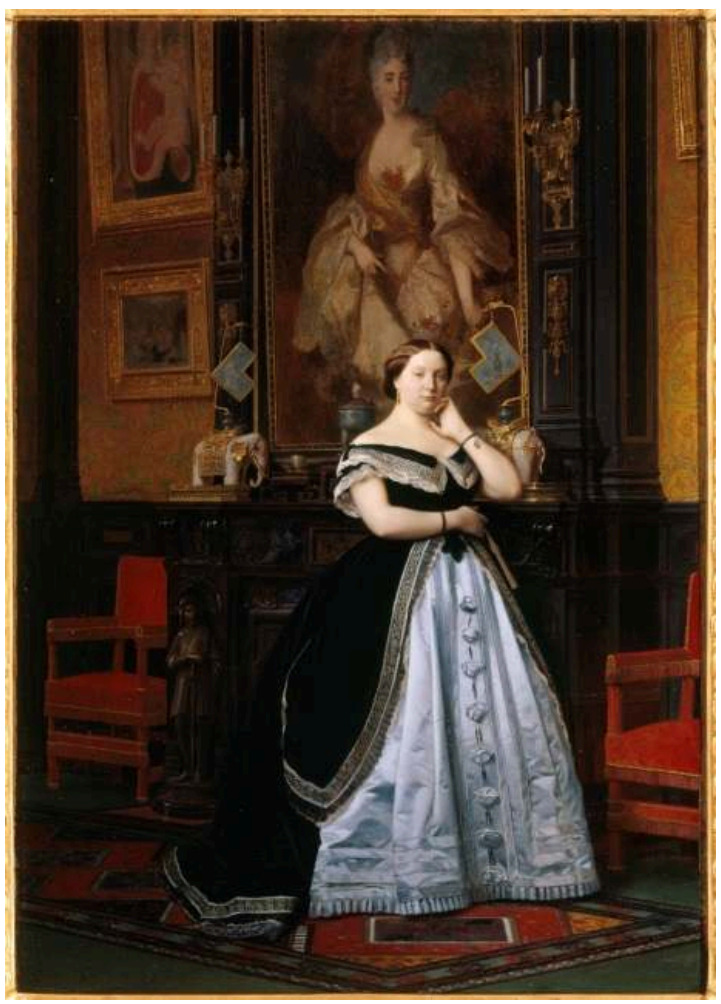

(c) RMN-Grand Palais (musée d'Orsay)/Hervé Lewandowski 


\section{La musique chez les Rothschild}

2 En juin 1836, Gioacchino Rossini s'est rendu à Francfort en compagnie du baron James de Rothschild pour être témoin au mariage de son cher ami Lionel Rothschild, le neveu de James de Rothschild. À cette occasion, Le Ménestrel a publié un article intitulé " Rossini à Francfort », qui est en réalité principalement consacré au baron James :

M. de Rothschild n'appartient point à cette classe de dilettanti fanatiques qu'un point d'orgue plonge dans des extases, qu'un bémol fait évanouir, et à qui un accord de septième donne des crises de nerfs. Comme vous et moi, M. de Rothschild adore la musique, admire les grands compositeurs, vénère le génie ; mais il a un genre de dilettantisme à lui, un dilettantisme concis, expressif, laconique, un dilettantisme qui ne craint pas la concurrence des trépignements de l'Académie royale et des bravo, brava bravi de Favart. Pour témoigner sa haute estime des artistes distingués, pour se les attacher, pour les fixer sur le sol de France, M. de Rothschild leur offre le portrait du chef d'État à plusieurs milliers d'exemplaires, autrement dire M. de Rothschild traduit son estime et son admiration en espèces monnayées. Et comment voudriez-vous qu'il en fût autrement? Pouvez-vous exiger qu'un grand banquier, absorbé par les affaires, consume ses précieux moments en phrases laudatives, en formules d'enthousiasme, qu'il jette à l'artiste des bouffées d'interjections banales, telles que Ah!... charmant !... délirant !... sublime !... incomparable! Non: le banquier a le sentiment des arts et la conscience du beau, mais il connaît aussi le prix du temps, le néant des phrases, et la chimère des exclamations. Le banquier répond à une cavatine par un billet de mille francs, à un duo par deux billets de mille francs, à un trio par trois billets de mille francs, à un acte d'Opéra par une inscription de rente au grand livre, et à une partition complète par une maison de campagne. Ainsi, quand M. de Rothschild ouvre son portefeuille, il en retire un syllogisme qui résume à la fois le suffrage des connaisseurs, les applaudissements de la foule et le feuilleton du journaliste [... $]^{3}$.

Le ton de cet article est ambigu: si l'auteur souligne l'admiration que nourrit le baron James de Rothschild pour la musique et les musiciens, il insinue, avec une pointe d'ironie, que cette admiration n'est que superficielle, car un homme d'affaires ne pourrait pas " perdre son temps » dans tout ce qui ne concerne pas ses spéculations et, surtout, il ne pourrait pas s'intéresser sérieusement à la musique. Un certain nombre d'anecdotes au sujet de différents membres de la famille Rothschild vont dans le même sens que les idées exprimées par le critique du Ménestrel. Selon une première anecdote, le compositeur allemand Ferdinand Hiller fut invité chez le baron James de Rothschild lors de son séjour à Paris, en 1830. Le baron le présenta à ses convives dans ces termes : «M. Ferdinand Hiller, de Francfort, excellent pianiste, mais n'a pas besoin de cela »cette dernière phrase faisant allusion à l'extrême richesse de la famille de Hiller. Lorsque, quelque temps plus tard, Hiller invita à son tour le baron, il voulut lui rendre la monnaie de sa pièce et le présenta ainsi : «M.le baron de Rothschild, célèbre banquier, également mécène, mais n'a pas besoin de cela ${ }^{4}$ ! Dans les deux cas, le jeu de mots signifie clairement que l'important n'est pas la célébrité que donne l'excellence musicale ni le goût dont on peut faire preuve dans l'appréciation de la musique, mais plutôt la richesse matérielle.

4 Une seconde anecdote, cette fois au sujet de Nathan, le frère de James et le fondateur de la branche anglaise de la famille, est encore plus explicite. En 1820, la Philharmonic Society invita Ludwig Spohr à Londres afin qu'il dirige l'orchestre et qu'il se produise comme soliste dans les concerts de la société. C'est à cette occasion que le public anglais 
découvrit la musique du compositeur et lui fit un accueil très chaleureux, qui devait perdurer tout au long du XIX ${ }^{\mathrm{e}}$ siècle. Dans son autobiographie, Spohr relate sa rencontre avec Nathan de Rothschild. Au lendemain de son premier concert, il lui remit une lettre de recommandation écrite par le frère de Nathan, Amschel Mayer, à son intention. Après avoir lu la lettre, Nathan lui dit : «Je vois là dans le journal (il tenait à la main un numéro du Times) que vous avez fait merveille hier au soir. » Tout en lui adressant ce compliment, il poursuivit : «Mais je n'entends rien à la musique; ma musique à moi, la voilà, dit-il en frappant sur la poche de son gilet pour y faire sonner ses écus, on la goûte fort à la Bourse!» En commentant cet épisode, Spohr déclara que la lettre de recommandation ne fut pas complètement inutile, car Nathan de Rothschild prit une loge entière pour son concert à bénéfice ${ }^{5}$.

5 Au-delà de leur aspect anecdotique, ces récits témoignent de l'importance et de la valeur sociale de la musique. Les Rothschild, grands financiers, nouveaux nobles (James est fait baron en 1822), doivent s'intéresser à la musique - on attend d'eux qu'ils cultivent cet art, moyen d'affirmation sociale. Ces considérations touchent une question importante, mais pas encore suffisamment explorée dans les études musicologiques, à savoir le statut de l'art musical dans les salons. La musique est omniprésente dans les réunions mondaines. Qu'il s'agisse des salons du faubourg SaintGermain, de ceux du faubourg Saint-Honoré, de ceux de la Chaussée d'Antin ou encore des ambassades d'Autriche et d'Angleterre, la musique y est toujours mise à l'honneur (il n'y avait que quelques salons politiques ou littéraires, où l'on n'en jouait pas). Cependant, tous les salons ne se valent pas. Si, dans les salons que l'on peut qualifier de "musicaux", la musique occupe une place centrale, son statut est beaucoup plus ambigu dans les salons mondains, où elle peut, dans certains cas, se réduire à une convenance, à un brillant divertissement, voire à un pur "accompagnement » de la conversation.

On peut donc se demander quel était le statut de la musique dans les soirées données par James et Betty de Rothschild dans leur hôtel particulier du 19, rue Laffitte à Paris. Ce salon, l'un des plus courus de la capitale, a été décrit en 1866 par Édouard Ferdinand de Beaumont-Vassy comme "l'un des splendides hôtels de Paris ", que l'on n'admire pas pour la richesse de ses ameublements mais plutôt pour les trésors artistiques qu'il renferme ${ }^{6}$. Si nous possédons plusieurs sources qui décrivent physiquement le salon des Rothschild, ses tableaux et ses objets d'art, celles qui témoignent d'activités musicales en son sein se révèlent peu nombreuses et ont souvent un caractère anecdotique. Lady Morgan - femme de lettres, elle-même salonnière et grande amatrice de musique - consacre quelques pages de son ouvrage La France en 1829 et 1830 à une soirée passée chez le baron James de Rothschild, au château de Boulogne. Tout en mentionnant la présence de Rossini, elle se concentre uniquement sur le célèbre cuisinier Antonin Carême, qu'elle a hâte de pouvoir juger :

Une société nombreuse, composée de personnes distinguées de toutes les nations, se livrait à une causerie assez amusante, pour faire passer sans ennui le mauvais quart d'heure qui précède le dîner. [...] Tout en causant avec Gérard et en attendant Rossini, je ne pouvais penser qu'à l'immortel Carême. Gérard était mon ancien ami, Rossini mon ancienne connaissance: mais leurs ouvrages m'étaient familiers [...]. Mais je ne connaissais par expérience aucune des productions de Carême : j'allais être à portée de juger, comme il le dit si bien lui-même, des progrès que les facultés intellectuelles de l'illustre praticien avaient fait faire à l'art [...] ${ }^{7}$. 
7 De son côté, le maréchal de Castellane relate dans son journal, en date du 10 novembre 1827, un dîner chez le baron de Rothschild. La musique y est évoquée, mais seulement " en passant ": "J'ai dîné chez le fameux banquier Rothschild; on a voulu, avant le dîner, pour l'édification du célèbre Rossini, faire chanter la petite [Charlotte] Rothschild, qui a deux ans et demi $^{8}$.» Après avoir longuement décrit les convives, Castellane continue :

M. Rossini, d'une taille moyenne, assez gros, ne m'aurait pas donné, en le voyant, l'idée d'un homme de génie, si je ne l'avais pas su; il a chanté et joué du piano. Il était à table à côté du Rothschild de Vienne, frère de James que nous possédons à Paris et père de sa femme, qui est assez jolie et très polie. Elle a bien chanté, en tremblant beaucoup; son accent allemand est désagréable ${ }^{9}$.

8 Les deux sources que je viens de citer mentionnent le nom de Rossini, un musicien qui fut particulièrement lié à la famille Rothschild : comme on l'a vu, il a été témoin au mariage de Lionel, qu'il considérait comme un ami très cher ( mio carissimo amico $\left.{ }^{10} »\right)$; il fréquentait régulièrement chez le baron James et, en fin gourmet qu'il était, il appréciait tout particulièrement la cuisine de Carême. Rossini avait même des intérêts financiers dans la banque Rothschild. En 1862, il composa une cantate pour la venue de Napoléon III au château de Ferrières ${ }^{11}$. En plus de fournir un témoignage sur ce lien avec Rossini, le journal de Castellane documente des activités musicales qui avaient lieu dans le salon de façon informelle, l'un ou plusieurs des hôtes se mettant au piano. Mais, dans l'hôtel Rothschild, on donnait également de véritables concerts privés. Ils étaient souvent organisés par Rossini lui-même, qui s'occupait d'engager des chanteurs de renom, comme Giuditta Pasta ${ }^{12}$ ou Laure Cinti-Damoreau ${ }^{13}$. Dans ce contexte, l'organisation de concerts privés dans une maison aristocratique n'est pas surprenante, puisque Rossini l'avait régulièrement fait pendant son séjour à Londres, en 1824. En revanche, il est beaucoup plus étonnant - et très significatif - que le baron de Rothschild prenne lui-même le temps de contacter les musiciens et s'occupe de l'organisation matérielle du concert ${ }^{14}$.

9 L'éclat des concerts donnés par les Rothschild était tel que, malgré leur caractère privé, ils pouvaient bénéficier d'une mention dans la presse musicale. En mars 1845, Le Ménestrel parle du :

[...] vaste hôtel, riche sanctuaire de la fortune des États et des têtes couronnées. Je vous ai nommé l'hôtel Rothschild. Là se réalisent des fêtes splendides, royales, de véritables rêves des Mille et Une Nuits. Nulle part on ne trouverait des fêtes mieux ordonnées que chez ce haut potentat financier; car il faut rendre cette justice à M. le baron Rothschild, qu'il ne s'est jamais prévalu de sa grande fortune pour abuser de la musique. Il en consomme juste ce qu'il en faut, et en homme de goût. Cette fois, il a réuni dans ses salons Lablache et $\mathrm{M}^{\mathrm{me}}$ Sabatier, qui, dans le duo de Don Pasquale, ont constamment excité l'enthousiasme. Le jeune violoncelliste Jacques Offenbach a également brillé dans cette soirée ${ }^{15}$.

10 On est là bien loin du portrait du banquier tout épris de ses affaires qu'un autre critique avait publié dans le même journal. Ici, James de Rothschild est considéré comme mécène dans le sens le plus noble du terme, un mécène qui apprécie l'art musical à sa juste valeur. Un tel portrait est confirmé par une lettre que le baron adressa, en 1865, à la célèbre cantatrice Adelina Patti pour la féliciter d'un concert qu'elle avait donné le soir précédent ${ }^{16}$ :

Ma chère Mademoiselle Patti,

Vous m'avez tellement enchanté hier que je veux vous faire mon compliment de

tout mon cœur, et vous remercier du véritable plaisir que je vous dois. Je vous sais 
gré tout particulièrement du choix que vous avez fait du petit air composé par ma nièce, et que votre talent fait si bien valoir! Chose à peine croyable, votre voix semble avoir encore gagné depuis l'an dernier, à moins que ce ne soit là une illusion chaque fois renouvelée par le charme magique sous lequel on est en vous entendant. Pour contribuer à entretenir dans tout son éclat cette voix admirable, je vous envoie, ma chère demoiselle, un ananas confit que j'ai rapporté de Nice à votre intention; et je vous prie en même temps d'agréer mes meilleurs sentiments,

Baron James de Rothschild

Paris, 6 mars $1865^{17}$.

11 Dans cette lettre, le baron fait allusion à l'une des romances de sa nièce Hannah Mathilde von Rothschild, la fille de Charlotte dite "Chilly » de Rothschild (1807-1859) et d'Anselm Salomon von Rothschild (1803-1874), de la branche de Vienne. Dès son enfance, Hannah Mathilde a montré des aptitudes pour la musique et a été particulièrement encouragée à cultiver cet art par sa mère, elle-même férue d'art et peintre amateur ${ }^{18}$. Après avoir passé son enfance entre Vienne et Francfort, Mathilde a fait un séjour à Paris en 1847 et elle a reçu quelques leçons de Chopin ${ }^{19}$. Contrairement à ce qui était permis aux jeunes filles de la haute société, elle a continué de se consacrer à la musique après son mariage avec son cousin Wilhelm Carl, dit "Willy ", de la branche de Naples (1849). Elle a publié ainsi quelques pièces pour piano, une valse pour orchestre et surtout un grand nombre de romances sur des textes de Victor Hugo, de Théophile Gautier et de Goethe. Parues sous son nom d'épouse, Willy de Rothschild, ses romances étaient très appréciées non seulement par les gens du monde fréquentant les salons, mais aussi par quelques critiques, qui sont allés jusqu'à affirmer que « la belle mélodie Appelle-moi ton âme, de la baronne Willy de Rothschild, [est] une production digne d'être signée : Schubert ${ }^{20}$ ». Bien qu'une telle opinion soit sans doute exagérée, la musique de Mathilde a joui de l'appréciation de nombre de musiciens, comme Adelina Patti qui, en 1905, a immortalisé la romance Si vous n'avez rien à me dire dans un enregistrement. Le public en était également enthousiaste : si l'on en croit une lettre de Charlotte, la femme de Lionel de Rothschild, à son fils Léopold, « cet hiver à Paris, Patti a omis de chanter la charmante Romance de la Baronne Willy et la fosse de l'Opéra s'est levée en masse en demandant "la Romance de $\mathrm{M}^{\text {me }}$ de Rothschild ${ }^{21}$ " ".

Mathilde de Rothschild n'était pas la seule musicienne de la famille. Sa cousine Charlotte, la fille de James et de Betty, avait également des penchants artistiques marqués. Si son talent s'est principalement manifesté dans le domaine des beaux-arts elle a exposé au Salon à partir de $1864^{22}$-, elle a été une bonne pianiste amateur, s'est distinguée dans le mécénat musical et s'est même essayée à la composition. Son statut social l'empêchait de se produire en public. Elle a essentiellement cultivé la musique en privé et nous n'avons donc pas de témoignage direct sur ses dons de musicienne. Néanmoins, le fait qu'elle ait reçu des leçons de Chopin pendant plusieurs années est très significatif, on sait que le compositeur polonais était très pointilleux dans le choix de ses élèves : il en acceptait difficilement et, en aucun cas, il ne donnait des leçons à ceux qui étaient dénués de talent. Les relations qu'elle entretint avec chopin permettent d'esquisser un portrait de la musicienne ${ }^{23}$.

Si l'on en croit une note d'Henri de Rothschild, le petit-fils de Charlotte, elle aurait commencé à étudier avec Chopin en 1840, mais le premier document attestant cet enseignement est le Tagebuch d'Anton Schindler, le biographe de Beethoven, qui, en date du 2 février 1841, indique qu'il se trouvait chez Chopin alors que $M^{\text {lle }}$ de Rothschild attendait pour recevoir sa leçon. Schindler précise également que chopin recevait d'elle l'importante somme de 50 francs pour chaque leçon. Le 17 août 1842, Charlotte 
épousa Nathaniel de Rothschild, son cousin de la branche anglaise: c'est très probablement à cette occasion qu'elle reçut de Chopin, peut-être comme cadeau de mariage, le manuscrit de la Valse posthume op. 69, $\mathrm{n}^{\circ} 1$ (fig. 3), «à Mademoiselle Charlotte de Rothschild / Hommage / Paris, 1842 / F. Chopin ${ }^{24}$ ». Après le mariage, les leçons ont été brièvement suspendues, mais dès l'automne 1842, Charlotte écrivit à Chopin qu' " elle désirerait de nouveau se compter parmi ses élèves ${ }^{25}$ ». Les cours ont continué au moins jusqu'au 29 mars 1849, comme l'atteste le nom «Rothschild» dans l'agenda de poche de Chopin. Par ailleurs, plusieurs éléments indiquent que leurs relations allaient bien au-delà de celles de maître à élève. Chopin était souvent l'hôte $\mathrm{du}$ salon Rothschild, aussi bien pour des réunions privées qu'à l'occasion de « réceptions officielles» (par exemple, le 2 janvier 1843, il a participé au concert d'inauguration des nouveaux salons Rothschild, en jouant son Concerto en mi mineur op. 11 à quatre mains avec son élève, l'enfant prodige Carl Filtsch, qui faisait ses débuts en cette occasion $\left.{ }^{26}\right)$. Signalons également qu'en octobre 1847 le compositeur a été invité à passer quelques jours au château de Ferrières. Enfin, l'agenda de poche de Chopin, en date du 21 mai 1849, porte l'inscription : «Rothschildowe 1000 » : étant à cette époque déjà très malade, Chopin n'était pas en mesure de donner une série continue de leçons ; l'inscription a été donc interprétée comme le mémento d'une aide financière qu'il a reçue des Rothschild.

3. Frédéric Chopin, Valse, op. $69, \mathrm{n}^{\circ} 1,1842,15,5 \times 25,5 \mathrm{~cm}$, Paris, Bibliothèque nationale de France, département de la Musique, ms. 121, consultable en ligne sur Gallica : gallica.bnf.fr/ark:/12148/ btv1b550010414/f3.image

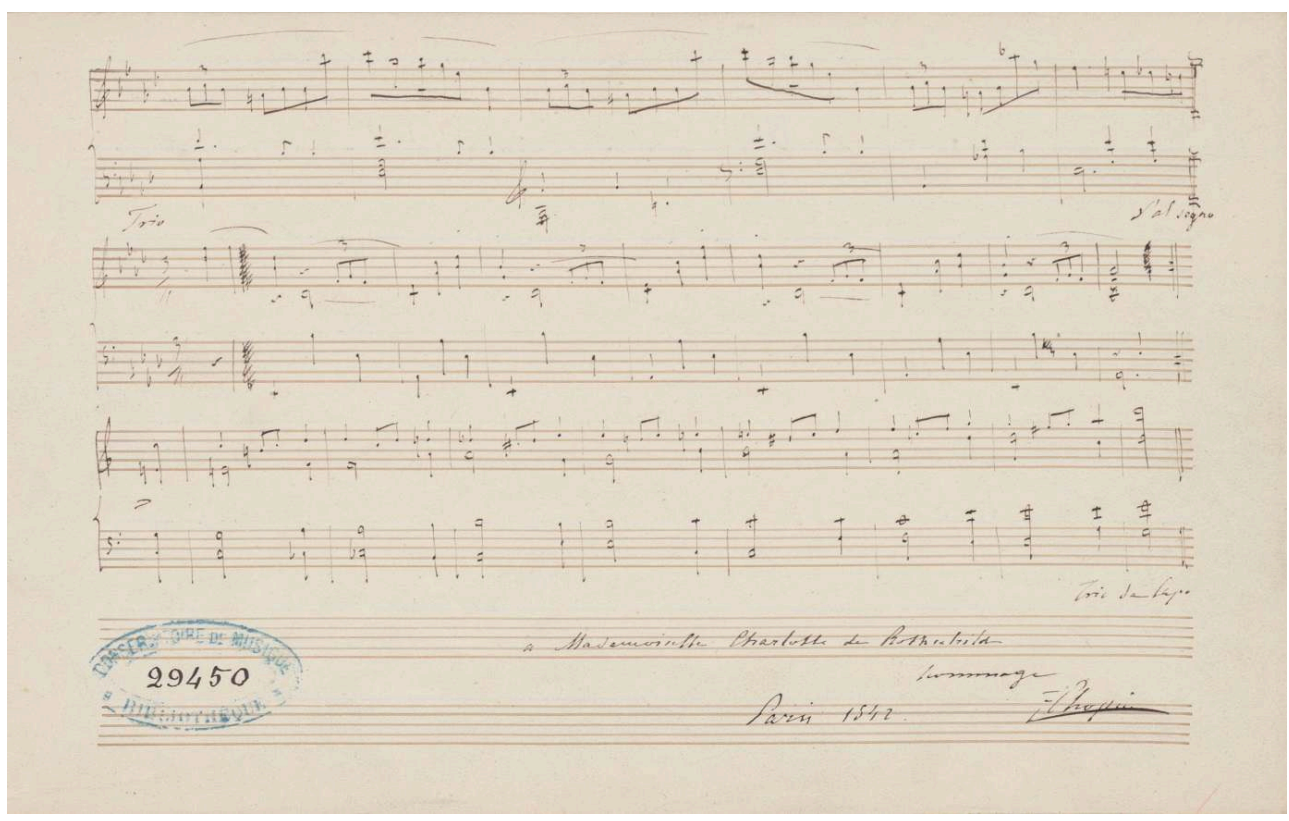

(c) BnF/Gallica

De son côté, le compositeur portait un attachement tout particulier à Charlotte, la seule élève qui, avec Delphine Potocka, s'est vu dédier deux œuvres : la quatrième Ballade (1843) et la Valse op. 64, $\mathrm{n}^{\circ} 2$ en ut dièse mineur (1847). En plus de ces dédicaces, elle a reçu sept manuscrits autographes du compositeur, qu'elle a légués par voie testamentaire à la bibliothèque du Conservatoire et sur lesquels je reviendrai. Après la mort de Chopin, Charlotte est restée en contact avec le cercle de son maître. Elle a étudié la composition avec le violoncelliste Auguste Franchomme, l'un des amis 
français les plus proches de Chopin, et le piano avec Thomas Tellefsen, un autre élève du compositeur polonais.

Comme ses parents, Charlotte de Rothschild donnait des soirées musicales dans son salon de la rue du Faubourg-Saint-Honoré. On connaît mal ces réceptions, les quelques mentions que l'on retrouve dans la presse font penser qu'elles étaient hebdomadaires et qu'elles commençaient dès le mois de janvier. Si l'on en juge par l'entrefilet suivant, la musique n'y était pas jouée de façon informelle, mais il s'agissait de véritables concerts privés, qui pouvaient se révéler le banc d'essai de compositions inédites :

Très beau programme aux deux derniers samedis de $\mathrm{M}^{\text {me }}$ la baronne Nathaniel de Rothschild, excellente musicienne, comme on sait. - Faure, Bosquin, $\mathrm{M}^{\text {lles }}$ Fidès Devriès et Rosine Bloch représentaient la partie vocale. - Immense effet de Faure dans une transcription concertante de M. de Hartog sur le Paulus de Mendelssohn. Grand succès aussi pour le Sancta Maria de Faure, chanté par $\mathrm{M}^{\text {lle }}$ Rosine Bloch, avec le violon de Garcin et l'auteur à l'orgue. Faure a aussi interprété un remarquable sonnet inédit de Périer, l'excellent violoniste-compositeur ${ }^{27}$.

Se renouvelant d'année en année, ces manifestations étaient considérées non seulement comme très à la mode, mais aussi comme très artistiques :

La semaine dernière, Le Figaro annonçait la prochaine ouverture des somptueux et artistiques salons de la baronne Nathaniel de Rothschild, pianiste de la bonne école, à laquelle nous prêtions même les remarquables productions de sa nièce, madame la baronne Willy de Rothschild, l'auteur de la mélodie popularisée par Madame Patti: Si vous n'avez rien à me dire, et de celle si expressive: Appelle-moi ton âme, interprétée à Londres par Madame Nilsson et à Paris par $\mathrm{M}^{\text {lle }}$ Albani.

Aujourd'hui, nous pouvons affirmer que tous les salons Rothschild se disposent à rouvrir cet hiver leurs portes dorées, et que bien d'autres s'apprêtent à suivre ce bon exemple ${ }^{28}$.

Une précision sur l'expression «tous les salons Rothschild»: outre la baronne Nathaniel, son frère Alphonse suivit l'exemple paternel et tint un salon très réputé, dont les soirées étaient agrémentées de musique par des musiciens très en vue à l'époque, comme les cantatrices Adelina Patti, Emma Albani, Christine Nilsson, le baryton Jean-Baptiste Faure et le pianiste Francis Planté. Un entrefilet publié dans Le Gaulois indique erronément qu'Alphonse de Rothschild ferma son salon "si artistiquement hospitalier, si princièrement élégant " de la rue de Monceau à la mort de la baronne Nathaniel de Rothschild, mort que le journal a annoncée en $1884^{29}$, quinze ans avant la disparition de la baronne !

\section{Le legs de Charlotte de Rothschild au Conservatoire}

Dans son testament, Charlotte de Rothschild «donne et lègue au Conservatoire de Musique de Paris tous [s]es instruments anciens de Musique ainsi que les manuscrits de Chopin et de Rossini ». Les huit instruments à cordes pincées (XVII ${ }^{e}$ et XVIII ${ }^{e}$ siècles) sont actuellement conservés au musée de la Musique $^{30}$. Les manuscrits donnés au Conservatoire, dont les collections sont sous la responsabilité scientifique de la Bibliothèque nationale de France depuis la réunion des bibliothèques en 1935, ont été transférés en 1964 au département de la Musique, rue de Louvois.

Le legs des manuscrits est entouré d'une « sorte de mystère » : on n'en retrouve aucune trace dans les archives de la bibliothèque du Conservatoire et, par conséquent, on ignore jusqu'au nombre de partitions faisant partie de ce legs. La présente reconstitution se fonde sur trois types de sources: les registres des entrées du Conservatoire, les carnets de cotes et les manuscrits musicaux eux-mêmes. En 
recoupant les informations - dans la plupart des cas contradictoires - qu'elles livrent, j'ai pu reconstituer les contours du legs.

19 Une première indication, très succincte, est fournie par le carnet d'entrées du Conservatoire qui, sous le numéro 29450, indique « autographes de Chopin légués par M.e de Rothschild», une inscription datant du troisième trimestre 1901. Ce numéro d'entrée est présent sur sept des vingt-cinq manuscrits autographes du compositeur polonais, conservés au département de la Musique (bibliothèque-musée de l'opéra comprise). Dans son catalogue des manuscrits des œuvres de Chopin, Krystyna Kobylańska a considéré l'autographe de la Berceuse op. 57 (conservé au département de la Musique sous la cote ms.115) comme faisant partie du legs de Charlotte de Rothschild ${ }^{31}$. Dans la notice qu'elle a consacrée à ce manuscrit, Kobylańska a cité un extrait de l'ouvrage de Moritz Karasowski, où l'on peut lire qu'Élise Gavard, l'élève de Chopin dédicataire de la Berceuse, était la propriétaire de l'autographe de l'œuvre. Kobylańska a ajouté un commentaire à cette citation, en affirmant qu'il est difficile de déterminer si l'autographe ayant appartenu à Élise Gavard était le même manuscrit, devenu la propriété de Charlotte de Rothschild quelque temps après ${ }^{32}$. Or, rien ne prouve que le manuscrit ms. 115 ait réellement appartenu à la baronne de Rothschild. En effet, contrairement à tous les autres autographes de Chopin qu'elle a légués au Conservatoire, il ne comporte pas le numéro d'entrée 29450. Il est fort probable que l'erreur de Kobylańska dérive d'une mauvaise lecture du carnet de cotes: pour le ms. 114, la colonne "provenance» indique «legs Rothschild», tandis que, pour le document suivant, c'est-à-dire ms. 115, cette colonne est laissée vide, ce qui a pu être interprété comme une indication d'« idem ». D'autres éléments portent à croire que ce manuscrit a été légué au Conservatoire par Élise Gavard et non par la baronne de Rothschild: lorsqu'en 1888 Moritz Karasowski publia sa biographie de Chopin, il affirma qu'Élise Gavard conservait le manuscrit de la Berceuse comme le souvenir le plus cher de son professeur ${ }^{33}$. Il est improbable qu'élise Gavard ait fait don de cette précieuse relique à Charlotte de Rothschild après 1888: non seulement la baronne possédait déjà plusieurs manuscrits de Chopin, alors qu'Élise, elle, n'en avait que deux, mais elle ne se serait pas séparée de l'œuvre qui lui était dédicacée. Selon toute vraisemblance, le ms. 115 a donc intégré les collections du Conservatoire à travers un legs fait par Élise Gavard ${ }^{34}$.

Les autographes de Chopin composant le legs Rothschild sont alors les suivants : la Valse posthume op. $69, \mathrm{n}^{\circ} 1^{35}$, dont il a déjà été question (autographe probablement offert par Chopin à Charlotte pour son mariage); une copie des Valses op. 64, $\mathrm{n}^{\circ} 1^{36}$, op. $64, \mathrm{n}^{\circ} 2^{37}$ (dédiée à Charlotte dans l'édition) et op. $70, \mathrm{n}^{\circ} 2^{38}$; deux copies de la Valse en la mineur sans numéro d'opus ${ }^{39}$; et deux copies du Nocturne en ut mineur sans numéro d'opus ${ }^{40}$. Ces deux dernières œuvres sont très particulières; elles ont été publiées de façon posthume, très tardivement: le Nocturne, en 1938, à Varsovie par Ludwig Bronarski et la Valse, en 1955, à Paris par Suzanne et Denise Chainaye. La forme et la structure simple de ces deux pièces ont toujours embarrassé les spécialistes du compositeur, qui les ont considérées soit comme des œuvres de jeunesse traduisant une certaine inexpérience, soit comme des œuvres tardives, marquées par l'épuisement. Or, en 2012, Louise Dubin a découvert et analysé en détail deux éditions de ces pièces, publiées au XIX ${ }^{e}$ siècle sous le nom de la baronne de Rothschild ${ }^{41}$. En 2015, ces éditions ont été publiées en fac-similé et ultérieurement étudiées par Jean-Jacques Eigeldinger ${ }^{42}$. (fig. 4) 
4. Frédéric Chopin, Valse en la mineur, sans numéro d'opus, Paris, Bibliothèque nationale de France, département de la Musique, ms. 119 A, consultable en ligne sur Gallica : gallica.bnf.fr/ark:/12148/ btv1b55001038v.

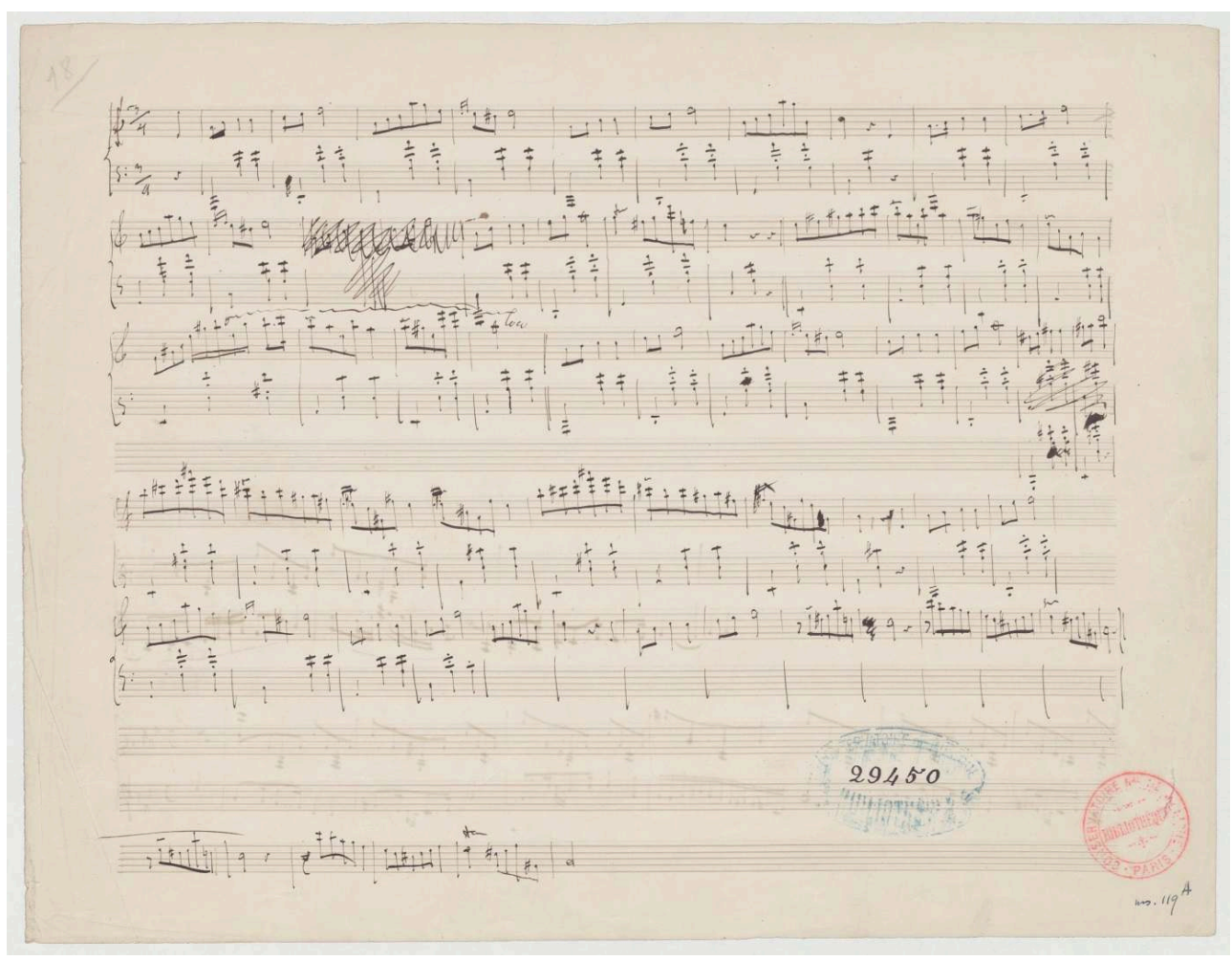

(C) BnF/Gallica

L'édition de Quatre Pièces pour piano par la baronne Nathaniel de Rothschild, parue chez Maho vers 1860, contient, en plus du Nocturne en do mineur et de la Valse en la mineur (que l'on connait aujourd'hui comme œuvres posthumes de Chopin), une Polka en do mineur et une Valse en fa mineur (fig. $5 a$ et $5 b$ ). Quant à l'édition de Deux Pièces pour piano et violoncelle par la baronne Nathaniel de Rothschild, publiée par Maho en 1872 et dédiée à Auguste Franchomme, elle ne comporte que deux pièces : la Valse en la mineur, arrangée pour violoncelle et piano, et une Valse en fa mineur. Une question se pose d'emblée: Charlotte de Rothschild se serait-elle approprié le Nocturne en do mineur et la Valse en la mineur de Chopin et les aurait-elle publiées sous son nom après la mort de son maître? $\mathrm{Si}$, au contraire, ces deux compositions sont effectivement dues à la plume de Charlotte, pourquoi Chopin les aurait-il recopiées?

Dans son étude, Louise Dubin a analysé ces deux pièces et les a comparées à d'autres œuvres posthumes de Chopin. En s'appuyant sur les résultats de cette analyse ainsi que sur des documents retrouvés dans les archives d'Auguste Franchomme, elle a conclu que le Nocturne et la Valse résultent d'une collaboration entre Chopin et la baronne : il s'agit soit d'un exercice de composition commencé par Chopin pour que Charlotte le complète, soit d'une pièce composée par Charlotte pendant ses leçons avec Chopin. Le compositeur aurait mis la musique sur le papier pour elle, comme l'a fait Franchomme pour l'arrangement des deux pièces pour piano et violoncelle ${ }^{43}$. Jean-Jacques Eigeldinger est arrivé à des conclusions semblables, en se fondant sur l'analyse des analogies existant entre la Polka de Charlotte de Rothschild et le Nocturne en ut mineur ${ }^{44}$. 
$5 a$ et $b$. Quatre pièces pour piano par la baronne Nathaniel de Rothschild, page de titre, Paris, J. Maho, 1860, Bibliothèque nationale de France, département de la Musique, VMG 6705, consultable en ligne sur Gallica : gallica.bnf.fr/ark:/12148/bpt6k8582393/f3.image.

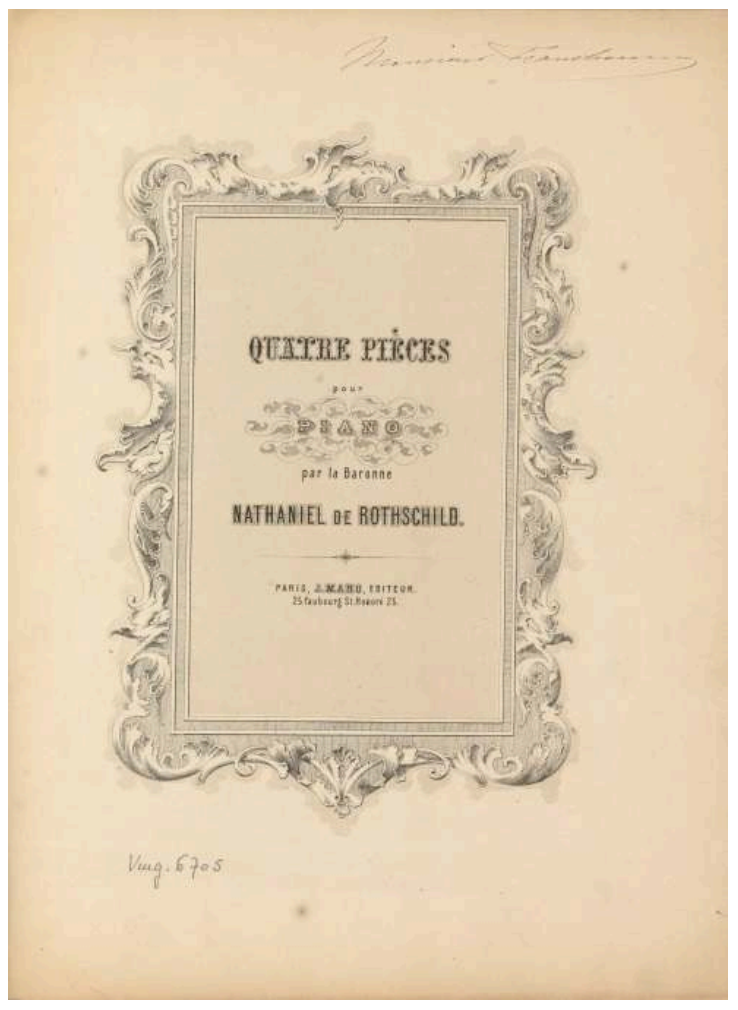

(c) BnF/Gallica

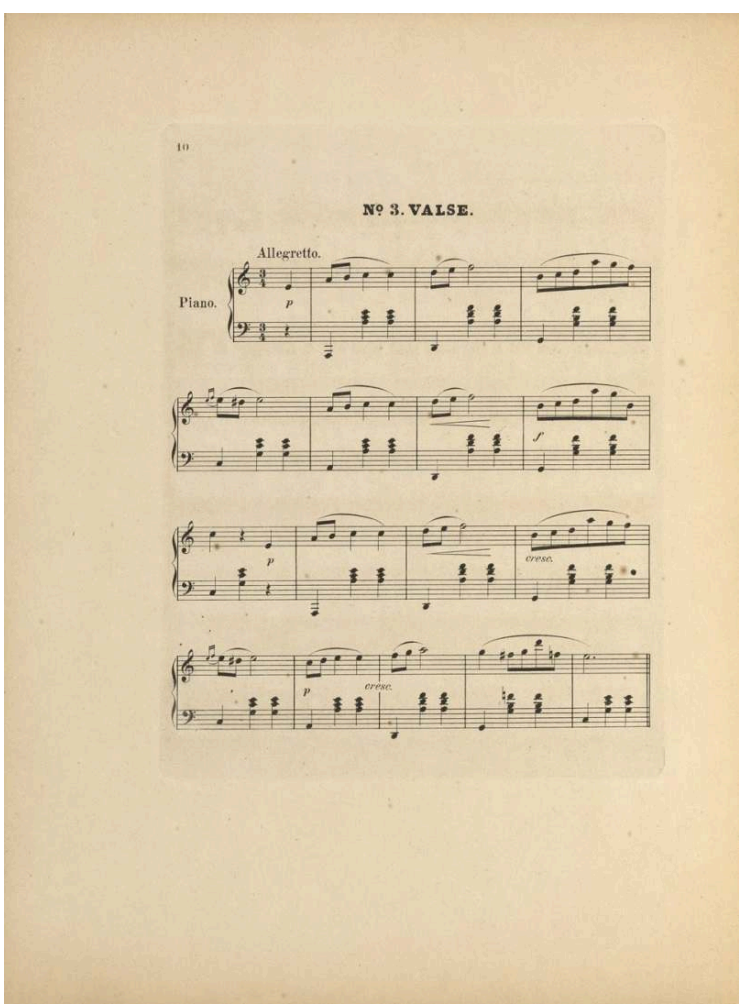

(c) BnF/Gallica 
En plus des manuscrits de Chopin, le testament de Charlotte de Rothschild fait mention d'un certain nombre de manuscrits de Rossini. Le département de la Musique conserve, dans le fonds du Conservatoire, un Scherzo pour piano en la mineur, recopié sur un papier à musique richement décoré d'un pastiche de miniature médiévale représentant une joueuse de harpe face à un ange, avec l'envoi autographe (fig. 6) : «Petit Souvenir offert à $\mathrm{M}^{\mathrm{me}}$ la baronne Charlotte Nathaniel de Rothschild par son très dévoué G. Rossini, Paris, 10 sett $1843^{45}$.»

6. Gioachino Rossini, «Petit souvenir offert à $\mathrm{M}^{\mathrm{me}}$ la baronne Charlotte Nathaniel de Rothschild par son très dévoué G. Rossini, Paris, 10 septembre $1843 », 27 \times 34 \mathrm{~cm}$, Paris, Bibliothèque nationale de France, département de la Musique, ms. 1338, consultable en ligne sur Gallica : gallica.bnf.fr/ ark:/12148/btv1b52502175j/f5.image.

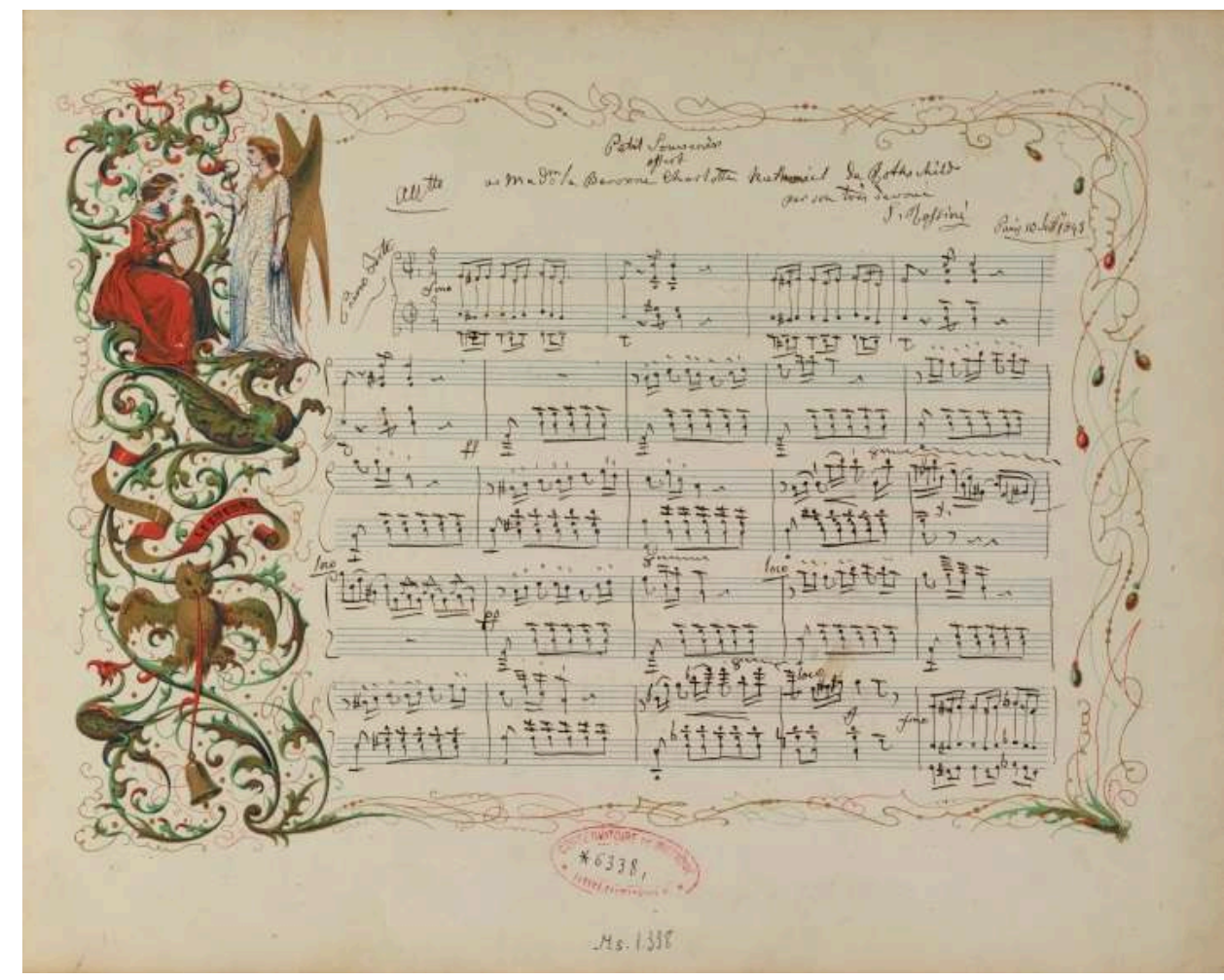

(c) BnF/Gallica

Étrangement, le numéro d'entrée de ce manuscrit $\left({ }^{*} 6338\right)$ est différent du numéro d'entrée inscrit sur les autographes de Chopin (29450). Le registre d'entrées ne donne aucun renseignement sur la provenance de l'autographe de Rossini. On sait néanmoins que les numéros d'entrée commençant par une étoile ont été inscrits dans les années 1920 ; on pourrait donc avancer l'hypothèse selon laquelle ce manuscrit est resté dans des cartons et a été traité par les bibliothécaires environ vingt ans après ceux de Chopin. Les choses ne sont toutefois pas aussi simples et cet autographe soulève un certain nombre de questions sur son histoire. Si, d'après le registre des entrées, sa provenance est inconnue, le carnet de cotes indique qu'il a intégré le fonds du Conservatoire à la suite du legs de Charles Malherbe. Yvonne Rokseth (1890-1948) a reporté cette information sur le carnet pour une série d'autographes de Rossini (allant de ms. 1335 jusqu'à ms. 1339) : tous ces documents comportent une estampille « Charles Malherbe ", tous... sauf un : le Petit Souvenir offert à Charlotte de Rothschild (ms. 1338). Il est donc difficile de trancher, car ces deux sources - carnet de cotes et document lui- 
même - sont en contradiction. Néanmoins, j'aurais tendance à penser que l'absence de cachet «Malherbe " indique que ce manuscrit n'a jamais fait partie des collections rassemblées par ce collectionneur.

Il existe, dans le fonds du Conservatoire au département de la Musique de la BnF, un deuxième document de la main de Rossini que l'on a rattaché au legs Rothschild ${ }^{46}$. Il s'agit d'un double feuillet renfermant une Valse en mi bémol, avec l'inscription "à Mad.lle Charlotte de Rothschild ${ }^{47}$ ». Toutefois, ce manuscrit ne faisait aucunement partie du legs Rothschild: il est entré au Conservatoire grâce au legs de Charles Malherbe, comme le montrent clairement les estampilles présentes sur le document et mentionnant le nom du collectionneur.

J'ai également retrouvé un troisième document que l'on peut mettre en relation avec Rossini : il s'agit d'une copie d'une pièce ne comportant ni de titre ni de nom d'auteur, mais qui est qualifiée de Tarentelle inédite et attribuée à Rossini (ms. 8623) sur la page de titre par Julien Tiersot ${ }^{48}$. Ce manuscrit, dont le numéro d'entrée $\left({ }^{*} 6338\right)$ correspond à celui de l'autographe du Scherzo en la mineur offert par Rossini à Charlotte de Rothschild, est entré dans les collections de la bibliothèque du Conservatoire en même temps que ce dernier et faisait probablement partie du legs de la baronne de Rothschild.

En plus des pièces de Chopin et de Rossini, j'ai pu retrouver un manuscrit de la main de Johann Baptist Cramer, intitulé Ricordo di Napoli et daté du 3 septembre 1838. Charlotte de Rothschild a presque certainement reçu ce manuscrit du compositeur qui, d'après François-Joseph Fétis, vécut à Paris entre 1832 et $1845^{49}$. La mention figurant sur le carnet de cotes est intrigante, car cet autographe est considéré comme "don Rothschild » et non comme un legs. Aucun élément matériel ne permet de rapprocher ce manuscrit des autres légués par Charlotte de Rothschild (il ne comporte pas de numéro d'entrée ni d'autre indication de provenance). Néanmoins, il faisait certainement partie du legs, car un entrefilet, paru le 10 décembre 1899 dans Le Ménestrel, mentionne le nom de Cramer aux côtés de ceux de Chopin et de Rossini :

La baronne Nathaniel de Rothschild a légué quelques souvenirs au Conservatoire de musique. La bibliothèque $\mathrm{a}$ eu pour sa part plusieurs pièces autographes de Chopin, un grand morceau de piano signé de Rossini, ainsi que diverses pièces pour le piano de la main de Cramer. De son côté le musée du Conservatoire s'est enrichi de sept instruments anciens très précieux, des mandolines, des mandores et deux splendides archiluths ${ }^{50}$.

Publié sous forme anonyme, cet entrefilet est assez précis pour laisser penser que c'était un bibliothécaire du Conservatoire ou, dans tous les cas, une personne qui lui était proche qui a demandé à l'éditeur Heugel d'insérer cette nouvelle dans son journal. Si cette hypothèse confère à l'entrefilet une forme d'autorité, je n'ai pas pu confirmer l'existence de plusieurs pièces pour piano de la main de Cramer dans le legs Rothschild. En effet, aucune autre source manuscrite des œuvres du compositeur conservée dans le fonds du Conservatoire (autographes et copies) ne peut être rattachée à la famille Rothschild. 
En plus des autographes, j'ai pu retrouver un certain nombre de copies manuscrites qui faisaient sans doute partie du lot «manuscrits de Chopin» mentionnés dans le testament. On peut ainsi dénombrer :

- deux copies de la Berceuse:

- - la première (D 10810) ne comporte pas les deux premières mesures d'ostinato à la main gauche que Chopin ajouta en vue de la publication et reproduit ainsi la version rejetée de l'œuvre, telle qu'elle figure dans l'autographe ayant appartenu à Élise Gavard ;

- la seconde (D 10809) (fig. 7) est incomplète : elle ne comporte que les 42 premières mesures et reproduit la version finale de l'œuvre, telle qu'elle a été publiée par le compositeur. Il ne s'agit cependant pas d'une copie de l'édition française; au contraire, elle partage certaines caractéristiques graphiques avec l'autographe, notamment l'absence de liaisons dans l'accompagnement de la main gauche et la position des hampes qui, à partir de la mesure 39, ne sont pas redoublées pour faire ressortir la mélodie ${ }^{51}$;

- une copie de la Marche funèbre op. 72, $\mathrm{n}^{\circ} 2$ (D 10807) ${ }^{52}$;

- une copie partielle des Mélodies polonaises op. 74 (D 10813) ${ }^{53}$.

7. Frédéric Chopin, Berceuse (copie), 1844-1880, $28 \times 22 \mathrm{~cm}$, Paris, Bibliothèque nationale France, département de la Musique, D 10809, consultable en ligne sur Gallica : gallica.bnf.fr/ark:/12148/ btv1b55000834r.

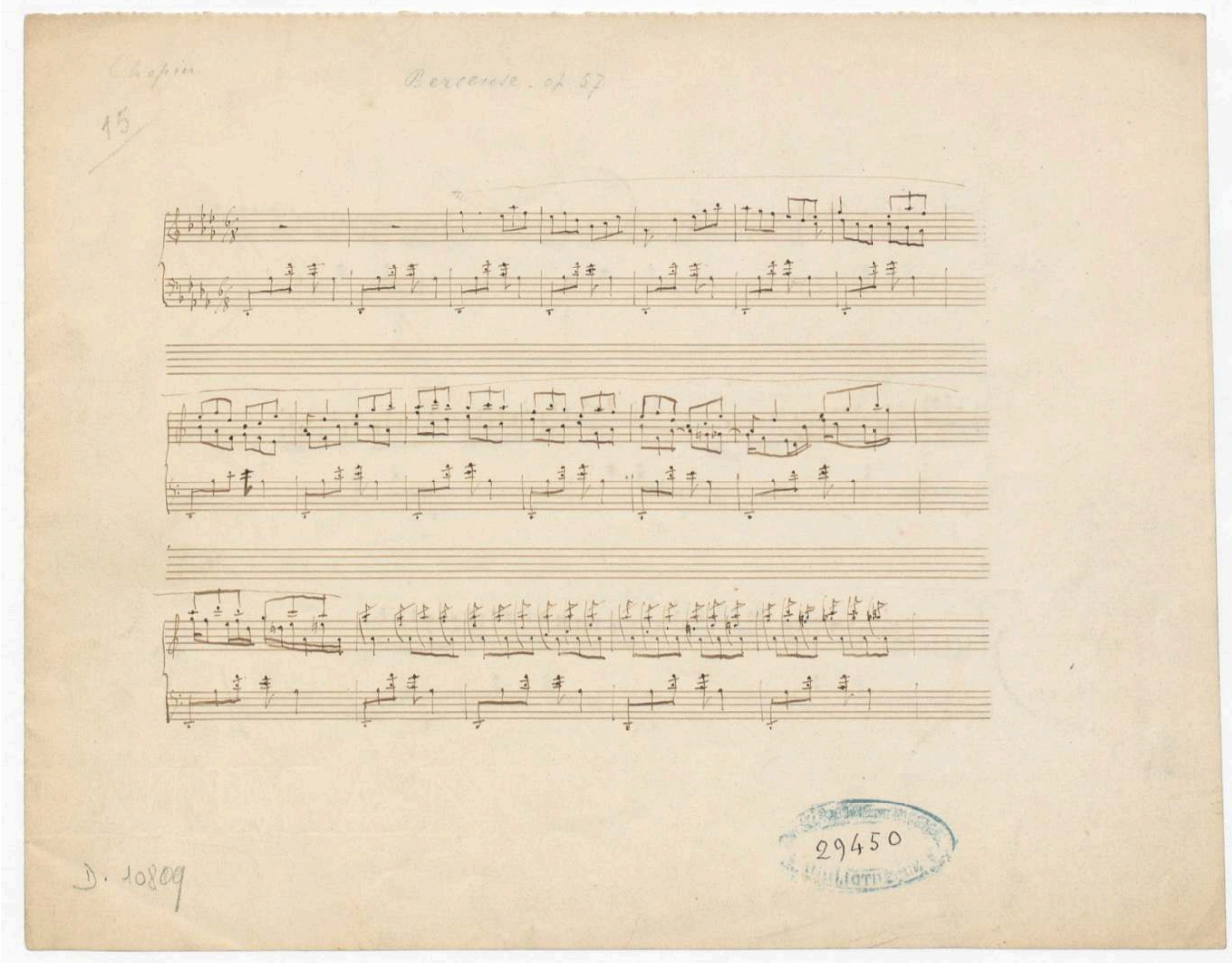

\section{(c) BnF/Gallica}

Deux de ces manuscrits - à savoir la copie incomplète de la Berceuse et la Valse op. 70, $\mathrm{n}^{\circ} 1$ - portent le même numéro d'entrée que les autographes de Chopin légués au Conservatoire par la baronne. Bien que ce numéro ne soit pas présent sur tous ces documents, il est certain qu'ils faisaient partie d'un lot unique. En effet, toutes ces 
copies se ressemblent: d'après l'analyse graphologique des clefs et des altérations, on peut affirmer qu'ils ont été écrits par une seule et même personne.

31 J'ai initialement émis l'hypothèse que cette personne était Charlotte de Rothschild ellemême: l'écriture (en particulier celle des copies de la Berceuse) ressemble étonnamment à celle de Chopin et il est connu que les élèves du compositeur polonais avaient la fâcheuse tendance à adopter par mimétisme une écriture similaire à celle de leur maître. Après tout, il ne serait pas étrange que la baronne, qui était restée proche du cercle de Chopin, recopie de sa propre main des œuvres posthumes comme la Marche funèbre ou les Mélodies polonaises, c'est-à-dire des pièces qui n'ont été publiées que très tardivement en France ${ }^{54}$. Néanmoins, cette hypothèse n'a pas pu être validée. En effet, lorsqu'on compare l'envoi autographe de Charlotte de Rothschild à Auguste Franchomme, présent sur la couverture des Quatre Pièces pour piano (VMG 6705), avec le texte de la copie des Mélodies polonaises, plusieurs différences émergent entre les deux graphies. Le copiste ne peut donc pas être identifié avec Charlotte de Rothschild. Toutefois, ces copies, réalisées par une seule et même personne qui faisait probablement partie de l'entourage de la baronne, lui ont appartenu, comme le confirme le numéro d'entrée présent sur certaines d'entre elles.

J'aimerais conclure en signalant un dernier manuscrit (D 10814). Bien qu'il ne porte pas de mention de provenance, il est écrit de la même main que les autres copies faisant partie du legs de la baronne de Rothschild. Lorsque ce lot de documents (D 10809-10814) a été catalogué dans les années 1950, les bibliothécaires ont eu des hésitations au sujet du dernier feuillet: dans le carnet de cotes, on retrouve le nom de Chopin, accompagné d'un point d'interrogation, mais aussi l'indication «esquisse anonyme ??». Cette pièce a une structure très rudimentaire et se caractérise par la simplicité de l'écriture mélodique et, surtout, harmonique ainsi que par une grossièreté dans l'accompagnement: il va sans dire que ce n'est certainement pas une œuvre de Chopin. Il ne s'agit pas non plus d'une composition de Charlotte de Rothschild: j'ai retrouvé une autre copie de cette pièce à la Bibliothèque royale de Belgique, dans un recueil rassemblant de la musique espagnole et ayant appartenu à François-Joseph Fétis ${ }^{55}$. Grâce à ce recueil, j'ai pu mettre un titre sur le feuillet anonyme D 10814 : El Jaleo de Jerez para piano. Ce dernier document laisse donc supposer que la collection musicale de Charlotte de Rothschild ne se limitait pas aux seules pièces de Chopin ou à celles d'autres compositeurs ayant fréquenté sa famille, dont Rossini et Cramer, mais qu'elle était plus vaste que ce que nous connaissons aujourd'hui. Pour des raisons évidentes, la baronne a décidé de faire don au Conservatoire des manuscrits autographes des grands compositeurs, même si certaines copies manuscrites se sont glissées dans son legs.

\section{NOTES}

1. L'article de Charlotte de Rothschild, «The Musical Association of the Rothschild family », dans Georg Heuberger (dir.), The Rothschilds: Essays on the History of a European Family, Woodbridge, 
Thorbecke/Boydell \& Brewer, 1994, p. 287-296, aborde l'importance qu'avait la musique pour la famille Rothschild.

2. Le legs de Charlotte de Rothschild à la bibliothèque du Conservatoire est actuellement conservé au département de la Musique de la Bibliothèque nationale de France.

3. [Anonyme], « Rossini à Francfort », Le Ménestrel, $3^{\mathrm{e}}$ année, $\mathrm{n}^{\mathrm{0}}$ 30, 26 juin 1836, p. 1.

4. Le Ménestrel, $57^{\mathrm{e}}$ année, $\mathrm{n}^{\circ}$ 40, 4 octobre 1891, p. 318.

5. Voir Louis Spohr's Autobiography, Translated from the German, London, Longman, 1865, p. 78.

6. Édouard Ferdinand de Beaumont-Vassy, Les Salons de Paris et la société parisienne sous LouisPhilippe $I^{e r}$, Paris, Sartorius, 1866, p. 328-331. Sur l'hôtel de la rue Laffitte, voir Pauline PrevostMarcilhacy, Les Rothschild, bâtisseurs et mécènes, Paris, Flammarion, 1995 ; et Pauline PrevostMarcilhacy, «Un hôtel au goût du jour », Gazette des beaux-arts, juillet-août 1994, p. 245-264.

7. Lady Morgan (Sydney Owenson), La France en 1829 et 1830, traduit de l'anglais par $\mathrm{M}^{\text {lle }}$ A. Sobry, Bruxelles, P. Meline, 1831, p. 133-135.

8. Boniface de Castellane, Journal du maréchal de Castellane (1804-1862), Paris, Plon, 1895, t. II, p. 200.

9. Ibid., p. 201.

10. Rossini qualifie Lionel Rothschild de "mio carissimo amico " dans une lettre à Loup du 26 juin 1836, citée dans Giuseppe Raidiciotti, Gioacchino Rossini, Vita documentata Opere et influenza du l'arte, Tivoli, Arti Grafiche Majella di Aldo Chicca, 1928, t. II, p. 193.

11. En dépit de mes recherches, je n'ai pas pu trouver de document de première main qui permette de détailler ultérieurement les relations que Rossini a eues avec les Rothschild.

12. Le 12 janvier 1825, Rossini écrivit à Giuditta Pasta : «Cara Giuditta, amerei sapere se mercoldì [sic] 12. Genajo Potete venire ad'un concerto in casa del Barone Rodchild [sic]. Colgo questa occasione per dirmi vos[tr]o Candido Estimatore. G. Rossini ", voir Bruno Cagli et Sergio Ragni (dir.), Gioachino Rossini. Lettere e Documenti. Vol. II, 21 marzo 1822-11 ottobre 1826, Pesaro, Fondazione Rossini, 1996, p. 308-309.

13. Dans une lettre non datée et connue uniquement dans une traduction en anglais, Rossini écrivit à Cinti : "Next Sunday, the $21^{\text {th }}$ of this month, there will be a concert at Baron Rothschild's and I should be so happy to procure for the company the pleasure of hearing you. If you are free and accept my invitation, please be so good as to reply, giving me a time when I may come to see you so that we can agree on the choice of the singers and on the music for the programme [...] », lettre citée dans Bruno Cagli et Sergio Ragni (dir.), Gioachino Rossini. Lettere e Documenti, op. cit., t. II, p. 308-309.

14. En 1824, le baron écrivit à Giuditta Pasta: «Par un hasard malheureux, je n'ai pu me rencontrer avec Mr. Bénédict ce matin. Veuillez bien me dire si le petit concert chez nous aura lieu Lundi, et si vous voulez que je passe chez vous demain pour pouvoir en parler plus en détail, et à quelle heure. Je puis venir quand vous voudrez, puisque je ne monterai pas à cheval. », lettre citée dans Maria Giulini Ferranti, Giuditta Pasta e i suoi tempi, Milan, Cromotipia Ettore Sormani, 1935 , p. 57.

15. Le Ménestrel, $12^{\mathrm{e}}$ année, $\mathrm{n}^{\circ} 16,16$ mars $1845, \mathrm{p}$. [2].

16. Il s'agit probablement d'une exécution donnée dans des cadres privés, peut-être chez les Rothschild, car la presse ne mentionne aucune prestation publique d'Adelina Patti pendant la première semaine de mars 1865 .

17. Lettre conservée à Londres (The Rothschild Archive, 000/1696) et reproduite en fac-similé dans l'article de Claude Collard, «La vie en société des Rothschild", dans Claude Collard et Melanie Aspey (dir.), Les Rothschild en France au XIX siècle, Paris, Bibliothèque nationale de France, 2012, p. 103.

18. Sur Charlotte de Rothschild, voir Evelyn M. Cohen, "Charlotte "Chilly" von Rothschild: mother, connoisseur, and artist ", The Rothschild Archive Review of the Year April 2012 to March 2013, p. 29-36, voir: rothschildarchive.org/materials/review_2012_2013_complete_pdf_reduced.pdf (consulté le 10 novembre 2018). 
19. Voir Charlotte de Rothschild, "The Musical Associations of the Rothschild Family ", dans Georg Heuberger (dir.), The Rothschilds. Essays on the History of a European Family, Woobridge, Boydell Press, 1994, p. 292.

20. Le Ménestrel, $39^{\mathrm{e}}$ année $\mathrm{n}^{\circ} 18,30$ mars $1873, \mathrm{p} .143$.

21. Cité dans Charlotte de Rothschild, "The Musical Associations of the Rothschild Family", art. cit., p. 293.

22. Voir Pauline Prevost-Marcilhacy, "Charlotte et Nathaniel de Rothschild», dans Pauline Prevost-Marcilhacy (dir.), Les Rothschild. Une dynastie de mécènes en France, 3 vol., Paris, Louvre/ BnF/Somogy, 2016, vol. I, p. 184-199.

23. Je m'appuie ici sur la chronologie des liens de Chopin avec la famille Rothschild reconstituée par Jean-Jacques Eigeldinger (voir Jean-Jacques Eigeldinger, Chopin et la baronne Nathaniel de Rothschild. Nocturne en ut mineur et valse en la mineur sans numéro d'opus. Problèmes d'attribution. Mazurka op. posth. $67 n^{\circ} 4$ (Manuscrit Rothschild), Varsovie, Narodowy Instytut Fryderyka Chopina, [2015], p. 34-35).

24. F-Pn /ms. 121. (gallica.bnf.fr/ark:/12148/btv1b550010414/f2.image)

25. Lettre citée dans Jean-Jacques Eigeldinger, Chopin et la baronne Nathaniel de Rothschild, op. cit., p. 35.

26. À l'occasion de ce concert, Escudier décrit le salon des Rothschild dans ces termes : «Les salons, cette année, se sont ouverts de bonne heure. Que de fêtes charmantes nous allons avoir cet hiver, à en juger par les soirées brillantes qui se sont données cette semaine. Et d'abord c'est M. de Rostchild [sic], l'illustre potentat de la banque, qui a illuminé le premier son palais. Voyez ! À ces portes de cristal, à ces tentures royales, à ces peintures merveilleuses, à cet ameublement tout revêtu d'or, à cet éclat magique qui partout vous étourdit, ne vous croiriez-vous pas endormi dans un monde d'illusions? Il n'y a que les rois et les princes qui puissent étaler un luxe aussi féérique ; et toutes ces femmes qui brillent par la beauté et par la richesse, regardez-les sourire de bonheur ", La France musicale, 15 janvier 1843, $6^{\mathrm{e}}$ année, $\mathrm{n}^{\circ}$ 8, p. 20.

27. Le Ménestrel, 16 mars 1873 , 39e année, $\mathrm{n}^{\circ} 16$, p. 126.

28. Le Figaro, 17 janvier $1873,20^{\mathrm{e}}$ année, $3^{\mathrm{e}}$ série, $\mathrm{n}^{\circ} 17$, p. 3.

29. Voir Le Gaulois, 18 mars 1884, $18^{\mathrm{e}}$ année, $\mathrm{n}^{\circ} 360$, p. 2.

30. Voir l'intervention de Marie-Pauline Martin et Thierry Maniguet, "Sur les collections d'instruments des Rothschild", au colloque "De la sphère privée à la sphère publique ", le 4 décembre 2018 : www.youtube.com/watch?v=17qkzcy0-BQ.

31. Krystyna Kobylańska, RĘkopisy utworów Chopina: Katalog, Cracovie, Polskie Wydawnictwo Muzyczne, 1977, t. I, p. 311-312.

32. Je remercie Magdalena Oliferko pour son aide dans la traduction du texte polonais.

33. Moritz Karasowski, Friedrich Chopin. Sein Leben und seine Briefe, Dresde, Ries, 1878, p. 338.

34. Le legs d'Élise Gavard est encore moins documenté que celui de Charlotte de Rothschild. En effet, on n'en trouve aucune mention dans les archives de la bibliothèque du Conservatoire, ni dans les carnets de cotes, ni dans les registres des entrées. Néanmoins, la dédicace inscrite sur une feuille séparée de toute partition : «À Mademoiselle Élise Gavard // son vieux professeur et ami // Chopin » (ms. 123) porte la mention de la main de Jean-Baptiste Weckerlin : «Legué au Conservatoire par $\mathrm{M}^{\text {lle }}$ Gavard ». Cette dédicace accompagnait soit l'autographe de la Valse op. 70, $\mathrm{n}^{\circ} 2$ (ms. 117), soit celui de la Berceuse (ms. 115).

35. F-Pn /ms. 121.

36. F-Pn /ms. 111 (B).

37. F-Pn /ms. 114.

38. F-Pn /ms. 110.

39. F-Pn /ms. 119 (A) et ms. 119 (B).

40. F-Pn /ms 118 et ms. 119 (A), le Nocturne se trouvant au verso de la Valse. 
41. Louise Dubin, «Charlotte or Chopin? An Examination of the Primary Sources Behind Unknown Compositions Published by the Baroness Charlotte Nathaniel de Rothschild Which Were Later Published as Posthumous Works of Fryderyk Chopin », dans Mark Cruse et Catherine Montfort-Howard (dir.), Women in French studies: Select essays from Women in French International Conference (Tempe, Arizona, 2012), Women in French, 2014, p. 143-157.

42. Jean-Jacques Eigeldinger, Chopin et la baronne Nathaniel de Rothschild, op. cit.

43. Voir Louise Dubin, « Charlotte or Chopin?», art. cit.

44. Jean-Jacques Eigeldinger, Chopin et la baronne Nathaniel de Rothschild, op. cit.

45. F-Pn / ms. 1338.

46. Voir Jean-Jacques Eigeldinger, Chopin et la baronne Nathaniel de Rothschild, op. cit., p. 34.

47. F-Pn / ms. 387.

48. Cette œuvre n'est pas recensée dans le catalogue thématique des œuvres de Rossini par Philip Gossett, voir Philip Gossett, "Catalogo delle opere ", dans Luigi Rognoni, Gioacchino Rossini, Torino, ERI, 1968, p. 439-503.

49. François-Joseph Fétis, Biographie universelle des musiciens et bibliographie générale de la musique, deuxième édition, Paris, Firmin-Didot, 1861, t. II, p. 385.

50. Le Ménestrel, 10 décembre $1899,65^{\mathrm{e}}$ année, $\mathrm{n}^{\circ}$ 50, p. 399.

51. La présence de ces deux copies de la Berceuse dans le legs Rothschild me semble une confirmation ultérieure du fait que l'autographe de l'œuvre n'appartenait pas à la baronne mais plutôt à Élise Gavard : pour aucun autre des manuscrits autographes qu'elle a reçus de Chopin, Charlotte de Rothschild ne possédait de copie.

52. Ce manuscrit comporte, au verso et écrite d'une autre main, une copie «Mazourka de Chlopicki » de Karol Kurpiński, datée du 23 novembre 1849.

53. Cette copie ne comprend que les mélodies suivantes: $n^{\circ} 16$ Piosnka litewska (texte de L. Osiński), $\mathrm{n}^{\circ} 14$ Pierścień (texte de S. Witwicki), $\mathrm{n}^{\circ} 12$ Moja pieszczotka (texte de A. Mickiewicz), $\mathrm{n}^{\circ} 8$ Śliczny chłopiec (texte de B. Zaleski), $\mathrm{n}^{\circ} 4$ Hulanka (texte de S. Witwicki), $\mathrm{n}^{\circ} 6$ Precz z moich oczu (texte d'A. Mickiewicz) et une autre copie du $\mathrm{n}^{\circ} 14$ Pierścień (texte de S. Witwicki).

54. Marche funèbre op. $72, \mathrm{n}^{\circ} 2$ parut en 1855 chez Meissonnier ; Mélodies polonaises parut en 1879 chez Hamelle.

55. B-Br /ms. II 4118 Mus Fétis 3646.

INDEX

Index géographique : France

Index chronologique : XIXe siècle

Thèmes : Musique, mécénat, Rothschild 
Objets d'art et Beaux-Arts et curiosités 


\title{
Les vitraux suisses de l'hôtel
} Salomon de Rothschild dans le contexte du patrimoine verrier de l'ancienne Confédération helvétique

\author{
Uta Bergmann
}

L'hôtel Salomon de Rothschild possède une quinzaine de vitraux suisses des $\mathrm{XvI}^{\mathrm{e}}$ et $\mathrm{XVII}^{\mathrm{e}}$ siècles ${ }^{1}$. Avec les rondels provenant pour la plupart des anciens Pays-Bas, ils ornent toujours les trois fenêtres du cabinet de curiosités, qui a été constitué à partir des collections d'Adèle de Rothschild (1843-1922) (fig. 1). Les verrières sont signées « $P$. Bitterlin " par le peintre verrier en 1878. Paul Bitterlin, fils du marchand de verre alsacien Jean Paul Bitterlin, ouvrit son atelier en 1855 à Paris et travailla jusqu'en 1889 en différents endroits: rue de l'Université, rue de l'Ouest et enfin rue Varin'2. Il participa à cinq Expositions universelles, dont celle de 1878. À cette époque, il employait quarante personnes dans son atelier d'« artiste peintre-graveur-verrier ». Son grand succès fut la gravure sur verre à l'acide fluorhydrique, technique qui lui valut la médaille d'honneur en 1868 et qu'il publia lors de l'Exposition de $1878^{3}$. Ses œuvres se trouvaient dans des cafés et des magasins, sur les plafonds de plusieurs théâtres de Paris ou sur le grand dôme du tribunal de commerce de Paris. À l'hôtel Rothschild, le peintre verrier intégra les vitraux suisses et néerlandais de manière décorative et symétrique, dans une vitrerie à bornes, constituée de pièces de verre carrées et hexagonales. Les verres d'ornement, aux bords colorés, sont simplement décorés de quelques rinceaux peints à la grisaille. À l'occasion d'une réfection complète du cabinet de curiosités aujourd'hui ouvert au public, les vitraux ont été restaurés en 2000 par l'atelier Courageux de Crèvecœur-le-Grand. 
1. Fenêtres du cabinet de curiosités de l'hôtel Salomon de Rothschild, Paris.

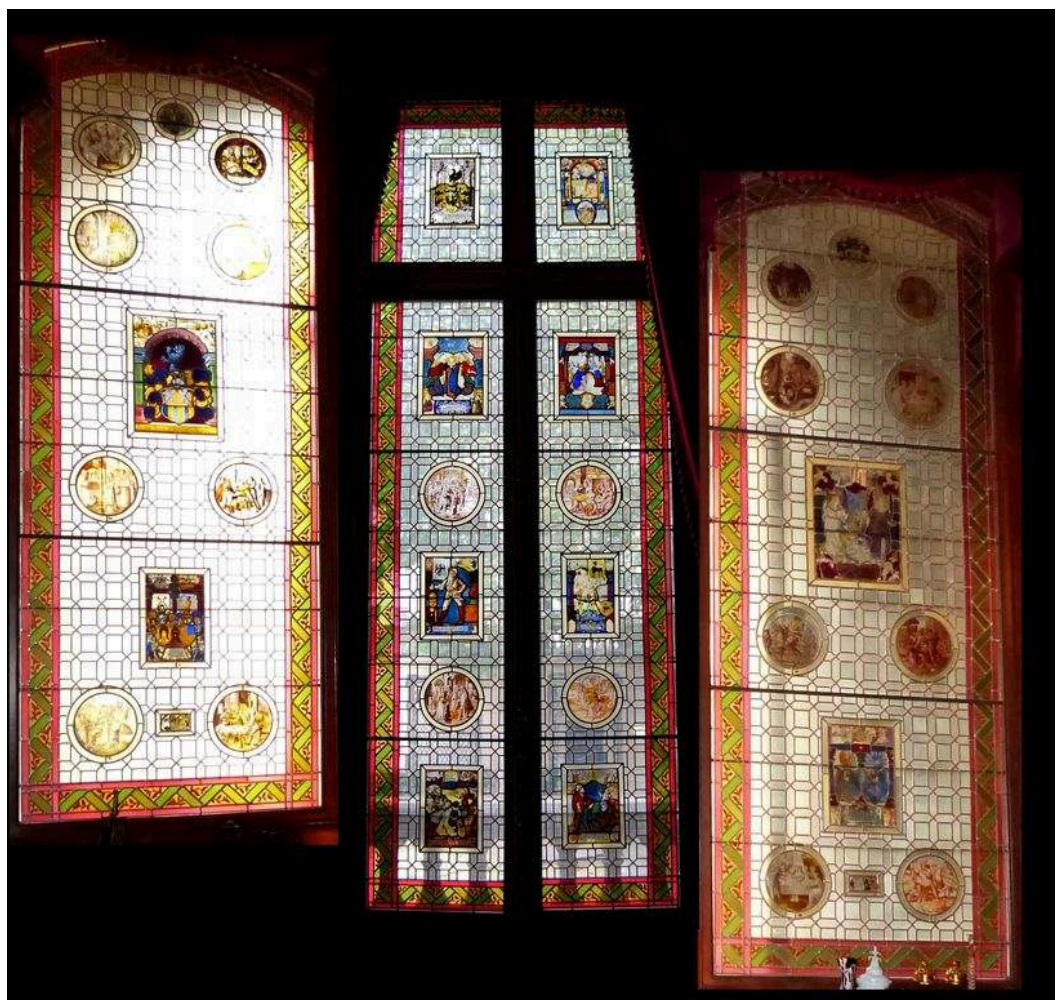

(c) Fondation des artistes/Uta Bergmann

2 Pour comprendre la signification de ces petits vitraux, il est utile de décrire l'histoire d'une coutume très répandue: celle de les offrir. En effet, "durant les $\mathrm{xVI}^{\mathrm{e}}$ et $\mathrm{XVII}^{\mathrm{e}}$ siècles, la peinture sur verre connut en Suisse un épanouissement remarquable ${ }^{4} »$. Dans le courant des $\mathrm{XV}^{\mathrm{e}}$ et $\mathrm{XVI}^{\mathrm{e}}$ siècles, la coutume a évolué de la donation de vitraux monumentaux dans les églises à celle de vitraux de petit format, armoriés ou figuratifs. Ceux-ci n'étaient plus seulement destinés à des institutions religieuses, mais aussi placés dans des bâtiments publics et des maisons privées, où entre-temps de coûteuses verrières commencèrent à remplacer les volets en toile ou en parchemin. Nous possédons à ce sujet des sources écrites du début du $\mathrm{Xv}^{\mathrm{e}}$ siècle, mais la donation de fenêtres et d'armoiries se manifeste avec certitude à partir de la seconde moitié du $\mathrm{Xv}^{\mathrm{e}}$ siècle et, vers 1530-1540, Valerius Anselm, dans sa Chronique de Berne, raconte que c'est vers la fin du $\mathrm{Xv}^{\mathrm{e}}$ siècle que l'on commence à placer des vitraux dans les fenêtres des maisons bourgeoises 5 .

\section{La coutume d'offrir des vitraux}

3 Les autorités, les institutions et les bourgeois renommés s'offraient ces vitraux de petit format à l'occasion de nouvelles constructions, de la transformation de bâtiments ou d'événements politiques ou familiaux ou autres encore ${ }^{6}$. L'initiative d'en faire la demande était prise par le propriétaire de la maison, qui s'adressait alors à son entourage public et privé. La fenêtre à vitre blanche formait la base de la donation, mais le vitrail incorporé montrait qui avait offert cette fenêtre si coûteuse. En général, la donation allait bien au-delà d'une simple aide financière du demandeur. On illustrait 
ainsi les liens d'amitié réciproques. Tout visiteur pouvait comprendre qui était sous l'autorité de qui et quel rang le fier propriétaire du panneau occupait dans la société. Le vitrail offrait aussi au donateur la possibilité de démontrer sa propre importance et sa position politique ou religieuse par une scène imagée, une inscription et des armoiries. La donation de la fenêtre et du vitrail se fondait sur un système de réciprocité et devint un médium de consolidation de la paix et de la concorde entre les États et leurs citoyens, entre citoyens et concitoyens.

5 C'est à travers cette coutume à caractère social et politique que se reflètent, d'une part, le changement fondamental de la composition de l'ancienne Confédération au cours du $\mathrm{Xv}^{\mathrm{e}}$ siècle et, d'autre part, la richesse et les prétentions grandissantes de la population. Libres de toute soumission à des rois ou à des princes, les confédérés développèrent, par les victoires sur le duc de Bourgogne (1476-1477), par le triomphe à la guerre de Souabe (1499) et par les campagnes milanaises, un fort "sens commun" et une conscience enthousiaste de leur propre valeur : ils étaient devenus un acteur important et influent en Europe. Par conséquent, le besoin de la représentation augmenta dans la vie de chacun. Des personnes haut placées commencèrent à revendiquer des lettres de noblesse. Des marchands, des aubergistes, des artisans et même des paysans se mirent à la recherche d'armoiries qu'ils arboraient fièrement. Ces prétentions trouvèrent dans les vitraux suisses leur expression la plus appropriée.

\section{Les vitraux suisses de l'hôtel Salomon de Rothschild}

Les armoiries des donateurs, placées dans un cadre architectural, appartiennent aux modèles standards utilisés à cette époque. Le vitrail de Claude (Glado) May (mort en 1568) de l'hôtel Salomon de Rothschild montre bien les armoiries, qui se détachent de manière lisible, simple et concise (fig. $)^{7}$. La structure de l'architecture et le fond rouge ornementé renforcent la sobriété de ce vitrail de la première moitié du XVI ${ }^{e}$ siècle. Le donateur se présente, dans l'inscription au bas du vitrail ${ }^{8}$, comme l'avoyer ou le bailli de Burgdorf (Berthoud en français), c'est-à-dire comme l'administrateur du territoire soumis à l'État de Berne. Claude May était aussi bailli de Morges, membre du petit conseil de Berne et souvent délégué à des audiences politiques, ayant parfois lieu en France (1557) ${ }^{9}$. 


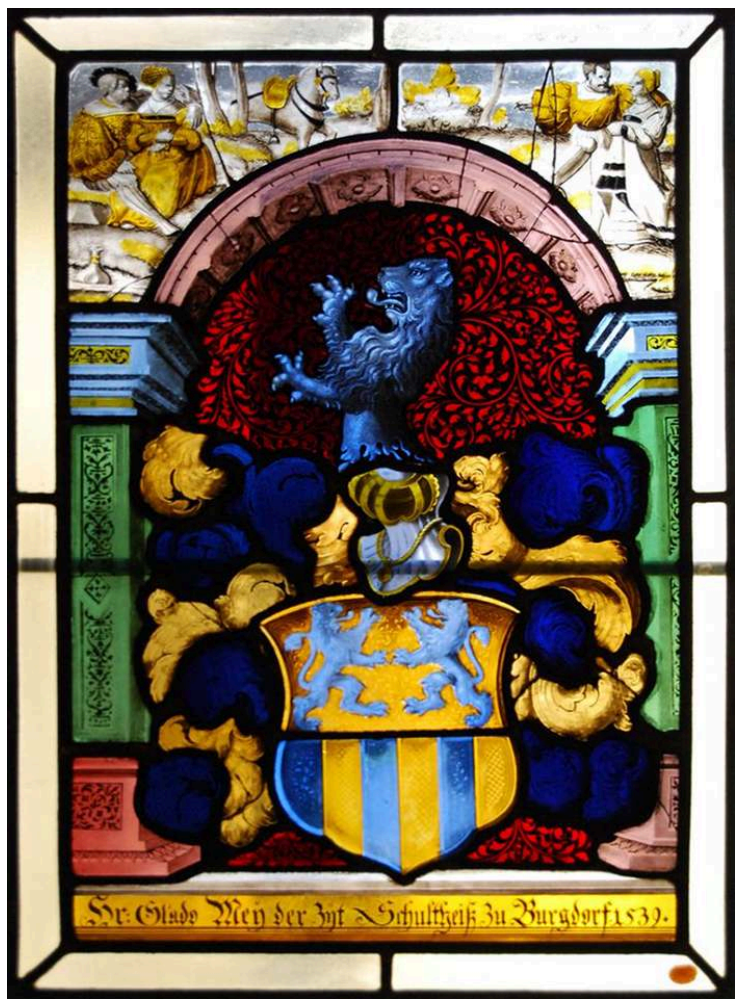

(c) Fondation des artistes/Uta Bergmann

7 Les registres supérieurs du vitrail offraient aux donateurs la possibilité de décrire leur vie quotidienne ou de présenter leurs saints patrons, des personnages bibliques, antiques ou allégoriques. Encore jeune à l'époque de la donation, Claude May - marié à trois reprises - choisit des scènes courtoises pour cette partie de son vitrail.

Les armoiries des donateurs sont souvent accompagnées de personnages aux attitudes fières. Ainsi, le vitrail de Jörg Reding (mort en 1599) (fig. 3) montre le donateur luimême comme tenant de ses armoiries ${ }^{10}$. Il est représenté en homme d'armes, tout équipé avec des bandeaux d'honneur à croix blanches et à fleurs de lys d'or sur fond noir. Ces dernières se réfèrent au fait que Reding était colonel au service du roi de France. À partir de 1583, il officia aussi comme bailli du Toggenbourg, une région sise à l'est de la Suisse, près de Saint-Gall ${ }^{11}$. Toute la partie supérieure du vitrail a été malheureusement détruite et remplacée. Le cartouche inférieur a en outre été repeint au XIX ${ }^{e}$ siècle, mais, avant 2000 , on pouvait encore y lire l'inscription originale qui a été reconstituée lors de la dernière intervention ${ }^{12}$. 
3. Vitrail aux armes de Jörg Reding, vers 1583-1584, Paris, hôtel Salomon de Rothschild.

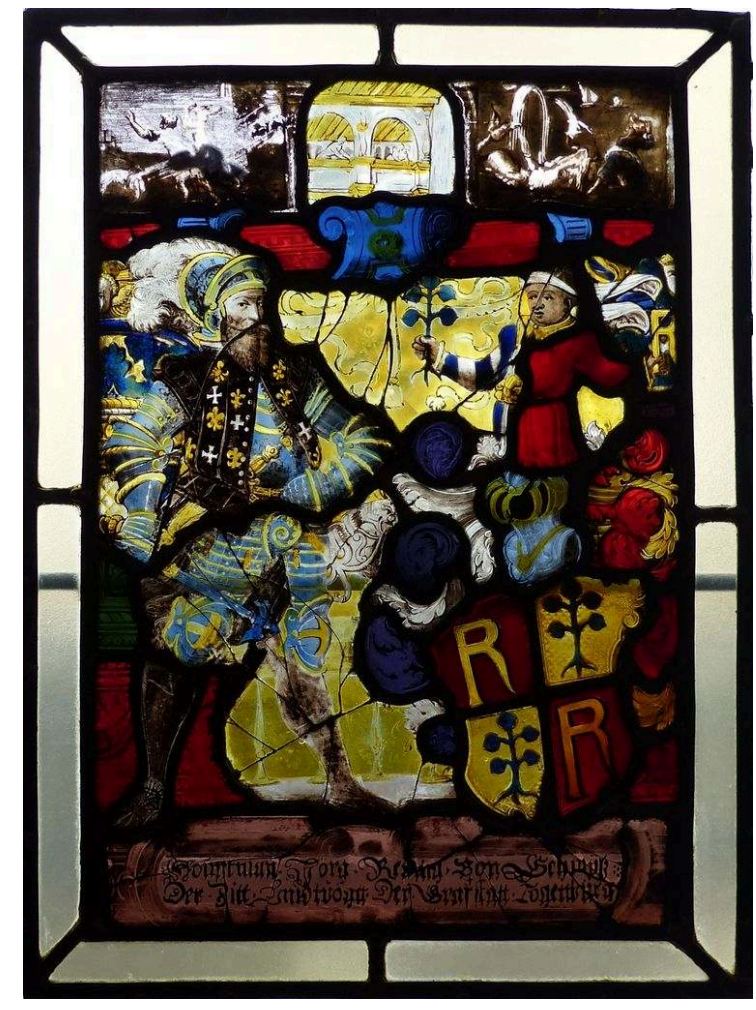

(c) Fondation des artistes/Uta Bergmann

9 L'inscription d'un autre vitrail indique, comme donateurs, en 1646, le banneret Martin Edelmann de Krummenau, juge régional du comté de Toggenbourg, et Anna Loser, son épouse (fig. 4$)^{13}$. En bas, les allégories de la Foi et de la Charité illustrent les vertus religieuses et morales que le couple a l'intention de suivre dans sa vie, tandis que la chasse, au registre supérieur, représente le privilège de la noblesse et du patriciat en Suisse. Même si tout semble en règle, l'inscription ne correspond pas aux armoiries de ce vitrail ! En effet, celles-ci appartiennent à Jakob Schlappritzi et à son épouse, Barbara Zollikofer. Un vitrail semblable de ce couple, portant la date de 1612, se trouve aujourd'hui au Musée national suisse de Zurich ${ }^{14}$. Il appartient à une série de vitraux que la famille avait offerts au couple, en 1612, pour décorer son petit château de Wiggen, dans le canton de Saint-Gall. L'iconographie et la composition sont bel et bien comparables : il est donc fort possible que le vitrail de l'hôtel Salomon de Rothschild corresponde à la demande d'un autre membre de la famille Schlappritzi pour sa propre maison. 
4. Vitrail aux armes de Jakob Schlappritzi et Barbara Zollikofer, Zurich ou Suisse orientale, vers 1610-1620, Paris, hôtel Salomon de Rothschild.

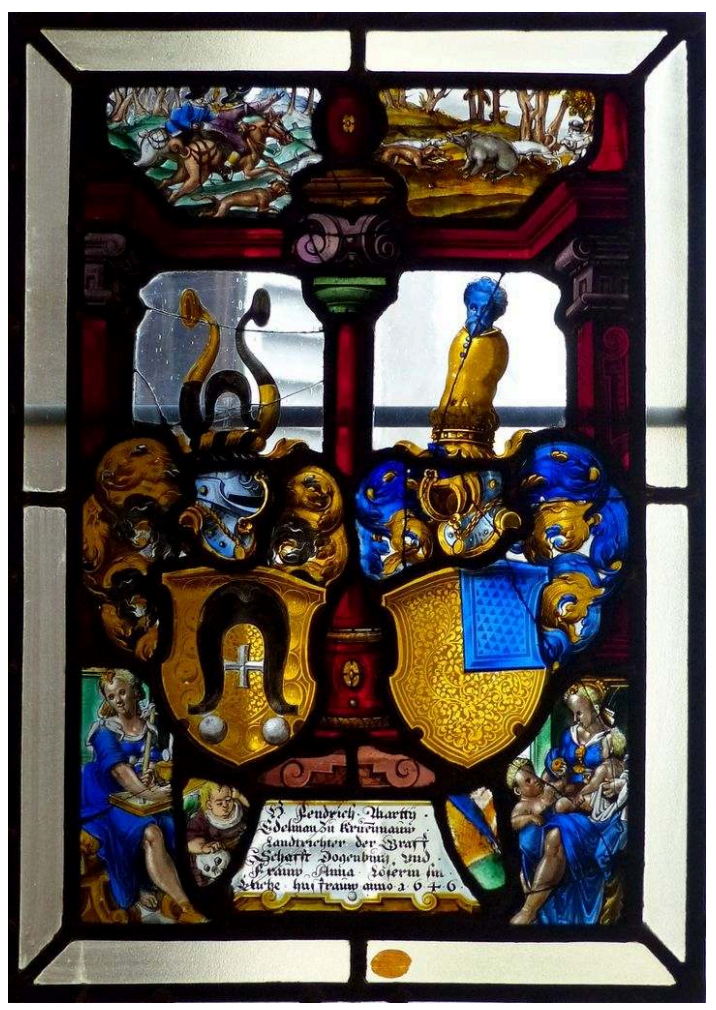

(c) Fondation des artistes/Uta Bergmann font pas partie du vitrail, qui date d'environ cinquante ans plus tôt. Le donateur y figure en costume d'époque, tenant l'épée d'un côté et le poignard suisse de l'autre ${ }^{15}$.

On trouve parfois, en bas du vitrail, la représentation des donateurs agenouillés en oraison à côté de l'inscription ou en face de leurs armoiries, comme sur ce vitrail, qui place au centre l'Ascension de la Vierge Marie ${ }^{16}$. L'inscription qui partage la scène de l'Annonciation, dans la partie supérieure, s'adresse à Jésus-Christ et exprime l'espoir d'une vie éternelle après la mort grâce à l'intercession de la mère de Dieu $^{17}$. L'inscription en bas, qui mentionne comme seul donateur Hector Bruodermann, n'appartient donc certainement pas à ce vitrail qui offre l'image d'un couple marié ${ }^{18}$. celui des corporations, des représentants officiels de l'Église, de l'État, des villes ou des communes.

13 Gallus Vögelin (mort en 1604), donateur d'un vitrail impressionnant (fig. 5) ${ }^{19}$, était originaire de Mindelheim. Entre 1585 et 1597, il fut abbé du monastère bénédictin de Saint-Pierre, prieur de Saint-Ulric et administrateur de l'église Sainte-Foy-et-SaintMarc à Sölden, tous trois situés en Forêt-Noire, en Allemagne. L'écartelé de ses armoiries montre les clés de l'abbaye de Saint-Pierre, les poutres du prieuré de SaintUlric et l'étoile du prieuré de Sölden. Sur le tout sont apposées les armoiries personnelles de l'abbé qui, comme souvent dans les vitraux ecclésiastiques, sont accompagnées par des anges. La scène du registre supérieur se réfère à saint Pierre, le patron de l'abbaye. Aux écoinçons sont représentés les quatre Pères de l'Église. Ces derniers se retrouvent sur un projet de vitrail pour l'abbé Laurentius Gutjahr des 
monastères d'Altdorf et d'Ettenheimmünster, en Forêt-Noire, de 1583 : un dessin de la main du peintre verrier zurichois Christoph Murer ${ }^{20}$. Plus proche encore de notre vitrail, il y a un autre projet que Murer a dessiné, monogrammé et daté en 1589 pour l'abbé Johann Ludwig Sorg de Gengenbach, près de Fribourg-en-Brisgau ${ }^{21}$. D'après une inscription au dos, Murer a réalisé ce travail pour le peintre verrier Bartholomé Lingg, installé à Strasbourg, qui a probablement exécuté le vitrail correspondant pour l'abbé de Gengenbach. Une seconde, datant de 1596, est postérieure et d'une autre main, ce qui prouve que le dessin a été utilisé encore une fois.

\section{Vitrail aux armes de l'abbé Gallus Vögelin, Rhin supérieur, 1587, Paris, hôtel Salomon de Rothschild.}

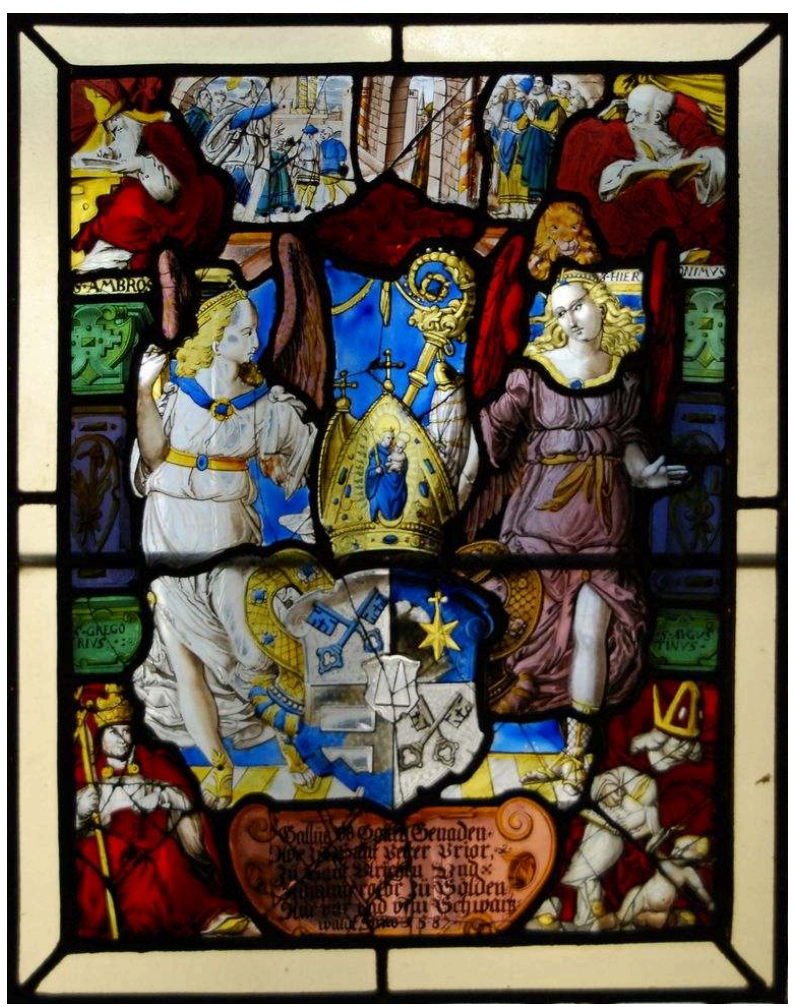

(c) Fondation des artistes/Uta Bergmann

Le vitrail de Gallus Vögelin est postérieur au premier, mais antérieur au second dessin de Murer, et il montre bien la popularité de cette iconographie auprès des religieux des monastères de cette région. Il est fort probable que Christoph Murer ait dessiné plusieurs projets semblables lors de son séjour, vers 1583, à Strasbourg, où il s'était lié d'amitié avec Bartholomé Lingg.

Dans d'autres cas, c'est une région entière qui peut prendre part à ces donations, comme l'indique ce vitrail du Toggenbourg de 1624 (fig. 6) ${ }^{22}$. La vallée de Toggenbourg tire son nom d'une famille de seigneurs, mentionnée pour la première fois en 1044. Les barons du Toggenbourg, devenus comtes en 1209, en étaient les possesseurs. Le dernier comte mourut en 1436. Les terres furent vendues à l'abbaye de Saint-Gall, qui exerça dès lors son gouvernement par l'intermédiaire d'un baillii'3 ${ }^{23}$ Signe de son pouvoir, la région se présente par un guerrier qui accompagne les armoiries de l'ancien comte et qui porte une bannière avec le même symbole héraldique : un chien noir. Au registre supérieur apparaissent la flagellation du Christ et le martyre de saint Sébastien, 
représentant les Églises reformée et catholique du Toggenbourg, où la coexistence des deux confessions était garantie. Un vitrail très semblable à celui de 1618 se trouve aujourd'hui au musée du Toggenbourg, sis à Lichtensteig ${ }^{24}$. Relevons dans notre contexte que tous ces vitraux du comté de Toggenbourg étaient financés par une caisse comptant passablement d'argent français. Il s'agissait des pensions que le roi de France avait octroyées à la région pour que soit mis à sa disposition un régiment entier.

6. Vitrail aux armes du comté de Toggenbourg, 1614, Paris, hôtel Salomon de Rothschild.

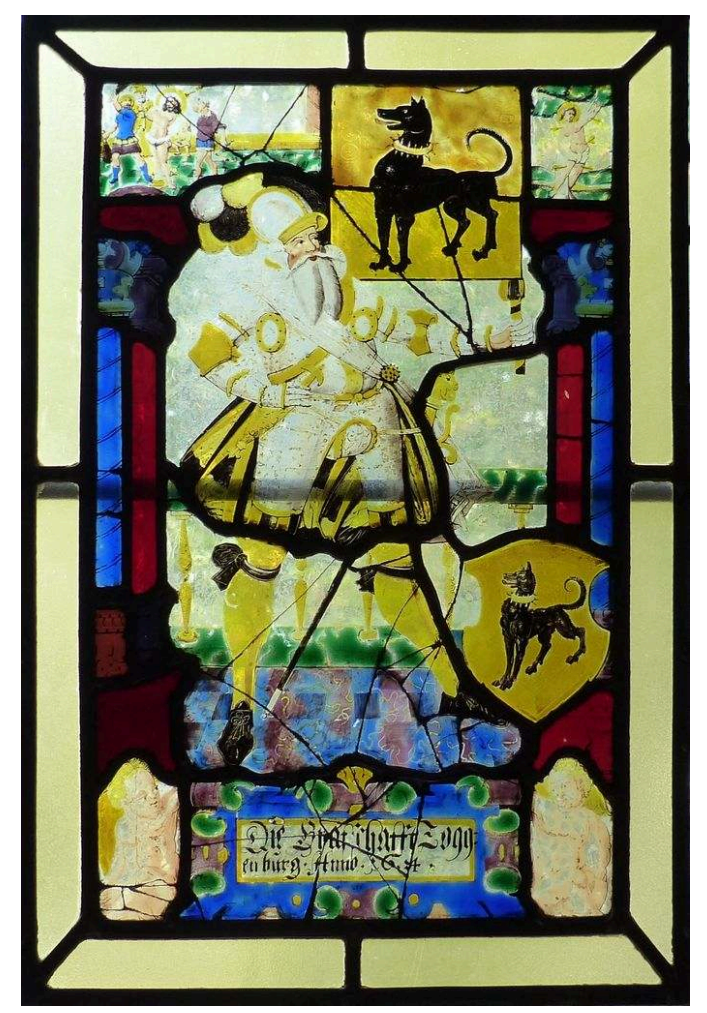

(c) Fondation des artistes/Uta Bergmann

16 Un autre vitrail de 1617 pourrait, d'après son inscription ${ }^{25}$, également faire croire à une donation de l'ancien comté du Toggenbourg (fig. 7 ${ }^{26}$. Il représente, au centre, un banneret qui est pratiquement devenu un topos pour les vitraux des communes et des villes. Mais les armoiries sont différentes du vitrail précédent. Il s'agit ici des armoiries du canton de Glaris, qui portent aussi l'écu et la couronne de l'Empire, comme signes de la soumission à l'autorité immédiate de ce dernier. Les armoiries du donateur montrent le saint patron de Glaris, saint Fridolin, qui apparaît aussi dans les écoinçons. Selon la légende, le fondateur du monastère de Säckingen, sur une île du Rhin, a littéralement réveillé un mort, nommé Ursus, afin qu'il puisse témoigner dans une controverse juridique. Ce dernier est représenté ici comme squelette auprès du saint. La bannière devrait porter la même figure héraldique que les armoiries, ce qui n'est pas le cas. Il est alors évident que l'inscription comme la bannière sont des fragments d'un autre vitrail, qui remplacent des parties manquantes. En outre, d'autres éléments ont été reconstitués lors de la dernière intervention en 2000. 
7. Vitrail d'État de Glaris, deuxième moitié du XVIe siècle, Paris, Hôtel Salomon de Rothschild.

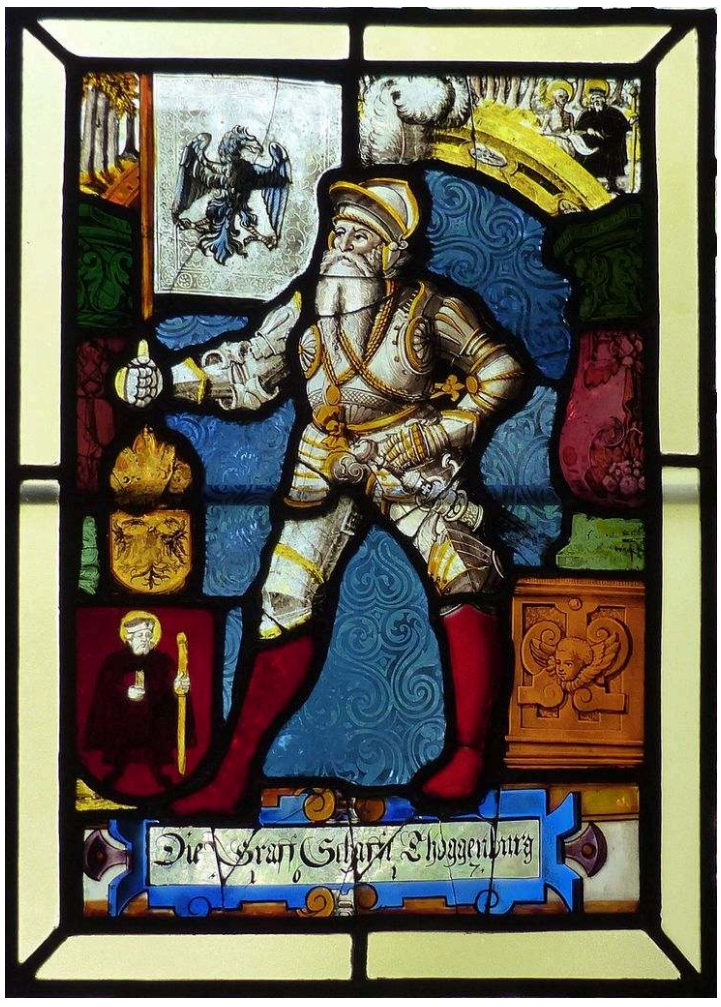

(c) Fondation des artistes/Uta Bergmann

17 Les vitraux endommagés par des intempéries - la grêle ou le vent - ou par destruction volontaire ont souvent été restaurés ou réparés avec des bouche-trous -, c'est-à-dire avec des fragments en verre provenant d'anciens vitraux, et ce dès les xviI et XVIII ${ }^{e}$ siècles. C'est surtout au XIX ${ }^{e}$ siècle que l'on a restauré, bouché et parfois entièrement recomposé les vitraux afin de pouvoir les vendre à des collectionneurs passionnés. À l'hôtel Salomon de Rothschild, un regard critique sur un certain nombre de ces pièces modifiées permet d'établir parfaitement l'historique de ce patrimoine.

Il en va ainsi du vitrail de Jerg Peyer (1586-1648) et d'Ursula Peyer (1593-1665), née Peyer im Hof, son épouse depuis $1612^{27}$. Les armoiries de droite, avec heaume et cimier, appartiennent bel et bien à un autre vitrail plus ancien. Un rondel de 1635 du même couple, au Sonnenburggut de Schaffhouse, avec les armoiries d'origine, permet de comprendre la restauration de cette époque ${ }^{28}$.

Dans un vitrail de 1686, signé "H.C.G. » pour Hans Caspar Gallati, originaire de Wil, dans le canton de Saint-Gall, et offert par Christoph Rüti du conseil de Wyl et Catherina Schenk, son épouse, les armoiries sont renvoyées au registre inférieur (fig. 8) ${ }^{29}$. La pyramide héraldique est cependant mise en évidence par une couronne de laurier, posée au milieu de l'inscription. Le tout a laissé place, au centre, à une scène figurative et narrative. Malheureusement, les verres formant la partie centrale sont là aussi des bouche-trous qui proviennent d'autres vitraux anciens. Des fragments de la scène originelle - qui montrait probablement un ermitage au bord d'un lac - sont toujours visibles sur les côtés ${ }^{30}$. 
8. Hans Caspar Gallati de Wil, Vitrail de Christoph Rüti et Catharina Schenk, 1686, Paris, hôtel Salomon de Rothschild.

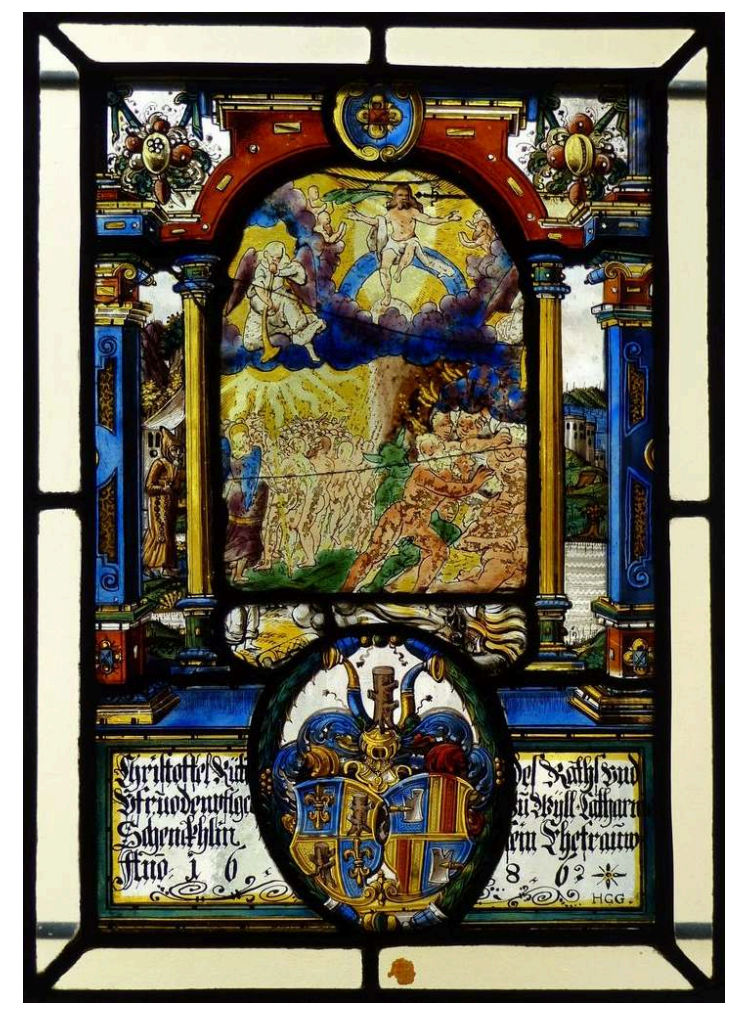

(c) Fondation des artistes/Uta Bergmann

Un autre vitrail de très belle qualité présente un bon état de conservation : il s'agit du vitrail figuratif de Peter (Pierre) Hunthum, daté de 1625 et représentant la parabole de Jésus et la femme adultère (fig. 9) ${ }^{31}$. Les armoiries du donateur se composent d'une marque qui reprend les initiales de son nom. Les Hunthum étaient originaires de Cologne. Johann (Jean) Hunthum, un marchand luthérien, émigra à Amsterdam pour des raisons religieuses. Un fils, également prénommé Johann, resta à Cologne ; les autres suivirent leur père à Amsterdam, notamment Peter, né en $1601^{32}$. Le vitrail ne s'apparente pas vraiment aux vitraux de la région du Rhin inférieur ou des Pays-Bas. Stylistiquement, il se rattache à la ville de Strasbourg, où plusieurs membres de la famille Lingg, originaire de la ville de Zoug en Suisse, exerçaient le métier de peintre verrier. On ignore encore les relations exactes entre Peter Hunthum et l'Alsace, qui étaient peut-être de nature commerciale ou de parenté. 
9. Pierre Hunthum Jésus et la femme adultère, vitrail, Strasbourg, 1625, Paris, hôtel Salomon de Rothschild.

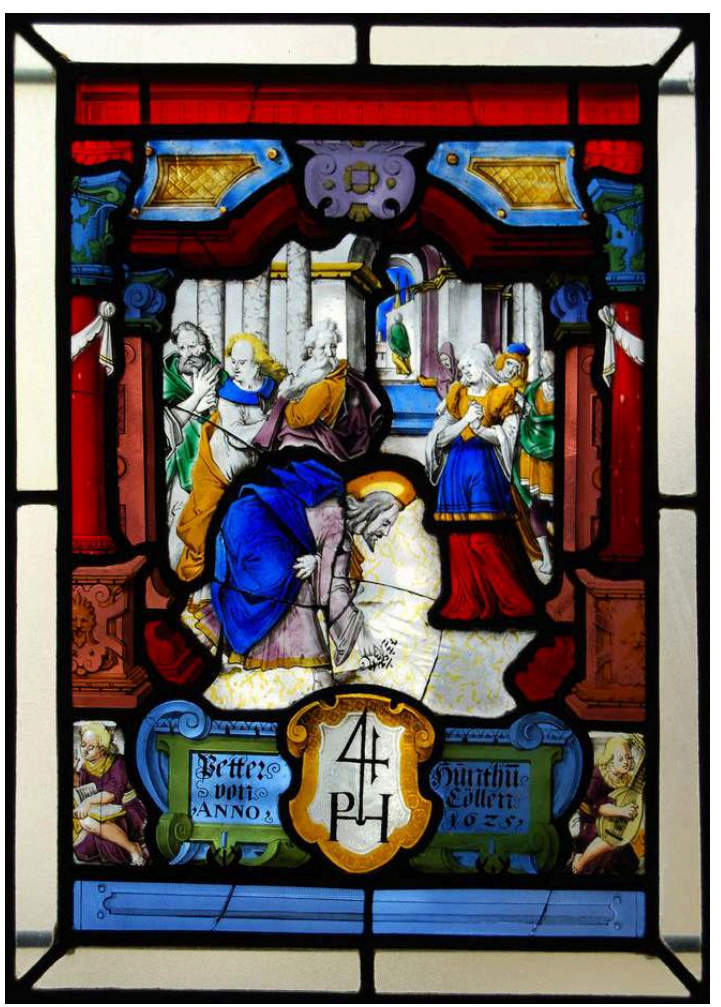

(c) Fondation des artistes/Uta Bergmann

\section{L'atelier et l'évolution des techniques du vitrail}

L'hôtel Salomon de Rothschild possède un très intéressant fragment de la partie haute d'un vitrail représentant un atelier de verrier (fig. 10) ${ }^{33}$. Alors que le compagnon ou un maitre menuisier apporte un grand cadre de fenêtre, l'apprenti peut compter sur l'aide de la femme du maître verrier. Ensemble, ils tirent des baguettes de plomb avec une petite machine en fer fixée sur la table et dotée d'un engrenage. Le modèle graphique qui a servi pour ce vitrail complète bien la suite du fragment : on y voit le maître de l'atelier en train d'assembler des cives sur sa table de travail. Le dessin anonyme se trouve à la Staatliche Kunsthalle de Karlsruhe, mais il en existe aussi une copie au Cabinet des estampes de Strasbourg ${ }^{34}$. 
10. Fragment d'un vitrail représentant un atelier de verrier, vers 1600, Paris, hôtel Salomon de Rothschild.

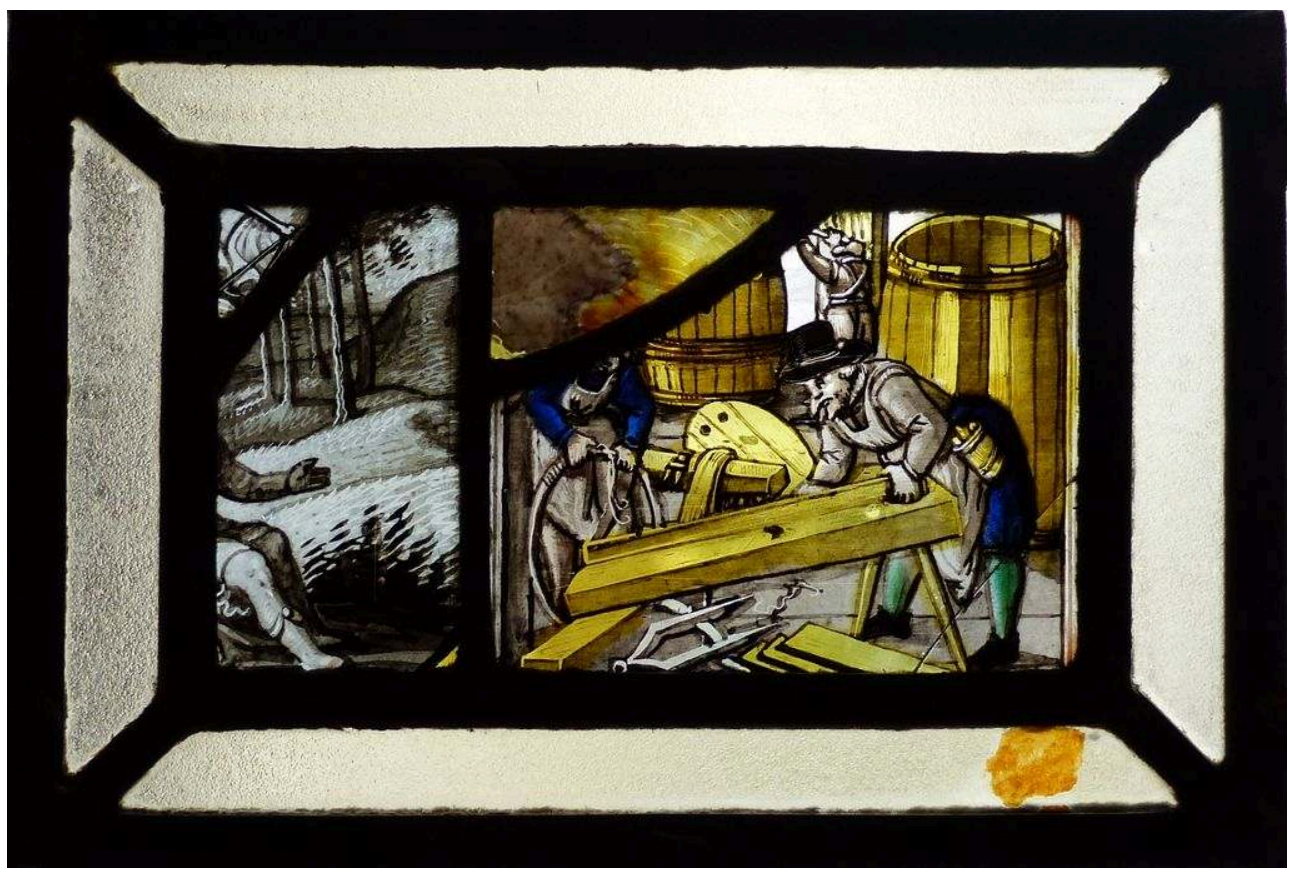

(c) Fondation des artistes/Uta Bergmann des vitraux médiévaux. Les verres, majoritairement colorés dans la masse, étaient coupés, peints et - après cuisson au four - montés dans des réseaux de plomb. Pour le dessin et la couleur, on utilisait les grisailles, le jaune d'argent et, dans une moindre mesure, la sanguine. Le vitrail de Claude May (fig. 2) nous en montre un bel exemple. Par gravure mécanique sur verre double, on pouvait obtenir deux ou trois couleurs au sein d'une même pièce. Le $\mathrm{XVI}^{\mathrm{e}}$ siècle vit apparaître un changement : à part le noir et le jaune d'argent, les peintres verriers utilisèrent alors d'autres couleurs vitrifiables afin d'obtenir des effets chatoyants et pittoresques : l'émail bleu et violet ainsi que l'émail vert. La matière première était devenue très chère et il n'était pas aisé de se procurer des verres de couleur. Les verres teintés dans la masse se limitent à quelques petites pièces, de préférence de couleur rouge, puisque aucun émail ne peut atteindre la qualité du verre rouge plaqué. Dorénavant, tous les verres sont des verres blancs peints à la grisaille, au jaune d'argent, au rouge Cousin et aux émaux. Par l'utilisation de ces couleurs, le peintre verrier échappe à l'obligation de limiter chacune par une ligne de plomb sombre et dure. Cela permet de créer des compositions de lumières plus subtiles.

1700, les vitraux prennent souvent une autre forme ou apparence, car ils sont peints avec peu de couleurs ou uniquement à la grisaille. On en a un bel exemple à l'hôtel Salomon de Rothschild avec un vitrail offert par Ursula et Anna Maria Stokar en $1685^{35}$. Les deux femmes, certainement des sœurs, appartenaient à une famille patricienne de Schaffhouse. Dans ce vitrail, seules les armoiries portent encore un peu de jaune d'argent. 
a signifie que les vitraux en mosaïque de couleur étaient tout simplement passés de mode. En ce siècle des Lumières, on tend à la clarté. Dans la maison, l'architecture, donc les fenêtres et les décors évoluent : les fenêtres à cives sont remplacées par des fenêtres à verres carrés. Il n'y a dès lors plus de place pour les vitraux. Au XviII ${ }^{e}$ siècle, on commence déjà à démonter les vitraux des anciennes fenêtres et à les vendre à des antiquaires aussi bien pour des raisons de goût que par nécessité financière. Des collectionneurs, en Suisse, mais surtout hors des frontières du pays, se mettent à acheter, parfois frénétiquement, ces témoins de l'époque pour décorer leurs maisons et leurs châteaux dans le goût de l'historicisme.

Depuis lors, un grand nombre de ces ensembles ont été revendus et dispersés, et parfois les vitraux ont retrouvé le chemin de la Suisse. Mais plusieurs grandes collections de vitraux suisses de cette époque ont survécu. Une des plus célèbres a été rassemblée par Léopold III d'Anhalt-Dessau (1740-1817) à la fin du XVIII siècle, pour ladite "Maison gothique » sise à Wörlitz ${ }^{36}$. Une autre, comptant plus de cinq cents vitraux suisses, orne toujours les fenêtres de l'église de Wragby en Angleterre. Ces vitraux ont été achetés et collectionnés par les barons Winn, propriétaires de Nostell Priory, au XIX ${ }^{\mathrm{e}}$ siècle $^{37}$. En France, on peut mentionner la collection de vitraux suisses qu'Alexandre Du Sommerard a acquise pour la décoration de l'hôtel de Cluny à Paris et qui a été déposée au musée national de la Renaissance, ouvert en 1977 au château d'Écouen ${ }^{38}$. Sans oublier la très belle collection de vitraux suisses du musée du Louvre, dont la plus grande partie provient de la donation d'Alexandre-Charles Sauvageot ${ }^{39}$.

ces collections ont été publiées et font de plus en plus souvent l'objet de recherches approfondies suivant les directives sévères du Corpus vitrearum. Un grand projet international de publication des vitraux suisses en Angleterre est en préparation. Ce regain d'intérêt se manifeste aussi dans la mise en ligne des vitraux de l'hôtel Salomon de Rothschild, réalisée par l'Institut national d'histoire de l'art (INHA).

\section{Conclusion}

Même si les circonstances d'achat n'en sont pas connues, les vitraux de l'hôtel Salomon de Rothschild s'inscrivent parfaitement dans l'intérêt que portent, à partir du XVIII ${ }^{\mathrm{e}}$ siècle, les collectionneurs étrangers à ce patrimoine suisse.

Ces vitraux sont, pour la plupart, issus de la Suisse orientale (entre Zurich, Schaffhouse et Saint-Gall), mais on y trouve aussi quelques rares pièces de la Suisse centrale (Zoug), de l'Alsace et du sud de l'Allemagne. Un seul vitrail porte le monogramme d'un peintre verrier. Outre les communes, des abbés, mais surtout des personnes privées comptent parmi les donateurs de ces vitraux.

30 La recherche sur ces œuvres - que nous venons de passer en revue - incite à beaucoup de prudence d'analyse, à une lecture très critique de chacun de leurs éléments constitutifs et à une connaissance approfondie des us et coutumes ainsi que des situations géopolitiques changeantes au temps de la Confédération helvétique, qui a connu, durant ces siècles, une histoire mouvementée. Ce regard critique est indispensable afin de reconstituer et d'apprécier - comme à l'époque de leur création toute la saveur de ces petits chefs-d'œuvre publics ou plus intimes. 


\section{NOTES}

1. Situé 9, rue Berryer à Paris. Aujourd'hui, Fondation des artistes. L'hôtel particulier a été construit par l'architecte Léon Ohnet (1813-1874) pour la baronne Salomon de Rothschild en 1872-1878. Voir Pauline Prevost-Marcilhacy, Les Rothschild, bâtisseurs et mécènes, Paris Flammarion, 1995, p. 318-319. Sur les collections, voir Pauline Prevost-Marcilhacy (dir.), Les Rothschild. Une dynastie de mécènes en France, Louvre/BnF/Somogy, 3 vol., 2016, vol. II, p. 8-19. Voir la notice suivante : agorha.inha.fr/inhaprod/ark:/54721/003229508.

2. Martine Callias Bey, Véronique Chaussé, Laurence de Finance, Françoise Gatouillat, «Les ateliers ", dans Revue de l'art, $\mathrm{n}^{\circ} 72,1986$, p. 55-56; Cellule du vitrail de l'inventaire général, «Enquêtes sur les peintres verriers du XIX siècle, ayant travaillé en France ", dans Revue de l'art, $\mathrm{n}^{\circ}$ 72, 1986, p. 67-90 et spéc. p. 70 ; Élisabeth Pillet, Le Vitrail à Paris au XIX ${ }^{e}$ siècle. Entretenir, conserver, restaurer, Corpus Vitrearum France, Études IX, Rennes, PUR, 2010, p. 59.

3. Paul Bitterlin, P. Bitterlin fils, artiste peintre-graveur-verrier. De la gravure sur verre à l'acide fluorhydrique (1878), Paris, Hachette/BnF, 2018.

4. Rolf Hasler et Stefan Trümpler, "Le vitrail suisse aux XVI ${ }^{\mathrm{e}}$ et $\mathrm{XVII}{ }^{\mathrm{e}}$ siècles ", dans $L^{\prime} A r t d u$ peintre verrier. Vitraux français et suisses XIV ${ }^{e}$-XVII ${ }^{e}$ siècle, cat. exp. (Bourges, Le Parvis des Métiers, 1998), Bourges, Le Parvis des Métiers, 1998, p. 31.

5. Stadtbibliothek Bern, Msc. Hist. Helv. I, 47. Die Berner Chronik des Valerius Anselm, Hrsg. vom Historischen Verein des Kantons Bern, Berne, K. J. Wyss,1884-1901, t. II, p. 340-341.

6. Uta Bergmann, Die Freiburger Glasmalerei des 16. bis 18. Jahrhunderts (Le Vitrail fribourgeois du XVI au XVIII siècle), Corpus Vitrearum Suisse, Époque moderne, vol.6, Berne, Peter Lang, 2014, p. 49-75.

7. H. : 44 cm, L. : 30 cm. Fondation des artistes (Paris), inv. MOA076/R 1307, legs d'Adèle Hannah Charlotte de Rothschild, 1922.

8. Il porte l'inscription : « Hr : Glado Meÿ der Zÿt Schultheiß zu Burgdorf 1539 ».

9. Theodor Im Hof, « May », dans Dictionnaire historique et biographique de la Suisse, Neuchâtel, Paul Attinger, 1928, t. IV, p. 695, $\mathrm{n}^{\circ} 7$.

10. H. : $31,5 \mathrm{~cm}$, L. : $21,5 \mathrm{~cm}$. Fondation des artistes (Paris), inv. MOA076/R 1324, legs d'Adèle Hannah Charlotte de Rothschild, 1922.

11. Franz Auf der Maur, "Georg Reding", dans Dictionnaire historique de la Suisse, Hauterive, Éditions Gilles Attinger, 2011, t. X, p. 260, voir : hls-dhs-dss.ch/textes/f/F19012.php (consulté en ligne le 12 décembre 2018).

12. « Houptman Jörg Reding von Schwÿtz / Der Zitt Landtvogtt Der Grafstatt Togenburg ».

13. H. : 32 cm, L. : 22 cm. Fondation des artistes (Paris), inv. MOA076/R 1310, legs d'Adèle Hannah Charlotte de Rothschild, 1922. « H. Fendrich Marttÿ / Edelman Zu Kru[m]enauw / Landrichter der Graff / schafft Dogenburg vnd / Frauw Anna Loserin sin / Eliche husfrauw anno 1646 ».

14. Inv. LM 137/8. Jenny Schneider, Glasgemälde. Katalog der Sammlung des Schweizerischen Landesmuseums Zürich, Stäfa, Th. Gut \& Co., 1971, t. II, p. 285, nº 492.

15. H. : $30,5 \mathrm{~cm}$, L. : $21,5 \mathrm{~cm}$. Fondation des artistes (Paris), inv. MOA076/R 1325, legs d'Adèle Hannah Charlotte de Rothschild, 1922. "Jacob Epper V[on] Hüttschwillen/ vnd Ursula Allenspachin Sin / Eheliche hussfrow An[n]o 1601 ».

16. H. : $34,5 \mathrm{~cm}$, L. : $26 \mathrm{~cm}$. Fondation des artistes (Paris), inv. MOA076/R 1316, legs d'Adèle Hannah Charlotte de Rothschild, 1922.

17. «O Gott in dinem Hochsten ttron / Wellest v[n]s arme sünder nitt verlon : / Durch das vürbit diner Muotter rein/ wellest vnd gnedig vnd barmherzig sin:/ Vnd vns noch disem zergenkhlichen leben / die ewig fröwd vnd selikeit geben / 1605 ».

18. « Hector Bruoderman Von Santt / Gallen. Anno Domini 1605 ». 
19. H. : 40 cm, L. : 32 cm, Fondation des artistes (Paris), inv. MOA076/R 1331, legs d'Adèle Hannah Charlotte de Rothschild, 1922.

20. Karlsruhe, Staatliche Kunsthalle, Kupferstichkabinett, inv. XI 265. Volker Himmelein et al., Die Renaissance im Deutschen Südwesten: zwischen Reformation und Dreissigjährigem Krieg, cat. exp. (Schloss Heidelberg, Badisches Landesmuseum, Karlsruhe, 1986), Karlsruhe, Badisches Landesmuseum, 1986, t. I, p. 344, $\mathrm{n}^{\circ} \mathrm{E} 31$; Ariane Mensger, Die Scheibenrisse der Staatlichen Kunsthalle Karlsruhe. II, Von Murer bis Zeiner, Anonym, Cologne/Weimar/Vienne, Böhlau, 2012, p. $306, \mathrm{n}^{\circ} 516$.

21. Karlsruhe, Staatliche Kunsthalle, Kupferstichkabinett, inv. XI 280. Thea Vignau-Wilberg, « Zu Christoph Murers Frühwerk», dans Jahrbuch des Bernischen Historischen Museums, 59-60, Berne, Historisches Museum, 1980, p.91-92, fig. 1; Ariane Mensger, Die Scheibenrisse der Staatlichen Kunsthalle Karlsruhe, op. cit., t. II, p. 342, $\mathrm{n}^{\circ} 587$.

22. H. : $31 \mathrm{~cm}$, L. : 19,5 cm. Fondation des artistes (Paris), inv. MOA076/R 1321, legs d'Adèle Hannah Charlotte de Rothschild, 1922.

23. Erwin Eugster, "de Toggenbourg ", dans Dictionnaire historique de la Suisse, op. cit., t. XII, p. 528-530. Voir : hls-dhs-dss.ch/textes/f/F19545.php (consulté en ligne le 28 janvier 2019).

24. Paul Boesch, Die Toggenburger Scheiben: Ein Beitrag zur Kulturgeschichte des Toggenburgs im 16. bis 18. Jahrhunderts, Saint-Gall, Zollikofers \& Co., 1935, p. 42, nº 98, fig. 12.

25. « Die GraffSchafft Thoggenburg / 1617 ».

26. H. : $32,5 \mathrm{~cm}$, L. : $22 \mathrm{~cm}$. Fondation des artistes (Paris), inv. MOA076/R 1320, legs d'Adèle Hannah Charlotte de Rothschild, 1922.

27. Diamètre : 19,5 cm. Fondation des artistes (Paris), inv. MOA076/R 1304, legs d'Adèle Hannah Charlotte de Rothschild, 1922.

28. Rolf Hasler, Die Schaffhauser Glasmalerei des 16. bis 18. Jahrhunderts, Corpus Vitrearum Schweiz, Reihe Neuzeit, vol. 5, Berne, Peter Lang, 2010, p. 309-310, $\mathrm{n}^{\circ} 110$.

29. H. : 32 cm, L. : 21 cm. Fondation des artistes (Paris), inv. MOA076/R 1315, legs d'Adèle Hannah Charlotte de Rothschild, 1922.

30. Wilhelm Wartmann, « Hans Caspar Gallati in Wil, der Glasmaler-Monogrammist HCG », dans Indicateur d'antiquités suisses, nouvelle série, vol.9, 1907, p.144-146; Paul Boesch, «Die Wiler Glasmaler HCG und HBG Hans Caspar und Hans Balthasar Gallati », Indicateur d'antiquités suisses, nouvelle série, vol. 37, 1935, p. 273-282; Paul Boesch, Die Wiler Glasmaler und ihr Werk, dans 89. Neujahrsblatt des Historischen Vereins des Kantons St. Gallen, Saint-Gall, Fehr, 1949, p. 32-34 ; Uta Bergmann, Die Zuger Glasmalerei des 16. bis 18.Jahrhunderts, Corpus Vitrearum Schweiz, Reihe Neuzeit, vol. 4, Berne, Benteli, 2004, p. 429-430, nº 208.

31. H. : $34,5 \mathrm{~cm}$, L. : $24 \mathrm{~cm}$. Fondation des artistes (Paris), inv. MOA076/R 1317, legs d'Adèle Hannah Charlotte de Rothschild, 1922.

32. Tijana Žakula, "Improving on Raffael: Gerard de Lairesse's "Heliodorus" ", Netherlands Quarterly of the History of Art, vol. 32, n 2-3, 2006, p. 149 (avec bibliographie plus ancienne).

33. H. : $5 \mathrm{~cm}$, L. : $10 \mathrm{~cm}$. Fondation des artistes (Paris), inv. MOA076/R 1336, legs d'Adèle Hannah Charlotte de Rothschild.

34. Karlsruhe, Staatliche Kunsthalle, Kupferstichkabinett, inv. XI 722. Ariane Mensger, Die Scheibenrisse der Staatlichen Kunsthalle Karlsruhe, op. cit., t. II, p. 540, $\mathrm{n}^{\circ} 978$.

35. H. : 32 cm, L. : $21 \mathrm{~cm}$. Fondation des artistes (Paris), inv. MOA076/R 1314, legs d'Adèle Hannah Charlotte de Rothschild, 1922.

36. Barbara Giesicke et Mylène Ruoss, Die Glasgemälde im Gotischen Haus zu Wörlitz, 2 vol., Berlin, Deutscher Verlag für Kunstwissenschaft, 2012.

37. Paul Boesch, "Schweizerische Glasgemälde im Ausland. Die Sammlung in Nostell Church », Indicateur d'antiquités suisses, vol. 39, 1937, p. 1-22, p. 103-123, p. 180-200, p. 257-304. 
38. Yves Jolidon, "Eidgenössische und oberrheinische Scheiben aus dem Museum Cluny", Archives héraldiques suisses, vol.109, 1995, p.5-44, p. 83-132; vol.110, 1996, p. 3-52, p. 99-112; vol. 111, 1997, p. 3-23.

39. Wilhelm Wartmann, Les Vitraux suisses au Musée du Louvre. Catalogue critique et raisonné précédé d'une introduction historique, Paris, Librairie centrale d'art et d'architecture, 1908.

INDEX

Index géographique : France, Suisse

Thèmes : Vitraux, collections, mécénat, Rothschild

Index chronologique : XVIe siècle, XVIIe siècle, XIXe siècle 


\title{
Les cuirs dorés des collections Rothschild dans les institutions publiques françaises
}

\author{
Jean-Pierre Fournet
}

1 Les objets en cuir doré des collections Rothschild, conservés dans les institutions publiques françaises, sont peu nombreux. Les seuls répertoriés sont la tenture murale, toujours en place, de l'hôtel Salomon de Rothschild à Paris ; celle provenant de l'hôtel Marigny, conservée au Mobilier national ; un panneau conservé à la Villa Ephrussi de Rothschild à Saint-Jean-Cap-Ferrat ${ }^{1}$; et un bouclier d'apparat, naguère conservé à l'hôtel Salomon de Rothschild et actuellement au musée du Louvre. Des tentures en cuir doré ornaient aussi le château Rothschild de Boulogne-Billancourt, mais, conséquence de la dégradation progressive du château, elles sont aujourd'hui détruites et leur décor nous est inconnu.

Ces objets sont très différents les uns des autres. Leur seul élément commun est qu'ils sont tous en cuir doré. Avant de les évoquer, il convient donc de préciser ce qu'il faut entendre par « cuir doré ». Ce sont des cuirs décoratifs apparus en Espagne, à Cordoue, à la fin du $\mathrm{I}^{\mathrm{er}}$ millénaire. Objets d'un engouement considérable en Espagne puis dans toute l'Europe, surtout $\mathrm{du} \mathrm{XVI}^{\mathrm{e}}$ à la fin du XvIII ${ }^{\mathrm{e}}$ siècle, ils ont été fabriqués dans la plupart des pays européens. Résultats d'un mode de réalisation stéréotypé, ils sont définis par leur structure univoque, constituée de six strates superposées (fig.1). La couche la plus profonde est le support de cuir (cuir de mouton, de chèvre ou de veau). La deuxième couche est faite de colle de parchemin et elle est suivie par une troisième couche constituée de feuilles d'argent juxtaposées qui recouvrent l'ensemble de la surface du cuir. Cette couche métallique est habituellement revêtue d'une autre couche de colle destinée à prévenir l'oxydation du métal. L'avant-dernière couche est constituée par le "vernis jaune »- ou "vernis d'or »-, composé de résines végétales chauffées dans de l'huile de lin. Enfin, la dernière couche - facultative - est une couche picturale, souvent polychrome, faite de peintures à l'huile. Les cuirs dorés ne comportent donc pas d'or : c'est le vernis appliqué sur l'argent qui produit leur teinte. 
1. Caractéristiques structurelles des cuirs dorés.

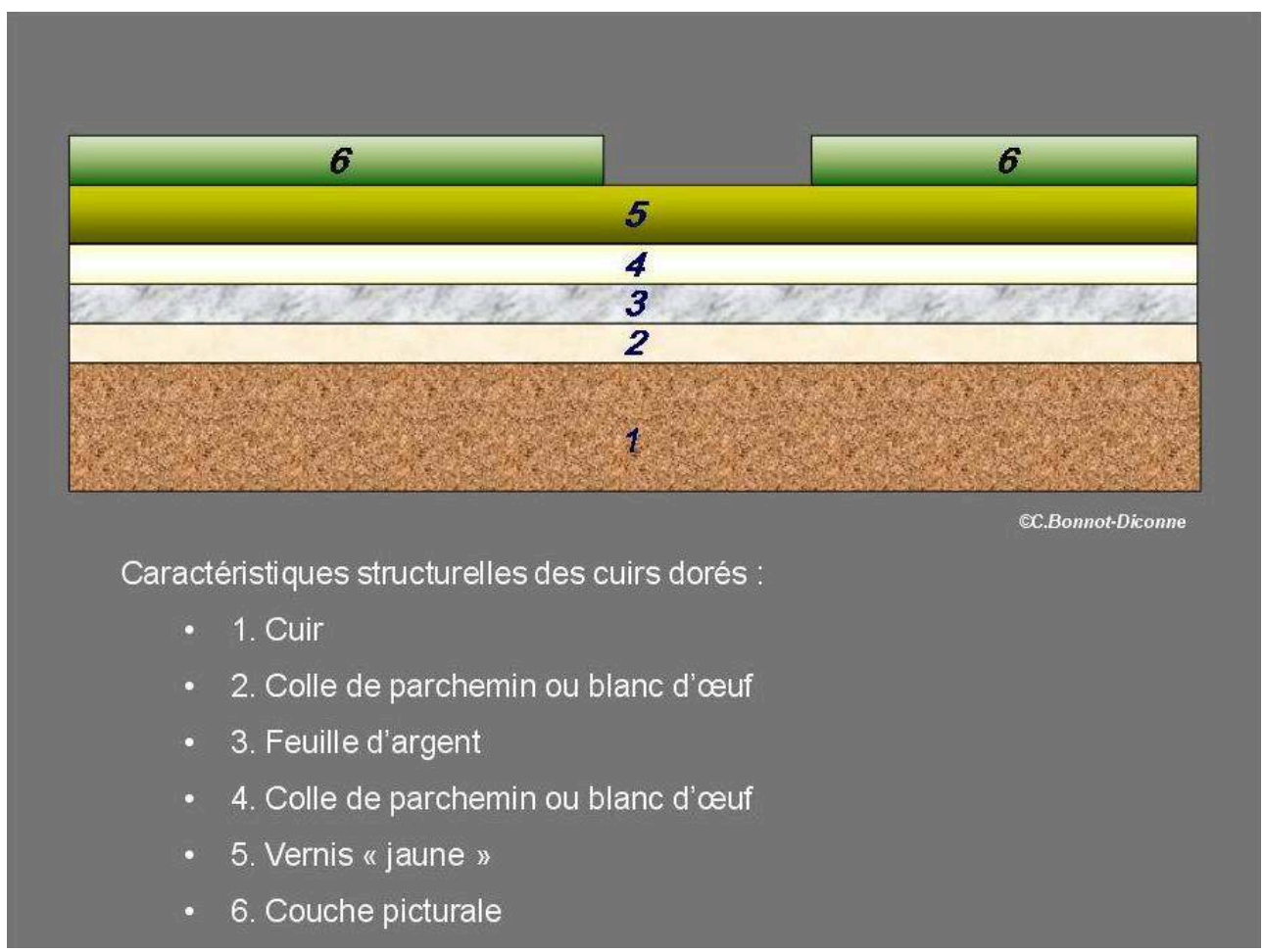

(c) Jean-Pierre Fournet

3 En fonction de leur morphologie externe, les cuirs dorés sont classés en deux grands groupes : les «cuirs dorés plats » et les « cuirs dorés repoussés ». Pour décorer les cuirs dorés « plats » (fig. 2), avant la pose des couleurs, les contours des motifs étaient le plus souvent portés à l'aide d'une planche d'impression en bois, sculptée et encrée. Ces cuirs plats sont fréquemment agrémentés de "ciselures» (fig.3), empreintes qui étaient réalisées avec des poinçons appelés "petits fers ». Très différents, les cuirs dorés « repoussés» (fig.4), apparus vers 1628 aux Pays-Bas, sont en relief. Leur fabrication requérait l'utilisation d'un moule sculpté en creux et d'une robuste presse. Toutes ces caractéristiques se retrouvent dans les cuirs dorés des collections Rothschild. 
2. Panneau de cuir doré plat ciselé, $x V I^{\mathrm{e}}$ siècle, Italie, $116 \times 91 \mathrm{~cm}$, collection privée Glass Tielker.

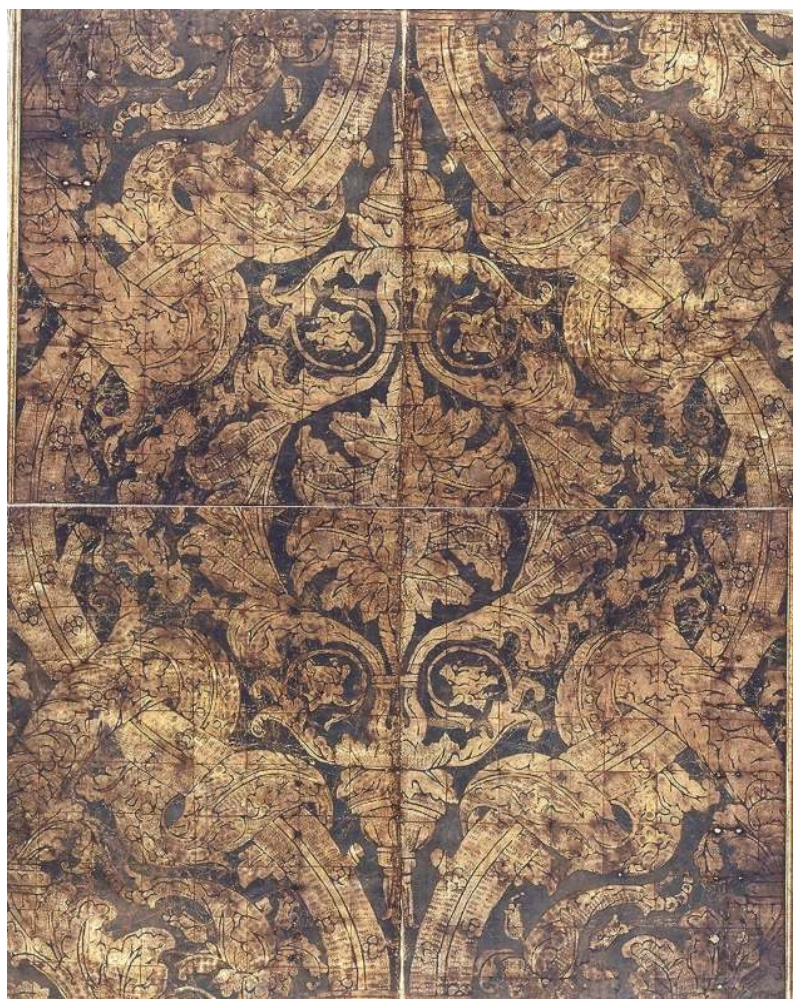

(c) Jean-Pierre Fournet

3. Exemple de motifs de ciselure sur un cuir doré plat italien, $\mathrm{XVI}^{\mathrm{e}}$ siècle.

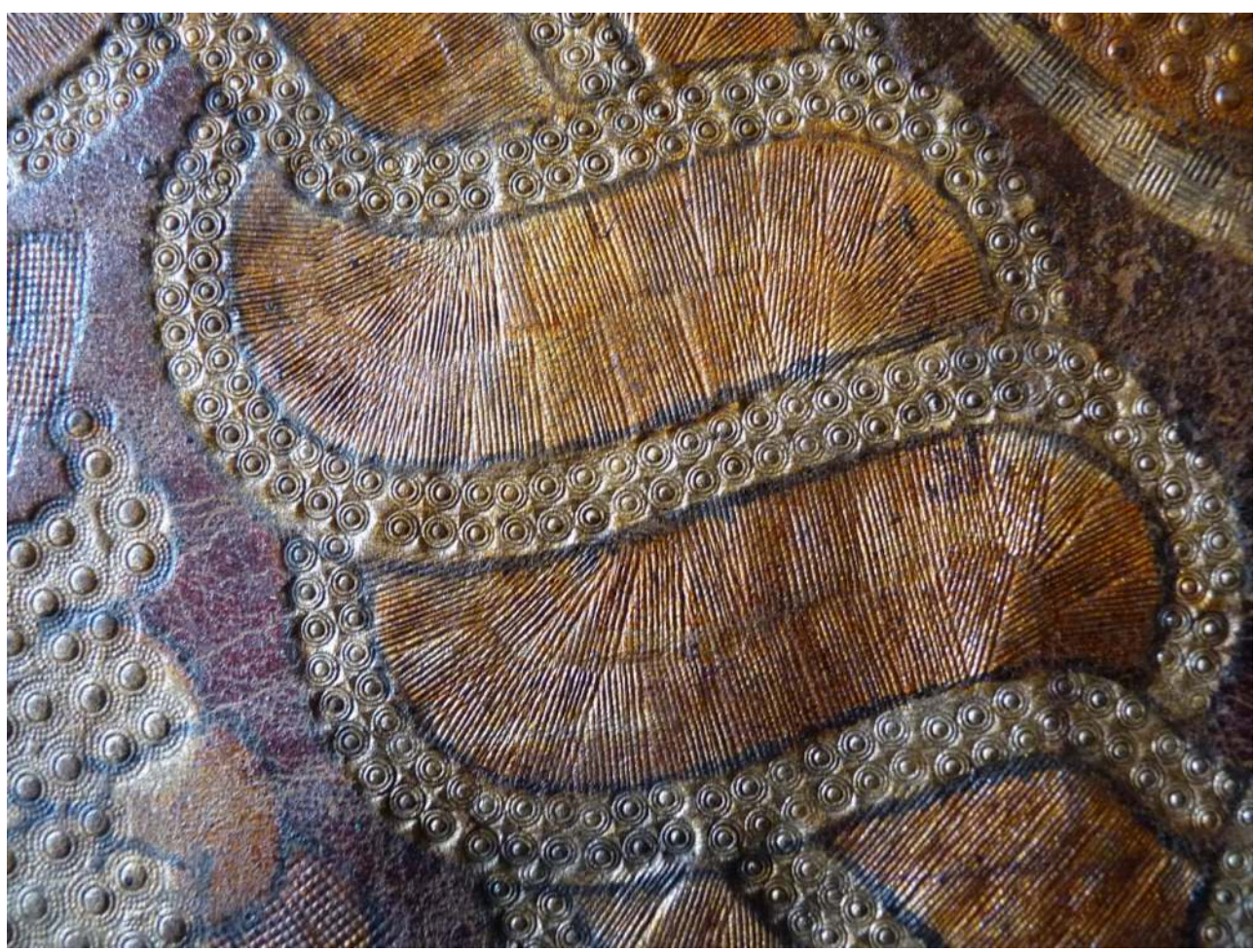

(c) Jean-Pierre Fournet 
4. Carreau de cuir doré repoussé, c. 1670-1680, $52 \times 53$ cm, Kassel, Deutsches Tapetenmuseum.

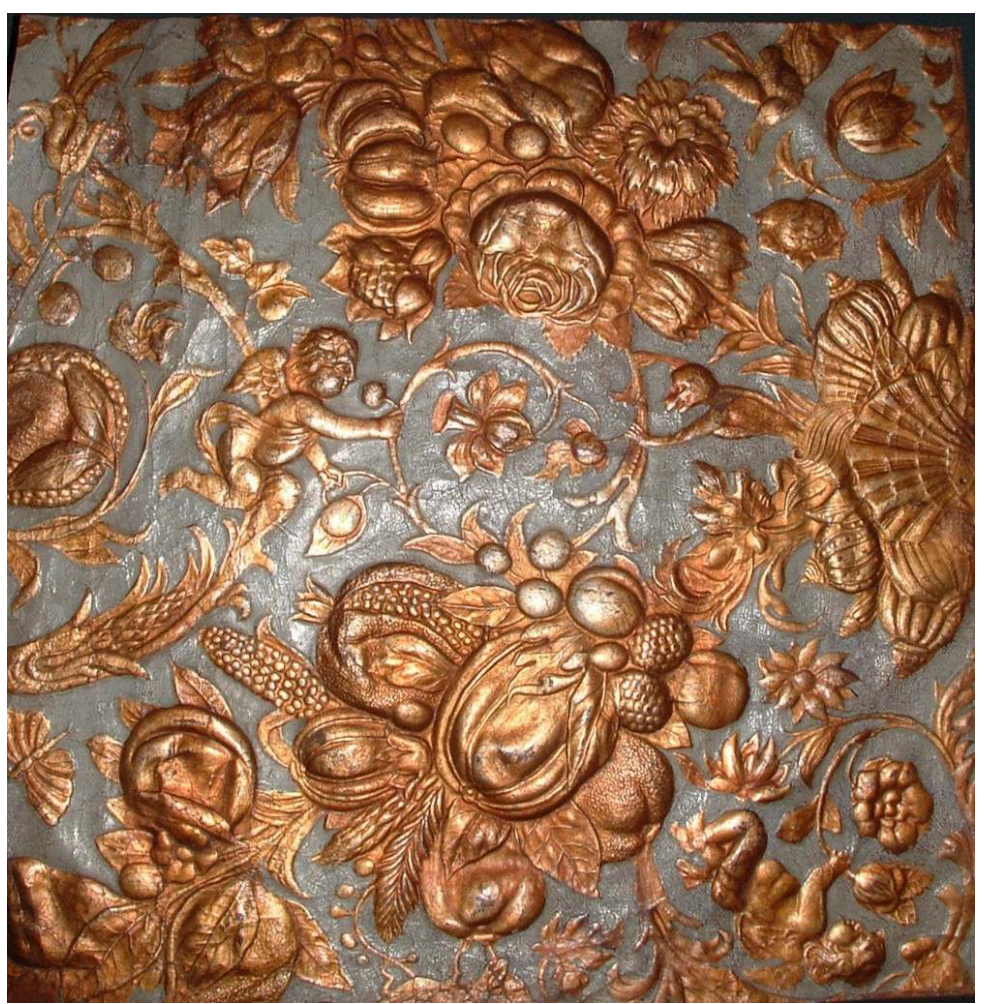

(C) Jean-Pierre Fournet

\section{La tenture murale de l'hôtel Salomon de Rothschild}

La tenture murale de cuir doré qui tapisse le cabinet de curiosités de l'hôtel Salomon de Rothschild est un bel exemple de cuir doré repoussé des Pays-Bas du début du $\mathrm{XVIII}^{\mathrm{e}}$ siècle $^{2}$. La pièce est en effet ornée, sur trois de ses murs, de tapisseries de cuir doré repoussé ; seul le mur nord en est dépourvu. Sur le mur est (fig. 5), un panneau de seize carreaux surmonte la cheminée. Sur le mur sud, deux panneaux sont disposés de part et d'autre de la porte d'entrée. L'un et l'autre sont en grande partie cachés par une vitrine, et seuls leurs six carreaux supérieurs sont bien visibles. Le dessus de la porte est occupé par un petit panneau de trois carreaux. Le dernier panneau orne le mur ouest : il est fait de la superposition de cinq rangées de quatre carreaux, mais seules les deux rangées supérieures sont visibles en raison de la présence d'une grande vitrine. 
5. Tenture de cuir doré repoussé des Pays-Bas, début du XVIII ${ }^{e}$ siècle, Paris, hôtel Salomon de Rothschild. Mur est du cabinet de curiosités.

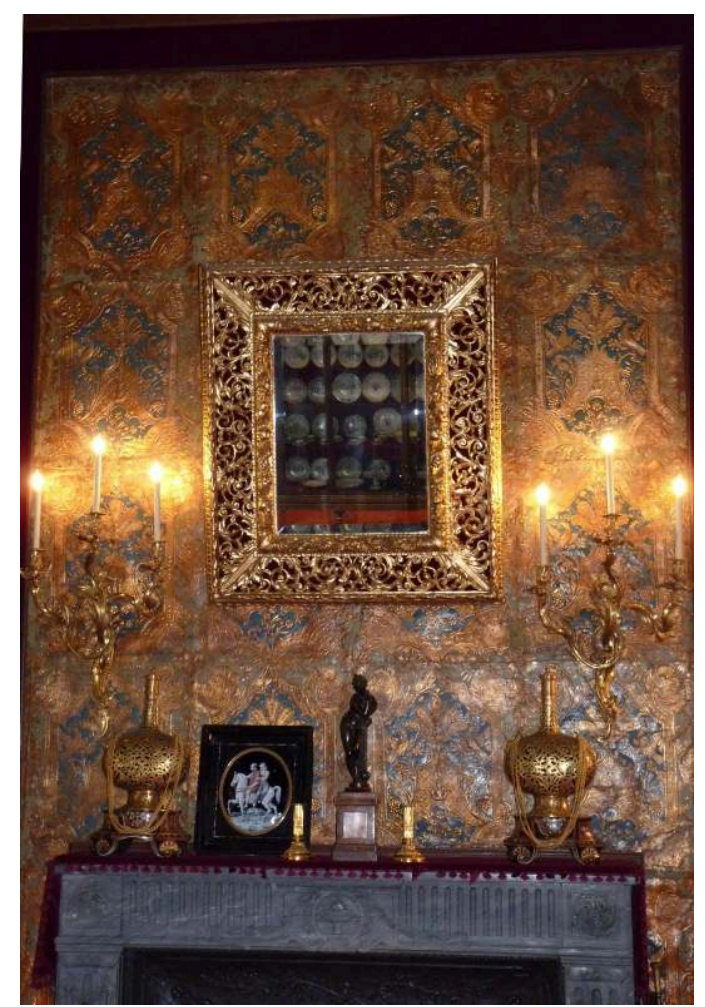

(c) Jean-Pierre Fournet

5 Tous les carreaux sont identiques (fig. 6) et mesurent chacun $75 \mathrm{~cm}$ de haut sur $60 \mathrm{~cm}$ de large. Ils sont aujourd'hui solidarisés entre eux par collage, mais étaient initialement cousus les uns aux autres. Leur décor, très élégant, est caractéristique du style Louis XIV tardif : sur le fond bleu se détachent les différents motifs en relief, tous uniformément dorés. Au centre, une sorte de piédestal de forme presque tronconique, effilé dans sa partie supérieure et orné de croisillons et de rosettes, supporte un motif de palmettes : de chaque côté du piédestal sont représentées des tiges fleuries et des grappes de raisin ; au-dessus figurent deux oiseaux, vraisemblablement des aigles, qui tournent la tête vers l'extérieur. Chaque oiseau tient dans son bec et dans ses serres une branche garnie de baies. L'ensemble est entouré d'un cadre presque hexagonal, dont les bords, rectilignes ou à peine incurvés, sont faits d'une large bande striée qui s'enroule aux angles supérieurs. Les motifs périphériques des carreaux s'articulent parfaitement avec les motifs correspondants des carreaux voisins. Ce décor, communément appelé « décor aux aigles ", semble avoir été inspiré par un dessin sur tissus réalisé par Daniel Marot (1661-1752) en $1712^{3}$. Le décor de cette tenture peut être rapproché d'un décor comparable qui est conservé à l'hôtel de ville de Furnes ${ }^{4}$, en Belgique (fig. 7) ; or celui-ci peut être formellement attribué à l'atelier de Carolus Jacobs à Malines, puisque l'attestation du paiement ${ }^{5}$ est conservée aux archives communales de Furnes ${ }^{6}$. Compte tenu de la similitude des décors, il est logique d'attribuer les cuirs dorés de l'hôtel Salomon de Rothschild à cet atelier malinois, sans toutefois se départir d'une certaine prudence, car ce décor, d'emblée très apprécié et aujourd'hui encore souvent rencontré, a été très abondamment copié. Ainsi, au moins six variantes de cette œuvre 
ont été reconnues ${ }^{7}$. Les différences portant sur des détails sont tantôt aisément visibles, tantôt plus difficiles à déceler.

6. Atelier de Carolus Jacobs à Malines, carreau de la tenture de l'hôtel Salomon de Rothschild, premier quart du XVIII ${ }^{\mathrm{e}}$ siècle, cuir doré repoussé, $75 \times 60 \mathrm{~cm}$, Paris, hôtel Salomon de Rothschild.

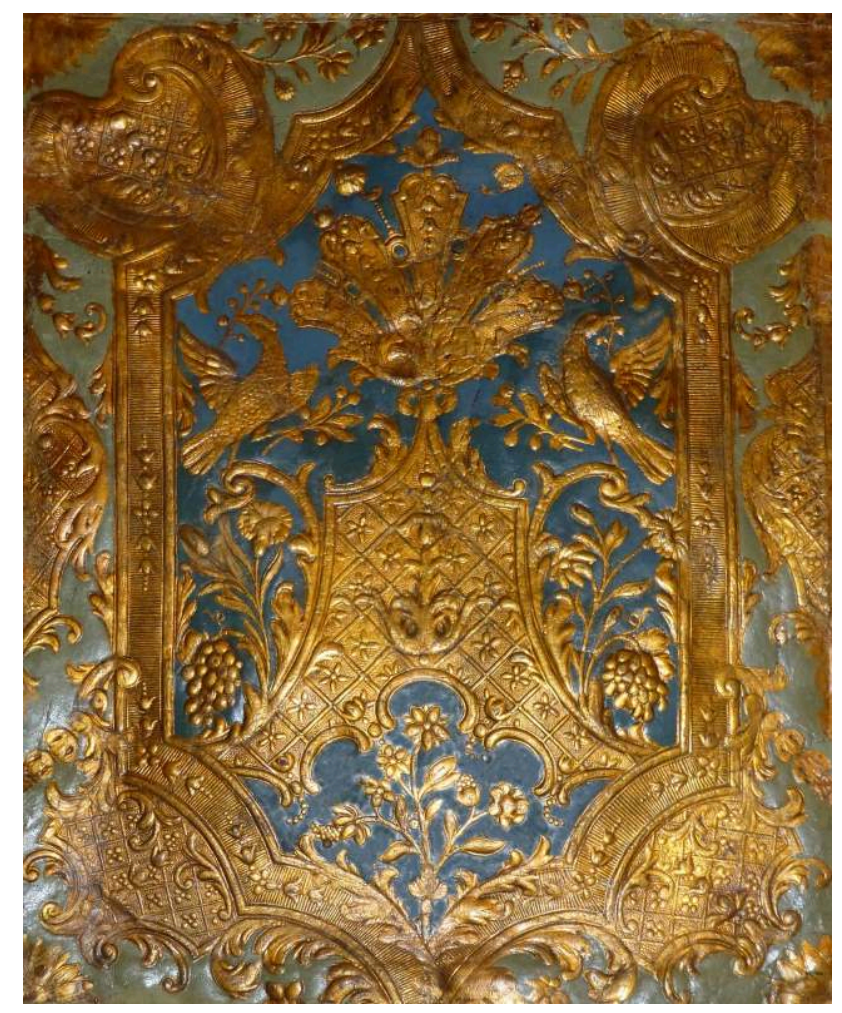

(c) Jean-Pierre Fournet 
7. Atelier de Carolus Jacobs à Malines, carreau de cuir doré repoussé, $1725,72 \times 60 \mathrm{~cm}$, Furnes, hôtel de ville, Albertzall.

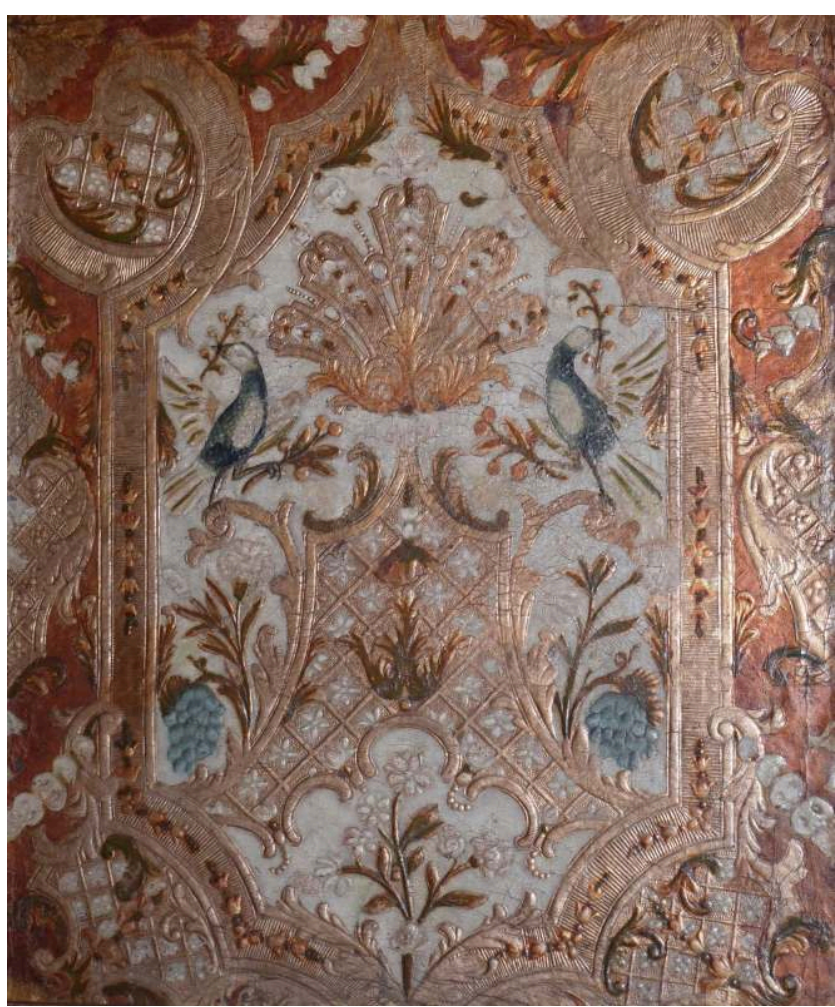

(c) Jean-Pierre Fournet

Les cuirs dorés de l'hôtel Salomon de Rothschild sont donc des cuirs de remploi. Leur provenance n'est pas connue avant la fin des années 1870, quand ils ont été mis en place au terme de la construction de l'hôtel. Ils représentent un rare et bel exemple de cet art décoratif luxueux, qui a charmé l'aristocratie et la grande bourgeoisie de l'Europe entière au début du XvIII siècle et qui a été opportunément remis au goût du jour dans la deuxième partie du XIX ${ }^{\mathrm{e}}$ siècle, tout imprégnée d'éclectisme et de la tendance à régénérer les styles du passé. La mise en place d'un tel décor dans un cabinet de curiosités est dans la tradition de ce qui se faisait dans les grandes demeures au XVII ${ }^{\mathrm{e}}$ siècle.

\section{La tenture murale de l'hôtel Marigny}

7 Très différente est la tenture murale de l'hôtel Marigny. Il s'agit aussi de cuirs dorés de remploi, dont la provenance est inconnue. Ils ont été mis en place dans l'hôtel de Gustave de Rothschild au terme de sa construction, à partir de 1872. Ils y décoraient vraisemblablement le "petit salon", encore appelé "salon rouge ${ }^{8}$ ", jusqu'à l'acquisition de l'hôtel par l'État en 1972, l'hôtel devenant alors dépendance du palais de l'Élysée. La tenture a été définitivement déposée en 1973 et est actuellement conservée au Mobilier national.

8 Aujourd'hui, les cuirs sont très détériorés, au-delà de toute possibilité de restauration. Les carreaux sont en effet très endommagés, déformés, rigides, déchirés, lacunaires. Leurs déformations et leur raideur empêchent, pour la plupart, de les étaler à plat et 
donc de lire et de photographier aisément le décor. Obtenir une vue d'ensemble de cette tenture est impossible - il est tout au plus possible d'avoir une image peu lisible de carreaux isolés (fig. 8). Chaque carreau mesure 65 sur $45 \mathrm{~cm}$ et il est réalisé en cuir doré plat ciselé. Le décor de base de la tenture s'étend sur quatre carreaux (fig. 9), mais, en réalité, les motifs décoratifs de deux des carreaux reproduisent en miroir ceux des deux autres. Ils sont dorés sur un fond rouge lie-de-vin. La reconstitution du décor de base montre que le dessin réalisé est complexe, fait de feuilles d'acanthe et de volutes, de courbes et de contre-courbes, avec des lambrequins et des croisillons. Tous les motifs sont limités par un trait foncé et ils sont abondamment ciselés. Les empreintes des ciselures sont surtout faites de carrés et de cercles entourés de points. Les quatre carreaux qui constituent l'élément décoratif de base sont disposés en alternance, aussi bien horizontalement que verticalement. Il en résulte un décor savant qui va se répétant à l'infini. La tenture était agrémentée d'une bordure assortie, elle aussi abondamment ciselée.

8. Hôtel de Marigny, carreau de cuir doré ciselé, $x V I^{e}$ siècle, Italie, $65 \times 45 \mathrm{~cm}$, Paris, Mobilier national.

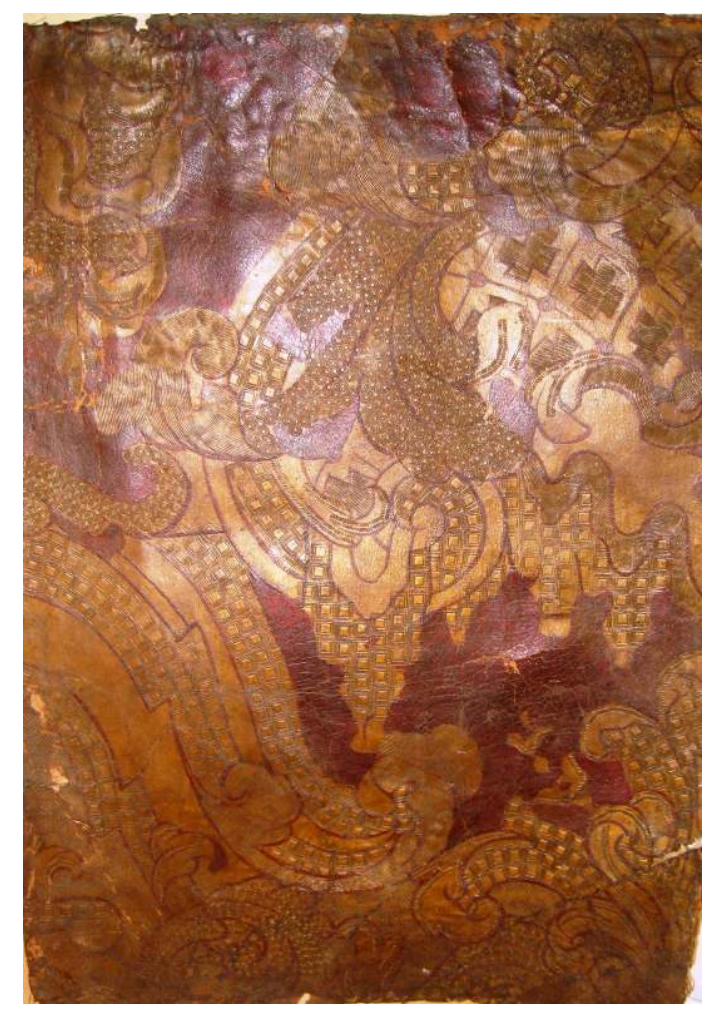

(C) Jean-Pierre Fournet 
9. Les quatre carreaux constituant le décor de base de la tenture en cuir doré de l'hôtel de Marigny, XVII e siècle, Italie, $65 \times 45 \mathrm{~cm}$ (par carreau), Paris, Mobilier national.

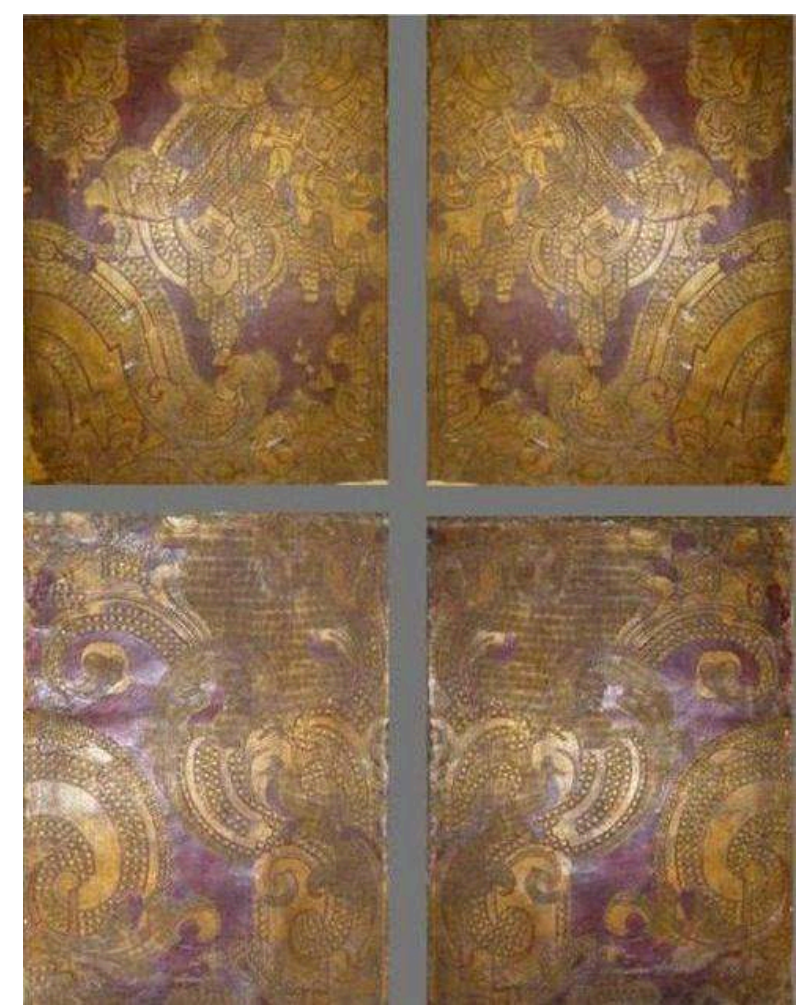

(c) Jean-Pierre Fournet

Cette tenture est un exemple caractéristique de cuir italien plat ciselé de la fin du $\mathrm{XVII}^{\mathrm{e}}$ siècle. Elle illustre aussi le remploi de cuirs dorés anciens dans l'aménagement d'une grande demeure édifiée à la fin du XIX siècle en France.

\section{Le panneau de la Villa Ephrussi de Rothschild}

10 À la Villa Ephrussi de Rothschild, à Saint-Jean-Cap-Ferrat, est conservé un panneau de cuir doré plat et ciselé du XVII siècle (fig.10). Il mesure 1,15 mètre de haut sur 2,15 mètres de large. Sur un fond uniformément bleu se détache le décor doré, dont la partie centrale est constituée de trois carreaux juxtaposés et identiques, complétés par un demi-carreau au décor similaire de part et d'autre. Chaque carreau complet mesure environ $70 \mathrm{~cm}$ sur $42 \mathrm{~cm}$. Le décor représente un enchevêtrement complexe de rinceaux fleuris superposés. Tous les motifs sont agrémentés d'une importante ciselure. À la périphérie du panneau court une bordure assortie à double décor, d'environ $23 \mathrm{~cm}$ de large : à l'intérieur est représentée une succession de pompons alternant avec des oves; plus à l'extérieur, des figures de chérubins alternent avec des anses de panier, des fleurons et des rosettes. 
10. Panneau de cuir doré ciselé, $X V I I^{\mathrm{e}}$ siècle, Italie, $115 \times 215 \mathrm{~cm}$, Saint-Jean-Cap-Ferrat, Villa Ephrussi de Rothschild.

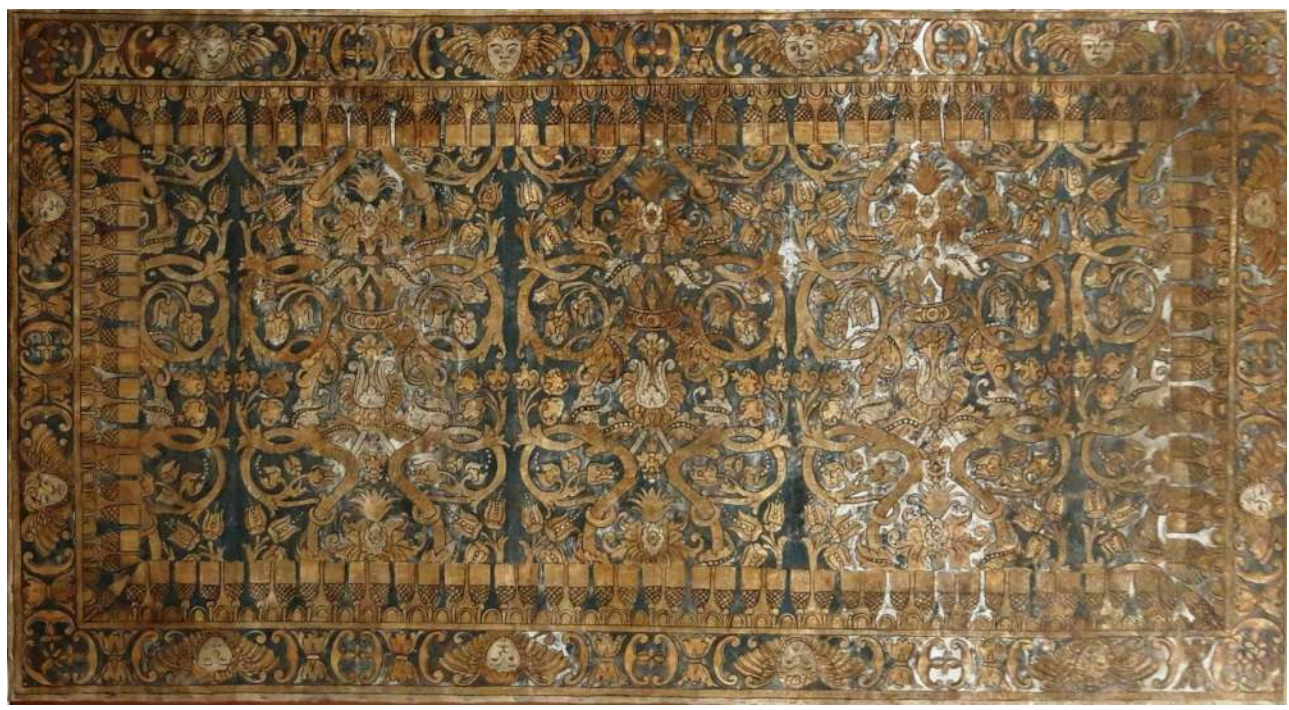

(c) Jean-Pierre Fournet

11 La morphologie des motifs du panneau et l'organisation du décor permettent de conclure qu'il s'agit d'un cuir doré italien du xvII siècle. Un devant d'autel au décor identique est conservé à Orvieto (Italie), au Museo dell'Opera del Duomo\%. Un carreau présentant le même décor se trouve au musée des Arts décoratifs à Paris ${ }^{10}$. Il porte au revers une marque d'atelier avec les initiales « $\mathrm{RB} »$ inscrites dans un cercle ${ }^{11}$.

L'usage auquel était destiné le panneau de la Villa Ephrussi de Rothschild est incertain. Ses dimensions, et plus précisément sa hauteur de 1,15 mètre, permettent d'écarter l'hypothèse d'un devant d'autel ; peut-être s'agit-il d'un simple panneau décoratif. En réalité, c'est probablement une couverture de meuble et très vraisemblablement une couverture de table ou une nappe. Des couvertures de meuble en cuir doré sont en effet très souvent mentionnées dans les inventaires des grandes demeures italiennes des $\mathrm{XVI}^{\mathrm{e}}$ et XVII ${ }^{\mathrm{e}}$ siècles, notamment à Rome ${ }^{12}$, sous le nom de panno (c'est-à-dire « drap, linge ou nappe »), soprapanno (" surnappe »), panno e cascate da tavola (« nappe et cascade - ou chute - de table»), coperta (« couverture» ou "recouvrement»), coperta da tavola (" couverture de table» ou «nappe»), sopracoperta («surnappe»). Tous ces mots désignent des "pièces ", " couvertures " ou "revêtements " destinés à recouvrir des meubles et surtout des tables, mais ils ne sous-entendent pas des usages strictement identiques... Ainsi en est-il pour les deux appellations voisines "coperta" et "sopracoperta ": s'agissant de cuirs dorés, coperta (comme panno) désignait une nappe posée directement sur la table ; en revanche, sopracoperta (comme soprapanno) désignait une nappe en cuir doré recouvrant une nappe en tissu qui était directement au contact de la table. Les nappes (coperta ou panno) étaient souvent entourées d'une cascate (" cascade » ou «chute»), bordure qui retombait à la verticale le long des côtés de la table, une fois la nappe étendue. Parfois, les quatre éléments d'angle (habituellement carrés) de la bordure faisaient défaut, de façon que les chutes, à ces emplacements, soient plus franches, comme c'est le cas sur une nappe de cuir damasquiné du XVII ${ }^{\mathrm{e}}$ siècle conservée au musée Stibbert, à Florence ${ }^{13}$. Le panneau de cuir doré de la Villa Ephrussi de Rothschild pourrait donc très bien correspondre à ce que les inventaires romains des $\mathrm{XVI}^{\mathrm{e}}$ et $\mathrm{XVII}{ }^{\mathrm{e}}$ siècles mentionnaient sous l'appellation "panno" 
et " cascate da tavola». Cependant, pour une " nappe avec chute ", le sens du montage de la bordure est surprenant. Son inversion avec la disposition des pompons en périphérie paraîtrait plus logique, permettant de voir les figures de chérubins à l'endroit, quand les pans de la nappe tombent verticalement.

Les conditions d'entrée du panneau à la Villa Ephrussi de Rothschild semblent inconnues. Il en est de même pour un autre objet en cuir décoré, également conservé à la Villa. Il s'agit d'un panneau de cuir plat qui mesure 72 sur $91 \mathrm{~cm}$. La partie centrale est entourée d'une bordure à fond vert ornée de rinceaux fleuris dorés; des bandes dorées limitent l'intérieur et l'extérieur de la bordure. Une frange a été ajoutée en périphérie. La partie centrale du panneau n'est pas en cuir doré. Ici aussi, il s'agit vraisemblablement d'une couverture de meuble. Certes, les motifs de la bordure sont de style Renaissance, mais la facture d'ensemble ainsi que la frange laissent penser qu'il s'agit d'une réalisation $d u \mathrm{xIX}^{\mathrm{e}}$ ou du début $\mathrm{du} \mathrm{xx}^{\mathrm{e}}$ siècle. Un autre panneau avec bordure mesurant 1,57 sur 2,66 mètres, mais de facture encore très différente, datant du XVIII ${ }^{e}$ siècle et peut-être italien, pouvant aussi évoquer une couverture de table, est conservé au musée de Charlieu (Loire).

\section{Le bouclier d'apparat vénitien}

Le dernier objet de cette courte série est un bouclier d'apparat vénitien de la fin du $\mathrm{XVI}^{\mathrm{e}}$ siècle $^{14}$ (fig. 11). Jusqu'au début des années 2000, il figurait parmi les œuvres conservées dans le cabinet de curiosités de l'hôtel Salomon de Rothschild à Paris ; il est actuellement déposé au musée du Louvre. C'était un achat précoce de Salomon de Rothschild, effectué entre 1862 et $1864^{15}$. Il s'agit d'un bouclier rond et galbé, mesurant $58 \mathrm{~cm}$ de diamètre. Il est constitué d'une âme de bois recouverte de cuir doré sur sa face antérieure et, au revers, de cuir peint de façon neutre; les deux poignées en cuir postérieures ont été perdues. Le décor du cuir de la face antérieure est de type islamique moyen-oriental. Le fond est de couleur vieux rouge ou lie-de-vin. Les motifs décoratifs dorés sont faits d'un enchevêtrement complexe de tiges végétales curvilignes qui traversent des feuilles et des fleurs. Au sein de cet ensemble sont disposés des médaillons dont la mise en place est très ordonnée. Le centre du bouclier est occupé par un grand médaillon doré, de forme arrondie, mais aux limites chantournées, centré par un rond noir, lui-même orné d'un cercle doré contenant une petite barre hachurée dorée. Six autres médaillons, plus petits, à fond doré et aux motifs polychromes, sont régulièrement répartis sur l'ensemble de la surface; il en existe deux types morphologiquement différents, disposés en alternance. Six demi-médaillons sont encore placés le long de la bordure dorée périphérique, dans laquelle courent des tiges sinueuses portant des feuilles et des fleurs. Une seconde bordure, plus étroite, polychrome et ornée de motifs juxtaposés en forme de tente, double la précédente et marque la limite du bouclier. À une date non précisée, vraisemblablement au xIx siècle, un galon d'ameublement à franges avait été ajouté. Il a été supprimé lors d'une restauration récente. 
11. Bouclier d'apparat en cuir doré, seconde moitié du $x v l^{e}$ siècle, Venise, $58 \mathrm{~cm}$ de diamètre, conservé à l'hôtel Salomon de Rothschild jusqu'au début des années 2000, actuellement déposé à Paris, musée du Louvre.

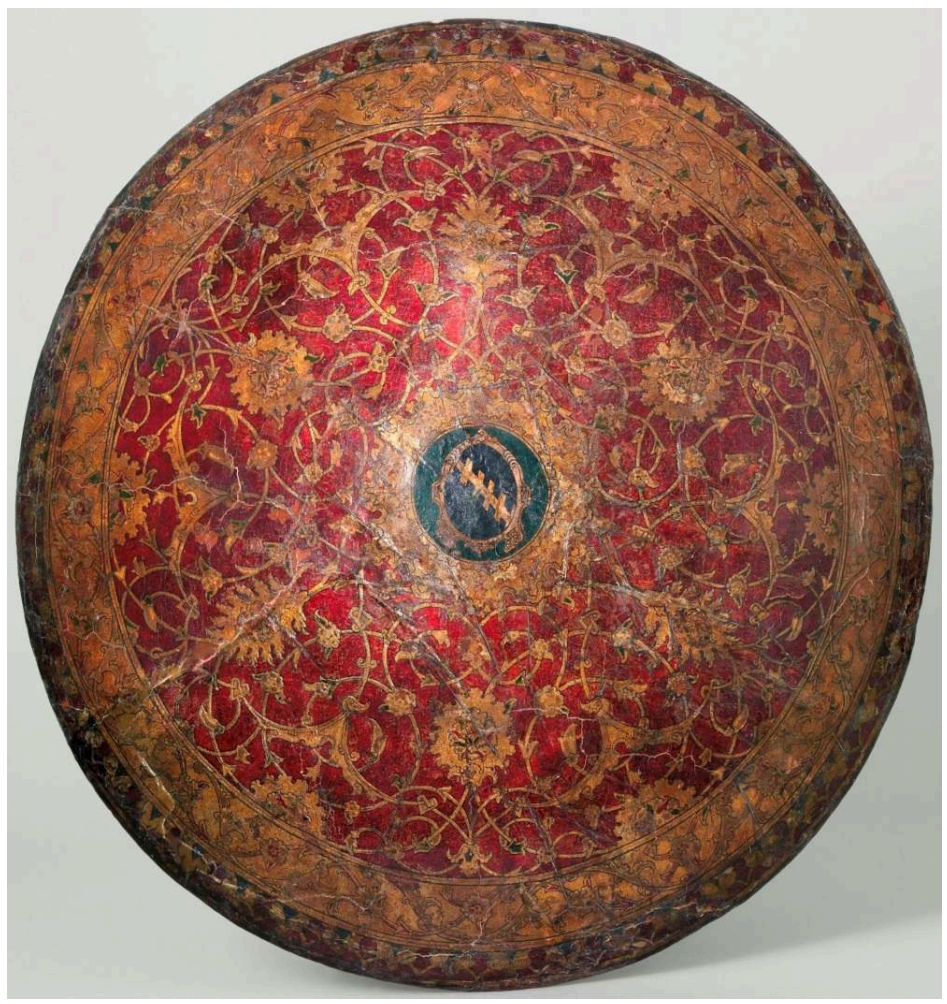

(c) Musée du Louvre

L'ensemble du décor, avec les feuilles et les fleurs percées par des tiges curvilignes, ainsi que la morphologie et la disposition des médaillons évoquent bien des représentations islamiques moyen-orientales et rappellent les céramiques d'Iznik ou les céramiques syriennes de la période ottomane (fig. 12).

12. Carreau de bordure en céramique, $x v l^{e}$ siècle, Iznik, $11 \times 25 \mathrm{~cm}$, Paris, musée du Louvre.

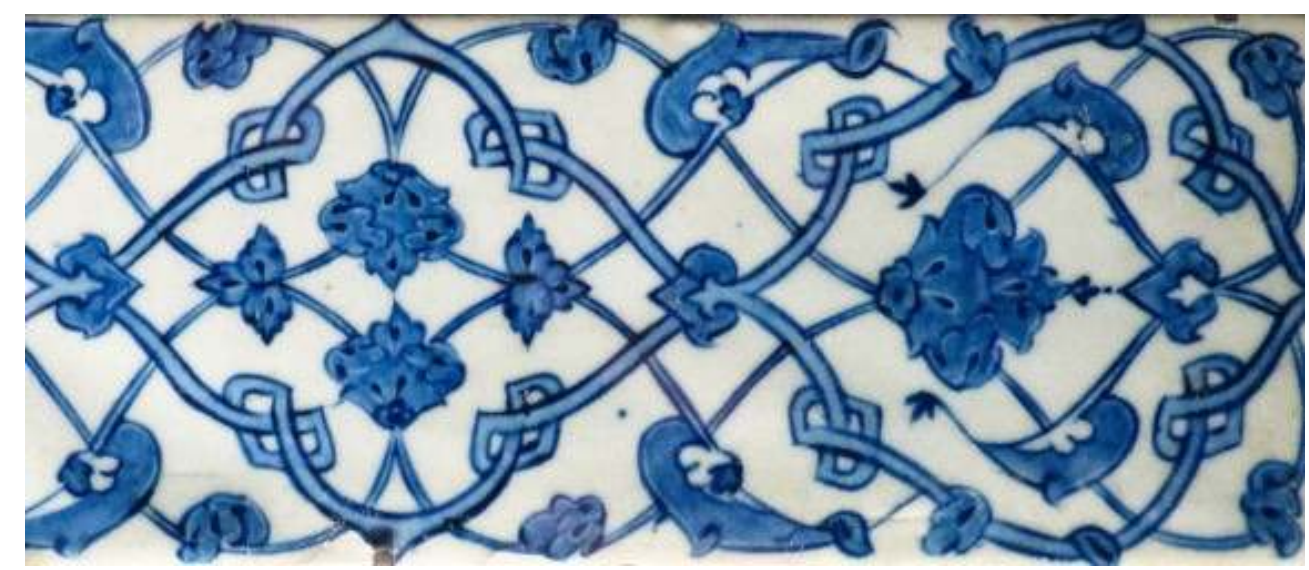

(c) Musée du Louvre

Des boucliers d'apparat au décor identique ou voisin sont conservés dans plusieurs musées et collections, notamment au palais des Doges à Venise ${ }^{16}$, au musée Stibbert à Florence, au musée Poldi-Pezzoli à Milan, au Palazzo Venezia à Rome, au Metropolitan 
Museum à New York, au Victoria and Albert Museum à Londres, à la tour de Londres, au Musée allemand du cuir d'Offenbach ou encore au Musée des armes anciennes de Dresde. Le musée Carolino-Augusteum de Salzbourg en possède aussi plusieurs exemplaires : ils avaient été commandés à Venise par le prince-évêque de Salzbourg ${ }^{17}$, Wolf Dietrich von Raitenau, qui détint sa charge épiscopale de 1587 à 1612, ce qui corrobore l'origine et la datation proposées pour ces œuvres. L'exemplaire de la collection Salomon de Rothschild est le seul répertorié en France.

17 Tous ces boucliers d'apparat vénitiens à décor islamique moyen-oriental sont très semblables ${ }^{18}$. La similitude de leur décor avec celui d'objets authentiquement moyenorientaux a pu mettre en doute, pendant un temps, l'attribution vénitienne de ces objets, si bien que l'on en a proposé une origine ottomane, turque notamment, ou syrienne. En réalité, ces boucliers sont bien des fabrications vénitiennes, car la technique des cuirs dorés était routinière et bien ancrée à Venise, alors qu'elle n'a jamais été pratiquée au Moyen-Orient ${ }^{19}$; de plus, les boucliers ronds et galbés sont de forme typiquement occidentale et non orientale; enfin, il est établi que les boucliers de Salzbourg ont été commandés à Venise par le prince-évêque ${ }^{20}$. De surcroît, des objets d'usage courant en cuir doré, comme des pichets ou des gobelets, ont été décrits dans des inventaires de la même époque comme étant décorés "à la turque ${ }^{21}$ "; une chope en cuir doré de ce type, très vraisemblablement vénitienne elle aussi, est conservée au département des Arts de l'Islam au Louvre ${ }^{22}$.

Parmi l'ensemble des cuirs dorés italiens du Xvie siècle, les boucliers d'apparat vénitiens représentent donc un ensemble iconographique tout à fait à part. Ils illustrent l'importance des influences islamiques moyen-orientales qui se sont manifestées à Venise au $\mathrm{xVI}^{\mathrm{e}}$ siècle ainsi que celle des échanges économiques et culturels qui existaient alors entre Venise et les pays de l'Est méditerranéen.

19 Ces quatre objets des collections Rothschild sont certes très différents les uns des autres, mais ils ont en commun d'être en cuir doré et d'avoir été remis en valeur presque simultanément, dans la seconde partie du xix siècle, par divers membres de la famille Rothschild. Ils doivent être rapprochés de la tenture italienne du XvII ${ }^{\mathrm{e}}$ siècle que Charlotte de Rothschild avait fait installer, vers 1875, à l'abbaye des Vaux-de-Cernay (aujourd'hui propriété d'une entreprise hôtelière privée) et surtout de la célèbre tenture en cuir doré des Pays-Bas du XVII siècle, représentant le cortège de David victorieux $^{23}$, que James de Rothschild fit installer au château de Ferrières, à la fin des années 1860, et qui est toujours propriété de la famille.

20 Tous ces décors représentent en réalité des moments particuliers de la longue histoire des cuirs dorés, histoire qui, presque tombée dans l'oubli aujourd'hui, fut brillante pendant plusieurs siècles.

21 La réunion de ces quatre œuvres en cuir doré, toutes maintenant dans des institutions publiques françaises, possède une double résonance : elle rappelle la gloire passée de ces superbes décors qui ont enchanté la plupart des grandes demeures de l'Europe, surtout du XVI à la fin du XVIII ${ }^{e}$ siècle ; elle est, par ailleurs, une claire illustration du mouvement de retour vers le passé qui s'est exprimé dans la seconde moitié du $\mathrm{XIX}^{\mathrm{e}}$ siècle, avec la remise au goût du jour de styles et de décors anciens, chers aux adeptes de l'éclectisme. 


\section{NOTES}

1. Sur les demeures de la famille Rothschild, voir Pauline Prevost-Marcilhacy, Les Rothschild, bâtisseurs et mécènes, Paris, Flammarion, 1995.

2. Cette tenture est désormais inventoriée dans la base de données de l'INHA Les Collections Rothschild dans les institutions publiques françaises, disponible via Agorha, avec l'ensemble des pièces qui étaient conservées au moment du décès de la baronne Adèle de Rothschild, en 1922, dans le cabinet des curiosités de l'hôtel Salomon de Rothschild. Voir Laura de Fuccia et JeanPierre Fournet, « Pays-Bas, vers 1710, "Quatre grands panneaux de cuir doré repoussé et dessus de porte" ", dans Agorha, Les Collections Rothschild dans les institutions publiques françaises, Paris, Institut national d'histoire de l'art, 2016 [en ligne]: agorha.inha.fr/inhaprod/ark:/ 54721/003229549 Sur le goût de Salomon et d'Adèle de Rothschild, voir Pauline PrevostMarcilhacy (dir.), Les Rothschild. Une dynastie de mécènes en France, 3 vol., Paris, Louvre/BnF / Somogy, 2016, vol. II, p. 8-179.

3. Publié dans le recueil Patrons d'étoffes et de velours, vers 1712. Voir Peter Jessen, Das Ornamentwerk des Daniel Marot, Berlin, Ernst Wasmuth, 1892.

4. « Veurne » en flamand, près de Dunkerque.

5. Le montant du paiement était de 299 florins.

6. Archives communales, Furnes, livre de comptes, 1725-1726. Voir Eloy Koldeweij, « Het gouden leer ", Monumenten en Landschappen (Bruxelles), $n^{\circ}$ 6, novembre-décembre 1992, p. 31, note 57.

7. Voir Eloy Koldeweij, «De verschijningsvorm en patronen van het goudleer " [Les décors des cuirs dorés], dans Frits Scholten (dir.), Goudleer Kinkarakawa. De geschiedenis van het Nederlands goudleer en zijn invloed in Japan [Les cuirs dorés. L'histoire des cuirs dorés néerlandais et leur influence au Japon], cat. exp. (La Haye, Haags Historisch Museum, 1989 ; Groningen, Groninger Museum, 1989), Zwolle, Waanders, 1989, p. 59.

8. Les notes manuscrites, datées de 1973, sont contenues dans le Dossier de restauration de l'hôtel Marigny, conservé au Mobilier national.

9. Voir Mara Nimmo, Mariabianca Paris et Lidia Rissotto, Cuoio dorato e dipinto. Schedatura di manufatti. Repertorio die punzoni, Roma, Istituto Centrale per il Restauro, 2008, p. 55 et p.72, dossier 12, fig. 123 ; p. 234-235, pl. VIId.

10. Voir Jean-Pierre Fournet, "Les cuirs dorés anciens en France", mémoire de recherche approfondie, Paris, École du Louvre, 2004, t. VI, p. 906.

11. Voir Mara Nimmo, Mariabianca Paris et Lidia Rissotto, Cuoio dorato e dipinto, op. cit., p. 238, p. 286 ; pl. XVI i.

12. Voir Académie de France à Rome, La Villa Médicis. V, Fonti documentarie, Rome, Académie de France à Rome, 2010, p. 44 ; Céline Bonnot-Diconne, " Method of use and importance of gilt leather in three Italian palaces during the $16^{\text {th }}$ and $17^{\text {th }}$ century through the study of inventories ", dans Céline Bonnot-Diconne, Carole Dignard, Jutta Göpfrich (dir.), $10^{\text {th }}$ Interim Meeting of ICOM-CC, actes de colloque (Offenbach, 2012), Offenbach, DLM-Deutsches Ledermuseum/Schuhmuseum, 2013, p.17, tableau 1; p.19, tableau 2; p. 20-21, tableau 4. L'inventaire du palais Ricci-Sacchetti de 1561 à Rome mentionne 13 nappes en cuir doré. L'inventaire de la Villa Médicis de 1588 mentionne 37 nappes et couvertures de table en cuir doré, alors que l'inventaire du palais Farnèse de 1644 en mentionne 38.

13. Voir Mara Nimmo, Mariabianca Paris et Lidia Rissotto, Cuoio dorato e dipinto, op. cit., p. 53 et p. 80, dossier 213, fig. 110.

14. Voir Céline Bonnot-Diconne et Jean-Pierre Fournet, «Study and restoration of a gilt leather venetian shield ", Interim meeting of ICOM-CC, actes de colloque (Athènes, 2004), Sturge/Lulu, 2007, p. 40 . 
15. Voir Marc Bascou, "Armes occidentales", dans Pauline Prevost-Marcilhacy (dir.), Les Rothschild. Une dynastie de mécènes en France, op. cit., vol. II, p. 102-104.

16. Voir Stefano Carboni (dir.), Venise et l'Orient (828-1797), cat. exp. (Paris, Institut du monde arabe, 2006-2007), Paris, Gallimard, 2006, p. 99 et p. 233-236.

17. Voir Anna Contadini, «"Cuoridoro". Tecnica e decorazione di cuoi dorati veneziani e italiani con influssi islamici», dans Ernst Grube (dir.), Atti del primo simposio internazionale sull' arte veneziana e l'arte islamica, Venise, L'Altra Riva, 1989, p. 241-242, n. 40.

18. Id., ibid., p. 231-251; id., "Artistic Contacts: Current Scholarship and Future Tasks », dans Charles Burnett et Anna Contadini, Islam and the Italian Renaissance, Londres, Warburg Institute, 1999, p. 1-60.

19. Ibid., loc. cit.

20. Voir Ernst J. Grube, "Le "laque" vénitien et la reliure au XVI ${ }^{\mathrm{e}}$ siècle ", dans Stefano Carboni (dir.), Venise et l'Orient (828-1797), op. cit., p. 336, note 140.

21. "[...] alla turchesca [...]», dans la formulation italienne, par exemple dans l'inventaire du palais Farnèse de 1644 à Rome. Voir Bertrand Jestaz, Le Palais Farnèse. III, 3, L'Inventaire du palais et des propriétés Farnèse à Rome en 1644, Rome, École Française de Rome, 1994, p. 82, nº 1758 ; Céline Bonnot-Diconne, « Method of use and importance of gilt leather in three Italian palaces during the $16^{\text {th }}$ and $17^{\text {th }}$ century through the study of inventories ", art. cit., p. 20.

22. Achat 1995 ; MAO 958. Voir aussi Sophie Makariou (dir.), Les Arts de l'Islam au musée du Louvre, Paris, Louvre/Hazan, 2012, p. 367-368.

23. Voir Jean-Pierre Fournet, "Une exceptionnelle tenture de cuir doré conservée à Paris : Le Triomphe de David victorieux ", L'Estampille. L'objet d'art, $\mathrm{n}^{\circ} 413,2006$, p. 76-79.

\section{INDEX}

Index géographique : France, Italie

Index chronologique : XIXe siècle

Thèmes : Cuir doré, collections, Rothschild 


\title{
La collection de porcelaines chinoises de l'hôtel Salomon de Rothschild
}

\author{
Pauline d'Abrigeon
}

1 L'écrin feutré que forme la salle des curiosités de l'hôtel Salomon de Rothschild, actuelle Fondation des artistes, renferme une centaine de porcelaines chinoises disposées dans d'imposantes vitrines en chêne doré. Les œuvres que l'on peut voir aujourd'hui représentent une partie seulement d'une collection bien plus vaste rassemblée par le couple Salomon (1835-1864) et Adèle-Hannah-Charlotte, dite Adèle de Rothschild (1843-1922) ${ }^{1}$. Salomon de Rothschild, fils du fondateur de la branche française des Rothschild, le baron James de Rothschild, entreprend une collection d'œuvres d'art qu'il rassemble entre 1862 et 1864, année de sa mort soudaine à l'âge de 29 ans. L'Extrême-Orient occupe une place considérable dans cette première collection, ce qui témoigne à la fois d'un goût ${ }^{2} e t$ du contexte d'épanouissement des arts asiatiques dans les ventes aux enchères parisiennes de la seconde moitié du XIX ${ }^{e}$ siècle ${ }^{3}$. Devenue veuve en 1864, Adèle de Rothschild quitte sa demeure familiale du 25, rue du FaubourgSaint-Honoré pour faire construire un hôtel situé au 11, de la rue Berryer, lequel sera achevé en $1878^{4}$. Elle y installe la collection de son mari qu'elle continue d'enrichir et de valoriser, en l'exposant ponctuellement jusqu'à sa mort en 1922. Dans son testament, elle lègue la majeure partie de sa collection à diverses institutions françaises, principalement le musée du Louvre, le musée de Cluny, la Bibliothèque nationale de France et le musée des Arts décoratifs. Seule subsiste une partie du décor de la salle des curiosités, destinée par dispositions testamentaires en 1922 à être conservée telle quelle avec les œuvres qu'elle contient ${ }^{5}$. C'est là que, à la mort d'Adèle, se trouvait exposée plus de la moitié des porcelaines chinoises de la collection ${ }^{6}$.

2 Fondé sur le remarquable travail d'inventaire réalisé à l'INHA pour l'identification et la localisation des œuvres initialement contenues dans cette salle des curiosités, le présent article se focalise principalement sur les objets actuellement conservés à la Fondation des artistes ${ }^{7}$. J'effectuerai néanmoins quelques excursus, en incluant aussi à cette analyse des pièces qui, quoiqu'actuellement présentées dans la salle des 
curiosités, étaient à l'origine destinées au musée du Louvre et ont finalement repris place dans l'hôtel Salomon de Rothschild au titre de dépôts. Cela devrait permettre de donner une vision plus globale de la collection au moment où elle a été rassemblée.

3 Tout au long de mes investigations, je me suis questionnée sur les raisons qui ont conduit Salomon puis Adèle à acquérir de la porcelaine chinoise, sur le sens et la valeur que les époux ont pu donner à ces objets en particulier. C'est pourquoi il m'a semblé nécessaire d'envisager la collection dans son ensemble, de non seulement comparer les inventaires des deux époux, mais aussi de confronter leurs collections à celles de leurs contemporains. Les porcelaines chinoises restent néanmoins des objets relativement peu décrits dans les inventaires et les catalogues de vente de l'époque, aussi est-il quasiment impossible de retracer un objet de manière précise dans le temps. Il est également impossible de distinguer clairement les pièces acquises du temps de Salomon de celles acquises du temps d'Adèle. Leurs inventaires après décès permettent néanmoins d'établir un décompte approximatif des porcelaines chinoises dans les deux collections ${ }^{8}$. Dans l'inventaire de Salomon, réalisé en 1864 au 25, rue du FaubourgSaint-Honoré, on ne dénombre pas moins de 283 porcelaines chinoises'. L'inventaire après décès d'Adèle de Rothschild, réalisé en 1922 dans son hôtel particulier de la rue Berryer, comprend, quant à lui, 448 porcelaines chinoises, dont 260 présentées dans la salle des curiosités. Ces chiffres montrent combien Adèle a continué d'enrichir la collection après la mort de son mari.

\section{Retracer l'histoire de la collection}

\section{Des intermédiaires en lien avec le commerce de la curiosité à Paris}

4 Pour effectuer ses achats, Salomon de Rothschild fait appel à des intermédiaires. Son carnet de comptes mentionne plusieurs personnalités éminentes du monde du marché de l'art parisien des années $1860^{10}$. Parmi celles-ci, certaines sont plus particulièrement liées au commerce d'objets d'art asiatique comme le baron Hippolyte Boissel de Monville (1795-1873), Louis Auguste Alfred Beurdeley (1808-1882) et surtout Nicolas Joseph Malinet (1805-1886) ${ }^{11}$.

5 Le baron de Monville est un acteur essentiel du monde de la curiosité dans les années $1860^{12}$. Dans sa thèse, Manuel Charpy le décrit comme «noble d'Empire désargenté et mandataire des collectionneurs Alfonse et Gustave de Rothschild $»^{13}$. Le carnet de vente de Salomon de Rothschild montre que le baron de Monville, reçoit des acomptes réguliers pour l'acquisition d'œuvres d'art jusqu'à la mort de Salomon en 1864. Il est lui-même collectionneur, ainsi qu'en atteste la vente de sa collection en $1866^{14}$. Dans la préface du catalogue, l'expert Carle Delange le décrit succinctement comme le « doyen des collectionneurs [...] si connu par le goût avec lequel il a collectionné toute sa vie, tant pour lui que pour ses amis » et indique qu'il «se défait aujourd'hui, bien qu'à regret, de sa dernière collection ${ }^{15}$ ». Il s'agit d'une collection essentiellement composée de porcelaines de Chine et du Japon, dont l'inventaire et la documentation ont été dressés par Albert Jacquemart.

6 Alfred Beurdeley quant à lui, fait partie d'une longue lignée de marchands d'art et de curiosités devenus ensuite fabricants d'objets d'art ${ }^{16}$. À la manière des marchandsmerciers au XVIII ${ }^{\mathrm{e}}$ siècle, il arrivait qu'Alfred Beurdeley fasse réaliser des montures en bronze pour les porcelaines chinoises qu'il destinait à la vente ${ }^{17}$. Dans le carnet de 
comptes de Salomon, on trouve des acomptes concernant des objets, mais aussi des cadres et des socles.

7 Enfin, Nicolas Joseph Malinet est une figure incontournable de la vente d'objets d'Extrême-Orient à Paris. Fils de Nicolas François Malinet, artisan, et de Marie Reine Crevecoeur ${ }^{18}$, il commence sa carrière comme tailleur et, à l'âge de 37 ans, il ouvre une boutique de curiosités au 25, quai Voltaire, « ce quai qu'on pourrait appeler le quai de la curiosité et du bibelot ", à en croire le marchand d'art Charles Pillet ${ }^{19}$. Dans un premier temps, il se consacre à la vente de tableaux, puis se spécialise dans celle des objets d'art d'Extrême-Orient, à la suite d'une vente qui marque un tournant dans sa carrière, celle de la duchesse de Montebello en $1857^{20}$ : «Dès lors, les objets de Chine devinrent la principale source de son commerce et en même temps de sa fortune ${ }^{21}$.» Pour Charles Pillet, Malinet acquiert alors une place incontestable dans le commerce de la curiosité :

Il sut donner à ce commerce des objets de l'Extrême-Orient une vive impulsion, il forma des clients et devint le fournisseur attitré de tous ceux qui recherchaient les assiettes coquille d'œuf, les bleus turquoise et les jaspés, il était l'âme de toutes les ventes qui se faisaient en ce genre et on se rappelle combien elles furent, en un certain temps, nombreuses et importantes ${ }^{22}$.

8 Ainsi, le seul nom des intermédiaires présents dans le carnet de comptes de Salomon montre son vif intérêt pour les objets d'Extrême-Orient et son désir de s'entourer des personnes les plus compétentes de son temps pour prendre en charge ses acquisitions. Il est vrai que, dans les années 1860, les experts dans le domaine des arts asiatiques ne manquaient pas, car il s'agissait d'un commerce florissant auquel les ventes du Yuanmingyuan (圓明園), plus connu en Occident sous le nom de Palais d'Été ${ }^{23}$, avaient donné une impulsion nouvelle ${ }^{24}$. La période d'acquisition de Salomon de Rothschild coïncide en effet avec les ventes du Yuanmingyuan, au cours desquelles les objets pillés dans cette résidence palatiale furent dispersés à Paris et à Londres. Le sac du Yuanmingyuan orchestré par les troupes franco-britanniques se produisit en 1860, à la fin de la seconde guerre de l'opium (1856-1860). Entre 1861 et 1869, pas moins de seize ventes comportant une mention explicite de la provenance du Yuanmingyuan eurent lieu à Paris, dont onze entre 1861 et la fin de l'année $1862^{25}$. Il ne fait guère de doute que plusieurs objets de la collection de Salomon et d'Adèle de Rothschild proviennent de ces ventes, en attestent leur style et la finesse de leur exécution ${ }^{26}$.

\section{Investisseur ou collectionneur?}

Dans ses travaux de 2016, Pauline Prevost-Marcilhacy a souligné la rapidité et l'anarchie avec laquelle a été rassemblée cette collection du vivant de Salomon; elle suppose même que l'acquisition d'œuvres d'art était chez lui un investissement, puisqu'il commence déjà à vendre une partie de sa collection, lors d'une vente organisée en $1864^{27}$. Salomon vend effectivement quelques-unes de ses assiettes de la famille rose, cependant on peut aussi penser qu'il cherche seulement à se défaire d'un certain nombre de doubles, étant donné l'important ensemble qu'il possède déjà. Un autre élément de l'histoire de cette collection pourrait bien contredire l'image d'un acheteur compulsif : celle du catalogue inachevé du fameux historien de la porcelaine Albert Jacquemart (1808-1875) ${ }^{28}$.

10 À la dernière page du carnet de comptes de Salomon de Rothschild se trouve une mention intéressante : Salomon verse 1200 francs à Albert Jacquemart pour réaliser le catalogue de sa collection ${ }^{29}$. Ce catalogue ne sera cependant jamais achevé. La mort de 
Salomon de Rothschild avait sans nul doute freiné ce projet, mais c'est la mort d'Albert Jacquemart lui-même qui y met un terme définitif. Une lettre inédite d'Adèle de Rothschild conservée à la bibliothèque de l'Institut national d'histoire de l'art indique en effet que celle-ci avait souhaité que Jacquemart reprenne la rédaction de ce catalogue dans le courant de l'année 1875, date à laquelle Jacquemart décède subitement. Peu de temps après sa disparition, Adèle reçoit de Jules Jacquemart, le fils d'Albert, le document inachevé :

J'avais une estime très grande pour votre excellent Père, et je me faisais un vrai plaisir de mettre sa bonté à contribution en lui demandant de vouloir bien achever cet hiver, le catalogue que je lui ai su un gré infini de faire, de mes objets d'art! Dieu en a décidé autrement, en le rappelant à lui, ce qui plonge sa famille dans la douleur, afflige ses amis, et prive la science et les arts de ses savantes lumières! Veuillez recevoir tous mes remerciements, de ce précieux catalogue, qui me sera un souvenir de prix de Monsieur votre père, et se mêlera à celui que je lui garde précieusement dans ma pensée, et qui me parlera souvent de lui ${ }^{30}$.

Ce projet de catalogue inachevé conduit à s'interroger: Salomon avait-il fait cette commande à Jacquemart pour préparer la vente de sa collection, ou bien est-ce, au contraire, un moyen de la figer dans son état, de se l'approprier et de la valoriser en la publiant en tant que possession?

Entre 1861 et 1875, Jacquemart réalise un grand nombre de catalogues pour des collectionneurs ayant en commun de posséder un nombre important de porcelaines orientales $^{31}$. La plupart devaient servir de catalogues de vente, mais ce n'est pas le cas de tous. Celui de Madame Malinet, par exemple, est resté un ouvrage en soi qui avait pour seul but d'immortaliser la collection, car, comme Albert Jacquemart le souligne dans son avant-propos : «On ne doit pas l'oublier : dès qu'un monument a figuré dans une suite inventoriée avec soin, il appartient à l'histoire ${ }^{32}$. " Il est donc possible que le catalogue demandé par Salomon de Rothschild à Jacquemart ait été envisagé de cette manière ${ }^{33}$.

Grâce au carnet de ventes de Salomon de Rothschild, nous en savons beaucoup sur ses méthodes d'acquisition, ses goûts et la temporalité de ses achats. Aucune source, en revanche, ne permet d'appréhender de manière précise la collection du temps d'Adèle, si ce n'est de façon numéraire, par comparaison des inventaires après décès, comme nous l'avons vu plus haut.

\section{Un ensemble insolite de plats à décors de la famille rose}

Considérée dans son ensemble, la collection de porcelaines chinoises de Salomon et Adèle de Rothschild se compose principalement de porcelaines émaillées datées entre le XVIII et le XIX ${ }^{e}$ siècle $^{34}$. Les porcelaines de la famille rose forment de loin l'ensemble le plus conséquent de la collection. Dans la salle des curiosités telles qu'elle se présentait en 1922, les assiettes de la famille rose à décors avec personnages sont les plus nombreuses. On trouve principalement deux types d'iconographie : une femme dans un intérieur avec deux ou trois enfants, symbole auspicieux, ou bien un lettré et son serviteur entourés des traditionnels attributs du lettré: la cithare qin, des livres, quelques objets d'art. Plusieurs pièces sont ornées de scènes historiques ou littéraires ${ }^{35}$. Ces œuvres ont toutes pour caractéristique commune l'emploi d'un émail rose opaque 
qui fait son apparition sous le règne de l'empereur Yongzheng 雍正 (1723-1735) ${ }^{36}$. Son utilisation se développe dans un premier temps dans les fours impériaux avant de se diffuser dans les ateliers des décorateurs de Canton qui réalisent des œuvres pour l'exportation ${ }^{37}$. La plupart de ces plats comportent un revers carmin qui leur a valu en anglais le nom de «ruby-back dishes » (fig. 1a et 1b) ${ }^{38}$.

1a. et b. Plat de la famille rose et son revers, porcelaine, d. 20,8 cm, Chine, dynastie Qing (1644-1911), époque Yongzheng 雍正 (1723-1736), première moitié du XVIII e siècle, Paris, Fondation des artistes, R 1070.

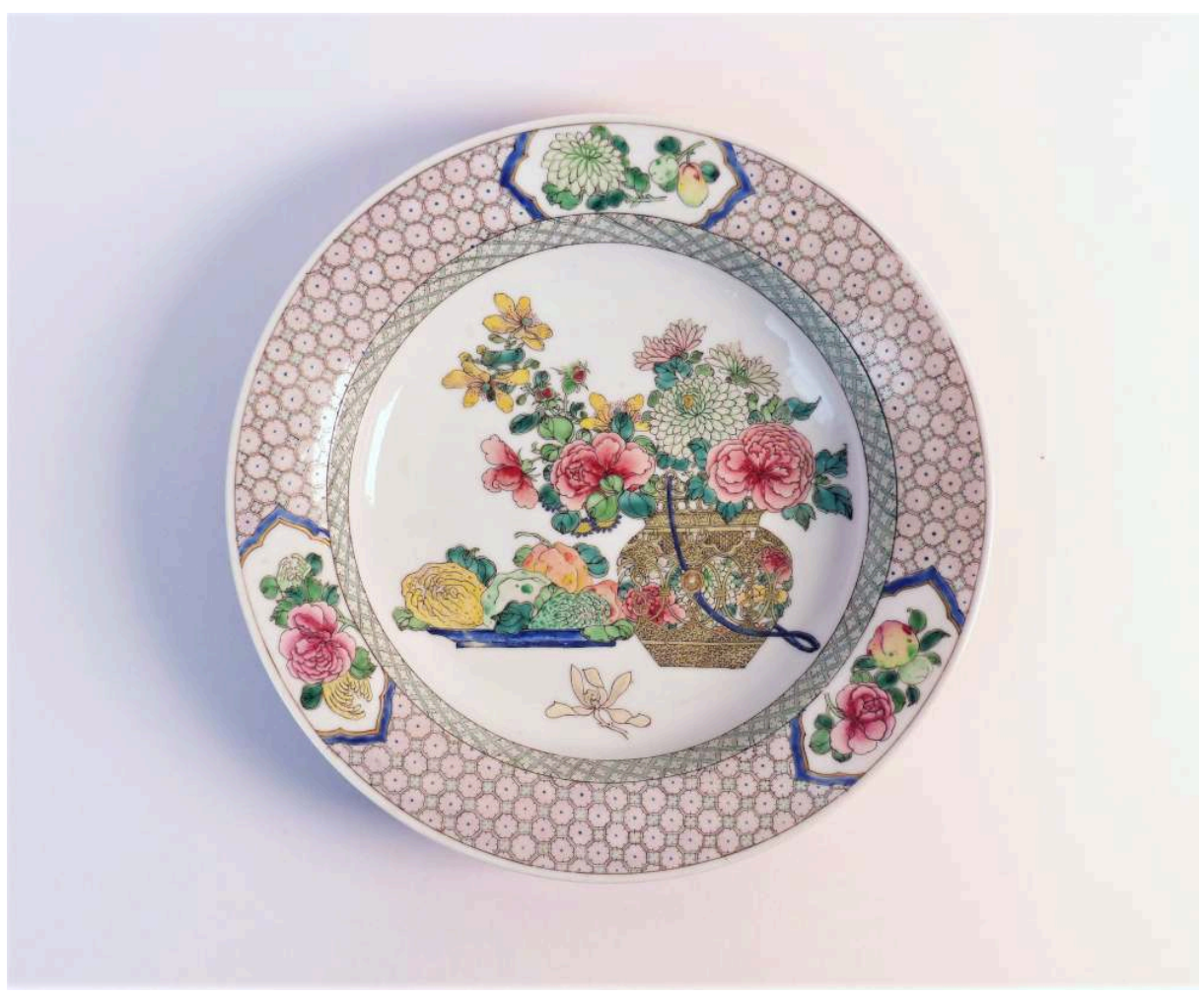

(C) Fondation des artistes 


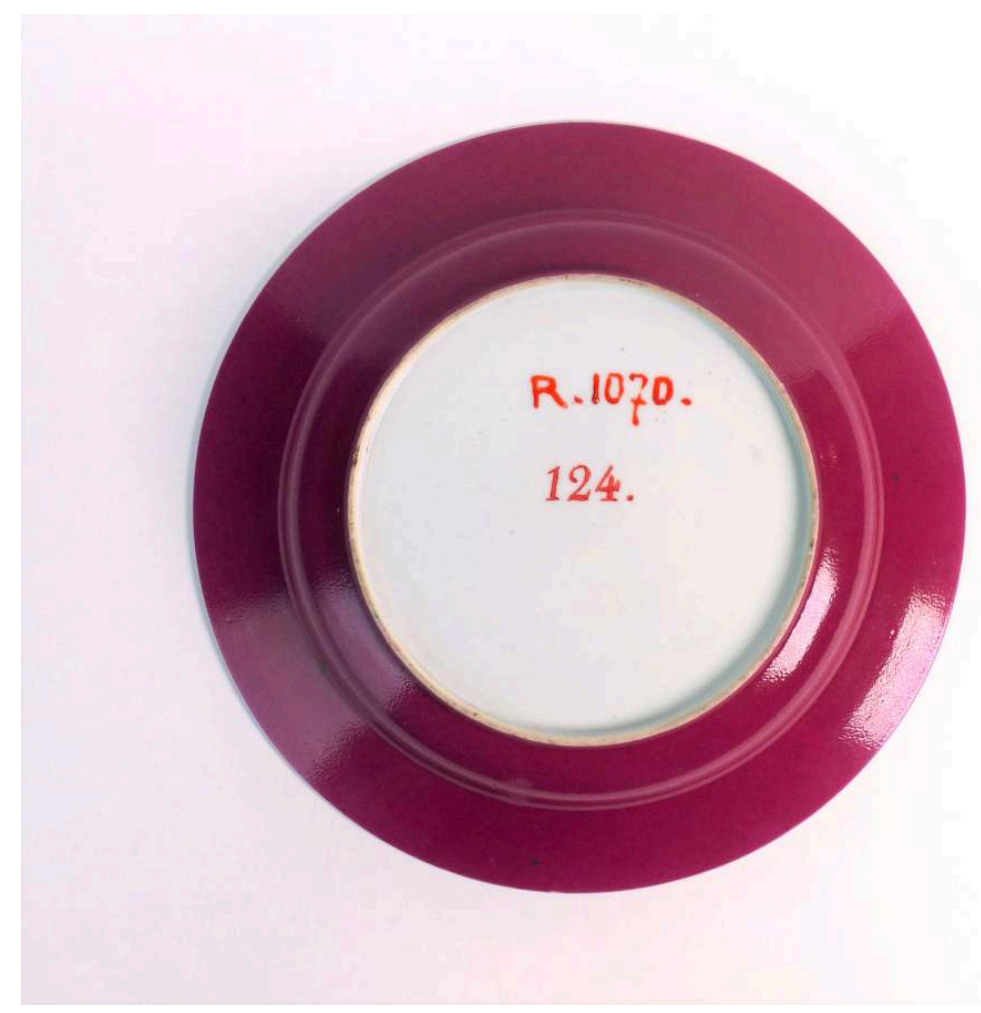

(c) Fondation des artistes

15 La permanence de certains motifs et de certains décors au sein de cet ensemble montre que Salomon et Adèle achètent leurs porcelaines chinoises par lot, voire par service entier. Parmi eux, le service au cerf est l'un des plus conséquents. Il s'agit d'un service de porcelaine famille rose, orné d'une armoirie de sable, un cerf d'or arrêté regardant qui pourrait appartenir à l'Anglais Morris de Caernarvon ${ }^{39}$. Bien que la plupart des pièces de ce service aient été données au Louvre où elles sont aujourd'hui conservées, une des assiettes était présentée dans la salle des curiosités à la mort de la baronne (fig. 2). 
2. Plat famille rose, porcelaine et émaux sur couverte, Chine, dynastie Qing (1644-1911), époque Yongzheng 雍正 (1723-1736), première moitié du XVIII ${ }^{\mathrm{e}}$ siècle, Paris, Fondation des artistes, R1112.

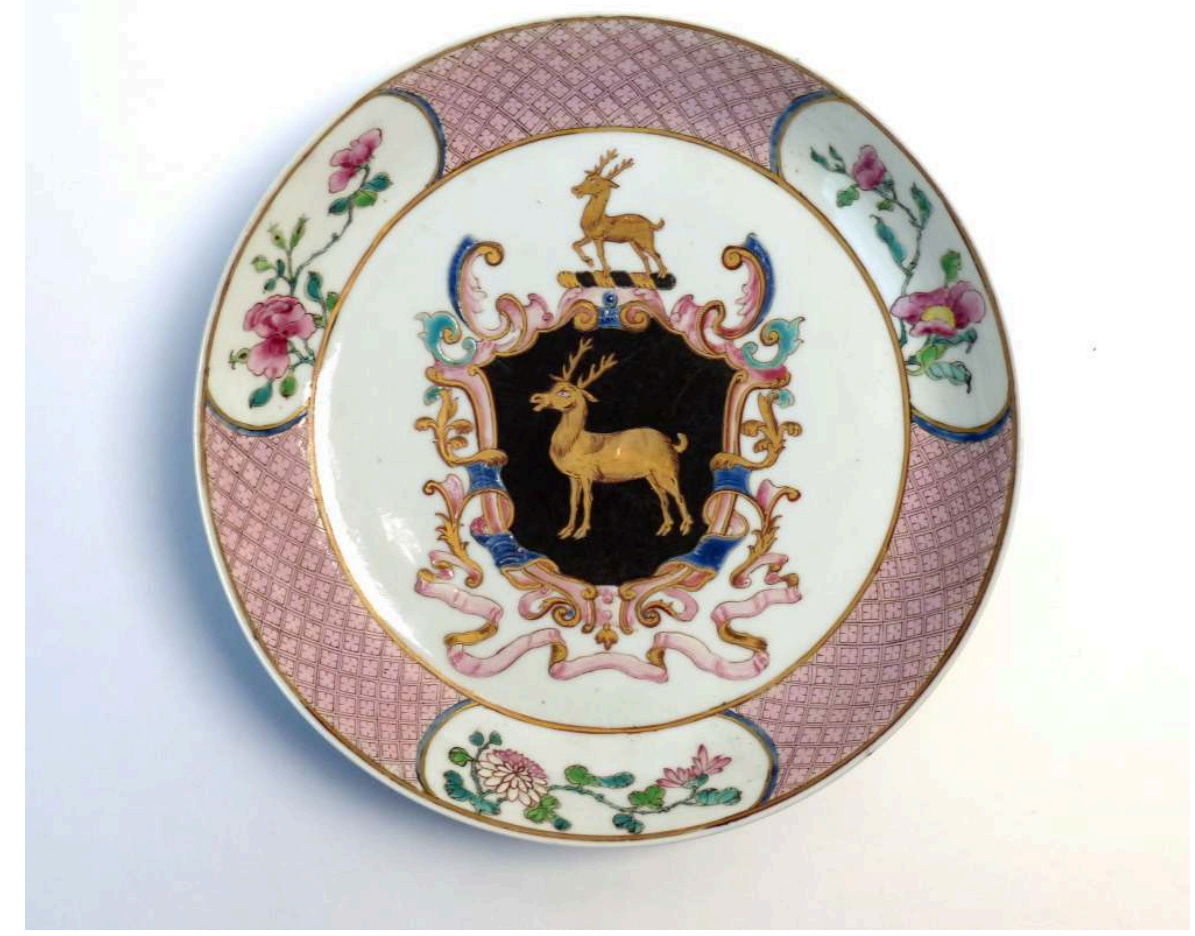

(C) Fondation des artistes

16 À quand remonte l'acquisition de cet ensemble d'assiettes de la famille rose? L'inventaire après décès d'Adèle fait état d'un ensemble important de pièces chinoises qui se détache du reste de la collection par son homogénéité : soixante-six assiettes à décors variés de personnages, fleurs et oiseaux qui se trouvaient dans la vitrine gauche de l'hôtel Salomon de Rothschild au moment du décès de la baronne ${ }^{40}$ (fig. $3 a$ et $3 b$ ). 
3a. et b. A. Gary, vitrines de gauche et vitrine de droite du cabinet de curiosités, hôtel Salomon de Rothschild, 11, rue Berryer, Paris, c. 1880, Paris, Bibliothèque historique de la ville de Paris.

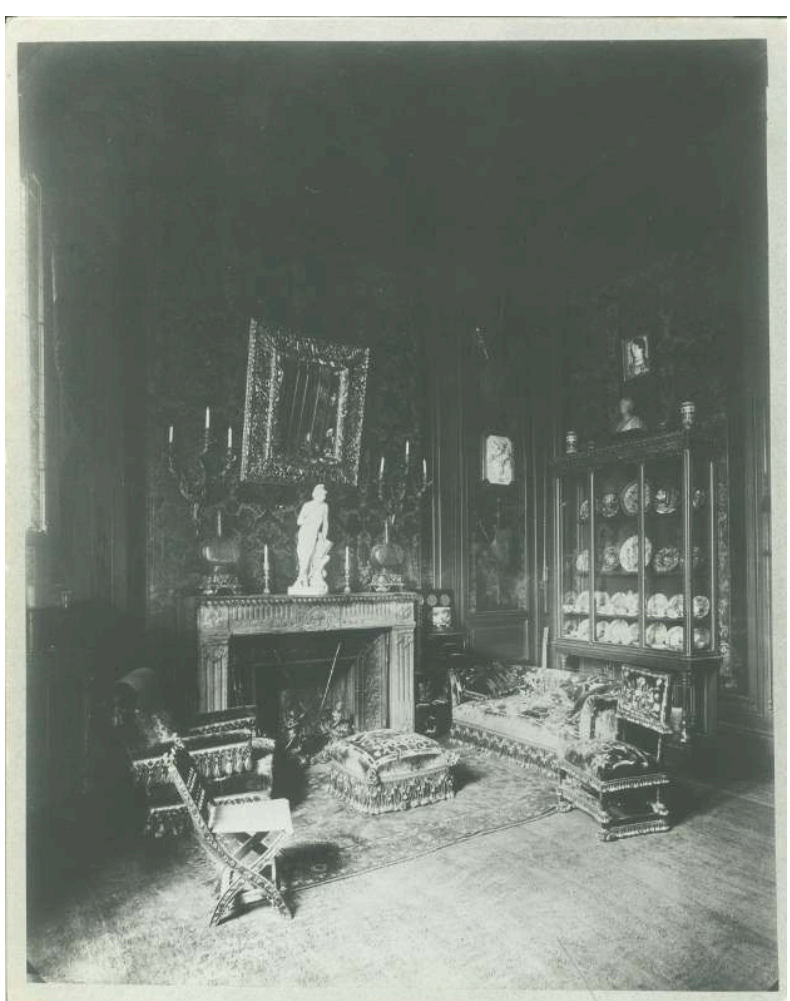

(c) BVHP

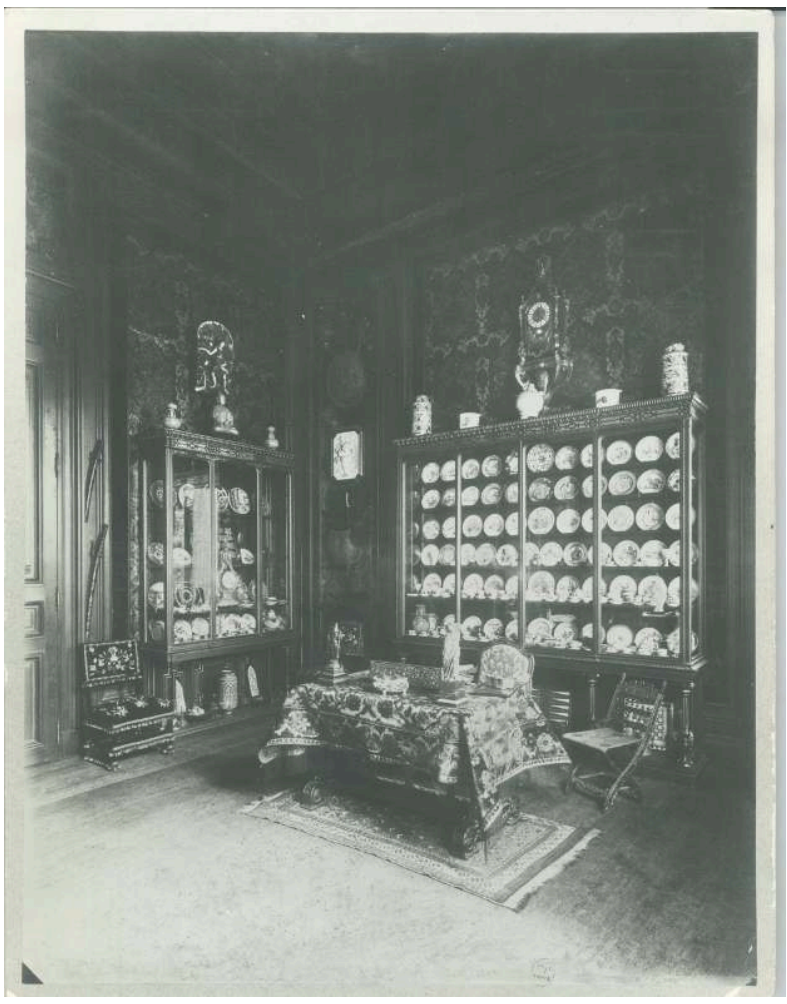

(c) BVHP 
trouve également chez Salomon, en 1864, la mention d'un seul ensemble significatif de "quatre-vingt-une assiettes ou compotiers » disposés dans de " grandes vitrines en bois de chêne" de la galerie de l'appartement rue du Faubourg-SaintHonoré. Même s'il est impossible de savoir à l'œuvre près s'il s'agit exactement des mêmes pièces, force est de constater que les assiettes en porcelaine émaillées chinoise ont, à deux reprises, été exposées comme un ensemble dans des vitrines individuelles et qu'il pourrait vraisemblablement s'agir en grande partie des mêmes pièces. La cohérence, la continuité recherchée dans les dispositifs d'exposition et le souhait de préserver cet ensemble dans la salle des curiosités semblent démontrer que le couple, du moins Adèle, éprouvait un attachement particulier pour ce type de pièces. S'il n'est pas rare de voir la porcelaine chinoise exposée de cette manière comme dans un vaisselier dans les intérieurs du $\mathrm{xIX}^{\mathrm{e}}$ siècle $^{41}$, ce qui frappe ici est le nombre particulièrement important et l'unité décorative des pièces.

Du temps où Salomon de Rothschild fait l'acquisition de ces œuvres, les porcelaines émaillées chinoises profitent d'un véritable retour en grâce dans les collections européennes en général ${ }^{42}$. À cette époque, ces œuvres sont très souvent considérées comme étant d'origine japonaise. On trouve en effet, dans le catalogue de la vente Salomon de Rothschild réalisée en mars 1864, dans la catégorie "Japon", plusieurs pièces arborant un revers rouge, décrites en ces termes : "Jolie assiette en porcelaine du Japon coquille d'œuf à très riches décors dit aux sept bordures. Sujet : femme et deux enfants dans un intérieur richement meublé. Revers rouge ${ }^{43}$.» Cette attribution était soutenue par Albert Jacquemart, qui faisait à l'époque figure d'autorité dans le domaine de la porcelaine chinoise, à la suite notamment de la publication avec Edmond Le Blant (1818-1897) de son Histoire artistique, industrielle et commerciale de la porcelaine ${ }^{44}$. Dans les années 1860 , ce type de pièces pouvait atteindre des prix très élevés. Le catalogue rédigé par Albert Jacquemart de la vente de M. de Monville de 1866 fait état d'un lot similaire à une pièce conservée dans la collection de la baronne de Rothschild, qu'il décrit en ces termes :

Compotier à bordure quadrillée et seconde bordure à guirlande en or de tons variés rehaussés de noir ; au centre un riche sujet, une femme et ses deux enfants dans un intérieur. Pièce la plus extraordinaire en porcelaine, en ce qu'il semble que l'artiste ait voulu y réunir tous les tons et les procédés les plus variés de la céramique japonaise; elle est d'une finesse d'exécution et d'une réussite admirable. Nous ne connaissons que deux spécimens de ce compotier: celui de la collection de $\mathrm{M}^{\mathrm{me}}$ la baronne Salomon de Rothschild, et celui-ci. On prétend cependant qu'il en existe un troisième spécimen en Hollande ${ }^{45}$.

La pièce est adjugée à 1315 francs $^{46}$, un prix record si l'on considère, comme l'a démontré Léa Saint-Raymond, que $75 \%$ des porcelaines chinoises vendues dans les années 1860 n'atteignaient pas des prix d'adjudication plus élevés que 180 francs $^{47}$. La description correspond sans doute à une assiette à décors avec femme et enfants conservée à l'hôtel Salomon de Rothschild reproduite ci-contre (fig. 4). 
4. Assiette à décor de femme et d'enfants dans un intérieur, bordure rehaussée d'or, porcelaine, d. 19,9 cm, Chine, dynastie Qing (1644-1911), époque Yongzheng 雍正 (1723-1736), Paris, Fondation des artistes, R1082.

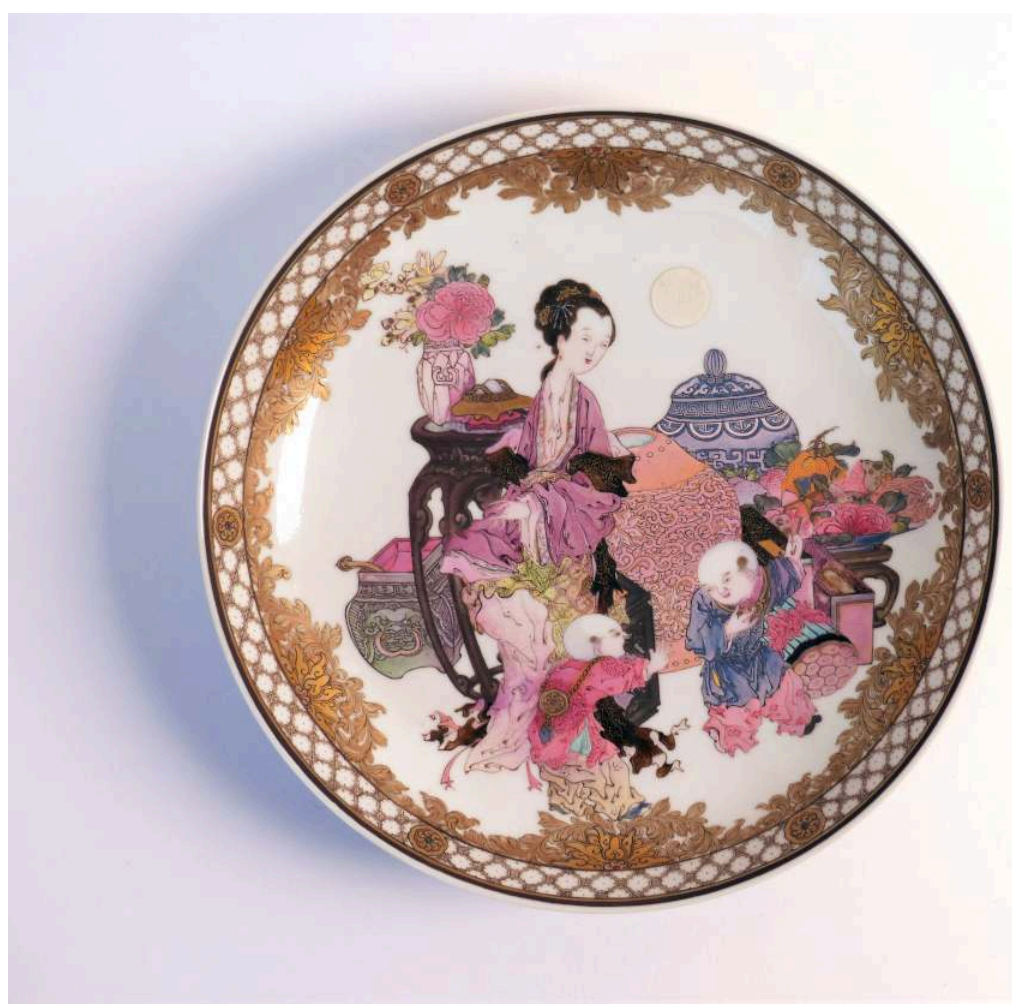

(c) Fondation des artistes

\section{Une pièce exceptionnelle provenant du Yuanmingyuan}

La collection d'Adèle et Salomon comprend également des œuvres tout à fait exceptionnelles qui proviennent sans nul doute des collections impériales chinoises, acquises, comme nous l'avons indiqué plus haut, au cours des ventes du Yuanmingyuan. L'une de ces pièces est actuellement exposée dans la salle des curiosités alors qu'elle se trouvait dans le hall de l'hôtel Salomon de Rothschild au moment du décès de la baronne (fig. $5 a$ et $b)^{48}$. 
5a. et b. Plat à marli ajouré et son revers, porcelaine yangcai 洋彩, Chine, dynastie Qing (1644-1911), époque Qianlong 乾隆 (1735-1796), première moitié du XVIII siècle, Paris, musée du Louvre, en dépôt à Paris, Fondation des artistes, R 1382.

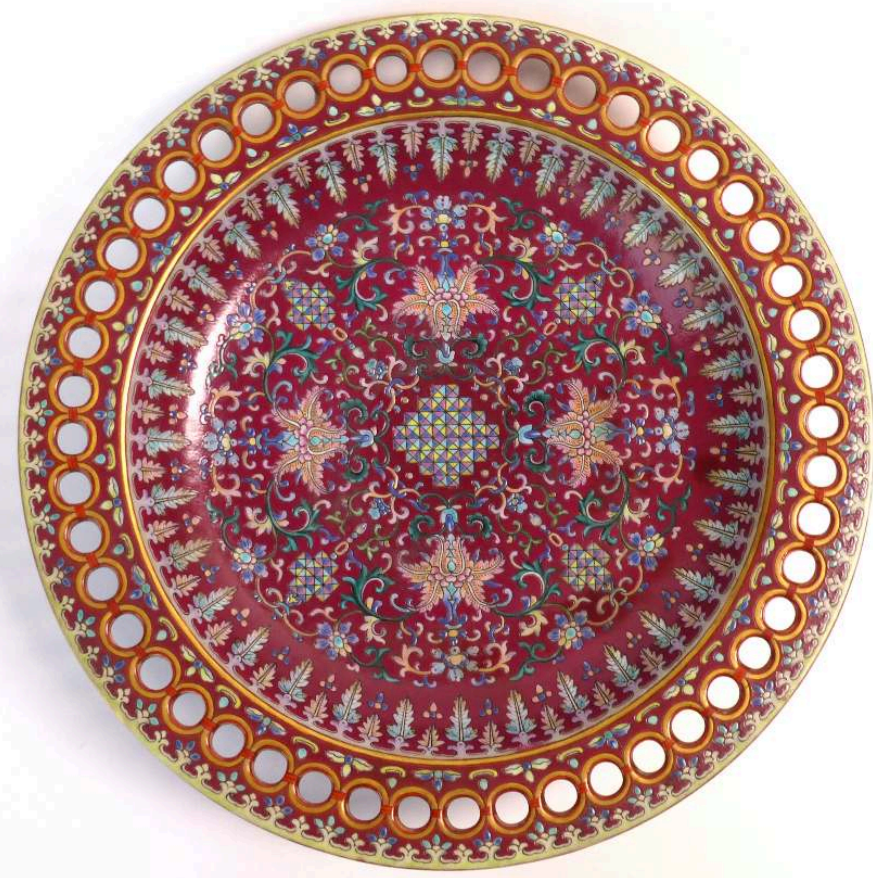

(C) Musée du Louvre/Fondation des artistes

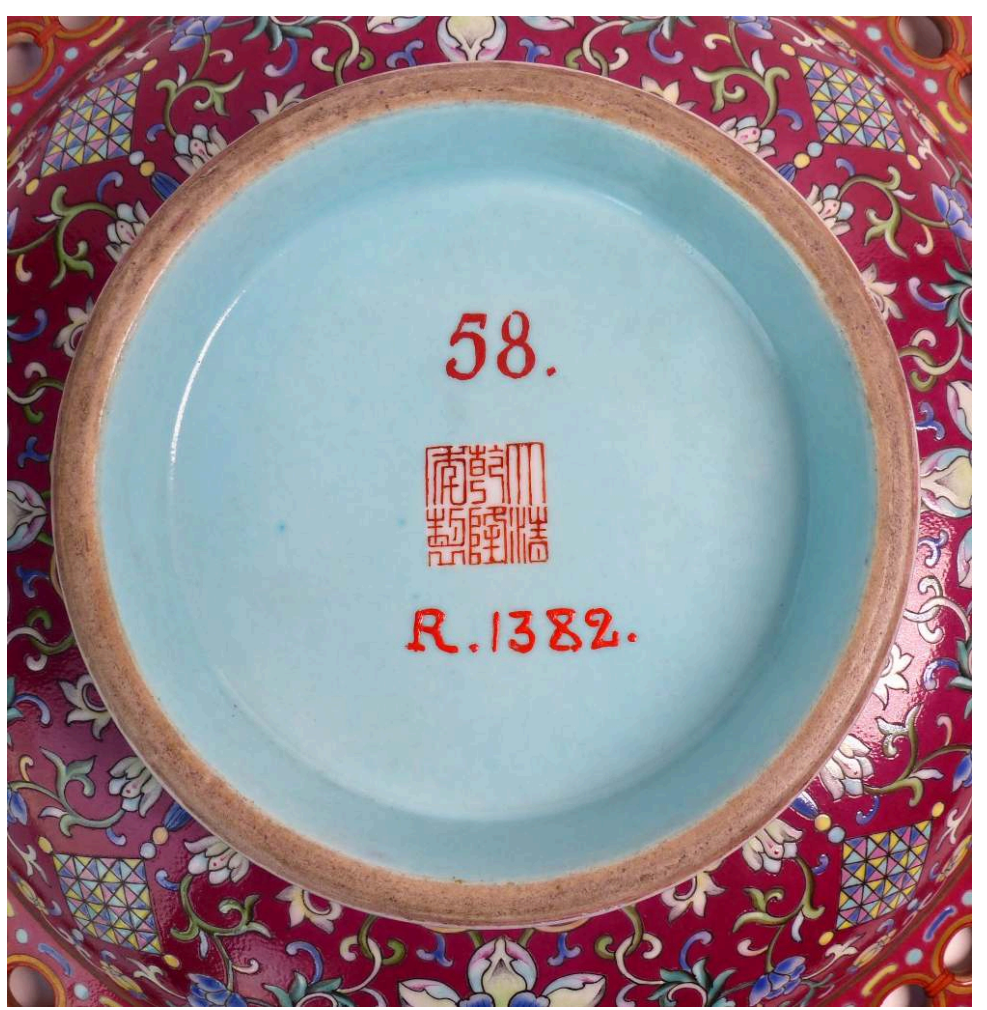

(c) Musée du Louvre/Fondation des artistes 
Il s'agit d'une coupe sur pied dont le marli est percé de jours circulaires. Sur un fond d'émail fuchsia, se détachent des arabesques et des motifs ornementaux de différentes couleurs. Le tout est organisé autour d'un motif de damier central. Le revers est recouvert d'une couche d'émail turquoise avec, en son centre, la marque impériale $D a$ Qing Qianlong nian zhi 大清乾隆年制 (littéralement: «fait pendant l'ère Qianlong des grands Qing»), ce qui nous permet, en plus du style, de dater l'œuvre du règne de Qianlong entre 1736 et 1796. La symétrie des décors, les motifs d'arabesque structurés en volutes sont des éléments d'inspiration européenne, ce qui valut à ce type de pièce le nom de yangcai, littéralement « couleurs étrangères ». En se fondant sur les Archives du Palais de l'époque Qing, la conservatrice taïwanaise Yu Peijin 余佩僅 considère que ce type de pièce à base bleu turquoise et à fond de décors couvrant d'arabesques florales apparaît entre 1742 et $1743^{49}$. Ce qui contribue une fois de plus à démontrer la provenance impériale de cette pièce est la présence d'une autre quasiment identique dans le Musée chinois de l'impératrice Eugénie, musée qui rassemblait le butin « officiel » de guerre ramené du Yuanmingyuan et offert au couple impérial en $1861^{50}$. Il est même probable qu'il s'agisse d'une paire, comme beaucoup d'œuvres de ce type produites pendant la période Qianlong.

La consultation des catalogues des ventes du Yuanmingyuan à Paris à partir de la base de données mise en ligne par Léa Saint-Raymond ne nous a pas permis d'identifier la vente au cours de laquelle cette œuvre a pu être acquise ${ }^{51}$. Il est néanmoins probable que la pièce fut achetée à Londres, ce qui nécessiterait de plus amples investigations.

Le carnet de comptes de Salomon ne comporte quasiment aucune description détaillée des objets acquis ${ }^{52}$. Alors que la plupart des notes d'achat concerne des lots indistincts d'objets (tel que " curiosités ", " porcelaines de Sèvres » etc.), on trouve néanmoins la mention d'un "grand plat porcelaine de Chine " acheté pour 600 francs auprès de Evans, le 4 septembre 1863. S'agirait-il de notre coupe sur pied ? Le marchand Evans, de même que Louis Auguste Alfred Beurdeley et Nicolas Joseph Malinet, c'est-à-dire tous les intermédiaires de Salomon, faisaient, en effet, partie des principaux acheteurs des ventes du Yuanmingyuan ${ }^{53}$. En 1922, l'œuvre se trouvait dans l'une des quatre grandes vitrines du hall d'entrée de l'hôtel Salomon de Rothschild ${ }^{54}$. Elle faisait partie des œuvres léguées au musée du Louvre par la baronne Adèle, avant d'être déposée à la Fondation des artistes où elle est actuellement exposée.

\section{La porcelaine dite bencharong}

Une autre pièce de la collection mérite qu'on s'y arrête (fig. 6). Il s'agit d'une coupe sur piédouche recouverte d'émaux, d'un style très différent: sur fond d'émail rouge se déploie un décor végétal compartimenté dans des pétales de lotus concentriques, chaque motif est cerné d'or. 
6. Coupe sur piédouche, porcelaine émaillée rehauts dorés de type bencharong, Chine, dynastie Qing (1644-1911), XVIII e siècle, Paris, musée du Louvre, en dépôt à Paris, Fondation des artistes, R1383.

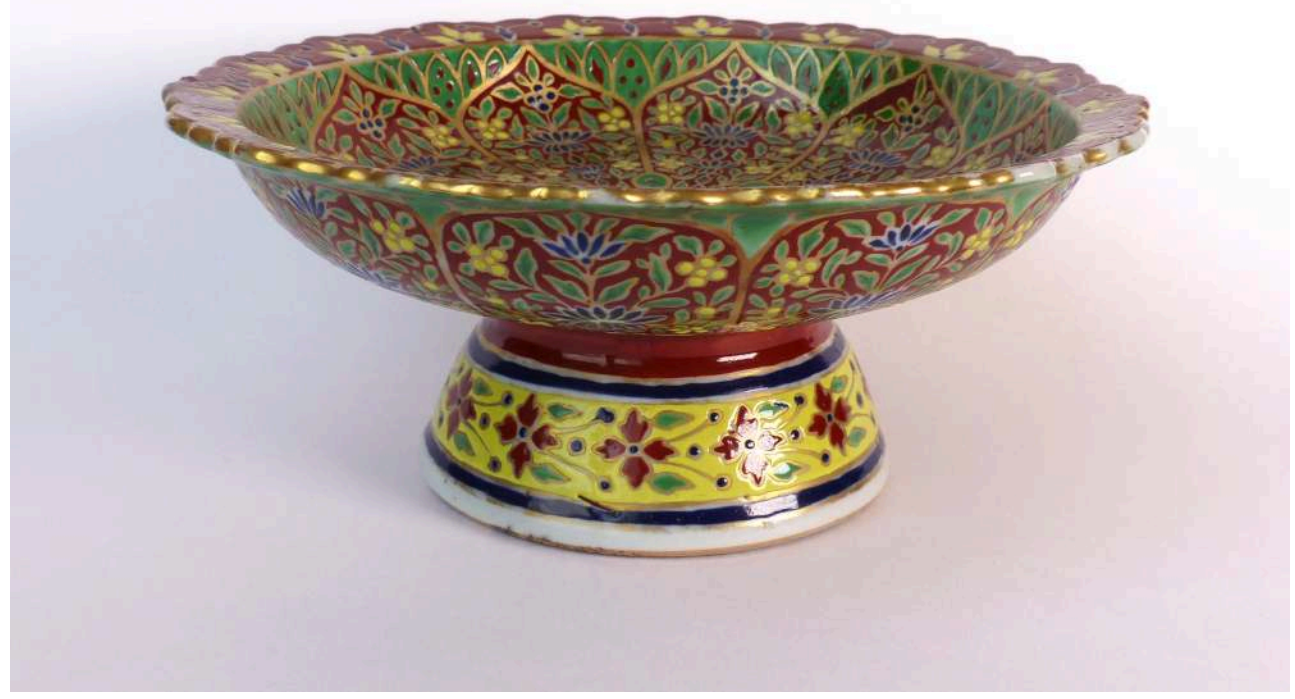

(c) Musée du Louvre/Fondation des artistes

Ce type de pièce est communément appelé bencharong, terme issu du sanscrit qui signifie littéralement « cinq couleurs", et correspond aux porcelaines faites en Chine pour être exportées à la cour du royaume du Siam. Ces œuvres étaient assez mal identifiées au XIX ${ }^{e}$ siècle. En se fondant sur les œuvres similaires visibles au musée national de la Céramique de Sèvres, Albert Jacquemart et Edmond Le Blant attribuaient ces objets à l'« Hindoustant » [sic] (fig. 7) $)^{55}$. 
7. Jules Jacquemart, coupe en porcelaine dure, couverte d'un riche décor imitant les émaux sur cuivre, planche gravée à l'eau-forte, dans Albert Jacquemart et Edmond Le Blant, Histoire artistique, industrielle et commerciale de la porcelaine, Paris, Techener, 1862, pl. XVIII, fig. 1.

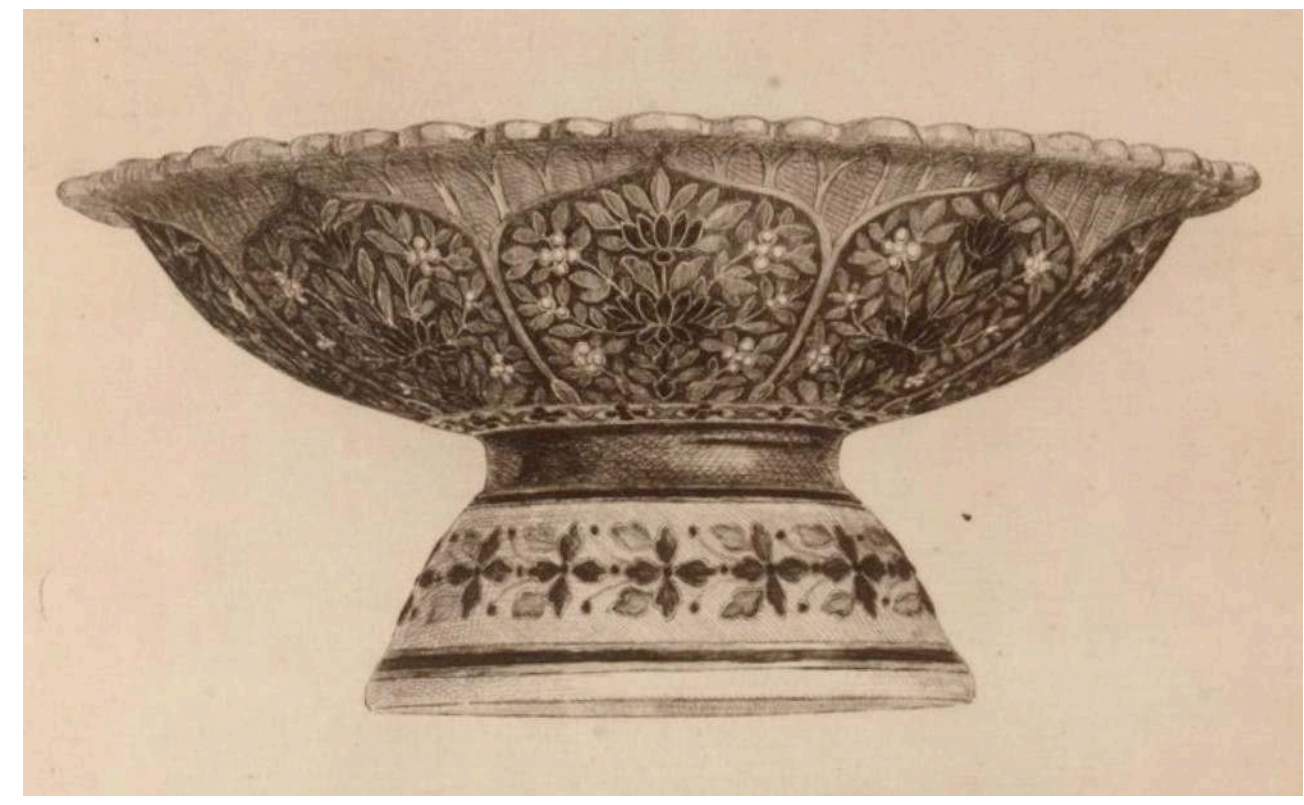

\section{Décorées en Europe}

La collection de Salomon et Adèle se compose également de quelques autres pièces intéressantes dont une partie de la décoration fut ajoutée en Europe. C'est le cas d'une tasse et de sa soucoupe à décors bleu et blanc et couverte brune dite zijin 紫金 ou jiangyou 獎釉 en chinois (fig. 8).

Dans le monde anglo-saxon, ces pièces sont appelées Batavian ware, Batavia étant le nom du quartier général de la Compagnie néerlandaise des Indes Orientales, (VOC pour Vereenigde Oostindische Compagnie), sur l'île de Java, (actuelle Jakarta). La pièce illustrée ici s'est vue en outre dotée d'un décor floral gravé en creux sur toutes les parois extérieures. Ce type de décors était effectué en Europe, au moyen d'une technique de gravure à la roue employée dans la décoration sur verre en Allemagne, notamment à Dresde, en Bohème, et en Silésie les autour des XVII ${ }^{e}$ et XVIII ${ }^{e}$ siècles $^{56}$. Les collections d'Auguste le Fort à Dresde comptent de très beaux spécimens de ce type ${ }^{57}$, plus rares dans les collections françaises. 
8. Tasse et soucoupe dite de Batavia, porcelaine bleu et blanc et couverte zijin 紫金, Chine, dynastie Qing (1644-1911), XVIII e siècle, Paris, Fondation des artistes, R1057.

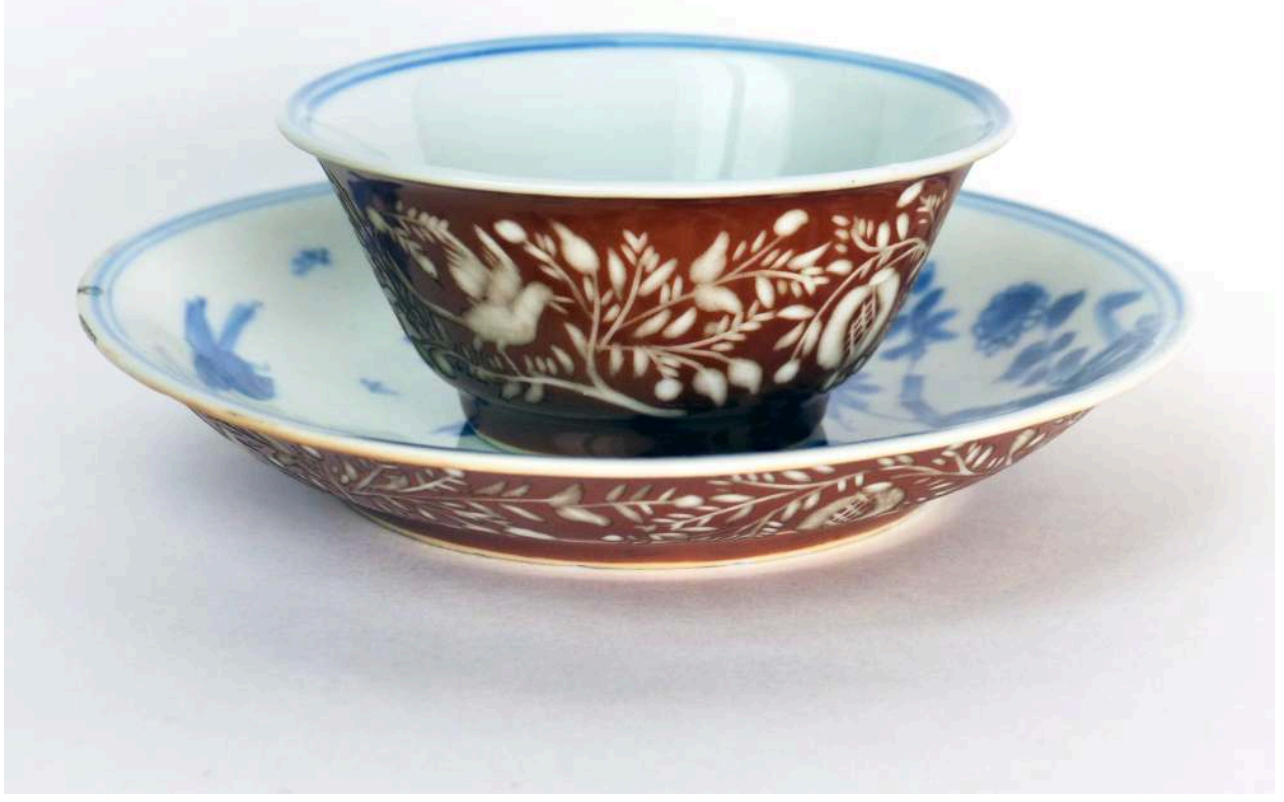

(C) Fondation des artistes

Entre autres pièces partiellement décorées en Europe, une tasse et sa soucoupe présentent à divers endroits des rehauts jaunes d'émail assez maladroits (fig. 9). Il était fréquent de voir certaines pièces chinoises rehaussées d'émaux voire intégralement peintes par des ateliers d'émailleurs européens, tels qu'il en existait à Londres. Ce qui frappe ici, c'est l'endroit choisi où s'appose le rehaut, comme si l'artisan avait voulu censurer le geste licencieux du personnage masculin vers la jeune femme et, de façon à ne pas trop briser la composition d'ensemble, avait ajouté une couche supplémentaire sur les vêtements du personnage. 
9. Soucoupe famille rose à décors de jeune couple, porcelaine et émaux sur couverte, Chine, dynastie Qing (1644-1911), époque Yongzheng 雍正 (1723-1736), Fondation des artistes, Paris, R1152.

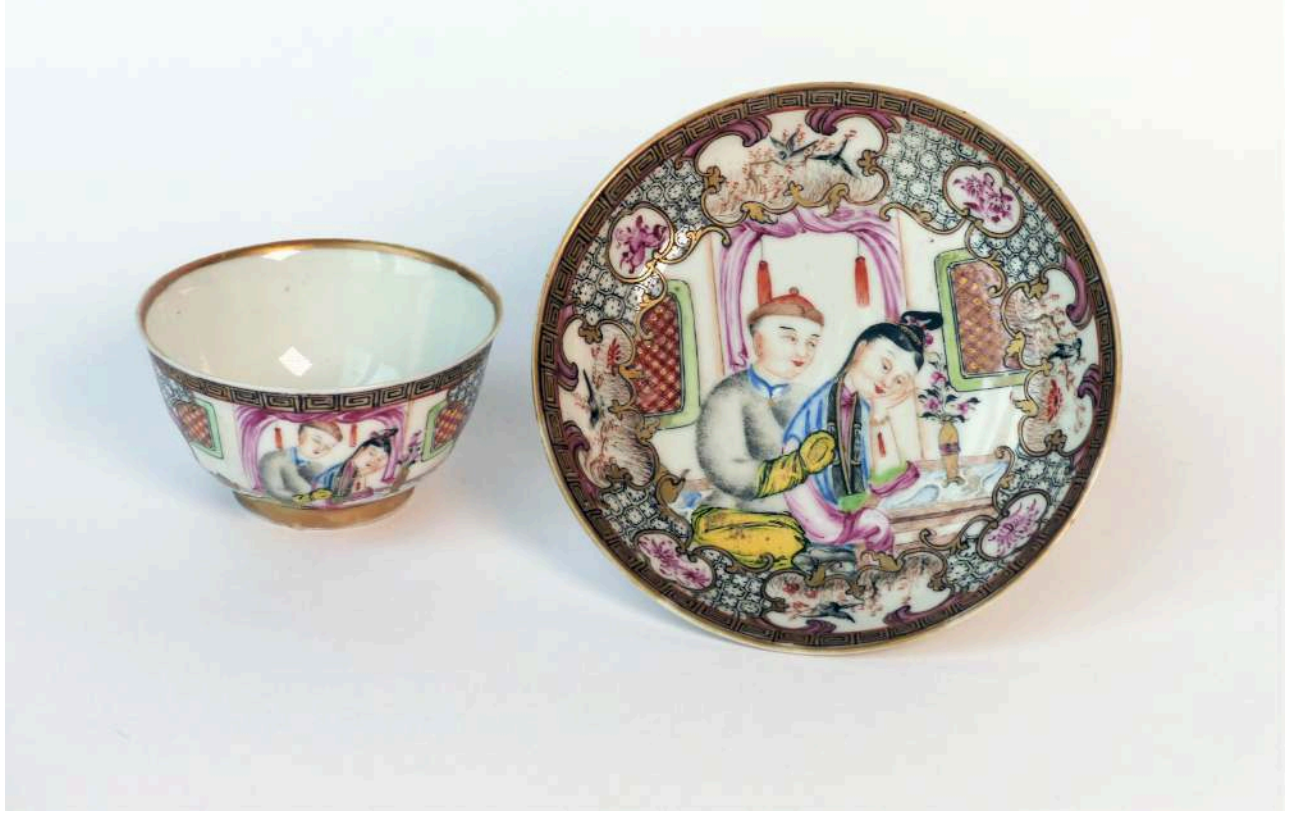

(c) Fondation des artistes

Ces deux dernières pièces illustrent à leur manière les différentes réinterprétations des porcelaines chinoises en Europe.

\section{Conclusion}

Les sources permettant d'aborder la collection de l'hôtel Salomon de Rothschild sont inégales. Il est beaucoup plus aisé de comprendre les procédés d'acquisition de Salomon sur une période de seulement deux ans, que ceux d'Adèle sur les cinquante-huit ans qui séparent sa disparition de celle de son mari. L'étude des objets apporte des informations supplémentaires. Il paraîtrait ainsi naturel de penser que les porcelaines impériales furent acquises dans les années 1860, mais rien ne nous dit qu'elles n'ont pas été achetées au cours d'une vente plus tardive par Adèle. Malgré ce manque d'information, on constate que le fait de s'entourer des personnes les plus compétentes dans le domaine de l'art asiatique en général et de la porcelaine orientale en particulier montre que l'acquisition de ces objets ne s'est pas faite au hasard. Le choix s'exprime aussi à travers la nature des œuvres : les porcelaines de la famille rose occupent la place la plus importante de la collection. Comparée avec certaines grandes collections de porcelaines chinoises des années 1850-1860, telles que celles de la duchesse de Montebello ${ }^{58}$ ou de Madame Malinet ${ }^{59}$, la collection de Salomon et Adèle est assez peu variée. On n'y trouve que rarement de la porcelaine bleu et blanc, famille verte, céladon, rouge de cuivre, etc. Enfin, on décèle également un véritable parti pris à travers le nombre d'œuvres collectionnées. Contrairement à beaucoup d'autres collections de la seconde moitié du XIxe siècle, y compris celle de James de Rothschild, 
les porcelaines chinoises, par leur nombre, n'occupent pas une place anecdotique. Elles n'ont pas simplement été conçues comme une décoration propre à ponctuer çà et là l'espace intérieur, comme on peut le voir sur les aquarelles du château de Ferrières peintes par Eugène Lami ${ }^{60}$.

Quel regard porter sur la salle des curiosités? Dans ses dispositions testamentaires, Adèle ne prévoit pas que les pièces qui, aujourd'hui, nous paraissent historiquement les plus importantes soient conservées dans la salle des curiosités. Dans cette salle qui pourtant porte aujourd'hui la mémoire de sa collection ainsi que celle de son époux, elle choisit d'exposer essentiellement les assiettes de la famille rose, destinées à l'exportation et en vogue au XIX ${ }^{e}$ siècle. Ainsi, la salle des curiosités ne doit sans doute pas être perçue comme l'écrin des pièces les plus rares de la collection, mais plutôt comme un florilège plus ou moins représentatif de ce que le couple a collectionné. L'ensemble de plats de la famille rose, déjà présent dans la collection du temps de Salomon, était sans doute plus à même de conserver la mémoire de son mari et de leur passion commune.

\section{Remerciements}

Cette communication a aussi été rédigée dans le cadre de la rédaction de ma thèse de doctorat consacrée au thème des collections de porcelaines chinoises en France au $\mathrm{XIX}^{\mathrm{e}}$ siècle et dirigée par Jean-Michel Leniaud (École pratique des hautes études) - je tiens à le remercier pour son aide précieuse. Ma profonde gratitude va aussi à Éléonore Dérisson (Fondation des artistes), à Laura de Fuccia (Institut national d'histoire de l'art) et à Pauline Prevost-Marcilhacy (université Lille 3) qui a tant œuvré pour la connaissance des collections Rothschild. Je souhaite également remercier Christine Shimizu et Agathe Jagerschmidt pour leurs conseils et leur relecture, ainsi que JeanBaptiste Clais et Vincent Droguet pour m'avoir donné accès aux porcelaines chinoises conservée au Louvre et au Château de Fontainebleau.

\section{NOTES}

1. L'inventaire et l'analyse des collections de la baronne Salomon de Rothschild et notamment de la salle des curiosités de l'hôtel Salomon de Rothschild ont été menés par les différents auteurs de la publication des trois volumes Les Rothschild. Une dynastie de mécènes en France et par Laura de Fuccia, dans le cadre du programme de l'INHA sur les «Collections Rothschild» dont le travail essentiel a pu identifier et localiser les pièces appartenant au cabinet, voir en particulier Pauline Prevost-Marcilhacy, «Salomon et Adèle de Rothschild », dans Pauline Prevost-Marcilhacy (dir.), Les Rothschild. Une dynastie de mécènes en France, Paris, Louvre/BnF/Somogy, 2016, vol. II, p. 8-19.

2. Sur la collection d'objets d'Extrême-Orient de Salomon et Adèle, voir Béatrice Quette, « Objets d'art d'Extrême-Orient 1922 », dans Pauline Prevost-Marcilhacy (dir.), Les Rothschild. Une dynastie de mécènes en France, op. cit., vol. II, p. 148-157. 
3. Sur la place de l'art asiatique dans le marché de l'art parisien à cette époque, voir Léa SaintRaymond, « Le pari des enchères : le lancement de nouveaux marchés artistiques à Paris entre les années 1830 et 1939 », thèse de doctorat sous la direction de Ségolène Le Men, Université Paris Nanterre, 2018.

4. Sur l'architecture des maisons construites par la famille Rothschild, voir Pauline PrevostMarcilhacy, Les Rothschild, bâtisseurs et mécènes, Paris, Flammarion, 1995.

5. La disposition d'époque n'a pas été préservée jusqu'à nos jours. Beaucoup d'œuvres ont été déplacées et enlevées par rapport aux dispositions testamentaires.

6. Sur les 448 porcelaines chinoises mentionnées dans l'inventaire réalisé par Georges Vigne, 260 étaient disposées dans la salle des curiosités, les 188 restantes ont pour la plupart été vendues en 1923, voir Catalogue des objets d'art de la Chine et du Japon, céramiques des XVII ${ }^{e}$ XVIII et XIX ${ }^{e}$ siècles, laques de la Chine et du Japon, pierres dures, bronzes et métaux divers, émaux cloisonnés..., Paris, impr. Georges Petit, 1923, et Georges Vigne, «Le Legs de la baronne Salomon de Rothschild (1922) », tapuscrit inédit, Direction des Musées de France, 2007.

7. L'inventaire de la collection de porcelaines se trouvant dans la salle des curiosités de l'hôtel Salomon de Rothschild au moment du décès de la baronne est désormais inventorié dans la base AGORHA de l'INHA, grâce au travail réalisé dans le cadre du programme "Les collections Rothschild dans les institutions publiques françaises » en partenariat avec la Fondation des artistes. Voir aussi, pour cette collection, les inventaires du notaire Maître Nottin, Inventaire après-décès de la baronne Salomon de Rothschild, le 25 mars 1922, avec complément d'inventaire le 5 juin 1923. Suivi de l'état descriptif et estimatif des objets mobiliers garnissant l'Hôtel de la baronne Salomon de Rothschild, 11 rue Berryer, rédigé le 29 mars [1922], Paris, 1922 (une copie de cet inventaire est conservée à la Fondation des artistes); Pierre Schommer, Inventaire de la donation de la baronne Salomon de Rothschild, 11 rue Berryer, Paris. Décret d'acceptation du 16 décembre 1922, [Inventaire R], Paris, 1922, et Georges Vigne, « Le Legs de la baronne Salomon de Rothschild (1922) », op. cit.

8. Pour l'inventaire après décès de Salomon, voir Paris, Archives nationales MC/ET/CXVIII 1091, 2 nov., 1864 ; pour celui d'Adèle, l'auteur s'appuie sur l'inventaire de Georges Vigne, « Le Legs de la baronne Salomon de Rothschild (1922) ", op. cit., lui-même basé sur l'inventaire après décès dactylographié conservé aux Archives nationales, Archives des musées nationaux, gestion des musées de France, 20150044/72, Legs de la baronne Salomon de Rothschild,16 déc. 1922.

9. Ce nombre se base sur tous les objets désignés comme de la porcelaine chinoise dans l'inventaire. Or nous le verrons plus tard, les porcelaines chinoises et japonaises étaient encore souvent confondues au XIX ${ }^{\mathrm{e}}$ siècle. L'huissier n'ayant recensé que cinq pièces japonaises, il ne semble pas pour autant qu'il se soit encombré de faire une véritable distinction entre les deux, attribuant la majeure partie des objets à la Chine.

10. Ce carnet de comptes a été découvert et identifié par Pauline Prevost-Marcilhacy aux Archives Rothschild à Londres dans Prevost-Marcilhacy (dir.), Les Rothschild. Une dynastie de mécènes en France, op. cit., vol. II, n. 55, Londres, Archives Rothschild, RAL 00/1037/123B : objets d'art achetés par le baron Salomon de Rothschild de 1862 à 1864. Sur les intermédiaires de Salomon de Rothschild en général, voir Pauline Prevost-Marcilhacy, "Salomon et Adèle de Rothschild », dans id. (dir.), Les Rothschild. Une dynastie de mécènes en France, op. cit., vol. II, p.12.

11. Le montant des sommes versées par Salomon de Rothschild pour chacun de ces intermédiaires correspond, pour Nicolas Joseph Malinet à 58 108,45 f., pour le Baron de Monville à $52354 \mathrm{f}$. et pour Alfred Beurdeley à 80815 f., RAL 00/1037/123B.

12. À ne pas confondre avec son homonyme et contemporain Hippolyte Boissel de Monville ( ? 1863), botaniste, grand amateur de cactus et maire de Montville entre 1831 et 1847, voir Alain Poulin, Montville: son histoire, Montville, Marie de Montville, 1988, p. 22. Je remercie Maryse Bideault pour ses indications concernant la biographie de Monville. 
13. Manuel Charpy, « Le Théâtre des objets. Espaces privés, culture matérielle et identité sociale. Paris, 1830-1914", thèse de doctorat sous la direction de Jean-Luc Pinol, Université de Tours, 2010, p. 525.

14. Archives de Paris, D.48E3 57, procès-verbal de la vente de M. de Monville, 1866.

15. Albert Jacquemart [attribué à], Catalogue d'objets d'art et de curiosité... composant la collection de M. de Monville, Paris, impr. de Pillet fils aîné, 12-13 février, 1866, p. 3.

16. Camille Mestdagh, «La dynastie Beurdeley (1818-1895) : de la boutique à l'atelier. Une histoire du commerce des curiosités et de la fabrication d'objets d'art au XIx siècle ", thèse de doctorat d'histoire de l'art, universités UBFC et Lyon 2 Lumière, 2019. Voir également les études pionnières de Bernard Dorival, "De la tabletterie à la collection d'œuvres d'art. La "saga" Beurdeley (1814-1919) », Bulletin de la Société d'histoire de l'art français, 20 mai 1989, p. 191-237.

17. Camille Mestdagh, «Ameublement et luxe au temps de l'éclectisme : le commerce et l'œuvre des Beurdeley ", dans Natacha Coquery et Alain Bonnet (éd.), Le Commerce du luxe. Production, exposition et circulation des objets précieux du Moyen Âge à nos jours, Paris, Mare \& Martin, 2015, p. 282.

18. Paris, Archives de Paris, acte de décès, AD 075EC/V4E/06247/0069.

19. C'est à Charles Pillet que l'on doit la plupart des informations sur la vie de Malinet, dans son avant-propos au catalogue de la deuxième vente après décès de la collection Malinet en 1887. Voir Catalogue d'estampes anciennes principalement de l'école française $d u$ XVIII ${ }^{e}$ siècle, portraits et eauxfortes modernes, composant la collection de feu M. Malinet..., Paris, Typ. Pillet et Dumoulin, 2 février, 1887.

20. Catalogue d'une riche et importante collection d'objets d'art et curiosités, porcelaines anciennes... dont les ventes successives auront lieu après décès de Mme la Maréchale Lannes, duchesse de Montebello..., Paris, imp. de Maulde et Renou, 3-5 mars, 1856.

21. Catalogue d'estampes anciennes principalement de l'école française du XVIII siècle, portraits et eauxfortes modernes, composant la collection de feu M. Malinet..., op. cit., p. V.

22. Ibid.

23. Le terme de Palais d'Été utilisé depuis le $x^{\mathrm{e}}{ }^{\mathrm{e}}$ siècle en Occident porte à confusion, à la fois parce que le Yuanmingyuan n'est pas un palais isolé mais un vaste espace de jardins et de résidences palatiales, parce qu'il ne s'agit pas d'une résidence d'été mais bien d'un des principaux lieux de pouvoir avec la Cité interdite à la fin de la dynastie des Qing (1644-1914), mais aussi et surtout parce qu'il est confondu avec le «nouveau " palais d'été, construit par l'impératrice Cixi 慈㐨太后 sur le modèle et à proximité de l'ancien à partir de 1886. Ce dernier est connu en chinois sous le nom de Yiheyuan 頋和園. Voir Young-Tsu Wong, Paradise lost : the Imperial Garden: Yuanming Yuan, Honolulu, University of Hawai'i Press, 2001.

24. Léa Saint-Raymond, «Les collectionneurs d'art asiatique à Paris: une analyse socioéconomique ", dans Marie Laureillard et Cléa Patin (dir.), À la croisée de collections d'art entre Asie et Occident. Du XIX siècle à nos jours, Paris, Hémisphères Editions, Maisonneuve \& Larose nouvelles éditions, 2019, p.229-247. .

25. Catalogues des ventes concernées : Lugt $n^{\text {os }} 26468,26514,26551,26559,26597,26610,26712$, 26744, 26760, 26779, 27022, 27058, 27118, 27149, 27232, 31333 ; voir Christine Howald et Léa SaintRaymond, "Tracking Dispersal: Auction Sales from the Yuanmingyuan Loot in Paris in the 1860s ", Journal for art market studies, 2018, no 2, p. 6.

26. Le musée du Louvre conserve ainsi deux chandeliers, un portant la marque Qianlong 乾隆, et l'autre Daoguang 道光 au revers, ainsi qu'un vase aux lèvres évasées sur lequel est inscrit en caractères sigillaires Da Qing Qianlong nian zhi 大清乾隆年製 (littéralement «fait pendant l'ère Qianlong des grands Qing»), la Fondation des artistes conserve seulement une pièce de provenance impériale décrite plus bas. 
27. Pauline Prevost-Marcilhacy (dir.), Les Rothschild. Une dynastie de mécènes, op. cit., vol. II, p. 11-12; Salomon vend une partie de sa collection deux mois avant sa mort le 18 et le 19 mars 1864 à l'Hôtel Drouot, voir Objets d'art et de haute curiosité, Imp. Pillet fils ainé, Paris, 1864.

28. Albert Charles Jacques Jacquemart, après une formation artistique rentre à l'Administration centrale des douanes, au ministère des Finances, où il officie toute sa vie. Il fut néanmoins très impliqué dans les milieux artistiques, contribuant régulièrement à la Gazette des Beaux-Arts, il œuvra pour la reconnaissance des céramiques au rang d'œuvres d'art. Il est particulièrement connu pour avoir mis au point, avec Edmond Le Blant, le système taxonomique des familles dont sont issus les termes "famille rose» et «famille verte», voir Pauline d'Abrigeon, "Albert Jacquemart (1808-1875) and his Work on Chinese Ceramics", Transactions of Oriental Ceramic Society, $\mathrm{n}^{\circ} 83,2020$, à paraître.

29. Note datée du 26 mai 1864, «à Jacquemart pour soins donnés à la confection d'un catalogue de la collection d'objets d'art 1200 ", voir RAL 00/1037/123 B.

30. Lettre de la baronne Salomon de Rothschild à Jules Jacquemart, Paris, 26 novembre 1875, Bibliothèque de l'Institut national d'histoire de l'art, fonds Jacques-Doucet, autographe 094, dossier 06, 85367-85369. Le catalogue inachevé transmis par Jules Jacquemart à Adèle de Rothschild n'a, à ce jour, pas été retrouvé.

31. Il réalise les catalogues des objets d'art de M. Daigremont (1861), de Mme Malinet (1862), de M. Ch. De Férol (1863), M. de Monville (1866), de M. l'amiral Page (1867), de Mme Beaven (1869), de M. Séchan (1875).

32. Albert Jacquemart, "Introduction" au Catalogue descriptif et raisonné des porcelaines, grès cérames, terres vernissées, laques de la Chine, du Japon, de l'Inde et de la Perse composant la collection de Madame Malinet, Paris, impr. de Renou et Maulde, 1862, n. p.

33. Par deux fois, Albert Jacquemart a publié à propos la collection Rothschild: Albert Jacquemart, "Les collections d'art ", Paris. Guide par les principaux écrivains et artistes de la France (Première partie: La science et l'art), Paris, A. Lacroix Verboeckhoven, 1867, p. 551-556, et ses notices dans Édouard Lièvre (dir.), Les Collections célèbres d'œuvres d'art, Paris, Goupil, 1866. Pourtant, aucune de ces publications n'évoque la collection de porcelaines chinoises. Jacquemart décrit plutôt les objets chinois en émail cloisonné. Peut-être le catalogue devait-il compléter ces deux publications? À moins que Jacquemart n'ait pas estimé la collection de Salomon de Rothschild au point de s'y attarder dans le détail ?

34. Ce constat se base sur l'étude des collections du Louvre et de la Maison des Artistes. L'étude approfondie de la collection de porcelaines d'exportation du musée du Louvre a fait l'objet d'un mémoire de recherche par Julie Defretin, "La datation de la porcelaine "coquille d'œuf» d'exportation du musée du Louvre ", sous la direction de Jean-Baptiste Clais et de Bing Zhao, Paris, École du Louvre, 2019.

35. On trouve notamment illustré, Le Récit de la ballade au pip a琵琶記 ex. : R 1121, La Romance au Pavillon de l'Ouest 西廂記 ex. : R1092, des scènes de rassemblement tirées sans doute du Roman des Trois Royaume 三國演義 ou de Au bord de l'Eau 水澈傳 ex. : R 1103.

36. La couleur rose, obtenue à partir de l'or est rendue opaque par l'adjonction d'oxyde d'étain à la frite.

37. Les œuvres faites pour l'exportation étaient souvent peintes à Canton (actuelle Guangzhou) : le corps de la pièce en porcelaine blanche était produit à Jingdezhen puis la pièce était acheminée vers le port de Canton où mouillaient les vaisseaux étrangers. On trouve sur certaines pièces l'inscription Lingnan huizhi 嶺南繪者, littéralement " un peintre de Lingnan », Lingnan étant l'un des noms de Canton, voir le plat à émaux de la National Gallery of Art de Washington, collection Widener, 1942.9.557, reproduit dans Virginia Bower et National Gallery of Art (éd.), Decorative arts. Far Eastern Ceramics and Paintings, Persian and Indian Rugs and Carpets, Washington D.C., National Gallery of Art, 1998, vol. II, p. 235. 
38. Selon Margaret Medley cela devait permettre d'opacifier la porcelaine rendue trop translucide du fait de l'extrême finesse des parois, voir Margaret medley, The Chinese Potter: À Practical History of Chinese Ceramics, Oxford, Phaidon, 1976, p. 247.

39. David Sanctuary Howard, Chinese Armorial Porcelain, Londres, Faber and Faber, 1974, vol. I, p. $217,232$.

40. Maître Nottin [notaire], Inventaire après-décès de la baronne Salomon de Rothschild, le 25 mars 1922, avec complément d'inventaire le 5 juin 1923. Suivi de l'état descriptif et estimatif des objets mobiliers garnissant l'Hôtel de la baronne Salomon de Rothschild, 11 rue Berryer, rédigé le 29 mars [1922], fol. 70, sans $\mathrm{n}^{\circ}$ [salle des curiosités, vitrine de gauche] : «Soixante-six assiettes en porcelaine de Chine, décors variés de personnages, fleurs, oiseaux, etc... prisées six mille six cents francs"; "Soixante-six assiettes en porcelaine de Chine », voir : https://agorha.inha.fr/inhaprod/ark:/ 54721/003229371 (consulté en octobre 2019).

41. Voir par exemple la représentation du cabinet d'Alexandre Du Sommerard peinte par LouisVincent Fouquet (1803-1863) en 1836, huile sur toile conservée au musée des Arts décoratifs, Paris, où l'on voit une collection de porcelaines japonaises XVIII ${ }^{\mathrm{e}}$ siècle côtoyer des œuvres de Palissy dans un vaisselier.

42. À propos du retour en grâce de ce type d'objet en Grande Bretagne voir : Stacey Pierson, Collectors, Collections and Museums: the Field of Chinese Ceramics in Britain, 1560-1960, Oxford/New York, P. Lang, 2007. En France, les collections les plus connues faisant état de ce goût pour les porcelaines émaillées sont celles d'Albert Jacquemart, de Paul Gasnault (1828-1898), aujourd'hui conservées au Musée national de la céramique Adrien Dubouché, et surtout celle d'Ernest Grandidier (1833-1912) conservée au Musée national des arts asiatiques - Guimet.

43. Objets d'art et de haute curiosité, Paris, 18-19 mars, 1864, lot 33, p. 10.

44. Albert Jacquemart, Edmond Le Blant, Histoire artistique, industrielle et commerciale de la porcelaine..., Paris, J. Techener, 1862.Dans cet ouvrage les auteurs classent ce type de pièce tantôt dans la catégorie des familles roses du Japon, tantôt dans celle des porcelaines japonaises à décor de « mandarin ».

45. Albert Jacquemart [attribué à], Catalogue d'objets d'art et de curiosité... composant la collection de M. de Monville, op. cit., 1866, p. 30, lot 190.

46. Acquise par Delange, voir la note manuscrite du catalogue conservé à la Bibliothèque nationale de France, cote 8-V-8201 (260).

47. Léa Saint-Raymond, «Les ventes aux enchères d'objets asiatiques à Paris entre 1858 et 1913: statistiques et listes des principaux acheteurs ", Harvard Dataverse, V1, 2016. http://dx.doi.org/ 10.7910/DVN/G96SRI(consulté le 10 décembre 2019). Voir dans l'onglet intitulé "prix» qui correspond au "prix au-dessous duquel ont été adjugés $75 \%$ des objets asiatiques", les porcelaines asiatiques sont vendues majoritairement en dessous de 184,5 f. en 1858, en dessous de 101,5 f. en 1862, en dessous de 121 f. en 1867, en dessous de 187,5 f. en 1868 et en dessous de 179 f. en 1873.

48. Concernant les autres pièces provenant du Yuanmingyuan, voir la note 23 . Pour cette pièce en particulier et sa localisation, voir Georges Vigne, «Le Legs de la baronne Salomon de Rothschild (1922) », op. cit., n 1382.

49. National Palace Museum 國立故宮博物院, The All Complete Qianlong: the Aesthetic Tastes of the Qing Emperor Gaozong 十全乾隆：清高宗的藝術品味, Taipei, National Palace Museum, 2013, p. 226-227.

50. Voir le plat au marli ajouré yangcai, conservé au Château de Fontainebleau, inv. F1425C.

51. Léa Saint-Raymond, "The Yuanmingyuan Loot at Parisian Auctions in the 1860: Artefacts, Hammer Prices, Sellers and Purchasers », Harvard Dataverse, V1, 2018, https://doi.org/10.7910/ DVN/OCOI5J (consulté le 1er décembre 2018).

52. RAL 00/1037/123B. 
53. Christine Howald et Léa Saint-Raymond, "Tracking dispersal: auction sales from the Yuanmingyuan loot in Paris in the 1860s ", art. cit., p. 14, fig. 7.

54. Georges Vigne, « Le Legs de la baronne Salomon de Rothschild (1922) », op. cit., $\mathrm{n}^{\circ} 1382$.

55. Albert Jacquemart, Édmond Le Blant, Histoire artistique, industrielle et commerciale de la porcelaine..., op. cit., p. 375

56. Helen Espir, European Decoration on Oriental Porcelain: 1700-1830, Londres, J. Welsh, 2005, p. 57-56.

57. Voir notamment, dans cette collection, les pièces PO 3377, PO 3195, PO 3196.

58. Catalogue d'une riche et importante collection d'objets d'art et curiosités, porcelaines anciennes... dont les ventes successives auront lieu après décès de Mme la Maréchale Lannes, duchesse de Montebello. En son hôtel à Paris, rue de Varennes, 73..., Paris, imp. de Maulde et Renou, 2 février-31 mars 1857, 1856.

59. Albert Jacquemart, Catalogue descriptif et raisonné des porcelaines, grès cérames, terres vernissées, laques de la Chine, du Japon, de l'Inde et de la Perse composant la collection de Madame Malinet, op. cit., 1862.

60. Ces aquarelles montrent ici et là quelques paires de porcelaines vraisemblablement chinoises ; elles sont pour la plupart montées et ornent les rebords des cheminées, certaines sont monumentales et occupent un espace sur un socle, voir Prevost-Marcilhacy (dir.), Les Rothschild, bâtisseurs et mécènes, op. cit., p. 106-109. 


\section{Perspectives nationales}




\title{
Béatrice Ephrussi de Rothschild et l'Italie. Architecture et mobilier
}

\author{
Louis Mézin
}

Lorsqu'en 1934 Béatrice Ephrussi (1864-1934), fille d'Alphonse de Rothschild, légua l'ensemble de ses collections d'art à l'Académie des beaux-arts, elle enrichit d'un patrimoine exceptionnel la Villa Île-de-France, qu'elle avait fait construire entre 1909 et 1912 à Saint-Jean-Cap-Ferrat, la destinant à les recevoir ${ }^{1}$. La villa devint ainsi le réceptacle d'un ensemble de mobilier et d'objets d'art, jusque-là partagé entre les quatre résidences qu'elle possédait : un hôtel particulier à Paris, sis 19, rue du Bois-deBoulogne; deux villas à Monaco, et enfin la Villa Île-de-France, qu'elle cessa de fréquenter durant les dernières années de sa vie. Pour l'ouverture au public de celle-ci, en 1938, son premier directeur, Albert Tournaire (1862-1958), architecte et membre de l'Académie des beaux-arts, fut chargé de réunir ces collections et de recomposer leur présentation dans un site qui ne les avait que partiellement connues. La Villa Ephrussi de Rothschild, autre nom de la villa Île-de-France, se transforma ainsi en un véritable musée, l'un des plus visités de la Riviera française aujourd'hui².

Durant de nombreuses années, la publicité qui en était faite se focalisait sur les collections françaises, très représentatives, comme en témoignent le bel ensemble des porcelaines de Sèvres, certaines pièces de mobilier, les peintures et dessins du $\mathrm{XVIII}^{\mathrm{e}}$ siècle, autant d'illustrations du goût des collectionneurs parisiens de la Belle Époque. Mais c'était oublier qu'une partie du mobilier acquis par Béatrice Ephrussi était d'origine et de facture italienne, comme l'attestent les ensembles exposés notamment dans le grand salon, qui ont pu être étudiés avec une plus grande attention lors de la campagne de restauration du mobilier entreprise depuis $2015^{3}$. La demeure elle-même fut conçue à la manière d'une villa italienne plantée à l'entrée du cap Ferrat, certains de ses éléments rappelant les palais vénitiens ${ }^{4}$ (fig. 1). 
1. Faust Picedi, façade sud de la Villa Ephrussi de Rothschild, c. 1930-1935, Saint-Jean-Cap-Ferrat, Villa Ephrussi de Rothschild.

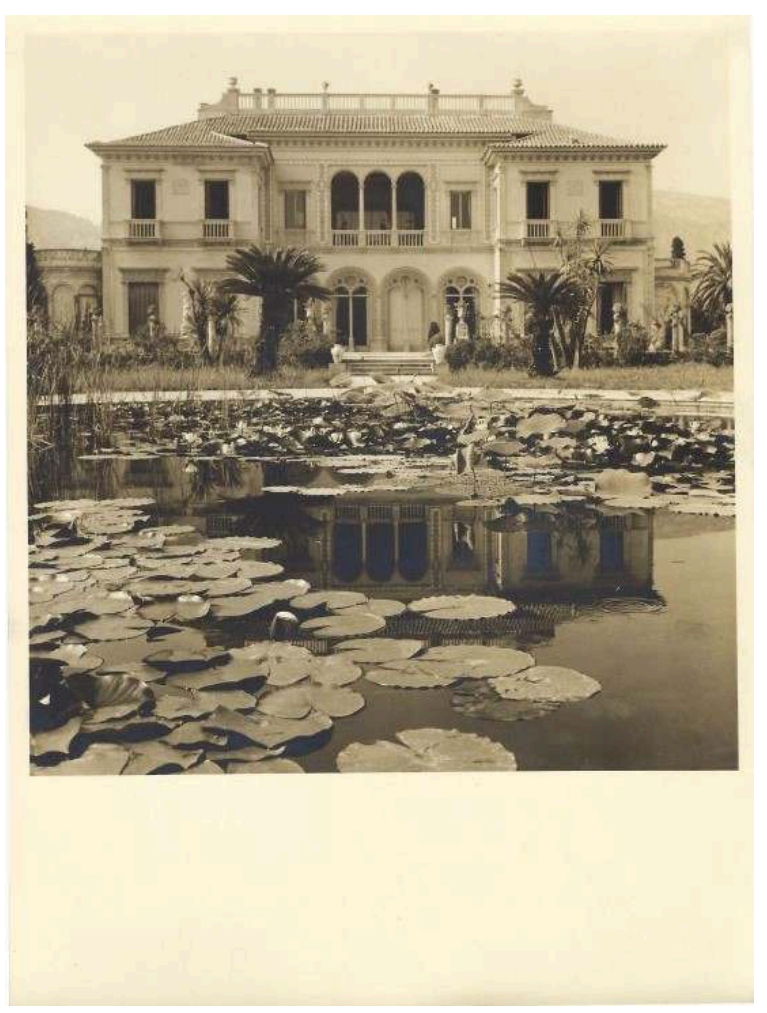

(c) Villa Ephrussi de Rothschild

3 Nombre de résidences de villégiature de la Riviera française construites au tournant du $\mathrm{xx}^{\mathrm{e}}$ siècle sont imprégnées de l'architecture italienne ${ }^{5}$. Bâties sous un même climat méditerranéen, elles s'ancrent dans une région rattachée depuis des années par des liens naturels et historiques au versant transalpin. La conception architecturale de la Villa Île-de-France est fortement influencée par le courant historiciste et italianisant en vogue au début $\mathrm{du} \mathrm{xx}^{\mathrm{e}}$ siècle, caractérisé par d'imposantes corniches, un étage noble avec de hautes ouvertures ou une loggia. La villa est l'œuvre de trois architectes: Jacques-Marcel Auburtin (1872-1926), second Grand Prix de Rome en 1897, Aaron Messiah (1858-1940), d'origine niçoise, et Gustave Majou (1862-1941), architecte de la Fondation Rothschild de 1905 à 1914.

4 L'édifice est construit sur une structure en brique ornée de parements moulurés et de pilastres adossés en granulat et en plâtre ${ }^{6}$. Ces éléments ornementaux sont pour la plupart visibles dans le projet initial d'Auburtin, comme le montrent les dessins de façades et de coupes de $1908^{7}$. Il y propose une abondante décoration tant à l'intérieur, tout autour du patio central, qu'à l'extérieur où, au sommet de l'édifice, sont projetés des belvédères ressemblant à ceux de la Villa Médicis à Rome. On aperçoit ces derniers sur la photographie d'une maquette d'étude proposée à Béatrice Ephrussi (fig. 2). 
2. Jacques-Marcel Auburtin, maquette, élévation de la façade sud de la Villa Ephrussi de Rothschild, projet Auburtin, 1908, Saint-Jean-Cap-Ferrat, Villa Ephrussi de Rothschild.

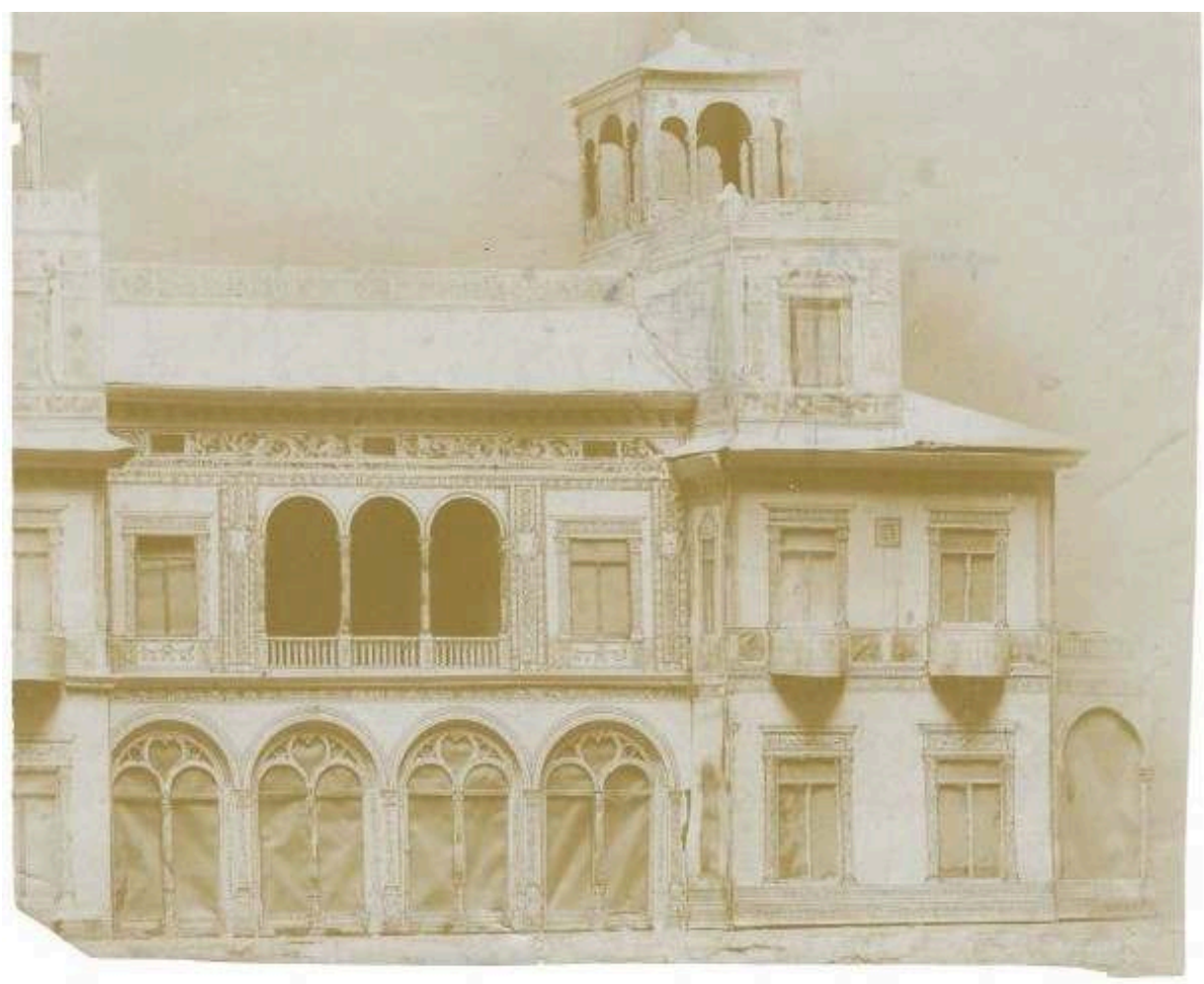

(C) Villa Ephrussi de Rothschild

Cette profusion ornementale est finalement modifiée au profit d'une composition simplifiée des façades. Gustave Majou, qui prend part aux travaux d'aménagement intérieur demandés par Béatrice Ephrussi, supervise certains travaux de modification de façade et, pour un meilleur jugement du rendu des volumes et de l'harmonie des ouvertures, recommande «le montage de gabarit grandeur nature en bâti de bois et toile clouée, ainsi que le désire Madame Ephrussi ». Cette recommandation concerne notamment la galerie située devant le salon, à propos de laquelle il conseille «pour cette maquette grandeur nature de reprendre le dessin d'Auburtin ». Gustave Majou est chargé de produire de nouveaux plans « remplaçant les démolitions de l'ancien projet d'Auburtin ${ }^{8}$ ", avant de les soumettre à l'accord de Béatrice Ephrussi. Il est principalement préposé à la conduite des travaux d'agencement intérieur, aux finitions en stuc et à l'installation des boiseries du grand salon Louis XVI, qui sont commandées à la maison Charles Fournier ${ }^{9}$ à Paris. Pour ces travaux d'aménagement, il semble que Béatrice Ephrussi ait sollicité plusieurs intervenants, notamment Antonio Salvadori à Venise, voire d'autres personnes, comme le suggère un télégramme adressé le 26 septembre 1910 à Milan: "Prie envoyer de suite à Mantegazza, 21 via Fatebene Fratelli, les plans et mesures petite antichambre où se trouve escalier femme de chambre et chambre d'entrée avant salle à manger [...]. Demandez explications à Messiah et envoyer par retour de courrier ", signé $\mathrm{M}^{\mathrm{me}}$ Ephrussi. « Le décorateur attend ces renseignements", comme le rappelle préalablement Gustave Majou dans un courrier daté du 14 juin $1910^{10}$.

6 Malheureusement, les archives lacunaires de la Villa Ephrussi de Rothschild nous renseignent trop peu sur la construction de cette demeure des années 1910, entrée dans 
les collections publiques en 1934. Seules quelques photographies d'époque montrant des monuments italiens jettent un éclairage sur son élaboration. Elles proviennent pour partie du studio Fratelli Alinari ${ }^{11}$, l'une des plus anciennes agences de photographie créée à Florence et dirigée dans les années 1900 par Vittorio Alinari (1859-1932). Conservées à la Villa Ephrussi, elles représentent principalement des vues intérieures de l'église Santa Maria dei Miracoli de Venise : détails des pilastres, du chœur et du chancel. Ces photographies pourraient paraître anodines si elles n'étaient mises en relation avec le décor architectural de la Villa Ephrussi, attendu qu'elles affichent des correspondances évidentes : les motifs décoratifs des pilastres des façades sud ou nord et de certains chapiteaux sont directement inspirés des motifs existant à l'église Santa Maria dei Miracoli, construite par Pietro Lombardo (1435-1515) à la fin du Xve siècle. La Villa Ephrussi conserve fort heureusement les modèles en bois sculpté, créés vers 1910, nécessaires à la fabrication des moules et qui, jusqu'à ce jour, n'avaient pas été rigoureusement identifiés pour cette utilisation (fig. $3 a, 3 b$ et $3 c$ ). Une photographie des années 1900, conservée à la Villa Ephrussi et montrant deux hommes posant autour d'un pilastre (pour mieux en déterminer l'échelle), est marquée au dos d'un cachet: «Bonivento Marcello/Scultore ornementale/Venezia ${ }^{12}$ ».

3a. Fratelli Alinari, Pilastres de l'église Saint Marie des Miracles à Venise, c. 1897, photographie, archives de la Villa Ephrussi de Rothschild, pl. 9-3, Saint-Jean-Cap-Ferrat, Villa Ephrussi de Rothschild.

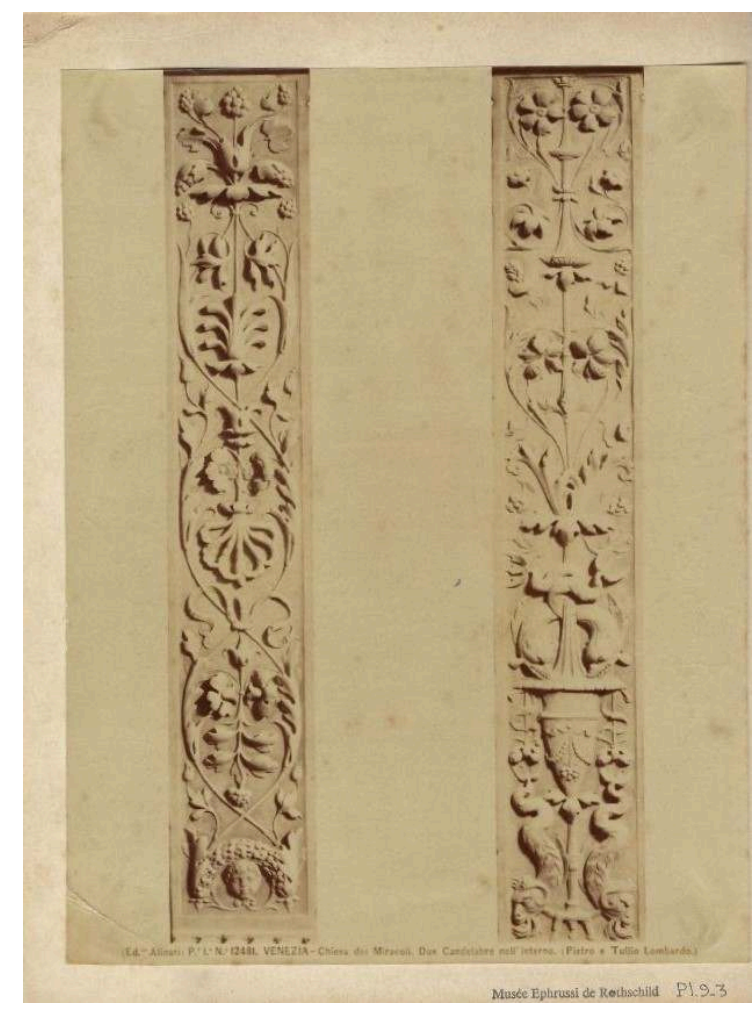

(c) Villa Ephrussi de Rothschild 
3b. Modèle en bois sculpté, détail de la partie inférieure, c. 1910, Saint-Jean-Cap-Ferrat, Villa Ephrussi de Rothschild, inv. EdR111.

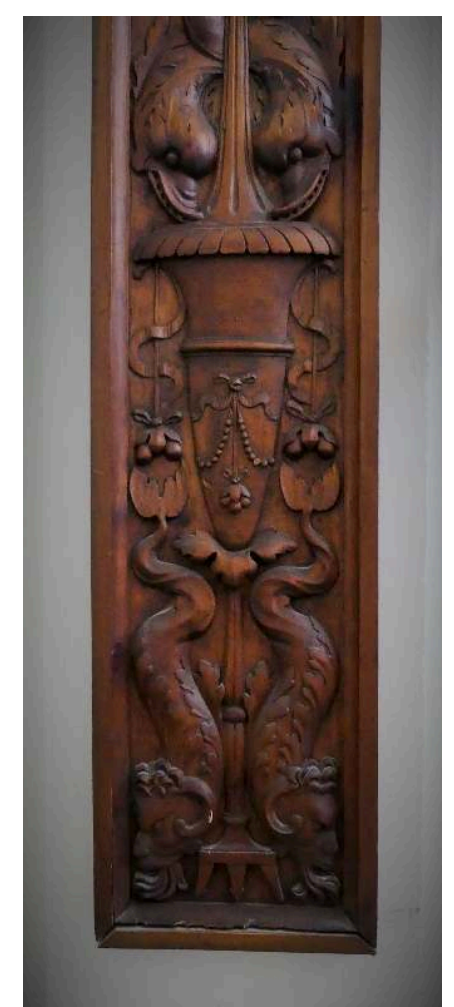

(c) Villa Ephrussi de Rothschild 
3c. Façade sud de la Villa Ephrussi de Rothschild, pilastre, encadrement de fenêtre, Saint-JeanCap-Ferrat, Villa Ephrussi de Rothschild.

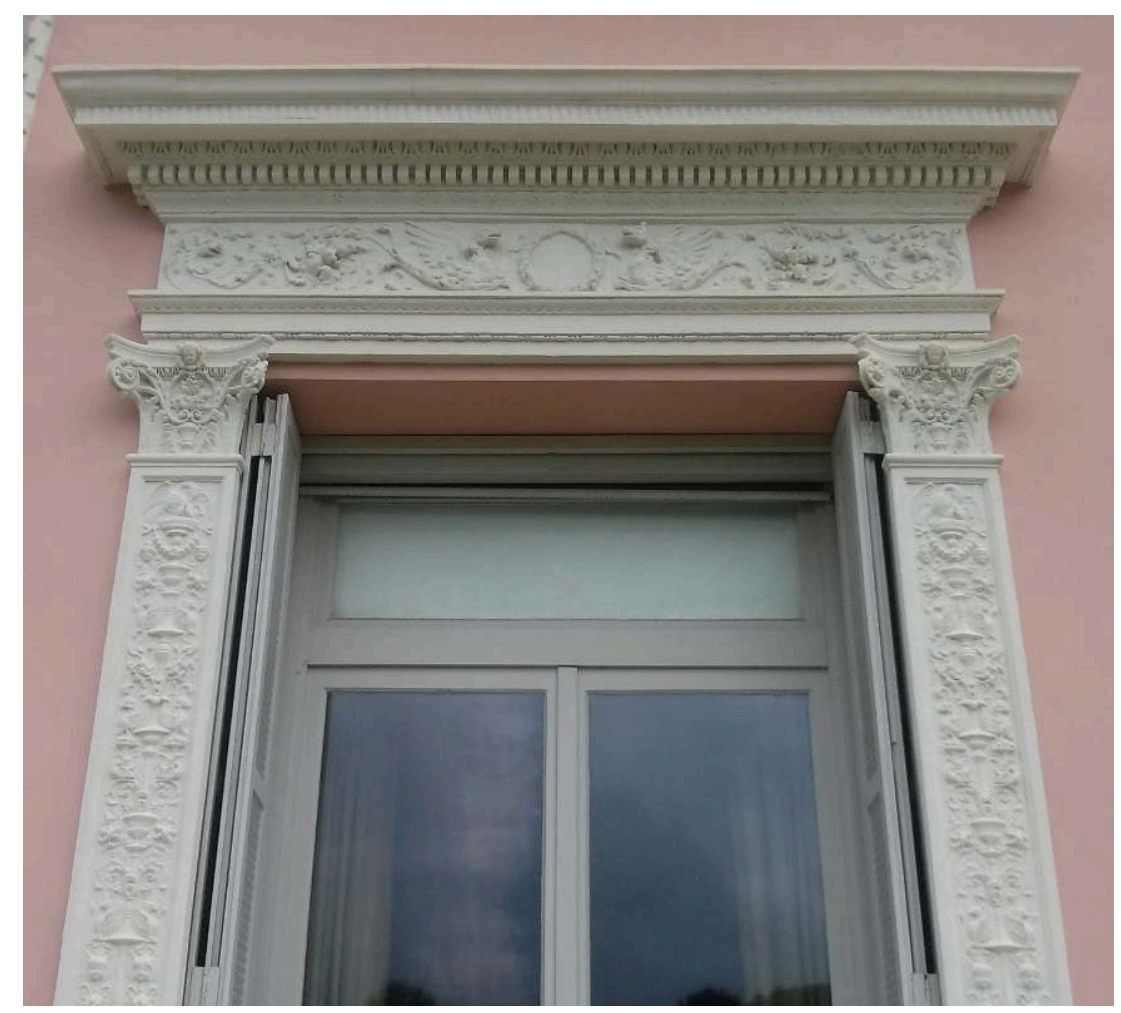

(c) Villa Ephrussi de Rothschild, 2019

7 L'église Santa Maria dei Miracoli est encore présente dans la décoration du patio conçu d'après un plan carré et formé d'arcatures en plein cintre voûtées. Le niveau du premier étage, ouvert sur le vide, est garni d'un parapet à motifs ajourés sur lequel reposent des arches. Le patio forme ainsi un ample volume qui apporte une grande noblesse à cet espace de circulation intérieur. Le motif de la balustrade à claire-voie est directement emprunté au chancel entourant l'autel de l'église des Miracles (fig. $4 a$ et 4b). Certains chapiteaux de la façade sud sont également empruntés à cette église, comme le révèlent les photographies d'Alinari conservées à la Fondation Federico Zeri de Bologne. 
4a. Fratelli Alinari, Vue du chancel de l'église Sainte-Marie-des-Miracles à Venise (détail), c. 1897, photographie, Bologne, Université de Bologne, Fondation Federico Zeri, photothèque Zeri, inv. 146302.

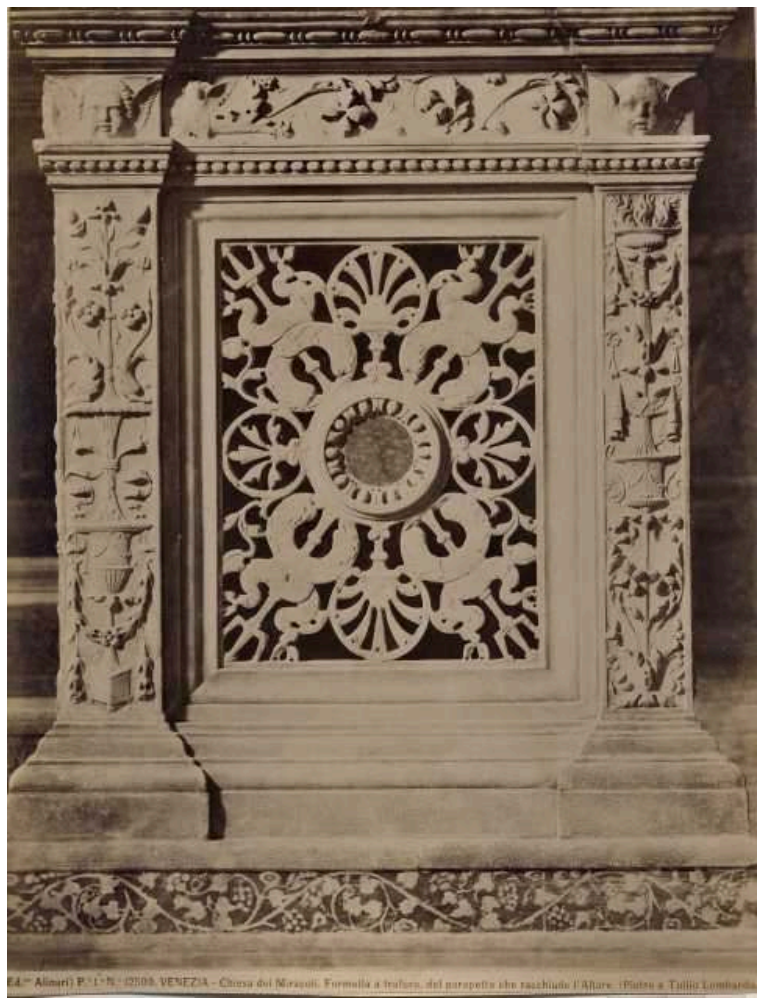

(c) Fondation Federico Zeri

4b. Parapet ajouré d'après le chancel de l'église Sainte-Marie des Miracles, Saint-Jean-Cap-Ferrat, Villa Ephrussi de Rothschild.

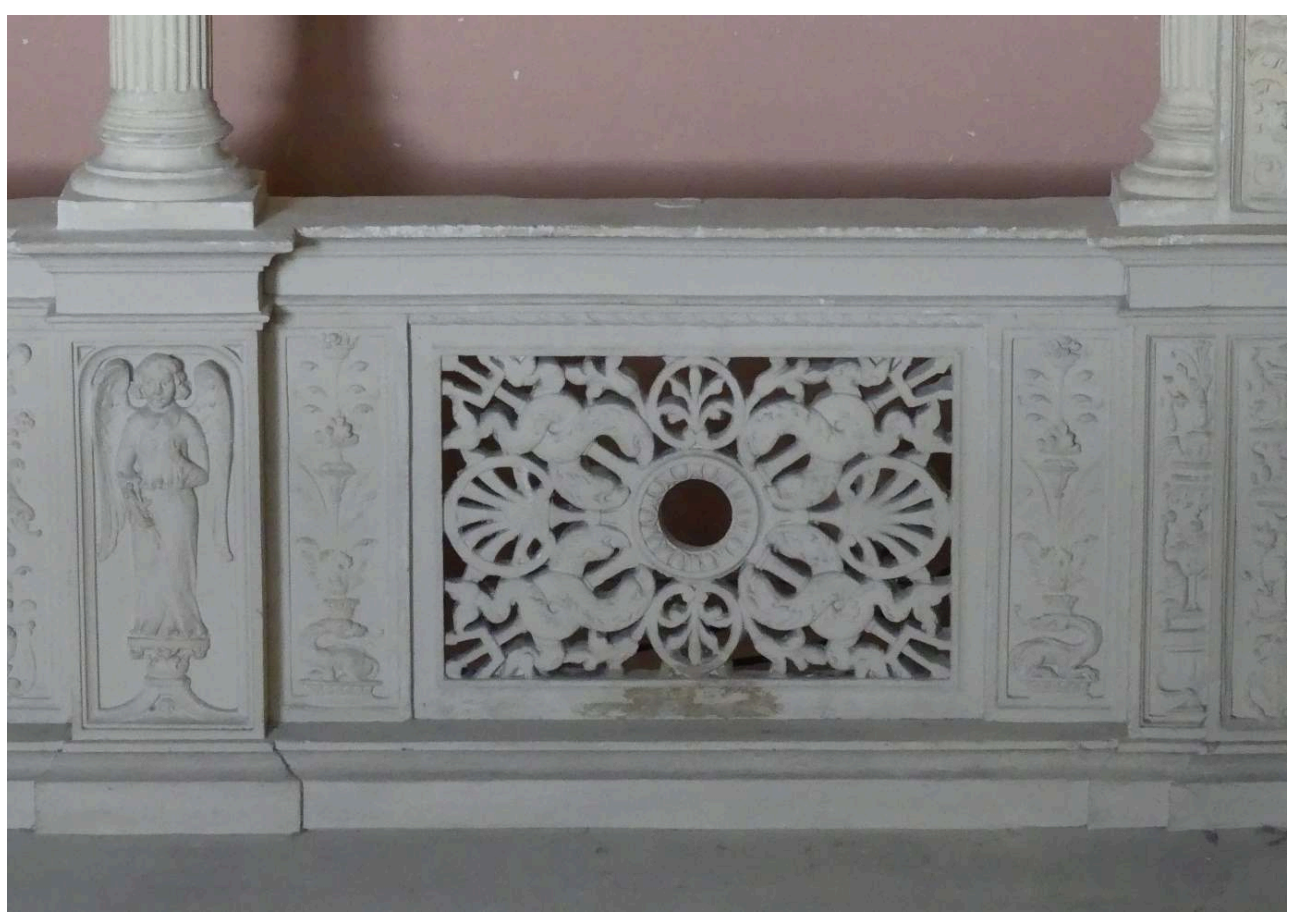

(c) Villa Ephrussi de Rothschild, 2019 
Le sol du patio est entièrement recouvert d'une mosaïque qui pourrait être due à Antonio Zanussi (1849-1911): les réserves conservent en effet trois panneaux d'échantillons de mosaïque $(46 \times 20 \mathrm{~cm})$ reprenant des motifs réalisés pour la Villa Ephrussi, dont l'un est signé de son nom : «Zanussi, mosaïste » (fig. 5).

5. Antonio Zanussi, échantillons de mosaïque sur panneau, Saint-Jean-Cap-Ferrat, Villa Ephrussi de Rothschild.

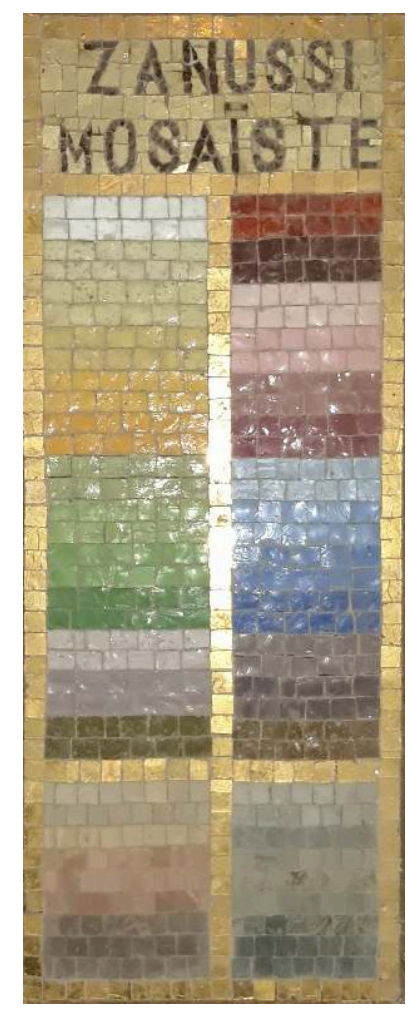

(C) Villa Ephrussi de Rothschild

Antonio Zanussi appartient, comme beaucoup de mosaïstes italiens, à une famille originaire du Frioul venue en France pour participer à d'importants chantiers de création de mosaïque décorative à l'époque de son remploi dans l'architecture de la seconde moitié du XIX ${ }^{e}$ siècle $^{13}$. Héritier de la maison Mazzioli-Chauviret en 1886, il exécute également beaucoup de mosaïques décoratives pour les villas et les immeubles qui naissent à la Belle Époque, à Nice, où il s'est fixé. Antonio Zanussi meurt dans cette ville en 1911, laissant inachevée la mosaïque de la Villa Ephrussi. C'est donc Clément Goyenèche (1893-1984) - futur collaborateur du décorateur Francis Jourdain (1876-1958) en 1919, alors jeune diplômé de l'École des arts décoratifs de Nice, lauréat en 1911 du concours général de composition décorative décerné par la Société d'encouragement à l'art et à l'industrie et par l'Administration des beaux-arts - qui poursuit et achève en 1912 l'œuvre d'Antonio Zanussi à la demande de Béatrice Ephrussi, comme en témoigne la date inscrite à même la mosaïque située devant la porte d'entrée.

10 Au tournant des années 1910, Béatrice Ephrussi réalise de nombreuses acquisitions d'œuvres d'art auprès de marchands d'origine vénitienne ou romaine, comme Attilio Simonetti, Giuseppe Sangiorgi ou Antonio Salvadori, antiquaires ou responsables de maisons de ventes renommées en Italie. Ces derniers sont en lien permanent avec les 
grands musées et les collectionneurs du début $\mathrm{du} \mathrm{xx}^{\mathrm{e}}$ siècle, tels qu'Achille Cantoni (1844-1914) à Milan ou Stefano Bardini (1836-1922) à Florence ${ }^{14}$.

11 Giuseppe Sangiorgi (1850-1928) est, en Italie, l'un des marchands les plus influents de son époque. Il poursuit une activité de maison de ventes et de commerce d'art à partir de 1892 au palais Sciarra puis au palais Borghèse à Rome ${ }^{15}$ et est référencé de 1911 à 1937 dans l'Annuaire de la curiosité et des beaux-arts à la rubrique des antiquaires de Rome. Il contribue à la vente des principales collections italiennes entre 1892 et 1910, dont celles de Carlo Varelli à Naples (1892), du prince Orsini à Rome (1896), d'Alessandro Pallavicino à Gênes (1899), de Felicita Bevilacqua La Masa à Venise (1900) ou de Joachim Ferroni à Rome (1909). Les catalogues de la galerie Sangiorgi sont régulièrement publiés en italien ou en français. L'introduction au Catalogue des objets d'art anciens pour l'année 1912 souligne que, parmi ses acheteurs, se trouvent les musées de New York, Boston, Chicago, Berlin, Copenhague, Londres, Vienne, Francfort et des principales villes d'Italie, mais également que la galerie « compte, parmi ses meilleurs clients, les plus grands collectionneurs du monde ». Dans la longue liste des amateurs d'art désignés, qui appartiennent à l'aristocratie européenne et au monde des affaires figure le nom de "Madame Béatrix Ephrussi ${ }^{16}$ ». Sa présence parmi quelques noms connus, tels John Pierpont Morgan, John Wanamaker ou Gertrude Vanderbilt, laisse penser que Béatrice Ephrussi a fait d'importantes et régulières acquisitions à la galerie Sangiorgi, même si aucune d'elles n'a pu être clairement identifiée au sein de la collection actuellement conservée à la Villa Ephrussi de Rothschild. Par ailleurs, la galerie dirigée par Giuseppe Sangiorgi n'est pas inconnue sur la Riviera française, puisque, dix ans auparavant, Victor Masséna, prince d'Essling et natif de Nice, a acheté, lors d'une vente organisée en 1898, un important ensemble de portes, boiseries et impostes peintes provenant du château de Govone, près de Turin, afin de les installer dans la Villa Masséna qu'il se fait construire sur la promenade des Anglais ${ }^{17}$. Dans la modeste collection de photographies des archives de la Villa Ephrussi figure un cliché de la vue de face et de profil d'une banquette en marbre (fig.6), acquise à la galerie Sangiorgi et destinée à être placée dans le jardin (inv. EdR4446). Au revers du cliché est imprimé le cachet «Galerie Sangiorgi/Palais Borghèse/Rome», annoté de la description de l'objet ${ }^{18}$. 
6. Vue de face et de profil d'une banquette en marbre, c. 1910, au dos un cachet indique : "Galerie Sangiorgi, Palais Borghèse, Rome ", archives de la Villa Ephrussi de Rothschild, pl. 10-21, SaintJean-Cap-Ferrat, Villa Ephrussi de Rothschild.

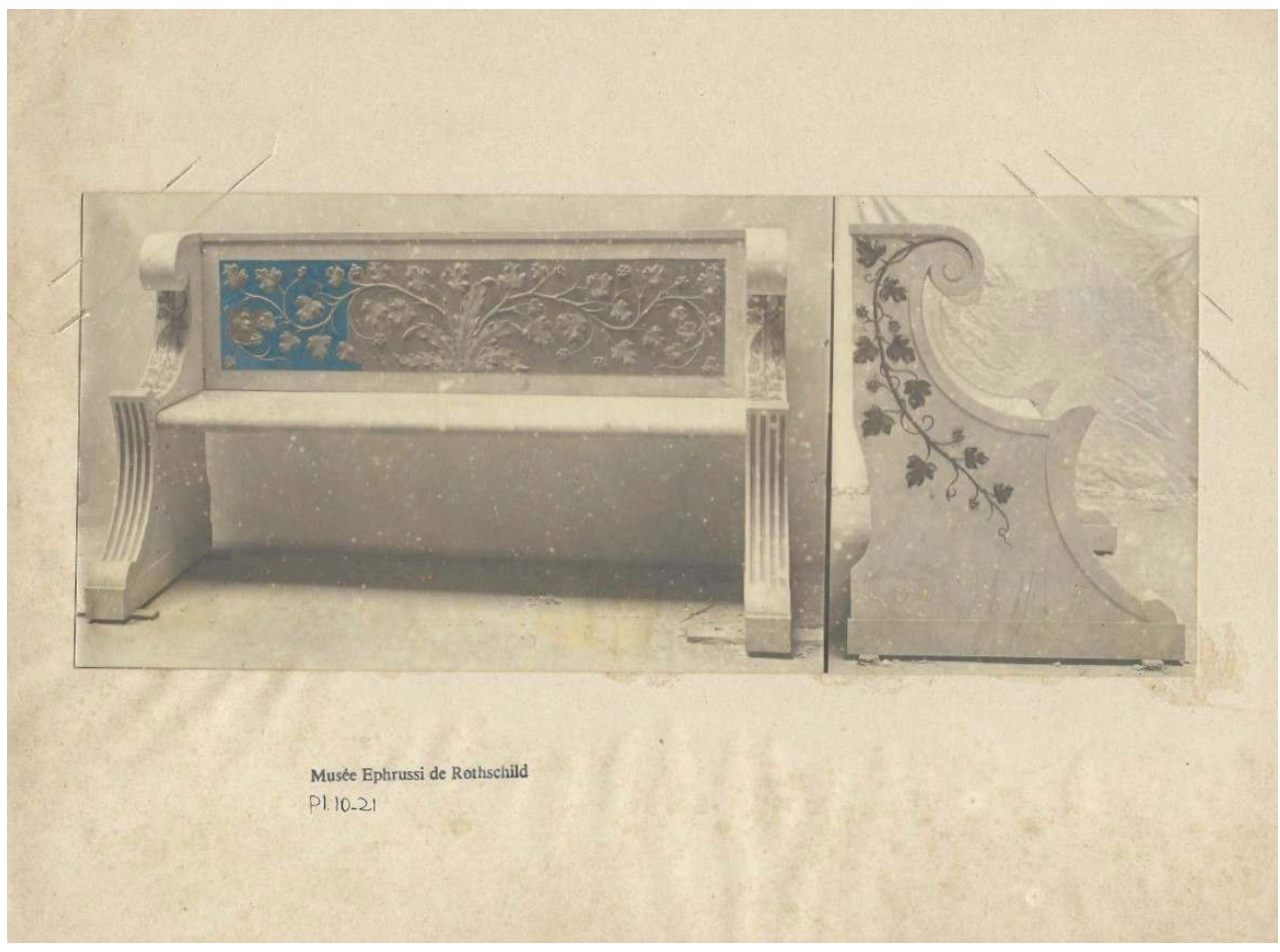

(c) Villa Ephrussi de Rothschild

L'antiquaire romain Attilio Simonetti (1843-1925) ${ }^{19}$ est la seconde personnalité du commerce d'art en Italie auquel on attribue des relations avec Béatrice Ephrussi. Également connu comme peintre, formé à l'académie Saint-Luc (1861), il a bénéficié grâce à ses expositions à Milan (1868), à Naples (1877) et à Rome (1883) - « d'une place notable parmi les peintres de genre romains ", surtout dans le domaine de l'aquarelle, étant à cet égard l'un des fondateurs de l'Associazione degli Acquarellisti Romani en 1875. Il fut l'élève et l'ami du peintre espagnol Mariano Fortuny y Marsal (1838-1874), partageant avec lui un atelier Via Flaminia à Rome, avant de s'installer Via Margutta. Comme Fortuny, Simonetti nourrissait une passion pour les textiles. Sa collection était exceptionnellement riche en costumes des $\mathrm{XVI}^{\mathrm{e}}, \mathrm{XVII}^{\mathrm{e}}$ et $\mathrm{XVIII}{ }^{\mathrm{e}}$ siècles et en étoffes précieuses. Il était actif dans les expositions romaines et notamment comme viceprésident du Musée artistique industriel, conçu dans le « but de fournir aux ateliers de la ville des modèles et des inspirations nouvelles". Il "avait fait appel à tous les possesseurs d'anciens objets en bois sculpté ou en marqueterie ayant valeur d'art " pour ces expositions, auxquelles participèrent de nombreux amateurs d'art ${ }^{20}$.

Ce n'est qu'à la mort de Fortuny que Simonetti entreprit une réelle activité de collectionneur et d'antiquaire. Celle-ci était orientée par le succès, en 1883, de l'exposition-vente de sa propre collection d'antiquités et d'objets d'art au Palazzo Teodoli de la Via del Corso à Rome, dont le livret, comprenant mille deux cents lots, est resté célèbre ${ }^{21}$. Grâce à son sens aigu de la recherche de l'objet rare, Simonetti fit d'importantes découvertes. Il acquit une notoriété croissante et une place éminente dans le commerce de l'art à Rome, ayant su établir de solides relations de confiance avec certains des plus prestigieux musées étrangers et avec un noyau d'amateurs 
importants, parmi lesquels Riccardo Gualino (1879-1964) ${ }^{22}$, propriétaire d'une collection de textiles remarquables, acquise en 1940 par le Musée civique de Turin.

14 Après la mort de l'antiquaire romain, une grande vente est organisée, en 1932, des derniers tableaux, meubles et objets d'arts de sa collection -se trouvant jusque-là au numéro 11 de la Via Vittoria Colonna à Rome, au palais Odescalchi, qu'il avait acquis en $1904^{23}$ et où la galerie est demeurée. Le cachet de la galerie Simonetti, avec son adresse romaine, figure au dos d'une photographie en noir et blanc conservée à la Villa Ephrussi de Rothschild. Celle-ci présente un encadrement de porte surmonté d'un tympan semi-circulaire avec des chambranles formés de deux colonnettes à chapiteaux corinthiens ${ }^{24}$. Elle se rapporte à la grande porte en bois doré et peint à ornements saillants, supportant, dans un tympan en demi-cercle, une peinture de la Vierge à l'Enfant entourée de deux anges, œuvre aujourd'hui exposée dans le patio de la Villa Ephrussi de Rothschild (inv. EdR826) (fig. $7 a$ et $7 b$ ). Selon l'usage et comme le précisait déjà la galerie Sangiorgi, « la galerie envoie sur simple demande des photographies en grande dimension des objets et de tous ceux qui enrichissent son importante collection ». Cette pratique, qui se confirme ici, démontre les liens d'affaires de Béatrice Ephrussi avec ses commissionnaires italiens.

7a. Encadrement de porte, c. 1910, au dos un cachet indique : « Galleria Simonetti/Roma/11 via Vittoria Colonna ", archives de la Villa Ephrussi, pl. 10-13, Saint-Jean-Cap-Ferrat, Villa Ephrussi de Rothschild.

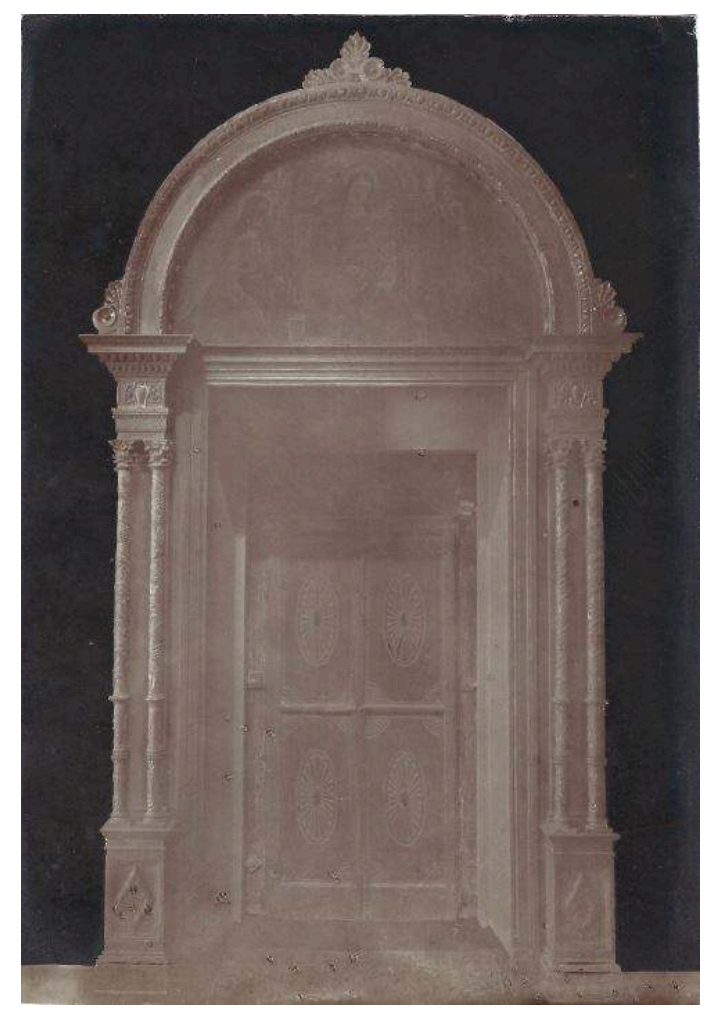

(C) Villa Ephrussi de Rothschild 
7b. Encadrement de porte surmonté d'une peinture représentant la Vierge et l'Enfant, Saint-Jean-Cap-Ferrat, Villa Ephrussi de Rothschild, inv. EdR826.

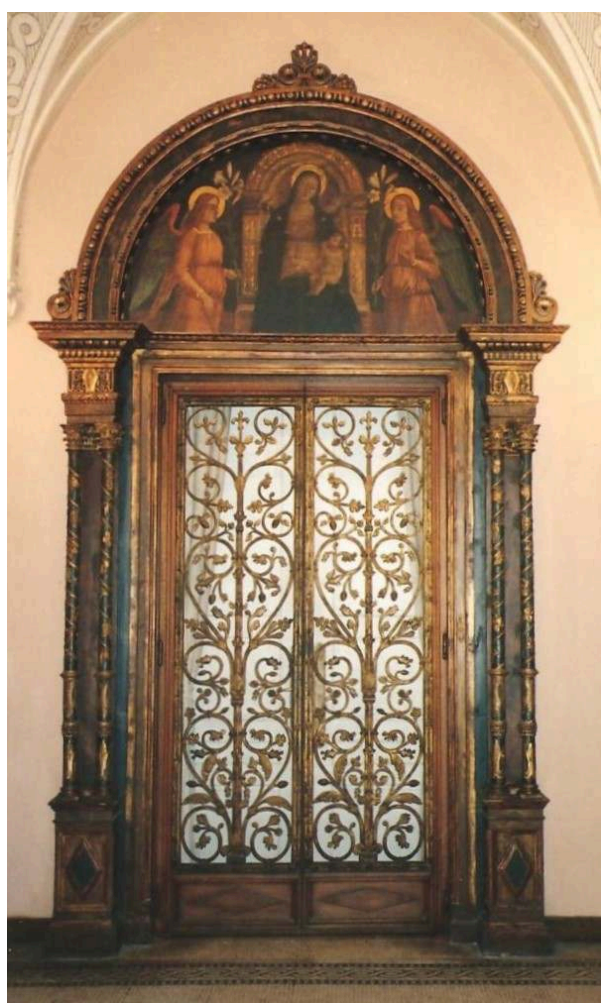

(c) Villa Ephrussi de Rothschild

Pour l'embellissement de l'intérieur de la Villa île-de-France et son aménagement en mobilier, Béatrice Ephrussi entretint aussi des relations d'affaires avec Antonio Salvadori, antiquaire à Venise, installé vers 1900 au Palazzo Moro-Lin, palais de style baroque situé sur le Grand Canal. Henri de Régnier (1864-1936), amateur d'antiquités et admirateur de Fortuny, qui se rendait régulièrement à Venise depuis 1899, comme hôte de la comtesse de La Baume-Pluvinel (1858-1911) au palais Dario, soulignait dans Images vénitiennes "qu'il y a beaucoup d'antiquaires ici. Certains mêmes occupent tous les étages d'un palais et l'encombrent de mille choses curieuses et vieilles...25 » Pensait-il à Antonio Salvadori, à son ami l'antiquaire Dino Barozzi, installé au palais Carminati, ou à l'un de ces marchands vénitiens très actifs dans le commerce d'art, en développement exponentiel au début du $\mathrm{xx}^{\mathrm{e}}$ siècle, qui se spécialisaient dans la vente des reliques de la gloire de Venise?

Salvadori y bénéficie d'une notoriété affirmée pour la qualité et la valeur des œuvres rassemblées dans son commerce d'art. Certaines sont mentionnées dans les catalogues de ventes de collections prestigieuses, comme celle de Cristoforo Benigno Crespi (1833-1920), où figurait un tableau de la Sainte Famille par Francesco Caroto (1480-1555), acquis auprès de l'antiquaire Antonio Salvadori de Venise ${ }^{26}$. L'antiquaire est engagé dans la vie artistique de sa ville. Il participe à la souscription ouverte pour l'acquisition d'une pièce de damas destinée à la salle du Conseil des Dix du Palais ducal ${ }^{27}$. Son nom est cité dans tous les bons guides utiles aux amateurs d'art, comme l'Annuaire de la curiosité et des beaux-arts ${ }^{28}$, le Handbook for Travellers de l'Italie du Nord de Karl Baedeker ${ }^{29}$ ou le Souvenir de Venise. Guide historique illustré de Ferdinand Baccovich ${ }^{30}$, qui le mentionne comme étant un cabinet d'antiquités au palais Moro-Lin. 

en juillet 1914, date à laquelle ce dernier intente à sa cliente un procès au tribunal de la Seine pour non-paiement d'honoraires et de frais. Durant l'assistance de Salvadori, c'est-à-dire pendant près de six ans, Béatrice Ephrussi acquit pour 18 674,30 francs d'objets d'art auprès de ce dernier. Par le jugement rendu par le tribunal de la Seine le 10 juillet 1914, «il apparaît que M. Salvadori a reçu de la baronne Ephrussi de multiples missions d'ordre les plus divers, soit pour conférer avec les architectes, sculpteurs, marbriers, décorateurs ou fabricants de céramiques, notamment pour les poses des fenêtres, pilastres ou portes de la villa [...]. Il s'est occupé de la mise en place des cheminées, fenêtres, grilles, plafonds, portes ou autres objets dont il n'avait pas été le fournisseur ${ }^{31}$. P Parmi les griefs avancés, le tribunal s'enquiert de l'affaire dite des quarante-quatre fresques de Tiepolo, non livrées par Salvadori à Béatrice Ephrussi. Des fresques de Giandomenico Tiepolo (1727-1804) - peintes entre 1759 et 1797 dans la tradition pulcinellesque et provenant de la villa du peintre à Zianigo - avaient été acquises en 1906 par l'antiquaire Antonio Salvadori. Ce dernier les avait fait enlever par Franco Steffanoni ${ }^{32}$, restaurateur de Bergame, réputé pour le transfert de fresques, afin de les vendre en France. Les fresques ont été transférées à Bergame et montées individuellement sur des supports en tissu avec des cadres de bois : elles étaient donc prêtes à partir en France. Mais l'opinion publique s'en est offusquée, amenant l'État italien et la Ville de Venise à acquérir, en 1908, ces chefs-d'œuvre de Tiepolo pour les exposer au musée Correr et, depuis 1936, au Museo del Settecento à Ca'Rezzonico.

La dépose de fresques ou de peintures de plafonds de palais vénitiens n'était pas rare à cette époque, c'est le cas de la fresque transposée sur toile attribuée à Costantino Cedini (1741-1811), aujourd'hui conservée à la Villa Ephrussi de Rothschild (inv. EdR363). Elle représente L'Apothéose de la famille Garzoni (c. 1780) et provient du palais Garzoni à Venise, où elle ornait le plafond du Portego. Elle a été détachée à une date inconnue et remplacée par une copie, opération qui pourrait être due également à une possible intervention d'Antonio Salvadori ${ }^{33}$.

19 Compte tenu de l'importance des relations de Béatrice Ephrussi avec les marchands d'art italiens - Giuseppe Sangiorgi, Attilio Simonetti et Antonio Salvadori-, il est probable que les meubles de facture italienne aient été acquis par l'intermédiaire de l'un d'entre eux, d'autant que le marché du mobilier italien était très peu développé en France au début du xx ${ }^{e}$ siècle. Le mobilier piémontais de la fin du XVIII siècle, conservé à la Villa Ephrussi de Rothschild, ne semble pas provenir directement du commerce d'art de Turin, qui n'était pas suffisamment développé en 1910. Ce n'est que beaucoup plus tard qu'un antiquaire de l'envergure de Pietro Accorsi (1891-1982) ouvrit son commerce sur la Via Po et s'intéressa au mobilier turinois, bien qu'il ait commencé cette activité dès l'âge de 18 ans. Béatrice Ephrussi bénéficiait donc d'un réseau considérable et solide en Italie lui permettant d'acquérir des œuvres d'art qui n'avaient pas encore attiré les amateurs. Il est utile de remarquer que le mobilier italien de la collection est en grande partie d'exécution piémontaise, de facture fort différente de celle que l'on trouvait à Gênes ou à Milan. Le goût de Béatrice n'était partagé par aucun des collectionneurs de la Riviera, ni par le comte de Belinet, la baronne de Bucamps, le comte de Montaldo, ancien secrétaire de la légation de Sardaigne, qui s'intéressaient aux peintures, meubles ou objets d'art classiques français, ni même par le comte polonais Leliwa de Rohozinski, intime du prince Louis-Napoléon, dont la passion pour les dessins de Félicien Rops ${ }^{34}$ n'avait pas d'égal. 
mobilier piémontais de la fin du XVIII ${ }^{e}$ siècle et du début du XIX ${ }^{e}$ siècle a connu une grande vogue à Turin, où les ébénistes étaient soutenus par les ducs de Savoie, de Victor-Amédée III (1726-1796) à Charles-Félix (1765-1831), grands ordonnateurs de l'ameublement des résidences de la famille royale de Savoie à Turin (Residenze Sabaude) et dans le Piémont. Le plus connu de ces ébénistes est Giuseppe Maria Bonzanigo (1745-1820), promoteur du meuble néoclassique. Il s'installe à Turin en 1773 et devient membre de la prestigieuse Pia Società e Sodalizio di San Luca l'année suivante. Pendant vingt ans, il travaille comme sculpteur et ébéniste pour une clientèle importante, dont la Maison de Savoie. Il est nommé sculpteur du roi de Sardaigne Victor-Amédée III en 1787, titre qu'il conserve jusqu'à l'invasion française de 1796 et qu'il retrouve après la chute de Napoléon I ${ }^{\text {er }}$, en 1815 , jusqu'à sa mort en 1820 . Il assoit sa réputation sur la finesse particulière de sa «microsculpture", faite de buis et d'autres bois, ainsi que sur la fabrication de meubles, certes plus classiques, mais d'une aussi délicate facture. Beaucoup de pièces de mobilier comportant ces caractéristiques lui ont été attribuées, notamment une commode en bois doré (fig. 8) présente dans les collections de la Villa Ephrussi (inv. EdR126), que l'on peut désormais identifier comme un travail de Francesco Bolgié (1752-1834) 35 .

8. Francesco Bolgié, commode en bois doré, Turin, c. 1780, Saint-Jean-Cap-Ferrat, Villa Ephrussi de Rothschild, inv. EdR126.

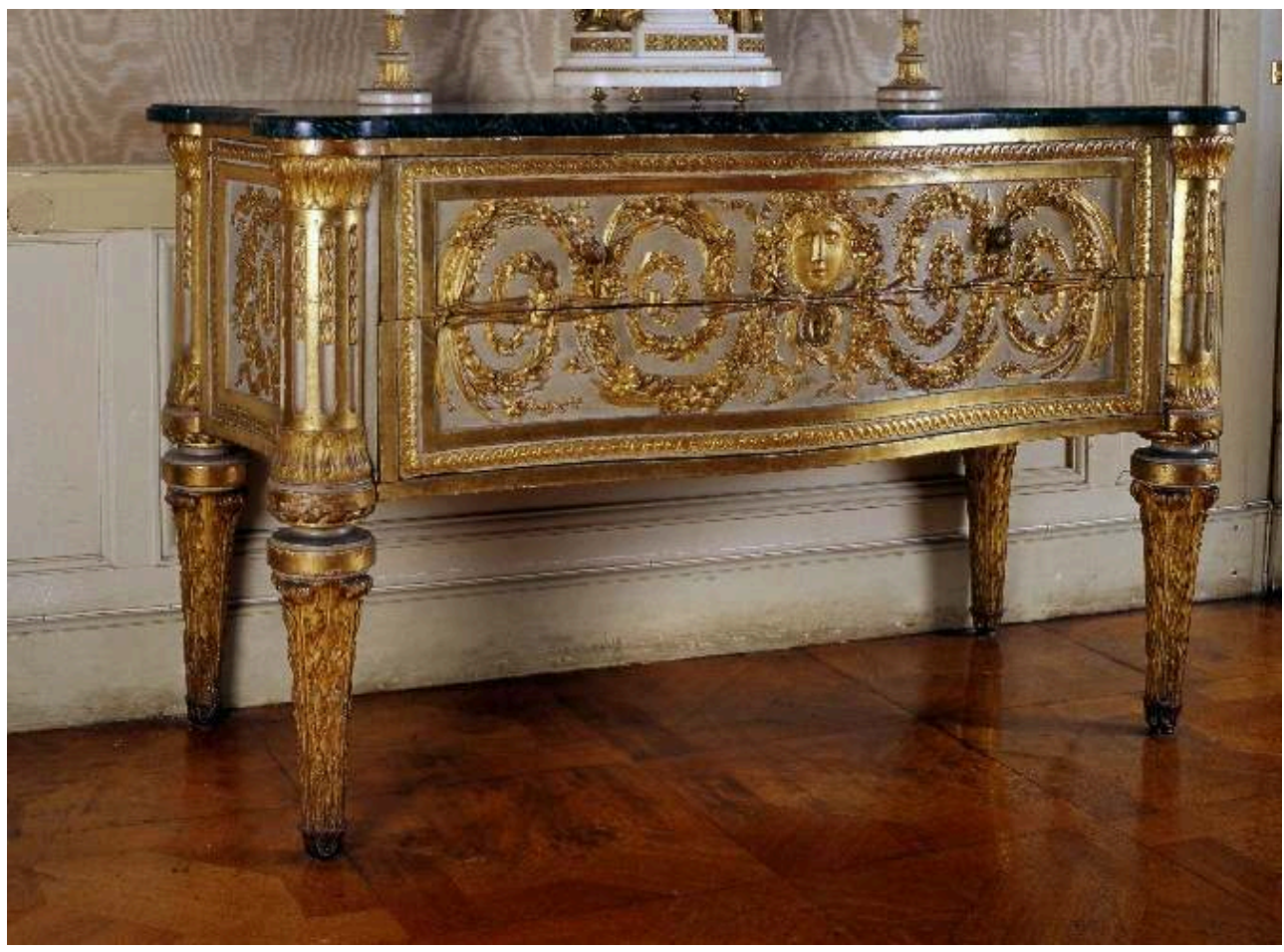

(C) Villa Ephrussi de Rothschild

21 Elle possède tous les caractères distinctifs du mobilier piémontais : une riche sculpture décorative de rinceaux et de volutes, des montants fortement soulignés et des pieds massifs et ventrus dans sa partie supérieure. Cette commode présente la singularité de conserver, partiellement collé sur les tiroirs, un papier marbré de l'époque du $\mathrm{XVIII}^{\mathrm{e}}$ siècle. Le père de Francesco Bolgié travaillait déjà pour la Maison de Savoie, comme ornemaniste pour les carrosses du roi de Sardaigne. Francesco Bolgié se 
perfectionne à Paris dans les années 1770 et est très tôt repéré par Victor-Amédée III, qui le fait revenir à Turin, où il obtient, en 1775 , le titre de sculpteur du roi ${ }^{36}$. Jouissant dès lors d'une notoriété croissante, il est chargé, avec la collaboration de Giuseppe Maria Bonzanigo, de la réalisation des appartements de la reine du Palazzo Reale de Turin. Il participe à la décoration des salons du remarquable Palazzina di Cacciade Stupinigi, édifié vers 1730 , ce qui reste sa plus grande contribution dans le domaine des arts décoratifs. Le mobilier d'origine de ce pavillon de chasse comprend des chefsd'œuvre d'ébénistes du Piémont, tels que Pietro Piffetti, Luigi Prinotto, Giuseppe Maria Bonzanigo et Francesco Bolgié. Plus tardivement et dans le pur style néoclassique, Francesco Bolgié réalise vers 1812 une paire de canapés pour la Villa della Regina, construite sur la colline turinoise, dont la décoration et l'ameublement des salons reflètent le goût pour les arts précieux qui est en vogue dans les cours européennes. Au lendemain de la Restauration, Francesco Bolgié et Giuseppe Maria Bonzanigo continuent de répondre à des commandes et sont sollicités pour la réalisation de la nouvelle salle de bal du Palais royal. La Villa Ephrussi conserve une commode en demilune en noyer sculpté et peint (1790), acquise par Béatrice Ephrussi (fig.9) et bénéficiant d'un rendu d'une grande finesse de sculpture, caractéristique du style de Bolgié. La forme en demi-lune se retrouve sur une autre commode à placage de bois de rose, embellie de bronzes dorés dans le style néoclassique propre au mobilier piémontais et exécutée dans le style de Giuseppe Antonio Viglione, ébéniste turinois et fournisseur de meubles pour les résidences royales, dont le château de Rivoli à la fin du $\mathrm{XVIII}^{\mathrm{e}}$ siècle $^{37}$. En raison de sa proximité géographique et historique, le Piémont a subi l'influence des arts décoratifs français, que l'on perçoit singulièrement dans les créations du mobilier turinois. Les ébénistes étaient en contact fréquent avec la France et certains poursuivaient leur formation à Paris. 
9. Commode demi-lune en bois peint, Turin, c. 1790, Saint-Jean-Cap-Ferrat, Villa Ephrussi de Rothschild, inv. EdR1569.

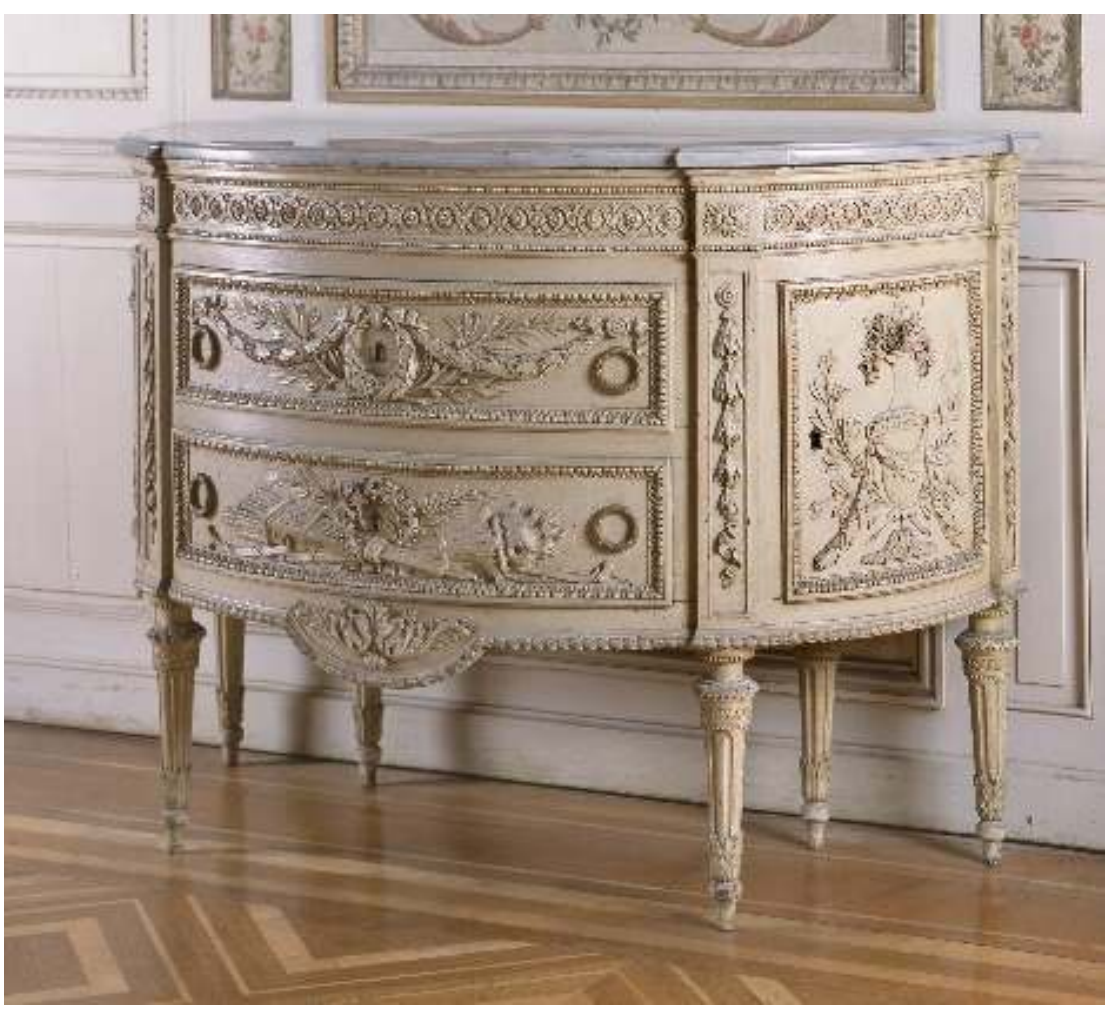

(c) Villa Ephrussi de Rothschild/Photographie Georges Véran

Dans les collections de la Villa Ephrussi se trouvent également une console à pieds torsadés en bois sculpté et doré et à entretoise surmontée d'une lyre ${ }^{38}$, et une paire de tables d'encoignure en bois sculpté doré et peint ${ }^{39}$, probablement exécutées par Bolgié. Une délicate paire de banquettes en bois doré finement sculpté (inv. EdR144-145) et un écran de cheminée, chef-d'œuvre de sculpture décorative en bois doré surmonté d'un cartouche monogrammé (inv. EdR154), font également partie de ces meubles de la Villa Ephrussi créés en Piémont à la fin du XviII ${ }^{e}$ siècle. D’autres exécutés en Émilie-Romagne, en Lombardie, dans la région des Marches ou à Naples complètent cette collection inattendue à Saint-Jean-Cap-Ferrat. Elle est enrichie de quelques commodes élégantes, témoignage de la production de mobilier «arte povera » italienne de la seconde moitié $\mathrm{du} \mathrm{xVIII}^{\mathrm{e}}$ siècle. Cette réunion exceptionnelle de meubles italiens forme certainement l'un des ensembles les plus riches de France. Béatrice Ephrussi, bien qu'elle soit entourée de collectionneurs particulièrement avisés dans sa famille, ne semble pas avoir souhaité seulement collectionner du mobilier et des œuvres, mais bien davantage créer un intérieur à son goût - avec ses meubles, ses peintures, ses sculptures, ses tapisseries, ses porcelaines -, donnant, au gré des années, libre cours à ses envies d'objets d'art et de fantaisie. 


\section{NOTES}

1. Sur les demeures de la famille Rothschild, voir Pauline Prevost-Marcilhacy, Les Rothschild, bâtisseurs et mécènes, Paris, Flammarion, 1995. Sur l'ensemble des collections de la Villa Ephrussi de Rothschild, voir Pauline Prevost-Marcilhacy (dir.), Les Rothschild. Une dynastie de mécènes en France, 3 vol., Paris, Louvre/BnF/Somogy, 2016, et notamment les dix textes dédiés aux collections de la Villa Ephrussi de Rothschild, vol. II, p. 258-381; et Régis Vian des Rives (dir.), La Villa Ephrussi de Rothschild, Paris, Éditions de l'amateur, 2002. Par ailleurs, dans le cadre du programme «Les collections Rothschild dans les institutions publiques françaises ", l'INHA a publié dans la base de données Agorha les inventaires des tableaux et des dessins, du mobilier, de la sculpture médiévale et de la porcelaine de la Villa Ephrussi, rédigés respectivement par Esther Moench, Ulrich Leben, Philippe Malgouyres et Guillaume Séret. Les recherches et les identifications sur le mobilier italien doivent beaucoup à Giulio Ometto, président de la Fondazione Accorsi-Ometto à Turin, à Luca Mana, conservateur des collections, à Stéphane Pêpe, expert CNES, et à Arianna Cocco, que nous remercions chaleureusement.

2. . Elle est classée " monument historique » en 1996 et labélisée " patrimoine du Xxe siècle » en 2010.

3. . Cet aspect a été évoqué en partie par Ulrich Leben, «Le XVIII ${ }^{\mathrm{e}}$ siècle à la villa Ephrussi de Rothschild, 1933 », dans Pauline Prevost-Marcilhacy (dir.), Les Rothschild. Une dynastie de mécènes en France, op. cit., vol. II, p. 286-315. Les restaurations sont entreprises par l'Académie des beauxarts avec le soutien de la Fondation du patrimoine et coordonnées par Louis Mézin, conservateur en chef des collections.

4. . La façade sud n'est pas sans rappeler l'ordonnancement des ouvertures en arcade du palais Vendramin Calergi ou du palais Corner Spinelli du Xvi ${ }^{\mathrm{e}}$ siècle à Venise.

5. . Michel Stève, Italianismes en architecture. La Riviera de 1840 à 1940, Nice, Grandi, 2000.

6. . Comme le montre le portail d'entrée de la Villa Ephrussi de Rothschild en cours de construction, visible sur une photographie du chantier, vers 1909. Archives de la Villa Ephrussi de Rothschild, Série 8, Pl. 8-5.

7. . Centre d'archives de la Cité de l'architecture et du patrimoine, Dossier 044 Ifa 1. Doc. 44-01-001.

8. . Lettre de Gustave Majou, 21 mai 1910. Archives de la Villa Ephrussi de Rothschild.

9. . La maison Charles Fournier, créée en 1875, participe à la réalisation des boiseries pour le Palais rose de Boniface de Castellane et pour la Villa Ephrussi de Rothschild. Voir Axelle Corty, "Féau et C Ce. Boiseries et décors ", dans Connaissance des arts, hors-série, n 479, 2011, p. 6.

10. . Lettre de Gustave Majou, 14 juin 1910. Archives de la Villa Ephrussi de Rothschild.

11. . Agence photographique fondée à Florence en 1852 et spécialisée dans la photographie d'œuvres d'art et de monuments historiques de l'Italie. Elle édite des photographies de Carlo Naya (1816-1882). Voir André Fermigier, Les Alinari, photographes à Florence (1852-1920), cat. exp. (Paris, Centre Pompidou, 1978-1979), Paris, Bibliothèque publique d'information, 1978 ; Arturo Quintavalle et Monica Maffioli, Fratelli Alinari, fotografi in Firenze. 150 anni che illustrano il mondo 1852-2002, cat. exp. (Florence, Palazzo Strozzi, 2003), Florence, Alinari, 2013; voir également alinari.it.

12. Photographie avec cachet au dos "Bonivento Marcello/Scultore ornementale/Venezia ", Archives de la Villa Ephrussi de Rothschild, pl.10-21. Les modèles en bois sculpté portent les numéros d'inventaire EdR1119, EdR1120, EdR1157, EdR1158, EdR1159 et EdR1160.

13. Antonio Zanussi est associé à la création du sol en mosaïque du cirque municipal d'Amiens, inauguré par Jules Verne en 1889 , et à la restauration, en 1885 , de la grande mosaïque de Lillebonne (Seine-Maritime) d'époque romaine, découverte en 1870, actuellement conservée au 
musée des Antiquités de Rouen. Voir Jean-Pierre Darmon, «Les restaurations modernes de la grande mosaïque de Lillebonne (Seine-Maritime)», Dans Gallia, Paris, CNRS, 1978, t. 36-1, p. 65-88; Xavier Barral y Altet, "Un aspect du renouveau de la mosaïque en France au $\mathrm{XIX}^{\mathrm{e}}$ siècle : la découverte et la restauration des mosaïques médiévales ", dans Comptes rendus des séances de l'Académie des inscriptions et belles-lettres, Paris, De Boccard, 1985, 129e année, $\mathrm{n}^{\circ} 4$, p. $780-862$.

14. Au sujet du commerce d'art, voir Lynn Catterson, Dealing Art on Both Sides of the Atlantic (1860-1940), Leyde, Brill, 2017.

15. La galerie Sangiorgi était située au 117 Via di Ripetta à Rome, actuellement ambassade d'Espagne. Voir Julia Barnighausen, The Galleria Sangiorgi in Rome: A Case Study on Photographic Practices in $19^{\text {th }}$ and early $20^{\text {th }}$ Century Art-Dealing, Florence, Kunsthistorisches Institut/Max-Planck Institut, 2018 ; Debora Loiacono, «Collezionismo e mercato artistico a Roma tra '800 e ' 900 : la Galleria Sangiorgi », thèse de maîtrise, Université de Bologne, 2008.

16. Le nom de Béatrix Ephrussi apparaît dans le catalogue de la galerie Sangiorgi en 1912 et en 1913.

17. Catalogue des objets d'art et d'ameublement du château royal de Govone et du château de Brignano (ancienne maison Visconti) et d'une collection d'objets ayant appartenu à Napoléon I ${ }^{\text {er }}$. La vente aura lieu au château de Govone sous la direction de M. le chevalier G. Sangiorgi de Rome, Unione cooperativa editrice, 1898. Voir Louis Mézin, La Villa Masséna. Du Premier Empire à la Belle Époque, Paris, Somogy, 2010, p. 19.

18. Archives de la Villa Ephrussi de Rothschild, pl. 10-21. La poursuite de nouvelles recherches et l'exploitation minutieuse des archives de la galerie Sangiorgi - conservées à la Fondation Federico Zeri-permettraient certainement de mieux cerner l'ampleur des acquisitions effectuées et la relation exacte entre le marchand d'art et la collectionneuse, Giuseppe Sangiorgi et Béatrice Ephrussi.

19. Sabrina Spinazze, « Artisti-antiquari a Roma tra la fine dell'Ottocento e l'inizio del Novecento: lo studio e la galleria di Attilio Simonetti ", dans Studiolo, Académie de France à Rome, $\mathrm{n}^{\circ}$ 8, 2010, p. 103-122. Giovanni Carboni, "Attilio Simonetti, pittore e antiquario romano, e via Margutta ", dans Valentina Mondaca di Paterno, Atelier a via Margutta. Cinque secoli di cultura internazionale a Roma, Turin, Allemandi, 2012.

20. Pierre de Nolhac, "L'exposition du bois sculpté à Rome", dans la Gazette des beaux-arts, $1^{\mathrm{er}}$ juin 1885, p. 540-544.

21. Catalogue des objets d'art et de haute curiosité composant la collection de M. le chevalier Attilio Simonetti, artiste peintre, dont la vente aura lieu à Rome sous la direction de M. Vincenzo Capobianchile 16 avril et jours suivants 1883

22. . Entrepreneur et collectionneur d'art, Riccardo Gualino était mécène et promoteur des artistes. Le siège turinois de Gualino fut un cénacle où se retrouvaient écrivains et peintres, tels Luigi Pirandello (1867-1936), Benedetto Croce (1866-1952), Ugo Ojetti (1871-1946) ou Jessie Boswell (1881-1956).

23. . Charles L. Hutchinson, qui avait acquis chez Simonetti la fameuse tête en marbre d'Antinous, en fit don en 1924 à l'Art Institute de Chicago (inv. 1924.979), tout comme du tapis réalisé sous la dynastie des mamelouks et désigné du nom de Carpet Simonetti en l'honneur de son ancien propriétaire. Celui-ci, considéré comme le plus fameux revêtement de sol de l'Égypte ancienne, est entré dans les collections du Metropolitan Museum de New York (inv. 1970.105) en 1970, après avoir fait partie des collections de la galerie Sangiorgi de Rome. Ludwig Pollak, Collezioni Simonetti: quadri, mobili e oggetti d'arte: Catalogo... degli oggetti che verranno posti in vendita alla pubblica auzione in Roma, via Vittoria Colonna 11, Roma, Casa di Vendite G. Tavazzi, 1932.

24. . Archives Villa Ephrussi de Rothschild, Pl. 10-13. Sur les tableaux italiens de la Villa Ephrussi, voir Esther Moench, «Peintures italiennes et espagnoles, 1933 », dans Pauline PrevostMarcilhacy (dir.), Les Rothschild. Une dynastie de mécènes en France, op. cit., vol. II, p. 272-285. 
25. Henri de Régnier, Images vénitiennes, Paris, Fontemoing et $C^{\mathrm{ie}}, 1912$.

26. Catalogue des tableaux anciens des écoles italienne, espagnole, allemande, flamande et hollandaise composant la galerie Crespi de Milan dont la vente aura lieu le 4 juin 1914, Paris, galerie Georges Petit, p. 36. La galerie de l'Académie à Venise conserve une Vierge à l'Enfant de Paolo Veneziano, acquise en 1913 de l'antiquaire Salvadori (inv. 786), et le Metropolitan Museum de New York, une statue véronaise $\mathrm{du} \mathrm{XV}^{\mathrm{e}}$ siècle en marbre provenant de la collection Théodore M. Davis (inv. 30-95-138). 27. . Max Ongaro, Le Palais des Doges de Venise, traduction de Maria Da Rin, Venise, Borin, Dal Poz $\& C^{\text {ie }}, 1923$, p. 108.

28. Annuaire de la curiosité et des beaux-arts, Paris, 1911.

29. Karl Baedeker, Northern Italy, including Leghorn, Florence, Ravenna and routes through France, Switzerland, and Austria: handbook for travellers, Leipzig/Londres/New York, Karl Baedeker/T. Fisher Unwin/Charles Scribner's Sons, 1913.

30. Ferdinand Baccovich, Souvenir de Venise. Guide historique illustrée (sic), Venise, 1903.

31. . Compte rendu donné par le journal Le Matin, vendredi 3 juillet 1914 et vendredi 10 juillet 1914.

32. . Il faut souligner le rôle central de Franco Steffanoni en tant que restaurateur spécialisé dans le transport et le transfert des fresques de Tiepolo, notamment lors de la destruction de la fresque de Giambattista Tiepolo de l'église vénitienne Santa Maria di Nazareth (chiesa degli Scalzi), causée par une bombe autrichienne le 24 octobre 1915. Voir Cristina Giannini, "Attilio Steffanoni restauratore e antiquario. Un diario inedito ", dans Alessandro Rovetta et Gianni Carlo Sciolla (dir.), Francesco Malaguzzi Valeri (1867-1928), actes de colloque (Milan, 2011 ; Bologne 2011), Sagrate, Scalpendi, 2014, p. 205-216; Cristina Giannini, «Franco Steffanoni per Giambattista Tiepolo ", dans Giulio Manieri et Chiara Piva (dir.), Tiepolo e la prima guerra mondiale : dagli Scalzi alle Gallerie dell'Accademia, Florence, Edifir, 2017, p. 71-79.

33. Voir Esther Moench, « Peintures italiennes et espagnoles, 1933 », art. cit., t. II, p. 272-285.

34. Annuaire de la curiosité et des beaux-arts, amateurs, collectionneurs et bibliophiles du département des Alpes-Maritimes, Paris, 1921, p. 189-191.

35. Roberto Antonetto, Il mobile Piemontese nel Settecento, Turin, Allemandi, 2010, p. 327.

36. Mémoires et documents publiés par la Société savoisienne d'archéologie et d'histoire, Chambéry, Albert Bottero, 1873, t. XIV, p. 259.

37. . Saint-Jean-Cap-Ferrat, Villa Ephrussi de Rothschild, inv. EdR1806. Voir Giancarlo Ferraris, Pietro Piffetti e gli ebanisti a Torino (1670-1838), Turin, Allemandi, 1992, p. 249-251.

38. . Saint-Jean-Cap-Ferrat, Villa Ephrussi de Rothschild, inv. EdR214.

39. . Saint-Jean-Cap-Ferrat, Villa Ephrussi de Rothschild, inv. EdR344-345.

\section{INDEX}

Index géographique : France, Italie

Index chronologique : XXe siècle

Thèmes : Architecture, mobilier, arts décoratifs, collections, Rothschild 
AUTEUR

LOUIS MÉZIN

Louis Mézin est conservateur en chef et directeur de la Villa Ephrussi. 


\title{
Les loggias aux sculptures à l'antique du château de Ferrières
}

\author{
Philippe Sénéchal
}

1 L'aile est demeure la plus italianisante du quadrilatère que forme le château de Ferrières (fig. 1). Certes, plusieurs châteaux français de la Renaissance, comme Challuau ou Madrid, possédaient des galeries superposées à l'italienne, mais, dans le premier cas, elles présentaient des arcs en plein cintre et, dans le second, en anse de panier ${ }^{1}$. En France, aucune demeure du XVI ${ }^{e}$ ni du $x x^{e}$ siècle ne fit une allusion aussi marquée à l'exemple vicentin d'Andrea Palladio au palais Chiericati ${ }^{2}$. Les deux loggias superposées de Ferrières, créées par Joseph Paxton, présentent des colonnes doriques à l'étage de réception - qui est un rez-de-chaussée surélevé - et ioniques à l'étage d'habitation. Eugène Lami, chargé de l'aménagement intérieur depuis 1857, greffa sur l'architecture de Paxton de multiples allusions à la Péninsule, transformant la demeure de James de Rothschild en un palais mélangeant le faste de diverses capitales régionales d'Italie ${ }^{3}$. Le patchwork qu'il créa renvoie autant aux grandes demeures florentines qu'aux villas et aux palais de Gênes et de Rome. Ainsi que l'a fort bien défini Pauline PrevostMarcilhacy, dans les quatre demeures Rothschild qu'il décora, Lami déploya « la même quête de l'effet par la mise en scène et la perspective, le même goût pour les matériaux rares, la polychromie et la profusion ${ }^{4}$ ». Nous allons examiner la conception d'ensemble de ces deux loggias offrant une superbe vue sur le parc, en nous concentrant sur les sculptures en marbre et en terre cuite qui les ornent et sur les stratégies de présentation. 
1. Joseph Paxton, aile est, 1855-1859, Ferrières-en-Brie, château de Ferrières.

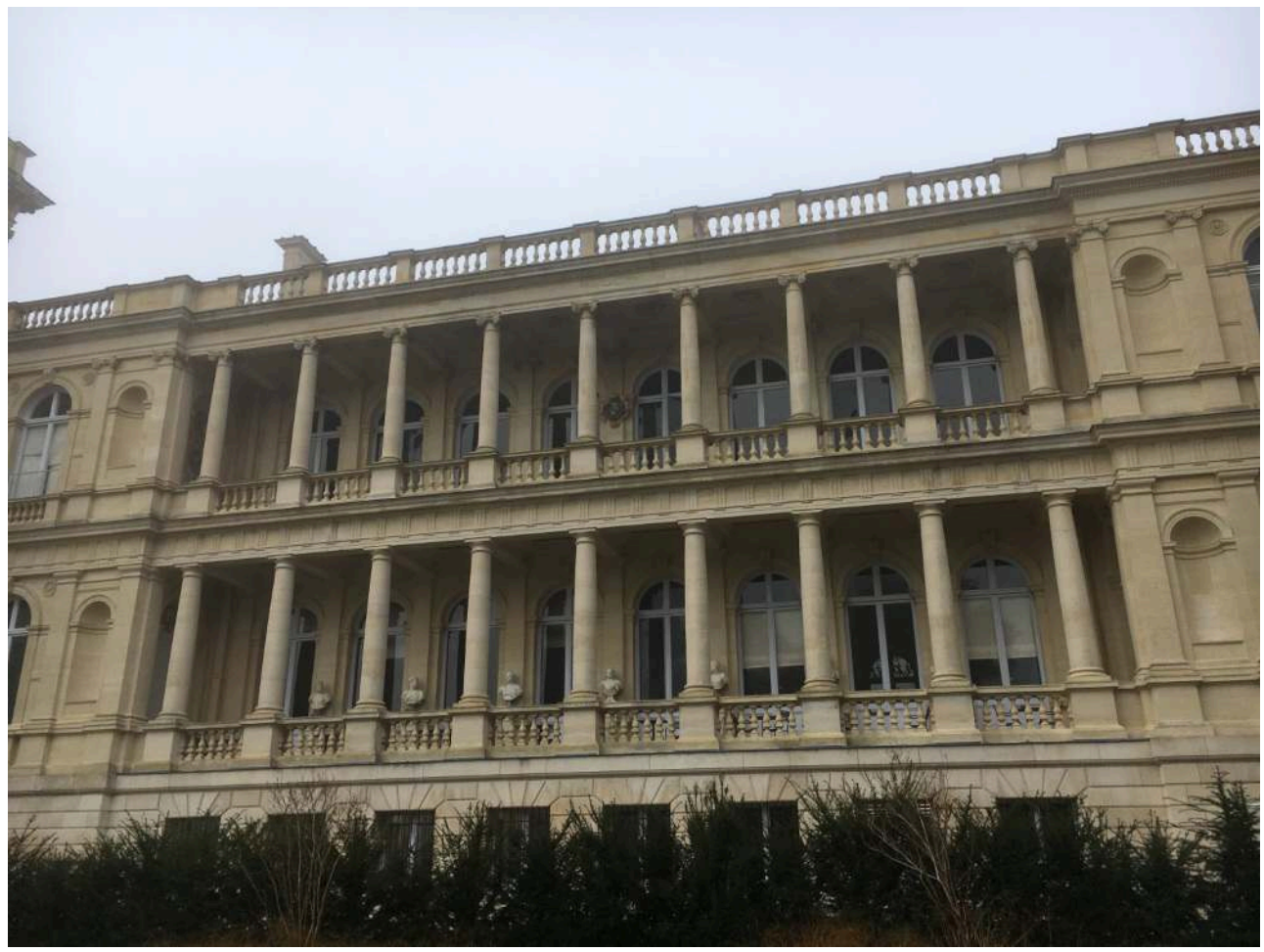

(C) Philippe Sénéchal

2. Joseph Paxton, loggia supérieure, 1855-1859, Ferrières-en-Brie, château de Ferrières.

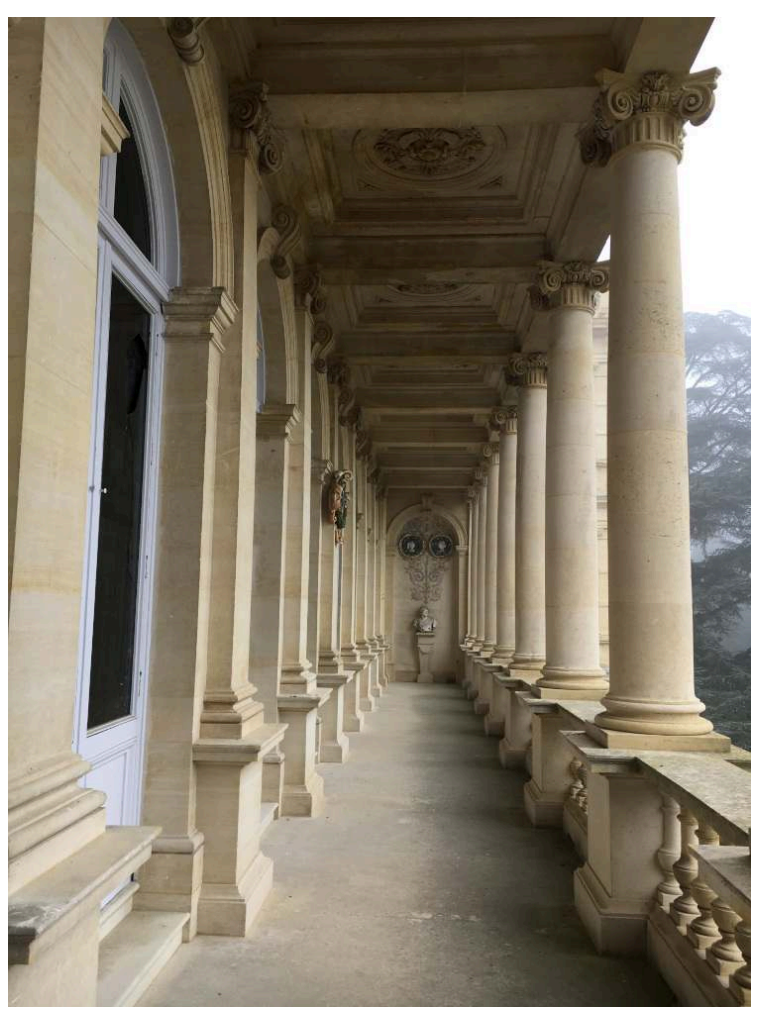

(c) Philippe Sénéchal 
La loggia supérieure sert de dégagement aux chambres (fig. 2). Assez dépouillée, elle est simplement scandée de pilastres avec un léger ressaut au-dessus de la plinthe. Du côté sud, elle est fermée par un mur au décor néo-Renaissance, peint de rinceaux violacés et gris, entre lesquels sont placés deux tondi à décor héraldique et guirlandes de fruits en terre cuite émaillée, créations du $\mathrm{xIX}^{\mathrm{e}}$ siècle dans le goût des Della Robbia ${ }^{5}$ (fig. 3). Les deux écus, au champ d'azur et aux meubles d'or, sont chromatiquement assortis. En haut, on voit les armes de la famille Contucci de Montepulciano et, en bas, celles d'azur aux trois brochets d'or - d'un casato non identifié, peut-être de la famille Iozzelli de Florence ${ }^{6}$. Les rinceaux inférieurs se terminent en griffons engainés de feuilles, de part et d'autre d'une hampe fleuronnée et entourée d'un tortil de baron, rappelant le titre du commanditaire. Entre les deux tondi, on lit dans un cartouche la date de réalisation de la galerie: 1861. Quant au médaillon supérieur, il est entouré d'un cartouche à cuirs découpés et sommé de phylactères blancs enroulés autour de l'extrémité de la hampe. Au milieu de la loggia est fixée, en hauteur, une autre terre cuite néorobbiesque $\mathrm{du}$ xIx $\mathrm{e}^{\mathrm{e}}$ siècle, au décor armorié, dans un cartouche à cuirs découpés, originellement badigeonné de blanc pour imiter le marbre (fig.4). Elle s'inspire de l'écu du Florentin Niccolò di Lorenzo Martellini, de la branche des Martellini del Falcone, exécuté en 1513 par l'atelier de Giovanni Della Robbia et fixé à la façade du palais du Podestat de Galluzzo, aux portes de Florence ${ }^{7}$. Le céramiste du $\mathrm{XIX}^{\mathrm{e}}$ siècle s'est trompé sur le métal du faucon, le mettant d'argent alors qu'il devrait être d'or (ou, au naturel, grilleté d'or), et il a ajouté aux armoiries un chef de gueules à la croix d'argent. Enfin le mur nord, également peint de guirlandes, arbore deux tondi en terre cuite émaillée, encadrés de guirlandes de fruits, qui représentent, en blanc sur fond bleu, Isotta degli Atti et Sigismondo Pandolfo Malatesta, seigneur de Rimini (fig. 5). 
3. Armoiries, $\mathrm{xIX}{ }^{\mathrm{e}}$ siècle, terre cuite émaillée, Ferrières-en-Brie, château de Ferrières, aile est, loggia supérieure.

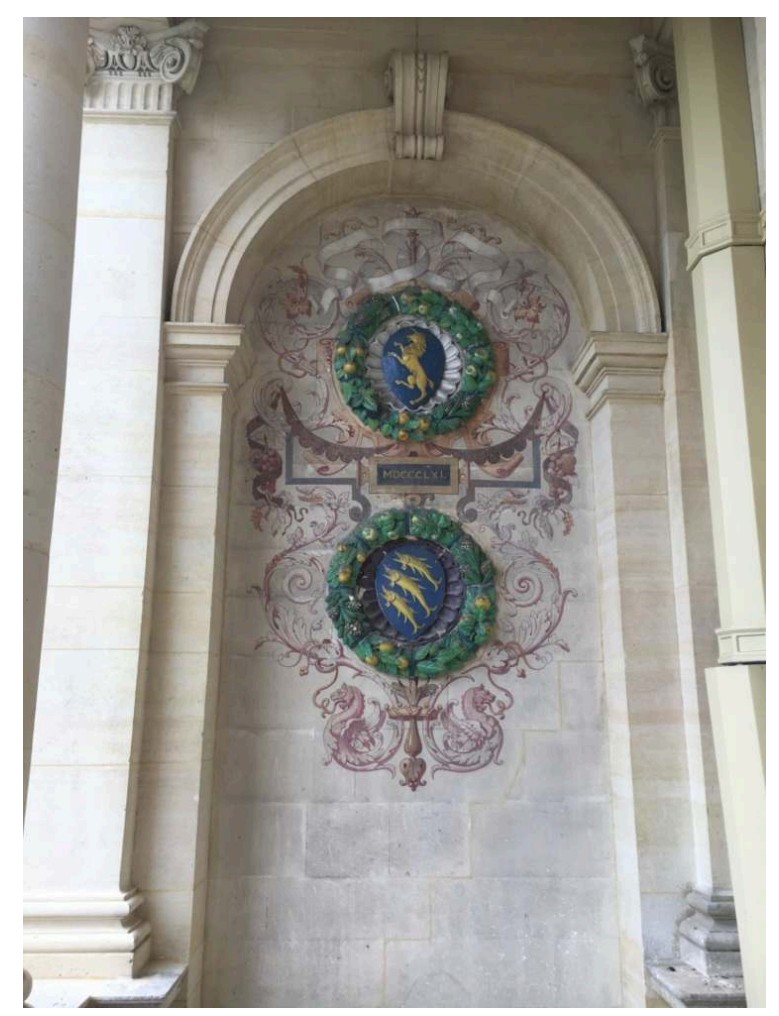

(C) Philippe Sénéchal 
4. Armoiries de la famille Martellini del Falcone, $X I X{ }^{e}$ siècle, terre cuite émaillée, Ferrières-en-Brie, château de Ferrières, aile est, loggia supérieure.

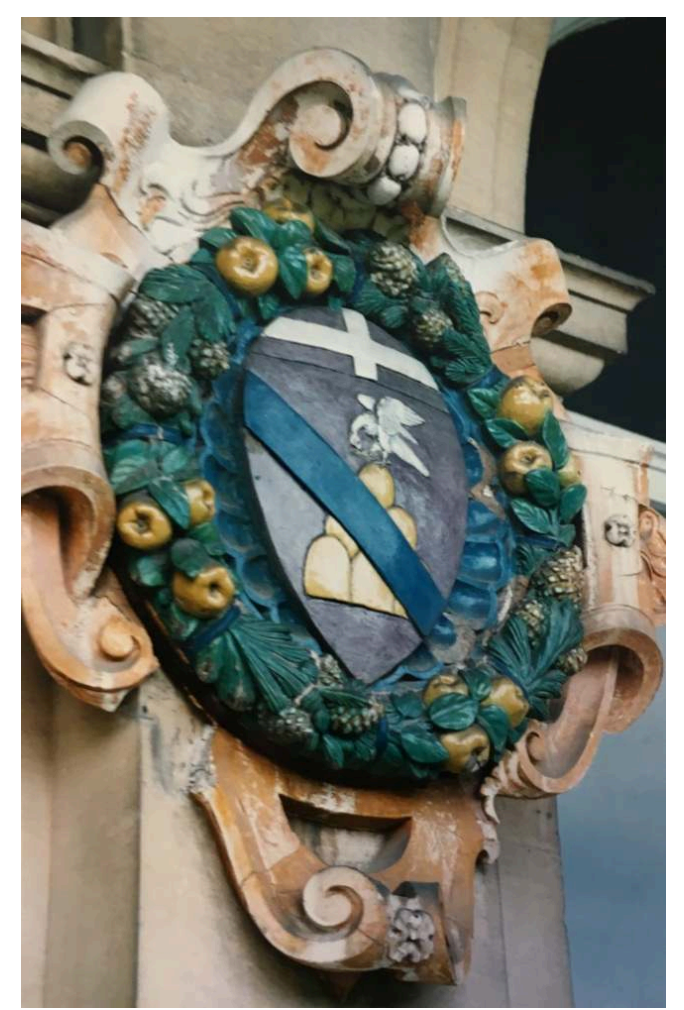

(C) Hervé Grandsart / Bibliothèque de l'INHA 
5. Isotta degli Atti et Sigismondo Pandolfo Malatesta, d'après Matteo de' Pasti, XIX ${ }^{\mathrm{e}}$ siècle, médaillons en terre cuite émaillée ; Hadrien jeune, fin XVII - début XVIII ${ }^{\mathrm{e}}$ siècle, buste, Ferrières-en-Brie, château de Ferrières, mur nord de l'aile est.

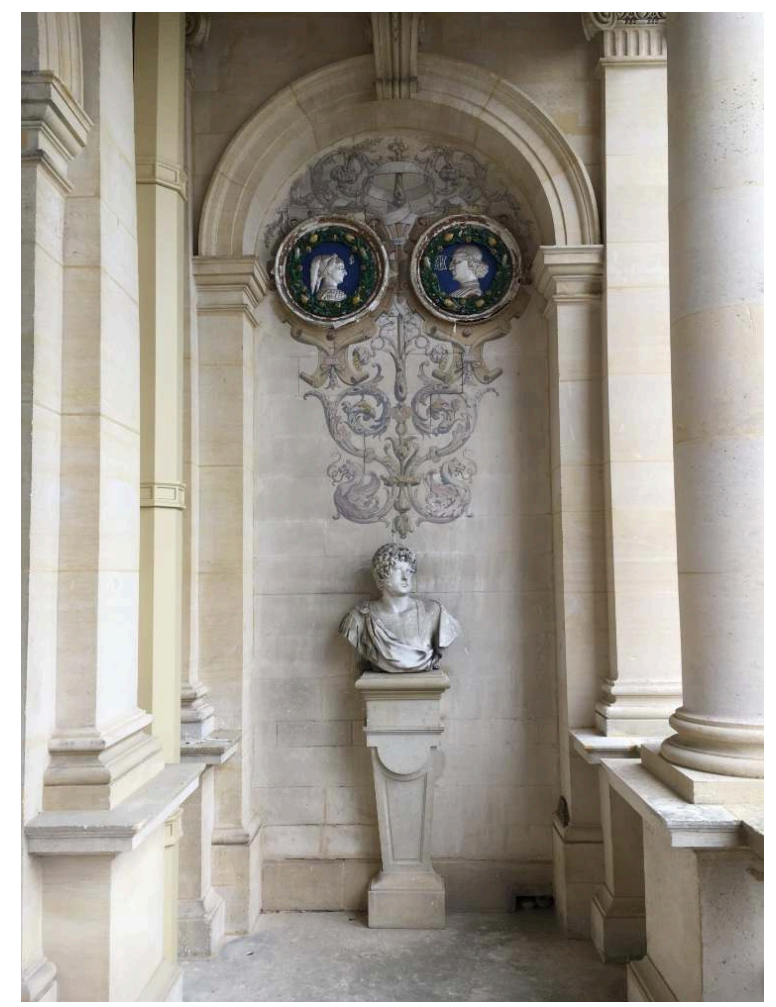

(C) Philippe Sénéchal

Ces médaillons sont de grossières copies agrandies datant $\mathrm{du} \mathrm{XIX}^{\mathrm{e}}$ siècle, réalisées d'après des médailles de Matteo de' Pasti exécutées vers $1453^{8}$. Comme cette loggia dessert les appartements privés, un hommage à la félicité conjugale d'Isotta degli Atti, fille d'un riche négociant en laine et banquier, et de l'audacieux condottiere et mécène artistique du $\mathrm{xv}^{\mathrm{e}}$ siècle que fut Sigismondo Pandolfo Malatesta, n'était pas totalement déplacé et pouvait constituer un clin d'œil aux commanditaires de Ferrières. En dessous, trône un grand buste à l'antique représentant un jeune Romain, le visage tourné vers la droite, arborant une fine moustache, des favoris et une chevelure aux boucles détachées avec virtuosité au trépan (fig. 6). Il ressemble à l'Hadrien jeune du type de la Villa Hadriana, qu'il reprend en sens inverse, et il est vêtu d'une cuirasse gravée de rinceaux et barrée d'un paludamentum retenu par une agrafe ronde sur l'épaule droite ${ }^{9}$. Son piédestal a un dessin original: au-dessous d'un profil demi-rond, un parallélépipède surmonte une gaine dont la partie supérieure plate s'achève, sur le devant, par un demi-disque et dont la partie inférieure, trapézoïdale, offre un décor de tables. Cette forme de piédestal sera également employée dans la loggia inférieure. L'Hadrien jeune de marbre a aujourd'hui perdu son piédouche carré de brèche violette, dont les morceaux sont piteusement rassemblés au dos ${ }^{10}$. Il s'agit là d'une œuvre italienne de belle qualité, sans doute de la fin du XVII ou du début du XVIII ${ }^{\mathrm{e}}$ siècle, que l'on peut rapprocher des larges bustes de divinités au visage de biais, produits à Bologne par Giuseppe Mazza (1653-1741) et son entourage ${ }^{11}$. 
6. Hadrien jeune, fin XVII ${ }^{\mathrm{e}}$ début XVIII ${ }^{\mathrm{e}}$ siècle, buste, Ferrières-en-Brie, château de Ferrières, aile est, loggia supérieure.

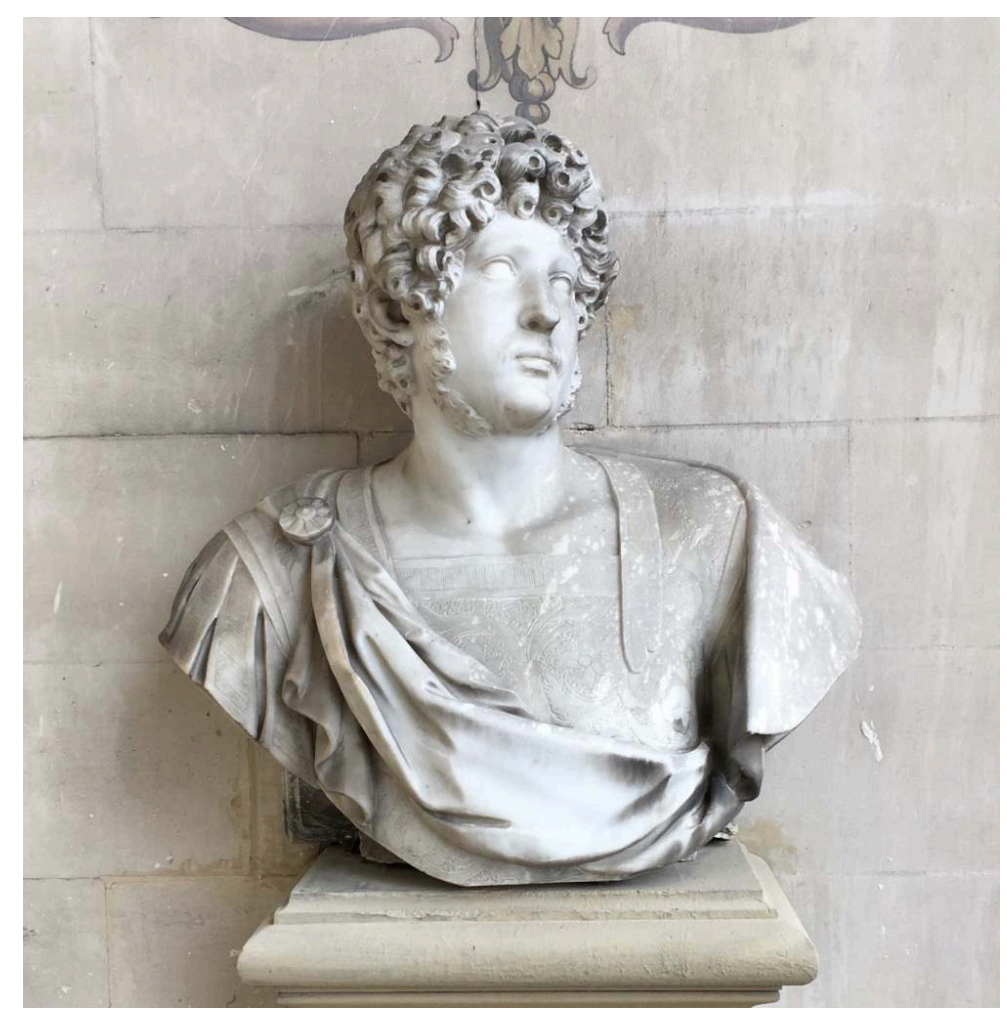

(C) Philippe Sénéchal 
7. Joseph Paxton, loggia du rez-de-chaussée, 1855-1859, vue en direction du sud, Ferrières-en-Brie, château de Ferrières.

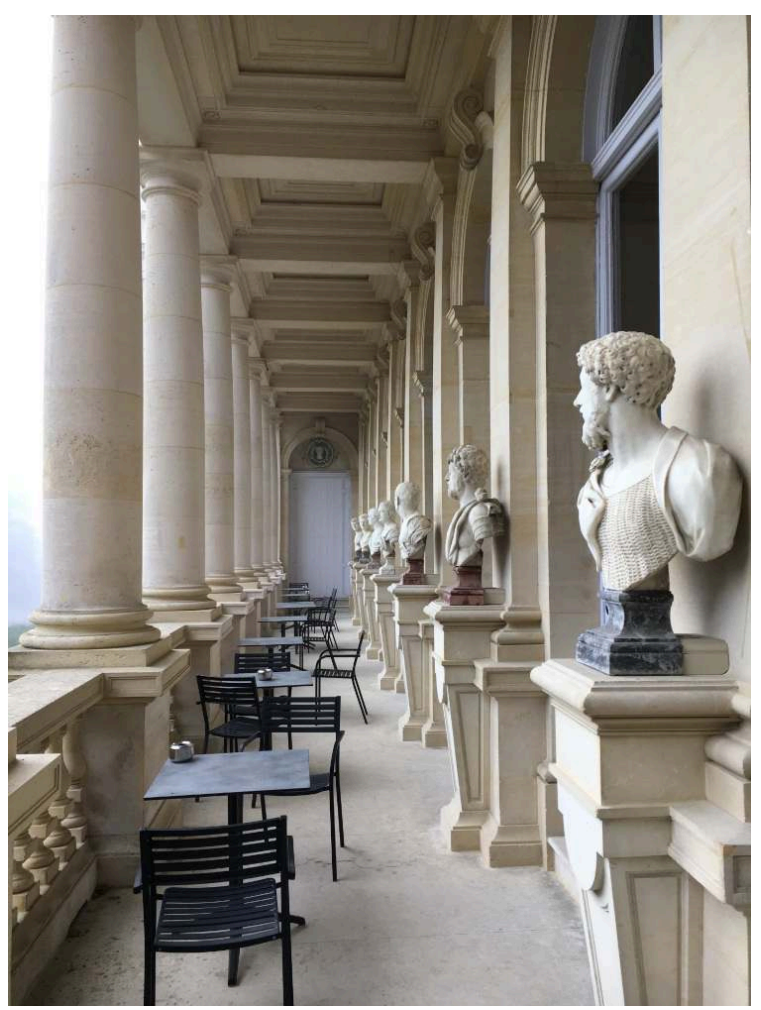

(c) Philippe Sénéchal 
8. Plan actuel du rez-de-chaussée du château de Ferrières, tiré de Pauline Prevost-Marcilhacy, "James de Rothschild à Ferrières : les projets de Paxton et de Lami ", Revue de l'art, nº100, 1993, p. 68 , fig. 31.

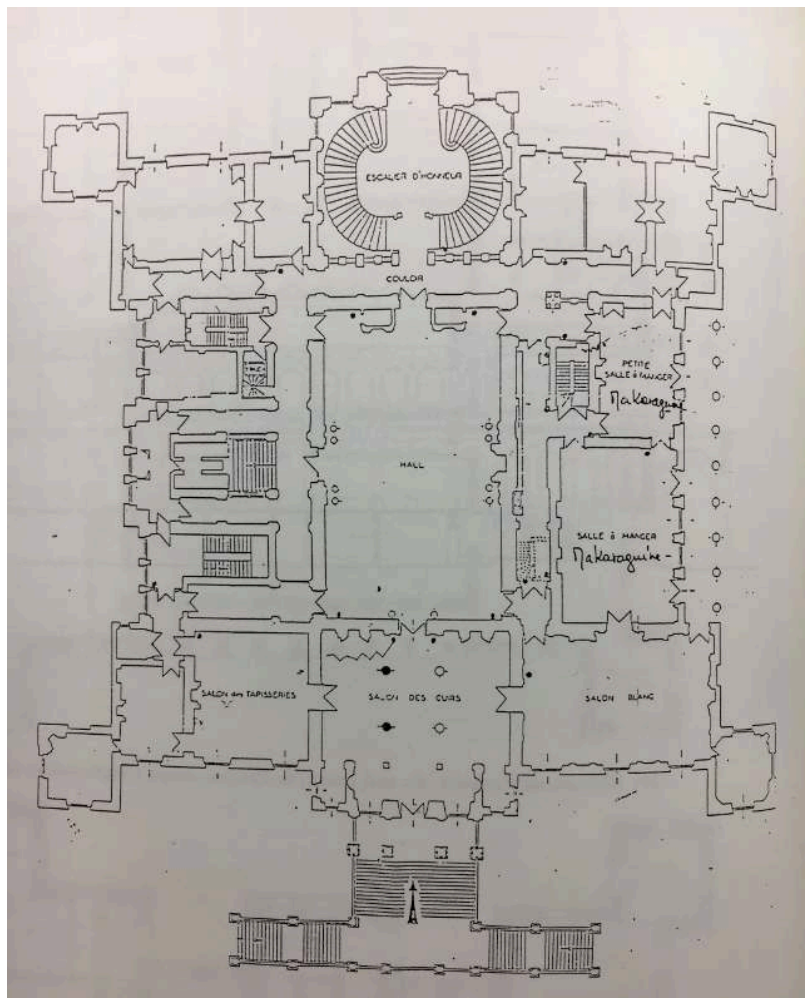

(C) D.R.

4 La loggia de l'étage de réception est beaucoup plus riche que celle qui dessert les appartements de l'aile est. Cette galerie ouverte permettait aux convives de prendre l'air et de faire quelques pas digestifs en sortant de la grande et de la petite salle à manger, voire du salon blanc Louis XVI (fig. 7 et 8$)^{12}$. Le côté sud reprend l'idée d'un décor à robbiesques sur le mur. Il ouvre sur une porte desservant ledit salon blanc, surmontée d'une lunette où trône un médaillon en terre cuite émaillée à l'effigie de Trajan (fig. 9 et 10), portant l'inscription «NERVA. .TRAIANVS» dans un cadre à guirlandes de fruits. Ce tondo est de bien meilleure qualité que les médaillons de l'étage supérieur. Il s'agit, selon nous, d'un remarquable original inédit, créé par Andrea Della Robbia ou par son atelier au tout début des années 1490. Il a pour frère un médaillon représentant Antonin le Pieux, acheté en juin 1876 par le Museo Civico d'Arte Antica du palais Madame à Turin (fig. 11), qui, de même que trois autres tondi fragmentaires, dont il ne reste plus que les encadrements à guirlandes, provient d'une suite d'empereurs romains commandée par l'humaniste Filippo Vagnone, seigneur de Trofarello ${ }^{13}$. Cet aristocrate piémontais, né vers 1450 et mort le 16 octobre 1499 , fut au service de la famille de Savoie. Vicaire de Cuneo en 1483-1484, il entra dans le conseil ducal en 1486, fut nommé grand châtelain de Moncalieri en 1488, puis fit partie, à partir de 1489 sans doute, des magistri hospicii, c'est-à-dire des majordomes du duc Charles $\mathrm{I}^{\mathrm{er}}$ de Savoie. Il fut chargé de nombreuses missions diplomatiques par la duchesse Bianca di Monferrato, devenue régente le 20 mars 1490, quelques jours après la mort prématurée de Charles I ${ }^{\text {er }}$. Filippo Vagnone se rendit en particulier à Milan en 1490 et 1491, et à la cour pontificale en 1493. Fin lettré et même poète, il avait commandé cette suite de médaillons all'antica pour le cortile du château de Castelvecchio di Testona à 
Moncalieri, près de Turin, qu'il avait acquis en 1489 et qu'il remania considérablement dans un goût all'antica ${ }^{14}$. Sur les deux reliefs, on retrouve les mêmes éléments : frise d'oves et de dards, pommes de pin, nom de l'empereur dans la même graphie en bleu sur blanc, rubans jaunes contre le fond bleu, tête blanche saillante, etc. Cette suite est d'un très grand intérêt, car il s'agit des seules œuvres que les Della Robbia aient produites pour le Piémont et un témoignage de premier ordre sur le milieu passionné par l'antique qui gravitait, à la fin $\mathrm{du} \mathrm{Xv}^{\mathrm{e}}$ et au début du XVI $\mathrm{Xvè}^{\mathrm{e}}$ se, autour des Della Rovere à Vinovo et des Vagnone à Castelvecchio di Testona ${ }^{15}$. Filippo Vagnone avait poussé l'amour pour la Rome antique jusqu'à faire remployer pour sa sépulture un sarcophage romain provenant de fouilles récentes à Turin et à y faire sculpter des reliefs avec, sur les longues faces, Apollon et les Muses, d'un côté, et des Scènes de l'histoire de Persée, de l'autre; et, sur les petits côtés, les armoiries Vagnone et une inscription encomiastique sur une tabula ansata expliquant que le gendre du défunt, Filippo di Valperga, s'était chargé de respecter la volonté testamentaire de son beau-père ${ }^{16}$.

9. Porte sud de la loggia du rez-de-chaussée, avec médaillon : Andrea Della Robbia ou atelier, Trajan, c. 1490, terre cuite émaillée, Ferrières-en-Brie, château de Ferrières.

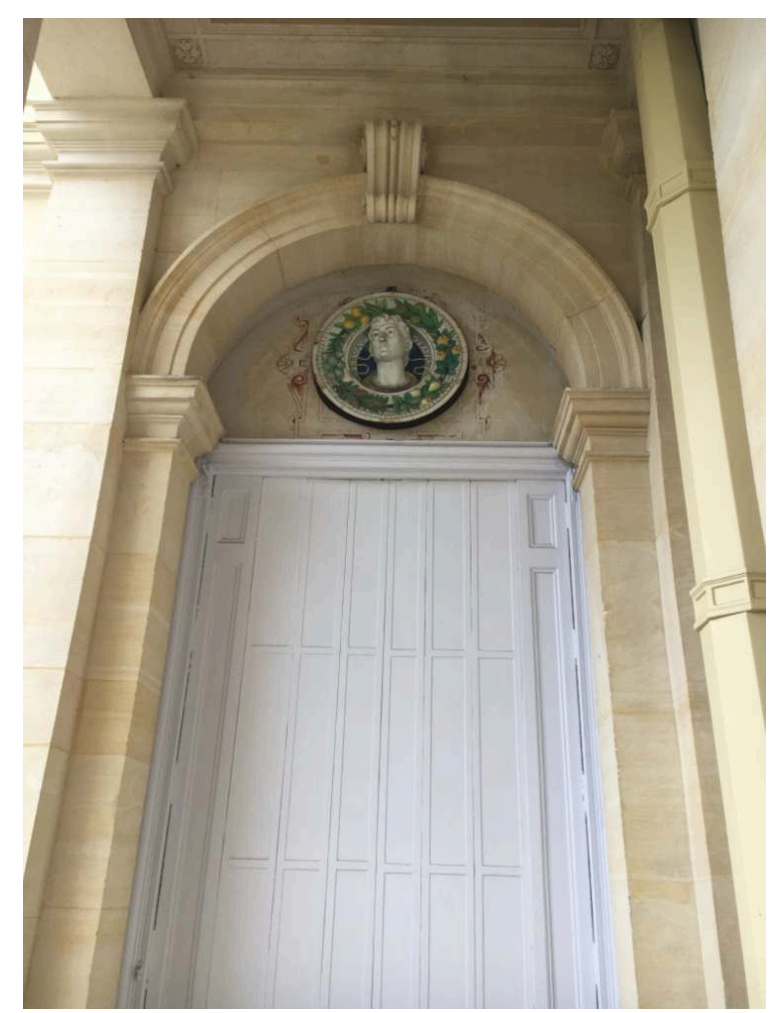

(C) Philippe Sénéchal 
10. Andrea Della Robbia ou atelier, Trajan, c. 1490, Ferrières-en-Brie, château de Ferrières, loggia supérieure.

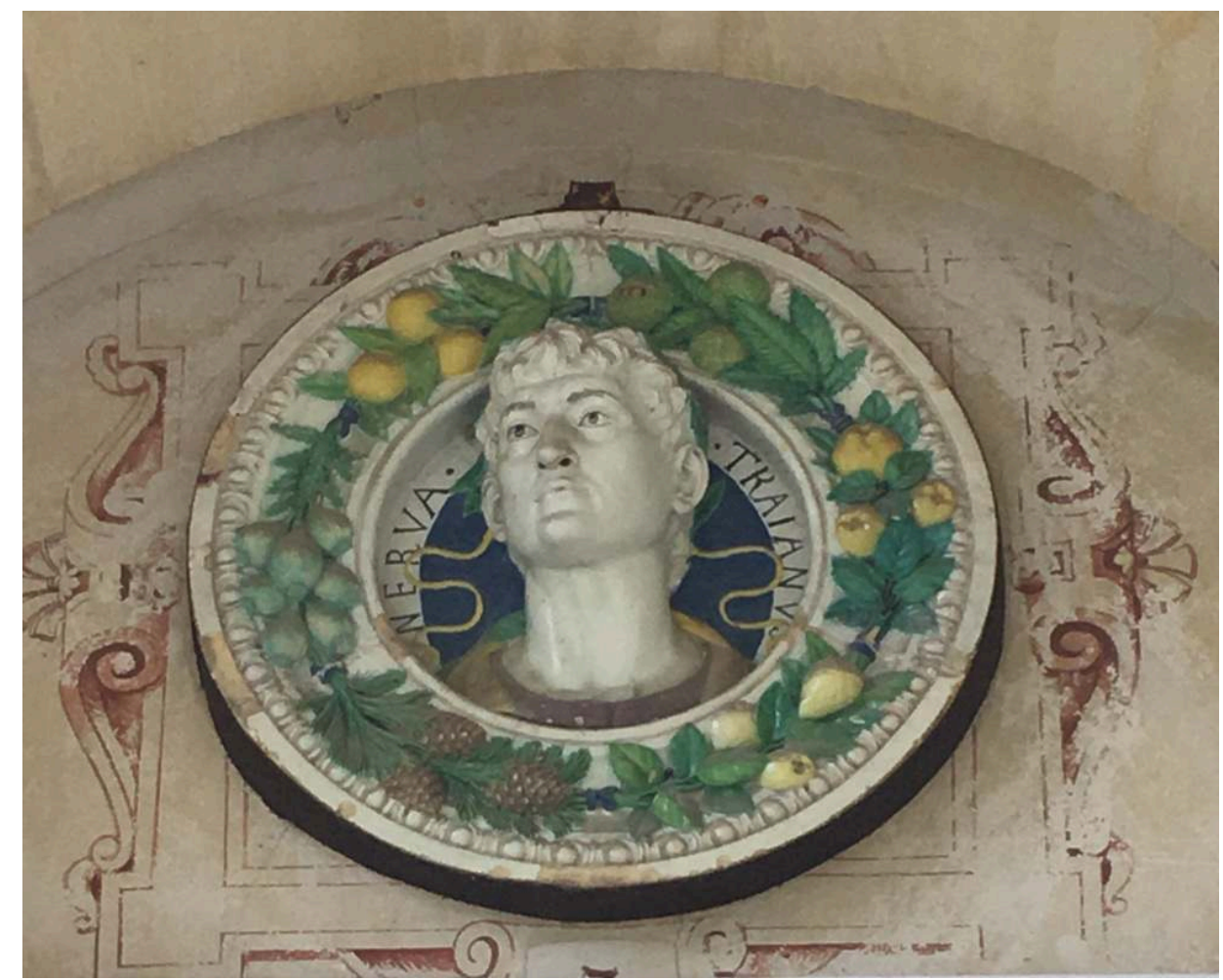

(c) Philippe Sénéchal

11. Andrea Della Robbia ou atelier, Antonin le Pieux, c. 1490, Turin, Palazzo Madama, Museo Civico d'Arte Antica.

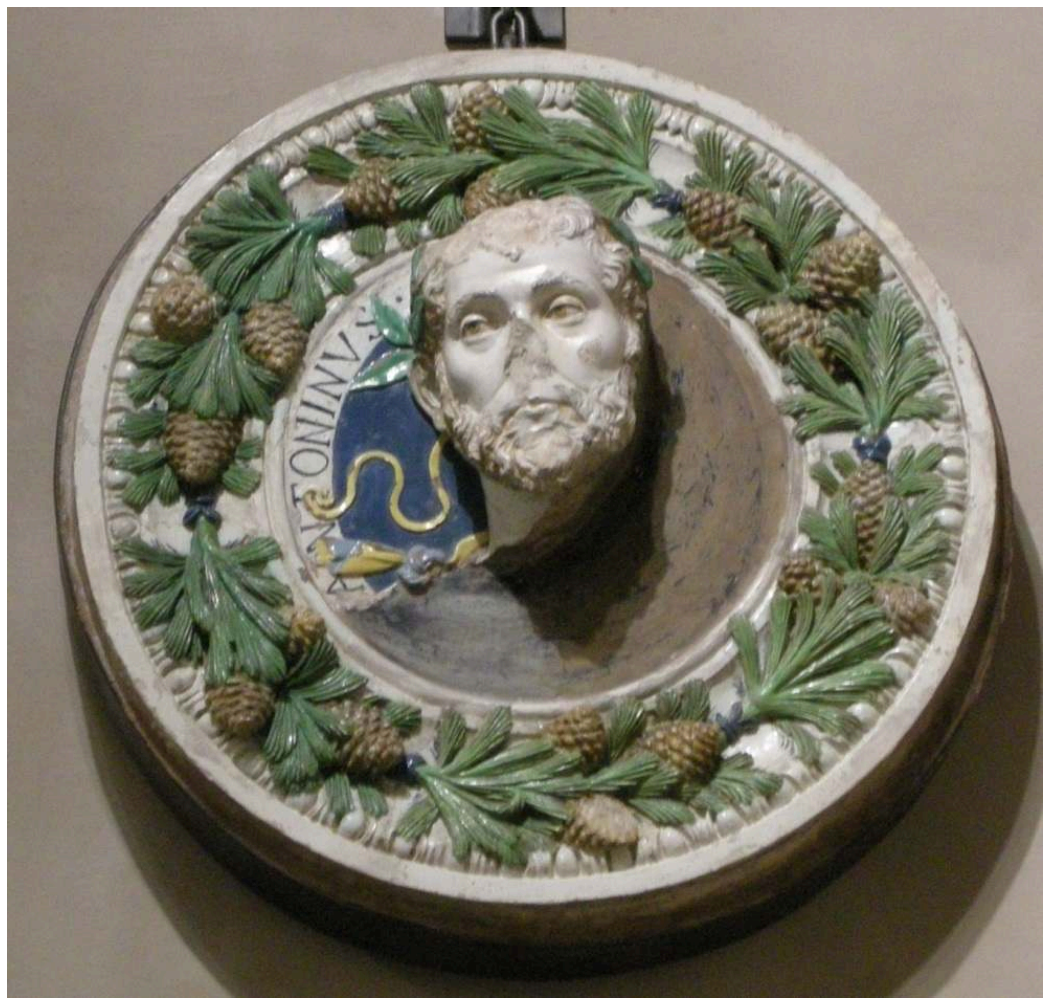


Le superbe médaillon d'Andrea Della Robbia est la seule terre cuite qui orne la galerie de l'étage de réception du château de Ferrières. De fait, à la différence de la loggia supérieure, la loggia inférieure fait la part belle à la sculpture en marbre. La galerie de bustes était un must have des demeures patriciennes, tant en Grande-Bretagne, avec laquelle James voulait rivaliser, qu'en Italie ${ }^{17}$. À Ferrières, Lami déploie une mise en scène efficace, qui tient compte de façon plaisante du rôle de promenoir que joue la loggia. Il place en point de fuite une superbe copie en marbre de l'Apollon du Belvédère, hélas partiellement endommagée (fig. 12), et plaque sur sept pilastres le même type de piédestal qu'à l'étage supérieur. Il dote en outre tous les marbres blancs - qui se détachent efficacement contre le calcaire blond - de piédouches de même profil, mais dans des marbres ou des brèches de couleurs différentes, ce qui apporte une note de variété et de gaieté et concorde avec un nouveau goût pour la polychromie en sculpture, dont le triomphe est le grand salon de Ferrières. Le plus amusant concerne la répartition des bustes. Lorsque l'on s'avance en direction de l'Apollon, les deux premiers personnages tournent la tête vers la droite, donc vers le dieu en pied, les trois bustes du milieu sont de face et les deux derniers sont tournés vers la gauche. Nous ne connaissons pas d'autre exemple d'une telle présentation associant à la fois symétrie, prise en compte de la déambulation et accentuation de la perspective ${ }^{18}$. On ignore si les bustes ont été spécifiquement achetés en fonction de l'orientation de leur visage, avec des instructions spéciales de Lami, ou si ce dernier avait fait son marché dans la collection du Grand Baron ${ }^{19}$. Tous représentent des personnages masculins et sont des œuvres italiennes à l'antique et non des marbres de l'Antiquité romaine plus ou moins restaurés, ce qui aurait vraisemblablement été le cas dans une country house du $\mathrm{XVIII}^{\mathrm{e}}$ siècle et n'aurait pas été difficile à constituer, si l'on songe au nombre de portraits sculptés antiques que Carl Jacobsen parvint à acquérir à Rome, à partir de 1887, par l'entremise de Wolfgang Helbig, pour constituer les collections de la future $\mathrm{Ny}$ Carlsberg Glyptotek de Copenhague ${ }^{20}$. Les bustes de cette loggia inférieure ne sont malheureusement pas tous de la même qualité. Il s'agit, pour moitié au moins, de marbres produits pour le décor par des praticiens efficaces mais sans grande personnalité. À l'évidence, ce n'était pas l'excellence de la facture qui était visée, mais l'effet scénique général ou la singularité de tel ou tel détail iconographique. 
12. Joseph Paxton, loggia du rez-de-chaussée, 1855-1859, vue actuelle en direction du nord, Ferrières-en-Brie, château de Ferrières.

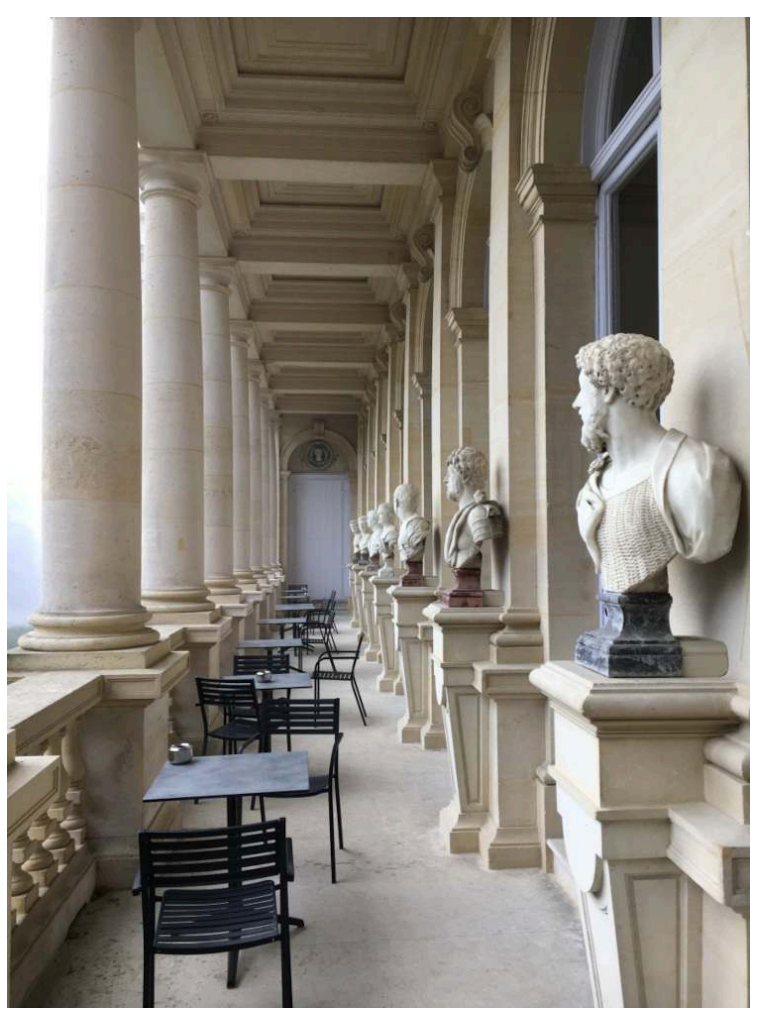

(C) Philippe Sénéchal 
13. Joseph Paxton, loggia du rez-de-chaussée, 1855-1859, vue en 1997 en direction du nord, Ferrières-en-Brie, château de Ferrières.

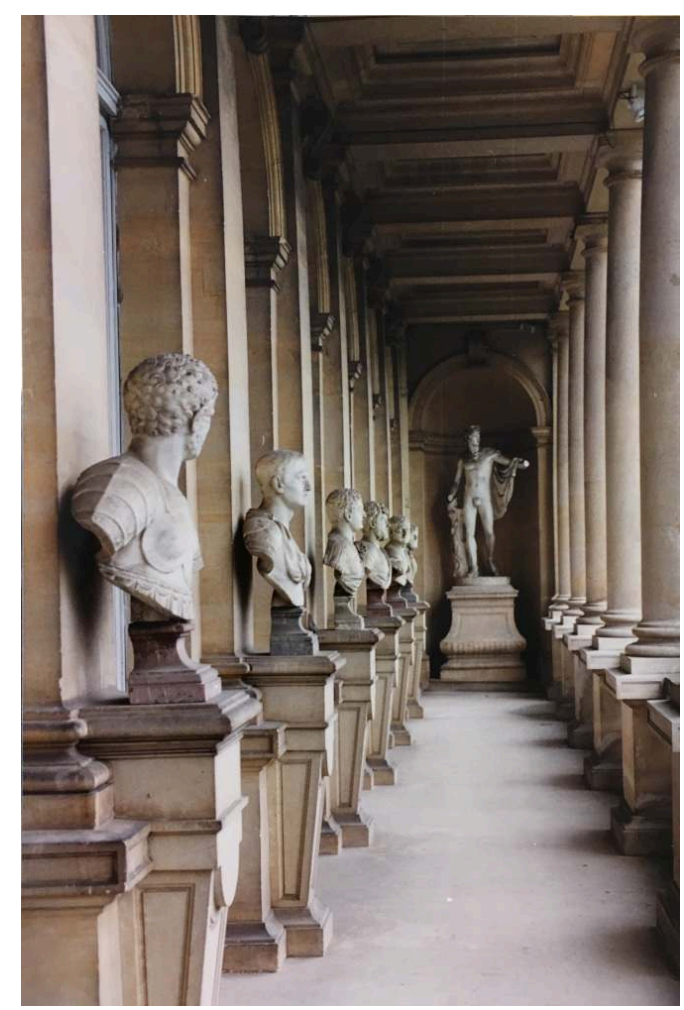

(c) Cliché Hervé Grandsart / bibliothèque de I'INHA

Commençons par examiner le clou de la galerie, l'Apollon du Belvédère, qui a malheureusement perdu ses avant-bras et - assez récemment - le bout de son nez. Il est daté de 1791 (fig. 14) et signé dans un latin approximatif par le sculpteur Pierre Petitot (1760-1840), originaire de Langres ${ }^{21}$. Ce dernier avait suivi, à Dijon, les cours de l'école de dessin de François Devosge à partir de 1771, au moins. Il s'était formé à Paris, à l'Académie royale, à compter d'avril 1781, avant de revenir à Dijon et de remporter, en 1784, le prix de Rome financé par les États de Bourgogne, ce qui lui permit de séjourner cinq ans dans la Ville éternelle. Son envoi de Rome, une copie en marbre du Gladiateur Borghèse, lui donna beaucoup de fil à retordre à cause de défauts découverts dans le bloc. Achevé en 1787, il fut installé la même année dans la salle des Statues du Muséum de l'école de dessin et se trouve aujourd'hui au musée des Beaux-Arts de Dijon ${ }^{22}$. Les expédients auxquels Petitot dut recourir pour achever la statue lui furent à l'évidence pardonnés. Au reste, il reçut même une gratification de mille livres en $1788^{23}$. En revanche, il n'était pas parvenu, en 1787, à convaincre les États de Bourgogne de lui commander la copie de ses rêves, celle du Laocoon ${ }^{24}$. Engager des frais si importants en une période de graves difficultés financières et politiques ne dut pas sembler raisonnable, d'autant plus qu'un condisciple et compatriote de Petitot, le sculpteur langrois Antoine-Henri Bertrand (1759-1834), était parvenu, en 1786, à acquérir pour l'école de Devosge un excellent moulage du Laocoon, provenant de la collection du peintre Anton Raphael Mengs, hélas détruit en $1940^{25}$. En outre, proposer un Apollon du Belvédère en marbre à l'école de Dijon n'aurait pas eu de sens, car un précédent lauréat du prix de Rome des États de Bourgogne, Charles-Alexandre Renaud (1756-1815), avait déjà réalisé une copie en marbre de cette antique en guise d'envoi de Rome. De qualité 
inférieure à celui de Ferrières, l'Apollon de Renaud, commandé en 1779, fut achevé et expédié en 1781; il est également exposé de nos jours au musée des Beaux-Arts de Dijon $^{26}$. En tout cas, avec son Gladiateur, Petitot était parvenu à montrer ses remarquables dons de technicien du marbre et de copiste d'après l'Antique. Son envoi lui servit de carte de visite pour des commandes ultérieures. Seul un riche commanditaire pouvait être intéressé par l'acquisition d'une copie grandeur nature de l'Apollon, pour laquelle un coûteux bloc de marbre était nécessaire.

14. Pierre Petitot, Apollon du Belvédère, 1791, Ferrières-en-Brie, château de Ferrières, loggia du rezde-chaussée.

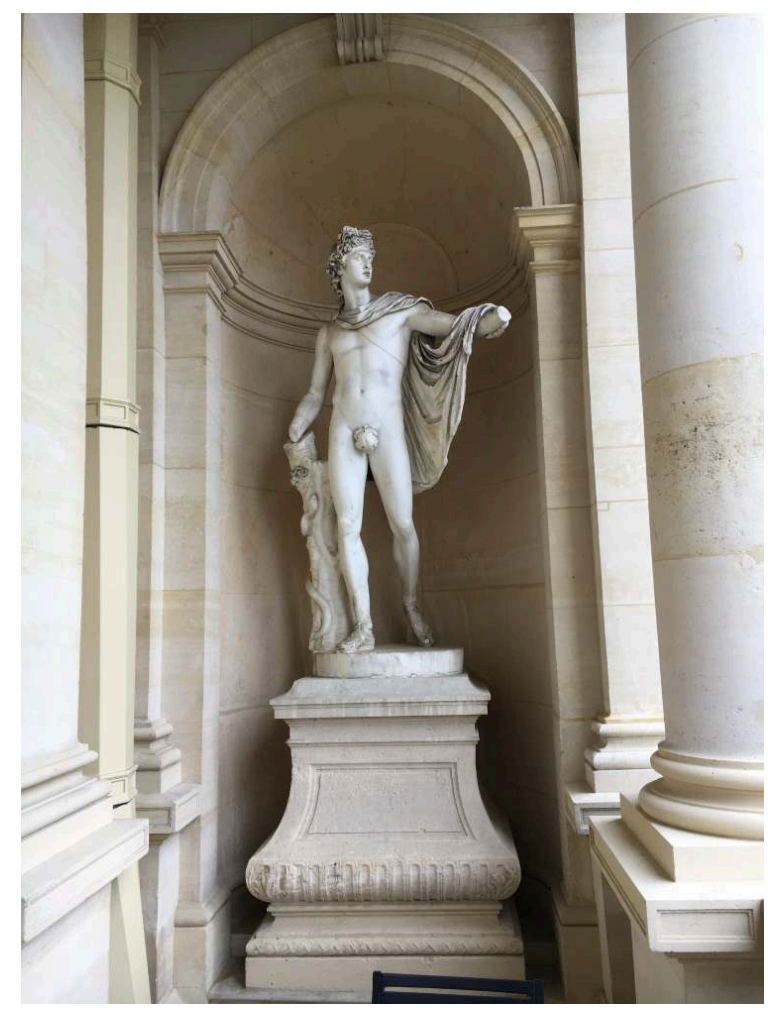

(c) Philippe Sénéchal

7 Dans une lettre d'Antoine Bertrand, envoyée de Rome à François Devosge le 20 mai 1789, on apprend que « $\mathrm{M}^{\mathrm{r} P e t i t o t} \mathrm{e}[\mathrm{s}] \mathrm{t}$ parti pour Carare [Carrare], toujour[s] indisposé d'une fièvre opiniâtre, pour laquelle les médecins lui ont conseillié [sic] de voyager et changer d'air. Il a beaucoup de travaux, à ce qu'il m'a dit, pour le cardinal de Briene [Brienne], qu'il va faire ébaucher à Carrare ${ }^{27}$. " Il y a fort à parier que l'Apollon de Ferrières ait été au départ une commande d'Étienne-Charles de Loménie de Brienne (1727-1794), qui avait été nommé principal ministre de Louis XVI le $1^{\mathrm{er}}$ mai 1787 , mais avait dû démissionner le 8 mai de l'année suivante. Parallèlement, il était devenu, en 1788, archevêque de Sens, avant d'être élevé à la pourpre cardinalice, le 15 décembre 1788. Le prélat se rendit en Italie pour recevoir le chapeau ; il y resta jusqu'en 1790, puis rentra dans son diocèse. Mais, comme il avait prêté serment à la constitution civile du clergé le 23 février 1791, il fut déposé par le pape Pie VI au consistoire du 26 septembre de cette année-là. Il dut se retirer avec sa famille dans l'ancienne abbaye déconsacrée de Saint-Pierre-le-Vif à Sens, qu'il avait rachetée et dont il fit sa résidence jusqu'à son arrestation et sa mort en février $1794^{28}$. Petitot avait donc pu rencontrer le cardinal de 
Brienne à Rome en 1789, quelques mois avant son retour en France. L'archevêque avait vraisemblablement songé à orner une de ses demeures avec une, voire des copies d'antiques célèbres. Cette même année 1789, Petitot avait exécuté un buste de Minerve en marbre, aujourd'hui dans les réserves des musées d'Angers, qui faisait peut-être aussi partie de la commande du prélat ${ }^{29}$. Il s'agissait d'une variation sur le magnifique buste d'Athéna du type Velletri, datant du II $^{\mathrm{e}}$ siècle apr. J.-C., alors dans la collection Albani à Rome ${ }^{30}$. Rappelons en outre que le sculpteur langrois connaissait bien le frère puîné du cardinal, Louis-Marie-Athanase de Loménie, comte de Brienne (1730-1794). Si l'on en croit le biographe des Petitot, Alfred Mettrier, "pris en affection par M. de Brienne à qui M. Devosge l'avait signalé, Pierre Petitot allait chaque année passer quelques semaines à son château et y rencontrait les plus brillants sujets de l'école que le noble comte se plaisait à y réunir ${ }^{31}$ ». Les deux frères avaient fait luxueusement reconstruire le château familial de Brienne, dans l'Aube, de 1770 à 1778 par l'architecte Jean-Louis Fontaine ${ }^{32}$. Quoi qu'il en soit, on ne sait pas si Petitot, revenu à Paris en 1789, envoya l'Apollon à Sens - or, on sait que le prélat avait fait meubler luxueusement l'abbaye de Saint-Pierre-le-Vif ${ }^{33}$ - ou au château de Brienne-le-Château, ni même s'il livra la statue à son commanditaire. Selon Stanislas Lami, qui cite un numéro des Affiches de Paris de 1791, aujourd'hui introuvable, l'Apollon de marbre figurait dans l'atelier du sculpteur en $1791^{34}$. Il n'avait plus été retrouvé depuis cette date. La présente redécouverte est donc une précieuse addition au catalogue de Pierre Petitot. Mais, pour l'instant, nous ne sommes pas parvenus à reconstituer le sort de la statue entre 1791 et son acquisition par le Grand Baron. L'incendie des archives de Ferrières, à la fin du siècle dernier, ne facilite certes pas la tâche des chercheurs.

15. Sculpteur anonyme génois, Buste de jeune Romain, c. 1690-1710, Ferrières-en-Brie, château de Ferrières, loggia du rez-de-chaussée.

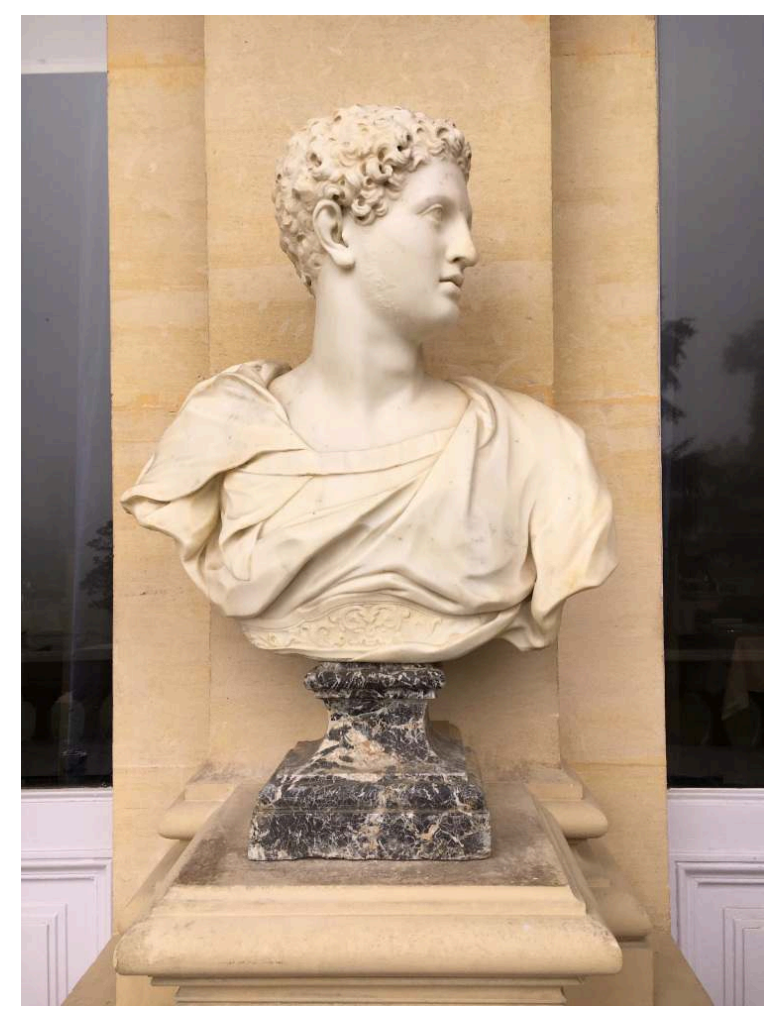

(c) Philippe Sénéchal 
Les deux bustes du côté sud ont le visage tourné en direction de l'Apollon. Le premier représente un jeune homme avec de légers favoris $\left(\right.$ fig. 15) ${ }^{35}$. L'arrière de sa chevelure est percé au trépan et il entrouvre rêveusement les lèvres. Son drapé, aux amples ondulations et à l'asymétrie savante, est retenu par une large ample ceinture à décor de rinceaux, un peu à la manière de la Diane de Giacomo Antonio Ponsonelli, dit aussi Jacopo Antonio Ponzanelli (1654-1735), conservée au Louvre et exécutée vers $1695-1700^{36}$. Nous proposons donc de voir dans ce beau buste une œuvre génoise de la fin $d u x I_{I}{ }^{e}$ ou du tout début $d u x{ }^{2}{ }^{e}$ siècle. Son voisin, qui se veut sans doute un empereur, est d'une qualité très inférieure $\left(\right.$ fig. 16) ${ }^{37}$. La chevelure aux boucles en spirales mécaniques encadre un visage farouche tourné vers la droite et surmontant une extravagante et improbable cuirasse à l'antique. Le sculpteur a inventé un curieux plastron bombé, se terminant en accolade et orné de rinceaux se détachant sur un fond rainuré. Au lieu des lambrequins qui conviendraient à une cuirasse romaine de l'Antiquité, il a inséré des arrière-bras articulés en métal, typiques de l'armement depuis la Renaissance. Quant au visage (fig. 17), il reprend, de façon raide et affadie, celui d'un type de portrait de Caracalla, dont les deux plus beaux exemplaires sont dans la collection Farnèse au Museo Archeologico Nazionale de Naples ${ }^{38}$. Ce collage d'éléments disparates nous semble trahir la main d'un créateur italien de la fin du $\mathrm{XVI}^{\mathrm{e}}$ ou du début du XVII e siècle.

16. Buste du type Caracalla, fin $X V I^{\mathrm{e}}$ - début XVII siècle, Ferrières-en-Brie, château de Ferrières, loggia du rez-de-chaussée.

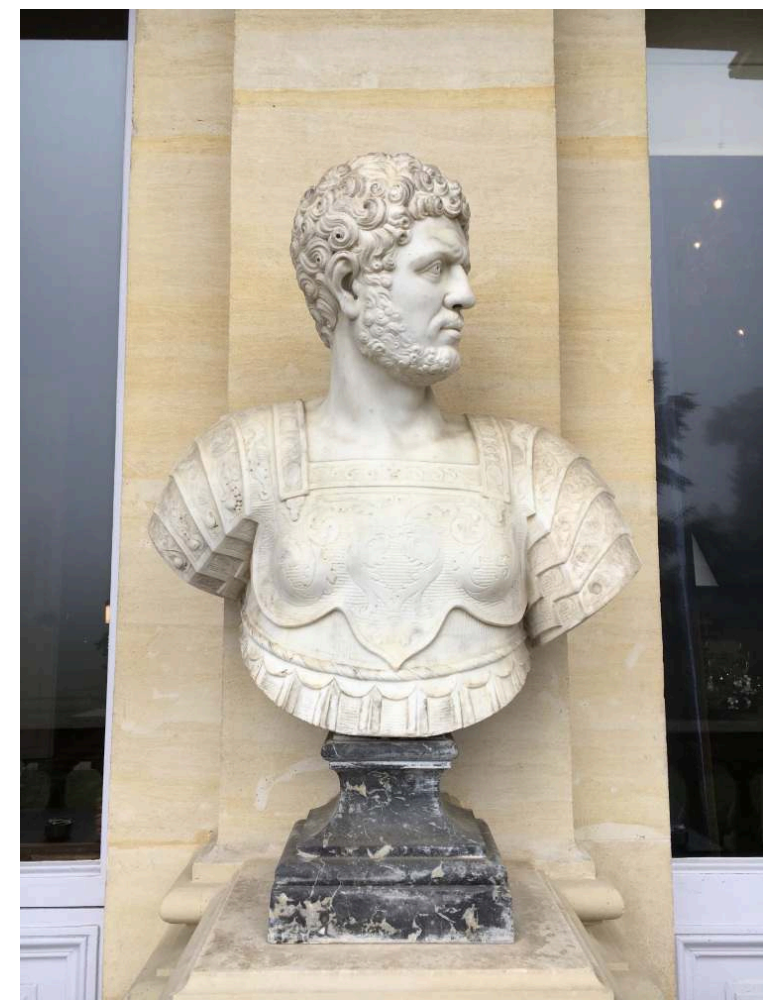

(C) Philippe Sénéchal 
17. Buste du type Caracalla, fin $\mathrm{XVI}^{\mathrm{e}}$ - début $\mathrm{xvII}{ }^{\mathrm{e}}$ siècle, vu de droite, Ferrières-en-Brie, château de Ferrières, loggia du rez-de-chaussée.

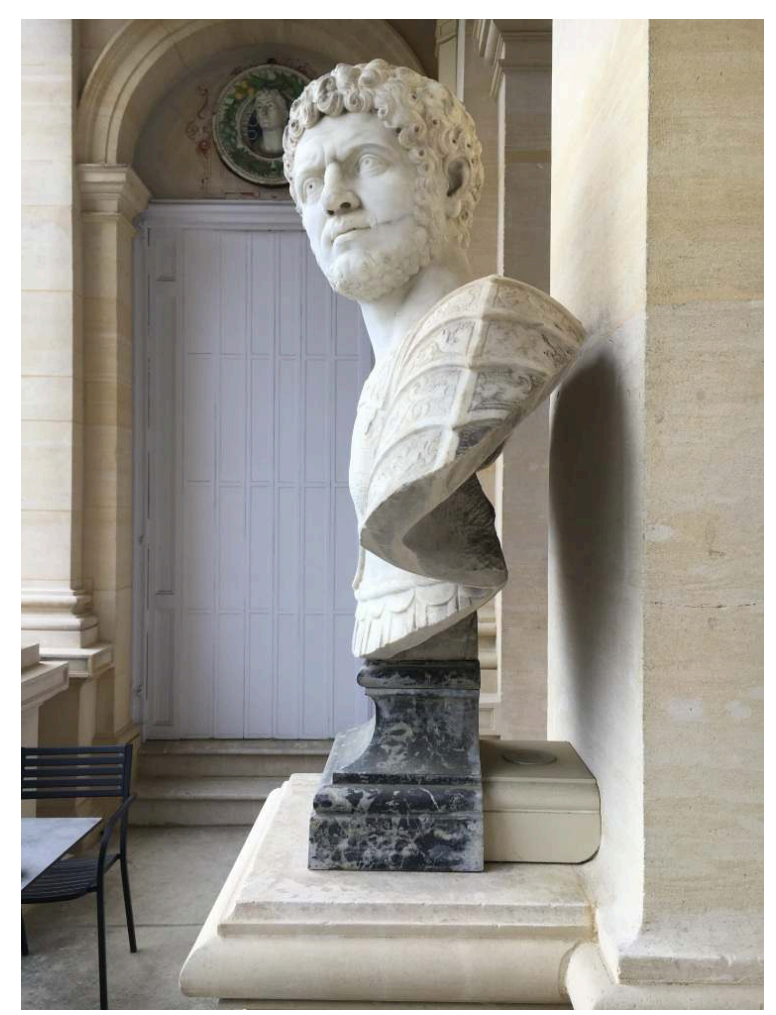

(C) Philippe Sénéchal

Les trois bustes de face portent tous une cuirasse à l'antique sur laquelle passe un paludamentum agrafé, retenu ou noué de façon fantaisiste. Comme ils sont de faible qualité, nous ne nous y attarderons pas. Le premier des trois, qui doit dater du $\mathrm{XVII}^{\mathrm{e}}$ siècle, est le meilleur (fig. 18) ${ }^{39}$. En dépit de l'usure et de nettoyages excessifs, on appréciera ses cheveux ondulés, le modelé souple de son visage glabre, la cuirasse à décor de rinceaux sur un fond piqueté et à arrière-bras articulés sous l'épaulière droite, ainsi que la souple abolla entortillée sur le devant avec désinvolture. Le deuxième, très médiocre, représente une sorte de jeune empereur hagard, très vaguement inspiré de bustes antiques de Néron enfant ou d'autres empereurs représentés jeunes, comme Géta ou Caracalla, mais avec une coiffure bouclée très différente et surtout la bouche ouverte, ce qui se voit plutôt dans les portraits d'enfants dits «souffrants » $\left(\right.$ fig. 19) ${ }^{40}$. Le troisième arbore une cuirasse à rinceaux réalisée de façon proche de celle du premier buste et un paludamentum noué sur l'épaule gauche (fig. 20 $)^{41}$. Il présente des ressemblances avec certains bustes de Septime Sévère du type "Sérapis ", particulièrement à cause des quatre mèches frontales ${ }^{42}$. Sa tête barbue est très légèrement tournée vers notre gauche, amorçant donc le renversement du regard en direction du sud et du tondo robbiesque qu'effectuent les deux derniers bustes, qui sont bien plus intéressants. L'avant-dernier (fig. 21) frise l'extravagance ${ }^{43}$ : il reprend le visage et le torse barré d'un baudrier de cuir du magnifique et célèbre buste du prétendu Lysimaque de la collection Farnèse, aujourd'hui au Museo Archeologico Nazionale de Naples (fig. 22), - que l'on appelait, à Rome, Démosthène et encore plus souvent Solon et qui fut souvent copié ${ }^{44}$. Le modèle antique était un buste au torse nu sans épaules, barré d'un baudrier. Le copiste moderne l'a agrandi jusqu'au-dessous des 
épaules et jusqu'à l'abdomen, qui est couvert d'un vêtement retenu par une corde, des sortes de braies brutalement coupées par la troncature du buste. On a l'impression que l'on a ouvert la tunique pour dévoiler la nudité du torse, ce qui fait que le vêtement réapparaît bizarrement au-dessous de l'épaule gauche, au milieu du biceps. De la sorte, le général hellénistique est devenu un prisonnier barbare luttant contre ses liens. La torsion du visage et la lanière barrant le torse ont dû faire penser au sculpteur moderne à l'Esclave rebelle de Michel-Ange, dont il devient un avatar froid et grotesque.

18. Buste de général romain, XVII siècle, Ferrières-en-Brie, château de Ferrières, loggia du rez-dechaussée.

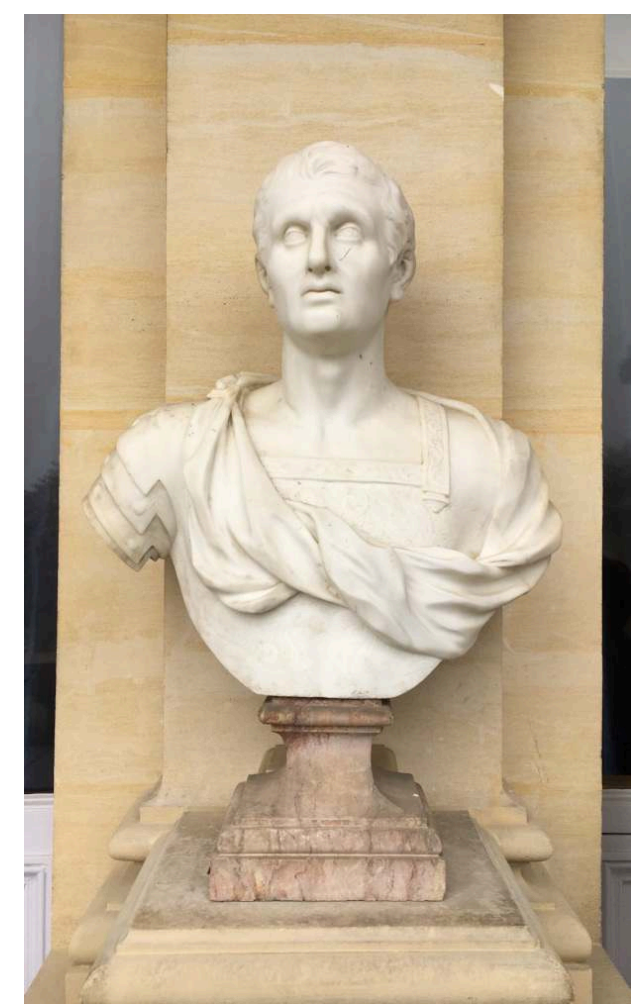

(C) Philippe Sénéchal 
19. Buste de jeune Romain (Néron ?), xVII siècle, Ferrières-en-Brie, château de Ferrières, loggia du rez-de-chaussée.

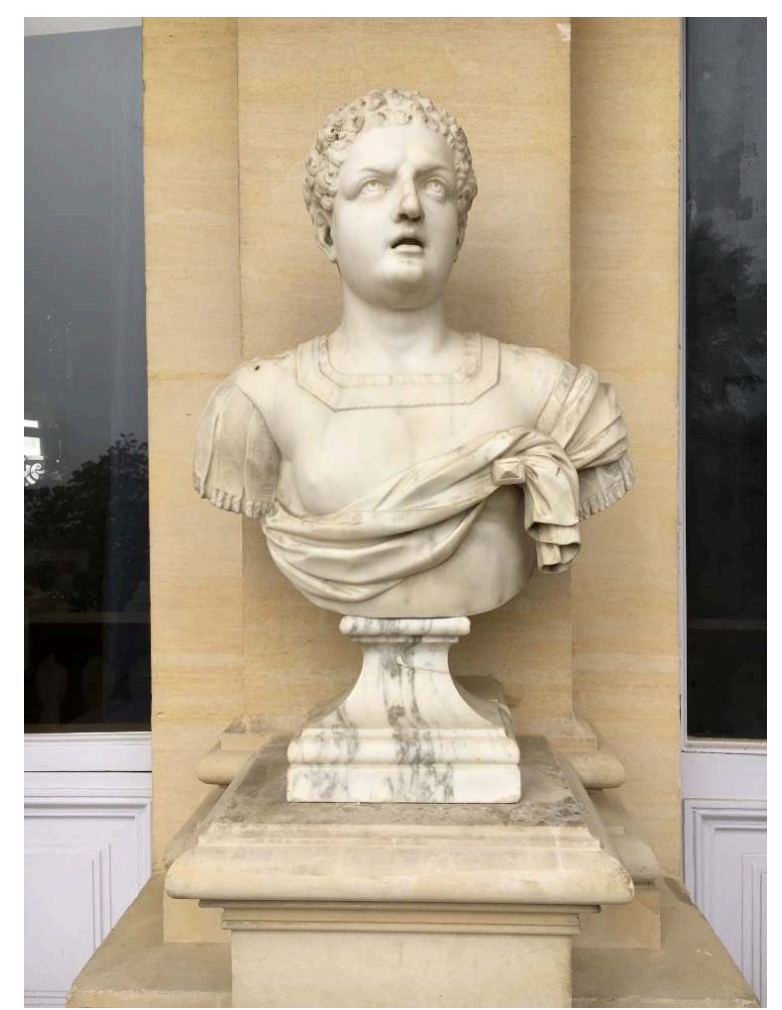

(c) Philippe Sénéchal 
20. Buste de Septime Sévère du type "Sérapis ", xvII siècle, Ferrières-en-Brie, château de Ferrières, loggia du rez-de-chaussée.

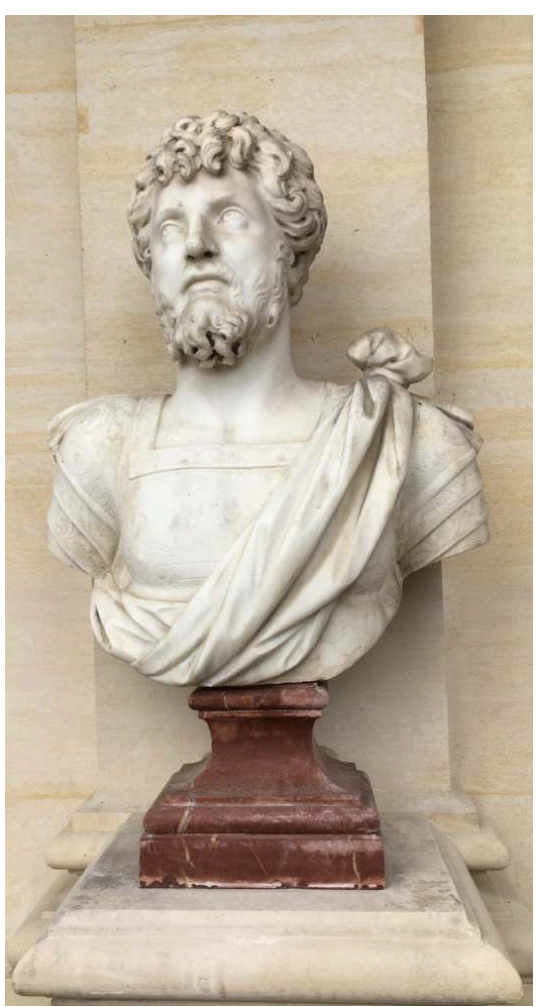

(c) Philippe Sénéchal 
21. Buste du Pseudo-Lysimaque, $\mathrm{XVIII}{ }^{\mathrm{e}}$ ou début $\mathrm{XIX} \mathrm{e}^{\mathrm{e}}$ siècle, Ferrières-en-Brie, château de Ferrières, loggia du rez-de-chaussée.

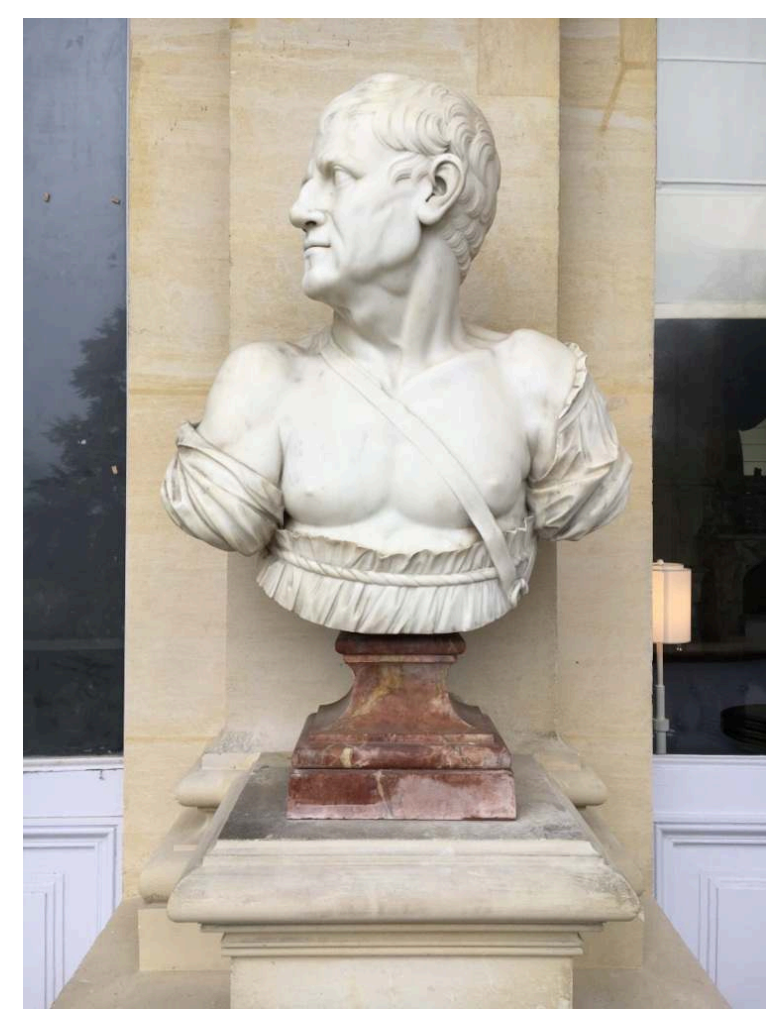

(c) Philippe Sénéchal 
22. Sculpteur romain anonyme, Buste du prétendu "Lysimaque ", début de l'époque augustéenne (23 avant J-C. - 14 après J.-C.), d'après un original grec du ॥ siècle avant J.-C., Naples, Museo Archeologico Nazionale.

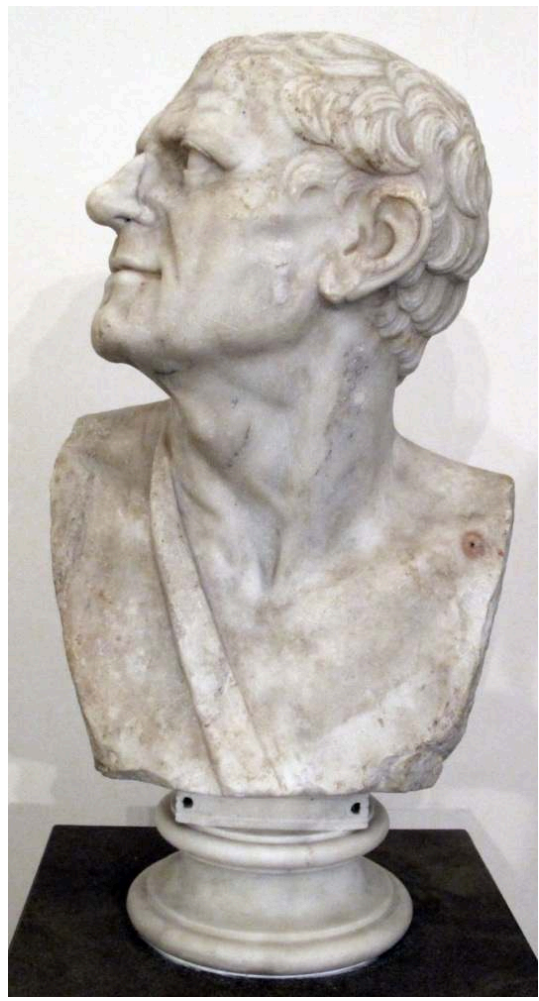

Wikimedia Commons

10 Le dernier buste de droite, de belle facture, est un empereur barbu et songeur, qui rappelle à la fois les portraits sculptés de Marc Aurèle du IV type et les têtes de Septime Sévère du type "de l'adoption " $(\text { fig. } 23)^{45}$. Il porte une cotte de mailles à lambrequins au-dessus de laquelle passe un paludamentum à fibule. Ce marbre s'inscrit dans une production génoise de la fin du XVII siècle, marquée par l'exemple de Pierre Puget (1620-1694), le premier à affubler un souverain antique d'une cotte de mailles dans son Roi guerrier, dit aussi Roi David, sculpté vers 1665, provenant du Palazzo Serra de Gênes et aujourd'hui conservé à la National Gallery of Canada à Ottawa ${ }^{46}$. On retrouve ce type d'armure dans le Mars de Giacomo Antonio Ponsonelli des collections Liechtenstein à Vaduz, exécuté vers $1695-1700^{47}$. Le buste de Ferrières est plus retenu, moins pathétique et moins ostensiblement moderne que ceux de Puget et de Ponsonelli. 
23. Sculpteur génois anonyme, Buste de Marc-Aurèle du Ive type ou de Septime Sévère du type " de l'adoption ", vers 1670-1700, Ferrières-en-Brie, château de Ferrières, loggia du rez-de-chaussée.

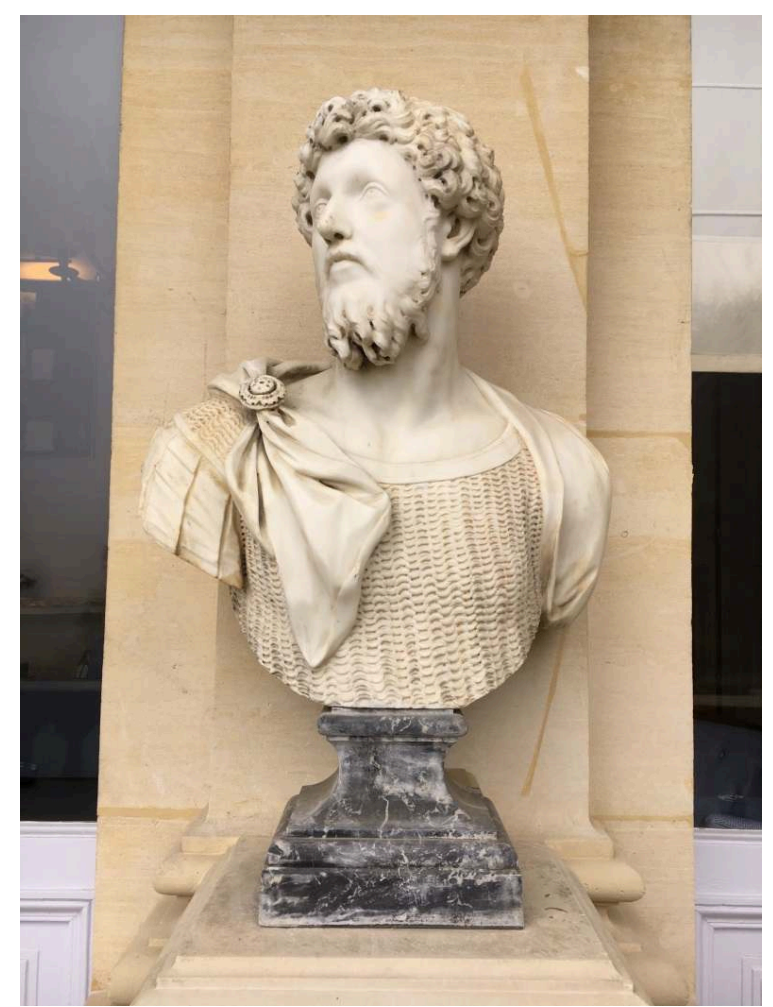

(C) Philippe Sénéchal

11 Même si elles font allusion à des types d'espaces bien connus en Italie et même si elles présentent des sculptures que l'on pourrait aussi trouver dans de grandes demeures allemandes, françaises et britanniques, les deux loggias de Ferrières sont donc tout à fait originales. Elles mélangent avec efficacité des sculptures de diverses époques, allant de la Renaissance au XIX ${ }^{e}$ siècle, des marbres et des robbiesques, des œuvres de grande qualité et des œuvres médiocres mais suffisantes pour l'effet scénographique recherché ${ }^{48}$. En particulier, dans la galerie desservant les pièces de réception du rez-dechaussée, Eugène Lami fait montre d'une grande ingéniosité en disposant les bustes en fonction de la déambulation des visiteurs. Dans ces galeries extérieures est évoquée une Italie palatiale de fantaisie et colorée, passant avec désinvolture d'allusions au Quattrocento à des échos de demeures patriciennes. Pour James de Rothschild, Eugène Lami rendit un hommage théâtral à l'antique - mais jamais, redisons-le, en utilisant des originaux romains -, et au faste des palais italiens de la Renaissance et de l'âge baroque $^{49}$. 


\section{NOTES}

1. Pour Challuau, voir la notice de Jean-Marie Pérouse de Montclos, «Challuau », dans Jean-Marie Pérouse de Montclos (dir.), Le Guide du patrimoine. Île-de-France, Paris, Hachette, 1992, p. 155-156 et Françoise Boudon et Claude Mignot, Jacques Androuet du Cerceau. Les dessins des plus excellents bâtiments de France, Paris, Picard/Cité de l'architecture et du patrimoine/Le Passage, 2010, p. 228-229. Sur le château de Madrid, voir Monique Chatenet, Le Château de Madrid au bois de Boulogne : sa place dans les rapports italiens autour de 1530, Paris, Picard, 1987 et Monique Chatenet, Florian Meunier et Alain Prévet, Le Château de faïence de François $I^{\text {er }}$. Les terres cuites émaillées de Girolamo della Robbia au château de Madrid (bois de Boulogne), Paris, Éditions du CTHS, 2012. Rappelons que, de 1855 à 1860, James de Rothschild fit édifier par Armand-Auguste-Joseph Berthelin le château de Boulogne, à courte distance des ruines de celui de François $\mathrm{I}^{\mathrm{er}}$. Voir Pauline Prevost-Marcilhacy, Les Rothschild, bâtisseurs et mécènes, Paris, Flammarion, 1995, p. $98-100$, p. 118-122, p. 158, et p. 307-308. Le souvenir du château royal du bois de Boulogne devait forcément être très présent à la mémoire du Grand Baron, et Joseph Paxton connaissait évidemment Androuet du Cerceau.

2. Dans son second projet de 1856-1857, Paxton avait superposé des baies en plein cintre aux piédroits traités en pilastres; dans le projet définitif, les baies cintrées ont disparu au profit de colonnes. Voir Pauline Prevost-Marcilhacy, «James de Rothschild à Ferrières: les projets de Paxton et de Lami ", Revue de l'art, $n^{\circ}$ 100, 1993, p. 58-73, et spécialement p. 61-63.

3. Pauline Prevost-Marcilhacy, Les Rothschild, bâtisseurs et mécènes, op. cit., p. 94-98, p. 105-109 et p. 308-310 ; et Pauline Prevost-Marcilhacy, "Le château de Ferrières ", dans id. (dir.), Les Rothschild. Une dynastie de mécènes en France, vol. III, 1935-2016, Paris, Louvre/BnF/Somogy, 2016, p. 326-339.

4. Pauline Prevost-Marcilhacy, «James de Rothschild à Ferrières: les projets de Paxton et de Lami », art. cit., p. 71.

5. Sur la production de robbiesques au XIX ${ }^{e}$ siècle, voir Lia Bernini, « Il revival robbiano ", dans Giancarlo Gentini (dir.), I Della Robbia e l'«arte nuova» della scultura invetriata, cat. exp. (Fiesole, Basilica di Sant'Alessandro, 29 mai - $1^{\text {er }}$ nov. 1998), Florence, Giunti, 1998, p. 380-386 ; voir aussi Giancarlo Gentilini, «Falsificazioni robbiane », dans Mark Jones et Mario Spagnol (dir.), Sembrare e non essere. I falsi nell'arte e nella civiltà, Milan, Longanesi \& C., 1993, p. 242-248.

6. La famille Contucci portait: " D'azzurro, al liocorno inalberato d'oro ». Voir la base de données de l'Archivio di Stato de Florence, Ceramelli Papiani, blasoni delle famiglie toscane nella Raccolta Ceramelli Papiani, fasc. 5478, archiviodistato.firenze.it/ceramellipapiani/index.php? page=Famiglia\&id=2572 (consultée le 25 novembre 2018). La famille Iozzelli, du quartier Santa Croce, gonfalon du Lion noir, portait en effet « D'azzurro, a tre pesci nuotanti al naturale (o d'oro), ordinati l'uno sull'altro", voir ibid., fasc. 2631, archiviodistato.firenze.it/ceramellipapiani/ index.php?page=Famiglia\&id=4139 (consultée le 25 novembre 2018).

7. Sur les armes Martellini, «Di rosso, al monte di sei cime d'oro sostenente un falcone sorante [sic pour sonante] dello stesso (oppure al naturale, sonagliato d'oro), talvolta con la zampa destra alzata, in atto di afferrare il sonaglio con il becco; e alla banda diminuita d'azzurro attraversante sul tutto ", voir la base de données de l'Archivio di Stato de Florence, Ceramelli Papiani, blasoni delle famiglie toscane nella Raccolta Ceramelli Papiani, fasc. 3034, archiviodistato.firenze.it/ceramellipapiani/index.php? page=Famiglia\&id=4780 (consultée le 30 novembre 2018). Pour l'écu de Galluzzo, voir Renzo Dionigi (dir.), Stemmi robbiani in Italia e nel mondo. Per un catalogo araldico, storico e artistico, Florence, Polistampa, 2014, p. 192, $\mathrm{n}^{\circ} 181$.

8. Le tondo représentant Isotta comprend aussi le chiffre des deux amoureux, leurs deux initiales « $\mathrm{S}$ » et « I » entrelacées; celui à l'effigie de Sigismondo arbore des armoiries avec un écartelé, au 
1 et 3, Malastesta (d'argent à trois bandes échiquetées d'or et de gueules) et au 2 et 4 , ce même chiffre «SI", comme ceux que l'on voit sur le Tempio Malatestiano de Rimini. Dans une collection privée parisienne, il existe un autre exemplaire, inséré dans un cadre en bois, de ce Sigismondo Pandolfo Malatesta en terre cuite émaillée produit par cet imitateur des Della Robbia. Voir Lia Bernini, "Il revival robbiano », art. cit., p. 382, repr. La médaille de Matteo de' Pasti représentant Sigismondo en capitaine de l'armée de l'Église romaine, mais sans cuirasse, a un diamètre de $83,5 \mathrm{~mm}$. Il en existe plusieurs variantes. Voir George F. Hill, Corpus of Italian Medals of the Renaissance before Cellini, Londres, British Museum, 1930, t. I, p. 39, $\mathrm{n}^{\circ}$ 163, et II, pl. 31 ; et John Graham Pollard, Renaissance medals, I, Italy, Washington, National Gallery of Art, 2007, p. 43, nº 27. Voir, par exemple, l'exemplaire du British Museum de Londres : metmuseum.org/art/collection/ search/195054, (consulté le 9 juillet 2019). Il porte au revers une représentation de la forteresse de Rimini, avec la date de 1446, où fut inauguré Castel Sismondo. La médaille à l'effigie d'Isotta degli Atti a un diamètre de $85 \mathrm{~mm}$. Voir George F. Hill, A Corpus of Italian Medals of the Renaissance before Cellini, op. cit., t. I, p. 43, n 187, et t. II, pl. 35 ; et John Graham Pollard, Renaissance medals, op. cit., p. 50, $\mathrm{n}^{\circ}$ 33. Il y en a également plusieurs variantes. Voir l'exemplaire du Victoria and Albert Museum de Londres, inv. A.175-1910 : collections.vam.ac.uk/item/0111541/isotta-degliatti-medal-de-pasti-matteo/ (consulté le 8 juillet 2019). Elle présente au revers un éléphant et la date de 1446, qui ne correspond pas à l'année d'exécution, mais à celle où Isotta devint la maîtresse de Sigismondo et où commença la rédaction du Liber Isottaeus, qui ne fut pas achevé avant 1451. Malatesta ne l'épousa pas avant 1453. Voir Pier Giorgio Pasini, "Matteo de' Pasti: Problems of Style and Chronology », dans John Graham Pollard (dir.), Italian Medals, Washington, National Gallery of Art (Studies in the History of Art, XXI), 1987, p. 143-159; et Costanza Dopfel, «Book and Temple: The story behind Matteo de' Pasti's Medals of Sigismondo Malatesta and Isotta degli Atti », The Medal, 55, automne 2009, p. 4-18, particulièrement p. 9-13.

9. H. : $69 \mathrm{~cm}$; L. : $66 \mathrm{~cm}$. Pour l'Hadrien en jeune héros de Tivoli, Villa Hadriana, Antiquario del Canopo, inv. 2260, voir la notice de Benedetta Adambri, dans Marina Sapelli Ragni (dir.), Villa Adriana. Una storia mai finita. Novità e prospettive della ricerca, cat. exp. (Tivoli, Villa Adriana, Antiquarium del Canopo, 2010), Milan, Electa, 2010, p. 181, $\mathrm{n}^{\circ} 9$; et beniculturali.it $/ \mathrm{mibac} /$ export/MiBAC/sito-MiBAC/Menu-Utility/Immagine/index.html_646084122.html. Il s'agit de la version sculptée d'un Hadrien du type "Renatus", connu par les émissions monétaires de 130 apr. J.-C. Voir Joachim Raeder, Die statuarische Ausstattung der Villa Hadriana bei Tivoli, Francfort-sur-le-Main/Berne, Peter Lang, 1983, p. 88-92, n I 88, et pl.1. Voir aussi une copie moderne de cette tête, dont le sujet n'a pas été identifié, indiquée de façon erronée comme antique dans le catalogue des sculptures du château de Versailles sous le titre de Romain, inv. MV 7439 ; voir Simone Hoog, Musée national du château de Versailles. Les sculptures, I, Le Musée, Paris, Éditions de la Réunion des musées nationaux, 1993, p. 188, nº 824.

10. Le buste est ainsi décrit au $\mathrm{n}^{\circ} 51$ dans le «Catalogue des Meubles et Objets d'Art de $\mathrm{M}^{\mathrm{r}}$ le Baron James de Rothschild", registre in-folio, toujours en mains privées, dont la transcription par Hervé Grandsart en 1997 a été déposée dans les collections patrimoniales de la bibliothèque de l'INHA : «Buste de jeune guerrier cuirassé sur piédouche carré en brèche violette (colonnade du 2 étage) ».

11. Pensons aux bustes des collections des princes de Liechtenstein (Vaduz et Vienne) : Vénus (1692), inv. SK 1365; Adonis (1692), inv. SK 1366; Bacchus (1695-1700), inv. 1367 ; et Ariane (1695-1700), inv. SK 1368. Voir les notices d'Olga Raggio dans John Philip O'Neill (dir.), Liechtenstein. The Princely Collections, cat. exp. (New York NYprince, The Metropolitan Museum of Art, 1985-1986), New York, NY, Metropolitan Museum of Art, 1985, p. 23-25, $n^{\text {os }} 11-14$.

12. Voir le plan actuel du rez-de-chaussée du château dans Pauline Prevost-Marcilhacy, «James de Rothschild à Ferrières : les projets de Paxton et de Lami », op. cit., p. 68, fig. 31.

13. Antonin le Pieux, avec inscription: "ANTONINVS .", diam. $70 \mathrm{~cm}$, Turin, Palazzo Madama, Museo Civico d'Arte Antica, inv. 3380/C. Voir la notice de Giovanni Donato dans Silvana Pettenati 
et Giovanni Romano (dir.), Il Tesoro della Città. Opere d'arte e oggetti preziosi da Palazzo Madama, cat. exp. (Turin, Palazzina di Caccia di Stupinigi, Il Tesoro della Città. Opere d'arte e oggetti preziosi da Palazzo Madama, 31 mars - 8 sept. 1996), Turin, Umberto Allemandi \& C., 1996, p. 22-23, nº 32. Sur le site du musée, la photographie est inversée: palazzomadamatorino.it/it/le-collezioni/ catalogo-delle-opere-online/imperatore-antonino-pio (consulté le 7 juillet 2019). Les autres médaillons à guirlandes ont respectivement pour numéro d'inventaire 3378/C, 3379/C et 3381/C. Voir Allan Marquand, Andrea Della Robbia and his Atelier, 2 vol., Princeton, NJ, Princeton University Press, vol. II, p. 12, $\mathrm{n}^{\circ}$ 329. Sur la base d'une description ancienne, on sait que figuraient au château un Néron, un Galba et un Hadrien. Voir Antonio Bosio, «Due monumenti inediti del Piemonte illustrati », Miscellanea di storia italiana, 15, 1874, p. 454-471, spécialement p. 455 ; Giovanni Donato, «Materiali di primo Cinquecento per i Della Rovere di Vinovo », dans Giovanni Romano (dir.), Domenico della Rovere e il Duomo nuovo di Torino. Rinascimento a Roma e in Piemonte, Turin, Cassa di Risparmio di Torino, 1990, p.329-389, et particulièrement p.374; et surtout Francesca Petrucci, «Filippo Vagnone, committente di sculture », dans Simone Baiocco (dir.), Il sarcofago di Filippo Vagnone. Committenza e gusto per l'antico, Savigliano, L'Artistica Editrice, 2011, p. 43-56, particulièrement p. 53-55. Francesca Petrucci émet deux hypothèses: le diplomate se serait arrêté en Toscane en 1493, à l'occasion de son ambassade à Rome auprès du pape Alexandre VI ou bien la duchesse Bianca - qui, dans une lettre du 28 mars 1491, appelait Laurent le Magnifique «caro amico » - lui aurait confié une autre mission à Florence, cité dont elle aurait cherché l'appui pour renforcer une alliance contre la France.

14. Sur Filippo Vagnone, voir Maria Clotilde Gentile, "Filippo Vagnone, "magnifico cavaliere" ", dans Simone Baiocco (dir.), Il sarcofago di Filippo Vagnone. Committenza e gusto per l'antico, op. cit., p. 33-42. Sur l'installation de Vagnone à Castelvecchio di Testona, voir Carlotta Margarone, " "Eius est salis, eius elegantiae et eruditionis. Fonti storiche e ricerche d'archivio" ", ibid., p. 19-31, et surtout p. 28 ; et Maria Clotilde Gentile, "Filippo Vagnone, "magnifico cavaliere" ", ibid., p. 36. Filippo avait acquis les trois quarts du château le 6 novembre 1489 , son père Paoletto le dernier quart; il reçut l'investiture de l'ensemble le 7 avril 1490. Voir Maria Clotilde Gentile, ibid., p. 36. Nous n'avons pas pu consulter l'ouvrage de Marina Paola Milia, Castelvecchio di Testona, Turin, Centro Studi Piemontesi, 2014.

15. Sur les médaillons produits par Andrea Della Robbia et son atelier présentant des héros à l'antique et, en particulier, pour le cycle commandé par Alphonse d'Aragon pour la villa de Poggioreale en 1492, voir Roberto Pane, Il Rinascimento nell'Italia meridionale, 2 vol., Milan, 1975-1977, t. II, p. 41-47 ; Giancarlo Gentilini, I Della Robbia. La scultura invetriata nel Rinascimento, 2 vol. Florence, Cantini, 1992, vol. I, p. 216-217 ; et Tommaso Mozzati, « “Fantasie” all'antica: temi mitologici e profani nella terracotta invetriata », dans Giancarlo Gentilini (dir.), I Della Robbia. Il dialogo tra le Arti nel Rinascimento, cat. exp. (Arezzo, Museo Statale d'Arte Medievale e Moderna, 2009), Milan, Skira, 2009, p.129-135. Le tondo avec personnage lauré et rubans blancs, d'un diamètre de $41 \mathrm{~cm}$ et provenant du cycle napolitain, qui avait figuré à la vente Stefano Bardini chez Christie's à New York en 1918, est actuellement proposé par la galerie Daniel Katz de Londres : katz.art/artworkdetails/810452/17957/andrea-della-robbia-florence-1435-florence (consulté le 8 juillet 2019).

16. Le tombeau était destiné à l'église conventuelle San Francesco de Moncalieri, détruite en 1788. À l'origine, une effigie équestre surmontait son couvercle. Il passa ensuite à la Villa Lascaris, près de Pianezza, propriété des Domaines. Son dépôt au Museo Civico d'Arte Antica de Turin fut autorisé en 1867. Il s'y trouve depuis 1870 (inv. 474/PM). Les reliefs sont sans doute dus à un artiste lombard, qui les sculpta vers 1500. Filippo Vagnone avait donné des instructions précises sur son tombeau dans son testament rédigé en septembre 1499 et conservé dans une transcription rédigée en 1581 par le notaire Giovanni Antonio Gregori de Moncalieri, conservée à l'Archivio di Stato de Turin (AsTo, Paesi, Torino, mazzo 30, inv. 16, Testamento di Filippo Vagnone [...]. Voir Simone Baiocco, «Introduzione (l'opera in museo)», dans Simone Baiocco (dir.), Il 
sarcofago di Filippo Vagnone. Committenza e gusto per l'antico, p. 9-18 ; Carlotta Margarone, " "Eius est salis, eius elegantiae et eruditionis. Fonti storiche e ricerche d'archivio" ", ibid., p. 24-25; Francesca Petrucci, «Filippo Vagnone, committente di sculture », ibid., p. 43-52; et la notice en ligne du musée : palazzomadamatorino.it/it/le-collezioni/catalogo-delle-opere-online/stemmadi-filippo-vagnone-storie-di-perseo-apollo-e-le (consultée le 29 novembre 2018).

17. Pour des exemples génois, voir Valentina Fiore, «Lo spazio dell'antico nelle residenze genovesi tra XV e XVIII: la diffusione e l'evoluzione della Galaria sive loggia », dans Lauro Magnani (dir.), Collezionismo e spazi del collezionismo. Temi e sperimentazioni, Rome, Gangemi, 2013, p. 75-88 ; et Alba Bettini, A Palazzo e in Villa. Busti antichi e all'antica di Gio. Vincenzo Imperiale patrizio genovese, Gênes, Sagep, 2017.

18. Précisons que la disposition actuelle est légèrement erronée. À l'occasion de l'impeccable restauration des murs, les deux bustes du côté sud ont été inversés par rapport au display ancien, dont témoigne une photographie, prise vers 1997, qui se trouve dans les dossiers déposés par Hervé Grandsart à l'INHA (fig.13). Lors de notre visite, nous avons signalé cette bévue aux services du château, qui, espérons-le, rétabliront la juste séquence, celle que nous allons suivre. Les deux premiers bustes du côté sud ont été inversés.

19. Pauline Prevost-Marcilhacy nous signale amicalement qu'« en 1859 (ce qui correspond à la construction de Ferrières) le marchand belge Van Cuyck achète pour James "3 grandes colonnes en marbre avec bustes", "2 bustes d'empereurs romains et deux bustes Renaissance" et un trône assyrien trouvé à Ninive (que je n'ai pas vraiment identifié !), le tout pour 11550 frs. Les autres bustes ont dû être achetés à la même époque » (communication écrite du 3 décembre 2018). Elle ajoute qu'«il ne semble pas que l'ensemble des bustes ait été placé rue Laffitte: il y a bien une commande pour 12 consoles en marbre avec gaine en 1837, mais pas de mention de bustes antiques. À cette date, quelques achats de statues en marbre : Vénus Médicis et Vénus pudique, les deux placées dans la serre de la galerie de l'hôtel de la rue Lafitte. Mentionnées également, " 2 figures de bustes sur leurs piédestaux face à face aux deux extrémités de la galerie" mais sans plus de précision, ainsi qu'un Apollon berger. » Sur l'hôtel de la rue Laffitte, voir Pauline PrevostMarcilhacy, « Un hôtel au goût du jour : l'hôtel de James de Rothschild, 19, rue Laffitte », Gazette des Beaux-Arts, CCXIV, n 1506-1507, juillet-août 1994, p. 35-54 ; et Pauline Prevost-Marcilhacy, Les Rothschild, bâtisseurs et mécènes, op. cit., p. 53-63 et p. 306-307. Sur Paul Van Cuyck, peintre, restaurateur, marchand d'art et expert, décédé en 1865, voir, entre autres, Pauline PrevostMarcilhacy, "Salomon et Adèle de Rothschild», dans Pauline Prevost-Marcilhacy (dir.), Les Rothschild. Une dynastie de mécènes en France, vol. II, 1922-1935, op. cit., p. 8-31, particulièrement p. 12. Sa vente, après décès, se tint à l'hôtel Drouot du 7 au 10 février 1866.

20. Sur la constitution de la collection d'antiques de la Ny Carlsberg Glyptotek, voir Mette Moltesen, Perfect Partners. The Collaboration between Carl Jacobsen and his Agent in Rome, Wolfgang Helbig, in the Formation of the Ny Carlsberg Glyptotek 1887-1914, Copenhague, Ny Carlsberg Glyptotek, 2012.

21. Il est signé et daté sur le tronc d'arbre, au-dessous de la queue du serpent : " petitot / fecite / 1791 ». Cet Apollon de Petitot est signalé dans Pauline Prevost-Marcilhacy, "Le château de Ferrières ", art. cit., p. 326-339, et particulièrement p. 330.

22. Sur la salle des Statues, voir Yves Beauvalot, «L'École de dessin et achèvement du Palais des États de Bourgogne", dans Emmanuel Starcky et Sophie Jugie (dir.), L'Art des collections. Bicentenaire du musée des Beaux-Arts de Dijon. Du siècle des Lumières à l'aube d'un nouveau millénaire, cat. exp. (Dijon, musée des Beaux-Arts, 2000), Dijon, musée des Beaux-Arts, 2000, p. 72-89, et spécialement p. 82-84. Pour le Gladiateur de Petitot, daté de 1786, H.:167 cm; L.:140 cm; Pr. 79 cm, inv. CA 1062, voir la notice de Sophie Jugie, ibid., p. 100-101; Sylvain Laveissière, "Dijon à Rome, 1776-1792. Les artistes et les œuvres", dans Christine Lamarre et Sylvain Laveissière, Les Prix de Rome des États de Bourgogne. Lettres à François Devosge, 1776-1792, Dijon, musée des Beaux-Arts de Dijon, 2003, p. 79-80 et pl. 12 ; et les lettres de Petitot à Devosge du 31 mai 1785, 
ibid., $\mathrm{n}^{\circ} 114$ Pe 2 ; du 12 janvier 1786, ibid., p. 203-205, no 130 Pe 3 ; du 10 avril 1786, ibid., p. 208-209, no 135 Pe 4 ; du 6 août 1786, ibid., p. 216-217, nº 144 Pe 5 ; du 10 janvier 1787, ibid., p. 226-227, no 151 Pe 6 ; du 7 mai 1787, ibid., p. 230-231, n 155 Pe 7 ; du 10 juillet 1787, ibid., p. 233-234, $\mathrm{n}^{\mathrm{o}} 159$ Pe 8 ; du $1^{\mathrm{er}}$ janvier 1788 , ibid., p. 243-245, no 170 Pe 10 ; et du 7 mars 1788 [?], ibid., p. $249, \mathrm{n}^{\circ} 178$ Pe 11.

23. Lettre du 7 mars 1788 de Pierre Petitot à François Devosge, ibid., p. 249, n ${ }^{\circ} 178$ Pe 11. La gratification des États de Bourgogne lui avait été accordée le 11 janvier 1788. Voir ibid., note 29.

24. Lettre de Pierre Petitot à François Devosge du 10 juillet 1787, ibid., p. 233-234, nº 159 Pe 8.

25. Voir les lettres d'Antoine Bertrand envoyées de Rome à François Devosge : 2 juillet 1786, ibid., p. 213-214, n 141 Be 29 ; été 1786 , entre le 2 juillet et le 13 septembre, ibid., p. $215, \mathrm{n}^{\circ} 143$ Be 30 ; 13 septembre 1786, ibid., p. 217-219, $\mathrm{n}^{\circ} 145$ Be 31 ; 29 novembre 1786, ibid., p. 221-223, $\mathrm{n}^{\circ} 149$ Be 32 ; et la lettre de Pierre-Paul Prud'hon envoyée de Rome à François Devosge le 3 octobre 1786, ibid., p. 219-220, n $146 \operatorname{Pr} 10$, qui précise : «Bertrand a fait toutes les acquisitions que vous lui avez demandées pour la Province; vous aurez, entre autres figures, un Laocoon superbe et extrêmement frais, le seul beau qui soit à Rome, excepté celui de l'Académie de France à Rome, mais qui est de plus monté au point d'après l'original. » Voir aussi Sylvain Laveissière, « De Dijon à Rome : les artistes et les œuvres ", dans Emmanuel Starcky et Sophie Jugie (dir.), L'Art des collections. Bicentenaire du musée des Beaux-Arts de Dijon, op. cit., p. 60-67 et particulièrement p. 65 ; Hélène Meyer et Emmanuel Starcky, «Le Muséum de l'École de Dessin », ibid., p.91-97, et spécialement p. 96-97; et Sylvain Laveissière, «Dijon à Rome, 1776-1792 : les artistes et les œuvres ", art. cit., p. 33-85. Hélène Meyer et Emmanuel Starcky précisent que le plâtre du Laocoon de la collection Mengs «fut en toute logique placé dans la salle des Statues, il y resta probablement jusqu'à ce que Gasc l'enlève en 1932 ; il aurait alors été déposé dans le préau d'un lycée et fut détruit en 1940 ! ", voir Hélène Meyer et Emmanuel Starcky, « Le Muséum de l'École de dessin », art. cit., p. 96. Selon Christine Lamarre et Sylvain Laveissière, « le moulage du Laocoon venant de Mengs a été brisé après avoir été déposé dans un lycée dijonnais vers 1939 ", dans Christine Lamarre et Sylvain Laveissière, Les Prix de Rome des États de Bourgogne. Lettres à François Devosge, 1776-1792, op. cit., p. 219, note 114.

26. Inv. CA 1070. H. : 2,20 m ; L. : 1,40 m. Voir Sylvain Laveissière, «De Dijon à Rome : les artistes et les œuvres ", art. cit., p. 64-65 ; et Sylvain Laveissière, « Dijon à Rome, 1776-1792 : les artistes et les œuvres ", art. cit., p. 46-51, et pl. 7.

27. Ibid., p. 261-262, n 193 Be 39.

28. Sur la famille de Brienne, voir Emmanuel Pénicaut, "Des Brienne à la Révolution", dans Emmanuel Pénicaut et al. (dir.), L'Hôtel de Brienne, Paris, Nicolas Chaudun et $C^{\text {ie }}, 2012$, p. 48-67.

29. Henry de Morant, Ville d'Angers. Sculptures du XVIII siècle au musée des Beaux-Arts, Baugé, impr. de E. Cingla, n. d. [1956], p. 18, repr. Cette Minerve (H. : 0,7 m ; L. : 0,41 m ; Pr. : 0,45 m; inv. MA 7 R 1140) fut donnée par $M^{m e}$ de La Broise au musée des Beaux-Arts d'Angers en 1946. Elle est signée et datée au dos : «Petitot 1789 »; elle est actuellement dans les réserves du musée. Vient en outre d'apparaître sur le marché de l'art britannique, dans la galerie Brun Fine Art de Londres, une réduction en marbre d'1,05 $\mathrm{m}$ de haut, de la Minerve Giustiniani, de très belle qualité, que Petitot signa et data en 1795. Voir la notice d'Andrea Bacchi, dans brunfineart.com/artworks/104/ (consultée le 23 novembre 2018). Enfin, la Tête d'homme en marbre d'après l'antique, qu'il exposa au Salon de 1793, avait peut-être été ébauchée en Italie. Voir Stanislas Lami, Dictionnaire des sculpteurs de l'École française au dix-huitième siècle, 2 vol., Paris, Honoré Champion, 1910-1911, t. II, p. 235.

30. L'œuvre avait été découverte à Tusculum (Tivoli) entre 1770 et 1780, dans une villa qui aurait appartenu à Lucinius Murena. Depuis son acquisition à Paris en 1815, elle est conservée à la Glyptothek de Munich, inv. Gl. 213, H. : 114 cm (avec le socle). Voir Barbara Vierneisel-Schlörb, 
Glyptothek München. Katalog der Skulpturen, II, Klassische Skulpturen des 5. und 4. Jahrhunderts v. Chr., Munich, C. H. Beck, 1979, p. 136-146, nº 12, et fig. 61-65.

31. Alfred Mettrier, Pierre Petitot (de Langres) et son fils Louis Petitot. Notice biographique, Langres, Imprimerie de E. L'Huillier, 1867, p. 34, note 1.

32. Philippe Seydoux, Gentilhommières en Champagne, II, Pays de l'Aube, Paris, Éditions de la Morande, 2016, p. 153-158 et p. 318-319.

33. Voir Joseph Perrin, Le Cardinal Loménie de Brienne, archevêque de Sens. Ses dernières années. Épisodes de la Révolution, Sens, Imprimerie de Paul Duchemin, 1896, p. 58, n.1, qui évoque l'inventaire dressé les 18, 19 et 21 octobre 1793 par le notaire Chandenier (Auxerre, Archives de l'Yonne, série Q, inventaires dressés pendant la Révolution, Sens, abbaye de Saint-Pierre-le-Vif) et le mobilier « fort riche » qui « ne fut pas estimé moins de 60771 livres».

34. Voir Stanislas Lami, Dictionnaire des sculpteurs de l'École française au dix-huitième siècle, op. cit., t. II, p. 235 et 237.

35. H. : $66 \mathrm{~cm}$; L. : $70 \mathrm{~cm}$, avec un piédouche en marbre portor (H : 20,8 cm ; L. : $27 \mathrm{~cm})$. Le buste porte au dos une inscription manuscrite peinte en bleu $: 3$.

36. Inv. R.F. 3649. H. : 79,2 cm ; L. : $67 \mathrm{~cm}$; Pr. $31 \mathrm{~cm}$ (plus un piédouche H. : 11,5 cm). Sur la Diane de Ponsonelli, acquise en 1983, voir la notice de Jean-René Gaborit dans Jean-René Gaborit, Musée du Louvre. Nouvelles acquisitions du Département des Sculptures, cat. exp. (Paris, musée du Louvre, 1984), Paris, Éditions de la Réunion des musées nationaux, 1984, p.58-60, nº 18 ; et Fausta Franchini Guelfi et al., Jacopo Antonio Ponzanelli. Scultore, architetto, decoratore. Carrara 1654 - Genova 1735, Fosdinovo, Associazione artistico culturale Per Corsi d'arte, 2011, p. 84-85, p. 92, pl. 35, et p. $394-395, \mathrm{n}^{\circ} 38$.

37. H. : $70 \mathrm{~cm}$; L. : $68 \mathrm{~cm}$, avec un piédouche en marbre rouge (H. : $21,2 \mathrm{~cm} ;$ L. : $27 \mathrm{~cm}$ ). Au revers, une inscription manuscrite peinte en bleu: 1. Il semble dater de la fin du XVI ${ }^{\mathrm{e}}$ ou du début du $\mathrm{XVII}^{\mathrm{e}}$ siècle.

38. Inv. 6033 et 6088. Voir Carlo Gasparri (dir.), Le Sculture Farnese, II, I ritratti, Naples, Electa, 2009 , respectivement p.111-112, $\mathrm{n}^{\circ} 86$, et p. 296-299, pl. LXXXI, 1-5; et p.112-113, $\mathrm{n}^{\circ} 87$, et p. 300-303, pl. LXXXII, 1-6.

39. H. : $67 \mathrm{~cm}$; L. : $58 \mathrm{~cm}$, sur un piédouche de marbre portor (H. : $21,5 \mathrm{~cm} ;$ L. : $27,4 \mathrm{~cm}$ ). Aucune inscription au dos.

40. H. : $63 \mathrm{~cm}$; L. : $61 \mathrm{~cm}$, sur un piédouche de marbre blanc veiné gris (H. : 22,7 cm; L. : 28,4 cm). $\mathrm{Au}$ dos, une inscription manuscrite peinte en bleu : 4. Il semble aussi dater du XVII ${ }^{\mathrm{e}}$ siècle. Pour les portraits d'enfants la bouche ouverte, du type « souffrant ", voir par exemple l'Enfant inconnu du musée du Louvre, inv. Ma 2332 (Kate de Kersauson, Catalogue des portraits romains, II, De l'année de la guerre civile (68-69 après J.-C.) à la fin de l'Empire, Paris, Réunion des musées nationaux, 1996, p. 106, $\left.\mathrm{n}^{\circ} 41\right)$.

41. H. : $66 \mathrm{~cm}$; L. : $61 \mathrm{~cm}$, sur un piédouche en marbre rouge (H. : $21,5 \mathrm{~cm} ;$ L. : $27,5 \mathrm{~cm})$. Au dos, une inscription manuscrite $: 6$.

42. Voir par exemple l'exemplaire des Musei Capitolini, inv. 461. Voir Klaus Fittschen et Paul Zanker, Katalog der römischen Porträts in den Capitolinischen Museen und der anderen kommunalen Sammlungen der Stadt Rom, I, Kaiser- und Prinzenbildnisse («Beiträge zur Erschließung hellenistischer und kaiserzeitlicher Skulptur und Architektur, 3 »), Mayence, Philipp von Zabern, 1985, p. 95-97, $\mathrm{n}^{\circ} 83$, et pl.102-103. Pour les portraits sculptés de Septime Sévère du type "Sérapis », voir Anna Margherite McCann, The Portraits of Septimius Severus (AD. 193-211), Rome, American Academy in Rome («Memoirs of the American Academy in Rome», 30), 1968, p. 151-178, et pl. LIV-LXXXII ; et Dirk Soechting, Die Porträts des Septimius Severus, Bonn, R. Habelt (« Habelts Dissertationsdrucke. Reihe klassische Archäologie », 4), 1972, p. 49-57.

43. H. : $68 \mathrm{~cm}$; L. : $61 \mathrm{~cm}$, sur un piédouche en marbre rouge (H.: $22 \mathrm{~cm} ; \mathrm{L} .: 27,5 \mathrm{~cm}$ ). Il porte au dos une inscription manuscrite $: 5$. et pourrait dater du XVIII ${ }^{\mathrm{e}}$ ou du début du XIX $\mathrm{X}^{\mathrm{e}}$ siècle. 
44. H. : 0,60 m. Naples, Museo Archeologico Nazionale, inv.6141. Sur cette copie du début de l'époque augustéenne d'un original grec du $\mathrm{II}^{\mathrm{e}}$ siècle av. J.-C., voir Carlo Gasparri, Le Sculture Farnese, II, I ritratti, op. cit.,p. 55-56, $n^{\circ}$ 32, et p. 188-189, pl. XXXII, 1-5. Cette tête acquit une grande notoriété dès le XVII ${ }^{\mathrm{e}}$ siècle. Sur les imitations de ce buste à l'époque moderne, voir Klaus Fittschen, Die Bildnisgalerie in Herrenhausen bei Hannover. Zur Rezeptions- und Sammlungsgeschichte antiker Porträts, Göttingen, Vandenhoeck \& Ruprecht ( Abhandlungen der Akademie der Wissenschaften zu Göttingen, Philosophisch-Historische Klasse», 3, 275), 2006, p. 284-293. Au château de Versailles est conservée une autre version fantaisiste du prétendu Lysimaque, avec un large torse et un manteau aux plis ondulés serré à la poitrine par un baudrier (inv. MV 7478), et cataloguée de façon erronée sous le titre de Romain et comme antique dans Simone Hoog, Musée national du château de Versailles. Les sculptures, I, Le Musée, op. cit., p. 188, nº 825. En outre, Antoine Devosge en possédait un moulage en plâtre, et Antoine Bertrand en fit une copie en marbre achevée en 1787 et envoyée à Dijon à la fin de cette même année, l'acquisition en ayant été agréée par les États de Bourgogne. H. : 0,61 m ; L. : 0,38 m. Dijon, musée des Beaux-Arts, inv. CA 949. Voir Sylvain Laveissière, «Dijon à Rome, 1776-1792 : les artistes et les œuvres », art. cit., p. 65 ; et les lettres de Bertrand à Devosge du 29 novembre 1787, ibid., p. 221-223, et fig. 29, n 149 Be 32 ; sans date [vers le 10 novembre ? avant 6-8 décembre 1787], ibid., p. 239-240, $\mathrm{n}^{\circ} 165$ Be 34 ; et sans date [après le 10 novembre ? avant 6-8 décembre 1787], ibid., p. 240, n 16 Be 35.

45. H. : $67 \mathrm{~cm}$; L. : $60 \mathrm{~cm}$, avec un piédouche en marbre gris (H.: $21 \mathrm{~cm} ;$ L. : $27 \mathrm{~cm})$. Aucun signe au dos. Pour les bustes de Marc Aurèle du IV type, voir Max Wegner, Das Römische Herrscherbild, II. 4, Die Herrscherbildnisse in antoninischer Zeit, Berlin, Gebr. Mann, 1939, p. 44-46, pl. 26-29. Pour l'exemplaire des Musei Capitolini à Rome (inv. 448), voir Klaus Fittschen et Paul Zanker, Katalog der römischen Porträts in den Capitolinischen Museen und der anderen kommunalen Sammlungen der Stadt Rom, I, Kaiser- und Prinzenbildnisse, op. cit., p. 76-77, $\mathrm{n}^{\circ}$ 69, et pl. 79, 81 et 82. Pour les bustes de Septime Sévère du type « de l'adoption », voir Anna Margherite McCann, The Portraits of Septimius Severus (AD. 193-211), op. cit., p. 101-106 et pl. XLI-L ; et Dirk Soechting, Die Porträts des Septimius Severus, op. cit., p. 41-48.

46. Inv. 17677. H. : 71,1 cm ; L. : $63,5 \mathrm{~cm}$; Pr. $38,1 \mathrm{~cm}$, sans la base. Selon Klaus Herding, Pierre Puget. Das bildnerische Werk, Berlin, Mann, 1970, p.66, p. 162-163, n³1, le buste fut sculpté vers 1667-1668. Voir aussi Davide Gambino et Lorenzo Principi, Filippo Parodi, 1630-1702. Genoa's Bernini: a Bust of Vitellius, "Undeci de essi busti sono di Monsu Puget, et un di Filippo Parodi », cat. exp. (Gênes, Museo di Palazzo Reale, 2016), Florence, Bacarelli et Botticelli, 2016, p. 44-61 et fig. 40, 41 et 43. Le bozzetto en terre cuite, provenant de la collection Bourguignon de Fabregoules $(17,5 \times 19 \times 9 \mathrm{~cm})$, est au musée Granet d'Aix-en-Provence, inv. 860-1-90-S. Voir la notice de Lauro Magnani dans Ezia Gavazza et Giovanna Rotondi Terminiello (dir.), Genova nell'età barocca, cat. exp. (Gênes, Galleria Nazionale di Palazzo Spinola/Galleria di Palazzo Reale, 1992), Bologne, Nuova Alfa Editoriale, 1992, p. 334, $\mathrm{n}^{\circ} 216$; et celle de Luc Georget dans Marie-Paule Vial (dir.), Pierre Puget. Peintre, sculpteur, architecte (1620-1694), cat. exp. (Marseille, Centre de la Vieille Charité/Musée des Beaux-Arts, 1994-1995), Marseille/Paris, Musées de Marseille/Réunion des musées nationaux, 1994, p. 128-129, nº 40.

47. H. : 68,5 cm ; L. : $71 \mathrm{~cm}$; Pr. 38 cm. Inv. SK 9. Voir Fausta Franchini Guelfi et al., Jacopo Antonio Ponzanelli. Scultore, architetto, decoratore. Carrara 1654-Genova 1735, op. cit., p. 84-85, p. 93, pl. 36, et p. 394-395, $\mathrm{n}^{\circ} 38$.

48. Sans doute le fait d'exposer des marbres à l'air libre a-t-il joué dans cette sélection, car des marbres, voire des bronzes à l'antique d'une valeur supérieure avaient été placés dans le grand salon.

49. Je remercie chaleureusement Laura de Fuccia et Pauline Prevost-Marcilhacy de m'avoir invité à me pencher sur ce dossier. La visite de Ferrières, en la compagnie de cette dernière, et les discussions avec elle ont été particulièrement précieuses. Mes remerciements les plus vifs vont au personnel du château pour son aimable accueil. Ma gratitude va aussi aux collègues et aux 
amis qui ont répondu à mes sollicitations et m'ont fourni avis et aides de toute nature : Federica Carta, Jérôme Delatour, Daniela Gallo, Giancarlo Gentilini, Emmanuel Lamouche et Ludovic Laugier. Enfin, les dossiers généreusement déposés par Hervé Grandsart à la bibliothèque de l'INHA m'ont été d'un grand secours, particulièrement pour l'identification des modèles antiques de certains bustes.

\section{AUTEUR}

\section{PHILIPPE SÉNÉCHAL}

Philippe Sénéchal est professeur à l'université de Picardie-Jules-Verne 


\title{
Alphonse de Rothschild, acteur de la " médaillomanie » fin $\mathrm{XIX}^{\mathrm{e}}$ - début $\mathrm{xx}^{\mathrm{e}}$ siècle
}

\author{
Katia Schaal
}

1 Entre 1886 et 1905, les Rothschild et, plus particulièrement, Alphonse de Rothschild effectuent cinquante-huit dons de médailles et de plaquettes contemporaines, totalisant plus de sept cents objets, en faveur de quarante-six musées de province ${ }^{1}$. Si la période la plus intense pour ces libéralités se situe entre les années 1890 et $1895^{2}$, c'est qu'elle coïncide parfaitement avec un contexte de "médaillomanie ${ }^{3}$ ». Ce phénomène d'essor et d'engouement pour la médaille est assez similaire au mouvement de «statuomanie ${ }^{4}$ » qui agite la production artistique française de la fin du XIX ${ }^{\mathrm{e}}$ siècle. Émergeant au début des années 1880 , le goût officiel, populaire et artistique pour la médaille connaît une progression dans la décennie 1890 pour atteindre son apogée en 1900. L'éclat est néanmoins aussi vif que soudain et, dès 1910, la médaille amorce un déclin pour se voir reléguer au fond des médailliers après la Première Guerre mondiale.

Collectionneur de son temps, Alphonse de Rothschild suit cette mode contemporaine de la production médaillistique, alors qu'il semble n'avoir aucun attrait pour la médaille ancienne. Ce domaine se retrouve exclusivement couvert par James Édouard et Thérèse de Rothschild qui pourvoient à quelques grandes acquisitions de camées et de monnaies romaines dont bénéficie le Cabinet des médailles de la Bibliothèque nationale de France $^{5}$. Le soutien du baron Alphonse à un groupe restreint de médailleurs par l'achat puis l'envoi de médailles dans les musées de province se place en réalité dans la droite ligne du système de mécénat et de dons qu'il déploie en faveur de l'art contemporain ${ }^{6}$. Comme pour la peinture et la sculpture contemporaines, la médaille est achetée pour être immédiatement donnée.

Cette démarche ambitionne une répartition des œuvres significatives du renouveau de la médaille sur tout le territoire dans le but de former le goût du public et d'offrir aux artistes une source d'émulation à leur art. En revanche, on ne peut pas imaginer que la volonté de favoriser l'éclosion de foyers artistiques locaux ait présidé à la mise en place 
de ce système. À cette époque, la production médaillistique française est bien trop concentrée à Paris, avec une mainmise sur le marché et la production industrielle par l'institution régalienne qu'est l'administration des Monnaies et Médailles, en dépit d'une libéralisation du monopole de frappe instaurée par la loi de 1893 au bénéfice des éditeurs privés.

Cette dispersion de médailles sur l'ensemble du territoire privilégie des institutions muséales de moyennes voire de petites dimensions ${ }^{7}$ et engendre une patrimonialisation paradoxale de cette production, qui eut des répercussions sur l'écriture de l'histoire du renouveau de l'art de la médaille au tournant du $\mathrm{xx}^{\mathrm{e}}$ siècle.

5 La synthèse que nous proposons ici présente quelques cas qui permettent comprendre dans quelle mesure Alphonse de Rothschild a suivi, contribué voire devancé l'engouement généralisé que connaît la France des années 1890-1910 pour la médaille contemporaine. En analysant le rythme, le contenu et les destinataires de ses donations, sans oublier les artistes qui ont été soutenus par cette entremise, nous voulons questionner la représentativité dans les collections des musées de France d'une production artistique jusqu'alors concentrée à l'environnement parisien.

\section{Un mécénat privilégiant une douzaine de médailleurs}

6 En préférant la qualité à l'exhaustivité, Alphonse de Rothschild a fait le choix de ne soutenir que douze médailleurs ${ }^{8}$. Se dessine alors un panorama de l'art de la médaille assez inattendu face à son essor contemporain. Si on comptabilise le nombre de médailles données en lots aux musées de province, Jules-Clément Chaplain est l'artiste le mieux représenté avec plus de trois cents objets, suivi de Jean Désiré Ringel d'Illzach avec près de cent cinquante médailles, de Victor Peter avec plus d'une centaine et enfin de Frédéric de Vernon et d'Oscar Roty, pour ne citer que les cinq premiers médailleurs qui sont aussi les plus renommés des douze ${ }^{9}$. En revanche, si on s'intéresse au nombre d'ensembles donnés, l'ordre du trio de tête s'inverse quelque peu. Les premiers bénéficiaires de ce mécénat sont désormais Victor Peter et Jean Désiré Ringel d'Illzach avec quinze commandes chacun, suivis de Jules-Clément Chaplain qui s'en voit attribuer dix ${ }^{10}$.

7 Ce noyau restreint s'explique par trois facteurs. En premier lieu, la volonté chez Alphonse de Rothschild de diffuser le meilleur du renouveau de la médaille par le biais de la production des chefs de file du mouvement. 
1. Jules-Clément Chaplain, Proposition de restitution d'un cadre de dix-sept médailles, Lille, musée des Beaux-Arts, inv. Sc. 158-1 à 17, don d'Alphonse de Rothschild, 1887.

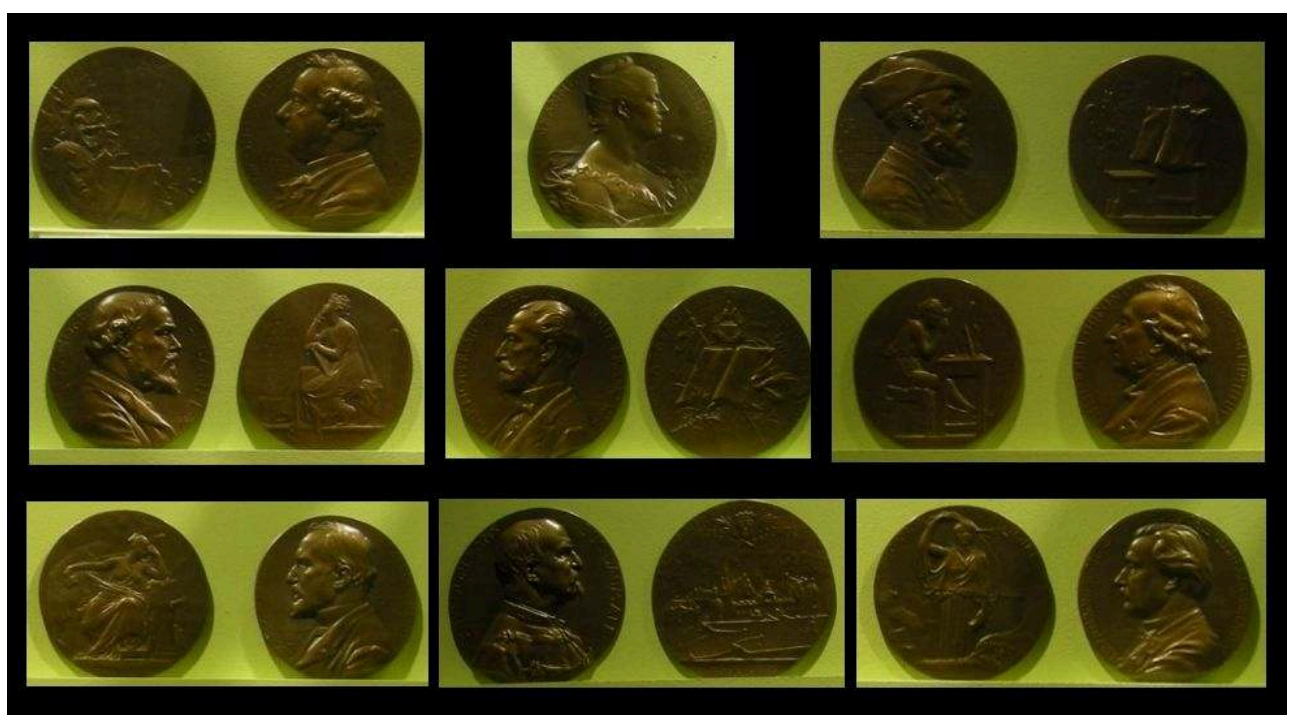

(c) Katia Schaal

8 L'œuvre de Jules-Clément Chaplain demeure à ce titre la plus répandue et respecte en cela la hiérarchie artistique qui fait de lui «le premier maître de l'école nouvelle ${ }^{11}$ ». L'attrait pour sa production émerge très tôt puisqu'elle suscite le premier don médaillistique ${ }^{12}$ : un cadre de dix-sept médailles (fig. 1) représentant quelques éminents artistes, hommes politiques et savants de l'époque, envoyé en 1887 à Lille ${ }^{13}$. En 1904, pour clore ce cycle de dix dons, c'est encore un cadre comprenant quatre-vingt-trois médailles et plaquettes qui est choisi pour rejoindre les collections du musée des Beaux-Arts de Caen ${ }^{14}$. Cette destination interroge d'ailleurs sur la motivation qui a pu présider à un envoi si fastueux. Ce cadre est-il parvenu à Caen parce que Chaplain était originaire de Mortagne-au-Perche et que le département de l'Orne était dépourvu de toute institution muséale? Aucune indication laissée par Alphonse de Rothschild ne permet d'expliquer ce choix. En revanche, d'autres intentions semblent régir son soutien indéfectible accordé à Chaplain pendant près de vingt ans. La véritable estime que se portent les deux hommes forme une première explication que vient confirmer l'exécution d'un portrait en médaille (fig.2). Comme pour d'autres collègues académiciens, Chaplain a pérennisé les traits du baron en ajoutant, au revers, une composition allégorique rendant hommage à l'acuité du goût du collectionneur. Assise derrière une console rocaille supportant un bronze représentant saint Michel terrassant le dragon, la personnification du savoir artistique contemple avec quiétude un tableau au cadre chantourné. La récurrence des achats, dont profite Chaplain, s'explique encore par le profond intérêt qu'Alphonse de Rothschild porte à son art. Il correspond en tout point à son goût pour le portrait et pour des compositions allégoriques véhiculant l'idée de progrès et les vertus des grands hommes. En outre, la médaille de Chaplain se rattache à un classicisme bien académique qui se traduit dans de petits objets toujours produits avec soin. 
2. Jules-Clément Chaplain, Baron Alphonse de Rothschild, 1899, médaillon biface, bronze fondu par Antonin Liard, d. $9,9 \mathrm{~cm}$, Paris, Bibliothèque nationale de France, département des Médailles et Antiques, inv. FL.Chaplain.137.
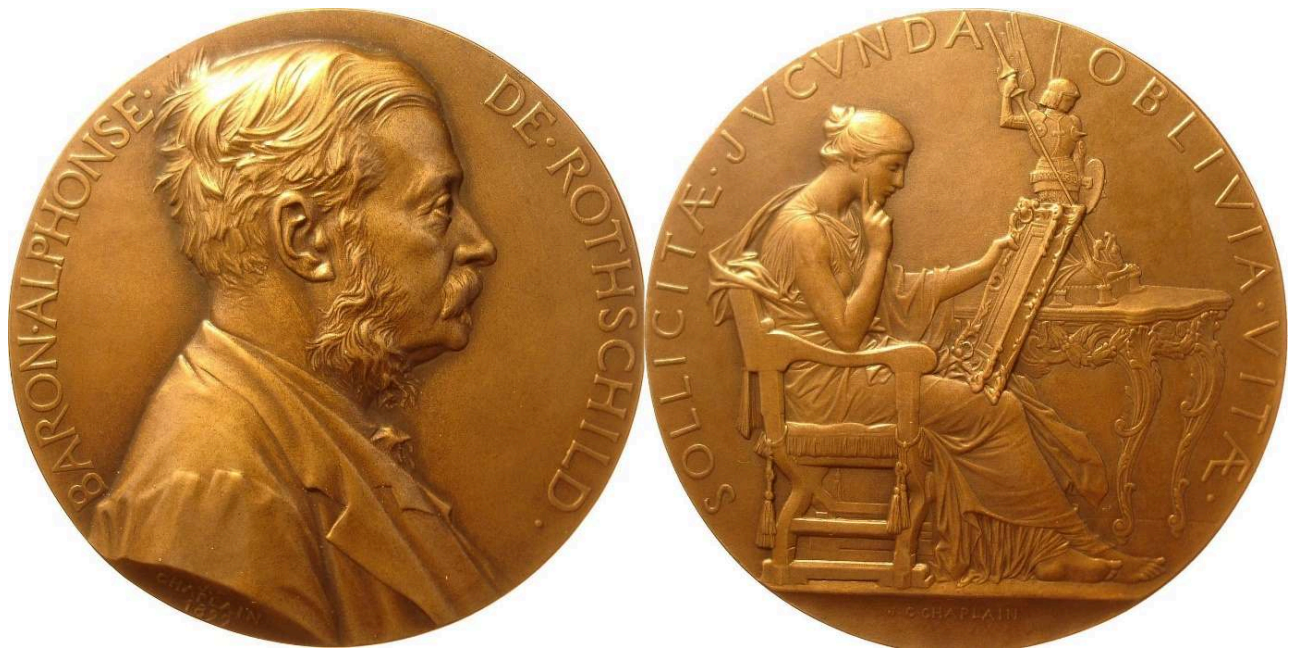

(C) Nicolas Vedelago

Oscar Roty s'avère beaucoup moins soutenu que son aîné, malgré une renommée et une activité tout aussi prolifique. Il ne semble pas avoir fréquenté les mêmes cercles de sociabilité que Chaplain, en dépit d'un fauteuil à l'Académie des Beaux-Arts situé à proximité de celui d'Alphonse de Rothschild. La question du réseau et des affinités électives s'avère ici cruciale pour comprendre le mécanisme de soutien à l'art de la médaille, auquel le donateur se consacre. Un unique cadre composé de vingt-huit médailles a ainsi été envoyé à Rouen en 1892 , cadre aujourd'hui introuvable ${ }^{15}$. Les autres dons se composent d'une seule médaille ou de plaques, comme Pittura, destinée au musée des Beaux-Arts de Lille en 1891, dont la dimension se rapproche davantage d'un bas-relief et, par conséquent, de la catégorie de la sculpture ${ }^{16}$.

Frédéric de Vernon, qui représente déjà la seconde génération du renouveau de la médaille puisqu'il a été l'élève de Chaplain, poursuit dans la même veine classique que son maitre. Des quatre dons que les inventaires mentionnent, il n'en subsiste aujourd'hui qu'un : un cadre de dix médaillons et plaquettes, destiné en 1892 au musée des Beaux-Arts de Valenciennes ${ }^{17}$.

11 Le second facteur ayant présidé au choix restreint de ces douze médailleurs est la volonté d'Alphonse de Rothschild d'encourager la production de la jeune et prometteuse génération. En se concentrant à partir de 1903 sur la production d'Hippolyte Lefebvre, Abel Lafleur, Émile-Adolphe Monier et Pierre-Charles Lenoir, le mécène développe un véritable goût précurseur et annonciateur de l'intérêt porté à leur travail, tout juste parvenu à maturité. Une question se pose alors : comment a-t-il pu détecter le talent des futurs animateurs de la discipline? Conseillé par des intermédiaires, Alphonse de Rothschild est en mesure de repérer les prédispositions de jeunes artistes. Il a ainsi sûrement bénéficié des recommandations de Chaplain qui a pu lui présenter quelques-uns de ses meilleurs élèves, comme Pierre-Charles Lenoir. Pour marquer le début de sa carrière, la date de 1907 était jusqu'à présent invoquée avec l'obtention d'un premier contrat signé avec la maison d'édition Arthus-Bertrand et Béranger ${ }^{18}$. Or, par l'achat d'un cadre de deux médailles (fig. $3 a$ et $3 b$ ), exposé au Salon de la Société des artistes français en 1904, et par son versement dans les collections du 
musée de Châteauroux, la production de cet artiste fait une entrée très précoce dans les musées ${ }^{19}$.

3a. Pierre-Charles Lenoir, Bucolique, 1904, plaquette, bronze fondu, Châteauroux, musée-hôtel Bertrand, inv. 2192, don Alphonse de Rothschild, 1904.
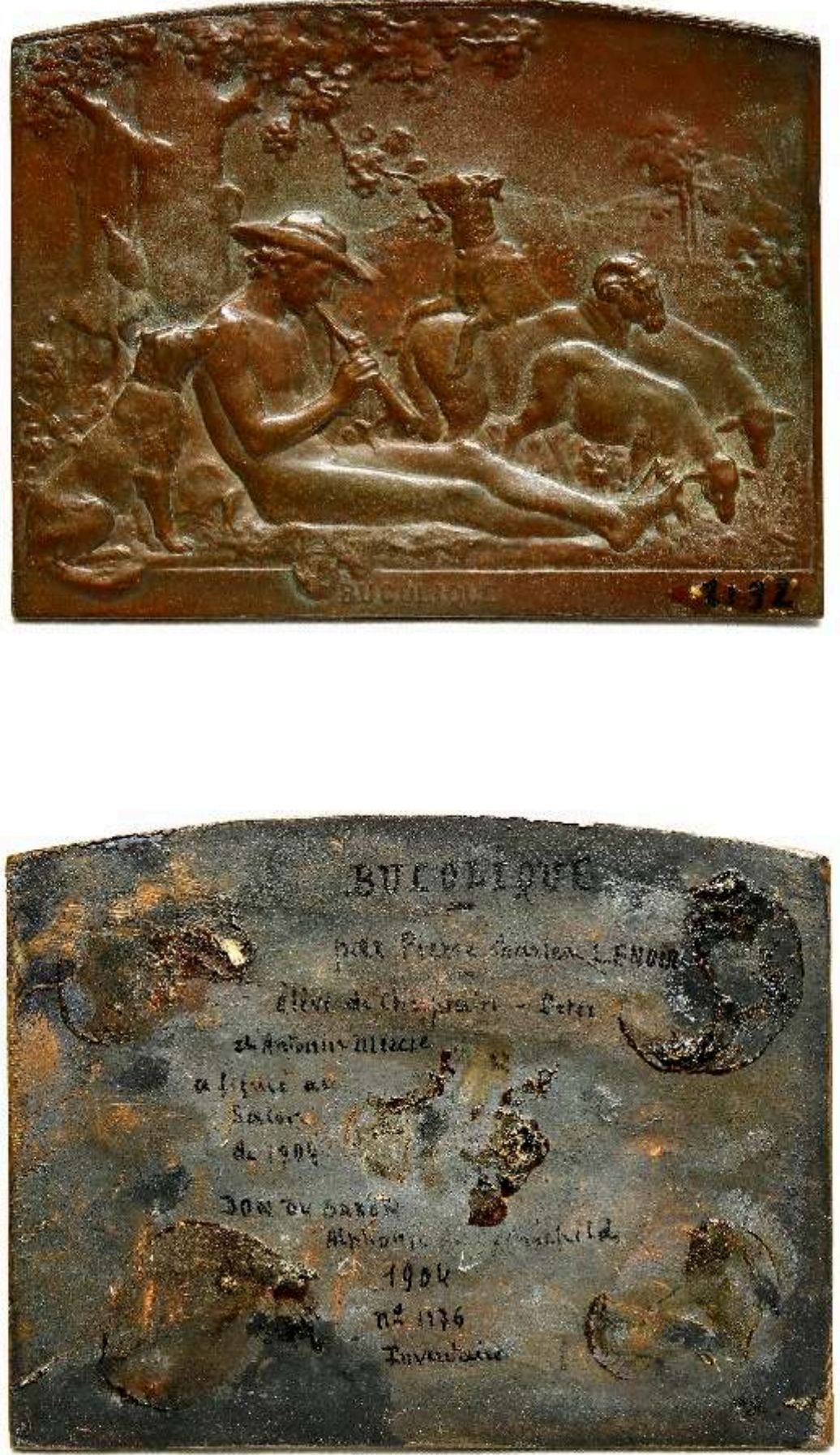
3b. Pierre-Charles Lenoir, Enfance de Bacchus, 1904, médaille, bronze fondu, Châteauroux, muséehôtel Bertrand, inv. 2193.
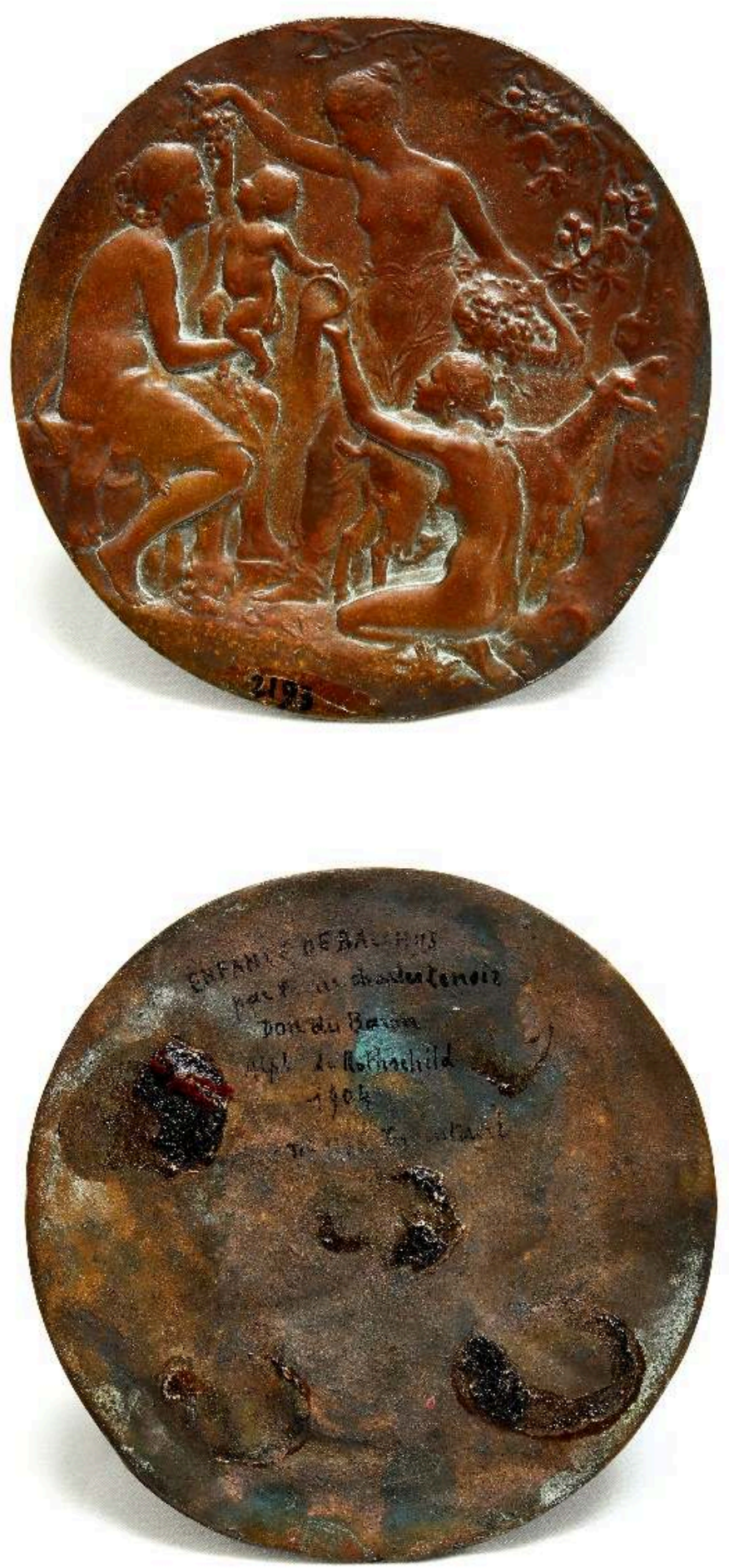

(C) Musée de Châteauroux

12 Enfin, le troisième facteur tiendrait davantage du goût personnel d'Alphonse de Rothschild qui porte certes sur des médailleurs de qualité, mais peut-être pas sur les plus éminents, comme le laisse entendre une histoire de cette discipline encore trop 
peu reconsidérée depuis les écrits de Jean Babelon ou de Fernand Mazerolle ${ }^{20}$. À l'engouement pour l'art de Chaplain s'ajoute très étonnamment un attrait pour la production de Victor Peter et de Jean Désiré Ringel d'Illzach.

Autour des années 1885, Victor Peter a été introduit par l'intermédiaire d'Auguste Rodin $^{21}$, pour lequel Victor Peter travaillait comme praticien ${ }^{22}$, dans le cercle de Léon Gauchez, fidèle conseiller artistique d'Alphonse de Rothschild. Appréciant ses compositions animalières autant que ses allégories renouvelées ou encore ses portraits intimistes, Alphonse de Rothschild lui achète chaque année plusieurs œuvres, qu'elles soient en ronde-bosse ou en médaille, puisque cet artiste était reconnu autant comme sculpteur que pour ses talents de médailleur. De fait, les œuvres signées Victor Peter inondent le territoire et viennent enrichir les collections d'une vingtaine de musées ${ }^{23}$. En retour, le sculpteur-médailleur a toujours eu un profond respect à l'égard de son mécène, auquel il rend un vibrant hommage en 1904 en composant un portrait en médaille (fig.4), dont un exemplaire se retrouve enchâssé dans le piédestal de La Bonté protégeant les arts, une statuette exécutée par Jean Escoula et offerte par souscription à Alphonse de Rothschild ${ }^{24}$.

4. Victor Peter, Alphonse de Rothschild, membre de l'Institut, 1905, médaillon uniface, bronze fondu par Antonin Liard, d. 8,9 cm, Paris, Bibliothèque nationale de France, département des Médailles et Antiques, inv. FL.Peter.122.

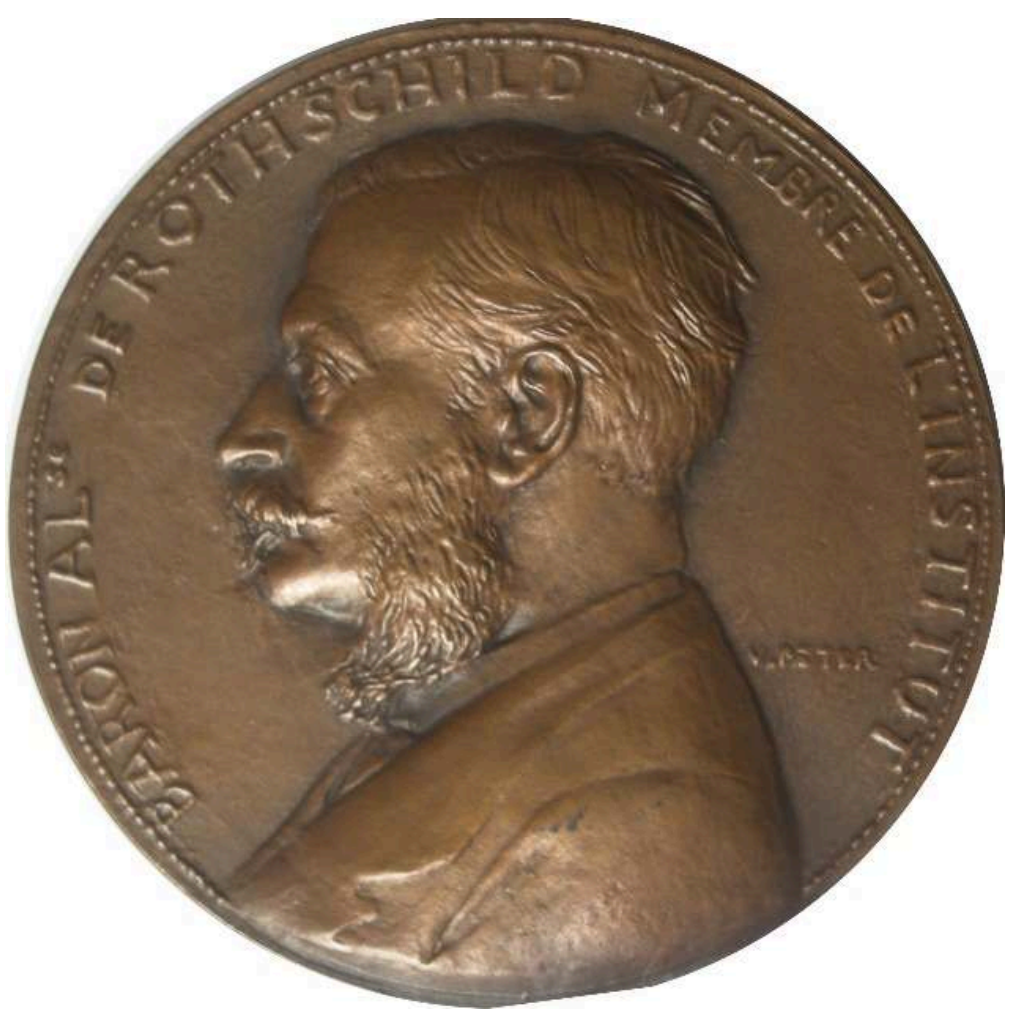

(c) Katia Schaal

Jean Désiré Ringel d'Illzach a également pu compter sur Léon Gauchez pour voir sa production soutenue par Alphonse de Rothschild. L'ensemble des achats se concentre sur trois ans, de 1893 à 1895, et exclusivement par lot de six, dix ou douze médaillons fondus en bronze, rassemblés dans des cadres ${ }^{25}$. Ce mécénat intensif offre au médailleur la possibilité de mener une carrière autonome. Il se passe d'ailleurs de toute exposition au Salon des artistes français à partir de $1890^{26}$. À ce titre, le rôle essentiel de Léon 
Gauchez dans l'accompagnement de la carrière de Ringel permet de s'interroger sur la réalité du goût du baron pour cet art expressif du portrait. L'omniprésence de Ringel dans les envois aux musées de province ne serait-elle pas la preuve d'une orientation du goût du mécène par son conseiller, voire n'émanerait-elle pas de l'omnipotence de Léon Gauchez en matière d'acquisition ${ }^{27}$ ? Dès 1880 , il commande en effet, par le biais de la revue L'Art dont il est aussi le directeur, une série de portraits de célébrités littéraires, scientifiques ou politiques afin d'aider l'artiste qui se trouve en grande difficulté28. Conservant ensuite le droit de reproduction, la Librairie de l'Art, attachée à la revue du même nom, poursuit l'édition et la vente de ces médaillons au prix unitaire de vingt francs ${ }^{29}$. Très subtilement, la dispersion de ces objets à travers les collections françaises a donc pu servir à promouvoir une production commerciale.

La question de l'influence exercée par Léon Gauchez sur le goût du mécène et son rôle d'intermédiaire pour faciliter les acquisitions se pose aussi dans les mêmes termes pour Roger $\mathrm{Marx}^{30}$. Défenseur des arts mineurs et promoteur d'un art à vocation sociale, il possède sûrement une part de responsabilité dans la sensibilisation d'Alphonse de Rothschild à l'art de la médaille par le biais de Léon Gauchez et ce, à partir de 1889 . Cette date correspond au début de la campagne de presse que le critique livre en faveur de la refonte des types monétaires et trouve elle-même sa source dans un contexte nouvellement propice à la médaille, depuis les présentations rétrospectives organisées dans le cadre de l'Exposition universelle ${ }^{31}$.

L'intervention de conseillers n'est donc pas à négliger pour aborder cette question cruciale de l'enrichissement des collections numismatiques des musées de France. Ne pouvant être l'œuvre d'un seul homme en raison de l'abondance des médailles données et $d u$ nombre d'institutions muséales touchées, il est bien davantage le fruit d'une concertation réfléchie entre différents acteurs et différents moyens d'approvisionnement.

\section{La multiplication des voies et du réseau d'approvisionnement}

17 Une partie des médailles dispersées à travers la France par le biais de dons provient d'achats réalisés aux Salons des artistes français, dans la section entièrement dédiée à cet art depuis sa création en $1867^{32}$. Pour exemple, en 1904, Victor Peter expose deux cadres de plaquettes acquis simultanément par Alphonse de Rothschild, mais qui ne rejoignent pas la même institution ${ }^{33}$. Le premier, figurant au $n^{0} 3465$ du catalogue, est destiné au musée de la Société archéologique d'Avesnes-sur-Helpe où il a disparu durant le conflit de 1914-1918 ${ }^{34}$. Heureusement, la mention du livret détaille son contenu de telle manière que nous pouvons recomposer son agencement en prenant pour référence des exemplaires similaires de plaquettes en provenance d'autres collections ${ }^{35}$. Quant au second, il a été envoyé au musée des Beaux-Arts d'Abbeville (fig.5) qui vient récemment de le retrouver à l'occasion du récolement de ses collections $^{36}$. 
5. Victor Peter, Cadre contenant six plaquettes en bronze, 1904, 64,5 $\times 80 \mathrm{~cm}$, Abbeville, musée Boucher-de-Perthes, inv. 92.13 161, don Alphonse de Rothschild, 1904.

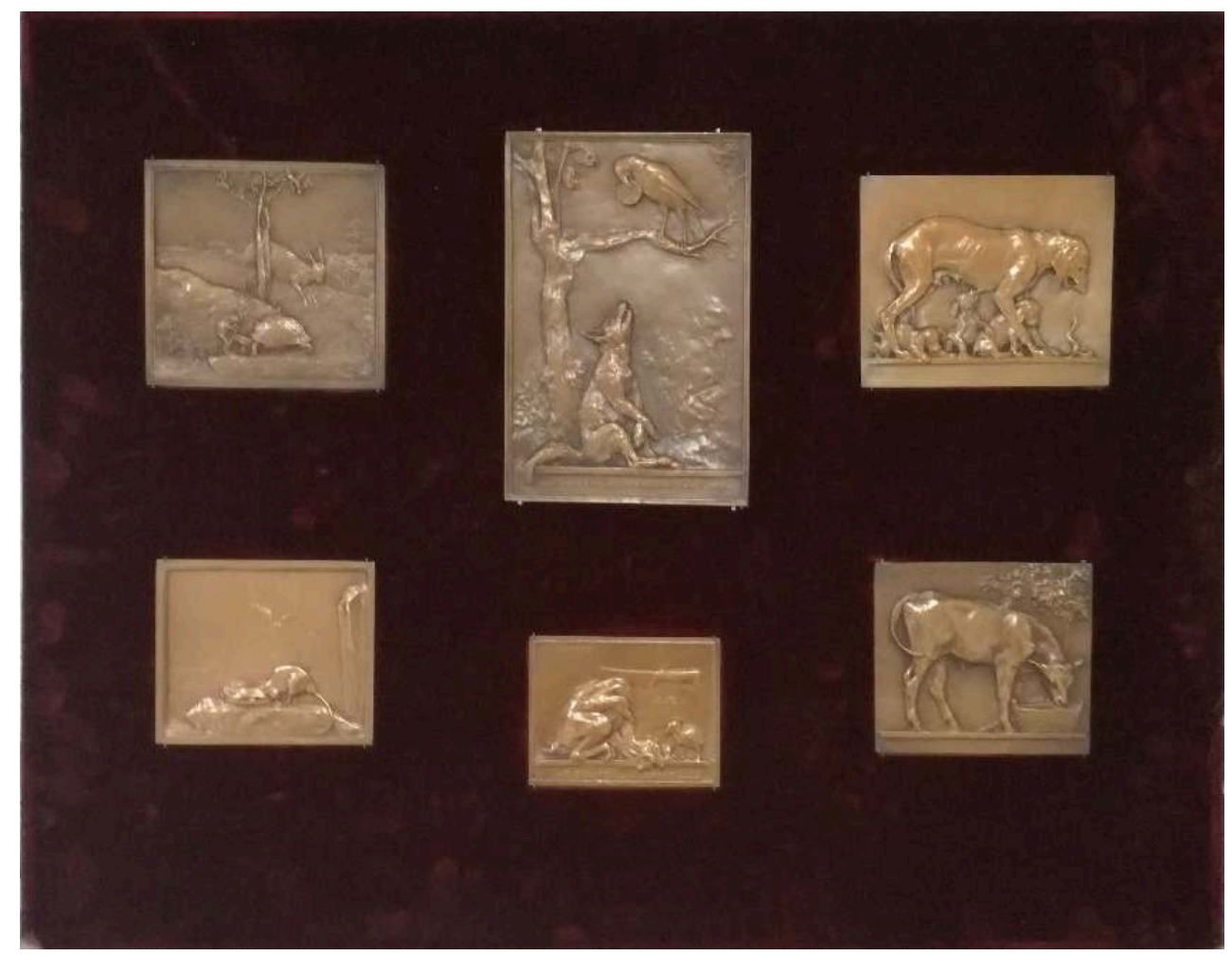

(c) Christian Migeon

Pour second circuit d'approvisionnement, on trouve l'artiste lui-même. L'absence de concordance entre les œuvres de Ringel réparties dans les musées et les mentions d'exposition aux Salons encourage à penser que la voie de la commande a été privilégiée pour cet artiste. En outre, ce processus lui donne la possibilité de composer des ensembles cohérents qui contiennent le meilleur de sa production de portraits. Le cadre de douze médaillons conservé au musée des Beaux-Arts de Tourcoing en est une illustration (fig. 6) ${ }^{37}$. La disposition des profils des grands hommes, qui se font face comme pour entretenir un dialogue, et la présence d'une branche de laurier doré circulant de façon naturelle entre les rondelles en bronze, témoignent d'une attention toute particulière à la mise en valeur des médaillons qui ne peut provenir que de l'artiste. Ce soin apporté à l'accrochage a d'ailleurs été dupliqué dans d'autres cadres. En 1893, six dispositifs similaires, composés de douze médaillons à l'effigie de Victor Hugo, Ernest Renan, Léon Lhermitte et Auguste Rodin, pour ne citer que la première ligne, sont commandés à Ringel puis donnés aux musées d'Armentières, d'Avignon, de Boulogne-sur-Mer, de Cannes, de Draguignan et de Tourcoing. Malheureusement, les quatre premiers cadres figurent parmi les œuvres détruites pendant la Première Guerre. De fait, la connaissance du contenu du cadre de Tourcoing permet par déduction de documenter les ensembles disparus ou non localisés ${ }^{38}$. 
6. Jean Désiré Ringel d'lllzach, Cadre en bois de douze médaillons en bronze, $95 \times 120 \mathrm{~cm}$, Tourcoing, musée des Beaux-Arts, inv. 893.3.1, don Alphonse de Rothschild, 1893.

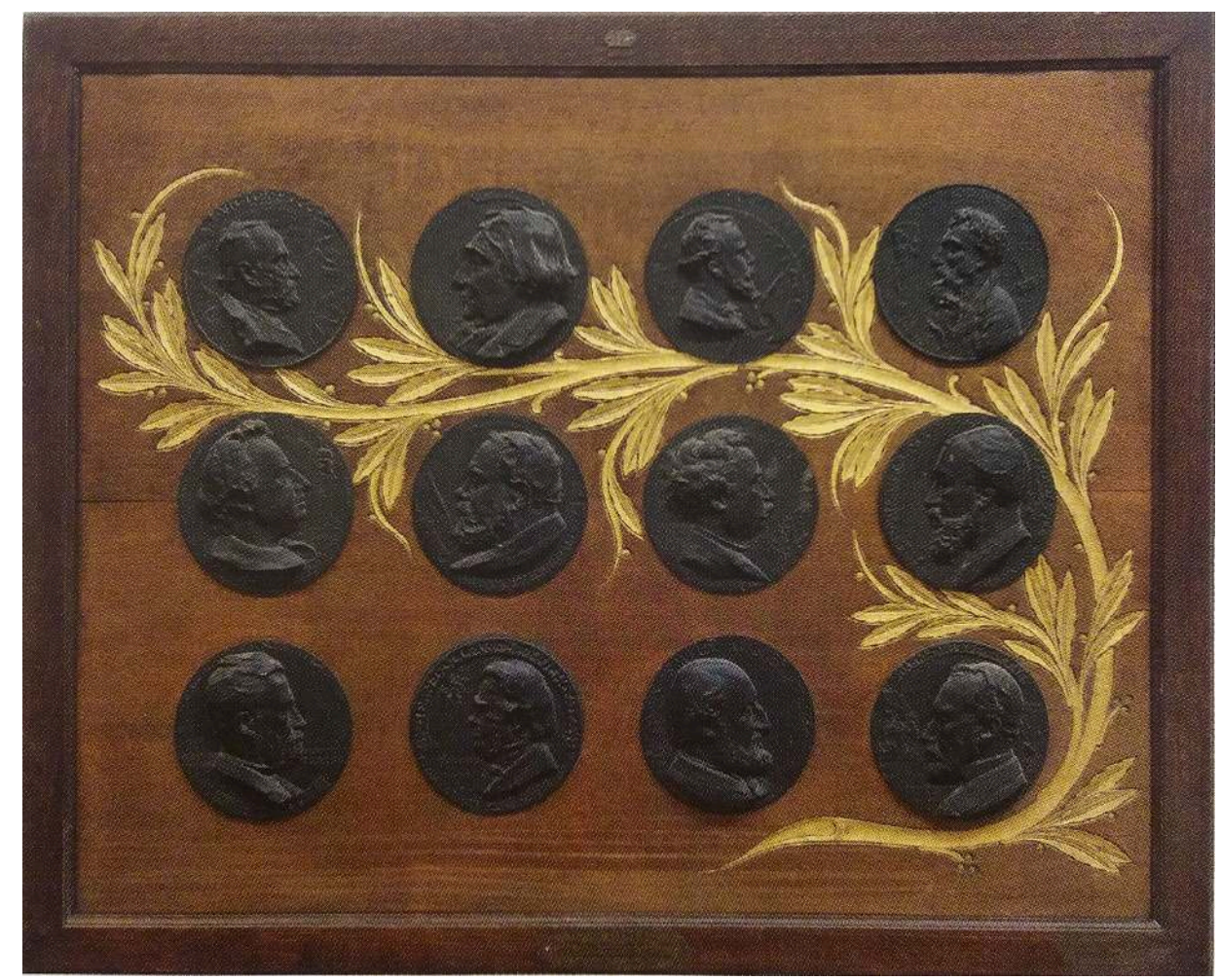

(C) D.R.

Pour finir sur la provenance des œuvres, il est une piste apparemment prometteuse mais qui reste encore suffisamment investie: celle du rôle de l'atelier du fondeur Antonin Liard, plébiscité par la majorité des médailleurs de l'époque pour la fonte de leurs modèles ${ }^{39}$. Les dix-huit médailles en bronze signées Victor Peter conservées au musée Bonnat-Helleu de Bayonne depuis leur don par Alphonse de Rothschild en 1903 sont toutes unifaces et surprennent par la qualité de leur fonte ${ }^{40}$. Leur relief ne présente aucune aspérité. Le métal a été réparti d'une façon homogène durant la coulée. Enfin, leur revers, une face que l'on néglige trop souvent, dévoile un traitement soigné. Le sable utilisé par le fondeur comme matière réfractaire et notamment la finesse du grain a laissé une trace similaire entre les exemplaires de Bayonne et les exemplaires provenant du fonds Liard, c'est-à-dire des matrices modèles utilisées dans l'atelier du fondeur. Par décret du 25 décembre 1936, La Médaille française contemporaine, une société d'amateurs, fait entrer cet ensemble, acquis quelques années plus tôt auprès des héritiers du fondeur, dans les collections nationales où il est réparti entre le musée du Luxembourg et le Cabinet des médailles de la Bibliothèque nationale. De cette comparaison, nous en déduisons la collaboration d'Antonin Liard dans l'exécution des médailles et plaquettes conservées à Bayonne.

\section{Le dispositif original du « cadre de médailles »}

Plus de la moitié des dons de médailles contemporaines privilégie une présentation sous la forme de cadre. Ce dispositif témoigne de la manière dont on exposait la médaille à la fin du XIX ${ }^{e}$ siècle et au début du $\mathrm{Xx}^{\mathrm{e}}$ siècle. Il diffère du «médaillier », ce 
meuble à tiroirs qui agrémente les cabinets de numismatique ou les cabinets de curiosités de certains amateurs éclairés. Dans cet environnement, la médaille ne s'offre qu'à la vue des numismates ou des visiteurs privilégiés, mais elle conserve l'avantage de se laisser manipuler. L'accrochage de la médaille en cadre possède une tout autre vocation. Le souci de pédagogie conduit à dissocier les droits et les revers des œuvres généralement bifaces, pour exposer la médaille frappée sous la forme de clichés et la production fondue sous l'aspect de médaillons unifaces. L'organisation de l'accrochage suit toujours des préoccupations de symétrie et tente de faire alterner avec beaucoup d'intelligence les portraits avec les compositions allégoriques. Le cadre de médailles conservé au musée de Limoux en est une parfaite illustration (fig. 7 $)^{41}$.

7. Jules-Clément Chaplain, Cadre de 53 médailles et plaquettes, Limoux, musée Petiet, inv. 905.002 à 905.054, don Alphonse de Rothschild, entre 1903 et 1905.

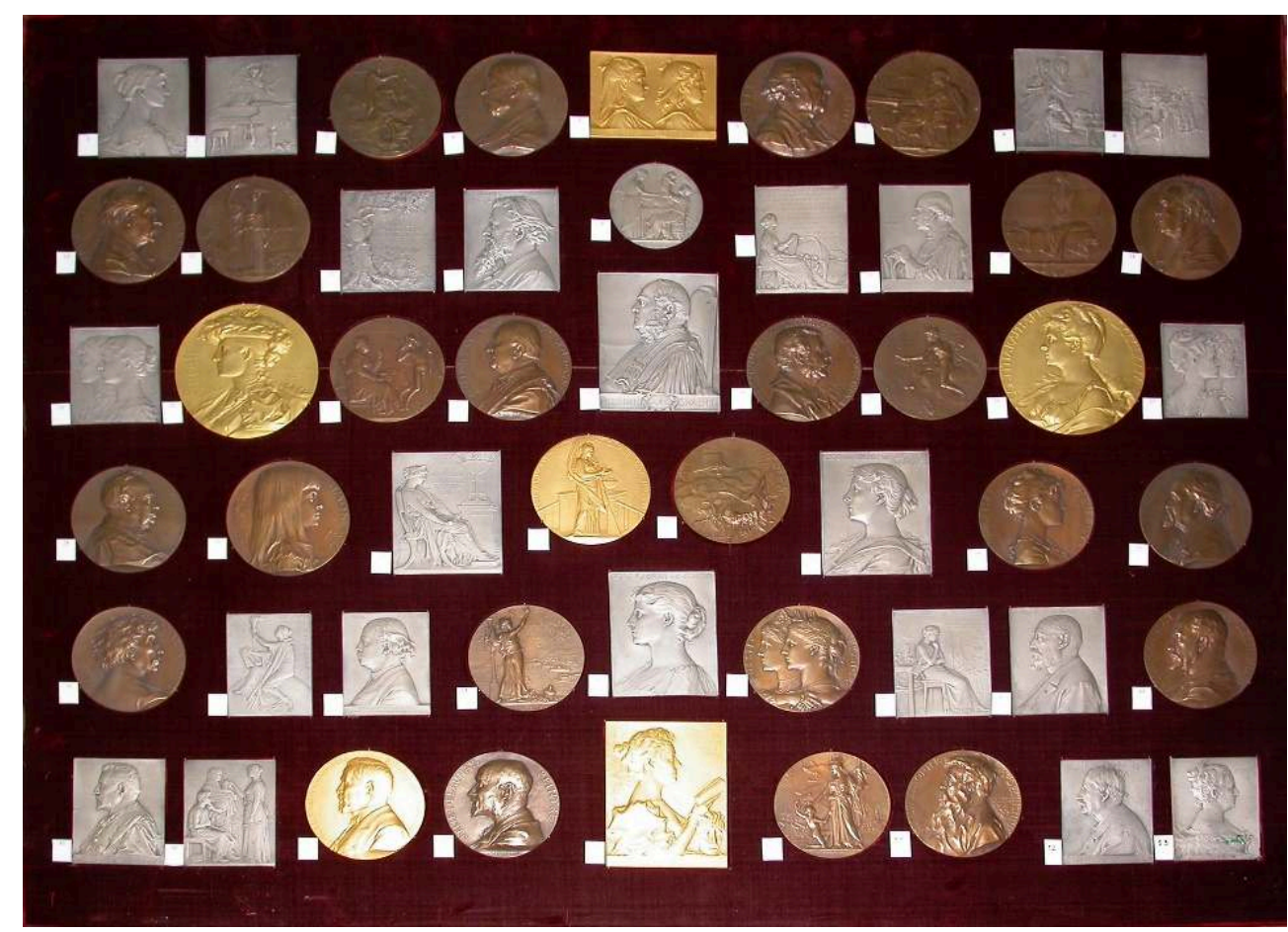

(C) Musée de Limoux / D.R.

21 Les clichés en bronze succèdent à ceux d'argent et les quelques exemplaires dorés viennent ponctuer l'ensemble. Ce dispositif, important d'un point de vue quantitatif puisqu'il regroupe cinquante-trois médailles et plaquettes signées Chaplain, cherche à présenter le meilleur de la riche production de ce médailleur. Dans un registre plus limité en nombre, le cadre de dix-huit médailles adressé au musée de Bayonne en 1903 apparaît tout aussi représentatif (fig. 8). Cet ensemble homogène composé de six plaquettes animalières, trois compositions historiées et neuf portraits dévoile parfaitement l'amplitude du talent de Victor Peter. La restriction du nombre de clichés est ici compensée par l'originalité et le dynamisme de son agencement. Cette composition dévoile bien la pratique de ce sculpteur-médailleur qui a toujours préféré le format circulaire pour ses portraits, tandis que la plaquette rectangulaire est réservée aux animaux pris dans l'action de leur mouvement. 
8. Victor Peter, Cadre de 18 médailles ou plaquettes en bronze (après démembrement), Bayonne, musée Bonnat-Helleu, inv. CM. 566/1 à 18, don Alphonse de Rothschild, 1903.

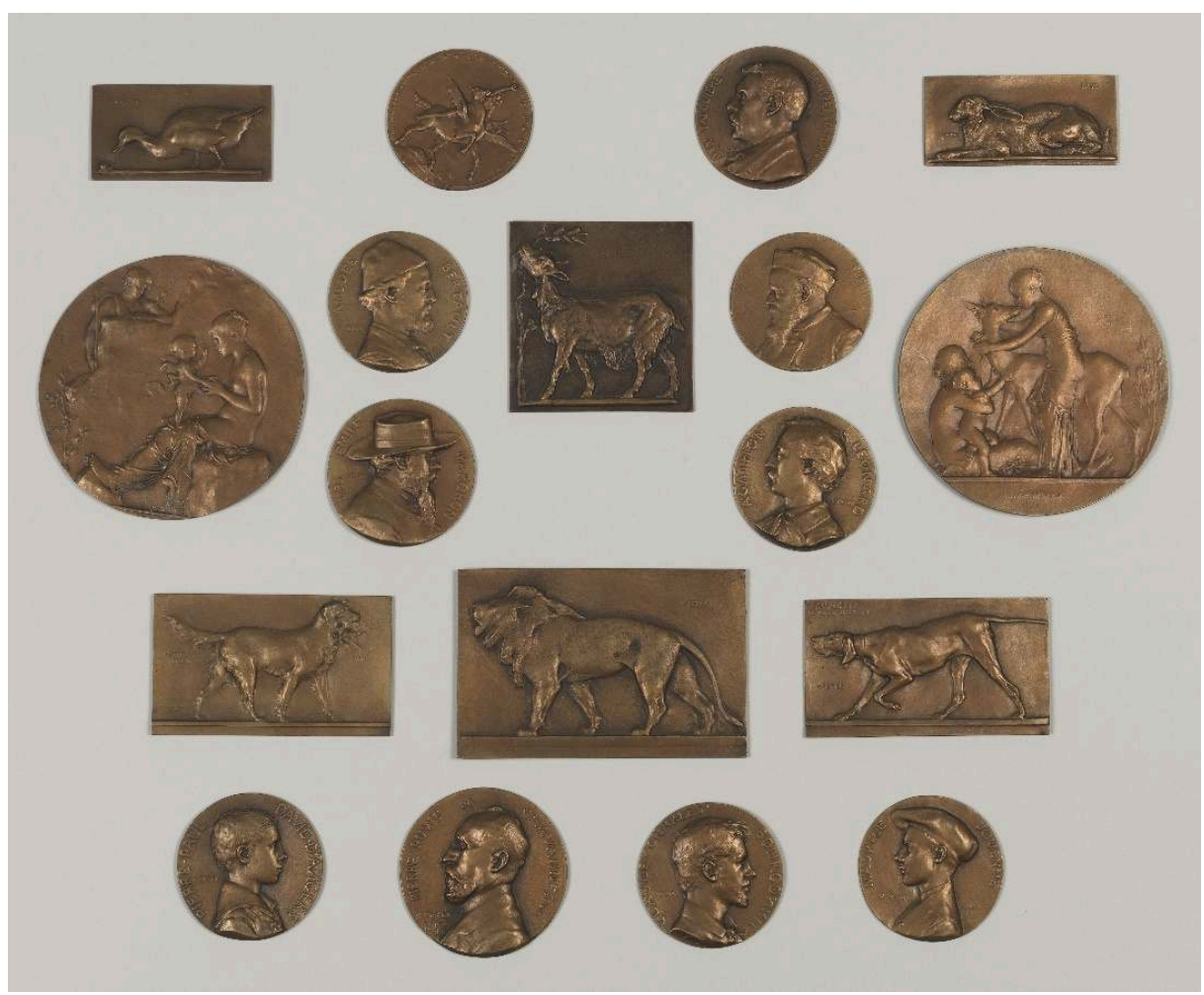

(c) Musée de Bayonne / D.R.

Pourtant, cette manière d'exposer la médaille a été perdue dans une grande partie des musées français par le démantèlement des cadres originels ${ }^{42}$. Pour faciliter le rangement en réserve d'une production qui cesse de plaire à partir de l'entre-deuxguerres, le choix des équipes de conservation s'est porté sur la suppression de ces dispositifs muséographiques, alors même que les clauses des donations Rothschild s'assortissent d'une demande de présentation permanente et d'un respect de l'intégrité des œuvres. À cela s'ajoutent de nouvelles normes de conservation préventive qui ont poussé les responsables de collections à retirer les fonds de velours cramoisi, un textile nocif pour la nature métallique des médailles car il délivre des substances acides en captant l'humidité. Beaucoup de ces médailles se trouvent aujourd'hui conservées dans des boîtes en carton neutre qui ont l'avantage de limiter l'oxydation de l'argent ou du métal argenté. Pourtant, ce choix a fréquemment entraîné une perte d'informations quant à la provenance des objets, comme pour le cadre de médailles parvenu en 1892 au musée Fabre de Montpellier ${ }^{43}$. Alors que l'inventaire des dons ne mentionnait qu'une grande plaque représentant Sarah Gustave Simon, son numéro d'inventaire nous suggère qu'elle fait partie en réalité d'une série. À l'occasion d'une mission, nous avons alors pu constater, en inspectant les revers des objets, que l'ensemble des médailles présentent des résidus de velours rouge autour d'anciens points de colle et que l'on dénombre ainsi désormais au moins quarante-six médailles et plaquettes ${ }^{44}$. Ce cas de figure encourage donc à nuancer le chiffre de sept cents médailles contemporaines données par Alphonse de Rothschild que l'on comptabilise actuellement et incite à poursuivre les investigations auprès des musées de France pour le préciser, notamment quand il ne figure qu'un unique item dans une donation ${ }^{45}$. 
il faut signaler que, malgré nos investigations et les recherches assidues menées par les responsables de collections, à ce jour, seules quatre cent dix-huit médailles ou plaquettes émanant des libéralités d'Alphonse de Rothschild sont localisées dans les collections des musées de France. Les pertes dues en majeure partie aux dommages de guerre représentent ainsi près de $40 \%$ des dons.

\section{Les dons Rothschild et l'histoire de l'art de la médaille 1900}

Par son action, Alphonse de Rothschild a offert aux musées de province la possibilité d'enrichir leurs collections numismatiques, ou tout du moins, de constituer un premier noyau de qualité. Cette initiative privée devance l'intervention de l'État en matière de soutien artistique au renouveau de la médaille. Ces libéralités pallient même l'absence de politique d'acquisition qu'aurait dû déployer l'administration des Beaux-Arts en faveur de ce médium qui bénéficie alors d'un engouement sans commune mesure à partir des années 1890.À la décharge du bureau des travaux d'art, le défi réside alors dans la constitution d'une section dédiée à l'art de la médaille qui finit par ouvrir en $1892 \mathrm{au}$ sein du musée du Luxembourg. À ce titre, il faut voir une corrélation entre cet évènement et le pic de l'activité donatrice qui intervient justement cette année. En se concentrant entre les années 1890 et 1895 , les dons d'Alphonse de Rothschild précèdent l'apogée de la «médaillomanie » française qui est atteint en 1900. Se dessine alors la figure d'un collectionneur esthète, dont le mécénat en faveur de la médaille contemporaine s'avère davantage nourrir l'engouement qu'il n'en serait la résultante.

Mais il est un paradoxe. Ces dons ne parviennent pas à illustrer à sa juste mesure une histoire de l'art de la médaille des années 1880-1910, en l'absence d'un échantillonnage plus large que les douze médailleurs sélectionnés. S'il est naturel de retrouver l'œuvre de Jules-Clément Chaplain abondamment répartie sur le territoire français, il est regrettable que ce mécénat artistique n'ait pas touché Oscar Roty ou Frédéric de Vernon avec une vigueur similaire et il est d'autant plus incompréhensible de ne voir figurer aucune médaille de Jean-Baptiste Daniel Dupuis, Hubert Ponscarme, Charles Degeorge, Louis Bottée ou Ovide Yencesse parmi ces dons. Enfin, même si les sculpteurs occupent une place éminente au sein de l'école du renouveau de la médaille et qu'à ce titre l'intérêt pour Victor Peter ou Hippolyte Lefebvre est justifiable, le soutien indéfectible dont bénéficie Jean Désiré Ringel d'Illzach fausse l'investissement réel de ce médaillonniste par rapport à ses homologues. Enfin, un problème de visibilité de ces ensembles médaillistiques se pose actuellement au sein des espaces d'expositions des musées de France, de telle manière qu'il est impossible de rendre compte au public de l'évolution de l'histoire du goût dont témoigne la médaille. Peu de cadres sont en effet exposés et la majorité de ceux-ci est toujours reléguée dans l'obscurité des réserves. 


\section{NOTES}

1. La synthèse que nous proposons de développer ici résulte d'une étude approfondie menée à partir du recensement des dons Rothschild présents dans deux cent cinquante musées de France que Pauline Prevost-Marcilhacy a rassemblé dans le cadre de la préparation de l'ouvrage Les Rothschild. Une dynastie de mécènes en France, Paris, Louvre/BnF/Somogy, 2016. Le programme de recherche que l'INHA a lancé en 2015 a pour objectif de poursuivre et publier cette enquête exhaustive. Nous avons collaboré à ce programme à partir de 2017 en apportant notre expertise sur la question des dons de médailles et plaquettes contemporaines. Pour cela, nous avons constitué un corpus dédié en extrayant tous les objets nous concernant de l'inventaire général établi par Pauline Prevost-Marcilhacy qui comptabilise près de cent trente mille œuvres d'art. Notre ensemble compte plus de sept cents médailles pour lesquelles nous avons affiné les attributions, retrouvé les titres originaux, détaillé leur date et leur technique de création, tout en cherchant à rendre la cohérence de chaque fonds en les documentant. Cet inventaire dédié a pour objectif de mieux identifier les ensembles sous la typologie du "cadre de médailles ", très souvent catalogués par les musées sous un seul item, alors que ces lots atteignent parfois jusqu'à quatre-vingts objets. Nous avons par conséquent proposé que cet inventaire, organisé par musée, soit désormais composé d'une notice mère informant sur l'ensemble du don et détaillant ensuite chaque médaillon, médaille, plaque ou plaquette, afin de respecter la spécificité de l'objet en terme de matériau et de mesure, ce qui est important pour la recherche dans le domaine numismatique. Il faut rappeler que la médaille est un art du multiple et que le chercheur a besoin de ces détails techniques pour caractériser l'exemplaire. Il nous a également paru important d'illustrer ce travail par des reproductions fournies par les musées et lorsque les médailles figurent au registre des œuvres disparues nous avons proposé de faire référence à des exemplaires similaires. L'inventaire des dons de médailles et plaquettes contemporaines est désormais consultable sur le portail Rothschild dans un dossier thématique dédié consultable ici : Les médailles parmi les dons Rothschild.

2. Récapitulatif du nombre de dons par année : $1886(1) ; 1887$ (1) ; $1888(0) ; 1889$ (0); 1890 (5) ; 1891 (3) ; 1892 (10) ; 1893 (9) ; 1894 (1) ; 1895 (8) ; 1896 (0) ; 1897 (1) ; 1898 (2) ; 1899 (0) ; 1900 (0) ; 1901 (3) ; $1902(0)$; 1903 (3) ; 1904 (4) ; 1905 (2) ; sans date (3) ; date imprécise (2).

3. Nous nous permettons de renvoyer à notre thèse : Katia Schaal, «La médaille de sculpteur, essor d'un genre à l'époque de la "médaillomanie" (1880-1920)", doctorat sous la direction de Claire Barbillon et d'Inès Villela-Petit, Poitiers-Paris, université de Poitiers/École du Louvre, en cours.

4. Voir Maurice Agulhon, «La statuomanie et l'histoire », Ethnologie française, vol. VIII, mars-sept. 1978, p. 145-172.

5. Mathilde Avisseau-Boustet, Dominique Hollard et Jullien olivier, « Monnaies et pierres gravées au Cabinet des médailles de la bibliothèque nationale, 1903-1904 », dans Pauline prevostMarcilhacy (dir.), Les Rothschild. Une dynastie de mécènes en France, op. cit., vol. I, p. 298-301.

6. Voir Pauline Prevost-Marcilhacy, « Le mécénat envers les artistes vivants en faveurs des musées de région, 1895-1905 ", ibid., vol. I, p. 134-183. Sans cette riche étude, nous n'aurions jamais pu comprendre la dynamique du mécénat appliqué au cas de la médaille.

7. Par exemple, le musée municipal d'Armentières, le musée du Mont de Piété de Bergues, le musée de la Castre de Cannes, le musée Gassendi de Digne-les-Bains, le musée des Beaux-Arts de Draguignan, le musée Eugène Boudin de Honfleur, le musée Petiet de Limoux, le musée d'Art et d'Histoire de Montmorillon, le musée d'Art et d'Archéologie de Senlis, le musée Paul Valéry de Sète, le musée des Beaux-Arts de Tourcoing ou encore le musée du Cloître - André Mazeyrie de Tulle. 
8. Jules-Clément Chaplain (Mortagne-au-Perche, 1839 - Paris, 1909), Jean Désiré Ringel d'Illzach (Illzach, 1847 - Strasbourg, 1916), Victor Peter (Paris, 1840 - 1918), Frédéric de Vernon (Paris, 1858 - 1912), Oscar Roty (Paris, 1846 - 1911), Hippolyte Lefebvre (Lille, 1863 - Arcueil, 1935), Auguste Patey (Paris, 1855 - 1930), Alexandre Coudray (Paris, 1864 - 1932), Émile-Adolphe Monier (Paris, 1883 - 1970) , Jean William Henri Pécou (Bordeaux, 1854 - ?, après 1913), Pierre-Charles Lenoir (Paris, 1879 - 1953) et Abel Lafleur (Rodez, 1875 - Boulogne-Billancourt, 1953) que nous classons selon l'importance quantitative de leur production parmi les dons.

9. Récapitulatif du nombre de médailles données par artiste : Chaplain (nous indiquons un chiffre de plus de 300, car les dons de Lyon et de Nogent-sur-Seine sont annoncés sans chiffre, mais nous les estimons au moins à une douzaine chacun) ; Ringel (151) ; Peter (119) ; Vernon (51) ; Roty (34) ; Lefebvre (14) ; Patey (14) ; Monier (6) ; Coudray (5) ; Pécou (4) ; Anonyme (4, pour le cas de SaintPol-sur-Ternoise) ; Lenoir (2); Lafleur (1).

10. Récapitulatif du nombre de dons par artiste : Peter (15); Ringel (15) ; Chaplain (10) ; Roty (6) ; Vernon (4) ; Lefebvre (1) ; Patey (1) ; Coudray (1) ; Monier (1) ; Pécou (1) ; Lenoir (1) ; Lafleur (1) ; Anonyme (1).

11. Jean Babelon, La Médaille et les Médailleurs, Paris: Payot, 1927, p. 210.Voir aussi Katia Schaal, «Jules-Clément Chaplain (1839 - 1909) médailleur, sculpteur et acteur de l'essor de la médaille ", Mémoire de Master 2 sous la direction. de Béatrice Coullaré et d'Anne Pingeot, Paris, École du Louvre, 2012. Dans le cadre du programme de recherche, nous avons rédigé ces notices: Katia Schaal, « Mes Enfants, par Jules-Clément Chaplain, au musée de Grenoble », Paris, INHA, 2017: collections.rothschild.inha.fr/fr/uvres/selection-d-oeuvres/toutes-les-oeuvres/mesenfants-par-jules-clement-chaplain.html ; Katia Schaal, « Princesse Marie Gortchakov-Sturdza (1849-1905), par Jules-Clément Chaplain, au musée Petiet de Limoux », Paris, INHA, 2018 : collections.rothschild.inha.fr/fr/uvres/selection-d-oeuvres/toutes-les-oeuvres/princesse-mariegortchakov-sturdza-1849-1905-par-jules-clement-chaplain.html.

12. Nous parlons bien ici de "don médaillistique», entendu comme un don de médailles métalliques. De fait, nous écartons le don du cadre de six médaillons de Ringel d'Illzach, destiné en 1886 au musée d'Art et d'archéologique du Pays de Laon, car ces six objets sont en terre cuite et correspondent à un état préparatoire à la confection de médailles.

13. Jules-Clément Chaplain, Cadre de dix-sept médailles, médaillons en bronze fondu, Lille, musée des Beaux-Arts, inv. Sc. 158-1 à 17, don Alphonse de Rothschild, 1887. Voir Pauline PrevostMarcilhacy, Katia Schaal, Inventaire des médailles et des plaquettes parmi les dons Rothschild, Paris, INHA, 2019, p. 95-99: collections.rothschild.inha.fr/fr/dossiers-thematiques/les-medaillesparmi-les-dons-rothschild-1.html.

Nous proposons ici une reconstitution que nous avons réalisée en suivant l'ordre des numéros d'inventaire des médailles et en nous servant de numérisation que nous avions faites à l'occasion de la présentation des objets dans l'exposition Au creux de la main [Lille : Palais des Beaux-arts, 11 décembre $2012-1^{\mathrm{er}}$ juillet 2013]. Voir Catherine chevillot, Édouard Papet, Au creux de la main : la médaille en France aux XIX et XX $X^{e}$ siècles, Paris, Skira-Flammarion/Musée d'Orsay, 2012.

14. Jules-Clément Chaplain, Cadre de quatre-vingt-trois médailles et plaquettes, bronze et bronze argenté, Caen, musée des Beaux-Arts, inv. 2007.0.1.1 à 2007.0.1.81, don Alphonse de Rothschild, 1904. Voir Pauline Prevost-Marcilhacy, Katia Schaal, Inventaire des médailles et des plaquettes parmi les dons Rothschild, art. cit., p. 27-44 : collections.rothschild.inha.fr/fr/dossiers-thematiques/lesmedailles-parmi-les-dons-rothschild-1.html.

15. Oscar Roty, Cadre de vingt-huit médailles, plaquettes et modèles de bijoux, Rouen, musée des Beaux-Arts, inv. : S.X.196, don Alphonse de Rothschild, 1892. Voir Pauline Prevost-Marcilhacy, Katia Schaal, Inventaire des médailles et des plaquettes parmi les dons Rothschild, art. cit., p. 147 : collections.rothschild.inha.fr/fr/dossiers-thematiques/les-medailles-parmi-les-donsrothschild-1.html. 
16. Oscar Roty, Pittura, bronze patiné uniface, h. $19 \times 1.13 \mathrm{~cm}$, Lille, musée des Beaux-Arts, inv. Sc. 186, don Alphonse de Rothschild, 1891. Voir Pauline Prevost-Marcilhacy, Katia Schaal, Inventaire des médailles et des plaquettes parmi les dons Rothschild, art. cit., p. 101-102. On peut encore citer : Fortuna, bronze, h. 25, $5 \mathrm{~cm} \times 1.13,3 \mathrm{~cm}$, Laon, musée communal, inv. II. Fd 1-222, don Alphonse de Rothschild, 1890 (voir Pauline Prevost-Marcilhacy, Katia Schaal, Inventaire des médailles et des plaquettes parmi les dons Rothschild, art. cit., p. 86-87) ; Portrait de ses parents et Portrait de ses beauxparents, deux plaquettes unifaces, fondues en bronze, Mâcon, musée des Ursulines, inv. 5549 et 5550, don Alphonse de Rothschild, 1891 (voir Pauline Prevost-Marcilhacy, Katia Schaal, Inventaire des médailles et des plaquettes parmi les dons Rothschild, art. cit., p. 118-119: collections.rothschild.inha.fr/fr/dossiers-thematiques/les-medailles-parmi-les-dons-

rothschild-1.html); Eudoxe Marcille, directeur du Musée d'Orléans, plaquette en bronze, Senlis, musée des Beaux-Arts, s. ${ }^{\circ}$ d'inv., don Alphonse de Rothschild (sans date) (voir Pauline PrevostMarcilhacy, Katia Schaal, Inventaire des médailles et des plaquettes parmi les dons Rothschild, art. cit., p. 151); Médaille commémorative de l'ouverture de la ligne d'Alger à Constantine, médaille en bronze dans un écrin, Sète, musée Paul Valéry, inv. 890.9.2 1.2, don Alphonse de Rothschild, 1890 (voir Pauline Prevost-Marcilhacy, Katia Schaal, Inventaire des médailles et des plaquettes parmi les dons Rothschild, art. cit., p. 152 [en ligne]).

17. Frédéric de Vernon, Cadre de dix médaillons et plaquettes, Valenciennes, musée des Beaux-Arts, 98.47. 1 à 10, don Alphonse de Rothschild, 1892. Voir Pauline Prevost-Marcilhacy, Katia Schaal, Inventaire des médailles et des plaquettes parmi les dons Rothschild, art. cit., p. 166-168: collections.rothschild.inha.fr/fr/dossiers-thematiques/les-medailles-parmi-les-dons-

rothschild-1.html. On peut encore citer Cadre de vingt-six médailles et plaquettes en argent et bronze, Arras, musée des Beaux-Arts, s. nº d'inv., don Alphonse de Rothschild, 1898 (voir Pauline PrevostMarcilhacy, Katia Schaal, Inventaire des médailles et des plaquettes parmi les dons Rothschild, art. cit., p. 12) ; L'Eucharistie, bas-relief en bronze, h. $21 \mathrm{~cm}$ x $1.15 \mathrm{~cm}$, Digne-les-Bains, musée Gassendi, inv. 545, don Alphonse de Rothschild, 1895 (voir Pauline Prevost-Marcilhacy, Katia Schaal, Inventaire des médailles et des plaquettes parmi les dons Rothschild, art. cit., p. 57) ; Quatorze médailles ou plaquettes en bronze, Le Mans, musée de Tessé, s. $\mathrm{n}^{\circ}$ d'inv., don Alphonse de Rothschild, 1894 (voir Pauline Prevost-Marcilhacy, Katia Schaal, Inventaire des médailles et des plaquettes parmi les dons Rothschild, art. cit., p. 88-93). Concernant le cadre d'Arras, nous avons rédigé une notice. Voir Katia schaal, «Cadre de vingt-six médailles et plaquettes, par Frédéric de Vernon au musée SaintVaast d'Arras. Les comptes rendus de Salons au secours des œuvres disparues de Frédéric de Vernon ", Paris, INHA, 2019 : collections.rothschild.inha.fr/fr/uvres/selection-d-oeuvres/toutesles-oeuvres/cadre-de-vingt-six-medailles-et-plaquettes-par-frederic-de-vernon.html.

18. On trouve dans l'inventaire des entrées de médailles dans les collections de la BnF par la voie du dépôt légal la première mention de Pierre-Charles Lenoir à la date du 14 juin 1907. Il s'agit de Chien, Étude et Apiculture, trois frappes citées sous les numéros DL 13050 à 13052, en provenance de la maison d'édition Arthus Bertrand et Béranger, installée au 46, rue de Rennes à Paris.

19. Pierre-Charles Lenoir, Cadre contenant une médaille et une plaquette, 1904, bronze fondu, Châteauroux, musée-hôtel Bertrand, inv. 2192 et 2193, don Alphonse de Rothschild, 1904 (voir Pauline Prevost-Marcilhacy, Katia Schaal, Inventaire des médailles et des plaquettes parmi les dons Rothschild, art. cit., p. 47 : collections.rothschild.inha.fr/fr/dossiers-thematiques/les-medaillesparmi-les-dons-rothschild-1.html)

20. Voir Jean Babelon, La médaille en France. Arts, styles et techniques, Paris, Larousse, 1948 ou les contributions de Fernand mazerolle dans la Gazette numismatique française qu'il a créée en 1899 et qui reste active jusqu'en 1914.

21. Pauline Prevost-Marcilhacy indique que «les liens privilégiés de Leroi avec Auguste Rodin [...] sont essentiels pour comprendre le choix de certains sculpteurs » et, dans notre cas de figure, ils permettent de comprendre pourquoi Victor Peter a été si soutenu par les libéralités du baron 
Alphonse de Rothschild. Pauline Prevost-Marcilhacy, Les Rothschild. Une dynastie de mécènes en France, op. cit., vol. I, p. 169.

22. Victor Peter a été praticien de Rodin durant vingt-sept ans en intégrant l'atelier du maître dès 1886. Voir Jacqueline Guillot, Victor Peter, 1840-1918, thèse de doctorat sous la dir. de Bruno Foucart, Paris, Paris IV - La Sorbonne, 1997. Nous avons également montré le lien évident entre Rodin et Peter autour de la production d'une plaquette réalisée pour commémorer le soixantedixième anniversaire de Pierre Puvis de Chavannes. Voir Katia schaal, « Portrait de Pierre Puvis de Chavannes d'après Auguste Rodin, par Victor Peter», Paris, INHA, 2017 : collections.rothschild.inha.fr/fr/uvres/selection-d-oeuvres/toutes-les-oeuvres/portrait-depierre-puvis-de-chavannes-d-apres-rodin-par-victor-peter.html.

23. Pauline Prevost-Marcilhacy, Les Rothschild. Une dynastie de mécènes en France, op. cit., vol. I, p. 156. Voir aussi Pauline Prevost-Marcilhacy, Katia Schaal, Inventaire des médailles et des plaquettes parmi les dons Rothschild, art. cit.: collections.rothschild.inha.fr/fr/dossiers-thematiques/lesmedailles-parmi-les-dons-rothschild-1.html

24. Pauline Prevost-Marcilhacy, Les Rothschild. Une dynastie de mécènes, op. cit, vol. I, p. 155. Le journal Le Figaro précise bien: «Les sculpteurs Victor Peter et Escoula ont offert, avec leur souscription, l'œuvre de leur talent : une statuette en bronze - La Bonté protégeant les Arts - posée sur un piédestal de vert antique, dans lequel est enchâssé un médaillon du baron Alphonse de Rothschild, signé par Victor Peter et que souligne cette dédicace: «Au baron Alphonse de Rothschild, membre de l'Institut, les artistes reconnaissants. ", Anonyme, "À travers Paris ", Le Figaro, 11 janvier 1905, p. 1.

Nous tenons également à remercier Laura de Fuccia de nous avoir permis ce rapprochement.

25. Nous avons étudié tous ces cadres pour tenter de mieux comprendre les modalités de constitution des ensembles à l'occasion d'une notice. Voir Katia schaal, "Cadre de douze médaillons en bronze, par Jean Désiré Ringel d'Illzach», Paris, INHA, 2019 : collections.rothschild.inha.fr/fr/uvres/selection-d-oeuvres/toutes-les-oeuvres/mes-enfants-parjules-clement-chaplain/cadre-de-douze-medaillons-en-bronze-par-jean-desire-ringel-dillzach.html.

26. Ringel expose au Salon des artistes français alternativement, mais aussi simultanément dans les sections de sculpture et de médaille à partir de 1873 et sans discontinuer entre 1877 et 1889 . L'année suivante, il est absent des vitrines du Salon officiel, préférant s'engager en faveur de la Société nationale des beaux-arts. Entre 1890 et 1908, il y envoie tous les ans des œuvres, devenant sociétaire en 1905, année où il quitte Paris pour s'établir définitivement à Strasbourg.

27. Voir Pauline prevost-Marcilhacy, "Alphonse de Rothschild et Léon Gauchez: un tandem artistique ", dans id., Les Rothschild. Une dynastie de mécènes en France, op. cit, vol. I, p. 139-142.

28. Léon Gauchez consacre d'ailleurs un article à Ringel dans la revue L'Art et y reproduit plusieurs des médaillons de cette série. Voir Paul Leroi [pseudonyme de Léon Gauchez], « Ringel, statuaire, médailleur, dessinateur, aquafortiste ", L'Art, 1885, t. 38, p. 3-10, 63-71.

29. Pauline Prevost-Marcilhacy, Les Rothschild. Une dynastie de mécènes en France, op. cit, vol. I, p. 143.

30. Roger Marx (Nancy, 1859 - Paris, 1913), inspecteur des Beaux-Arts et critique d'art, a une part essentielle et déterminante dans la défense de la médaille. Voir Catherine Meneux, « Roger Marx, le parcours d'un défenseur de la médaille et de l'art monétaire ", dans Béatrice Coullaré (dir), L'Essor de la médaille aux XIX ${ }^{e}$ et XX $X^{e}$ siècles, Wetteren, Moneta, 2003, p. 139-141

31. Voir la première synthèse que donne Roger Marx sur le sujet, publiée dans la Revue des arts décoratifs puis reprise dans le rapport officiel de la Commission des Beaux-Arts. Roger Marx, «Les médailleurs français depuis cent ans ", Revue des arts décoratifs, 1889-1890, p. 227-233 ; Roger Marx, "La médaille», dans Antonin Proust (dir.), L'Art Français, publication officielle de la commission des beaux-arts, Paris, Ludovic Baschet, 1891, p. 137-147. 
32. Le chapitre trois de notre thèse revient sur la création de cette section rendue indépendante de la sculpture à partir de 1867 et dresse un état exhaustif de l'évolution des pratiques d'exposition des médailleurs et artistes assimilés en ayant dépouillé l'intégralité des catalogues de Salon pour la seconde moitié du XIX ${ }^{\mathrm{e}}$ siècle.

33. Ces deux cadres n'avaient pas été mentionnés dans les travaux que Jacqueline Guillot a consacrés à Victor Peter. Nous les avons identifiés dans le cadre du programme de recherche mené par l'INHA.

34. Victor Peter, Cadre contenant neuf plaquettes en bronze, Avesnes-sur-Helpe, musée de la Société archéologique, s. nº d'inv., don Alphonse de Rothschild, 1904 (voir Pauline Prevost-Marcilhacy, Katia Schaal, Inventaire des médailles et des plaquettes parmi les dons Rothschild, art. cit., p. 13-15: collections.rothschild.inha.fr/fr/dossiers-thematiques/les-medailles-parmi-les-donsrothschild-1.html).

35. Société des artistes français, Explication des ouvrages de peinture, sculpture, architecture, gravure et lithographie des artistes vivants exposés au Grand Palais des Champs-Élysées, le $1^{\text {er }}$ mai 1904, Paris: imp. Paul Dupont, 1904, p. 378, n³465: «Un cadre contenant neuf plaquettes; bronze. 1. Portrait de Mme René Huet. - 2. Marceau. - 3. Portrait de Mme Victor Peter. - 4. Pigeons sur un buste de Minerve. - 5. Lièvres. - 6. Portrait de M. José Clara, statuaire. - 7. Sans-Peur (chien). - 8. Bouc. - 9. Portrait de M. Amy, statuaire. ». La mise en rapport avec des exemplaires similaires peut être réalisée de manière très simple en se référant au fonds Liard du département des Médailles et Antiques de la BnF. Ce fonds se constitue des chef-modèles issus de l'atelier du fondeur Antonin Liard. Il a été numérisé et est actuellement consultable sur le portail medaillesetantiques.bnf.fr. Pour comprendre la démarche qui a présidé à notre proposition de reconstitution, voir Katia schaal, « Un cadre de plaquettes, par Victor Peter à Avesnes-sur-Helpe. Tentative de restitution d'un cadre de médailles disparu", Paris, INHA, 2019, : collections.rothschild.inha.fr/fr/uvres/selection-d-oeuvres/toutes-les-oeuvres/un-cadre-deplaquettes-par-victor-peter.html.

36. Victor Peter, Cadre contenant six plaquettes en bronze, 1904, $64,5 \times 80 \mathrm{~cm}$, Abbeville, musée Boucher-de-Perthes, inv. 92.13.161, don Alphonse de Rothschild, 1904 (voir Pauline PrevostMarcilhacy, Katia Schaal, Inventaire des médailles et des plaquettes parmi les dons Rothschild, art. cit., p. 3-5: collections.rothschild.inha.fr/fr/dossiers-thematiques/les-medailles-parmi-les-donsrothschild-1.html). Les équipes du service de la conservation ont là encore mis à profit le détail du contenu du cadre figurant dans le catalogue du Salon que nous leur avons fourni pour en faciliter l'identification. Voir Patrick Absalon et Justine Grémont, «Un cadre de plaquettes, par Victor Peter» Paris, INHA, 2019 : collections.rothschild.inha.fr/fr/uvres/selection-d-oeuvres/ toutes-les-oeuvres/un-cadre-de-plaquettes-par-victor-peter/cadre-avec-six-plaquettes-parvictor-peter.html.

37. Jean Désiré Ringel d'Illzach, Cadre en bois de douze médaillons en bronze, h. $95 \mathrm{~cm} \mathrm{x} 1.120 \mathrm{~cm}$, Tourcoing, musée des Beaux-Arts, inv. 893.3.1, don Alphonse de Rothschild, 1893 (Pauline Prevost-Marcilhacy, Katia Schaal, Inventaire des médailles et des plaquettes parmi les dons Rothschild, art. cit., p. 155-157 : collections.rothschild.inha.fr/fr/dossiers-thematiques/les-medailles-parmiles-dons-rothschild-1.html.

38. Voir Katia schaal, «Cadre de douze médaillons en bronze, par Jean Désiré Ringel d'Illzach au musée des Beaux-Arts de Tourcoing », Paris, INHA, 2019 : collections.rothschild.inha.fr/fr/uvres/ selection-d-oeuvres/toutes-les-oeuvres/mes-enfants-par-jules-clement-chaplain/cadre-dedouze-medaillons-en-bronze-par-jean-desire-ringel-d-illzach.html.

39. Antonin Liard (Paris, 1869-1944), poursuit l'héritage familial comme fondeur de médailles en étant actif jusque dans l'entre-deux-guerres. Il privilégie la fonte au sable, mais comme elle ne permet pas la fonte double, il s'adonne aussi à la fonte à la cire perdue. Il figure dans le Bottin du 
Commerce sous le titre de "mouleur-fondeur en tous métaux » et obtient une médaille d'or à l'Exposition universelle de 1889.

40. Victor Peter, Cadre de 18 médailles ou plaquettes en bronze, Bayonne, musée Bonnat-Helleu, inv. CM. 566/1 à 18, don Alphonse de Rothschild, 1903 (Pauline Prevost-Marcilhacy, Katia Schaal, Inventaire des médailles et des plaquettes parmi les dons Rothschild, art. cit., p. 17-21: collections.rothschild.inha.fr/fr/dossiers-thematiques/les-medailles-parmi-les-dons-

rothschild-1.html). Nous avons eu l'opportunité de manipuler ces exemplaires à l'occasion d'une mission menée au musée Bonnat-Helleu de Bayonne. Sans cette mise en contact directe avec l'objet, jamais nous n'aurions pu émettre cette hypothèse.

41. Jules-Clément Chaplain, Cadre de 53 médailles et plaquettes, Limoux, musée Petiet, inv. 905.002 à 905.054, don Alphonse de Rothschild, entre 1903 et 1905 (voir Pauline Prevost-Marcilhacy, Katia Schaal, Inventaire des médailles et des plaquettes parmi les dons Rothschild, art. cit., p. 103-114: collections.rothschild.inha.fr/fr/dossiers-thematiques/les-medailles-parmi-les-donsrothschild-1.html).

42. En dépit de ce choix malheureux, mais inévitable, il faut saluer la déontologie des équipes de la conservation du musée de Bayonne qui a documenté son état avant de s'en séparer. L'archive a permis de conserver le souvenir de cet agencement au dessin si particulier (fig. 8), pratique qui n'est malheureusement pas la norme.

43. Jules-Clément Chaplain, Cadre de (46) médailles et plaquettes, Montpellier, musée Fabre, inv. 892.2.1 à 46, don Alphonse de Rothschild, entre 1892 (voir Pauline Prevost-Marcilhacy, Katia Schaal, Inventaire des médailles et des plaquettes parmi les dons Rothschild, art. cit., p. 122-132: collections.rothschild.inha.fr/fr/dossiers-thematiques/les-medailles-parmi-les-donsrothschild-1.html).

44. Une recherche en archives devrait encore confirmer ce chiffre.

45. Nous pensons au cas du musée Gassendi de Digne-les-Bains où il n'est mentionné parmi les collections qu'une seule plaquette de Jules-Clément Chaplain et qu'une seule plaque de Frédéric de Vernon. Ce chiffre parait curieux quand on sait que pour ces deux médailleurs Alphonse de Rothschild a toujours donné des cadres comprenant au minimum une dizaine de médailles. Voir Pauline Prevost-Marcilhacy, Katia Schaal, Inventaire des médailles et des plaquettes parmi les dons Rothschild, art. cit., p. 57 : collections.rothschild.inha.fr/fr/dossiers-thematiques/les-medaillesparmi-les-dons-rothschild-1.html.

\section{AUTEUR}

\section{KATIA SCHAAL}

Katia Schaal est chargée d'études au sein du département des Études et de la Recherche à INHA. 


\title{
Les écailles piquées napolitaines : une « passion Rothschild»
}

\author{
Alexis Kugel
}

1 À l'automne 2018, à la galerie J. Kugel, s'est tenue, sous le titre Complètement piqué, la première exposition consacrée à un art méconnu : l'écaille piquée napolitaine ${ }^{1}$. Aucun ouvrage n'avait jusqu'à présent traité ce sujet, et l'origine même de ces pièces n'était pas clairement définie, éparpillée entre l'Allemagne, la France et l'Italie. La préciosité des matières et la beauté des objets en écaille piquée ne pouvaient qu'exciter la passion dévorante que les différents membres de la famille Rothschild eurent pour l'art à partir du milieu du XIXe siècle. En quelque sorte, les écailles piquées constituaient, avec les émaux peints de Limoges, les majoliques et l'orfèvrerie allemande de la Renaissance, un symbole du "goût Rothschild». On les retrouve en France, en particulier chez les barons James et Gustave, mais également en Angleterre chez Lionel, chez son fils Alfred $^{2}$, chez Mayer Amschel de Rothschild, à Mentmore ${ }^{3}$, et chez Ferdinand, au Waddesdon Manor, où se trouvent encore aujourd'hui onze pièces ${ }^{4}$. Et encore en Autriche, chez Nathaniel et son frère Albert. Mais le Rothschild le plus passionné d'écailles piquées fut sans doute Mayer Carl de Francfort (1820-1886), dont la fille, la baronne Salomon, Adèle Hannah Charlotte (1843-1922), légua cinq beaux objets aux musées nationaux français.

\section{L'art du piqué}

2 L'art du piqué tient son nom de la multitude de petits clous sans tête, en or, incrustés dans l'écaille et qui forment le fond du décor de ces pièces. La technique d'incrustation sur écaille était répandue dans toute l'Europe, mais essentiellement dévolue à de petits objets, tels que des couvercles de tabatières ou des montures d'éventails. Deux planches de l'Encyclopédie de Diderot et d'Alembert sont ainsi consacrées à l'atelier du " piqueur de tabatières, étuis et autres bijoux ", gage de l'importance de cette technique dans la France $d u \mathrm{XVIII}^{\mathrm{e}}$ siècle ${ }^{5}$. Il fallait un artisan de génie, en l'occurrence le Napolitain Giuseppe Sarao, actif dans la première moitié du XVIII siècle, pour imaginer et créer des 
œuvres aux formes et aux décors extravagants à l'aide de trois matières : l'or, la nacre et l'écaille.

3 Sarao put réaliser ces œuvres en perfectionnant la technique qui consistait à ramollir l'écaille en la plongeant dans l'eau bouillante, à laquelle on ajoutait de l'huile d'olive. Cela permettait non seulement de souder parfaitement deux plaques d'écaille, mais aussi de lui donner la forme désirée, qu'elle gardait en refroidissant, à l'aide de moules en bois dur ou en métal. Enfin, probablement dans l'écaille encore ramollie ou réchauffée, Sarao incrustait le décor d'or et de nacre, découpé et gravé. Les archives napolitaines fournissent très peu d'informations sur Sarao, qui, heureusement, a signé un certain nombre d'œuvres, permettant ainsi de cerner sa production.

4 La première œuvre datée est un cadre pour une plaque en bronze gravé de la plus ancienne délibération du Sénat en langue latine, datée de 186 av. J.-C. Le cadre, aux armes de l'empereur Charles VI, porte la dédicace de son donateur : Giovanni Cigala, prince de Tiriolo, ainsi que la date du don: 1727. Cette œuvre se trouve dans le département des Antiques du Kunsthistorisches Museum de Vienne (fig. 1).

1. Giuseppe Sarao [attribué à], cadre d'une plaque antique en bronze, Naples, 1727, Vienne, Kunsthistorisches Museum.

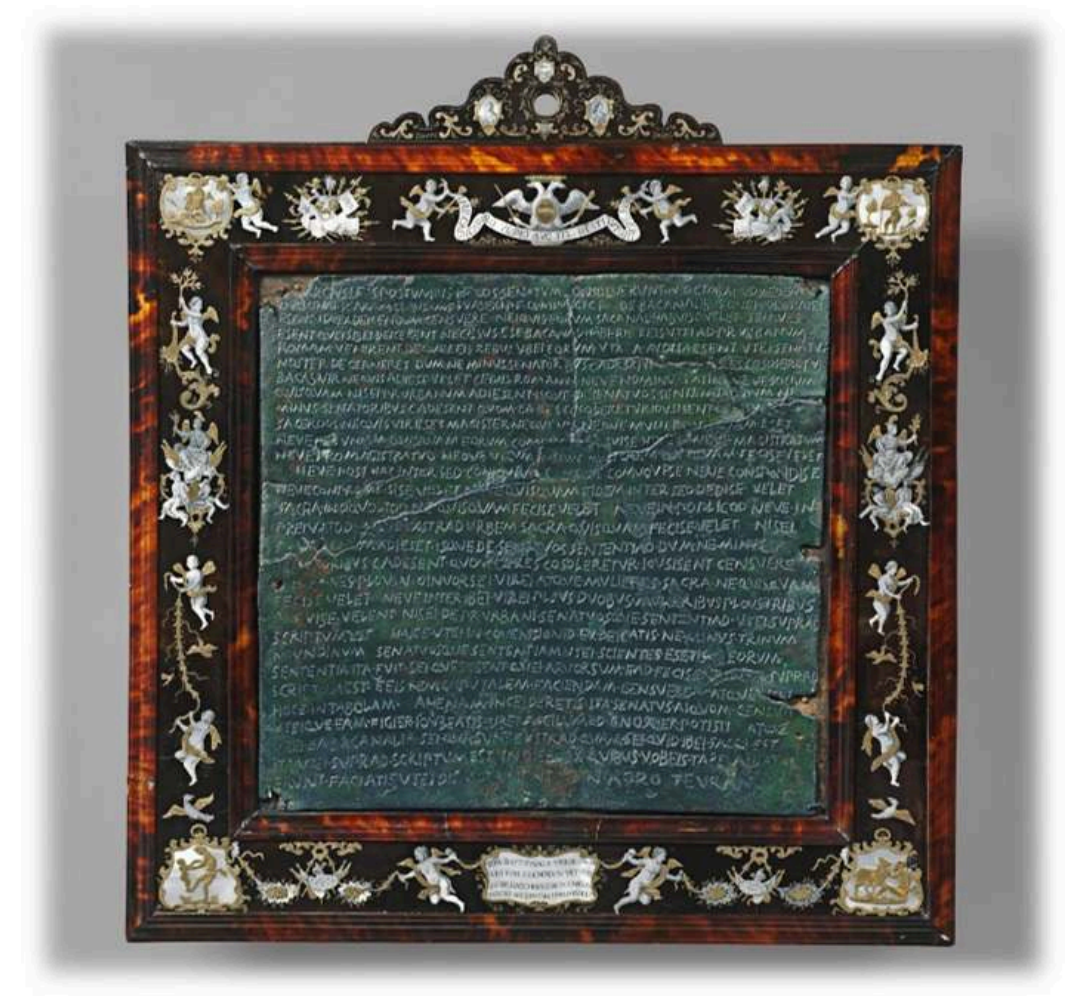

(c) Kunsthistorisches Museum

5 L'objet le plus important pour l'étude stylistique de cette production, car il porte une signature, est le coffret formant nécessaire à liqueur, conservé au château de Rosenborg à Copenhague, offert à la reine du Danemark, signé et daté : «Sarao 1731 » (fig. 2). 
2. Giuseppe Sarao, détail avec signature et date sur coffret nécessaire, 1731, Naples, château de Rosenborg, Copenhague.

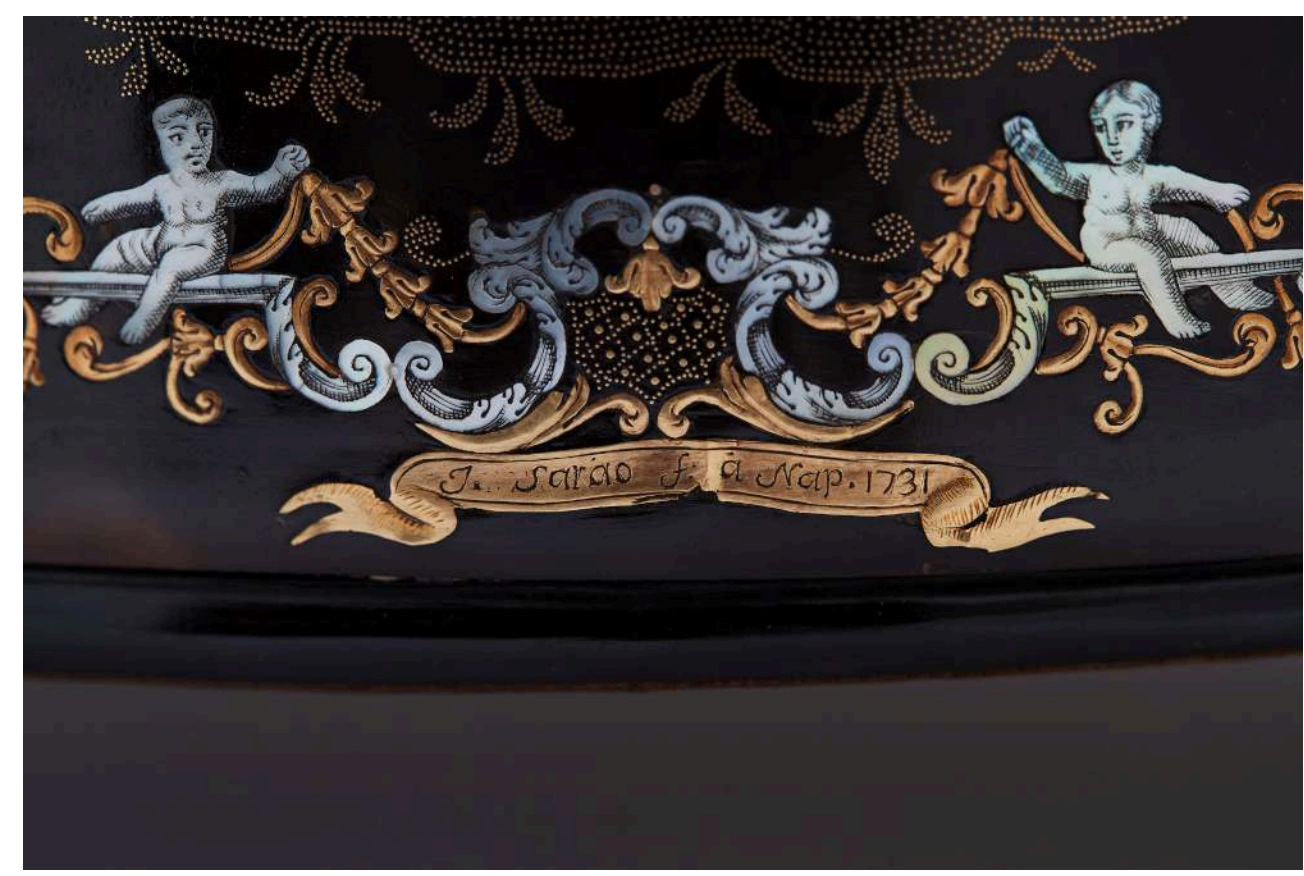

(c) Rosenborg

6 L'œuvre la plus ambitieuse et la plus grande réalisée en piqué par Sarao est la table du musée de l'Ermitage à Saint-Pétersbourg ${ }^{6}$ (fig. 3 et 4). Elle porte les armes royales des Habsbourg d'Espagne, qui régnèrent sur Naples jusqu'en 1734, et fut donc réalisée avant cette date. Elle fut achetée en 1886 par le baron Stieglitz, pour son musée des Arts décoratifs à Saint-Pétersbourg, chez l'antiquaire Goldschmidt de Francfort, l'un des principaux fournisseurs de Mayer Carl. À n'en pas douter, la table aurait été le fleuron de sa collection, mais le décès de Mayer Carl, survenu la même année, a certainement permis à Stieglitz de l'acquérir. 
3. Giuseppe Sarao, table en or, nacre et écaille sur âme de bois, Naples, c. 1730, Saint-Pétersbourg, musée de l'Ermitage.

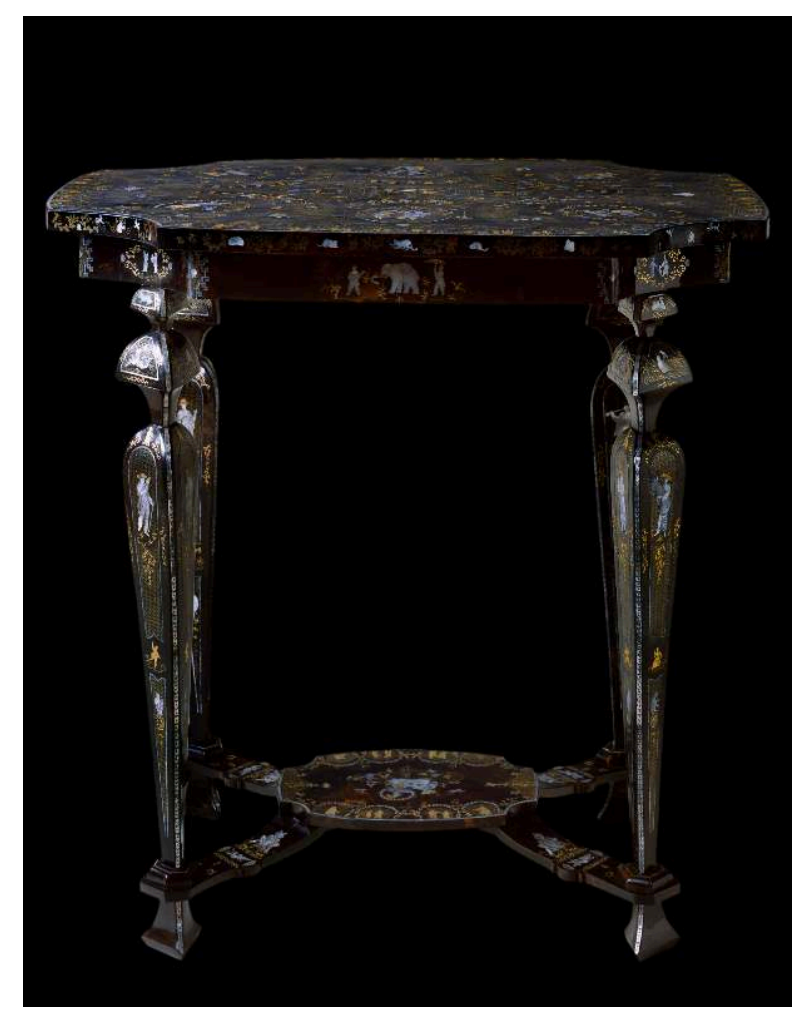

(c) Guillaume Benoît / Galerie Kugel

4. Giuseppe Sarao, plateau d'une table en or, nacre et écaille sur âme de bois, Naples, c. 1730, Saint-Pétersbourg, musée de l'Ermitage.

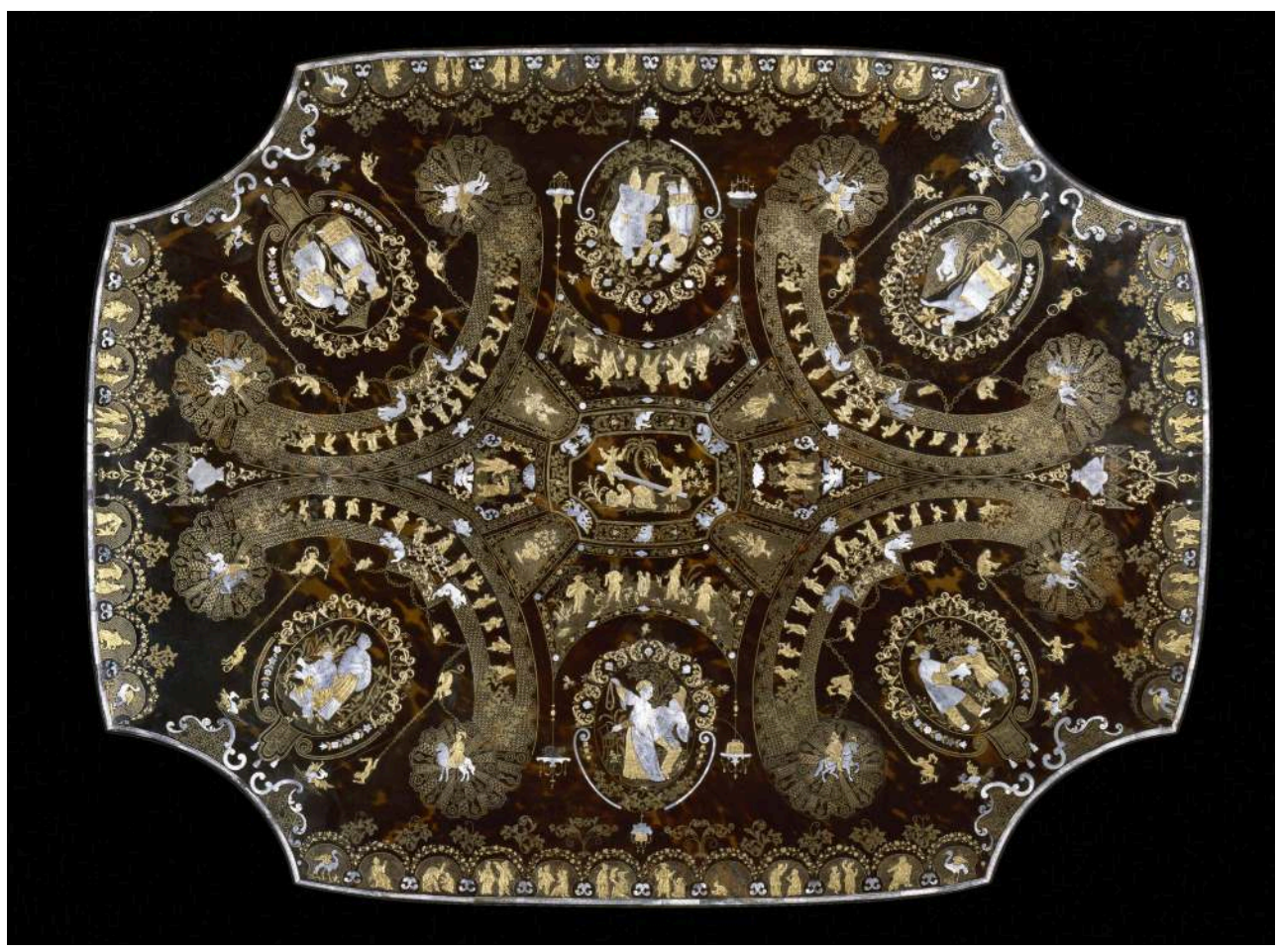

(c) Guillaume Benoît / Galerie Kugel 
7 Un grand coffret de Sarao, reprenant le même décor de chinoiseries que la table, porte, lui, les armes de Charles de Bourbon, qui entra triomphalement dans Naples en 1734 (fig.5). Pour la première fois depuis plus de deux siècles, un roi et sa cour vivaient à Naples. Charles de Bourbon en fit une ville brillante et cosmopolite, transformant la cité en État moderne, en contact avec les grands centres européens, ouvert à l'influence des Lumières. Marié à Marie-Amélie de Saxe, fille d'Auguste III de Dresde, Charles était en contact étroit avec l'art de Saxe, et des analogies existent entre les décors piqués et ceux de la porcelaine de Meissen. Les décors extravagants combinent élégamment chinoiseries, singeries et grotesques. Les autres ateliers de "tartarugari», comme ils étaient appelés, du nom de la tortue en italien (tartaruga) - connus par des archives ou des pièces signées d'Antonio De Laurentii, Nicolas De Turris, Nicola Starace, Giovanni et Tomaso Tagliaferro - reprennent l'art de Giuseppe Sarao. L'atelier de ce dernier sera poursuivi par son fils Gennaro, mentionné pour la première fois en 1741 et répertorié dans les comptes royaux jusqu'en 1770 .

5. Giuseppe Sarao, grand coffret à décor de chinoiseries sur quatre pieds en forme de tortues, aux armes de Charles de Bourbon, Naples, c. 1735-1740, $28 \times 48 \times 33,5 \mathrm{~cm}$, ancienne collection Firestone.

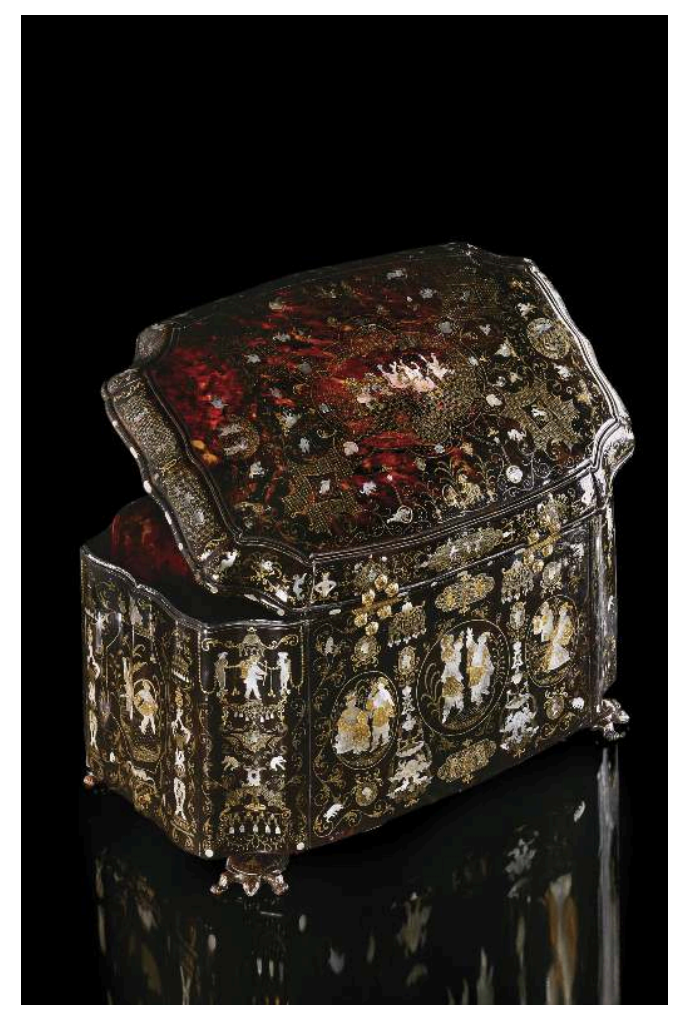

(c) Guillaume Benoît / Galerie Kugel

8 L'âge d'or du piqué coïncide ainsi avec le règne de Charles de Bourbon et prendra fin avec son départ pour l'Espagne, en 1759, où il fut couronné Charles III d'Espagne.

9 Il s'agit donc d'une des productions les plus raffinées et éphémères que les arts décoratifs nous ont laissées. 


\section{La collection d'écailles piquées de Mayer Carl von Rothschild}

Le baron Mayer Carl von Rothschild (fig. 6), originaire de Francfort, était le petit-fils du fondateur de la dynastie, Mayer Amschel (1744-1812), et le fils de Carl Mayer, qui dirigea la branche napolitaine de la banque familiale. Il se pourrait d'ailleurs que son goût pour les piqués provienne de son père, de même que certaines pièces. Il amassa, dans ses deux résidences de Francfort, une incomparable collection d'orfèvrerie, de tabatières et d'objets précieux ${ }^{7}$.

6. Mayer Carl de Rothschild (1820-1886), miniature dans un cadre en or émaillé, c. 1880, collection particulière.

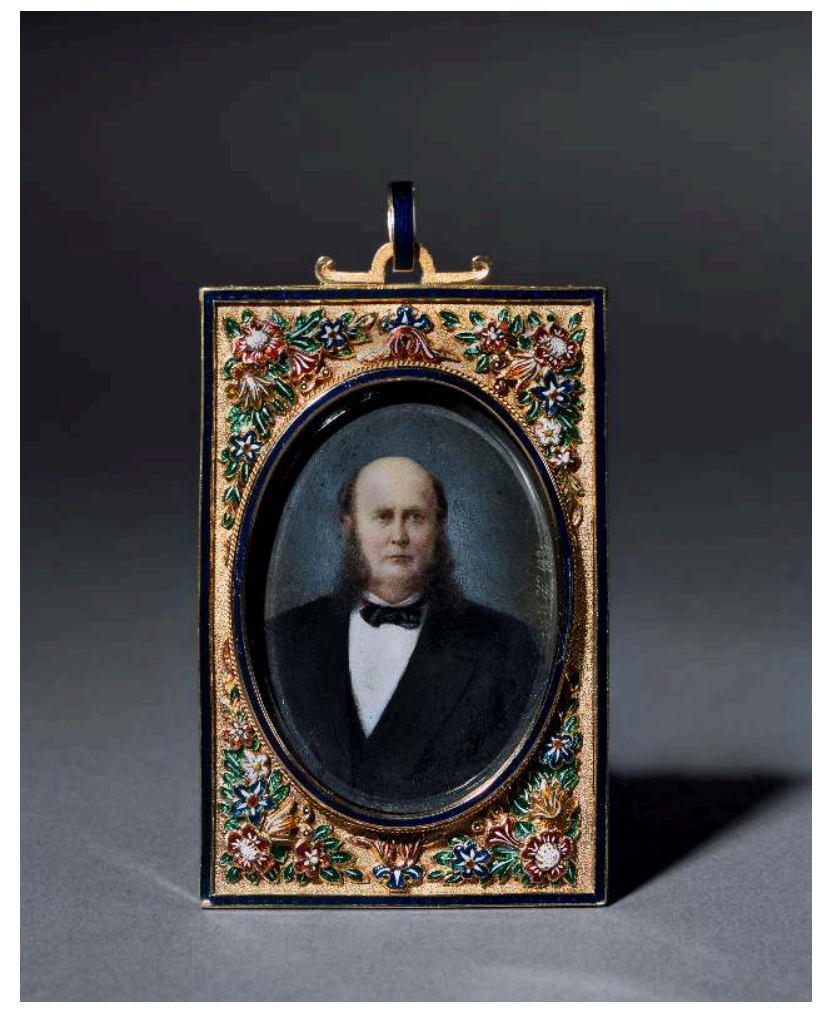

(c) D.R.

11 Dans sa résidence principale sise Untermainkai, 15, l'inventaire imprimé vers 1888, après sa mort, contient un petit chapitre consacré au "Schildkrot ${ }^{8}$ ". Il recense 28 objets en piqué, la plupart réunis dans la seconde vitrine de la salle à manger. Les descriptions en allemand sont relativement précises et incluent les dimensions, ce qui nous a permis d'identifier seize objets et, parmi ceux-ci, sept firent partie de notre exposition en 2018.

Pourtant, certaines descriptions sont malheureusement trop succinctes ou trop vagues pour permettre une identification. On relèvera alors simplement la mention de petits objets, tels que carnet, brosse ou corne à poudre modestes, un rouet, quelques plats et coffrets... On regrettera de ne pas avoir pu identifier précisément une belle écritoire, dont il existe trop d'exemplaires, et une paire de bougeoirs à six pans que l'on ne désespère pas de retrouver un jour. Et il n'existe aucune photographie de la 
présentation de ces objets à Francfort. À sa mort, la collection fut divisée entre ses cinq filles et la partie échue à Adèle, baronne Salomon de Rothschild, fut léguée à l'État en 1922. Cinq beaux objets en écaille, aujourd'hui exposés au Louvre, proviennent de ce legs9. Il s'agit d'un plat à décor de chinoiseries, attribué à Sarao. Représentant l'empereur de Chine assis sur son trône, à qui l'on présente un bol de thé, il s'inspire des recueils de gravures allemandes contemporaines réalisées par Paul Decker ou Martin Engelbrecht. Ces gravures servirent également de modèles pour les peintres de porcelaine de Meissen, les peintres sur verre, les laqueurs et les orfèvres (vers 1730-1740, fig. 7-8 $)^{10}$.

7. Giuseppe Sarao (attribué à), plat ovale figurant l'empereur de Chine, Naples, c. 1730-1740, écaille piquée d'or et de nacre, $29,5 \times 22,5 \mathrm{~cm}$, Paris, musée du Louvre, département des Objets d'art, R 25 .

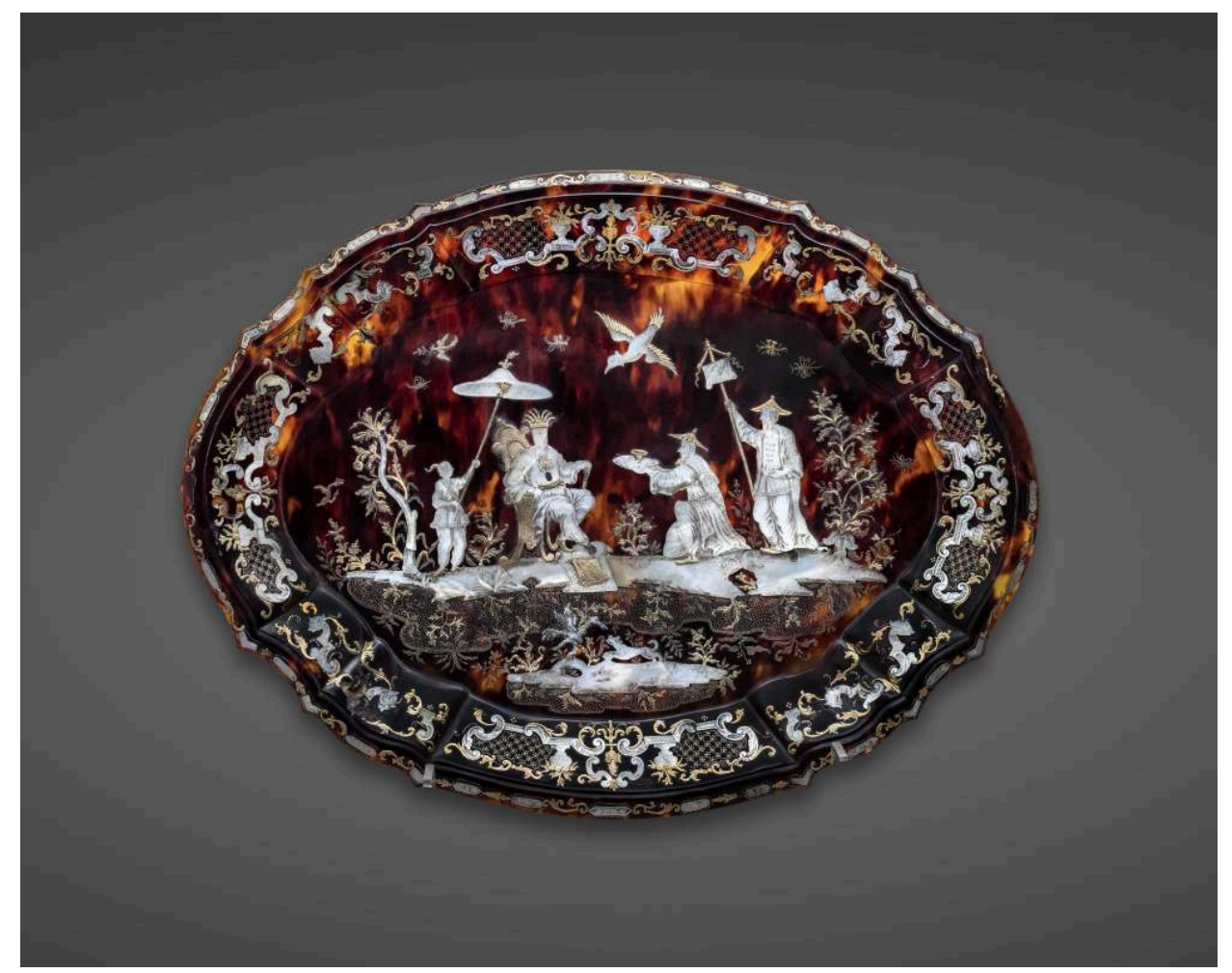

(C) Musée du Louvre

13 Un coffret-écritoire en forme de livre, décoré de scènes de l'Ancien Testament (fig. 8), est un objet unique dans la production de Sarao, sans doute en rapport avec son commanditaire. Il s'ouvre à la charnière et laisse apparaître un encrier et une boîte à poudre indépendants ainsi qu'un compartiment couvert pour la plume. 
8. Giuseppe Sarao (attribué à), coffret en forme de livre formant écritoire à décor de scènes de l'ancien testament, Naples, c. 1725-1735, écaille piquée d'or et de nacre, 19,5 × 13 cm, Paris, musée du Louvre, département des Objets d'art, R 27.

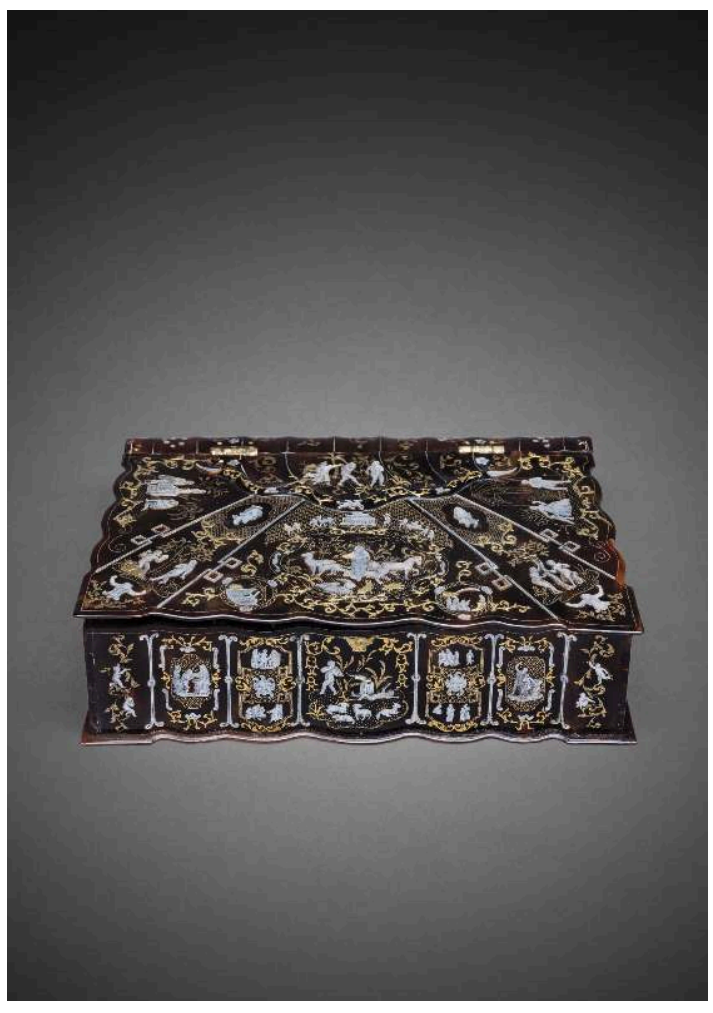

(c) Musée du Louvre

$14 \mathrm{Au}$ Louvre est également conservé un grand plat signé par Giuseppe Sarao (c. 1725-1735), présentant un décor à la Bérain, plein de fantaisie (fig. 9 ${ }^{11}$. 
9. Giuseppe Sarao (attribué à), grand bassin figurant Diane et Bacchus au centre, Naples, c. 1725-1735, écaille piquée d'or et de nacre, $48 \times 34,5 \mathrm{~cm}$, Paris, musée du Louvre, département des Objets d'art, R 26.

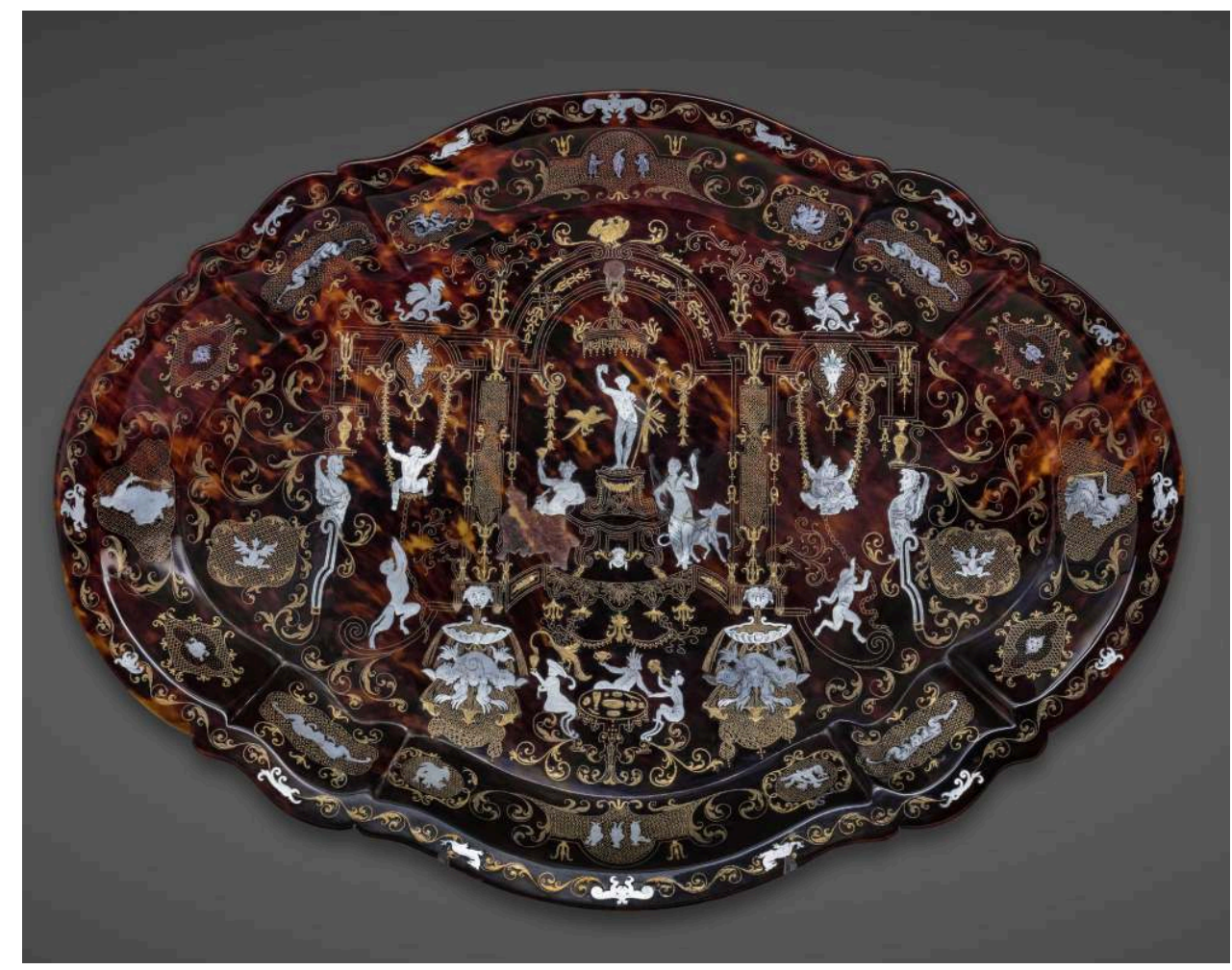

(c) Musée du Louvre

15 Chez Mayer Carl, il formait une paire avec un plat de mêmes dimensions, tous deux directement copiés d'une gravure avec le char d'Apollon de Bérain ${ }^{12}$. Un cabinet en forme d'armoire miniature, typique du style de Sarao, reposant sur des pieds en forme de pattes de lion, datable de 1725-1735, est l'un des plus beaux objets en écaille piquée appartenant aux collections du musée (fig. 10) ${ }^{13}$. Comme d'autres cabinets conservés, il n'est pas construit sur une structure en bois mais entièrement en écaille, et les portes ouvertes, décorées sur leurs faces internes de singes et d'oiseaux, laissent passer la lumière en transparence. Enfin, il y a un étonnant rouet, retrouvé par Michèle Bimbenet-Privat dans les réserves du château d'Écouen et déposé aujourd'hui au musée du Louvre. Datant de 1740-1750, il présente un beau décor intégralement en or et il est signé par Tomaso Tagliaferro ${ }^{14}$. 
10. Giuseppe Sarao [attribué à], cabinet en forme d'armoire miniature, Naples, c. 1725-1735, écaille piquée d'or et de nacre, $28 \times 18,5 \mathrm{~cm}$, Paris, musée du Louvre, département des Objets d'art, R 21 .

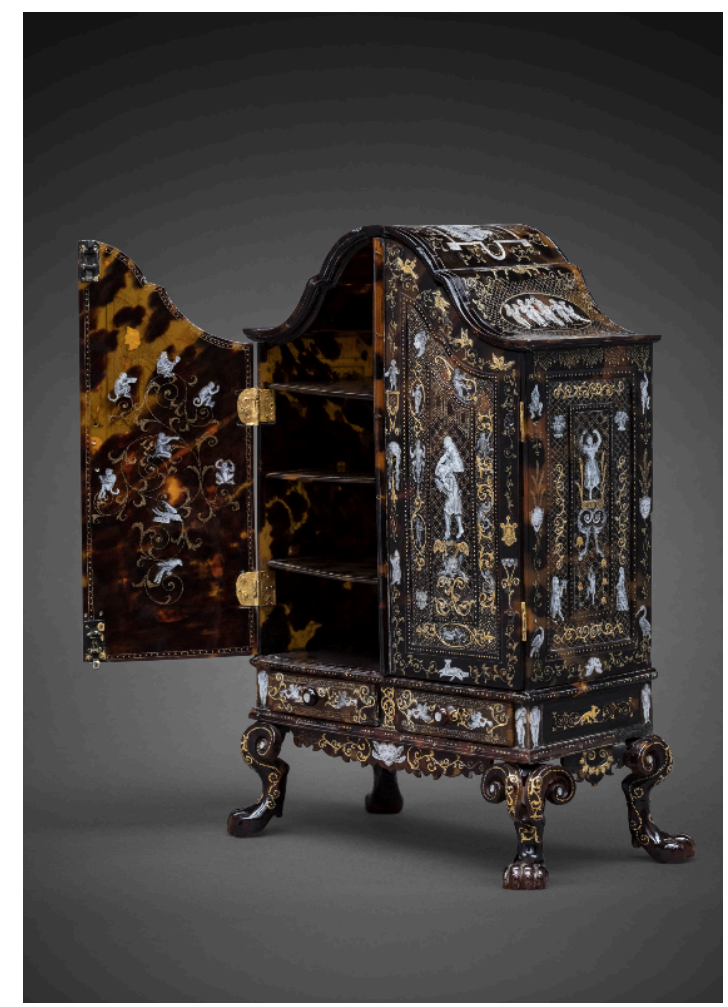

(c) Musée du Louvre

16 Cet usage de l'écaille blonde et de l'or à décor de volutes et de piqué, qui caractérise l'œuvre de l'artiste, a permis l'attribution d'un certain nombre d'autres œuvres à Tagliaferro (fig. 11) ${ }^{15}$. 
11. Tomaso Tagliaferro, rouet, Naples, c. $1740-1750$, écaille piquée d'or, $17,5 \times 16,5 \mathrm{~cm}$, Paris, musée du Louvre, département des Objets d'art, dépôt du Musée national de la Renaissance d'Écouen, ECl 20691.

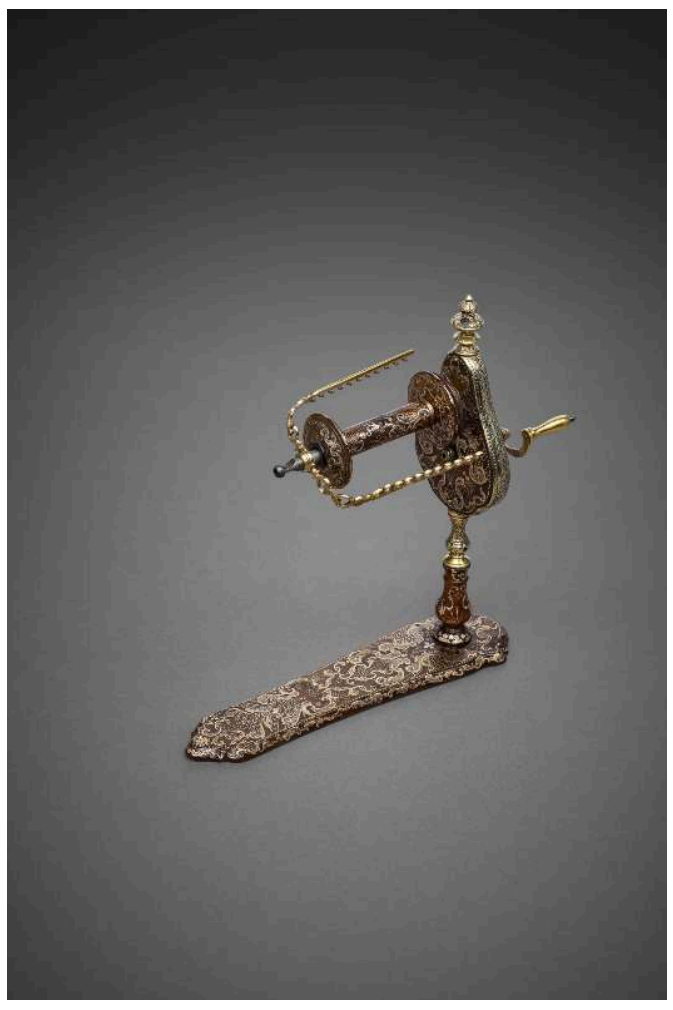

(C) Musée du Louvre

17 Citons enfin, dans une collection privée, l'objet le plus spectaculaire de la collection : le plateau de table, déjà décrit dans l'inventaire comme ayant été réalisé d'après un plafond de la Villa Madame à Rome, peint à la Renaissance par Giovanni da Udine (fig. 12). 
12. Giuseppe Sarao [attribué à], plateau de table carré d'après le plafond de la Villa Madame, Naples, c. 1730-1740, écaille piquée d'or et de nacre, (le piétement en placage d'ébène et bronze doré est d'époque postérieure), 76 ×60,5 cm, collection particulière.

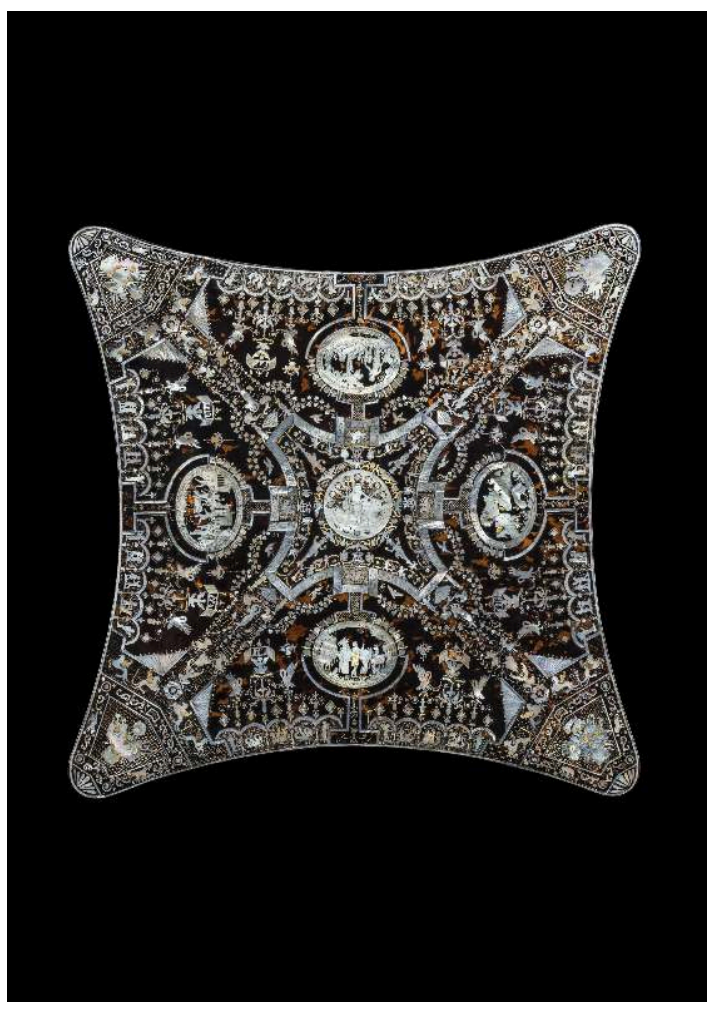

(c) D.R.

18 Les objets identifiés dans la collection de Mayer Carl nous permettent de mesurer l'importance à la fois du nombre et de la qualité de ces pièces, et de redécouvrir un art jusqu'ici négligé, car trop rare dans les collections publiques. Les objets du Louvre, aujourd'hui bien exposés dans une vitrine qui leur est dédiée, ne furent sortis des réserves par Michèle Bimbenet-Privat qu'à l'occasion de la restructuration des salles du XVIII ${ }^{\mathrm{e}}$ siècle du département des Objets d'arts, en 2014.

\section{NOTES}

1. Alexis Kugel, Complètement piqué. Le fol art de l'écaille à la cour de Naples, cat. exp. (Paris, galerie Kugel, 12 sept. - 8 déc. 2018), Paris, Éditions Monelle Hayot, 2018. Ce sujet avait été abordé par Marc Bascou, « Montres et écailles piquées, 1922 », dans Pauline Prevost-Marcilhacy (dir.), Les Rothschild. Une dynastie de mécènes en France, Paris, Louvre/BnF/Somogy, 2016, vol. II, p. 142-143. Concernant cette technique, voir également : Luciana Arbace, « L'arte della tartaruga a Napoli nel Settecento ", dans L'Arte della tartaruga. Le opere dei Musei napoletani e la donazione Sbriziolo-De Felice, Naples, Casa editrice Fausto Fiorentino, 1994 ; Alvar González-Palacios, Il tempio del gusto. Le arti decorative in Italia fra classsicismi e barocco, Roma e il Regno delle due Sicilie, 2 vol., Milan, Longanesi \& 
C., 1984 ; Alvar González-Palacios, «Tartaruga », dans Civiltà del Settecento a Napoli (1734-1799), 2 vol., Naples, Centro Di, 1979.

2. Voir Alexis Kugel, Complètement piqué, op. cit., p. 75, notes 139 et 140.

3. Ibid., loc. cit., note 141.

4. Ibid., loc. cit., note 142 .

5. Encyclopédie ou Dictionnaire raisonné des sciences, des arts et des métiers. Recueil de planches sur les sciences, les arts libéraux, et les arts mécaniques, tome IX, $3^{\mathrm{e}}$ édition, Livourne, 1776.

6. Voir Alexis Kugel, Complètement piqué, op. cit., p. 48-50 ; Tamara Rappé, Masterpieces of European Furniture from the $15^{\text {th }}$ to Early $20^{\text {th }}$ Centuries in the Hermitage Collection, Saint-Pétersbourg, The State Hermitage Publishers, 2016; Tamara Vladimirovna Rappe, « New Attribution of a Tortoiseshell Table from the Hermitage Collection », Transactions of the State Hermitage Museum, vol. 35, 1985.

7. Voir Michèle Bimbenet-Privat et Alexis Kugel, « Un ensemble exceptionnel d'orfèvrerie et de bijoux, 1922 », dans Pauline Prevost-Marcilhacy (dir.), Les Rothschild. Une dynastie de mécènes en France, op. cit., vol. II, p. 32.

8. Hans Luthmer, Verzeichnis des Freiherrlich Carl von Rothschild'schen Sammlung, Untermainquai, $n^{\circ} 15$, vers 1888, chap. IV « Schildkrot », p. 61, n 2-28.

9. Paris, musée du Louvre, département des Objets d'art, R 21, R 25, R 26 et R 27 et dépôt du Musée national de la Renaissance au musée du Louvre à Paris, département des Objets d'art, ECl 20691.

10. Alexis Kugel, Complètement piqué, op. cit., p. 62, ill. 87.

11. Ibid., p. 66, ill. 94.

12. Ibid., p. 57, ill. 76 .

13. Ibid., p. 53, ill. 72 .

14. Ibid., p. 36-37.

15. Ibid., p. 37, ill. 41.

\section{INDEX}

Index géographique : France, Italie

Index chronologique : XVIIIe siècle, XIXe siècle

Thèmes : Mobilier, arts décoratifs, collections, Rothschild

\section{AUTEUR}

\section{ALEXIS KUGEL}

Alexis Kugel est historien de l'art, collectionneur et antiquaire. Il codirige avec son frère Nicolas la galerie J. Kugel. 


\title{
La collection de pipes d'Alice de Rothschild à Grasse
}

\author{
André Leclaire
}

1 Expliquer les motivations d'un individu à réaliser une collection reste une entreprise hasardeuse et aux ramifications multiples. Son histoire personnelle peut parfois apporter des indices sur l'acquisition, la réunion et la conservation d'objets qui ne possèdent qu'une valeur subjective. Issu de la pratique des cabinets de curiosités apparue à la Renaissance, l'acte de collectionner s'ouvre, à l'époque moderne, à un nombre croissant de personnes. Concernant les objets liés au tabac, les premières collections apparaissent notamment sous l'impulsion des fabricants ou des négociants de cette plante. Les premiers musées voient le jour afin de séduire une nouvelle clientèle et de promouvoir des articles et des usages neufs. Si les pipes en terre du $\mathrm{XVII}^{\mathrm{e}}$ siècle offrent des formes simples, l'apparition de matériaux modernes va stimuler l'intérêt des fumeurs et faire naître chez eux le désir d'en posséder plusieurs modèles de conception différente. L'utilisation du bois, de la porcelaine lors du XviII siècle ou de l'écume de mer par les pipiers va amplifier cette quête d'exemplaires aux formes attrayantes, collectionnés par des personnalités telles quel qu'Armand Emmanuel du Plessis, duc de Richelieu (1766-1822), Auguste Frédéric de Sussex (1773-1843) ou le septième président des États-Unis, Andrew Jackson (1767-1845), pour ne citer que ces personnages ${ }^{1}$. William Bragge (1823-1884) de Birmingham laisse notamment une trace indélébile dans le domaine de la collecte de ces objets, puisqu'il s'est composé une prestigieuse bibliothèque d'ouvrages sur ce thème et qu'il a rassemblé 7000 pipes ou objets liés au tabac, issus du monde entier. Certaines de ces pipes, mises en vente en 1882 à Londres, apparaissent dans la collection évoquée ci-dessous²

Notre collectionneuse, Alice Charlotte de Rothschild, voit le jour le 17 février 1847 dans la demeure familiale du 45 Neue Mainzer Straße, à Francfort. Ses parents, le baron Anselm Salomon et Charlotte de Rothschild, accueillent avec bonheur ce septième enfant, promis à un bel avenir. En 1855, Anselm doit reprendre en main les affaires familiales et déménage avec toute sa famille à Vienne. Quatre années plus tard, Charlotte décède, et l'éducation de la jeune Alice est confiée à Cécile Hofer, une gouvernante française qui deviendra, pendant de longues années, son inséparable dame 
de compagnie. Son enfance et son adolescence sont vécues dans deux pays différents, qui auront vraisemblablement une influence sur le choix des objets qu'elle collectionnera à sa majorité. En 1867, Alice réside en Grande-Bretagne, avec son frère Ferdinand, qui entreprend, en 1874, la construction du manoir de Waddesdon. Elle décide, en 1875, d'acquérir le domaine d'Eythrope, situé dans une boucle de la Tamise. Sujette à des problèmes de santé, Alice passera désormais toutes les saisons hivernales sur la Côte d'Azur, où plusieurs membres de sa famille possèdent des résidences : Laura Thérèse à Cannes et Béatrice Ephrussi de Rothschild à Saint-Jean-Cap-Ferrat. Elle découvre ainsi la ville de Grasse, qu'elle apprécie plus particulièrement pour la richesse de sa végétation méditerranéenne ${ }^{3}$. Lors d'un séjour en 1887, alors âgée de 40 ans, elle décide d'acquérir une modeste parcelle de 13 ares contenant la Villa Césarie. À chacune de ses villégiatures, Alice achète de nouvelles parcelles jusqu'à posséder une propriété de 135 hectares. Elle peut ainsi de nouveau, après les aménagements des jardins de Waddesdon et d'Eythrope, laisser libre cours à sa passion pour l'horticulture. Cette demeure prendra le nom de Villa Victoria à la suite de la réception, en ses murs, de la souveraine britannique en 1891. Dès septembre 1889, Alice de Rothschild commence une collection d'objets liés au tabac: principalement, les boîtes d'allumettes et les pipes $^{4}$. Elle s'y consacrera avec passion et sans partage, même si nous ignorons ses motivations exactes. Seuls ses invités ont la possibilité d'admirer ces pipes, lorsqu'ils accèdent au fumoir de la demeure. Si la presse locale relate ses déplacements dans la ville et ses diverses actions sociales, elle n'évoque jamais la collection de la baronne. Celle-ci semble se préserver d'éventuelles critiques de ces objets, principalement utilisés par les hommes et non par une dame de la bonne société.

\section{Une âme de collectionneuse}

3 L'auteur d'un ouvrage publié en $1885^{5}$ mentionne que $\mathrm{M}^{\text {lle }}$ Alice, son frère Ferdinand et son cousin Alfred de Rothschild recherchaient avec passion, chez les marchands de Bond Street, des pièces anciennes en porcelaine de Sèvres. Au-delà des divers aménagements de leurs demeures, les membres de la famille Rothschild manifestaient une réelle motivation pour trouver et acquérir des objets d'art, quête enthousiaste proche de la chasse aux trésors ${ }^{6}$. La baronne Alice incarne ainsi le type de la collectionneuse à la recherche de l'objet insolite digne de valoriser ceux qui sont déjà en sa possession. Elle apprécie les beaux objets, même si ceux-ci sont utilitaires et réservés habituellement aux hommes. Si les femmes n'étaient pas admises dans le fumoir du manoir de Waddesdon, Alice profite pleinement de celui de sa demeure, en y fumant le cigare ou la pipe ${ }^{7}$. Il s'agit vraisemblablement de pipes plus ordinaires que celles exposées sur les murs de la Villa Victoria. D'ailleurs, nombre d'entre elles sont incomplètes, comme le précise son inventaire, ou possèdent des fourneaux d'une grande capacité, susceptible de décourager les plus enthousiastes des fumeurs.

4 Trente-six pièces proviennent de la collection de William Bragge, vendue par Sotheby's à Londres en 1882, et d'autres sont acquises lors de la vente des biens de Sir Goldsmid chez Christie's ou lors de celle des frères Goncourt à Paris, en 1897. Ces achats personnels s'ajoutent aux présents reçus des nombreux visiteurs de la Villa Victoria : outre la reine Victoria, le shah de Perse, l'impératrice d'Autriche Élisabeth (Sissi), le prince et la princesse de Galles, MM. de Vilmorin et Chamberlain honorent de leur visite le domaine grassois ${ }^{8}$. Comme beaucoup de collectionneurs, Alice devait aussi 
posséder un carnet d'adresses spécifique, rassemblant de nombreux contacts et relations capables de lui fournir des éléments intéressants pour sa collection. Récemment, une facture adressée à Alice de Rothschild fut proposée à la vente sur Internet, concernant une pipe ancienne en porcelaine cédée par un marchand d'antiquités berlinois.

5 Alice de Rothschild notera méticuleusement chacune de ses acquisitions sur un petit cahier d'écolier, où figure la description de chaque pipe avec, parfois, ses observations personnelles sur leur origine ${ }^{9}$. Jusqu'à son décès à Paris, le 3 mai 1922, elle complétera les sept panneaux en bois qui ornent le fumoir de la Villa Victoria. Certains de ces présentoirs adoptent une forme d'écu à la manière des trophées présents à Waddesdon, rappelant l'intérêt porté par Alice aux armes et aux armures. Une photographie ${ }^{10} \mathrm{de}$ l'un d'entre eux fut prise lors de la donation des collections de pipes et de boîtes d'allumettes, faite en 1927 par le baron Edmond de Rothschild, à la ville de Grasse (fig. 1). Ce legs fut effectué sous la condition que les pièces soient exposées dans un bâtiment public. Si les panneaux de présentation n'ont pu être conservés, le souhait du baron Edmond est encore aujourd'hui respecté, puisque la préservation des pièces revient à la Villa Saint-Hilaire, bibliothèque patrimoniale de la ville de Grasse ${ }^{11}$. Son ancien conservateur, Yves Cruchet, a fait réaliser en 2013 un inventaire exhaustif de ces pipes et valorisé sa publication sur la base de données nationale Joconde ${ }^{12}$. Depuis 2018, la Villa Saint-Hilaire a mis en place un blog coopératif proposant chaque mois aux chercheurs une nouvelle pièce de la collection, en vue d'en préciser l'origine ou d'en identifier le fabricant ${ }^{13}$. Ces informations enrichiront ainsi les fiches d'identification individuelles établies pour l'ensemble de la collection lors de l'inventaire de 2013, démarche qui n'avait pas été réalisée depuis la donation. 
1. J. Weyer, Panneau en bois de présentation des pipes pour le fumoir de la Villa Victoria, vers 1927, photographie, Grasse, Villa Saint-Hilaire.

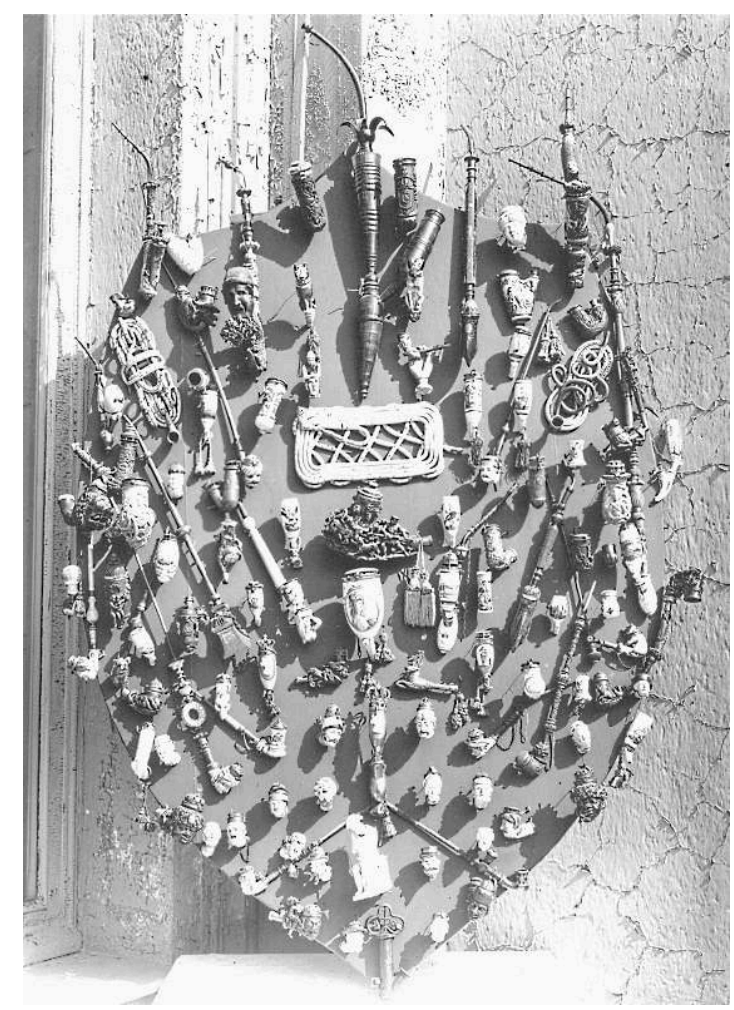

(c) Villa Saint-Hilaire, Grasse

Présenter les 407 éléments de cette collection nécessite d'opérer un choix. Comment privilégier telle pièce plutôt qu'une autre et sur quels critères: esthétique, fonctionnalité, rareté ou ancienneté ? L'évocation des matériaux entrant dans la fabrication des fourneaux permet finalement d'aborder ce corpus dans son ensemble, en indiquant en même temps la période de création de ces objets ainsi que leur origine géographique.

\section{La porcelaine}

7 Les 202 fourneaux en porcelaine, soit la moitié de la collection, proviennent majoritairement des ateliers allemands de Saxe ou de Thuringe en activité à la fin du $\mathrm{XVIII}^{\mathrm{e}}$ siècle. Des exemplaires issus des fabriques de Meissen, Limbach, Nymphenburg, Berlin ou Wallendorf sont identifiables dans la collection, notamment par leur marque apposée sur la douille des fourneaux. Ces objets sont ainsi parmi les premières productions européennes de pipes en porcelaine, matière qui vit le jour dans l'électorat de Saxe. D'autres marques peuvent apparaitre sur un fourneau en porcelaine, telles que celle du mouleur (signe souvent énigmatique) ou du décorateur (initiales dans le décor).

Des fourneaux anthropomorphes illustrent des visages anonymes ou des personnages en pied, moulés en relief et parfois issus de la mythologie, tels que Neptune ou une sirène représentée en cariatide (fig.2). Mais on trouve aussi des exemplaires zoomorphes qui figurent des animaux domestiques (chien, chat ou oiseau), voire plus exotiques, tels que des ours ou des singes. Les thèmes restent très variés et abordent 
fréquemment les sujets d'actualité de l'époque, comme celui des conflits. Représentations de chefs d'armées (Napoléon I Ir, Frédéric II) ou de soldats côtoient les évocations de conflits militaires ou de traités internationaux (célébration de la Confédération germanique ou illustrations de la Sainte-Alliance). Quelques fourneaux en porcelaine possèdent des dimensions impressionnantes, avec une hauteur de 26 à $30 \mathrm{~cm}$ pour un diamètre maximal de $10,8 \mathrm{~cm}$.

2. Pipes en porcelaine allemande, fin du XVIII ${ }^{\mathrm{e}}$ siècle, porcelaine, émail et métal, Grasse, Villa SaintHilaire.

De gauche à droite et de haut en bas : Satyre, Allemagne, porcelaine, $6,8 \mathrm{~cm}, 1760 / 1780$; Neptune, Brückberg (Allemagne), porcelaine, 6,8 cm, 1760/1780 ; Pipe à décor floral, Allemagne, porcelaine, 18 cm, 1780/1820 ; Sirène, Volkstedt (Allemagne), porcelaine, 11,3cm, 1795/1815.

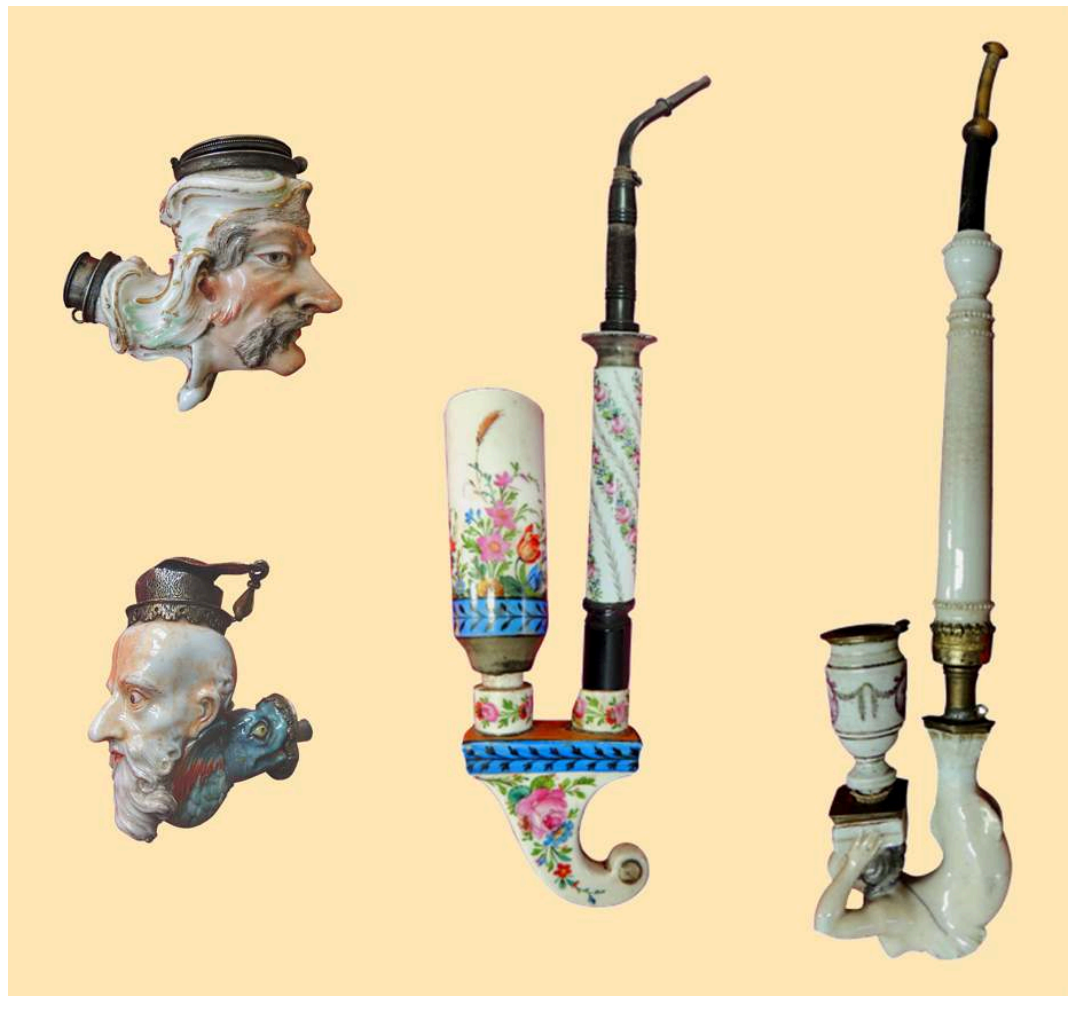

(c) Villa Saint-Hilaire, Grasse

9 Les tuyaux, parfois absents des exemplaires de la collection, offrent une ornementation intéressante. Généralement simples et en merisier, ils peuvent aussi être exécutés en d'autres matières. La corne, les bois de cervidés sont également travaillés par des artisans spécialisés, qui fournissent en tuyaux les fabriques de porcelaine. Ces objets s'agrémentent de diverses bagues en argent ou d'éléments décoratifs en ivoire ou en nacre. Le métal intervient pour la confection des diverses viroles ou ornements, mais surtout pour celle des couvercles en laiton, en métal argenté et très souvent en argent. Cette dernière matière présente parfois des poinçons indiquant le titre de l'argent et le chiffre de l'orfèvre. Ces mentions restent difficilement lisibles, car elles sont souvent mal frappées ou usées par l'utilisation de la pipe et donc par ses fréquents nettoyages. Parmi les poinçons identifiés figure une marque de Nuremberg ( $\mathrm{du}$ XVIII ${ }^{\mathrm{e}}$ siècle) et une seconde de la ville de Vienne (1830). 

d'ateliers français et autrichiens (fig.3). En ce qui concerne la France, il s'agit de productions de la manufacture de Sèvres, rehaussées notamment de la couleur qualifiée de « vert empire» et mise au point par le chimiste Nicolas Louis Vauquelin en $1798^{14}$. Une scène de chasse (avec un chien couché sur le couvercle) orne une forme de pipe dite « hongroise », issue des ateliers autrichiens.

3. Fourneaux en porcelaine produits en France et en Autriche, début XIXe siècle, porcelaine, émail et métal, Grasse, Villa Saint-Hilaire.

De gauche à droite : Jeu de cartes, France, porcelaine, 8,8 cm, 1820/1850; Napoléon ler. France, porcelaine, $14 \mathrm{~cm}$, 1820/1840 ; Scène de chasse, Hongrie, porcelaine, 9,8 cm, 1830/1860.

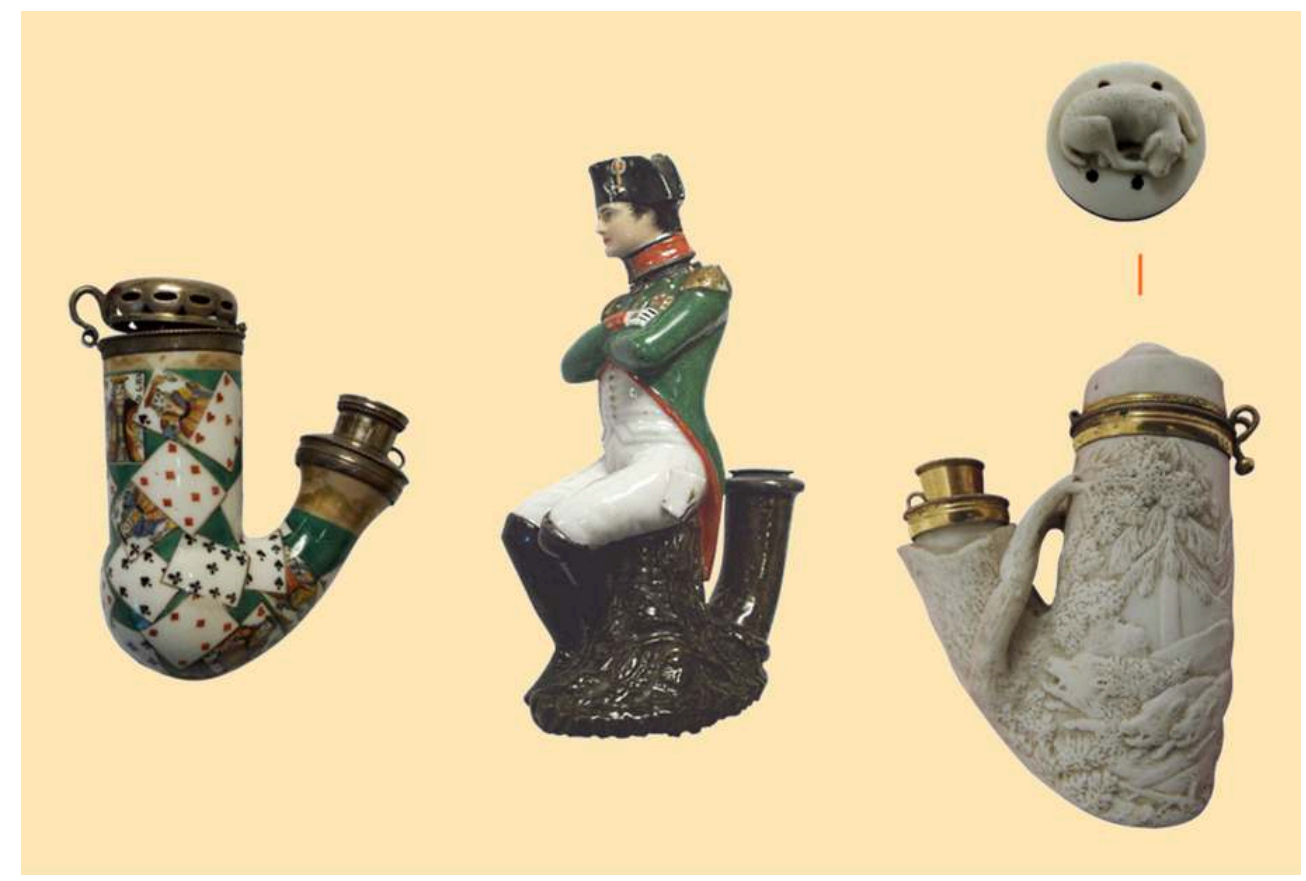

(c) Villa Saint-Hilaire, Grasse

\section{Les bois}

11 Le bois représente le deuxième matériau privilégié par la baronne Alice, avec 123 éléments, dont la moitié date $\mathrm{du}$ XVIII ${ }^{\mathrm{e}}$ siècle. L'analyse de ces pièces reste délicate, car leur fabrication n'est plus réservée seulement aux ateliers de pipiers professionnels, mais aussi aux sculpteurs occasionnels et relève de l'art populaire. Si l'attrait de la baronne Alice pour les fourneaux en porcelaine peut s'expliquer par leur origine géographique (l'Allemagne est son pays natal), les pipes en bois lui font apprécier la dextérité de leurs créateurs, exercée parfois sur des fourneaux de petite taille $(4,5 \mathrm{~cm}$ de hauteur pour l'un des plus petits). Par l'intermédiaire de ces pièces sculptées avec minutie, elle peut appréhender des univers très variés, où les épisodes mythologiques côtoient des scènes de la vie quotidienne ou des représentations héraldiques.

La liste des divers bois sculptés ou tournés pour confectionner des pipes reste impressionnante. Dès 1880, au moins 36 essences de bois différentes sont utilisées par cet artisanat ${ }^{15}$. Néanmoins, pour leur résistance à la combustion du tabac, les artisans 
préfèrent essentiellement travailler le buis, le noyer ou certains bois fruitiers, avant l'avènement de la racine de bruyère au début du XIX ${ }^{e}$ siècle. Contrairement aux pipes en porcelaine ou en terre cuite, moulées et donc reproduites à de nombreux exemplaires, celles en bois demeurent des pièces uniques. Sculptés avec minutie, les thèmes abordés prouvent la dextérité de leurs auteurs, qui n'hésitent pas à recouvrir l'intégralité de la surface du fourneau en mettant en scène divers acteurs, hommes ou animaux. Les têtes de personnages de la précédente catégorie apparaissent moins fréquemment au profit de scènes comportant de multiples acteurs. Scènes de la vie quotidienne, parties de chasse (fig. 4) ou combats militaires révèlent ainsi les tenues vestimentaires typiques des protagonistes de l'époque. Parfois le thème développé sur le fourneau trouve une continuité sur le tuyau, lorsque celui-ci est réalisé dans le même bois. Le couvercle devient un élément indispensable sur les pipes ornées de scènes de chasse, vraisemblablement réservées aux adeptes de cette activité. Il évite ainsi l'envol de menues braises par l'orifice du fourneau et, donc, tout risque de mettre le feu à la végétation environnante.

4. Pipes avec scènes de cabaret et de chasse, $\mathrm{XIX}{ }^{\mathrm{e}}$ siècle, bois sculpté ou tourné et métal, Grasse, Villa Saint-Hilaire.

De gauche à droite et de haut en bas : Scène de Cabaret, Allemagne, bois, 4,5 cm, 1780/1800; Chasse à l'autruche, Autriche/Hongrie, bois, 8,4 cm, 1790/1820; Chasse au sanglier, Autriche, bois, 14,8 cm, $1790 / 1820$.

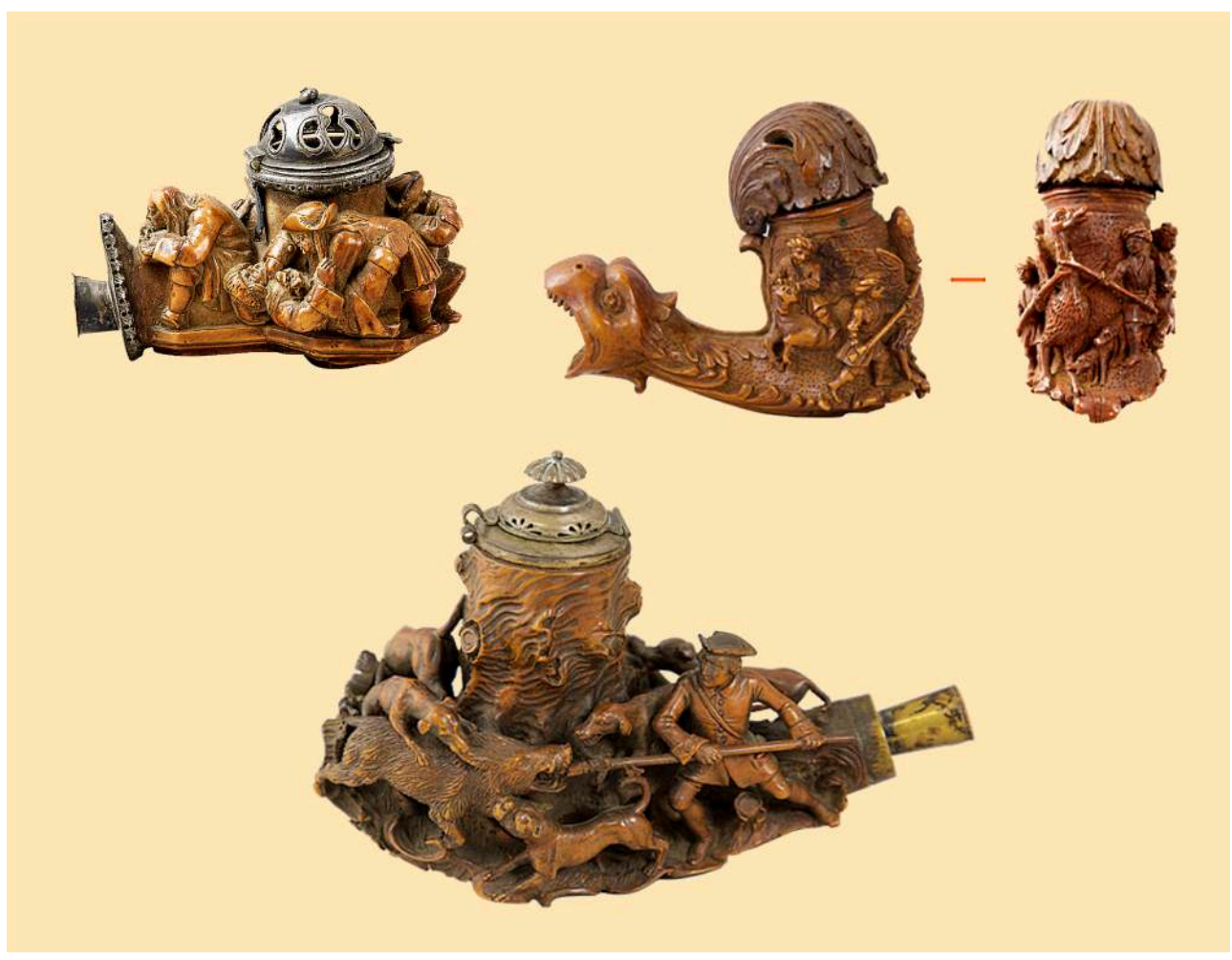

(c) Villa Saint-Hilaire, Grasse

13 Certaines scènes demeurent plus délicates à interpréter, car elles se composent d'images symboliques créées par les pipiers ou à la demande des fumeurs destinataires de ces objets. Eux seuls connaissent le sens profond de ces représentations, souvent énigmatiques pour un non-initié, telle cette allégorie de ville évoquée par une tête féminine reposant sur un dauphin ailé et par une couronne en guise de couvercle, 
constituée par des remparts crénelés surmontés d'un canon (fig.5). Une autre pipe représente un singe anthropomorphe jouant de l'orgue, dont la tige sort de la gueule d'un dauphin, alors qu'un atlante sous le fourneau porte des armoiries dont l'écu est resté vierge. Sur l'exemplaire suivant, deux chevaux cabrés entourent une corbeille de fruits surmontée d'une tête de taureau; sur le couvercle, un rapace dévore un serpent. Sur le dernier exemplaire, on aperçoit l'évocation d'une scène biblique avec un animal marin serpentiforme qui engloutit l'infortuné Jonas, située sous la tête d'un personnage, munie de cornes et d'oreilles proéminentes.

5. Pipes avec représentations allégoriques et biblique, $\mathrm{XIX}$ siècle, bois sculpté ou tourné, Grasse, Villa Saint-Hilaire.

De gauche à droite et de haut en bas : Allégorie de ville, France, bois, 9,5 cm, 1800/1820 ; Singe jouant de l'orgue, Autriche, bois, 10,6 cm, 1780/1820 ; Scène allégorique, Allemagne, bois, 11 cm, 1780/1820 ; Jonas, Allemagne, bois, $26 \mathrm{~cm}, 1780 / 1800$.
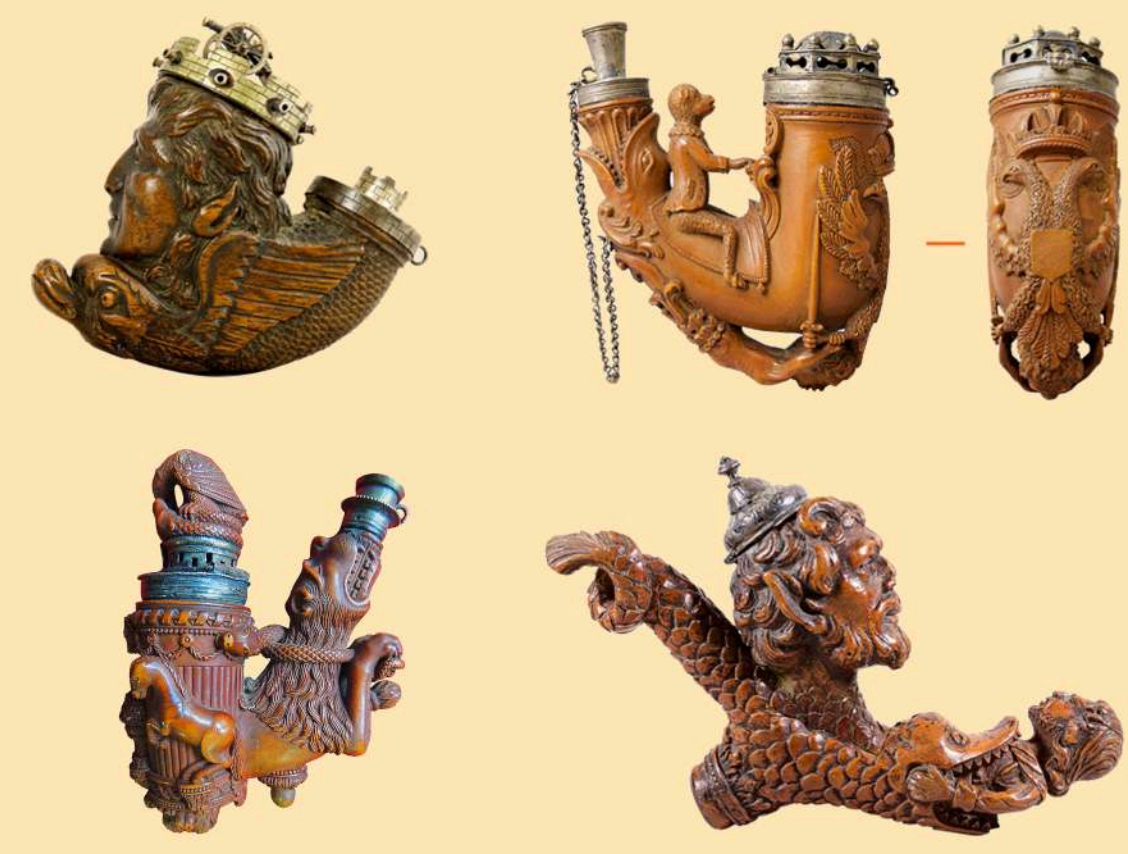

(C) Villa Saint-Hilaire, Grasse

Un fourneau, issu de la collection Bragge et contenu à l'origine dans un étui en cuir aux armes du duc de Sussex, oncle de la reine Victoria, évoque la mythologie (fig. 6). Sculpté dans du buis, ce fourneau présente des dieux romains sur ses flancs: Mars, Vénus, Jupiter et Mercure. Des têtes de grotesques ornent le couvercle et les deux orifices qui permettaient d'adapter le tuyau suivant les désirs du fumeur, soit verticalement, soit horizontalement. Les diverses montures et chaînettes sont en or. Il s'agit d'une pièce intéressante, car son ancien propriétaire, Auguste Frédéric de Sussex, figure parmi les éminents collectionneurs de pipes. Dans sa demeure, ces objets recouvraient les murs d'un salon, alors que deux autres pièces étaient consacrées respectivement aux tabatières et aux cigares ${ }^{16}$. Plus spectaculaire par sa taille $(17 \mathrm{~cm})$ et sa facture, nous pouvons mentionner un jockey dont le corps bascule vers l'avant, avec la partie antérieure du cheval, pour dévoiler l'orifice du fourneau situé au niveau de la sangle de la selle (fig. 7). La tête négroïde associe diverses matières : le bois avec des rehauts de 
peinture, l'argent pour les montures et les divers ornements, des plaquettes de nacre pour le turban, sur lequel est serti un rubis. Un fourneau en bois, sculpté de feuillages et recouvert d'une mince feuille d'or, complète cet objet.

6. Pipe en buis du duc de Sussex, fin XVIII ${ }^{e}$ siècle-début XIX ${ }^{e}$ siècle, Grasse, Villa Saint-Hilaire.

Dieux romains, France, bois de buis, $13 \mathrm{~cm}, 1740 / 1780$.

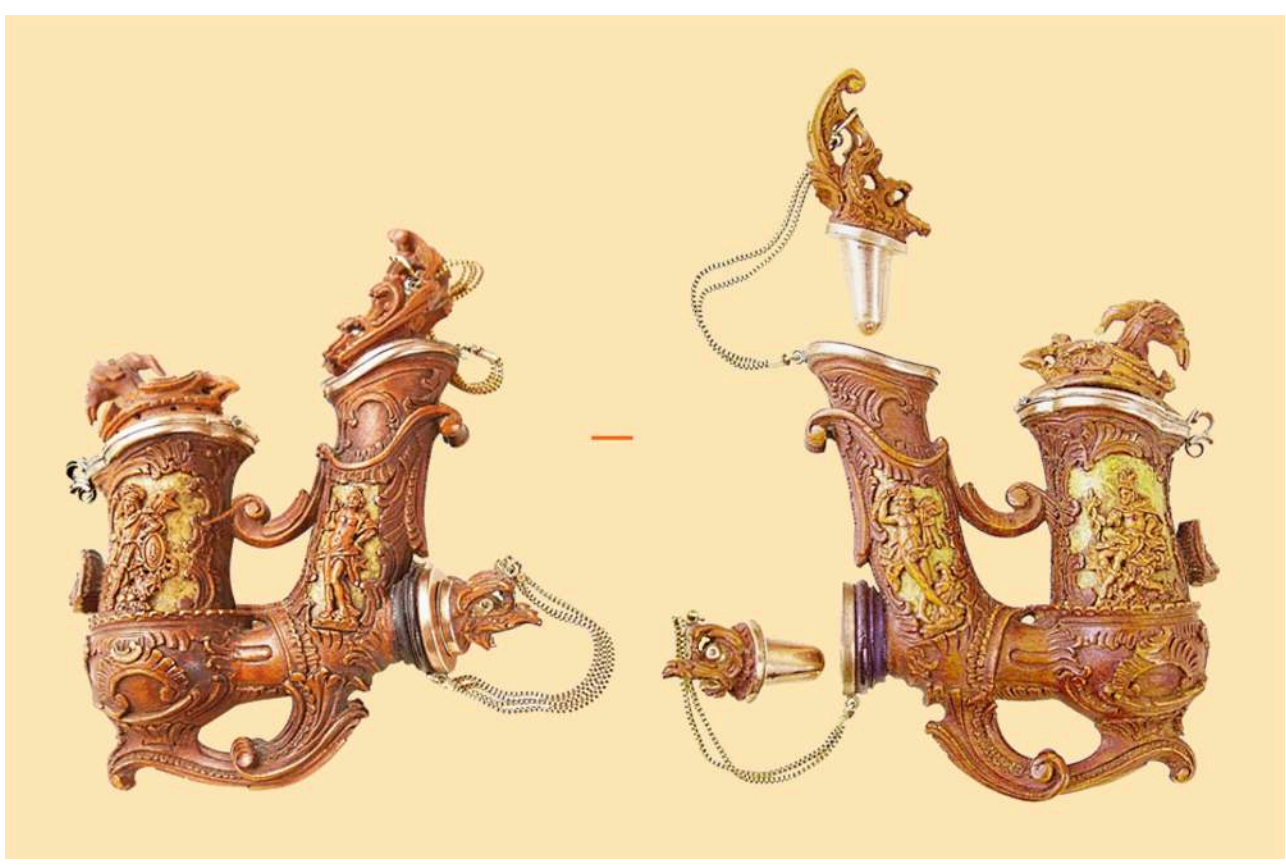

(C) Villa Saint-Hilaire, Grasse

7. Pipes figurées, début XIXe siècle, bois sculpté, métal et pierres, Grasse, Villa Saint-Hilaire.

De gauche à droite et de haut en bas : Jockey, France, bois, $17 \mathrm{~cm}, 1770 / 1800$; Nègre, Autriche, bois, 9,9 cm, 1800/1830; Feuillages, France, bois, 8,3 cm, 1840/1870. 


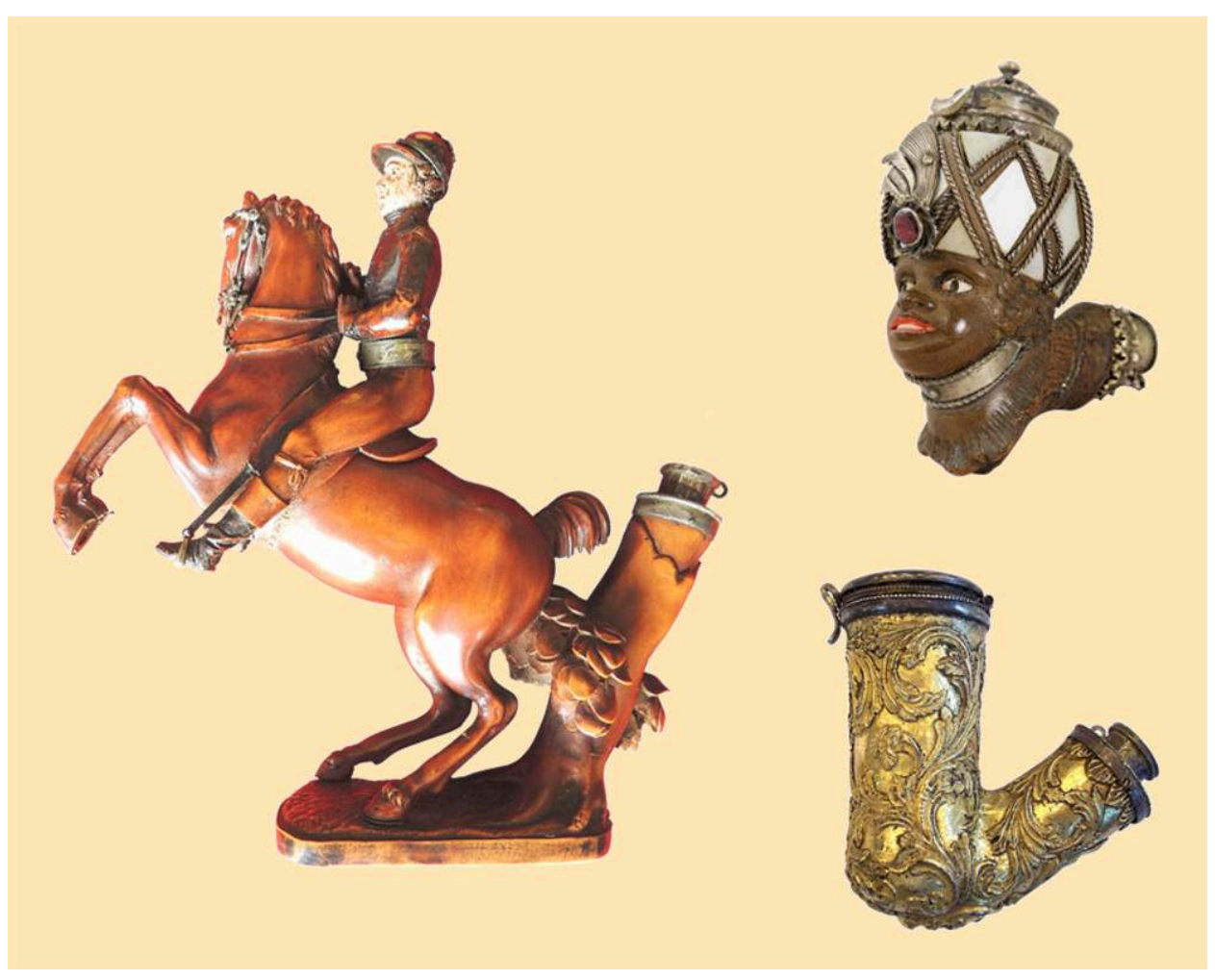

(c) Villa Saint-Hilaire, Grasse

\section{Des matières fort diverses}

La terre cuite est principalement représentée par des pipes vernissées originaires de Grande-Bretagne, issues de la collection Bragge (fig. 8). Les 21 pièces de cette catégorie, qualifiées de "pipes enroulées » ou de "pipes serpentines » et présentes à Grasse, constituent la plus importante collection européenne de ces objets décoratifs produits au début $\mathrm{du} \mathrm{XIX}^{\mathrm{e}}$ siècle $^{17}$. Plus ancienne, une pièce réalisée vraisemblablement par un potier (non moulée) s'orne d'initiales couronnées et de la date de 1748. Quelques pièces moulées en terre cuite proviennent de divers ateliers européens (Italie, France et Belgique).

8. Pipe serpentine en terre vernissée, fourneaux en argent, fer, et pierre de Kelheim, $\mathrm{xIX}{ }^{\mathrm{e}}$ siècle, Grasse, Villa Saint-Hilaire.

De gauche à droite et de haut en bas : Pipe serpentine, Grande-Bretagne, céramique, $32 \mathrm{~cm}$,

1790/1830; Grotesque, argent, Italie, 6,5 cm, 1800/1830 ; Tête d'homme barbu, Allemagne, pierre de Kelheim, 7,2 cm, 1830/1870 ; Clé, France, fer, 120 cm, 1800/1850. 


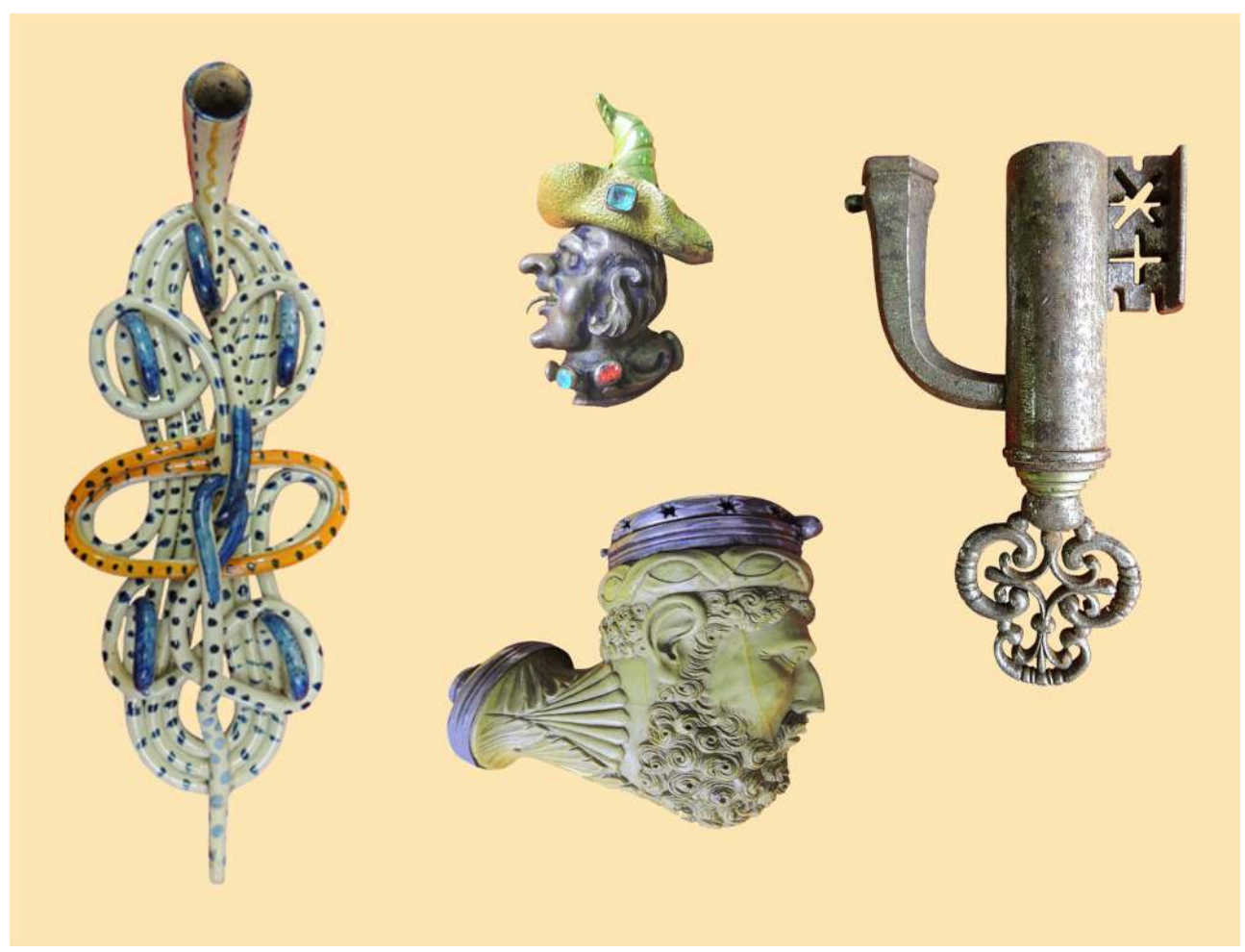

(c) Villa Saint-Hilaire, Grasse

Les métaux: prouesse technique de la part du fabricant ou désir des fumeurs de posséder un objet réalisé avec des matériaux insolites, ces pipes en métal ne devaient guère procurer de plaisir à leurs utilisateurs. Outre la fumée plus ardente que dans une pipe en bois, la combustion du tabac provoquait une chaleur intense, transmise par le métal aux doigts du fumeur qui tenaient le fourneau. Le vermeil mais aussi l'argent, le fer et la pierre de Kelheim entrent dans la composition de certains fourneaux, tels que celui d'un exemplaire de pipe serpentine en terre vernissée (fig.8). Cette tête caricaturale, ornée de pierreries de diverses couleurs, porte un chapeau en bronze constituant le couvercle de la pipe. Deux autres exemplaires en argent de la collection arborent la signature du graveur viennois Franz Detler (1785-1835 ?). Les clés de serrures inspirèrent également les pipiers, puisque, sur les 17 exemplaires recensés dans les diverses collections européennes, trois apparaissent dans la collection de la baronne Alice (deux en fer et une en bronze), datées du début du xix ${ }^{e}$ siècle ${ }^{18}$.

Les minéraux: leur utilisation est bien réelle, comme celle de la pierre de Kelheim, variété de calcaire lithographique exploitée en Allemagne (fig. 8), ou du marbre vert sculpté pour une tête de personnage aux yeux en pâte de verre (fig.9). Matériau plus classique, l'écume de mer n'a apparemment pas retenu l'attention de notre collectionneuse, alors que le $\mathrm{xIX}^{\mathrm{e}}$ siècle fut l'âge d'or de ce type de pipe produit notamment dans les ateliers autrichiens, auteurs de véritables œuvres d'art. Ce silicate de magnésium hydraté, poreux et de couleur blanchâtre, provient d'Anatolie. Facile à sculpter, légère, cette matière avait la particularité de se revêtir d'une magnifique patine après son usage par le fumeur, allant de la couleur crème à un brun-rouge qui faisait la fierté de son propriétaire. Parmi les dix modèles en écume de mer présents dans la collection Rothschild figure un important fourneau non sculpté, mais dont le couvercle en métal argenté s'orne de la figurine d'un hussard fumant la pipe à côté de 
son cheval (hauteur totale: $21 \mathrm{~cm}$ ). Sur un de ces exemplaires (fig. 9), un couple de chasseurs évolue dans un décor forestier. À ce propos, l'acquisition par Alice d'objets ayant un rapport avec la cynégétique peut surprendre, alors qu'elle interdisait à tous les Grassois de chasser sur les terres de la Villa Victoria afin d'en protéger la faune.

9. Pipes, matériaux divers : marbre vert, verre de Murano, ivoire, bois de cervidé et écume de mer, XIX ${ }^{e}$ siècle, Grasse, Villa Saint-Hilaire.

De gauche à droite et de haut en bas : Tête de diablotin, Autriche, marbre vert, 8,5 cm, 1840/1860; Coq aux ailes déployées, Murano (I), verre soufflé, $44 \mathrm{~cm}, 1820 / 1860$; Guirlande de fleurs, France, ivoire, 20,5 cm, 1780/1810 ; Chasse à courre, Allemagne, bois de cervidé, 15,5 cm, 1820/1850 ; Couple de chasseurs, Autriche, écume de mer, 11,8 cm, 1820/1850.

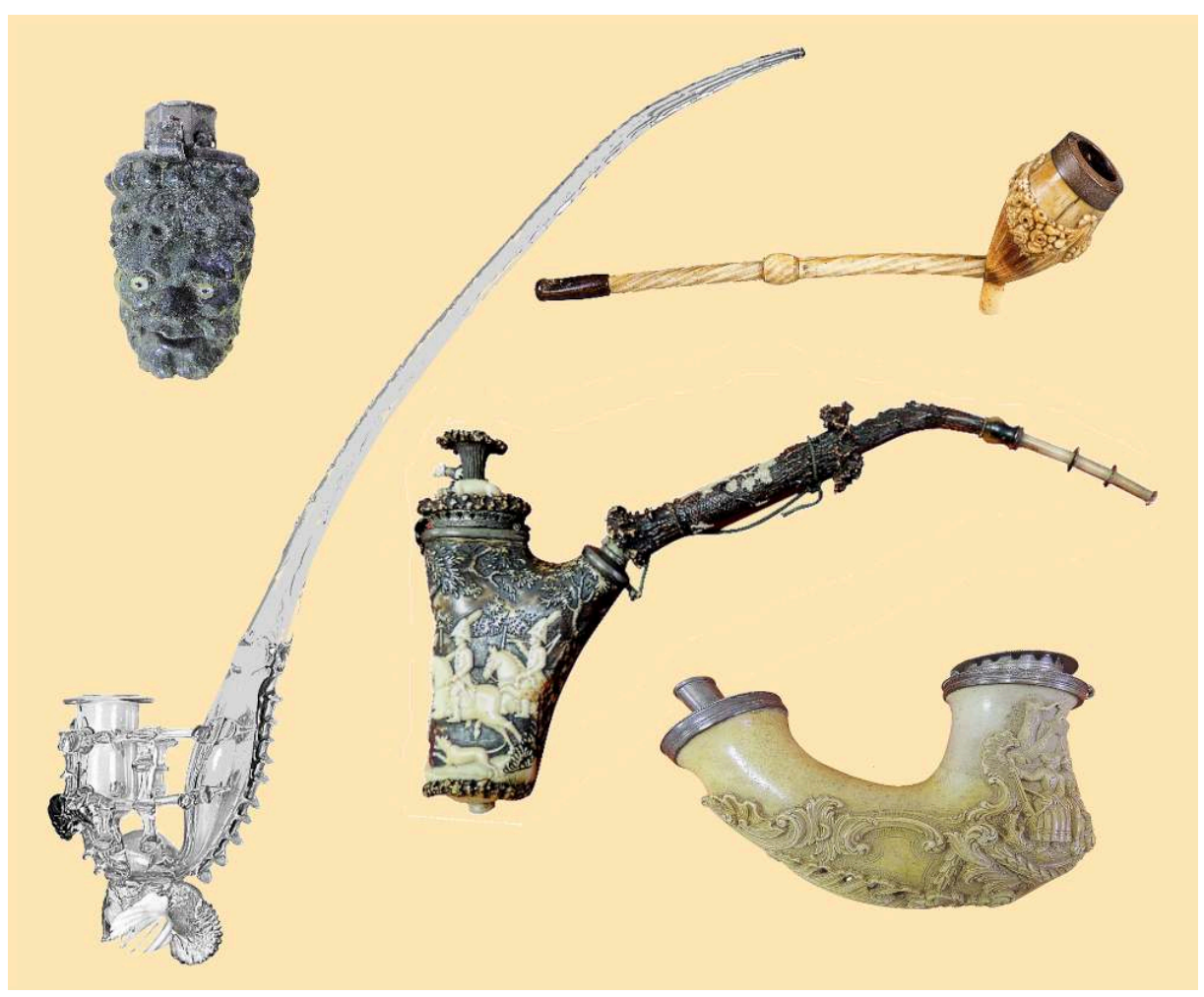

(c) Villa Saint-Hilaire, Grasse

Les bois de cervidés : sept exemplaires de la collection sont confectionnés avec ce matériau apprécié des chasseurs. Des scènes de chasse ornent les fourneaux comportant parfois des éléments en ivoire. La fabrication d'objets en bois de cervidés ou en corne remonte à l'Antiquité. Les andouillers de ces mammifères avaient la faveur des artisans pour leur dureté, alors que les cornes des bovidés, après plusieurs traitements, pouvaient prendre diverses formes et être transformées notamment en tuyaux. Des tronçons de bois de cervidés (rondelles décoratives) agrémentent parfois ces derniers.

L'ivoire : trois pipes de la collection sont confectionnées entièrement en ivoire, articles fabriqués en Allemagne, en France et en Italie. Vu cette matière fragile et peu résistante à la chaleur, une feuille de métal tapisse l'intérieur du foyer de l'une de ces pipes, attestant ainsi son utilisation.

Le verre : uniquement décoratives, les pipes en verre, au nombre de sept, proviennent de diverses contrées : Bohême, Italie (Venise) et Grande-Bretagne (Bristol ?). En verre 
soufflé, translucide ou coloré, elles comportent parfois des collages d'éléments décoratifs inspirés des domaines animal et végétal.

21 Au-delà de l'objet lui-même, il convient de considérer les informations fort diverses offertes par les sujets illustrés par les pipiers. Les événements historiques et leurs acteurs, contemporains de la réalisation de ces objets, sont ainsi mis à l'honneur. Certains thèmes reviennent en permanence lors $d u$ XVIII $^{\mathrm{e}}$ et $\mathrm{du} \mathrm{XIX}^{\mathrm{e}}$ siècle, comme la vénerie, les représentations d'animaux (exotiques ou familiers) ou les scènes de la vie quotidienne. Ces dernières apportent ainsi des éléments chronologiques intéressants par l'observation de l'habillement des personnages. D'autres fourneaux évoquent des figures issues de la mythologie (grecque ou romaine), de l'héraldique avec la représentation de blasons, ou des motifs d'inspiration orientale. Quelques sujets plus insolites, que nous qualifierons de "curiosités ", restent plus délicats à interpréter. Plusieurs exemplaires illustrent des vanités sous la forme de nombreux objets hétéroclites, dont le seul point commun est de faire référence à la brièveté de la vie sur terre. Chacune de ces pièces mériterait une description individuelle pour apprécier pleinement la richesse de leurs données iconographiques.

\section{Les boîtes d'allumettes}

Alice de Rothschild ne rassemble pas seulement des pipes, mais également des boîtes d'allumettes anciennes. Prochainement, ces dernières vont faire l'objet d'une étude approfondie par la Villa Saint-Hilaire. Cette collecte, plus modeste par le nombre de pièces recueillies (environ 110 éléments), possède néanmoins un intérêt indéniable. Ces objets furent fabriqués à de nombreux exemplaires, mais à une époque plus récente que la majorité des pipes de la collection précédente.

L'histoire de l'allumette, telle que nous la connaissons, ne date que du début du $\mathrm{XIX}^{\mathrm{e}}$ siècle; elle résulte des recherches de plusieurs chimistes qui, pendant plusieurs dizaines d'années, vont perfectionner son système d'allumage. En 1809, le français Jean-Joseph-Louis Chancel conçoit l'allumette oxygénée, qui s'enflamme lorsqu'on la trempe dans de l'acide sulfurique. Mais il faudra attendre 1831 et les travaux du Jurassien Charles Sauria pour faire connaissance avec l'allumette phosphorique à friction. L'allumette dite " de sûreté » que nous connaissons aujourd'hui a été inventée par le Suédois Gustaf Erik Pasch en 1844.

Jusqu'en 1870, les allumettes sont fabriquées par des centaines de petits ateliers. Mais les charges financières, au lendemain de la guerre franco-allemande, poussent l'État français à instituer une série d'impôts, dont une taxe sur les allumettes, établie en 1871 et matérialisée par un timbre fiscal scellant la boîte. De 1875 à 1889, un monopole afferme leur fabrication à la Compagnie générale des allumettes chimique (CGAC). De 1890 à 1935, les usines d'allumettes sont gérées par les manufactures de l'État. Depuis 1935, les allumettes sont réunies aux tabacs et distribuées par la Société d'exploitation industrielle des tabacs et allumettes (Seita).

L'utilisation d'une boîte (en carton ou en bois) pour contenir ces allumettes devient indispensable, puisque celle-ci comporte le frottoir indispensable à leur combustion. Elle est munie d'une ou de plusieurs étiquettes mentionnant le nom du fabricant associé à une illustration abordant des thèmes variés. Les formes épousées par ces boîtes sont fort diverses : à coulisse (avec tiroir), en portefeuille, tabatière, pochette, 
cylindrique, etc. Celles rassemblées par Alice de Rothschild appartiennent à tous ces types, issus de multiples fabricants. Dans l'état actuel de nos connaissances, elles furent confectionnées dans la seconde moitié du xix ${ }^{e}$ siècle dans des ateliers situés à Paris, Toulouse, Marseille, ou en Haute-Vienne, etc. Quelques exemplaires proviennent de pays étrangers : Italie, Espagne, Uruguay. L'étude programmée de ces éléments pourrait préciser leur datation et apporter des données essentielles sur certains ateliers méconnus. La fragilité de ces premiers emballages d'allumettes (parfois en papier) a mené à leur presque totale disparition. Ceux sauvegardés dans la collection de Grasse permettent d'apprécier leur diversité, tant dans leur type de conditionnement que dans la richesse de leur iconographie.

En conclusion, la collection de la baronne Alice de Rothschild offre un attrait indéniable de par la qualité esthétique de ses pièces et un intérêt historique unique, car elle est constituée entre les années 1889 et 1922. Nombre de ses éléments sont des pièces uniques qui apportent un témoignage incontournable pour l'étude des pipes anciennes, puisque la baronne Alice a rassemblé des pipes fabriquées entre les années 1770 et 1850 . Ce choix de collecter des pipes anciennes (pour son époque) s'explique vraisemblablement par son goût pour les pièces ornées avec soin, où la maîtrise du fabricant s'exprime pleinement avec les matériaux à sa disposition. Les porcelaines commercialisées après 1850 ne sont plus que rarement peintes à la main, les porcelainiers utilisant dès lors la chromolithographie pour réaliser les décors.

Si quelques pièces de la collection de la baronne Alice de Rothschild ont participé à de nombreuses expositions temporaires, l'importance quantitative de celle-ci ne permet pas de la présenter dans son intégralité. Plusieurs études, menées par des membres de l'Académie internationale de la pipe dans leur revue annuelle, apportent des compléments d'informations sur ces objets. Les supports de diffusion actuels offrent la possibilité de présenter la richesse documentaire de cet ensemble. Certaines de ces pièces figurent désormais dans la base de données nationale Joconde, sur le site créé par la bibliothèque patrimoniale de Grasse ou sur le portail Rothschild de l'Institut national d'histoire de l'art (INHA), ce qui met à la disposition du public ces modestes objets de consommation que les pipiers ont transformés en œuvres d'art et ce qui réalise pleinement les vœux de leur généreuse donatrice, Alice de Rothschild.

\section{NOTES}

1. Voir ce site internet : tobaccopipeartistory.blogspot.com/p/famous-collectors.html

2. William Bragge, Bibliotheca Nicotiana: A First Catalogue of Books about Tobacco, Birmingham, J. Allen, 1874.

3. Christian Zerry, Alice de Rothschild. Une hivernante passionnée sur la French Riviera, SophiaAntipolis, Campanile, 2014.

4. Francine Guibert et Luc Buchet (dir.), Collection Alice de Rothschild, Pipes, cat. exp. (Grasse, Bibliothèque municipale et Photothèque, 1989), Grasse, Bibliothèque municipale et Photothèque, 1989 ; Francine Guibert et Aurélie Dandoy (dir.), La Collection de pipes et de boîtes d'allumettes de la baronne Alice de Rothschild, cat. exp. (Grasse, Bibliothèque municipale, 2004), Grasse, Bibliothèque 
municipale, 2004. Pour cette collection, voir aussi Bénédicte Rolland-Villemot, «Pipes et boîtes d'allumettes. Don d'Alice de Rothschild à la bibliothèque de Grasse, 1927 », dans Pauline PrevostMarcilhacy (dir.), Les Rothschild. Une dynastie de mécènes en France, 3 vol., Paris, Louvre/BnF/ Somogy, vol. II, p. 245-249.

5. Paul Eudel, L'Hôtel Drouot et la curiosité en 1883-1884, Paris, Charpentier, 1885, p. 185.

6. «Les collections Rothschild dans les institutions publiques françaises»: collections.rothschild.inha.fr.

7. Christian Zerry, Alice de Rothschild. Une hivernante passionnée sur la French Riviera, op. cit.,

p. 146-147.

8. Ibid., p. 148.

9. Document conservé à la Villa Saint-Hilaire, bibliothèque patrimoniale de la ville de Grasse : Registre $n^{\circ} 17$.

10. Plaque photographique réalisée par le photographe grassois J. Weyer (collection Villa SaintHilaire).

11. Villa Saint-Hilaire : 1 , impasse Ernest-Boursier-Mougenot 06130 Grasse (Alpes-Maritimes).

12. Cet inventaire est consultable à partir du portail Rothschild de l'INHA à l'adresse suivante : collections.rothschild.inha.fr/fr/institutions/cartographie-des-etablissements/autres-

institutions/grasse-bibliotheque-municipale.html?search-keywords=grasse.

13. Voir le blog de la Villa Saint-Hilaire : pipesrothschild.wixsite.com/alice/blog.

14. André Leclaire, "Les fourneaux de pipes en porcelaine de Paris ", Journal of the Académie Internationale de la Pipe, vol. 6, 2013, p. 43-50.

15. Jacques Cole, «Pipes en bois, avec une attention plus particulière pour le merisier ", dans Le Livre de la pipe, Paris, Académie internationale de la pipe, 2006, p. 37-44.

16. Pierre Durand, « Revue de Paris », Le Compilateur, Paris, 1843, p. 141.

17. Peter Davey, Snake Pipes, Coiled Pipes and Pipe Figures: an Introductory Note, Isle of Man, Curragh Environmental Consultancy, 2015.

18. André Leclaire, « Les pipes en métal en forme de clés ", Journal of the Académie Internationale de la Pipe, vol. 8, 2015, p. 55-62.

\section{INDEX}

Index géographique : France

Index chronologique : XVIIIe siècle, XIXe siècle, XXe siècle

Thèmes : Arts décoratifs, pipes, collections, Rothschild

\section{AUTEUR}

\section{ANDRÉ LECLAIRE}

André Leclaire est chercheur indépendant 


\section{Perspectives internationales}




\title{
L'exception anglaise ? Constance Battersea et la philanthropie artistique des Rothschild d'outre- manche
}

\author{
Thomas Stammers
}

Je tiens à remercier Lindsay Macnaughton, Joseph Plumb et Juliette Trey pour leur aide à la traduction en français.

1 La publication monumentale sur les Rothschild français, dirigée par Pauline PrevostMarcilhacy, met en relief leur rôle remarquable de mécènes au cours de la III République. Alphonse de Rothschild est à compter parmi les donateurs de premier rang, il légua près de deux mille œuvres d'art à environ deux cent cinquante musées de province, c'est-à-dire une bonne moitié des musées français fondés avant la Grande Guerre. L'exemple d'Alphonse illustre la tendance, chez les Rothschild, à soutenir les institutions publiques, soit par la donation d'œuvres d'art (surtout entre la fin du XIX et le début $\mathrm{du} \mathrm{xx}^{\mathrm{e}}$ siècle), soit par les dons financiers (à partir des années 1960) ${ }^{1}$ et cela représentait, à leurs yeux, une mission sociale.

2 La situation en Grande-Bretagne est tout à fait différente. Il y eut assez peu de donations réalisées par la branche anglaise de la famille envers les musées à la même époque; les deux exceptions notables sont les collections d'histoire naturelle rassemblées par Lionel Walter Rothschild à Tring (Hertfordshire) et qu'il a ouvertes au public en 1892, et, bien sûr, le Waddesdon Bequest, cédé par Ferdinand de Rothschild au British Museum en $1898^{2}$. De manière générale, peu d'objets provenant des Rothschild se trouvent dans les collections publiques en Angleterre, et les maisons privées qui les hébergeaient autrefois furent souvent démolies ou défigurées, l'exemple le plus notoire étant l'abandon par le gouvernement britannique, au milieu des années 1970, de Mentmore Towers, la résidence construite en 1850 par Joseph Paxton pour Mayer Amschel de Rothschild ${ }^{3}$. 
Comment expliquer cette divergence frappante? On parle souvent du contraste de culture politique existant entre les deux nations, en opposant une tradition française de civisme, issue de la Révolution et qui proclamait l'art comme un patrimoine appartenant à tous les citoyens, à la tradition anglaise, où l'initiative privée et les efforts personnels [self-help] primaient et étaient mis en œuvre à une échelle plus locale. De plus, ce contraste dans la manière de considérer le patrimoine s'incarna dans des institutions différentes, comme l'a remarqué Francis Haskell : le musée municipal en France et la country house en Angleterre ${ }^{4}$. Cette différence eut des conséquences sur la manière dont les Juifs anglais et français poursuivirent leur intégration sociale et affirmèrent leur patriotisme.

Le contraste entre ces deux pays ne suffit cependant pas à expliquer la transformation du statut de la propriété privée en Angleterre à la fin du XIX siècle. Comme l'indique Jordanna Bailkin dans son livre The Culture of Property:

Le statut des objets culturels - définis par leurs traits toujours discutables d'inaliénabilité et de possession non exclusive - nous incite à réfléchir sur les liens entre la propriété et les identités politiques en Grande-Bretagne avant la Première Guerre mondiale. Selon la pensée politique de l'époque, la personne du propriétaire s'associe à la figure du gardien, du régisseur, du mandataire - c'est-à-dire du propriétaire non exclusif -, et cette évolution porte sur des questions plus vastes de citoyenneté et de participation politique ${ }^{5}$.

Le crépuscule du libéralisme victorien suscita de féroces débats pour savoir qui pouvait posséder des propriétés privées (par exemple, les femmes ou les syndicats de travailleurs) et jusqu'à quel point (par exemple, les fermiers en Irlande). En refusant de concevoir la propriété comme un droit absolu et exclusif, les réformateurs mirent aussi en question le statut du patrimoine comme ressource nationale. Au tournant du nouveau siècle, la fondation de The National Art Collections Fund, en 1903, suscita le projet d'enregistrement national de toutes les œuvres d'art en Grande-Bretagne, lancé en $1910^{6}$.

6 Cette courte présentation vise à décrire les usages de la jeune génération des Rothschild anglais, qui furent les plus inspirés par ces débats et placèrent les arts sous le signe de l'utilité sociale et du bonheur public. Pourquoi leur vision libérale n'aboutitelle pas à une culture de la donation publique ? Pour interroger ce paradoxe, l'analyse se concentre sur l'exemple de Constance de Rothschild (1843-1931), fille d'Anthony de Rothschild, qui, tout au long de sa vie, afficha une volonté politique progressiste et laissa des journaux intimes et des souvenirs - publiés en 1922 - révélateurs de l'esprit calculateur de la famille ${ }^{7}$ (fig. 1). Constance fut élevée à Paris et à Londres, où son père acquit une maison élégante sur Grosvenor Place. Selon ses souvenirs, la décoration de la maison fut confiée à des artistes français, en accord avec le goût raffiné de son père. «Parmi d'autres œuvres, il y avait une splendide peinture de Van Dyck, un cadeau de ma grand-mère maternelle [Henriette de Rothschild (1791-1866)] $]^{8}$ » Plus tard, son père acheta la résidence d'Aston Clinton dans le Buckinghamshire, qu'il embellit et meubla. Deux tableaux de Jean-Baptiste Greuze, ayant fait partie des collections de Dubois et Tilliard au XVIII ${ }^{e}$ siècle, et six scènes de genre néerlandaises, provenant de la vente de la duchesse de Berry, se trouvaient parmi les plus importants tableaux réunis par Anthony dans sa petite galerie de maittres néerlandais, flamands et français9. 
1. Alessandro Bassano, Lady Constance Battersea, 1897, tirage à partir d'un négatif sur demi-plaque de verre, Londres, National Portrait Gallery.

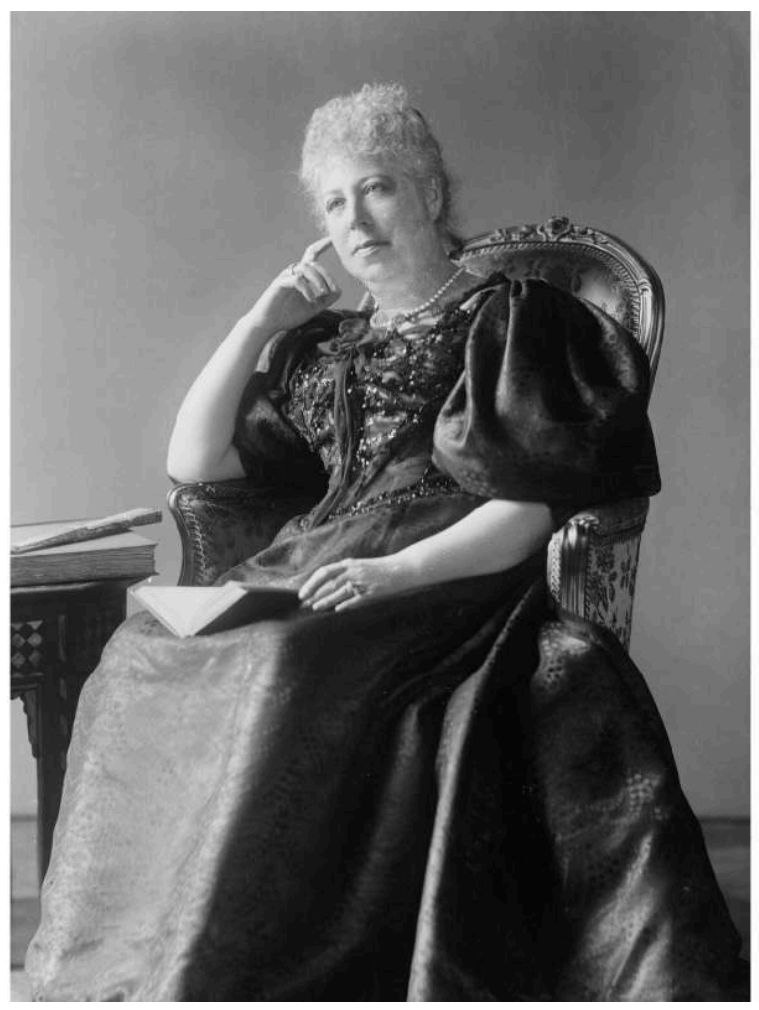

(c) National Portrait Gallery

Grâce à l'éducation dispensée par sa mère, Louisa de Rothschild (1821-1910), Constance acquit un sens profond de la responsabilité envers ses proches. Dans l'hommage à sa mère qu'elle publia en 1912, Constance résume ainsi la leçon apprise :

Ma première préoccupation ne doit plus être la connaissance pour elle-même, mais de savoir faire le meilleur usage de cette connaissance afin de faire progresser le bonheur et le confort de ceux qui nous entourent ${ }^{10}$.

Le premier bénéficiaire de cette générosité fut le village d'Aston Clinton, où elle allait souvent visiter les maisons simples des habitants. Pour son seizième anniversaire, son père répondit à son désir en fondant l'école du village, dont elle posa la première pierre $^{11}$. Cette expérience fut une grande réussite et inspira la création d'une école semblable au village de Halton. De plus, la famille dota le village d'Aston Clinton de maisons ouvrières, d'une bibliothèque et de l'Anthony Hall (une salle de réunion édifiée en 1884 par Louisa en mémoire de son mari) ${ }^{12}$.

9 Cette charité rurale était liée à une conscience sociale s'exerçant à la capitale. Si Louisa servait comme présidente de la Jews Free School dans l'est de Londres, Constance consacrait son temps à améliorer les prisons, à combattre l'alcoolisme et à encourager l'enseignement pour les filles. En 1885, elle créa la Jewish Association for the Protection of Girls and Women (JAPWG), qui visait à mobiliser les femmes juives anglaises pour lutter contre le trafic des prostituées à l'est de Londres, suite aux vagues d'immigration, un trafic où les Juifs étaient à la fois criminels et victimes ${ }^{13}$.

Cette passion pour l'activisme social trouva un écho chez le séduisant mari de Constance, Cyril Flower, homme politique du parti libéral et esthète renommé. Le père de Cyril, Philip William Flower, avait émigré en Australie dans les années 1830, où il 
avait fondé une entreprise lucrative d'exportation de laine, de suif et d'or, et il possédait de nombreuses propriétés commerciales dans le Surrey et à Westminster ${ }^{14}$. Cyril hérita de son père une partie du quartier de Battersea à Londres, qu'il voulut transformer en construisant des logements ouvriers. Les noms des rues, dans le quartier, qui faisaient référence à Dickens, Thackeray et Montefiore, révélaient son attachement à la philanthropie juive et son ambition d'améliorer le niveau culturel des classes laborieuses. Dans ses souvenirs, Constance constate :

Au début de mon mariage, je fus déçue que nous ne nous installions pas à Battersea, au milieu de la classe ouvrière. Je proposais de construire une maison d'art (a House Beautiful) dans ce quartier afin d'approcher et de mieux connaître les hommes et les femmes dont les chemins étaient si différents du mien et que, par conséquent, je comprenais si mal ${ }^{15}$.

11 Cette pensée étonnante pour la fille d'un millionnaire s'explique par l'influence du Settlement Movement, qui incita plusieurs étudiants d'Oxford et de Cambridge, tels que Cyril, à vivre, pendant les années 1860, dans les quartiers populaires afin d'aborder les maux de la société urbaine. Le curé Samuel Barnett et sa femme, Henriette, se rendaient souvent à Aston Clinton et ce fut grâce à eux que «la galerie d'art de Whitechapel fut créée, dans laquelle une collection très honorable de peintures est montrée chaque année à un grand nombre de visiteurs reconnaissants ${ }^{16} »$. La galerie de Whitechapel - le fruit des expositions temporaires dans les «Brompton Boilers» de Bethnal Green - ainsi que la South London Gallery, fondée en 1891, symbolisaient l'effort audacieux de créer un milieu propice à la culture artistique des ouvriers. La South London Gallery reçut le soutien d'un groupe de donateurs libéraux, y compris John Lubbock, Octavia Hill (cofondatrice du National Trust en 1895), Baroness BurdettCoutts, sans oublier Cyril et Constance ${ }^{17}$.

Ces institutions londoniennes restaient assez modestes en comparaison du nombre de musées établis dans les villes du nord du pays. Là, la philosophie morale de John Ruskin faisait écho à la volonté qu'avaient les grandes manufactures de trouver un abri permanent pour leurs collections de peinture contemporaine. Pour citer le regretté Giles Waterfield, le "new money" (les nouveaux riches) se trouvait à l'origine de ces nouveaux musées : par exemple, Frederick Mappin à Sheffield et Alexander Laing à Newcastle (tous deux brasseurs), Thomas Ferens à Hull (important commerçant), William Henry Wills à Bristol (millionnaire du tabac) ou William Lever à Liverpool (entrepreneur du savon). La plupart de ces donateurs étaient de philosophie politique libérale et pratiquaient le protestantisme ; il y avait peu de Juifs, et la contribution des aristocrates et du « old money » était modeste et très rare ${ }^{18}$. 
2. Frederick Sandys, Portrait de Cyril Flower, Lord Battersea, 1877, craie sur papier, 109,8 $\times 74,9 \mathrm{~cm}$, Norwich, Norwich Castle Museum.

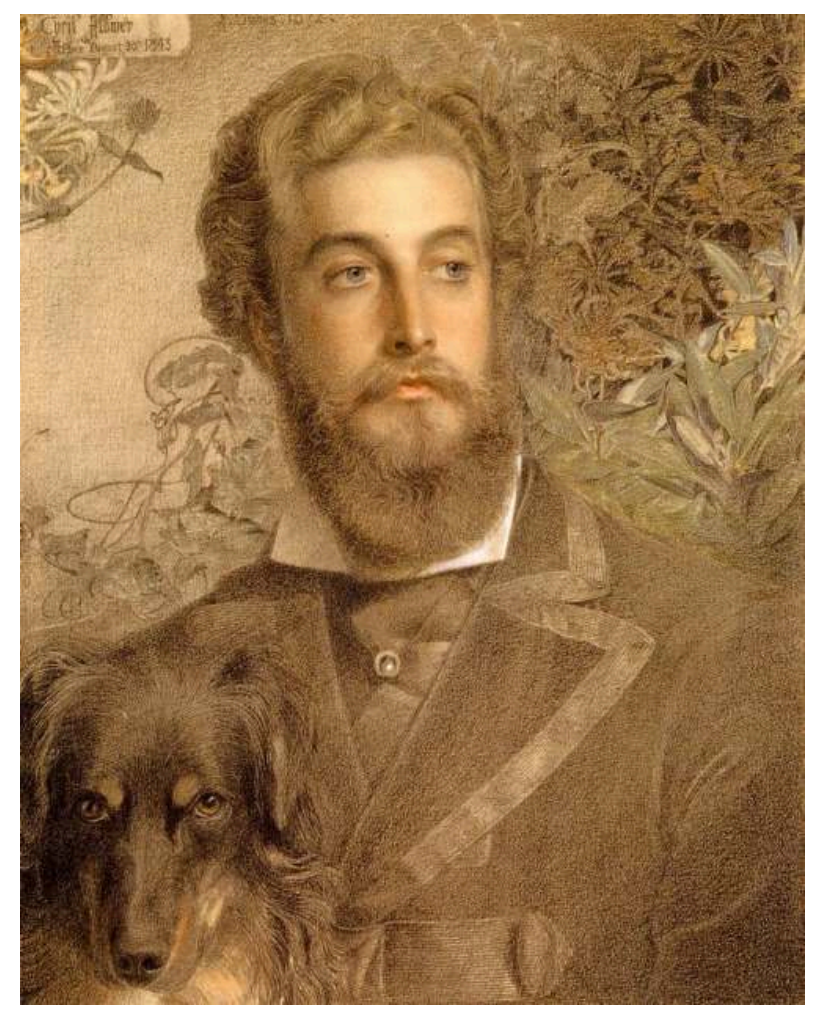

(c) Norwich Castle Museum

$13 \mathrm{Au}$ lieu de s'installer parmi les ouvriers de Battersea, Constance et son mari achetèrent une belle maison en face de Marble Arch, qui s'appelait Surrey House et que Cyril rénova et élargit considérablement. Comme de nombreux collectionneurs et mécènes de l'Aesthetic Movement, Cyril était un artiste amateur, surtout dans le domaine de la photographie ${ }^{19}$. La maison incarnait l'amour de Cyril pour le voyage et l'histoire de l'art européen, avec ses décors de marbre provenant d'une chapelle démolie à Brescia et ses boiseries hollandaises $d u \mathrm{xvII}^{\mathrm{e}}$ siècle. Cet éloge des styles historiques se mêlait à des éléments modernes; par contraste avec leurs cousins Rothschild d'Angleterre, Constance et Cyril étaient surtout des mécènes de l'art moderne. Le mobilier du boudoir avait été commandé à l'ébéniste et décorateur Carlo Bugatti, et Cyril soutenait aussi le peintre Frederick Sandys (fig. 2) et le sculpteur novateur Alfred Gilbert. Il était avant tout un ami intime d'Edward Burne-Jones, et ce dernier créa le tableau iconique The Golden Stairs (fig. 3) pour embellir l'escalier principal de Surrey House ${ }^{20}$. Ce décor somptueux était destiné à accueillir l'élite politique et artistique. Contrairement à ce qu'indique le cartel de l'œuvre à la Tate Britain, ce fut Constance (et non Cyril) qui donna The Golden Stairs au musée, en 1924, en souvenir de son mari ${ }^{21}$. 
3. Edward Burne-Jones, The Golden Stairs, 1880, huile sur panneau, $269,2 \times 116,8 \mathrm{~cm}$, Londres, Tate Britain.

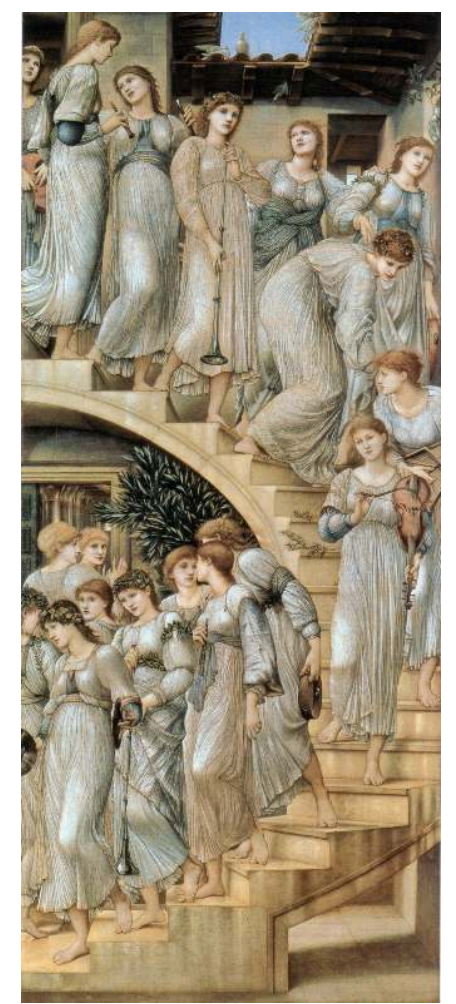

(C) Tate London, 2014

Bien qu'elle fonctionnât comme un palais d'art et un noyau de sociabilité mondaine, Surrey House accueillait aussi un grand nombre d'œuvres caritatives soutenues par Constance, qui offrit un asile à l'Union of London School Teachers, l'Association of Working Girls' Clubs, le Children's Country Holidays Fund et le Recreative Evening Schools Association, le dernier étant né sur les lieux mêmes ${ }^{22}$. Cette résidence privée ouvrait régulièrement ses portes à des concerts et conférences publics, mais surtout à des expositions. Par exemple, l'argent récolté lors des fréquentes expositions organisées par la Royal Amateur Art Society servit à subventionner les œuvres philanthropiques au profit des femmes pauvres de l'est de Londres, comme les associations Parochial Mission Women's Fund et East London Nursing Society ${ }^{23}$. Sous l'égide de la Royal Amateur Art Society, des expositions se déroulèrent dans les maisons londoniennes d'autres collectionneurs éminents de l'époque, notamment celles de Philip Sassoon, de Lady Leyland, du baron John Gretton et des exécuteurs testamentaires de l'homme politique libéral Julian Goldsmid ${ }^{24}$.

Malgré un début prometteur dans le monde de la politique, le parcours de Cyril fut interrompu par son refus d'occuper le poste de gouverneur en Australie et par un mystérieux scandale homosexuel ${ }^{25}$. Après ce choc, le couple consacra de plus en plus de temps à une maison excentrique dans le village d'Overstrand, dans les environs de Cromer (Norfolk). Cette énorme résidence sur la côte avait pour architecte Edwin Lutyens, qui décrivit à sa femme la bonté et l'ambition de ses clients dans une lettre de 1898 ( Lord B. veut encore faire des travaux et a envie de se faire plaisir ${ }^{26} »$ ). L'ami de Constance et de Cyril, John Morley, avait baptisé la demeure « The Pleasaunce ${ }^{27}$ ». Alors que Gertrude Jekyll se chargea du parc, Cyril travaillait surtout sur les jardins italiens 
et adopta comme devise personnelle Flores curat Deus (« Dieu prend soin des fleurs »). The Pleasaunce devint un foyer de plus pour accueillir les invités de la haute société, mais ses propriétaires décidèrent aussi d'ouvrir leur porte à la population du village, qui put ainsi profiter des courts de tennis et des pelouses de cricket $^{28}$. Dans son autobiographie, E.F. Benson établit une comparaison entre cette maison fantastique (un Xanadu) et son créateur :

Je suis certain que, derrière ses joyeuses fanfaronnades, il y avait de la peur et une appréhension perpétuelle, et que cette splendeur était une protection contre cela. Il savait que c'était seulement une façade et, quand il est mort, on découvrit qu'il n'avait laissé qu'une montagne de dettes ${ }^{29}$.

Comment expliquer la décision de ne pas faire don à la nation de ces bâtiments ou des collections à la mort du couple ? La première réponse à cette question doit souligner la tendance, parmi les membres de la famille, à préserver une quantité de capital pour la prochaine génération, une pratique nécessaire pour les dirigeants d'une banque. Les Rothschild anglais donateurs étaient souvent sans enfants, comme Ferdinand (1839-1898), ou ne s'étaient pas mariés, comme Walter (1868-1937). La famille poursuivait une stratégie matrimoniale qui conservait les ressources financières et le patrimoine au sein de la famille : parmi les vingt-et-un mariages organisés pour les descendants de Mayer Amschel entre 1824 et 1877, un total de quinze furent arrangés entre descendants immédiats ${ }^{30}$. Constance n'eut pas d'enfants, mais elle décida de léguer la plupart de ses richesses à ses cousins préférés, Léopold et Lionel. Ceux-ci profitèrent de la vente de Grosvenor House, qui eut lieu après la mort de Louisa de Rothschild en 1910.

La seconde réponse réside dans le statut social des Rothschild anglais, membres d'une aristocratie qui investissait énormément dans les terres agricoles. Les années 1870 témoignèrent des effets de la Grande Dépression en Europe, dont la baisse des valeurs des terres et des rentes. Cette crise encouragea les aristocrates, rendus vulnérables, à vendre les éléments de leurs terrains qui n'étaient pas « exclus » ou " entailed », c'est-àdire des biens qu'on ne pourrait pas vendre selon les lois britanniques sur l'héritage ${ }^{31}$. Après l'entrée en vigueur de la loi intitulée Settled Lands Act de 1882, de nombreux tableaux historiques et œuvres d'art apparurent sur le marché. Par exemple, grâce à sa position dans le second cabinet libéral de Gladstone, Cyril put convaincre le gouvernement d'acheter les peintures vendues par le duc de Marlborough pour la National Gallery ${ }^{32}$.

Constance fut sévèrement attristée de voir le démembrement des domaines qu'elle connaissait depuis sa jeunesse - une crise accélérée par l'introduction des impôts de succession, dont les conséquences sont résumées par Peter Mandler ${ }^{33}$. Dans son journal, Constance répète la prophétie de Ferdinand, énoncée dans ses souvenirs intitulés Bric$\grave{a}-B r a c$ : que les tours du Waddesdon Manor même pourraient un jour tomber en ruine et que le contenu du château pourrait succomber à la spéculation.

Puisse-t-il être encore lointain le jour où les ronces viendront envahir les jardins, les terrasses tomber en poussière, les peintures et cabinets traverser la Manche ou l'Atlantique, et le cri mélancolique du hibou [nightjar] résonner depuis les tours désertées ${ }^{34}$ !

Elle plaint le sort du château Ashridge, propriété de son amie Lady Brownlow, qui reste solitaire et vide, ses trésors, comme ceux de tant d'autres résidences anglaises, offerts à la vente [stands lonely and empty, its treasures, like those of so many others of England's stately homes, offered for sale $]^{35}$. 
Malgré son patriotisme, Constance regretta vivement la décision de son cousin Alfred de donner les forêts de hêtres de Halton au gouvernement pour un usage militaire, pendant la Grande Guerre.

Un immense aérodrome, d'innombrables ateliers et tout l'attirail d'un très grand campement se sont imposés de tous côtés dans notre champ de vision, tandis que le vrombissement des moteurs d'avions au-dessus de nos têtes ne s'arrête quasiment jamais durant la journée ${ }^{36}$.

Elle déplora que ces réquisitions aient abîmé la beauté des lieux, mais aussi détruit les liens traditionnels qui avaient uni les propriétaires et leurs locataires.

Malgré sa fortune par héritage, Constance connut des difficultés pour maintenir en l'état ses résidences. En plus des dettes accumulées pour les rénovations architecturales et l'achat d'œuvres d'art, son journal expose ses problèmes à trouver du personnel après la guerre: "Tout est devenu extrêmement difficile et compliqué...Ai payé les gages et écouté les plaintes récurrentes des domestiques ${ }^{37}$. Après la mort de sa mère Louisa, la résidence à Grosvenor Place fut vendue en 1909, un événement figurant dans son journal : « À Londres jusqu'au 26 novembre. Une période très fatigante, éprouvante. Presque toutes nos possessions vendues... à peu près 132000 livres en espèces ${ }^{38} . .$. » Les années 1920 virent la démolition d'une quantité effarante de châteaux et de villas luxueuses, surtout des grands palais aristocratiques à Londres, dont la fonction politique était devenue superflue et dont la vente rapportait facilement de l'argent ${ }^{39}$. Après sa conversion en bibliothèque militaire pendant la Grande Guerre, où des bénévoles avaient distribué gratuitement livres et journaux aux soldats dans les tranchées (fig. 4), Surrey House disparut, et un cinéma énorme, le Regal, fut construit à la place ${ }^{40}$. 
4. Comité de femmes aidant l'Armée royale de l'air, en empaquetant des rations de nourriture à Surrey House, 1918, Londres, Surrey House (inv. BL24109-002).

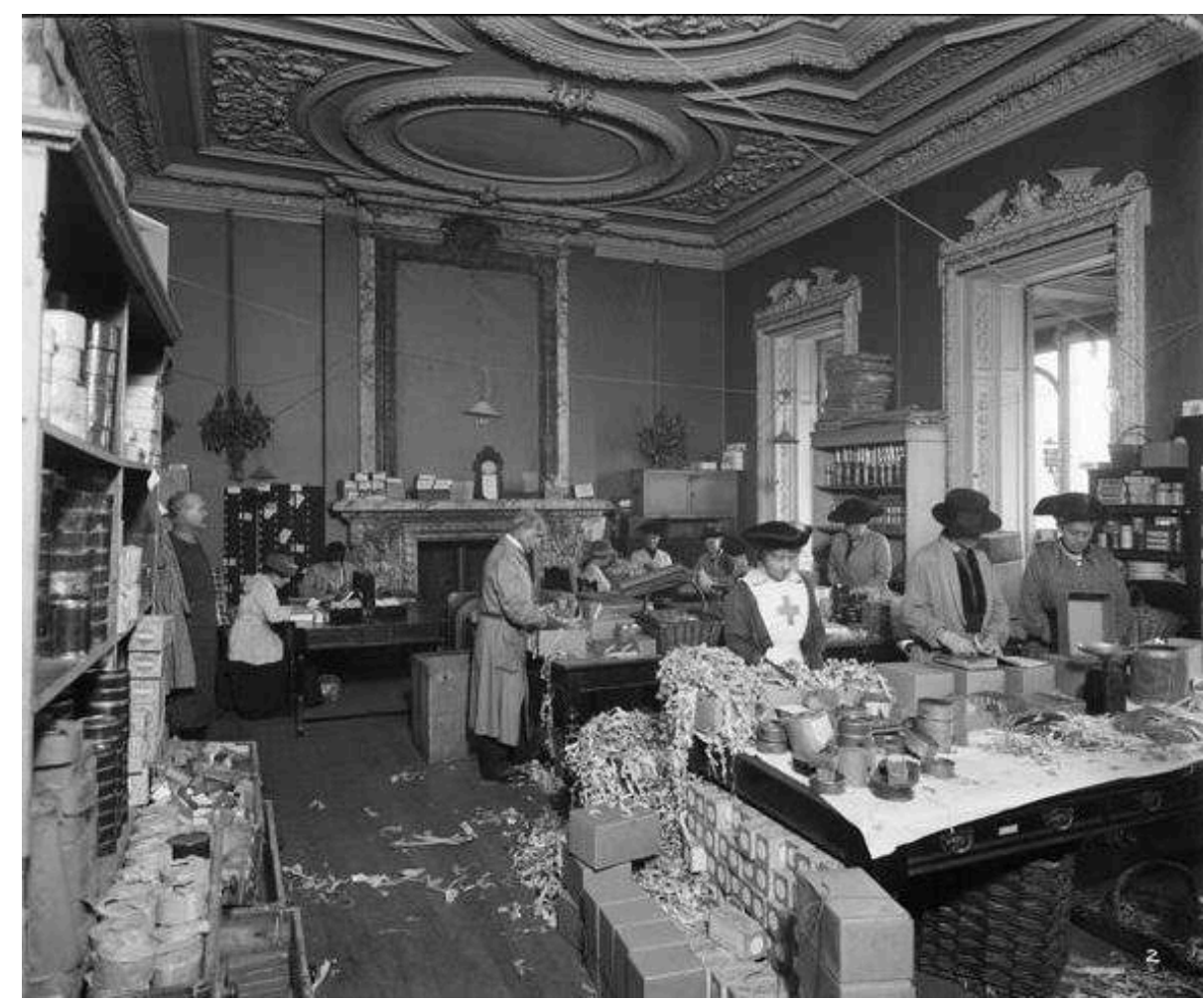

(C) D. R.

Quelques années plus tard, en 1936, The Pleasaunce tomba entre les mains d'une association chrétienne de maisons de vacances, qui acquit la demeure à un prix très modeste dû au risque grave d'érosion côtière ${ }^{41}$. À la mort de Louisa Lady Rothschild en 1910, les trois fils de Lionel - Nathaniel, Alfred et Leopold - héritèrent de la demeure d'Aston Clinton. Constance et Annie y demeurèrent néanmoins jusqu'en 1923, date à laquelle elles vendirent la demeure pour la maigre somme de quinze mille livres au $\mathrm{D}^{\mathrm{r}}$ Albert Crawford, qui la convertit en école. Evelyn Waugh, directeur de l'établissement en 1925, décrivit « une maison inconcevablement laide mais un joli parc [an inconceivably ugly house but a lovely park] ». De 1959 à 1967, le conseil régional du Buckinghamshire (Buckinghamshire County Council) en devint propriétaire et procéda à sa démolition ${ }^{42}$. Il est difficile de retracer le sort des collections laissées par Constance. En ce qui concerne les catalogues de ventes d'Aston Clinton, ceux-ci sont dominés par les arts décoratifs. Son exécuteur testamentaire, Ruth Leonora Rothschild, la fille de Lionel, reçut un certain nombre de peintures. La Madone de Filippo Lippi et celle d'Antonio del Pollaiolo, qui avaient été exposées à la New Gallery en 1893-1894, apparurent lors d'une vente, portant le nom d'épouse de Ruth Leonora, Mrs Denis Gomer Berry, chez Christie's en $1935^{43}$.

Bien que Constance fût fièrement libérale et progressiste sur le plan politique, elle n'envisagea point de léguer ses riches collections à la nation britannique. À part le tableau de Burne-Jones et une aquarelle de l'Annonciation exécutée par Burne-Jones, que Constance avait offert à Norwich Castle, en 1910, en signe de reconnaissance de ses heureuses années passées à Norfolk, la quasi-totalité de la collection fut vendue ou bien conservée au sein de la famille ${ }^{44}$. Il est fort probable que ces décisions reflétèrent 
l'attachement des Rothschild à la société aristocratique et terrienne. Dans ses souvenirs, Constance souligne cette différence entre sa famille et ses cousins français :

En plus de leurs maisons dans la ville, ils possèdent tous des résidences de campagne ; mais le vrai génie pour la vie campagnarde n'appartient pas, je crois, à la nation française, et les paysans se méfient des relations avec les autres classes sociales $^{45}$.

Pauline Prevost-Marcilhacy souligne l'investissement de la branche anglaise de la famille Rothschild dans les maisons historiques, la politique rurale et la vie communale (surtout dans le Buckinghamshire), qui ne connut aucun parallèle chez leurs cousins français ${ }^{46}$. Il s'ensuit que cet attachement à la vie rurale et aux terrains agricoles influençait leur attitude envers les questions de succession. En contraste avec les industriels devenus donateurs aux musées municipaux et nationaux, les Rothschild partageaient les valeurs d'une aristocratie qui luttait pour conserver l'intégralité de son fragile patrimoine.

Comme dernier exemple, considérons la place d'Alfred de Rothschild au conseil d'administration de la National Gallery de Londres. Fils de Lionel et premier directeur juif de la Banque d'Angleterre, Alfred fut décrit par Frances Greville, comtesse de Warwick, comme " un connaisseur des arts du bien-vivre ». Son château Halton, dans le style flamboyant de la Renaissance française, construit entre 1881 et 1883, était rempli de tableaux magnifiques de Pater, Watteau, Cuyp, Boucher, Romney et Gainsborough ${ }^{47}$. Alfred fit don de dix mille livres à la National Gallery pour l'acquisition des précieux tableaux provenant du château d'Earl of Radnor et, par conséquent, il lui fut rapidement offert une place au conseil. Mais à partir de ce moment, Alfred ne versa que deux sommes de cinq cents livres et ne donna après sa mort qu'un tableau de Joshua Reynolds (Lady Bamfylde), laissant le reste de sa collection à son neveu Lionel et à sa fille illégitime, Almina Wombwell. Bien qu'Alfred vécût dans l'espoir que ces biens de famille restent entre les mains de ses héritiers (par exemple, le portrait imposant de Mrs William Villebois, peint par Gainsborough ${ }^{48}$ ), Almina organisa rapidement un grand nombre de ventes en association avec Joseph Duveen et Michael Knoedler afin de contribuer au financement des fouilles du tombeau de Toutankhamon, dont son mari, le cinquième Earl de Carnarvon, était mécène. Andrea Poole insiste sur le fait qu'Alfred, concernant la succession de ses biens, était l'exemple typique des aristocrates anglais qui s'occupaient de primogéniture :

Pour bien des raisons, souvent financières, les contributions de l'aristocratie terrienne édouardienne consistaient en services et rarement en art [For a variety of reasons, often financial, the Edwardian landed aristocracy's gifts lay in service, rarely in art $]^{49}$.

Pour conclure, il apparaît que la générosité remarquable de la famille Rothschild d'Angleterre en ce qui concerne les hôpitaux, les écoles et les associations bénévoles ne se traduisait pas en philanthropie culturelle. Finalement, les Rothschild français ont été les seuls à avoir mené différentes formes de philanthropie, culturelle mais aussi sociale. Il en résulte que, hormis au British Museum, la piste des objets qui ont appartenu à la famille d'Angleterre est difficile à retrouver dans les institutions publiques ou civiques. En 1935, Anthony Gustav de Rothschild présenta à la National Gallery le tableau de L'Abbé Scaglia vénérant la Vierge et l'Enfant (fig.5) - un don en souvenir de ses anciens propriétaires, Louisa et Constance ${ }^{50}$. De manière générale, si l'on veut considérer ce qu'il reste des précieuses collections aujourd'hui, il faut visiter les country houses: non seulement Waddesdon Manor, mais aussi ce qui reste de la collection de Mentmore, 
conservée à Dalmeny House près d'Édimbourg, ou la résidence rustique d'Ascott, qui fut rénovée par Léopold de Rothschild et donnée au National Trust par son fils Anthony en 1947. Léopold avait hérité de vingt-huit tableaux de son père Lionel (dont seize se trouvent toujours à Ascott aujourd'hui); en plus des tableaux néerlandais qui provenaient de la collection Van Loon, figuraient aussi des meubles français du XVIII ${ }^{\mathrm{e}}$ siècle ainsi que des porcelaines orientales ayant appartenu à son oncle, Anthony ${ }^{51}$. Ascott conserve aussi une esquisse pour le plafond de l'église Santa Maria della Fratta à San Daniele, dans le Frioul, de la main de Giambattista Tiepolo, qui appartenait autrefois à Lord et Lady Battersea ${ }^{52}$. Cependant, une ambivalence persiste : tandis que la maison d'Ascott et ses terrains appartiennent au National Trust, les œuvres d'art accrochées aux murs des pièces et des chambres appartiennent encore à la famille. Cette dualité, qui juxtapose l'accès du public et la propriété privée, symbolise l'ambiguïté historique des Rothschild anglais en tant que protecteurs des arts.

5. Anthony van Dyck, L'Abbé Scaglia vénérant la Vierge et l'Enfant, 1634-1635, huile sur toile, $106,7 \times 120 \mathrm{~cm}$, Londres, The National Gallery, (inv. : NG4889).

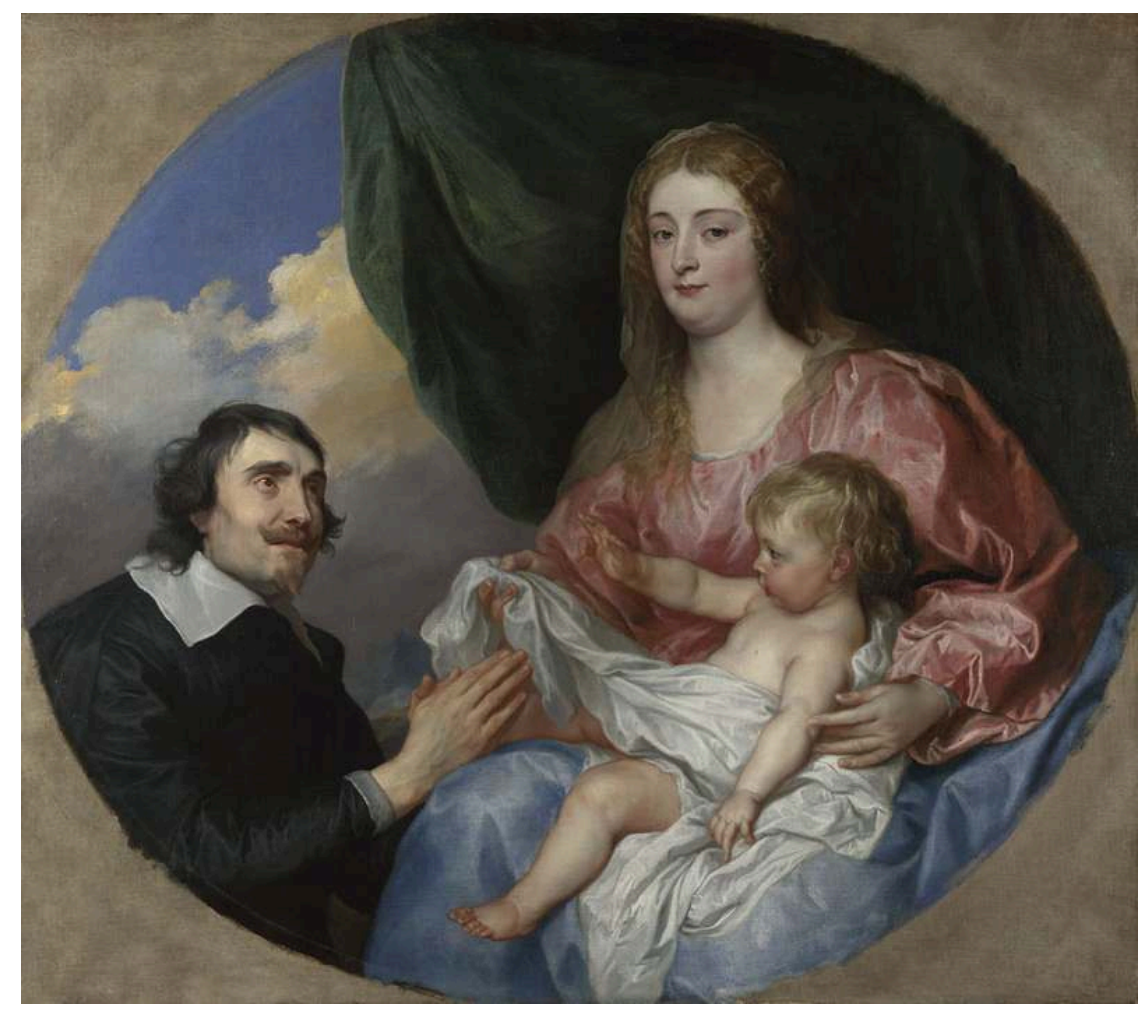

(c) The National Gallery, 2019

\section{NOTES}

1. Voir Pauline Prevost-Marcilhacy, «Le mécénat envers les artistes vivants, 1906-1920 » et «Le mécénat envers les artistes vivants en faveur des musées de région, 1895-1905 », dans Pauline 
Prevost-Marcilhacy (dir.), Les Rothschild. Une dynastie de mécènes en France, 3 vol., Paris, Louvre/ BnF/Somogy, 2016, vol. I, p. 92-111 et p.135-181, ainsi que le dossier thématique "Les dons offerts aux musées de région par Alphonse et Edmond de Rothschild»: collections.rothschild.inha.fr/fr/dossiers-thematiques/les-dons-offerts-au-musees-de-regionpar-alphonse-et-edmond-de-rothschild.html (consulté en ligne en juillet 2019).

2. Le don de Walter Rothschild (1868-1937) de ses collections d'histoire naturelle à Tring est fait en parallèle avec les dons de la branche française au musée du Mans (voir le dossier concernant ce musée sur le portail Rothschild: collections.rothschild.inha.fr/fr/institutions/cartographiedes-etablissements/musees-de-france/le-mans-museum-d-histoire-naturelle-du-mans.html (consulté en ligne en juillet 2019). Miriam Rothschild, Walter Rothschild: The Man, the Museum and the Menagerie, Londres, Natural History Museum, 2008 ; Dora Thornton, A Rothschild Renaissance: Treasures from the Waddesdon Bequest, Londres, British Museum Press, 2015.

3. James Fenton, « The Rothschild Taste », The New York Review of Books, 25 juin 2015.

4. Francis Haskell, «The British as collectors », dans Gervaise Jackson-Stops (dir.), The Treasure Houses of Great Britain: Five Hundred Years of Patronage and Art Collecting, cat. exp. (Washington, DC, National Gallery of Art, 1985), New Haven et Londres, Yale University Press, 1985, p. 50-59.

5. Jordanna Bailkin, The Culture of Property: The Crisis of Liberalism in Modern Britain, Chicago, Chicago University Press, 2004, p. 4.

6. Ibid., p. 15 et p. 206.

7. Sur Constance, Lady Battersea, voir Chaim Bermant, The Cousinhood: The Anglo-Jewish Gentry, Londres, Eyre \& Spottiswoode, 1971, p. 145-152.

8. Constance Battersea, Reminiscences, Londres, Macmillan, 1922, p. 10.

9. Michael Hall, «The English Rothschilds as collectors" dans Georg Heuberger (dir.), The Rothschilds: Essays on the History of a European family, Woodbridge, Thorbecke/Boydell \& Brewer, 1994, p. 273.

10. Louisa Montefiore Rothschild et Constance Battersea, Lady de Rothschild: Extracts from her Notebooks: with a Preface by her Daughter Constance Battersea, Londres, Arthur Humphreys, 1912, p. 5 .

11. Constance Battersea, Reminiscences, op. cit., p. 27.

12. Justin Cornelius Frost, «Mr Warren's Photograph album: Memories of a Vanished Rothschild Estate », The Rothschild Archive Annual Review, 2012-2013, p. 40-41.

13. Lloyd P. Gartner, "Anglo-Jewry and the Jewish International Traffic in Prostitution", Association for Jewish Studies, vol. VII, 1982, p. 129-178 ; Rachael Attwood, « Looking beyond "White Slavery": Trafficking, the Jewish Association, and the Dangerous Politics of Migration Control in England, 1890-1910 ", Anti-Trafficking Review, nº 7, 2016, p. 115-138.

14. Diana Sachko-Macleod, Art and the Victorian Middle Class: Money and the Making of Cultural Identity, Cambridge, Cambridge University Press, 1996, p. 414-1415.

15. Constance Battersea, Reminiscences, op. cit., p. 171.

16. Ibid., p. 220.

17. Giles Waterfield, "Art for the People", dans Art for the People: Culture in the Slums of Late Victorian Britain, cat. exp. (Londres, Dulwich Picture Gallery, 1994), Londres, Dulwich Picture Gallery, 1994, p. 38, p. 43-44, p. 52-53.

18. Giles Waterfield, The People's Galleries: Art Museums and Exhibitions in Britain (1800-1914), New Haven et Londres, Yale University Press, 2015, p. 257, p. 260, p. 262-263.

19. Diana Sachko-Macleod, Art and the Victorian Middle Class: Money and the Making of Cultural Identity, op.cit., p. 279. La National Portrait Gallery compte 116 photographies de la société mondaine par Cyril Flower.

20. Lucy Cohen, Lady de Rothschild and her Daughters (1821-1931), Londres, John Murray, 1935, p. 172, p. 196-197 ; Constance Battersea, Reminiscences, op. cit., p. 173.

21. Voir la notice relative au tableau Inv. N04005. 
22. Constance Battersea, Reminiscences, op. cit., p. 196.

23. Royal Amateur Art Society Exhibition: Catalogue of the Art Loan Exhibition, Surrey House, London. By kind Permission of Lady Battersea, 19-22 March 1903, Londres, 1903 ; Daily Mail, 12 février 1903. D'autres expositions avaient eu lieu à Surrey House du 10 au 13 mars 1912 et du 24 au 26 février 1913.

24. Voir la série des catalogues conservés à la National Art Library (V \& A).

25. Matt Cook, London and the Culture of Homosexuality (1885-1914), Cambridge, Cambridge University Press, 2003, p. 68, p. 74.

26. Clayre Percy et Jane Ridley (dir.), The Letters of Edwin Lutyens to his Wife Emily, Londres, Collins, 1985 , p. 65 [13 oct. 1898 ].

27. Il s'agit d'une forme obsolète de « plaisance » en anglais.

28. Constance Battersea, Reminiscences, op. cit., 1922, p. 379.

29. E. F. Benson, Final Edition: Informal Autobiography, Londres, Longmans \& Green, 1940, p. 47.

30. Klaus Weber, «Nathaniel Meyer, first Lord Rothschild. Individual Philanthropy and Community Bonds », dans Peter Mandler, David Cesarini (dir.), Great Philanthropists: Wealth and Charity in the Modern World (1815-1945), Portland, Vallentine Mitchell, 2017, p. 17.

31. David Cannadine, The Decline and Fall of the British Aristocracy, New Haven, CT et Londres, Yale University Press, 1990 ; Peter Mandler, The Fall and Rise of the Stately Home, New Haven, CT et Londres, Yale University Press, 1997.

32. Constance Battersea, Reminiscences, op. cit., p. 173.

33. Peter Mandler, « Art, Death and Taxes: The Taxation of Works of Art in Britain, 1796-1914 », Historical Research, vol. LXXIV, n 185, 2001, p. 271-297.

34. Voir Michael Hall (dir.), « Ferdinand de Rothschild, “Bric-à-Brac” », Apollo, vol. CLXVI, n 545 , 2007, p. 50-77.

35. Constance Battersea, Reminiscences, op. cit., p. 53, p. 147.

36. Ibid., p. 43-44.

37. Lucy Cohen, Lady de Rothschild and her Daughters (1821-1931), op. cit., p. 338.

38. Ibid., p. 290.

39. Giles Worsley, England's Lost Houses: from the Archives of Country Life, Londres, Aurum, 2002, p. 12.

40. Lucy Cohen, Lady de Rothschild and her Daughters (1821-1931), op. cit., p. 288.

41. "The Pleasaunce, Overstrand, Norfolk, England », The Rothschild Archive [en ligne].

42. Diana Gulland, "Aston Clinton House, Buckinghamshire ", The Rothschild Archive Annual Review, 2002-2003, p. 36.

43. Catalogue of Pictures by Old Masters and early British portraits, the Rt. Hon. Earl Stanhope, Rt. Hon. Earl Grey, Mrs Denis Gomer Berry, Sir Harold Clayton Bart, Mrs. D. H. Luttrell, Madame Paravicini and others, on Friday May 31 $1^{\text {st }}$ 1935, Londres, Christie Manson \& Woods, 1935, p. 7. Je remercie Silvia Davoli pour son aide dans mes recherches sur la dispersion de ces collections.

44. Andrew Moore et Charlotte Crawley (dir.), Family \& Friends: a Regional Survey of British Portraiture, cat. exp. (Norwich, Norwich Castle Museum, 1992), Londres, Stationery Office Books, 1992, p. 162.

45. Constance Battersea, Reminiscences, op. cit., p. 80.

46. Pauline Prevost-Marcilhacy, « Rothschild Architecture in England, France, Germany, Austria and Italy », dans Georg Heuberger (dir.), The Rothschilds: Essays on the History of a European Family, op. cit., p. 249-250.

47. Andrew Adam, Beechwoods \& Bayonets, Buckingham, Barracuda Books, 1993, p. 25, p. 39.

48. Le portrait par Gainsborough fut vendu à Christie's le 5 juillet 2011 (voir Old Master \& British Paintings Evening Sale : lot 10).

49. Andrea Poole, Stewards of the Nation's Art, Toronto, University of Toronto Press, 2010, p. 43-46, p. 56 ; Michael Hall, « The English Rothschilds as Collectors », art. cit., p. 282-283. 
50. Antony Van Dyck, L'Abbé Scaglia vénérant la Vierge et l'Enfant, 1634-1635, National Gallery of London, inv. NG 4889.

51. Michael Hall, « The English Rothschilds as Collectors », art. cit., p. 276.

52. Giambattista Tiepolo, L'Assomption de la Vierge, 1720-1730, Ascott House, inv. 1535125.

INDEX

Index géographique : Angleterre

Index chronologique : XIXe siècle, XXe siècle

Thèmes : Mécénat, philanthropie, collections, Rothschild

\section{AUTEUR}

\section{THOMAS STAMMERS}

Thomas Stammers est professeur assistant en histoire culturelle européenne et moderne à

l'université de Durham 


\title{
Alice de Rothschild's collection of arms and armour at Waddesdon Manor
}

\author{
Pippa Shirley
}

Waddesdon Manor, the great Rothschild house near Aylesbury in Buckinghamshire (fig. 1), is generally associated with the name of the man who built it, Ferdinand de Rothschild (1839-98), but although the house and its contents were indeed his creation, the collections were very significantly enhanced by his sister, Alice de Rothschild (1845-1922), who inherited the estate on his death. Alice, like her brother and many other members of the Rothschild family, was an active and discerning collector in her own right; this paper focuses on a particular aspect of her taste, namely for arms and armour. This was part of her interest in the material culture of the 16 th and 17th centuries, but should also be seen in the context of her life and wider collecting, and the influences of the Rothschild family. ${ }^{1}$ 


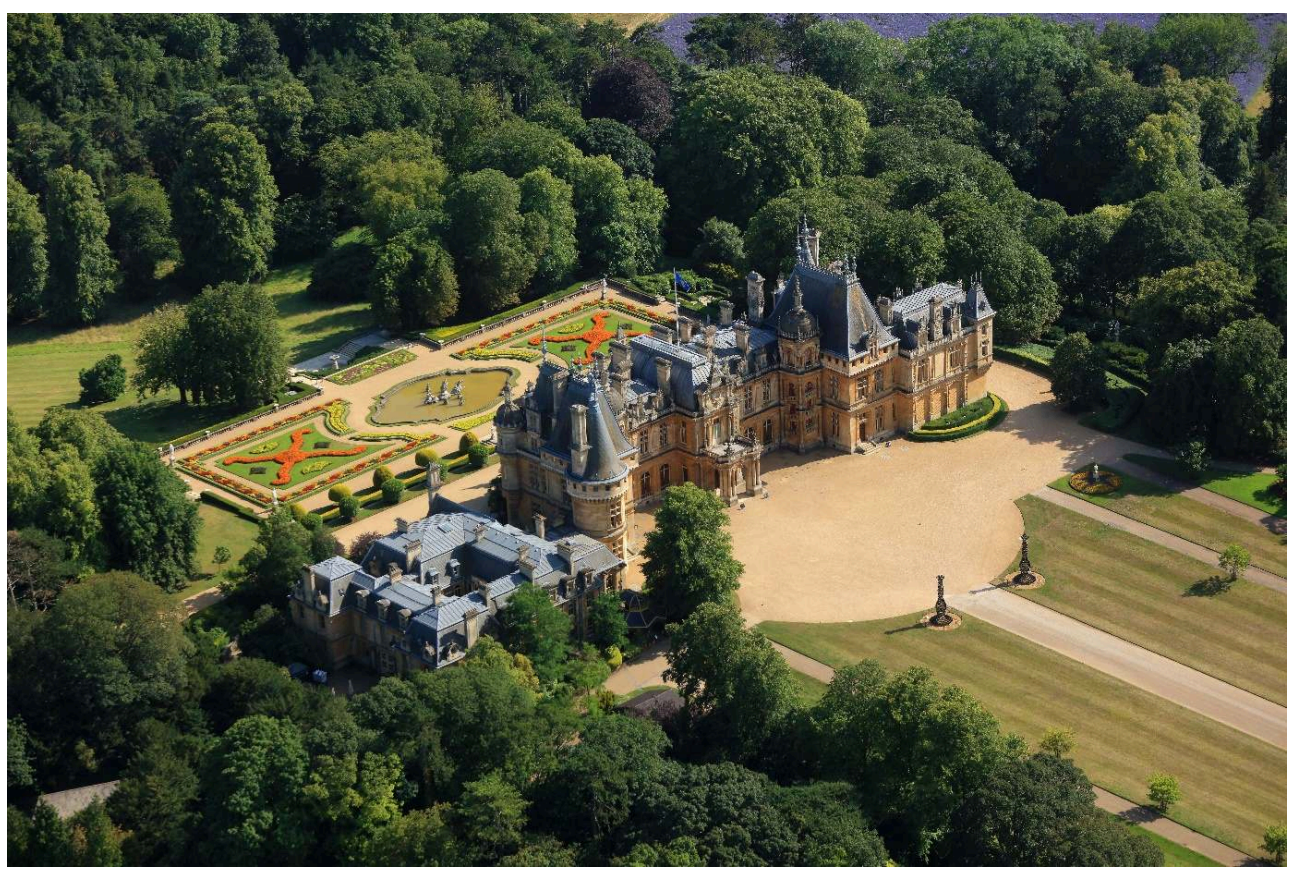

Fig. 1: Aerial view (2019) of Waddesdon Manor, built for Baron Ferdinand de Rothschild from 187486.

(c) Photo: Waddesdon Image Library.

Ferdinand and Alice (fig. 2 and 3) were from the Viennese branch of the Rothschild family, two of the eight children of Anselm (1803-74) and Charlotte (1807-59). Charlotte was an English Rothschild, the daughter of Nathan Mayer (1777-1836), the founder of the London branch of the family business, so her children, particularly Ferdinand and Alice, grew up with an attachment to England, which led to Ferdinand's decision to move to London and settle there. Ferdinand in turn moved to England and married an English cousin, Evelina, daughter of Lionel, who died in 1866. He built Waddesdon as a country retreat, a place where he could entertain friends and family through the summer and on weekends, but also as a treasure house, a setting for his growing collection. The design of Waddesdon, conceived by his French architect GabrielHyppolite Destailleur, was a reflection of his historical interests-an architectural echo of French 16th-century chateaux, but inside an homage to 18th-century Parisian hôtels particuliers. 


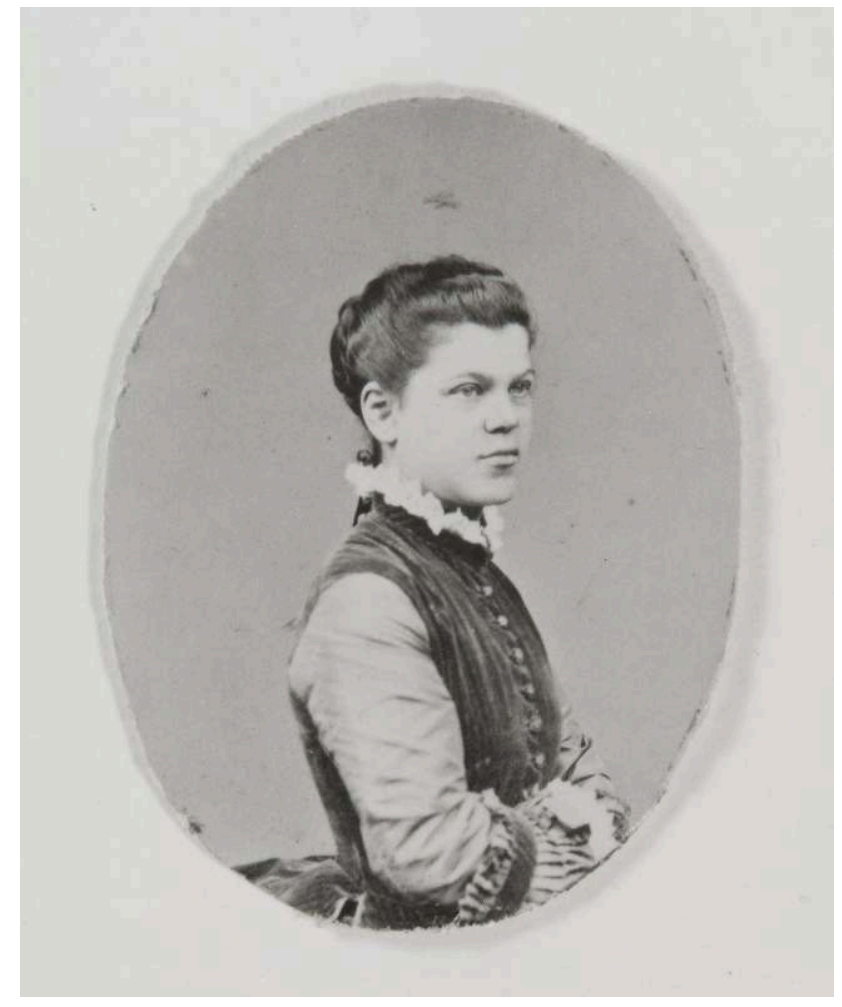

Fig. 2: Alice de Rothschild as a Young Woman, c. 1865, photographic print, Aylesbury, Waddesdon, acc. no. 7310.

(c) Photo: Waddesdon Image Library.

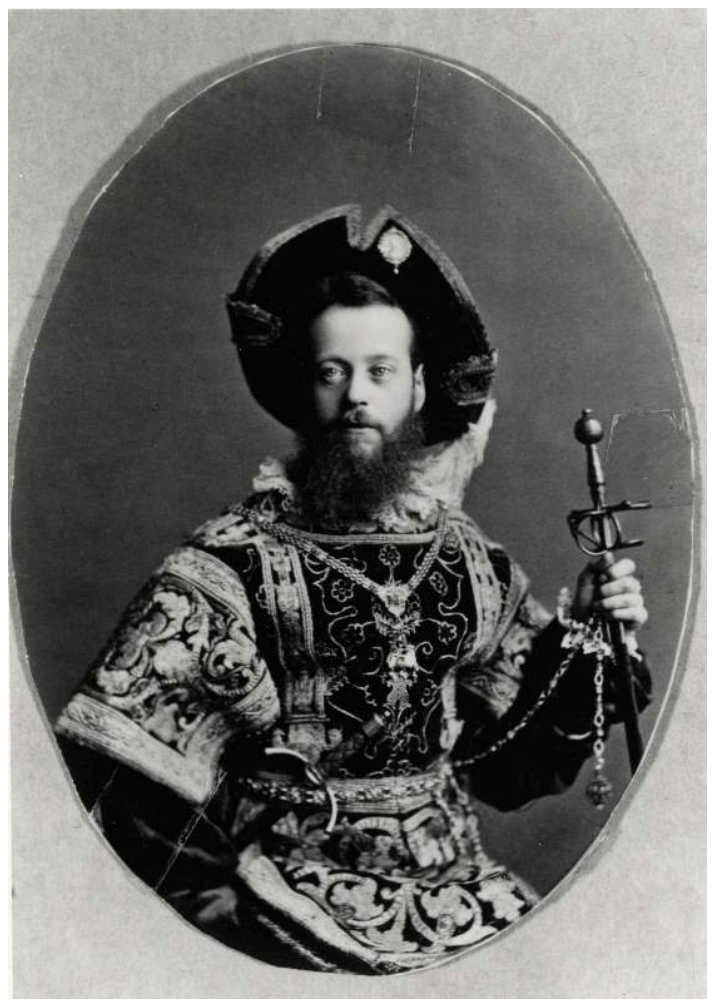

Fig. 3: Baron Ferdinand de Rothschild dressed as a Renaissance prince at the Devonshire Ball, c. 1865, photographic print, Aylesbury, Waddesdon, acc. no. 3747, Gift of Dorothy de Rothschild, 1971. (c) Photo: Waddesdon Image Library. 
3 From the moment that he purchased the Waddesdon estate in 1874, Ferdinand embarked on a monumental effort to create the house and its grounds on a site on which, by his own account, "there was not a bush to be seen nor a bird to be heard" ${ }^{2}$ at the outset. The top of the hill was levelled, the drives and terraces excavated, water had to be piped in from Aylesbury and materials brought to site on a specially constructed tramway. Mature trees were imported to landscape the grounds and mounds; grottoes of artificial Pulham rock were constructed to house a menagerie of exotic species. Inside, the house exemplified what became known as "le goût Rothschild," opulent interiors in which magnificent English 18th-century portraits looked down from silk or boiserie-hung walls onto the finest examples of 18th-century French marquetry furniture, Sèvres and Meissen porcelain, Savonnerie carpets woven for the French royal palaces, marble and terracotta sculptures, gold boxes and other precious objects. The collection was to become famous in its owner's lifetime.

4 The creation and furnishing of the Manor was witnessed by Alice, the youngest of Anselm and Charlotte's daughters. Like her siblings, Alice's childhood was divided between Paris, where she was born, then Vienna and Frankfurt, where the roots of the family laid. ${ }^{3}$ Alice, like Ferdinand, spent a good deal of time with her mother's family in England, particularly at Gunnersbury, then just outside London. She formed some exceptionally strong bonds, in particular with her cousins Constance (1843-1931) and Annie (1844-1926), daughters of her uncle Anthony (1810-76), reinforced when Alice arrived from Vienna in 1865, aged 20, to join Ferdinand in England after the death of Evelina. They lived together, first in London, where Alice bought the adjoining house to his, 142 Piccadilly, and at Leighton House in Leighton Buzzard, from where they both enjoyed hunting with the Rothschild stag hounds. The death of their father, Anselm, in 1874 left them both independently wealthy, and Ferdinand started to look for a country house. Opportunely, the Waddesdon estate came on the market the same year, so Ferdinand bought it, and then set about building the Manor.

5 The following year, the adjoining estate at Eythrope, bordering the River Thame, was also acquired, and then passed on to Alice, who had the existing house demolished and rebuilt by a local architect, George Devey. It was a day residence only. After a bout of rheumatic fever, she preferred not to sleep by water, so Ferdinand provided her with a bedroom and sitting room at Waddesdon. She divided her time between London and Buckinghamshire from 1880 onwards, when the first part of the Manor, the Bachelors' Wing, was ready for occupation. This year was marked by the first of her brother's many Saturday-to-Monday house parties, which became legendary in their day for luxury and hospitality. Guests, who included the Prince of Wales (the future King Edward VII), described sumptuous meals, cooked by Ferdinand's French chef, and visits to the gardens, the aviary, the dairy (where they could taste the milk and cream), the glass houses and the water garden. Alice would often take the whole party across the estate to Eythrope, where they would admire the gardens and have tea in a river-side pavilion with a mosaic floor.

6 Alice's forceful, not to say formidable, personality was laced with great charm and intelligence, and this, combined with their closeness, must have made Alice the obvious choice to inherit the estate on Ferdinand's death. Life at Waddesdon under Alice followed a familiar pattern. She continued to host house parties, although only twice a year. Guests, who included Sir Winston Churchill, Lord Kitchener, and Henry James, enjoyed every possible luxury, although some visitors found their hostess could be both 
intimidating and a little strange. Ottoline Morrell, who visited in 1909, later described Alice as "a lonely old oddity." "Even Edward VII, who made a nostalgic visit to his old friend's house in 1906, was famously told to keep his hands off the furniture. This concern to protect the collection was manifested in what became known later as "Miss Alice's Rules," which remain a significant force in the management of the collection to this day.

7 Alice's presence during the formation of her brother's collection must have been a major influence on her own taste, brought to bear in her own houses in London and Eythrope while Ferdinand was alive, but more energetically after his death. She must also have known other Rothschild family collections such as those of her uncle Lionel (1808-79) and aunt Charlotte (1818-74) and of her cousin Alfred (1842-1918). She may also have been aware of the collections of other Rothschilds who collected in the fieldparticularly that of her brother-in-law Adolphe Carl (1823-1900) from the Naples branch who had married her elder sister Caroline Julie Anselme (known as Julie-18301907). Both Adolphe and Julie were keen collectors, for their Parisian hotel on the rue Monceau, and for their country house at Pregny on Lake Geneva. ${ }^{5}$ She may also have known the arms and armour collection of Baron Salomon (1835-64), displayed by his widow Adèle in her house on rue Berryer. She would also have come into contact with connoisseurs outside the family circle. She knew the famous collection assembled by the Marquis of Hertford and Sir Richard Wallace (now the Wallace Collection), and is recorded in the Visitors' Book there with Ferdinand in $1885 .{ }^{6}$ In most respects, her taste followed familial lines. A rare early colour view of her sitting room at the Manor, taken around 1910 (fig. 4), shows an interior with a Savonnerie carpet on the floor, red-silk hung walls, densely hung with a variety of works on paper, including four of the original drawings by Moreau le Jeune for the famous edition of the Monument $d u$ costume made between 1775 and 1783. There are garnitures of Sèvres porcelain, sculpture and on one wall, a magnificent gilt-bronze-mounted commode by JeanHenri Riesener, made in 1776 for Louis XVI's sister-in-law, the Comtesse de Provence, bought via the dealer Wertheimer for $£ 2,310$ as early as 1882 , at a time when Ferdinand was making some of his most important purchases. ${ }^{7}$ 


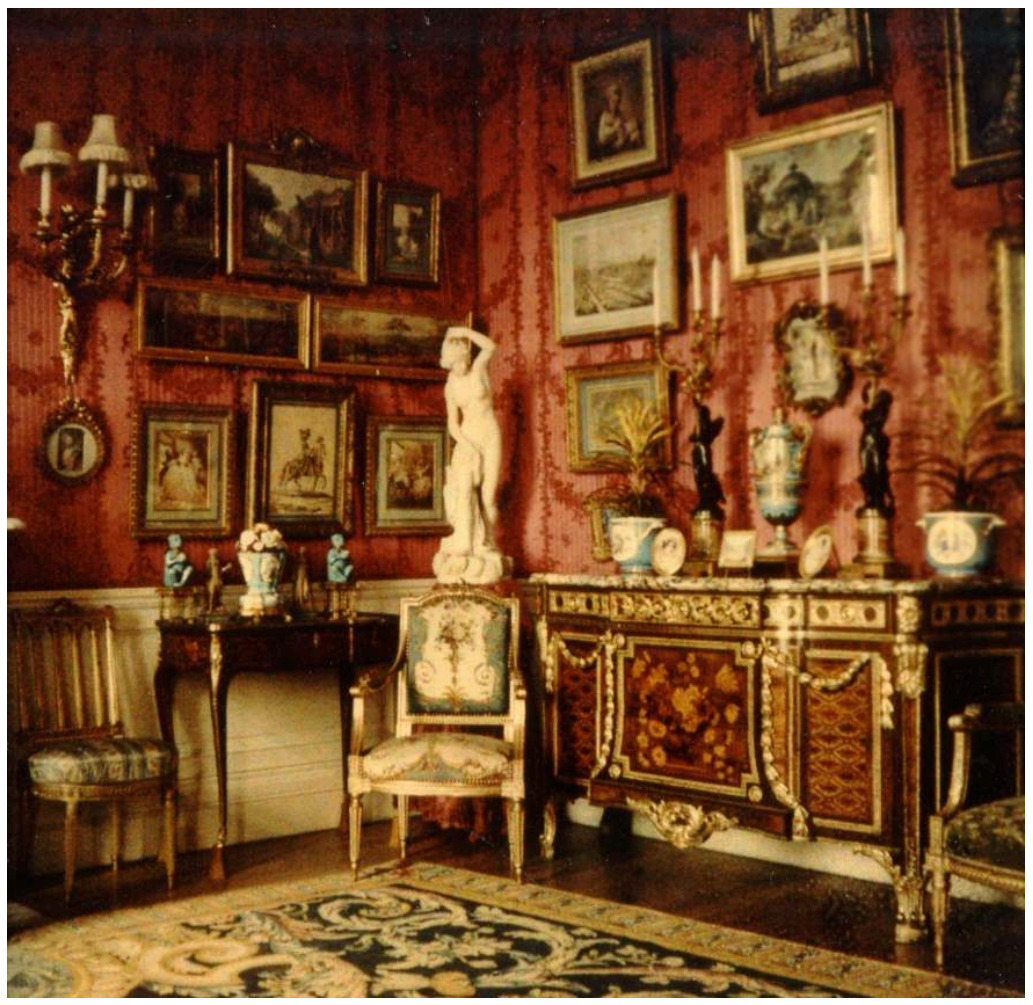

Fig. 4: Alice's sitting room at Waddesdon, c. 1910, colour autochrome, Aylesbury, Waddesdon.

(c) Photo: Waddesdon Image Library.

8 However, some of her collecting was much less typical, perhaps partly explained by her independent outlook. The fact that she focussed on arms and armour is in itself unusual, aligning with the collection of pipes and matchboxes which she assembled in her villa in Grasse. ${ }^{8}$ Both of these would have been seen as largely masculine areas for collecting in the late 19th century. 


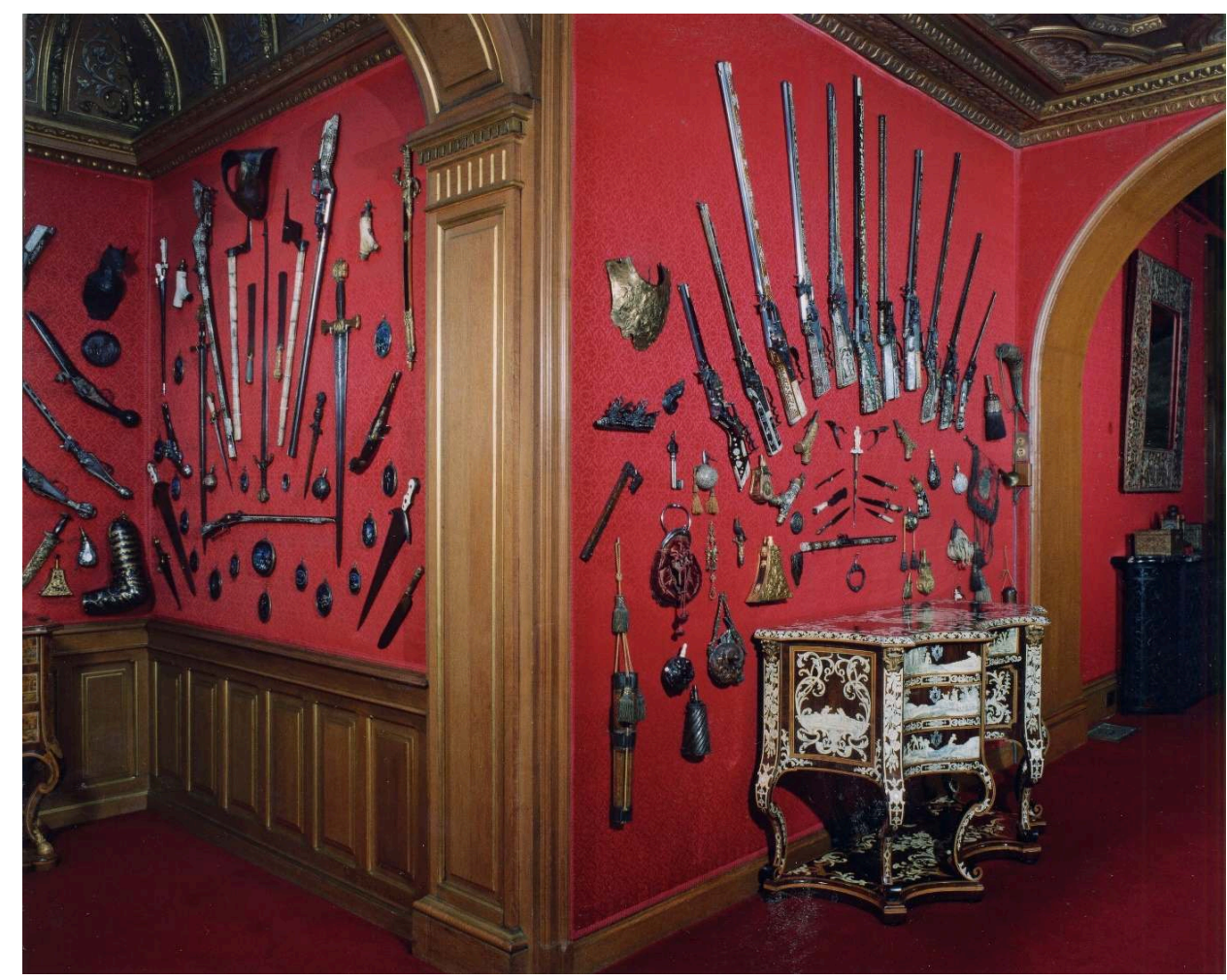

Fig. 5: The Armoury Corridor at Waddesdon, showing the arrangement of Alice's collection of arms, 2010s, Aylesbury, Waddesdon.

(c) Photo: Waddesdon Image Library.

One of the most important elements of the Waddesdon collection was what Ferdinand referred to as his "Renaissance Museum," the 16th and 17th-century ivory, Limoges enamels, goldsmiths' work, maiolica, glass and rock crystal, a 19th-century equivalent of a princely Kunstkammer. This collection, displayed in the Smoking Room in the Bachelors' Wing, was bequeathed in its entirety to the British Museum on Ferdinand's death in 1898, where it remains as the Waddesdon Bequest. ${ }^{9}$ Alice was his executor, and so it fell to her to organise the transfer. The departure of the bequest led to a collecting opportunity for Alice, which she approached in a methodical way, both to preserve the existing character of the Bachelors' Wing and the collections it had contained and to exercise her own taste for such objects. It was this project which created the impetus for the arms and armour acquisitions. The documentary sources are incomplete, but a number of receipts for works of art do survive, for acquisitions largely made between 1904 and 1922, slowing after the outbreak of the First World War, and then resuming at a slower pace in 1918. These record a number of purchases of arms, alongside enamels, maiolica, Sèvres, gold boxes and paintings. Some of the major names of the commercial art world in London, Frankfurt and Berlin are represented, including Wertheimer, 21 Norfolk St, London, and Harding, St James's Square, and the picture dealers Charles Davis and Colnaghi, but the largest suppliers of objects for the Bachelors' Wing were the furniture, porcelain and objets d'art specialist Durlacher Brothers, of 142 New Bond Street London, Seligmann and J\&A Goldschmidt, with receipts from their London, Paris and Frankfurt businesses. ${ }^{10}$

10 Alice did not start completely from scratch in her collecting of arms. Ferdinand had also embellished the Bachelors' Wing with a small collection-his probate inventory, taken in 1898, lists "trophies of arms and various articles on the Walls" displayed in 
what was then called the Billiard Room Corridor, the main access to the Bachelors' Wing from the main house, and which led to both the Billiard and Smoking Rooms. ${ }^{11}$ The exact number of pieces is not known, but some at least remain at the Manor. They include a collection of early 17th-century possibly Netherlandish and Swiss halberds, French 18th-century pistols and a group of knives. ${ }^{12}$ There is also a piqué powder flask from the Spitzer Collection, which in 1898 was in Ferdinand's private sitting room, where he had other piqué and gold boxes. ${ }^{13}$ Whether Alice took these categories of pieces as a guide or not, she built on these foundations, because the collection as it stood when she died consisted of mainly 16th and 17th-century pieces, in particular swords, daggers, firearms and powder flasks. As Claude Blair says, the emphasis was on their decorative qualities, rather than their history, chronology or typology. They come mainly from the great European centres of production in Italy, Germany, Austria, the Low Countries, France and Britain. Although several pieces have illustrious provenances, this does not appear to have been a major motivation. Like Ferdinand, she generally did not keep records of where she was acquiring the pieces (apart from the receipts mentioned above, which seem to have survived accidentally), but she made a few notes on provenance in a set of manuscript notes entitled "Catalogue of the Principle Pictures etc." ${ }^{14}$

11 She seems to have largely bought privately, rather than at auction. Some pieces came from major late 19th and early 20th-century collections, such as Spitzer Collection and the sales of the merchant and collector of medieval art, Hollingworth Magniac (17861867), and the collector Richard Zschille (1847-1903). But the main influence on the formation of the collection was Sir Guy Francis Laking, Bart., one of the foremost connoisseurs of arms and armour of the time.

Laking was one of the most prominent, intriguing and colourful personalities of the early 20th-century art market. ${ }^{15} \mathrm{He}$ was born in 1875 , the son of Sir Francis Laking, physician to the Royal Household. He therefore had close connections to the royal family from an early age, which greatly helped him in his later career. He was passionate about arms and armour from boyhood, and by the time he was 21, was acting as an Art Advisor for Christie's. In 1900, at age 24, he was appointed Honorary Inspector of the Armouries at the Wallace Collection, then two years later, King Edward VII created the post of Keeper of the King's Armoury at Windsor especially for him. Later on, from 1911 to 1919, he was instrumental in setting up the London Museum (now the Museum of London), becoming its first Keeper. In 1920-22, he published an immense and seminal work, based on the Royal collections, A Record of European Armour and Arms through Seven Centuries, in five volumes. All of this demonstrates the level and extent of his scholarship, but also the extraordinarily high regard in which he was held.

13 He was also legendary for his charm-he seems to have been loved by almost everyone who knew him, not least by women-his great kindness, immense generosity and wild extravagance. He was renowned for his expensive tastes, which extended to his personal collection of arms and armour, and his lavish parties. Famously, he entertained the members of the Meyrick Society, ${ }^{16}$ established in honour of the arms and armour collector and Antiquary, Sir Samuel Rush Meyrick, to a medieval feast at his home which featured a banquet with a roast peacock in its feathers and his children's governess dressed up in armour, handing around a loving cup. He had a penchant for dressing up and taking part in mock tournaments, taking the role of The 
Esquire of the Knight Martiall of the Lists in a tournament he helped to organise as part of "The Triumph Holden at Shakespeare's England," a medieval pageant and extravaganza which took place in London at Earl's Court to great acclaim in 1912. ${ }^{17}$

However, this celebrity lifestyle meant that Laking was generally living beyond his means. His friend the journalist and heraldic scholar Oswald Barron wrote that "he spent money like one who has a store of gold angels and gold nobles in an iron chest rather than one who draws cheques on a banking account." ${ }^{18}$ Laking was frequently in debt, and it seems only too likely that he supplemented his income with commissions and fees from advice given on purchases to both dealers and his wealthy collector friends, whom he assiduously cultivated. He was also less than scrupulous on occasion in passing off objects that he knew to be either problematic, or outright fakes to his clients.

Although we don't know when they met, Laking was closely involved as an advisor to Alice in the formation of her arms and armour collection. At the same time, he was also advising William Waldorf Astor, 1st Viscount Astor, who was furnishing his newlybought house, Hever Castle in Kent. Alice was clearly susceptible to his charm and regarded him as a friend; while he only appears in the Visitors' Book at Waddesdon once, in August 1913, Alice soon stopped entertaining due to the outbreak of the First World War. He was also one of the few people singled out for a specific legacy in her will of $£ 1,000$, a considerable sum at the time, suggesting she saw him as part of her inner circle. Whether he was already a friend to whom she turned when she began the project, or whether the friendship grew out of what was originally a commercial relationship we don't yet know, but Alice was both loyal and generous to those liked. The surviving receipts suggest that she made no significant purchase of arms after Laking's death in 1919, although by then, Alice herself was in declining health.

Laking ensured that she acquired some exceptional objects. He was instrumental in her purchase of the most important pieces in the collection, including a helmet which was part of a parade armour for Emperor Charles V (fig. 6), probably made by the Caremolo Modrone, who was born in Mantua and then worked there for the Gonzaga from $1521 .^{19}$ He was also involved in the acquisition of a pair of 1539 elbow pieces from another of Charles V's parade armours, by Filippo Negroli, from the famous Milanese family of armourers, renowned for the quality of their embossing. ${ }^{20}$ Like the helmet, they were illustrated in the Inventario Illuminado, the illustrated inventory of Charles V's armoury. Alice probably bought them directly from the collection of Baron Charles Alexander de Cosson, a great authority on arms and armour, who was also a friend of Laking. In another mark of her affection for him, both elbow pieces and helmet were also left to Laking in Alice's will, listed as "Embossed helmet of Charles V, also pair of elbow pieces of Negroli in the Armoury at Waddesdon." They only remain at Waddesdon because Laking died before she did, at the young age of $44 .^{21}$ 


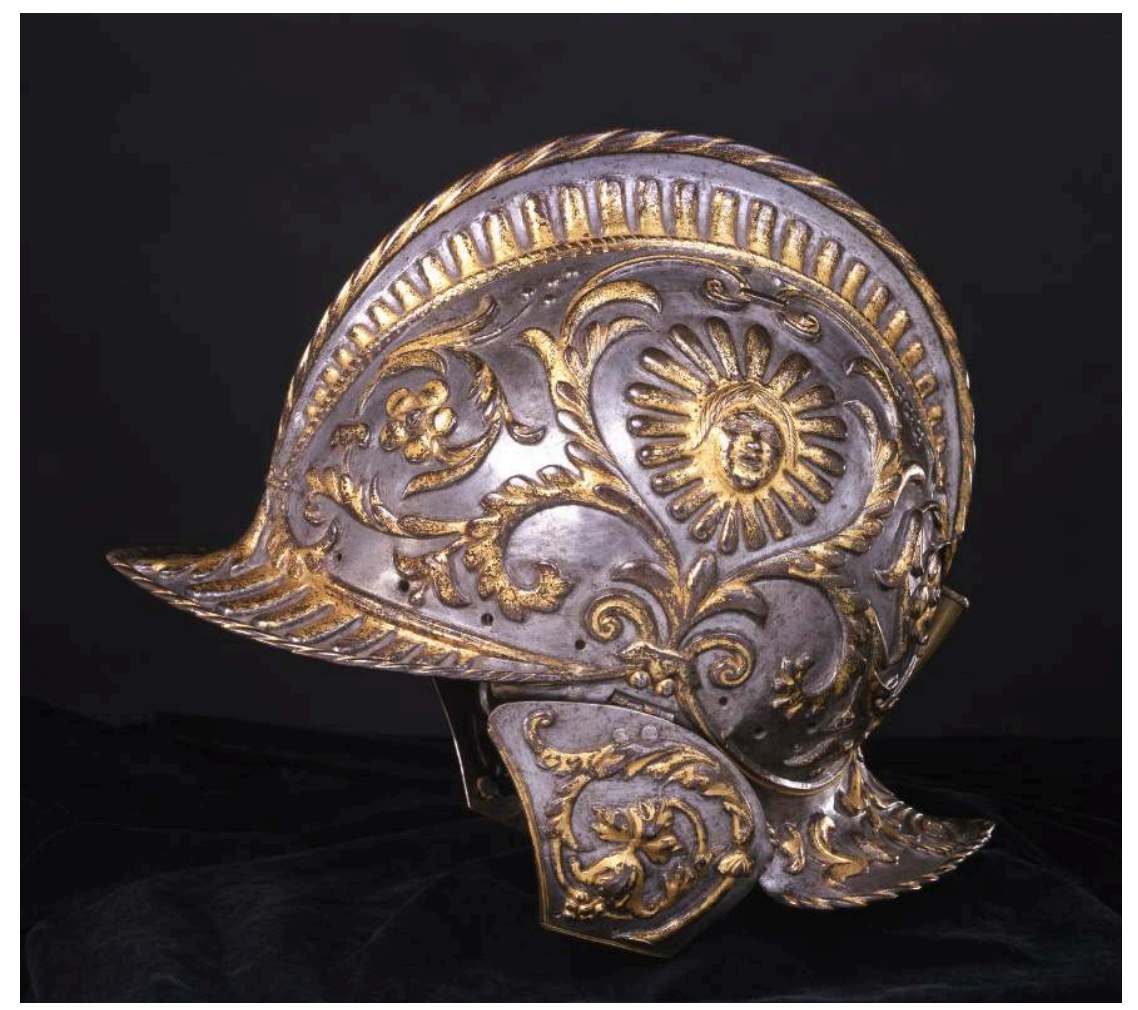

Fig. 6: Burgonet from a parade armour made for Emperor Charles V, attributed Caremolo Modrone, c. 1543, steel, gold and wood, Aylesbury, Waddesdon, acc. no. 3461, Bequest of James de Rothschild, 1957.

(c) Photo: Waddesdon Image Library.

17 Body armour forms a small but important group, including another pair of shoulder and arm defences made for Guiseppe Matei, Duke of Giove, possibly in Rome or Brescia, around 1750. Another important acquisition was again prompted by Laking, as a circular parade shield probably made in the Antwerp workshop of Eliseus Libaerts c. 1555 for Henri II of France, embossed in low relief with a battle scene based on designs after Étienne Delaune. ${ }^{22}$ This came from the celebrated collection of Sir Adam Hay and was exhibited at the Special Exhibition of Works of Art on Loan at the South Kensington Museum in 1862, where it was described as "Italian work of the 16th century." In the 1830s, it had been associated with Francis I. 


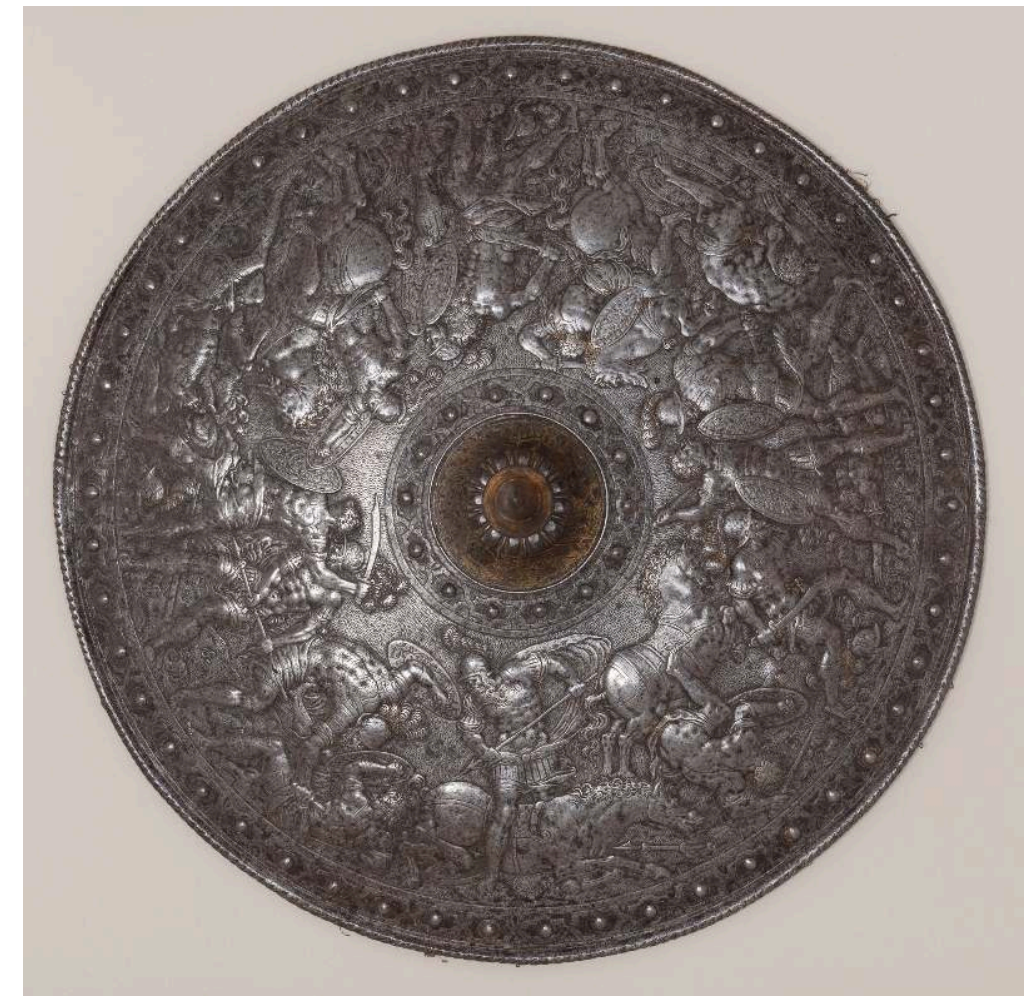

Fig. 7: Parade shield embossed with a battle scene, attributed Eliseus Libaerts, c. 1555-9, iron, gold, canvas and velvet, possibly made for Henri II of France, Aylesbury, Waddesdon, acc. no. 2778, Bequest of James de Rothschild, 1957.

(c) Photo: Waddesdon Image Library, Mike Fear.

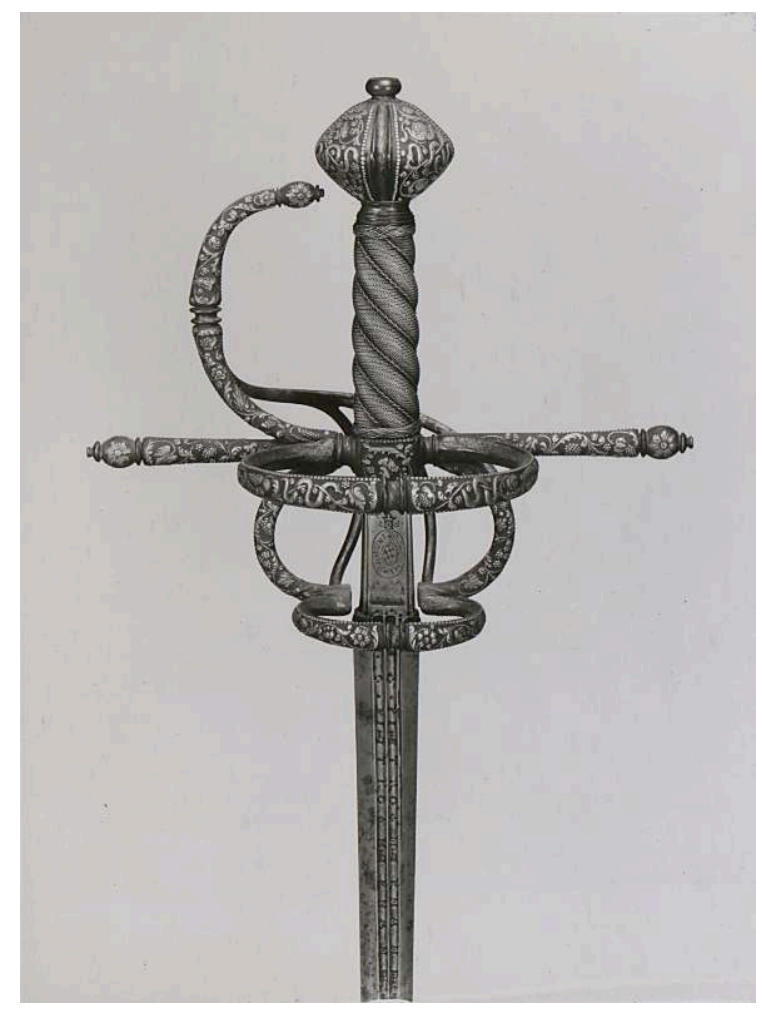

Fig. 8: Rapier, 1600-25, steel, iron, wood, silver and gold, signed for Pietro Hernandez, Toledo, the blade marked for Sandro Scacchi, Brescia, probably assembled in Toledo, Aylesbury, Waddesdon, acc. no. 679, Bequest of James de Rothschild, 1957.

(c) Photo: Waddesdon Image Library, Eost and Macdonald. 
largest groupings in the collection are the swords and rapiers, supplemented by daggers and knives, perhaps because these, along with long barrel rifles, lend themselves to the kinds of impressive visual displays seen in major European armouries, such as that at Schloss Ambras in Innsbruck. Alice acquired examples from England, Germany, Spain, and Italy. Many of them have degrees of alteration. One such example is a rapier acquired from Durlacher Bros. in 1908, described as a "Ring hilted rapier, straight quillons encrusted with vine ornaments and serpents in silver and fire gilt in panels. The blade inscribed on the ricasso SANDRI SCACCHI. N. Italian 2nd half of the 16th century ${ }^{23}$." It was sold with another rapier, a left-hand dagger, spurs and présentoir for $£ 2000$. It has a blade bearing two marks of famous makers from Toledo in Spain, and Brescia in Italy, suggesting that is was made in Solingen, Germany, where it was common practice to add spurious signatures to increase value. Alice bought several other similarly decorated rapiers for display. ${ }^{24}$ The same 1908 purchase, the largest group brought from Durlacher, included another example which was attributed to the armourer La Roche d'Argent on the basis of an almost identical one in the Royal Collection, made for James I and signed. Laking, as Keeper of the Windsor Armouries, knew the Royal Collections intimately, and so must have encouraged Alice to buy this closely comparable example. ${ }^{25}$

Firearms are the other most significant category, particularly wheel-lock rifles and pistols and like the rapiers and swords, acquired for their decorative features. Most have intricately worked barrels and stocks. One of the most outstanding was made in the 1670 s by Christian Herold, a leading Dresden gun-maker. It has been altered, but probably shortly after it was made, with the addition of five enamel plaques, which cover some of the inlaid staghorn decoration. Herold's family also worked as enamellers and painters in the Meissen porcelain factory and a group of four other guns by him with similar plaques survives. ${ }^{26}$

By contrast, there are also rifles which are examples of 19th-century invention. One of these (fig. 9), with an extraordinarily decorated stock and barrel, has ornament derived from the prints of Étienne Delaune but the original barrel was probably 16th or 17th century, and plain. In the 19th century, the metal was blued, catering for late 19th-century taste for highly decorated guns, and ornamented with leaves, grotesques, and naked figures. It was gilded, and finally decorated sections with a technique known as counterfeit-damascening, setting thin gold wires into the base metal. The lock is similarly decorated. ${ }^{27}$ It was probably put together in the workshop of the dealer Frédéric Spitzer (1815-90), whose activities in this respect are well known. A number of Rothschilds acquired objects from Spitzer, either in his lifetime or after his death and sale in 1890 , and the decoration on this gun compares with that on some of the guns Ferdinand is known to have acquired from the same source that are now in the Waddesdon Bequest. ${ }^{28}$ 


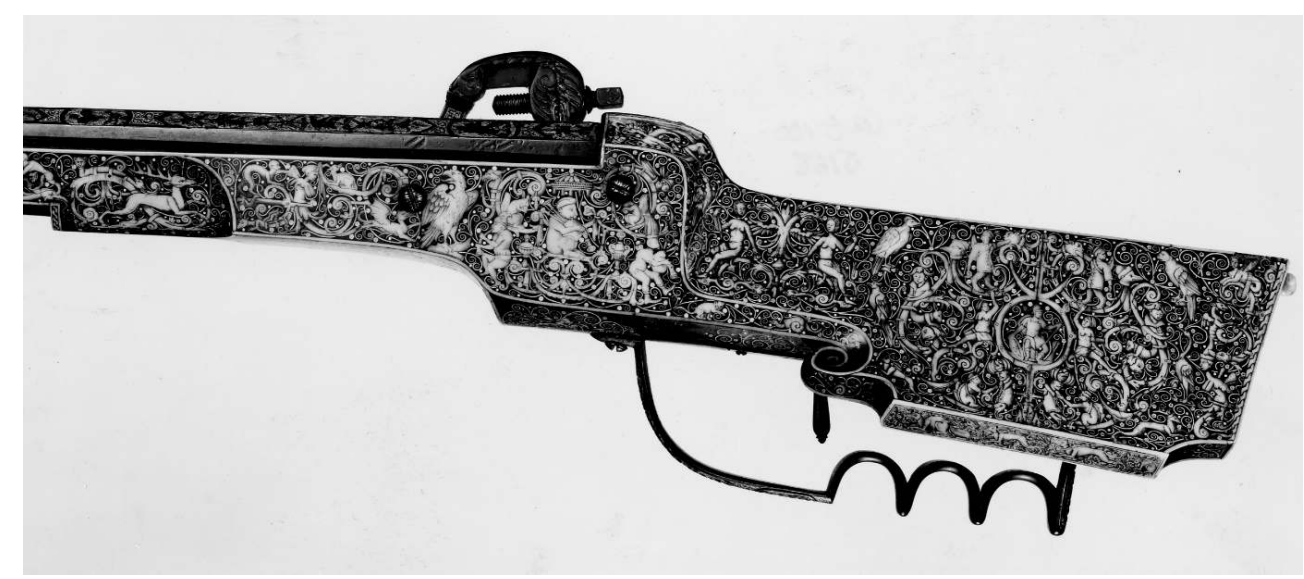

Fig. 9: Wheel-lock rifle, early 17th century, steel, wood, staghorn, and gold. Lock, trigger guard and ornament, Germany and Paris, 19th century, probably altered in the Frédéric Spitzer workshop, 168090, Aylesbury, Waddesdon, acc. no. 5168, Bequest of James de Rothschild, 1957.

(c) Photo: Waddesdon Image Library, Eost and Macdonald.

21 Powder flasks (fig. 10) form another distinct and large group, many of them decorated with engraved ivory or staghorn, with scenes based on popular 16th-century print sources including Jost Amman (1539-91) and Virgil Solis, and made in the metalworking centres of Augsburg and Nurnberg. Several of these also come from the Spitzer Collection. ${ }^{29}$ The number of pieces that have been added to, altered, remade and redecorated is not in itself surprising for a collection formed in the early 20th century. Alice was collecting at the end of a period when the market for arms and armour, particularly Renaissance and later pieces, was very lively, thanks to the activities of several wealthy collectors, amongst them Sir Richard Wallace, who had assembled an impressive collection (now in the Wallace Collection, London). There was also increasing competition from America, and particularly Bashford Dean, Curator of Arms and Armour at the Metropolitan Museum of Art, in New York, who likewise was advising and selling to a network of wealthy collectors. The trade had responded to meet the demand. Alice was also buying extensively, and at speed, as the surviving receipts show. In June 1909 alone, Durlacher Bros billed Alice for "a pair of Deruta dishes, a pair of Louis XVI candelabra, a fine gilt steel hilted sword, French, and gold inlaid rapier, Henri II, a dagger and sheath, Italian, c. 1530, an inlaid wood flask, damascened, German, 16th century, an embossed cartridge box, a small metal flask, a knife, French, Henri II and a left-handed dagger and sheath, c. 1570," all for a total of $£ 1,273$. The following year a single receipt in July 1910 lists "a pair of pistols, German, c. 1590, untouched (rare on account of the brass bands), a pair of small 17th-century pistols, silver mounts, signed Lazarino Comminazo, a large gilt powder flask, mythological subjects, German 16th century, a carved ivory powder flask, 16th century" all for $£ 500$. The Italian pistols were made in Brento, a centre of gun-making between Florence and Bologna, in the second half of the 18th century, with barrels supplied and signed by a by a member of the specialist Brescian family of gunsmiths and barrel makers. ${ }^{30}$ 


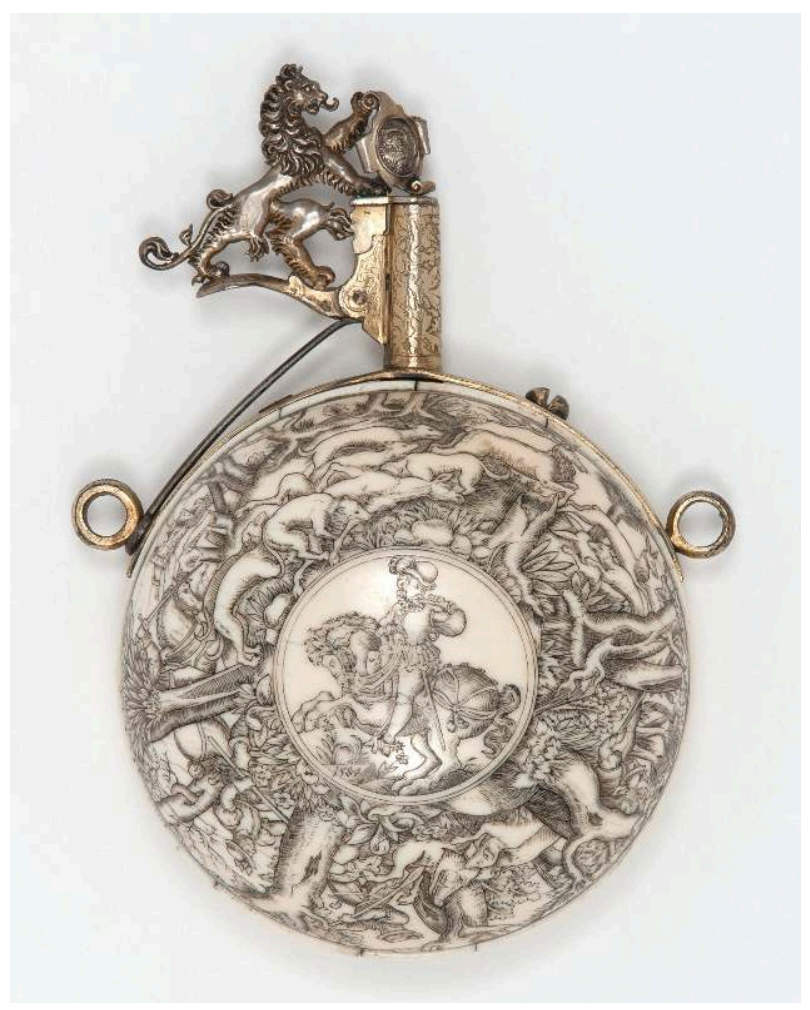

Fig. 10: Powder flask with the Imhof coat of arms, dated 1584, ivory, steel, silver and gold, owned by Frédéric Spitzer, Aylesbury, Waddesdon, acc. no. 5195, Bequest of James de Rothschild, 1957.

(c) Photo: Waddesdon Image Library, Mike Fear.

There is no visual evidence for the display of the arms and armour at Waddesdon in Alice's time. It is known from the probate inventories that she showed them largely in the corridor in the Bachelors' Wing, with a few examples in the Smoking Room itself. The current layout is based on that devised by Dorothy de Rothschild, who oversaw the opening of the house to the public after her husband, James de Rothschild (1878-1957) bequeathed it to the National Trust in 1957. Dorothy managed the Manor until her death in 1988. She knew the Manor in Alice's time, having visited soon after her marriage, and had the greatest respect for her husband's great aunt, so we presume that her arrangement was based on Alice's. It emphasises visual impact, rather than arrangement by maker, technique, type or period. After Dorothy's death in 1988, the present Lord Rothschild took over the management of the Manor, and oversaw a major restoration project, as part of which the Armoury Corridor, as it is now known, was redisplayed again. However, the historic arrangement was maintained to ensure that this atmospheric part of the house retains its historic links to both Ferdinand and Alice and their collecting. ${ }^{31}$ 


\section{NOTES}

1. For a comprehensive history of Waddesdon and the Rothschilds who were particularly involved with it, see Michael Hall, Waddesdon: The Biography of a Rothschild House (New York, Abrams, 2002), 3rd ed. London, The Rothschild Foundation, 2012. See also Pauline PrevostMarcilhacy, Les Rothschild, bâtisseurs et mécènes, Paris, Flammarion, 1995. For a personal account, see Dorothy de Rothschild, The Rothschilds at Waddesdon Manor, London/New York, Vendome Press, 1979, which includes her own memories of Alice. For the arms and armour specifically, this paper is drawn largely from the work of the late Claude Blair, the author of the volume on the collection in the Waddesdon Catalogue Series; Claude Blair, The James A. de Rothschild Collection at Waddesdon Manor: Arms, Armour and Base Metalwork, Fribourg, Office du Livre, 1974. I am indebted to him, and also to my former colleague Phillippa Plock, whose extensive research on the arms and armour collections is published online as part of the Waddesdon Collections database. For Alice de Rothschild, see also Bénédicte Rolland-Villemot, "Pipes et boîtes d'allumettes. Don d'Alice de Rothschild à la bibliothèque de Grasse, 1927," in Pauline Prevost-Marcilhacy (ed.), Les Rothschild, une dynastie de mécènes en France, vol. II, Paris, Louvre/BNF/Somogy, 2016, pp. 245-9.

2. For Ferdinand's own account of the building of Waddesdon, see The Red Book, privately published, 1897.

3. For a history of the Rothschild family, see Niall Ferguson, The World's Banker: The History of the House of Rothschild, London, Weindenfeld \& Nicolson, 1998

4. Lady Ottoline Morrell recorded a visit to Waddesdon with the novelist Henry James in her diary in May 1909. Quoted in Michael Hall, Waddesdon, op. cit., p. 193; Robert Gathorne-Hardy (ed.), Ottoline: The Early Memoirs of Lady Ottoline Morrell, London, Faber and Faber, 1963, pp. 170-1.

5. For Adolphe and Julie's collection, see Dimitrios Zikos, "Adolphe et Julie de Rothschild," in Pauline Prevost-Marcilhacy, Les Rothschild, une dynastie de mécènes, op. cit., vol. I, pp. 238-51.

6. London, The Wallace Collection Archive, acc. no. HHVB.

7. One of a set of stereoscopic autochromes recording interiors and the gardens at Waddesdon, by an unknown photographer and undated, although probably taken around 1910. Aylesbury, Waddesdon Archive at Windmill Hill (Waddesdon), acc. no. 3684.

8. Alice spent winters from 1888 at her villa, the Villa Victoria, in Grasse, in the Alpes-Maritimes. Her collection of smoking paraphernalia is now in the Bibliothèque municipale in Grasse. See also B. Rolland-Villemot, "Pipes et boites d'allumettes," and the presentation of this collection by Yves Cruchet and André Leclaire, "Grasse, bibliothèque municipale," in Les Collections Rothschild dans les institutions publiques françaises, INHA, n. d.

9. For the Waddesdon Bequest, see Dora Thornton, A Rothschild Renaissance: Treasures from the Waddesdon Bequest, London, British Museum Press, 2015.

10. Waddesdon, acc. no. 282.2016.

11. Ferdinand's probate inventory, taken in 1898, the year of his death, records the contents of every room at the Manor, ibid.

12. Claude Blair, The James A. de Rothschild Collection, op. cit., cat. 84-86, 139 and 140.

13. Ibid., cat. 173. On the Spritzer collection, see Paola Cordera, La Fabbrica del Rinascimento, Frédéric Spitzer mercante d'arte e collezionista nell' Europa delle nuove nazioni, Bologna, Bononia University Press, 2015.

14. Claude Blair, The James A. de Rothschild Collection, op. cit., p. 9.

15. For the following on Laking, see ibid. See also Dictionary of National Biography; J. F. Hayward, "Sir Francis Laking," Armi Antichi, 1964, pp. 265-72; Claude Blair, "Crediton: The Story of Two Helmets," in Studies in European Arms and Armor: The C.Otto von Kienbusch Collection in the Philadelphia Museum of Art, Philadelphia, Philadelphia Museum of Art, 1992, pp.152-83; id., 
Introduction to the reprint of Laking's Record of European Armour and Arms through Seven Centuries, Cambridge, Trotman, 2000.

16. For the Meyrick Society, see id., The Meyrick Society, 1890-1990, privately published, 1991. Laking was Vice President of the Society from 1910 until his death.

17. Jean E. Howard and Marion F. O'Connor (eds.), Shakespeare Reproduced: The Text in History and Ideology, Oxford, Routledge, 1987, pp. 92-4; Claude Blair, Introduction, op. cit.

18. Ibid.

19. Waddesdon, acc. no. 3461. Claude Blair, The James A. de Rothschild Collection, op. cit., cat. 1. See also Phillippa Plock's commentary.

20. Waddesdon, acc. no. 5096.1 and 2; Claude Blair, The James A. de Rothschild Collection, op. cit., cat. 2-3; Phillippa Plock's commentary.

21. A copy of Alice's will is held in Waddesdon.

22. Waddesdon, acc. no. 2778; Claude Blair, The James A. de Rothschild Collection, op. cit., cat. 9; Phillippa Plock's commentary.

23. For the 1908 receipt, see Waddesdon, acc. no. 282.1996.

24. Waddesdon, acc. no.679; Claude Blair, The James A. de Rothschild Collection, op. cit., cat. 26; Phillippa Plock's commentary.

25. Waddesdon, acc. no. 282.1996.

26. Waddesdon, acc. no. 5174; Claude Blair, The James A. de Rothschild Collection, op. cit., cat. 107; Phillippa Plock's commentary.

27. Waddesdon, acc. no. 5168; Claude Blair, The James A. de Rothschild Collection, op. cit., cat. 100; Phillippa Plock's commentary.

28. For a full account of Spitzer and the Rothschild family, see Paolo Cordera, "Art for the Rothschilds: The Career of the Dealer Frédéric Spitzer," in Pippa Shirley and Dora Thornton (eds.), A Rothschild Renaissance: A New Look at the Waddesdon Bequest in the British Museum, London, The British Museum, 2017, pp. 168-77.

29. For one example, see Waddesdon, acc. no. 5202; Phillippa Plock's commentary; Claude Blair, The James A. de Rothschild Collection, op.cit., cat. 155 and ref. to Spitzer sale; Frédéric Spitzer, Collection Spitzer, n.p., n.d., vol. VI, p. 85, no. 404; sale, Paris, 10-14 June 1895, lot 409 (1,020 francs).

30. Waddesdon, acc. nos. 3464.1 and 2; Claude Blair, The James A. de Rothschild Collection, op. cit., cat. 141-2. For Durlacher receipts, see Waddesdon, acc. nos. 282.201659 and 60.

31. Waddesdon is now managed by the Rothschild Foundation under the chairmanship of Jacob, 4th Lord Rothschild (b. 1936), on behalf of the National Trust. 